PROGRESS REPORT

CONTRACT DE-AS09-76EV00889

Larry P. Atkinson

-SKIO-

VOLUME 3

TECHNICAL REPORTS 


\section{DISCLAIMER}

This report was prepared as an account of work sponsored by an agency of the United States Government. Neither the United States Government nor any agency Thereof, nor any of their employees, makes any warranty, express or implied, or assumes any legal liability or responsibility for the accuracy, completeness, or usefulness of any information, apparatus, product, or process disclosed, or represents that its use would not infringe privately owned rights. Reference herein to any specific commercial product, process, or service by trade name, trademark, manufacturer, or otherwise does not necessarily constitute or imply its endorsement, recommendation, or favoring by the United States Government or any agency thereof. The views and opinions of authors expressed herein do not necessarily state or reflect those of the United States Government or any agency thereof. 


\section{DISCLAIMER}

Portions of this document may be illegible in electronic image products. Images are produced from the best available original document. 


\section{INDEX VOLUME 3}

Note: The technical reports are in order according to their tech report series numbers. In a case where data has been excluded, a yellow blank sheet has been inserted. The reports included are as follows:

Series \#

$80-1$

$79-5$

$79-3$

$79-1$

$78-7$

$78-5$

$78-1$

\section{Title}

Hydrographic Observations off Savannah and Bruniswick, lieorgia (March, May and September, 1977 and January, 1978).

Hydrographic Observations in the Georgia Bight (April 1978).

Hydrographic Observations in the Georgia Bight (Juiy 1977).

Hydrographic Observations in the Georgia Bight (December 1976).

ACTD System: Description, Operation, Data Acquisition and Processing.

Hydrographic Observations in the Georgia Bight (April 1977).

The Results of Four Oceanographic Cruises in the Georgia Bight. 
HYDROGRAPHIC OBSERVATIONS OFF SAVANNAH AND BRUNSWICK, GEORGIA

(MARCH, MAY AND SEPTEMBER, 1977 AND JANUARY, 1978)

TECHNICAL REPORT 80-1

J. J. Singer
L.P. Atkinson
W.S. Chandler
S.S. Bishop

The Technical Report Series of the Georgia Marine Science Center is issued by the Georgia Sea Grant Program and the Marine Extension Service of the University of Georgia on Skidaway Island (P.0. Box 13687, Savannah, Georgia 31406). It was established to provide dissemination of technical information and progress reports resulting from marine studies and investigations mainly by staff and faculty of the University System of Georgia. In addition, it is intended for the presentation of techniques and methods, reduced data and general information of interest to industry, local, regional, and state governments and the public. Information contained in these reports is in the public domain. If this prepublication copy is cited, it should be cited as an unpublished manuscript. 
List of figures ....................... i List of Tables ........................ iv

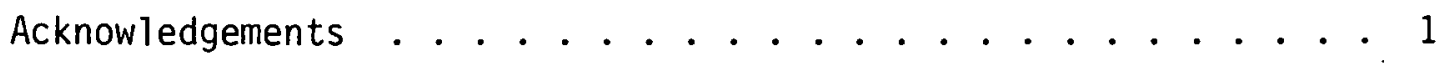

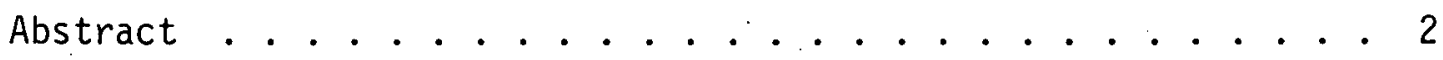

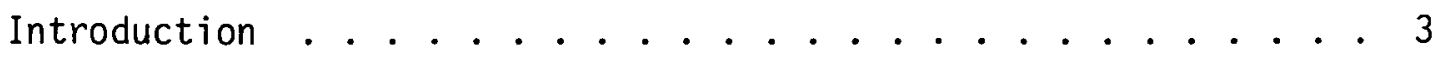

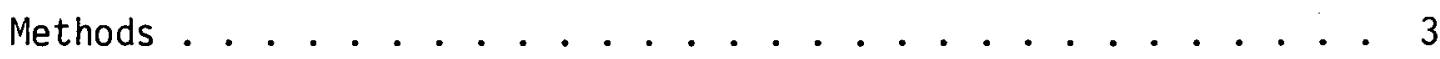

Sampling . . . . . . . . . . . . . 3

Chemical and Physical Procedures ......... 3 XBT Data Acquisition and Processing ......... 4 CTD Data Acquisition and Processing ........ . 4

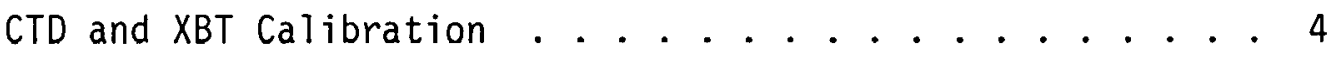

CTD Error Analysis . . . . . . . . . . . . . . . 7 Meteorological Conditions ............. . . 9

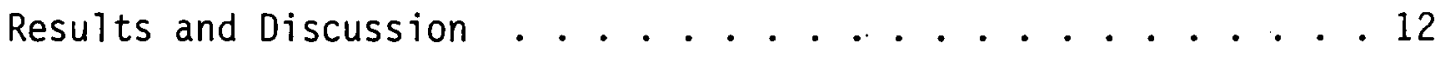
Summary . . . . . . . . . . . . . . . 14

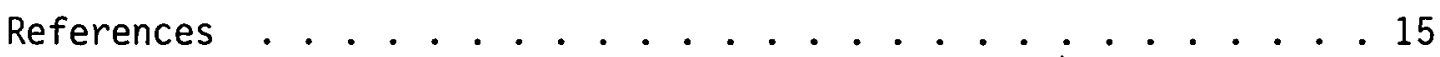

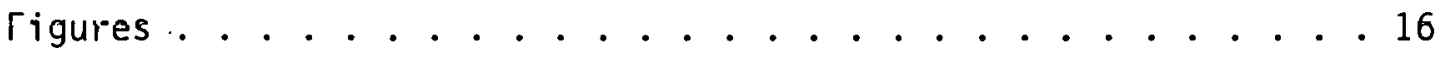
Appendix: Hydrographic Data . . . . . . . . . 36 BF-14-77, 8-9 March $1977 \ldots . . . . . . . . .38$ BF-38-77, 26-27 May $1977 \ldots 57$ BF-57-77, 13-14 September 1977 .......... 69 CI-01-78, 23-26 January 1978 . . . . . . . . . 88

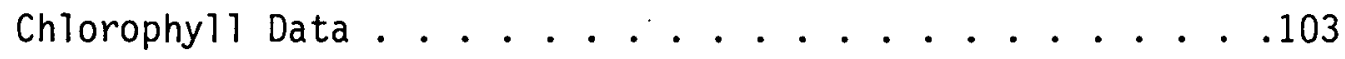




\section{LIST OF FIGURES}

Page

Figure 1. Station Locations (March 1979) . . . . . . . . 17

Figure 2. Station Locations (May 1977) . . . . . . . . . 18

Figure 3. Station Locations (September 1977) . . . . . . . 19

Figure 4. Station Locations (January 1978) . . . . . . . . 20

Figure 5. Meleurulugical Dald From Savannah, Georgla (March 1977)................. 21

Figure 6. Meteorological Data from Savannah, Georgia (May 1977)................ 22

Figure.7. Meteorological Data from Savannah, Georgia (September 1977) .............. 23

Figure 8. Meteorological Data from Savannah, Georgia (January 1978)................. 24

Figure 9. Vertical temperature structure for the Savannah and Brunswick sections, 8-9 March 1977 . . . . . 25

Figure 10. Vertical temperature, salinity and sigma-t structure for the Savannah section, 26-27 May 1977 . . . . . 26

Figure 11. Vertical nitrate, phosphate and silicate structure for the Savannah section, 26-27 May 1977 . . . . 27

Figure 12. Vertical temperature, salinity and sigma-t structure for the Brunswick section, 13-14 September 1977 ............... 28

Figure 13. Vertical nitrate, phosphate and silicate structure for the Brunswick section, 13-14 September 1977 .................. . . 29 


\section{LIST OF FIGURES (continued)}

Page

Figure 14. Vertical temperature, salinity and sigma-t structure for the Savannah section, 14 September 1977

Figure 15. Vertical nitrate, phosphate and silicate structurc for the Savannah section, 14 Septemher 1977 . . . . . . . . . . . . . 31

Figure 16. Vertical temperature, salinity and sigma-t structure for the Savannah section, 23-24 January 1978 . . . . . . . . . . . . 32

Figure 17. Vertical nitrate, phosphate, silicate and chlorophyll-a structure for the Savannah section, 23-24 January 1978 . . . . . . . . . . . . 33

Figure 18. Vertical temperature, salinity and sigma-t structure for the Brunswick section, 24-25 January 1978 . . . . . . . . . . . . 34

Figure 19. Vertical nitrate, phosphate, silicate and chlorophyll-a structure for the Brunswick section 24-25 January 1978 . . . . . . . . . . . 35 


\section{LIST OF TABLES}

$\underline{\text { Page }}$

Table 1. Georgia Bight Cruises . . . . . . . . . . . 3

Table 2. CTD Data Flow. Shipboard Acquisition to

NODC Submitted ............... . . 5

Table 3. Cruise BF-38-77 Salinity Calibration Data . . . . . 6

Table 4. "Cruise BF-57-77 Salinity Calibration Data . . . . . 6

Table 5. CTD Salinity Offset Equations . . . . . . . . . 7

Table 6. Cruise BF-38-77 Temperature Calibration Data . . . 8

Table 7. Cruise BF-57-77 Temperature Calibration Data . . . 8

Table 8. Сто Temperature Calibration Check . . . . . . . . 7

Table 9. Specifications for Plessey Model 9400 CTD System. . . 9

Table 10. Broenkow's Salinity Equations . . . . . . . . 10

Table 11. Flow Using Broenkow's Salinity Equation . . . . . 11 


\section{ACKNOWLEDGEMENTS}

The authors thank all those who participated in these cruises. These include the following scientists, technicians and students: Jack Blanton, Beth Bonnett, Tom Creighton, Don Deibel, Marilyn DeVand, Jeff Goodwin, Paul Magid; Jean Nichols, Pat 0'Malley, Gus Paffenhofer, Don Rịce, Lynn Rubicam and Frank Taylọr.

Special thanks go to the captains, mates and crews of the R/V Blue Fin and the R/V Columbus Iselin. Pat $0^{\prime}$ Malley directed nutrient analyses with the able assistance of Terry DeLoach, Paul Magid and Lynn Rubicam. Bob Redmond, Lori Knight and Dan McIntosh provided drafting and graphics assistance and Linda Land typed the text.

Funding for this research and report preparation was provided by the Department of Energy under contract EY-76-S-09-0889 to Dr. Atkinson.

This report is published as part of the Georgia Marine Science Center's Technical Report series issued by the Georgia Sea Grant Program under NOAA Office of Sea Grant 04-7-158-44126. 


\section{ABSTRACT}

Seasonal onshore-offshore sections were run in March, May and September, 1977 and January, 1978 off Savannah and Brunswick, Georgia. In each instance upwelling was observed at the shelf break with significant nutrient fluxes into the surface and/or shelf waters. There are indications that eddies may have been responsible for some of these observations. 


\section{INTRODUCTION}

This report contains data obtained during the following seasonal Georgia Bight cruises:

Table 1. Georgia Bight Cruises.

These investigations were part of a larger multi-institutional Department of Energy program to understand event scale, physical, chemical and biological processes of the South Atlantic Bight, the continental shelf region from Cape Canaveral, Florida to Cape Hatteras, North Carolina. The studies reported here were concentrated in the Georgia Bight near Brunswick and Savannah, Georgia. The hydrographic data will be used to compare with data from moored instruments deployed by the University of Miami (Dr. Tom Lee). All data are presented in the Appendix and are on file with the National Oceanographic Data Center (NODC).

METHODS

SAMPLING

One or two onshore/offshore hydrographic sections were run during each cruise. These consisted of conductivity/temperature/depth (CTD) or expendable bathythermograph (XBT) casts along sections extending ESE of Savannah and Brunswick, Georgia. The stations were 10 to 20 kilometers apart and extended out to the shelf break (Figures 1-4).

At CTD stations, General Oeeanics Model 1015 Mark 5 Roscttc multi-bottle array was used for water sampling. A Plessey Model 9400 CTD sensor system was attached below the array. Water sampling depths were determined from the temperature structure. Samples were taken near the surface, just above or below the thermocline, at the bottom and ocassionaliy at other selected depths. Data are reported for temperature, salinity, nitrate, phosphate and silicate concentrations. Niskin bottle casts were also made at some but not all of the XBT stations.

CHEMICAL AND PHYSICAL PROCEDURES

Salinity samples were analyzed conductometrically using a Plessey Model $6230 \mathrm{~N}$ laboratory salinometer. Values obtained were used to calibrate the Plessey CTD system. A separate section of this report details the CTD calibration procedure. Temperature was determined with deep sea reversing thermometers, XBT's and the CTD system. 
Nutrient samples were immediately frozen in $125 \mathrm{ml}$. polyethylene bottles and stored in the dark until thawed and analyzed ashore. Colorimetric determinations of the nutrient concentrations were made using a Bausch and Lomb Spectronic 88 Spectrophotometer. Silicate was determined by the method of Mullin and Riley (1955) as modified by Strickland and Parsons (1972), phosphate by the method of Murphy and Riley (1962) and nitrate by the cadmium column reduction technique of Gardner et al. (1976).

Chlorophyl1-a was determined fluorometrically using the method of Yentsch and Menzel (1963) as described by Strickland and Parsons (1972).

XBT Data Acquisition and Processing

A Sippican Model LM3A handheld launcher and an MK2A-1 recorder were used for XBT casts. The temperature/depth plots were manually digitized and these data were placed in NODC format and merged with processed CTD data. Depths at which temperature is a whole or half degree are reported as are depths at which a significant mixed layer begins or ends.

CTD Data Acquisition and Processing

The CTD unit consisted of a Plessey Model 9400 CTD sensor system with a Model 8400 digital data logger and Kennedy Model 1600 incremental magnetic tape recorder for data acquisition and storage. A redundant $X Y Y^{\prime}$ plot was made of all casts using a Hewlett-Packard Model $7046 \mathrm{X}-\mathrm{Y}-\mathrm{Y}$ recorder calibrated with a precision 10VDC source.

A second data acquisition system under development was also used during these cruises. It involved the addition of an HP 9825A Calculator to control the casts and to record the data on cartridge tape, and an HP $9862 \mathrm{~A}$ Plotter to plot temperature during the cast and salinity immediately afterwards. This permitted immediate confirmation of data acquisition and its relative quality.

Details of the operation of these systems and the processing of data are presented in Chandler et al. (1978). A general outline of the magnetic tape data processing is presented in Table 2.

CTD and XBT Calibration

For primary calibration of temperature and salinity, a Niskin bottle equipped with paired protected deep sea reversing thermometers was tripped after a four-minute equilibration period at the maximum sample depth in mixed layers.

Additional salinity calibration data were collected from mixed layers during the upcast. At the bottom and at selected sampling depths, the CTD sampling rate was slowed and salinity calibration data were acquired before the bottles were tripped.

From analysis of these data (Tables 3 and 4 ), the following sal inity offsets were applied to the CTD data from cruises BF-38-77 and BF-57-77. (Table 5). 
Table 2. CTD Data Flow. Shipboard Acquisition to NODC Submitted.

\begin{tabular}{|c|c|}
\hline Data Source/Disposition & Data File \\
\hline Tape from data logger & $\begin{array}{c}\text { CTDRUN (Copies tape data to computer } \\
\text { file) } \\
\text { CRUISE }\end{array}$ \\
\hline & $\begin{array}{l}\text { MAGREAD (Converts binary coded data } \\
\text { to decimal) } \\
\text { BIRANG }\end{array}$ \\
\hline Enter depth offset & $\begin{array}{l}\text { CTDUNIT (Converts decimal units to } \\
\text { engineering units } \\
\text { LAG }\end{array}$ \\
\hline & $\begin{array}{c}\text { LAGFILT (Coarse filters and temperature } \\
\text { lag) } \\
\text { LATCH }\end{array}$ \\
\hline & $\begin{array}{l}\text { DLATCH (Removes decreasing and repeated } \\
\text { depths) } \\
\text { CTDATA }\end{array}$ \\
\hline & $\begin{array}{l}\text { CTDAVES (One meter average data) } \\
\text { AVE }\end{array}$ \\
\hline $\begin{array}{l}\text { Primary calibration from } \\
\text { bottle casts } \\
\text { Enter salinity offset }\end{array}$ & $\begin{array}{l}\text { BROENK (Calculates salinity and sigma-t) } \\
\text { SGSA }\end{array}$ \\
\hline & $\begin{array}{l}\text { NODCFO (Converts ton NODC format) } \\
\text { NODC }\end{array}$ \\
\hline $\begin{array}{l}\text { Type in headers on file } \\
\text { HEAD }\end{array}$ & $\begin{array}{r}\text { XBTMERG (Merges headers and XBT data) } \\
\text { NODC + HEAD }\end{array}$ \\
\hline & $\begin{array}{c}\text { NUTMERG (Merges NODC data with headers } \\
\text { and chemical data) }\end{array}$ \\
\hline Submitted to NODC & $\begin{array}{l}\text { FINAL } \\
\text { CEMLIST (Calculates sigma-t specific } \\
\text { volume anomaly, oxygen utilization, } \\
\text { and creates technical report } \\
\text { pages) }\end{array}$ \\
\hline & LIST (Creates station list) \\
\hline
\end{tabular}

IECHNICAL REPORT 
Table 3. Cruise BF-38-77 Salinity Calibration Data.

\begin{tabular}{|c|c|c|c|c|}
\hline $\begin{array}{l}\text { Station } \\
\text { No. }\end{array}$ & $\begin{array}{l}\text { Depth } \\
(\mathrm{m})\end{array}$ & $\begin{array}{l}\text { Bottle } \\
0 / 00\end{array}$ & CTD $\%$ & $\begin{array}{c}\text { Difference } \\
\text { Bottle-CTD }(0 / 00)\end{array}$ \\
\hline $\begin{array}{l}2 C \\
3 C \\
4 C \\
5 C \\
6 C \\
7 C \\
7 C \\
8 C \\
9 C \\
10 C \\
11 C \\
13 C \\
14 C \\
16 C\end{array}$ & $\begin{array}{l}14 m \\
13 m \\
14 m \\
15 m \\
24 m \\
28 m \\
16 m \\
31 m \\
34 m \\
40 m \\
41 m \\
53 m \\
74 m \\
10 m\end{array}$ & $\begin{array}{l}32.634 \\
32.738 \\
33.303 \\
33.869 \\
34.651 \\
35.456 \\
35.455 \\
35.810 \\
36.026 \\
36.095 \\
36.116 \\
36.316 \\
36.316 \\
32.513\end{array}$ & $\begin{array}{l}32.57 \\
32.68 \\
33.27 \\
33.81 \\
34.59 \\
35.42 \\
34.42 \\
35.75 \\
35.94 \\
36.02 \\
36.06 \\
36.27 \\
36.27 \\
32.45\end{array}$ & $\begin{array}{l}+.06 \\
+.06 \\
+.0 . \\
+.06 \\
+.06 \\
+.04 \\
+.04 \\
+.06 \\
+.09 \\
+.08 \\
+.06 \\
+.05 \\
+.05 \\
+.06\end{array}$ \\
\hline
\end{tabular}

Table 4. Cruise BF-57-77 Salinity Calibration Data.

\begin{tabular}{ccccc}
\hline $\begin{array}{c}\text { Station } \\
\text { No. }\end{array}$ & $\begin{array}{c}\text { Depth } \\
(\mathrm{m})\end{array}$ & $\begin{array}{c}\text { Bottle } \\
0 / 00\end{array}$ & CTD \%/oo & $\begin{array}{c}\text { Difference } \\
\text { Bottle-CTD } \% \text { oo })\end{array}$ \\
\hline $1 \mathrm{C}$ & $138 \mathrm{~m}$ & 36.191 & 36.074 & +.117 \\
$2 \mathrm{C}$ & $16 \mathrm{~m}$ & 36.268 & 36.151 & +.117 \\
$3 \mathrm{C}$ & $18 \mathrm{~m}$ & 32.218 & 36.101 & +.117 \\
$4 \mathrm{C}$ & $22 \mathrm{ill}$ & 36.219 & 36.111 & +.108 \\
$5 \mathrm{C}$ & $26 \mathrm{~m}$ & 36.229 & 36.126 & +.103 \\
$6 \mathrm{C}$ & $28 \mathrm{~m}$ & 36.238 & 36.138 & +.100 \\
$7 \mathrm{C}$ & $31 \mathrm{~m}$ & 36.250 & 36.154 & +.096 \\
$8 \mathrm{C}$ & $33 \mathrm{~m}$ & 36.228 & 36.135 & +.109 \\
$9 \mathrm{C}$ & $37 \mathrm{~m}$ & 36.327 & 36.218 & +.083 \\
$10 \mathrm{C}$ & $40 \mathrm{~m}$ & 36.325 & 36.242 & +.019 \\
$12 \mathrm{C}$ & $196 \mathrm{~m}$ & 35.034 & 35.015 &. \\
& & & & \\
\hline
\end{tabular}


Table 5. CTD Salinity Offset Equation

\begin{tabular}{|c|c|c|c|}
\hline Cruise & Date & Data Source & $\% / 00$ Offset Equation \\
\hline $\mathrm{BF}-38-77$ & $5 / 26-27 / 77$ & HP-Cartridge & $+0.06 \pm 0.015$ \\
\hline $\mathrm{BF}-57-77$ & $9 / 13-14 / 77$ & Magnetic Tape & ${ }^{\star} \mathrm{S}=\mathrm{S}_{0}+.118-5.19 \times 10-{ }^{4} \mathrm{D}$ \\
\hline
\end{tabular}

$S_{0}=$ Uncorrected CTD Salinity
$D^{0}=$ Depth

* It was necessary to apply an additional correction of $-0.11 \%$ to Station 16-C after processing.

The magnetic tape data were normally our primary data source at this stage in the development of our acquisition system. However, the HP cartridge data were used for cruise $B F-38-77$ because a defective frequency plug resulted in erroneous magnetic tape data. The absence of an apparent depth effect for this same cruise is attributed to the shallowness of the samplings (deepest was 74 meters). Here, the normal instabilities of the instrumentation prohibit the determination of any discernible depth relationship. (See CTD Error Analysis).

The temperature of the CTD system was checked against reversing thermometers (Tables 6 and 7). Since the CTD temperature sensor agreed with protected reversing thermometers within the range of accuracy $\left( \pm 0.02^{\circ} \mathrm{C}\right)$, no offset was applied (Table 8$)$. A +2.29 meter depth offset was applied to both sets of CTD data.

Table 8. CTD Temperature Calibration Check.

\begin{tabular}{|c|c|c|c|}
\hline Cruise & Date & Reversing Thermometer - CTD & $\begin{array}{l}\text { SLándarid } \\
\text { Deviation }\end{array}$ \\
\hline $\mathrm{BF}-38-77$ & $5 / 26-27 / 77$ & +.018 & .009 \\
\hline $\mathrm{BF}-57-77$ & $9 / 13-14 / 77$ & +.006 & .010 \\
\hline
\end{tabular}

The XBT system was checked for proper calibration before and during each cruise with a test canister and periodically with surface bucket and/or near bottom reversing thermometer readings. These indicated that the system operated within acceptable error $\left( \pm 0.1^{\circ} \mathrm{C}\right)$.

\section{CTD Error Analysis}

The Plessey Model 9400 CTD system has the following rated accuracy, resolution, and time constants (Table 9). 
Table 6. Cruise BF-38-77. Temperature Calibration Data.

\begin{tabular}{|c|c|c|c|c|c|c|}
\hline \multirow[b]{2}{*}{$\begin{array}{l}\text { Station } \\
\text { No. }\end{array}$} & \multirow[b]{2}{*}{$\begin{array}{l}\text { Depth } \\
(\mathrm{m})\end{array}$} & \multicolumn{3}{|c|}{$\begin{array}{l}\text { REVERSING THERMOMETER } \\
\text { TEMPERATURE }\left(0^{\circ} \mathrm{C}\right)\end{array}$} & \multirow{2}{*}{$\begin{array}{c}\text { CTD } \\
\text { Temperature } \\
\left({ }^{\circ} \mathrm{C}\right)\end{array}$} & \multirow[b]{2}{*}{$\begin{array}{l}\text { Difference } \\
\left({ }^{\circ} \mathrm{C}\right)\end{array}$} \\
\hline & & $\overline{1}$ & 2 & Ave & & \\
\hline $\begin{array}{r}2 C \\
4 C \\
5 C \\
6 C \\
10 C \\
11 C\end{array}$ & $\begin{array}{l}14 m \\
14 m \\
15 m \\
24 m \\
40 m \\
41 m\end{array}$ & $\begin{array}{l}24.17 \\
23.74 \\
23.48 \\
22.65 \\
23.90 \\
23.91\end{array}$ & $\begin{array}{l}24.15 \\
23.74 \\
23.45 \\
22.66 \\
23.88 \\
23.90\end{array}$ & $\begin{array}{l}24.160 \\
23.740 \\
23.465 \\
22.655 \\
23.890 \\
23.905\end{array}$ & $\begin{array}{l}24.14 \\
23.73 \\
23.43 \\
22.64 \\
23.88 \\
23.89\end{array}$ & $\begin{array}{l}+.020 \\
+.010 \\
+.035 \\
+.015 \\
+.010 \\
+.015\end{array}$ \\
\hline
\end{tabular}

Table 7. Cruise BF-57-77. Temperature Calibration Data.

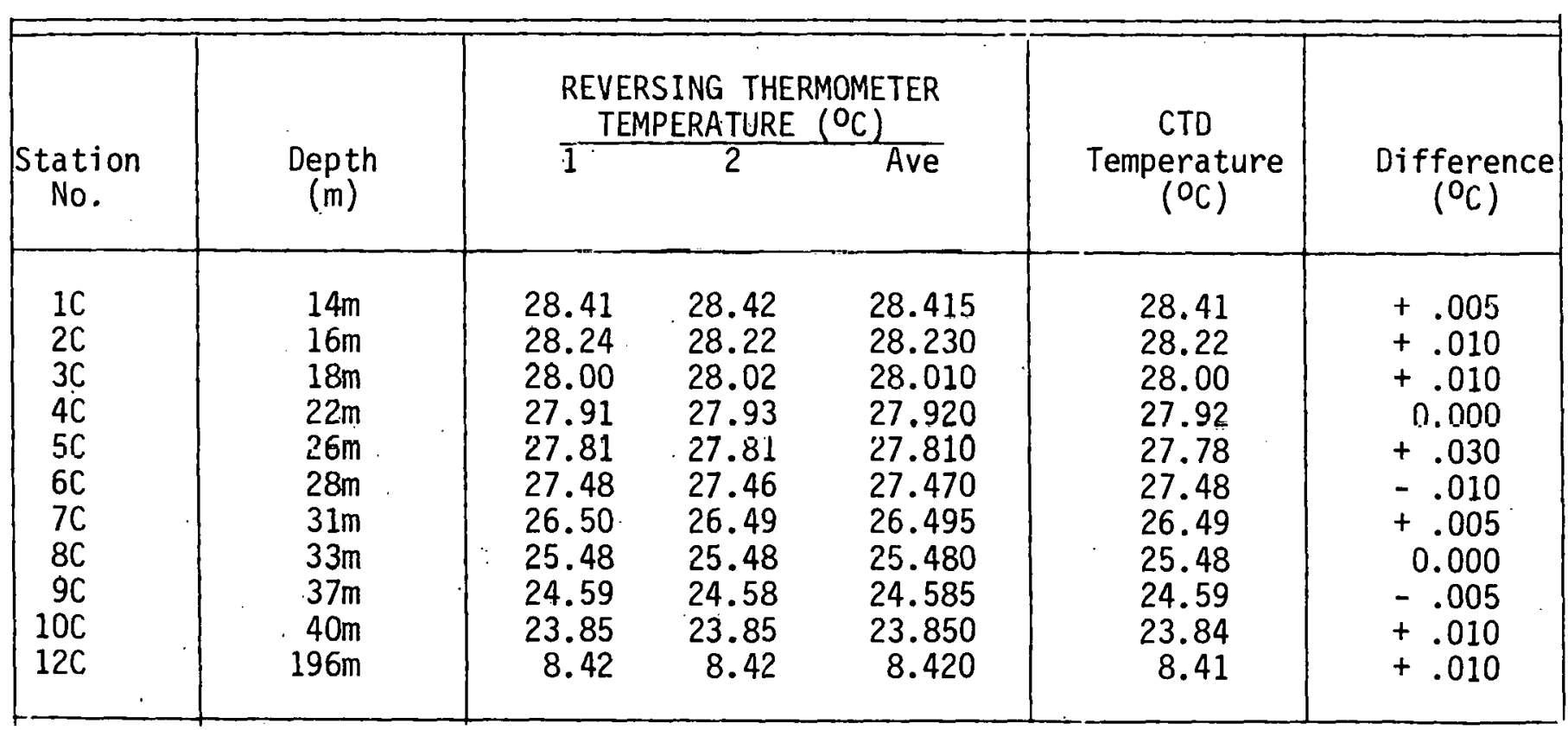


Table 9. Specifications for Plessey Model 9400 CTD System

\begin{tabular}{llll}
\hline & Conductivity & Temperature & Depth \\
\hline Accuracy & $\pm 0.03 \mathrm{mmho} / \mathrm{cm}$ & $\pm 0.02^{\circ} \mathrm{C}$ & $\pm 1.5 \mathrm{~m}$ \\
Resolution & $0.0001 \mathrm{mmho} / \mathrm{cm}$ & $0.0001^{\circ} \mathrm{C}$ & $0.0012 \mathrm{~m}$ \\
Time Constant & $0.1 \mathrm{sec}$ & $0.35 \mathrm{sec}$ & $0.1 \mathrm{sec}$ \\
\hline
\end{tabular}

Since salinity is not measured directly, it must be calculated from the above parameters, resulting in the composite errors of the $C, T$ and $D$ sensors and the salinity equation.

By varying "real" C, T and D by the rated sensor accuracies in the Broenkow CTD salinity equation (see Chandler et al. 1978, and Tables 10 and 11) the maximum error attributable to each sensor can be determined. The composite maximum error is approximately $\pm 0.06 \%$ oo for "rea. 7 " data sets. However, the standard deviation of all mixed layer samples taken for salinity calibration implies greater accuracy, namely $\pm 0.02 \%$ after offset. We believe this value is a more realistic measure of the quality of the data set.

\section{METEOROLOGICAL CONDITIONS}

Wind and temperature data from Savannah, Georgia are presented in Figures 5-8. These data were derived from the monthly summaries for the respective months (U.S. Department of Commerce: March 1977, May 1977, September 1977 and January 1978) and are plotted in GMT at three-hour intervals. Additional meteorological data, collected by the ships personnel, are presented with the hydrographic data. 
Table 10. Broenkow's Salinity Equations.

$$
\begin{aligned}
R_{Z}= & 1+.01\left\{\left(1.551-.0453 T+59 \times 10^{-5} T^{2}\right)\right. \\
& \left.+\frac{1}{4}(35-S)\left(.043-.0017 T+23 \times 10^{-6} T^{2}\right)\right\} 1.037 \times 10^{-3} Z \\
& \left.-32 \times 10^{-9} Z^{2}\right\} \\
A_{T}= & \left(676547+20131.5 T+99.89 T^{2}-.1943 T^{3}-.00672 T^{4}\right) 10^{-6} \\
R_{T}= & \frac{C(S, T, Z)}{R_{Z} A_{T} 42.896} \\
\Delta_{15}= & R_{T}\left(R_{T}-1\right)(T-15)\left\{96.7-72 R_{T}+37.3 R_{T}^{2}\right. \\
& \left.-\left(.63+.21 R_{T}^{2}\right)(T-15)\right\} 10^{-5} \\
R_{15}= & R_{T}+\Delta_{15} \\
S^{0} / 00= & .08996+28.2972 R_{15}+12.80832 R_{15}{ }^{2}-10.67869 R_{15}^{3} \\
& +5.98624 R_{15}{ }^{4}-1.32311 R_{15}^{5}
\end{aligned}
$$

where: $R=$ conductivity ratio

$Z$ = depth (meters)

$T=$ temperature $\left({ }^{\circ} \mathrm{C}\right)$

$C=$ neasured conductivity $(\mathrm{mmhos} / \mathrm{cml})$

$S=$ salinity $(\% / 00)$ 
Table 11. Flow Using Broenkow's Sàlinity Equation

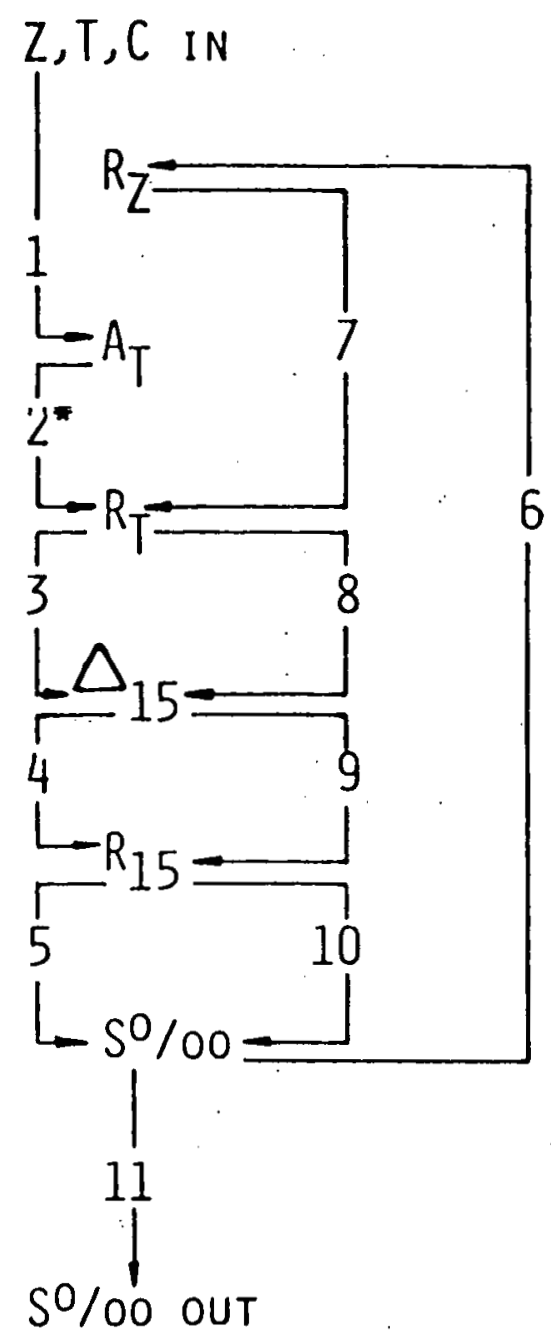

*without the $R_{Z}$ term

$R_{Z}=$ pressure effect on conductivity

$A_{T}=$ temperature effect

$R_{T}=R(S, t, p)$ conductivity ratio

$\Delta_{15}=t_{15}$ correction (International Oceanographic

Tables, 1966)

$R_{15}=R\left(S, 15^{\circ} \mathrm{C}, 0\right)$ 
RESULTS AND DISCUSSION

Savannah Section, 8-9 March 1977. (Figure 9)

Deep upwelling at the shelf break is indicated, and there is the appearance of cascading along the mid to outer shelf (stations $8 x$ and $9 x)$. This, however, may be due to by warmer offshore waters. No nutrient data were collected. Brunswick Section, 9 March 197\%. (FIgure 9.)

Upwelling is occurring at the shelf break. The $21^{\circ} \mathrm{C}$ lobe at stations $25 x$ and $2 \hbar x$ suggests that the upwelling may have resulted from an eddy. Note the differences in the vertical structure on the shelf between this section and the Savannah section, a horizontal distance of less than 60 nautical miles (111 kilometers). No nutrient data were collected.

Savannah Section, 26-27 May 1977. (Figures 10-11)

The temperature and sigma-t plots reveal an upwelling regime centered around station $13 x / C$. The nutrient data, however, reveal that significant nutrient concentrations did not occur in the surface waters because of the high temperatures.

The warm surface lobe at stations $11 C$ and $12 X$ with cooler waters at stations $13 \mathrm{X} / \mathrm{C}$ and $14 \mathrm{C}$, and then warmer waters again at station $15 \mathrm{X}$ suggest an eddy. A similar trend is seen in the density field where density increases and then decreases moving offshure at the sheif hreak. Brunswick Section, 13-14 September 1977. (Figures 12-13).

A strong upwelling regime has been established at the shelf break with significant nutrient enrichment of the surface waters. The upwelling is evident in all parameters. Cooler, high nutrient waters are producing an "intrusion" on the shelf. 
Savannah Section, 14 September 1977. (Figures 14-15)

Upwelling similar to that shown for the Brunswick section on 13-14 September is evident. However, nutrient concentrations in the shallower waters are not as great.

Savannah Section, 23-24 January, 1978. (Figures 16-17)

There is an overriding of shelf waters by warmer offshore waters with the $20^{\circ} \mathrm{C}$ isotherm roughly depicting the western wall of the Gulf Stream. Deep upwelling is apparent at the shelf break and high levels of nitrate, phosphate and silicate have reached the surface. In addition, there are extremely high clorophyll concentrations in the surface waters at the shelf break, a further indication of strong upwelling. Brunswick Section 24-25 January 1978. (Figures 18-19)

Strong upwelling at the sheif break is indicated by the nitrate and silicate data. This upwelling feature is less obvious in plots of the other parameters. 


\section{SUMMARY}

Upwelling was observed at the shelf break during each of the cruises in March, May, September and January. This resulted in significant nutrient enrichment of surface and shelf waters. Nutrient concentrations as high as $5 \mu M$ nitrate, $.2 \mu M$ phosphate and $2 \mu M$ silicate were observed in the top $30 \mathrm{~m}$.

Gulf Stream eddies and meanders are probable explanations for at least some of the observed upwelling. However, confirmation will depend upon analysis of current meter data from moorings placed in the study area by the University of Miami (Dr. Tom Lee). 


\section{REFERENCES}

Chandler, W.S., L.P. Atkinson, J.J. Singer, P.G. O'Malley and C.V. Baker. 1978. A CTD system: Description, Operation, Data Acquisition and Processing. Georgia Marine Science Center Technical Report 78-7.

Gardner, W.S., D.S. Wynne, and W.M. Dunstan. 1976. Simplified procedure for the manual analysis of nitrate in sea water. Mar. Chem., 4: 393-396.

Mullin, J.B, and J.P. Riley. 1955. The colorimetric determinaliun of silicate with special reference to sea and natural waters. Anal. Chim. Acta, 12: 162-176.

Murphy, J. and J.P. Riley. 1962. Modified single solution method for the determination of phosphate in natural waters. Anal. Chim. Acta, 27: 31-36.

Strickland, J.D. and T.R. Parsons. 1972. A practical handbook of seawater analysis. Bull Fish. Res. Bd. Canada, 167: 1-311.

U.S. Department of Commerce, NOAA, EDS. Local Climatological Data, Monthly Summary, Savannah, Georgia, March, May and September 1977 and January 1978. National Climatic Center, Asheville, N.C.

Yentsch, C. and D.W. Menzel. 1963. A method for the determination of phytoplankton chlorophy 11 and phaephytin by fluorescence. Deep-Sea Res, 10: 221-231. 


\section{FIGURES}




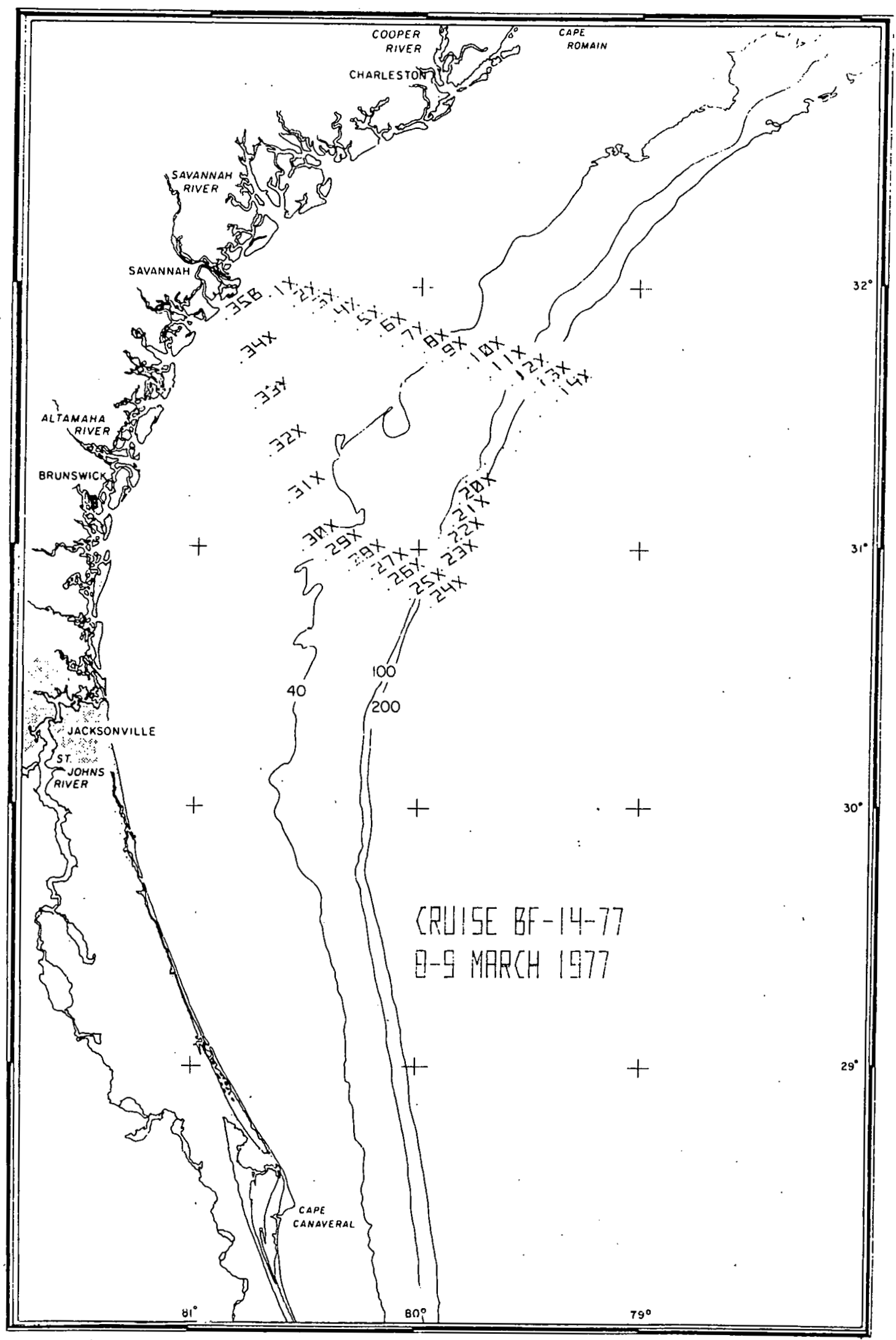

Figure 1. Station locations (March 1977) 


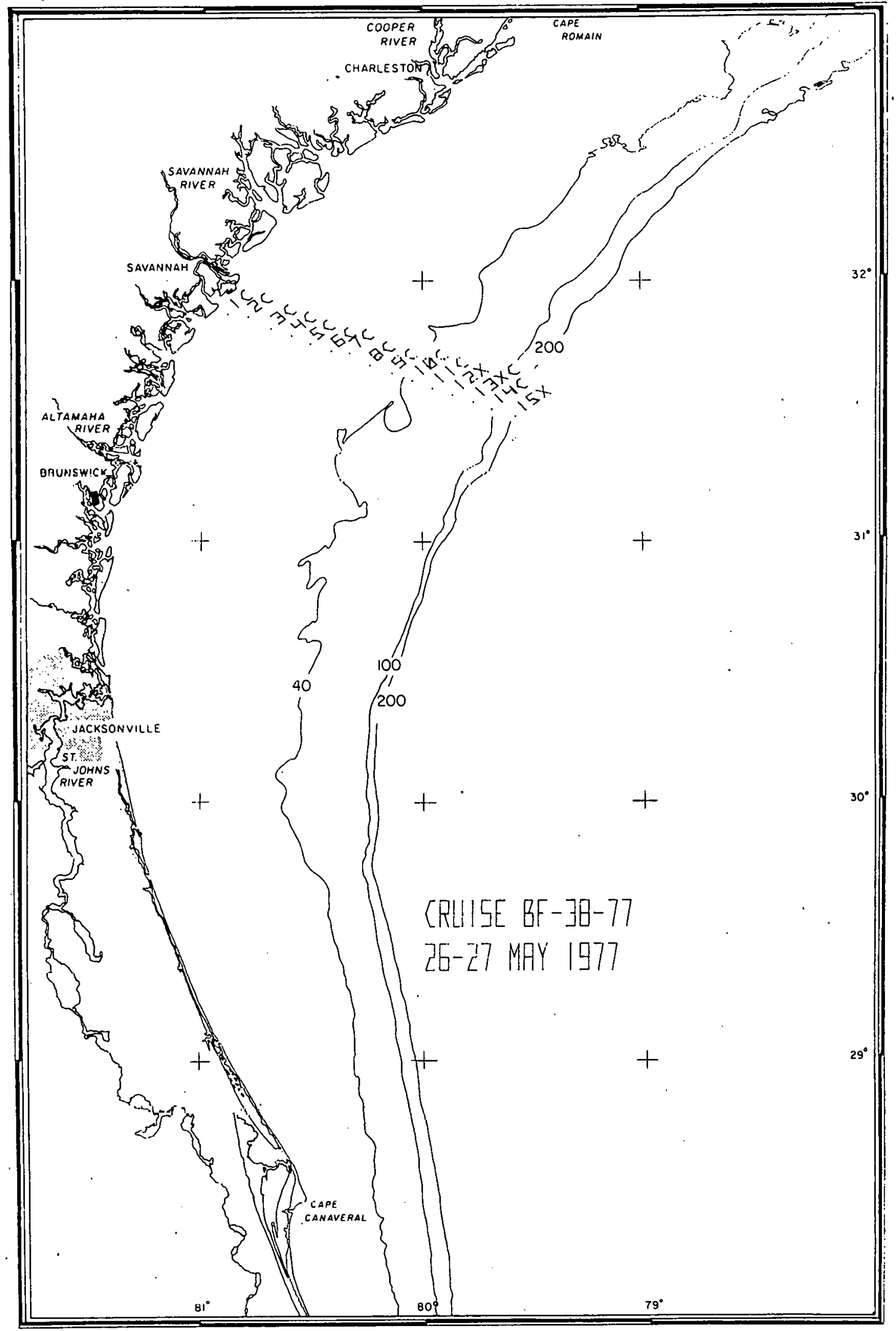

Figure 2. Station locations (May 1977) 


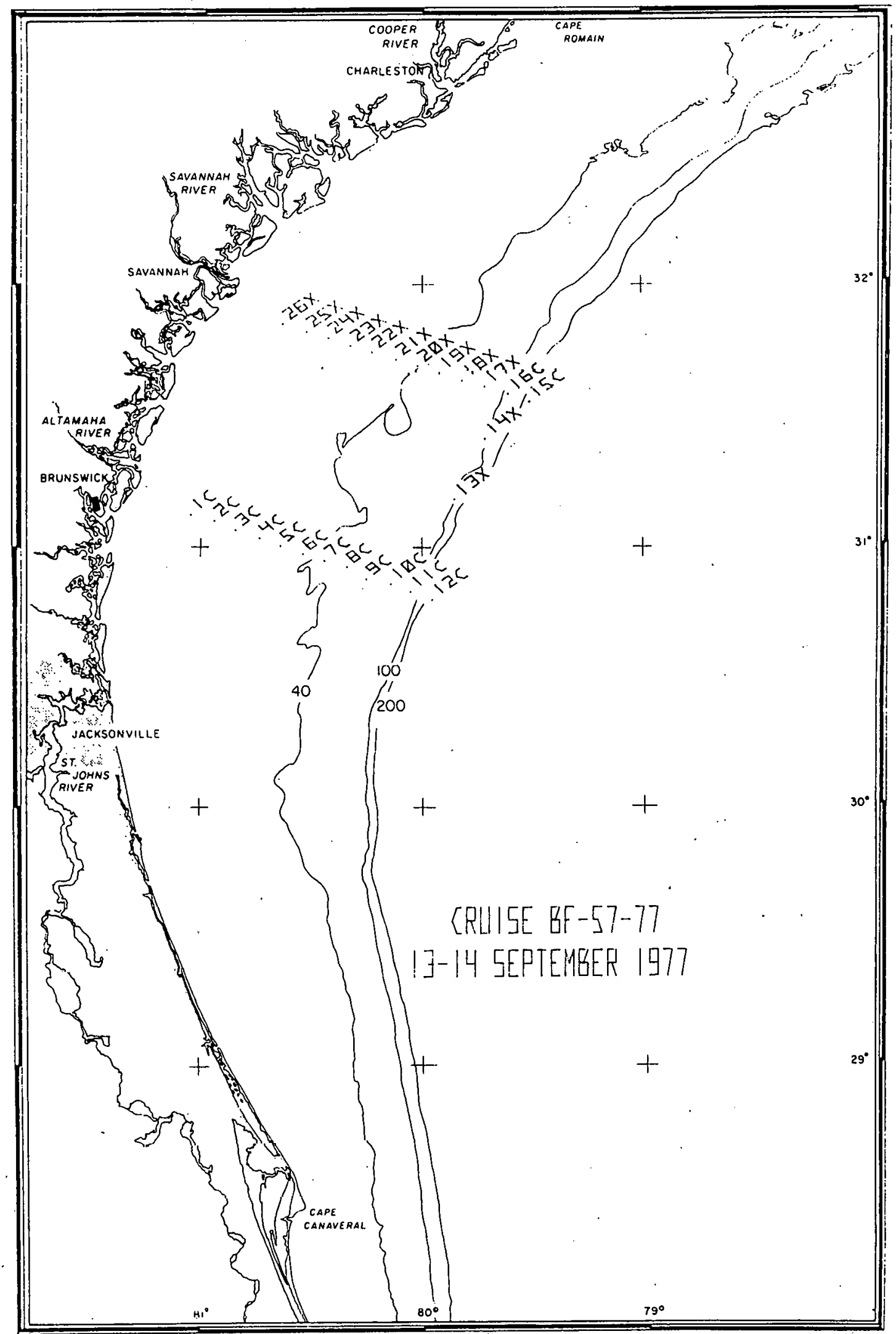

Figure 3. Station locations (September 1977) 


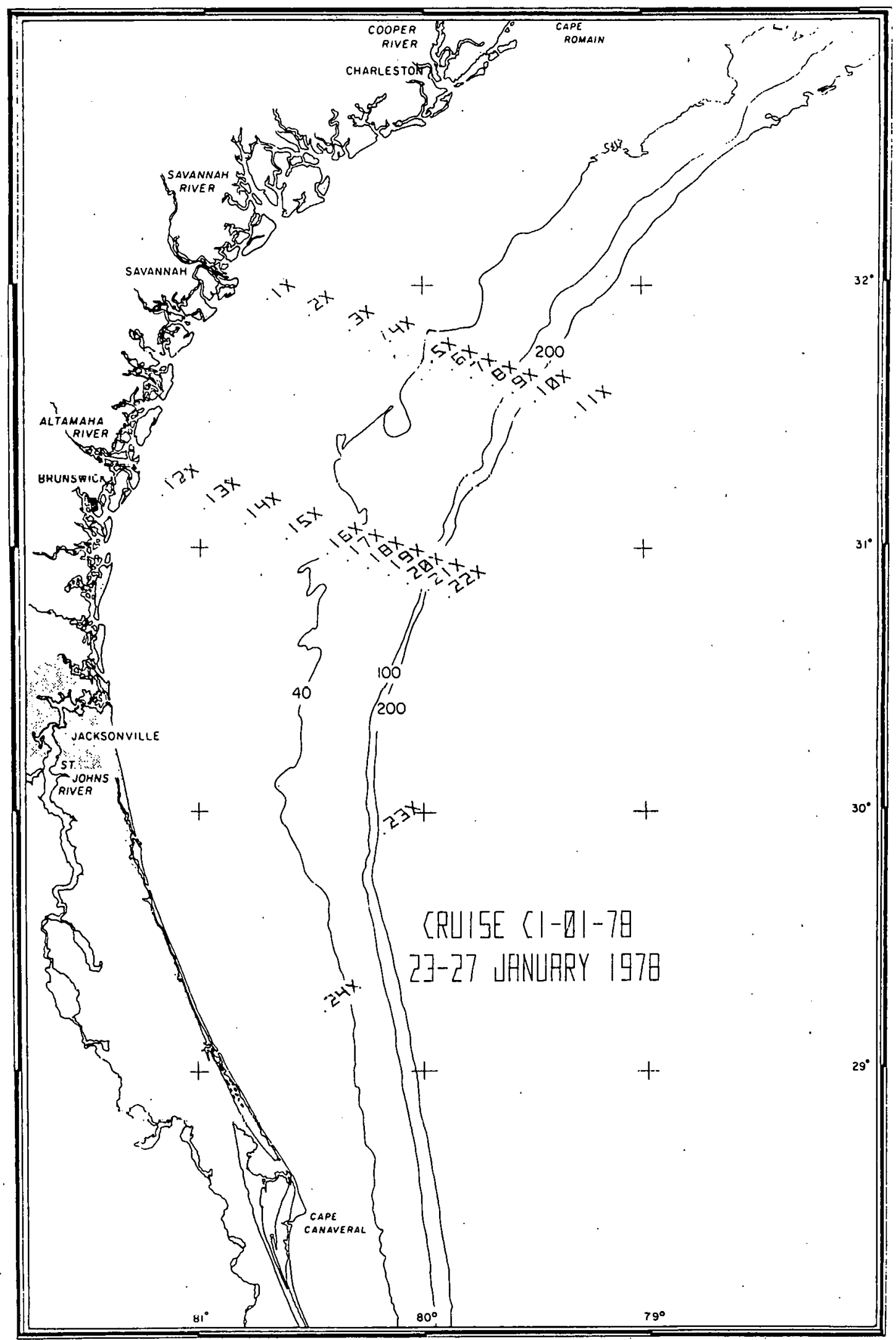

Figure 4. Station locations (January 1978) 

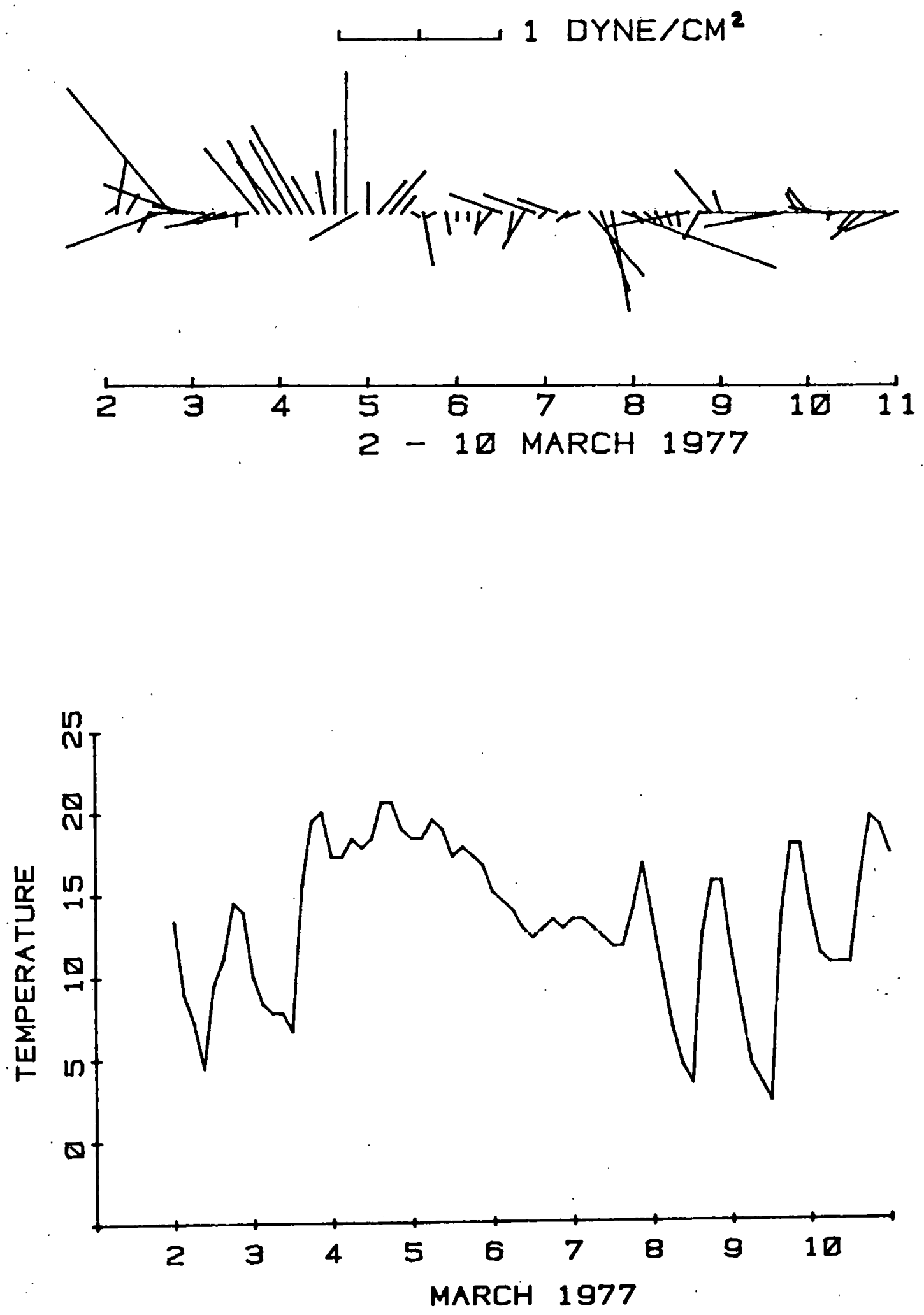

Figure 5. Meteorological Data from Savannah, Georgia (March 1977). 

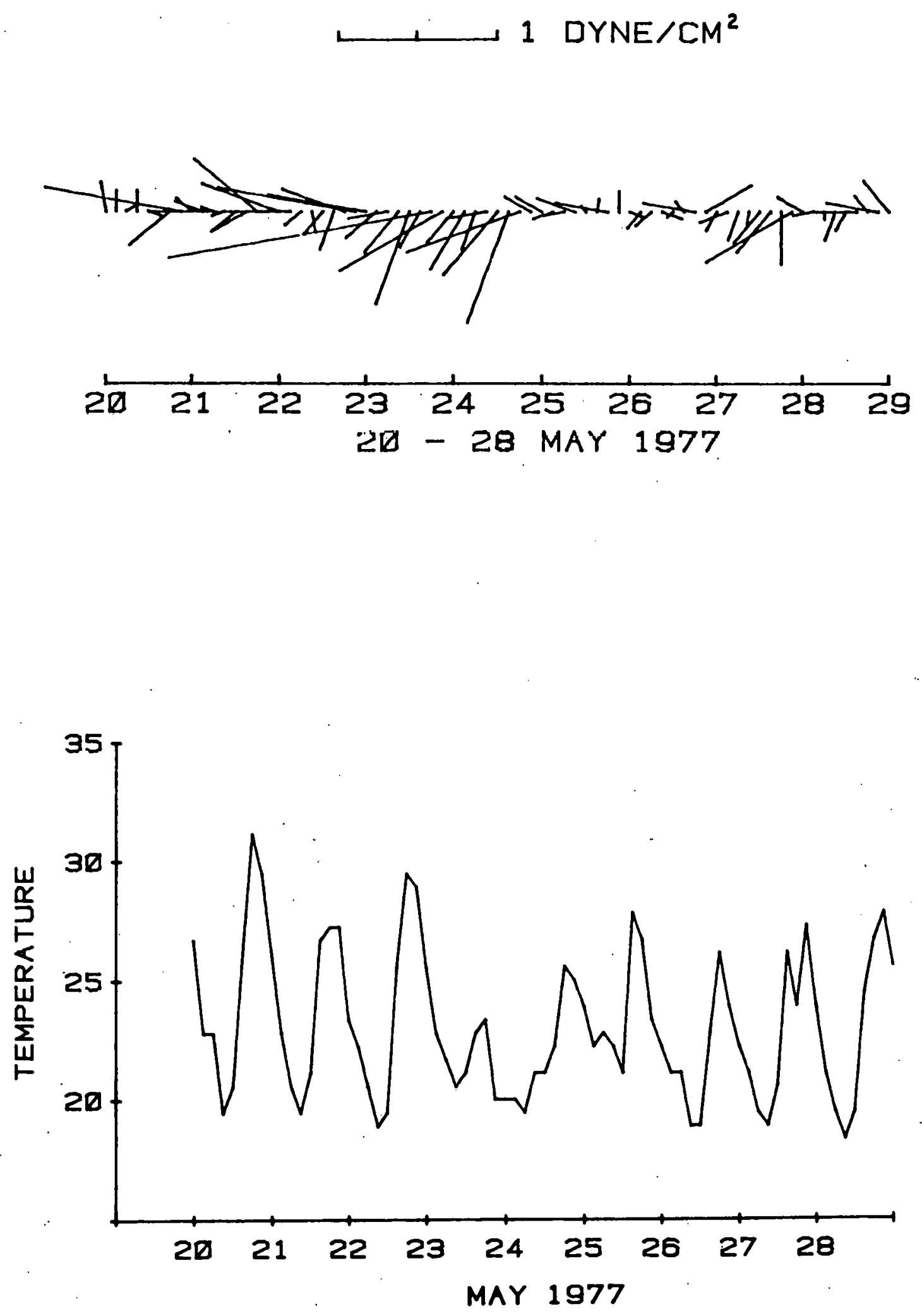

Figure 6. Meteorological Data from Savannah, Georgia (May 1977). 

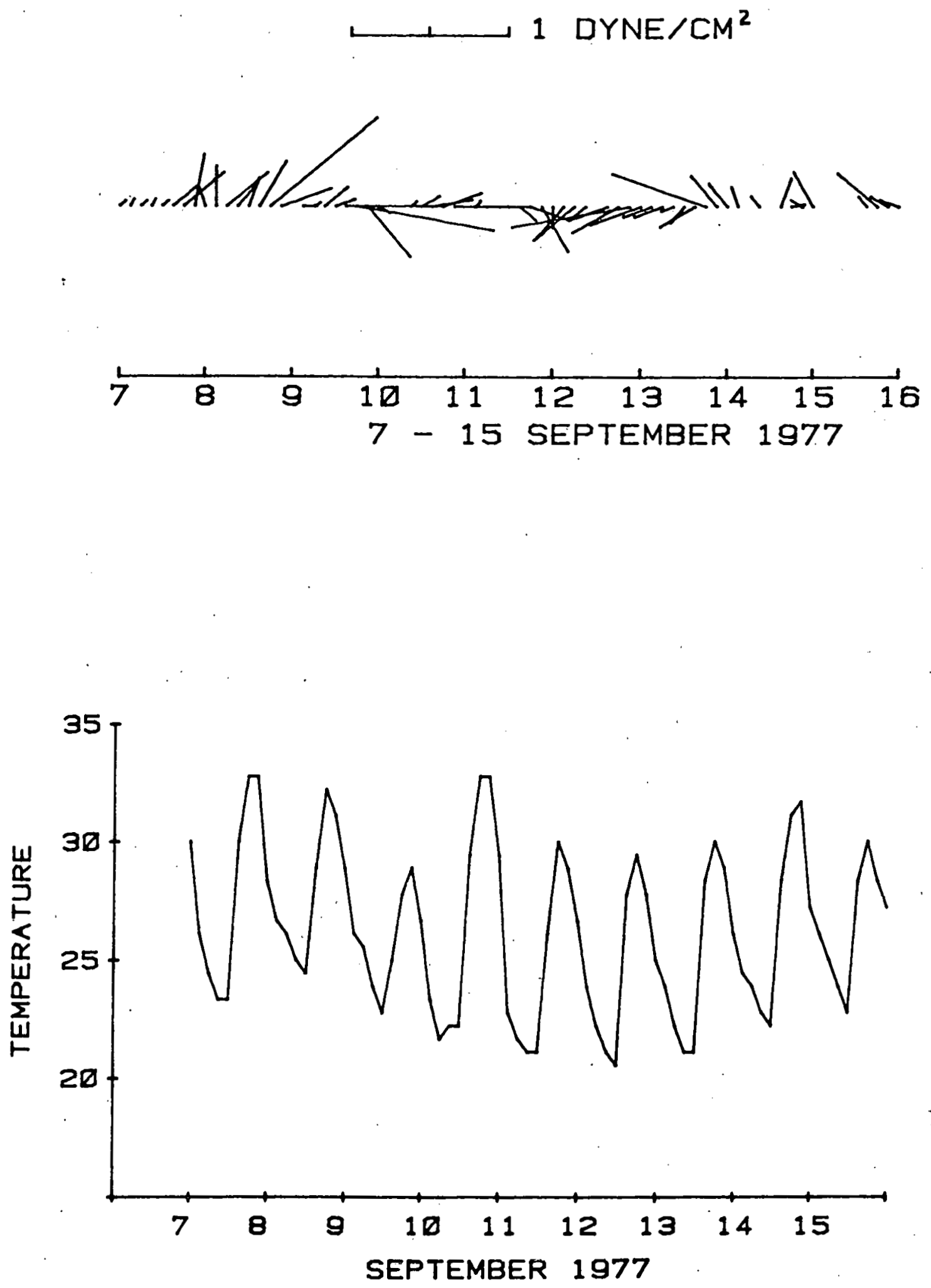

Figure 7. Meteorological Data from Savannah, Georgia (September 1977). 

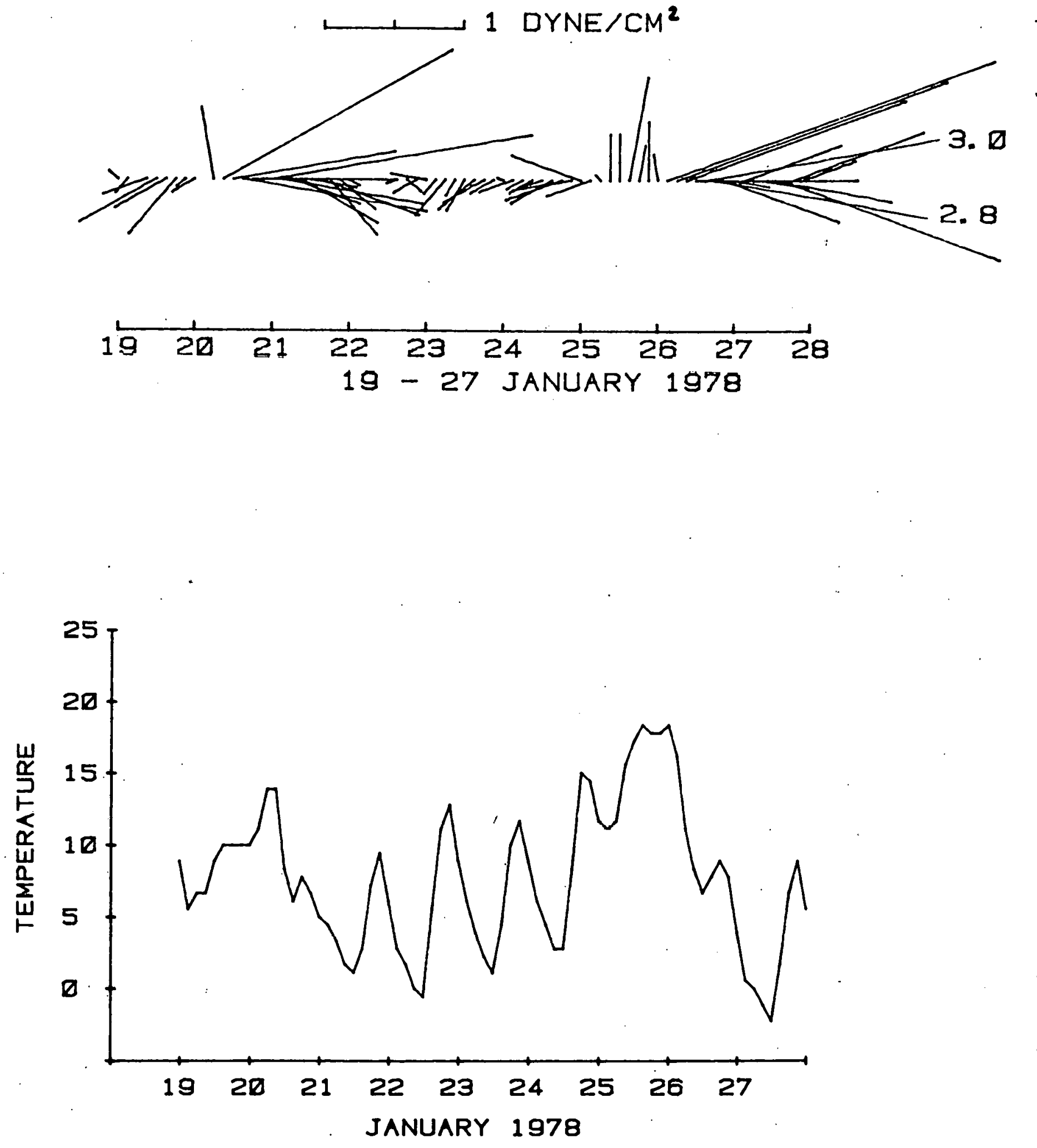

Figure 8. Meteorological Data from Savannah, Georgia (January 1978). 

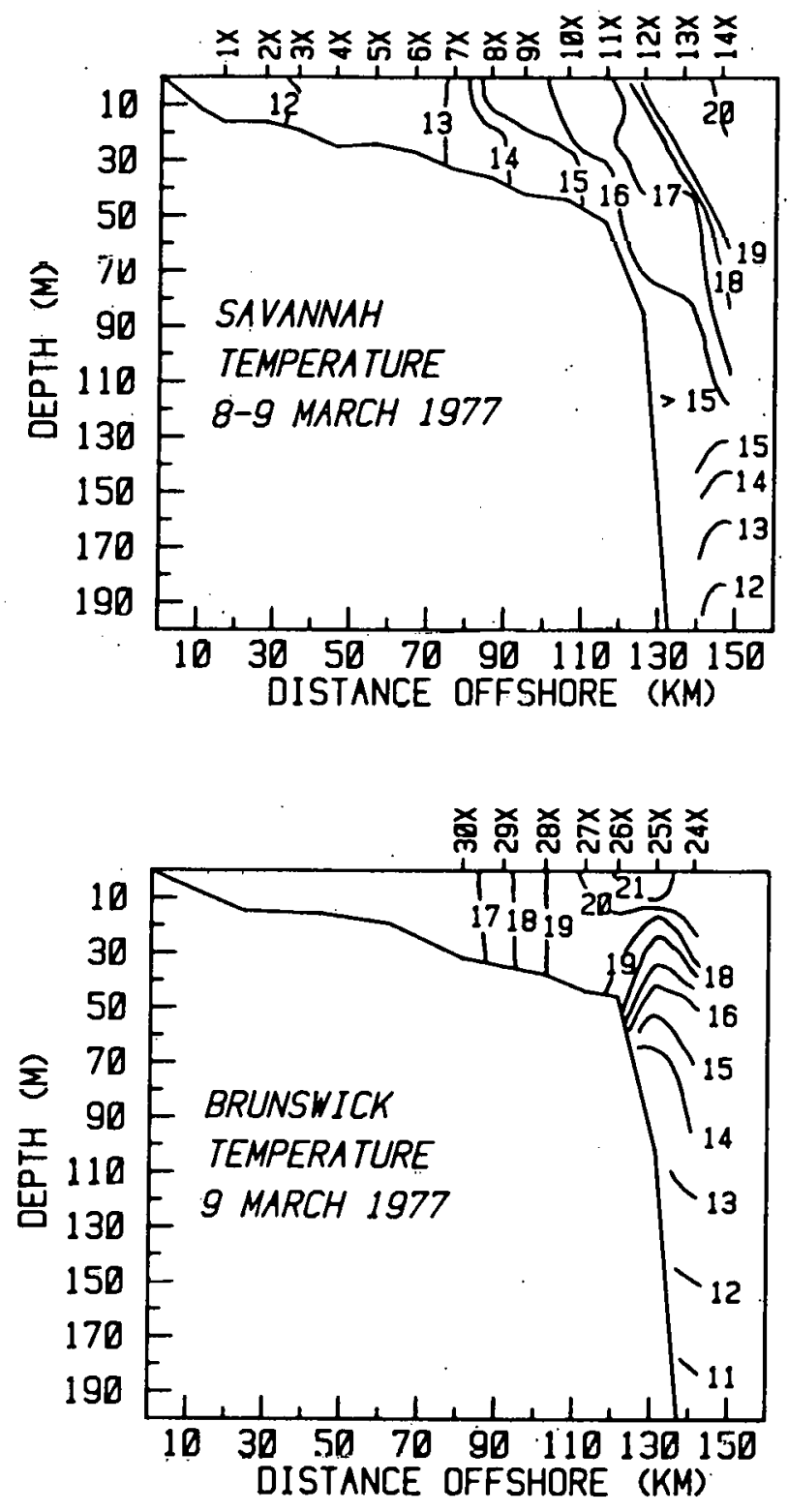

Figure 9. Vertical temperature structure for the Savannah and Brunswick sections, 8-9 March 1977. 

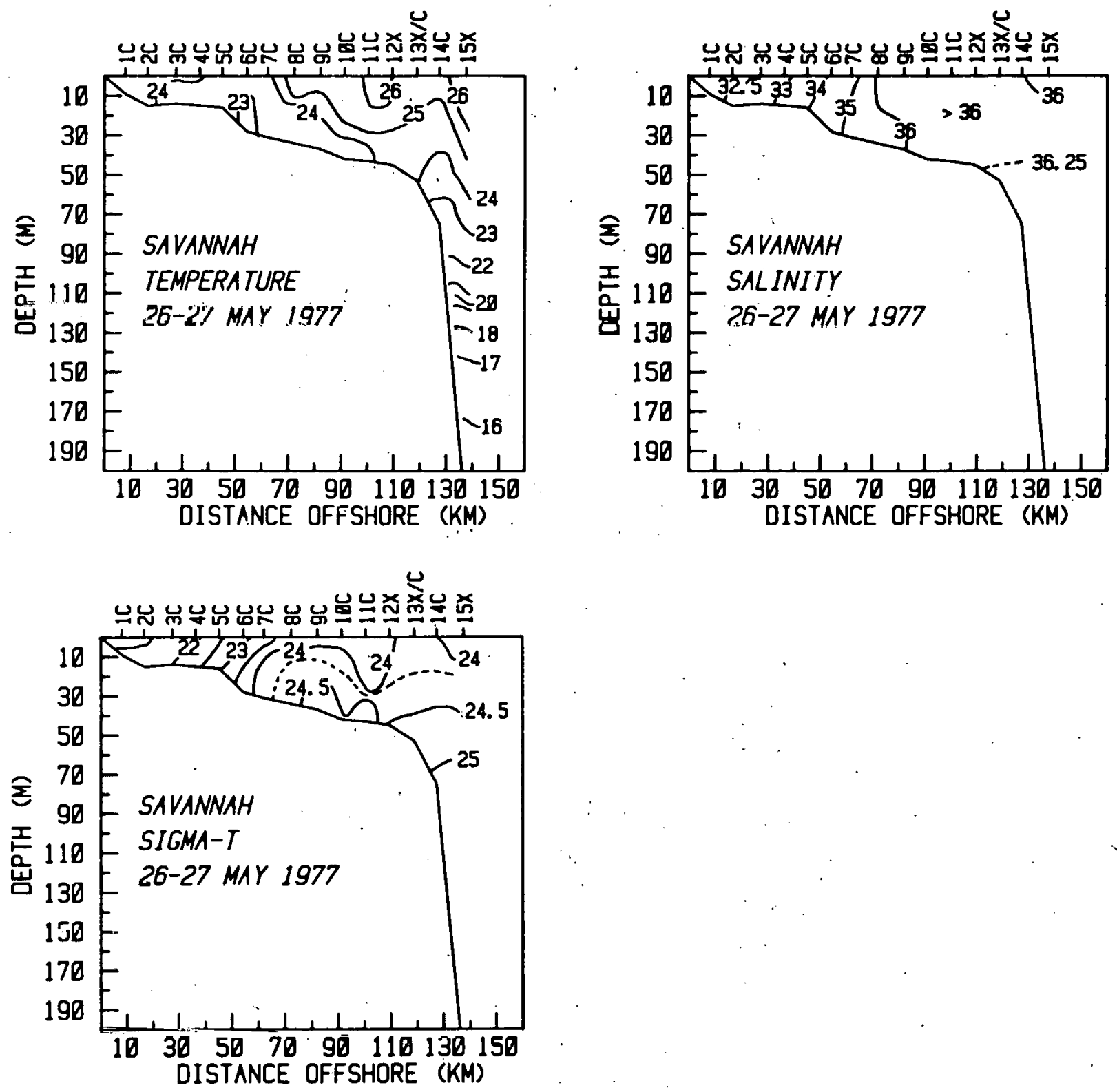

Figure 10. Vertical temperature, salinity and sigma-t structure for the Savannah section, 26-27 May 1977. 

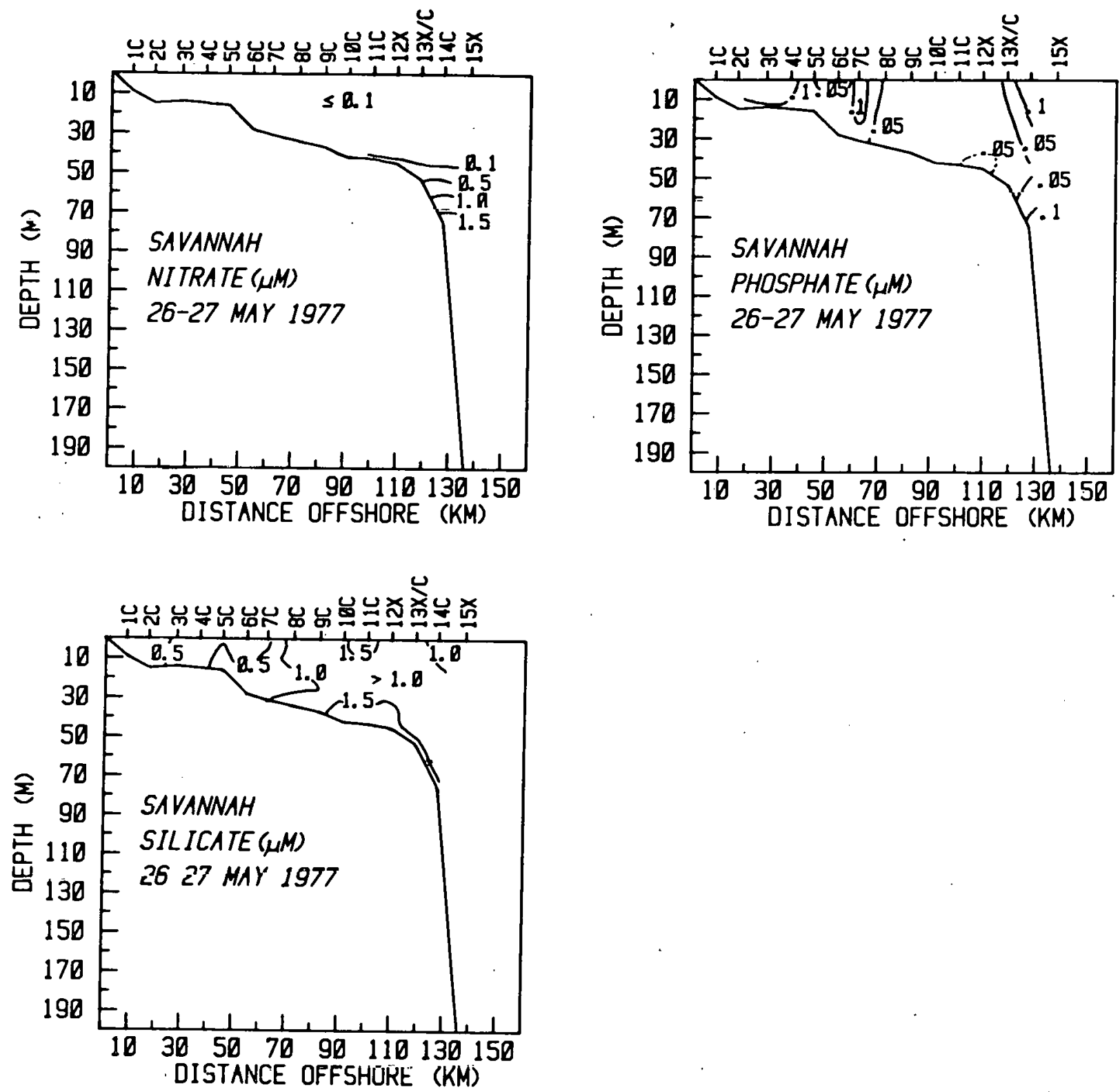

Figure 11. Vertical nitrate, phosphate and silicate structure for the Savannah section, 26-27 May 1977. 

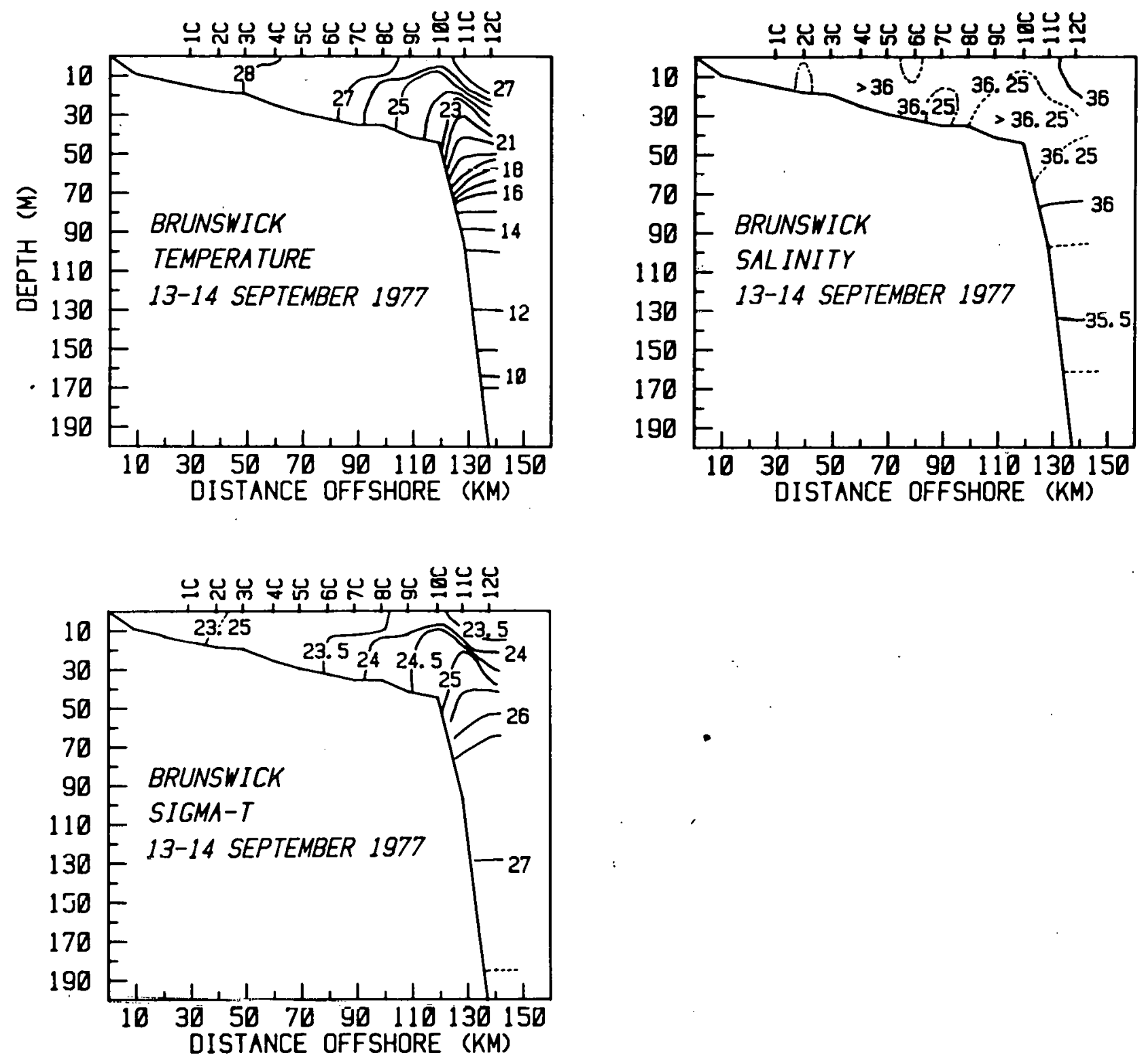

Figure 12. Vertical temperature, salinity and sigma-t structure for the Brunswick section, 13-14 September 1977: 

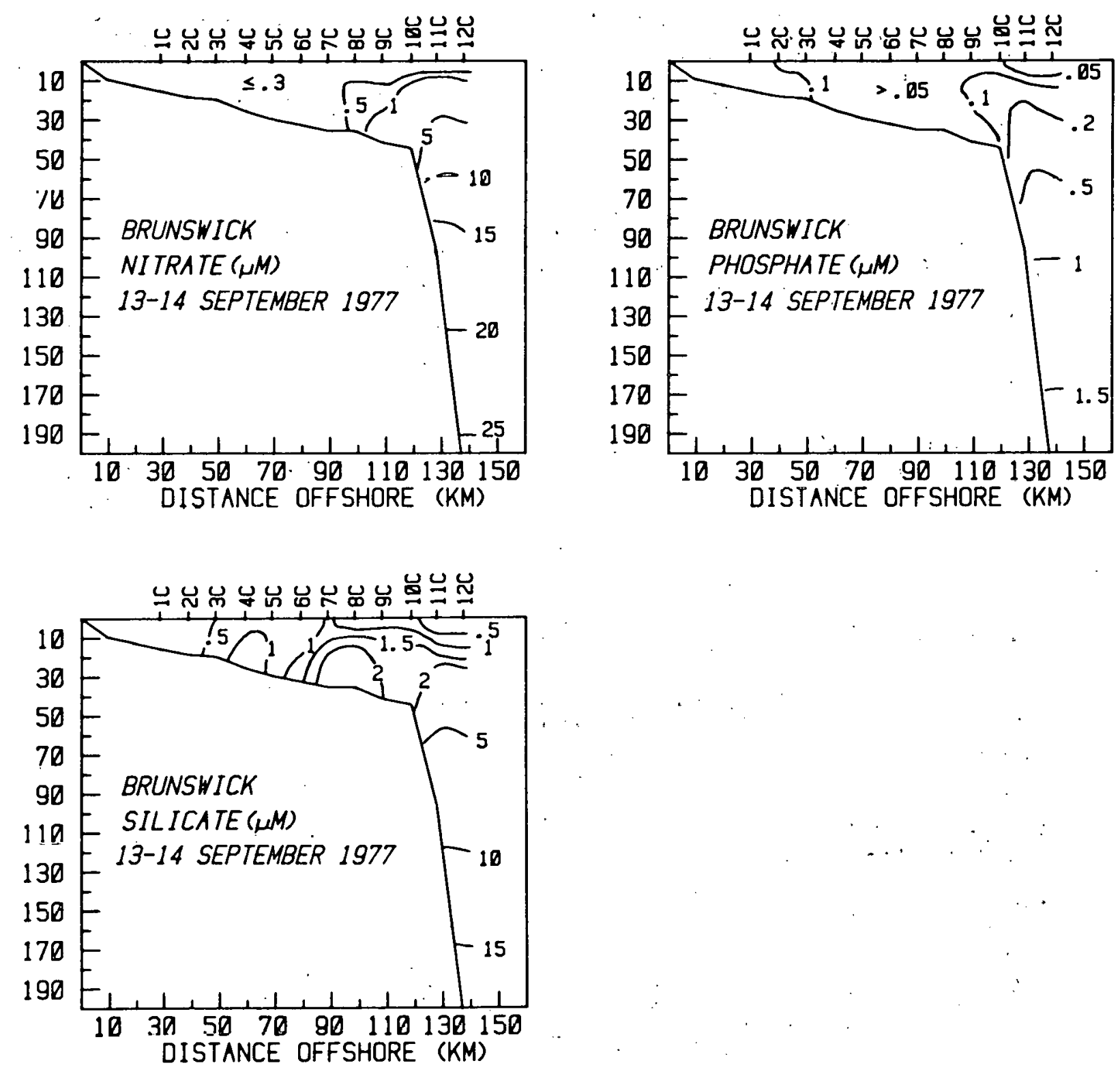

Figure 13: Vertical nitrate, phosphate and silicate structure for the Brunswick section, 13-14 September 1977. 


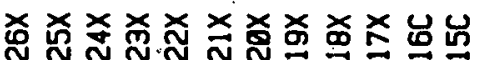

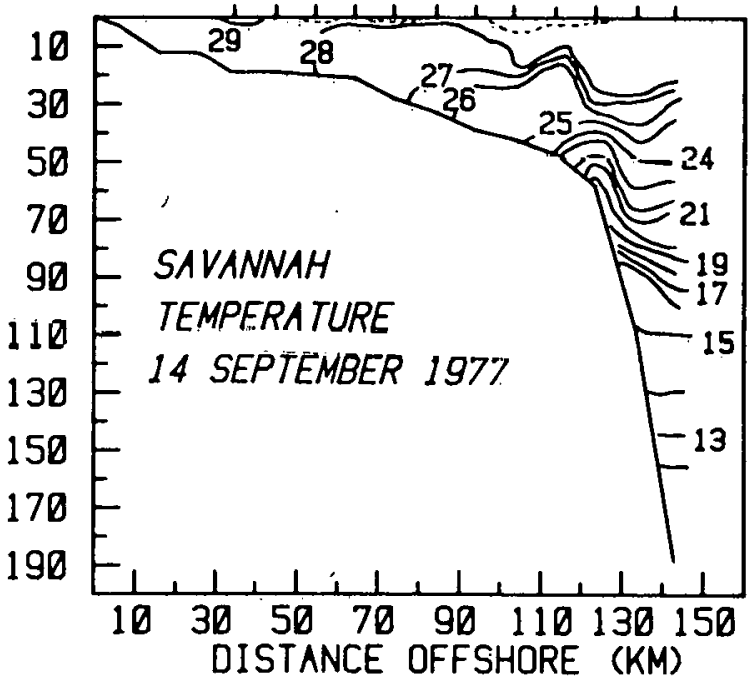

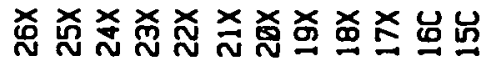

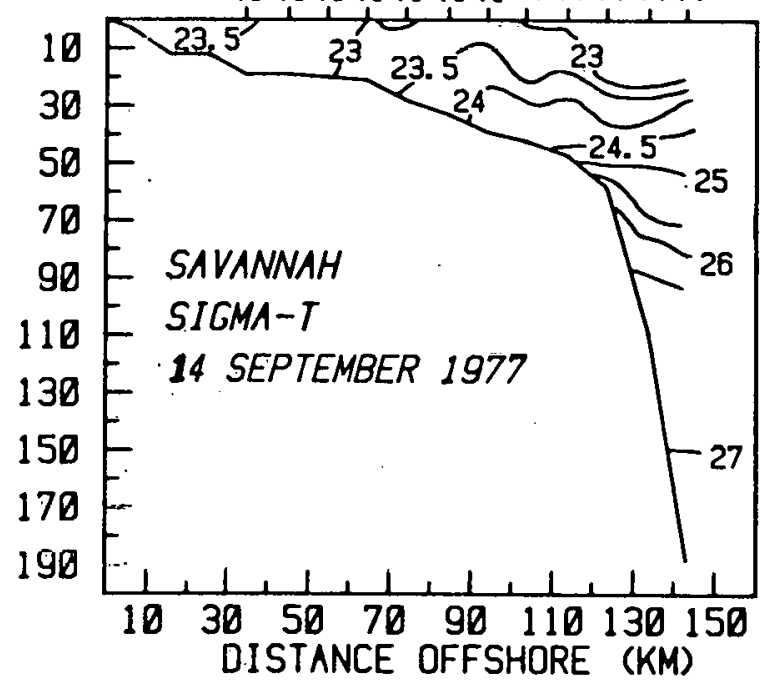

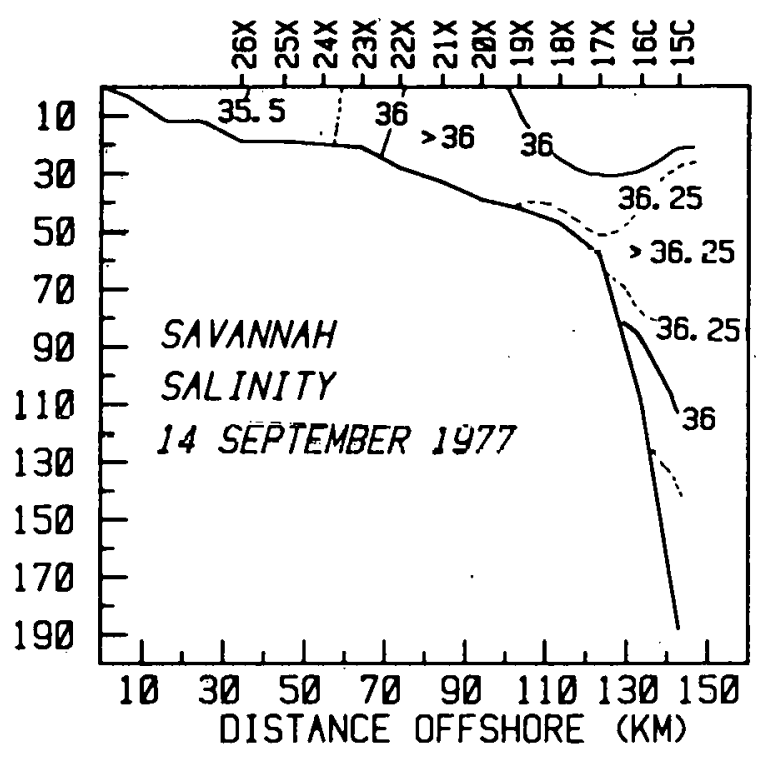

Figure 14. Vertical temperature, salinity and sigma-t structure for the Savannah section, 14 September 1977. 

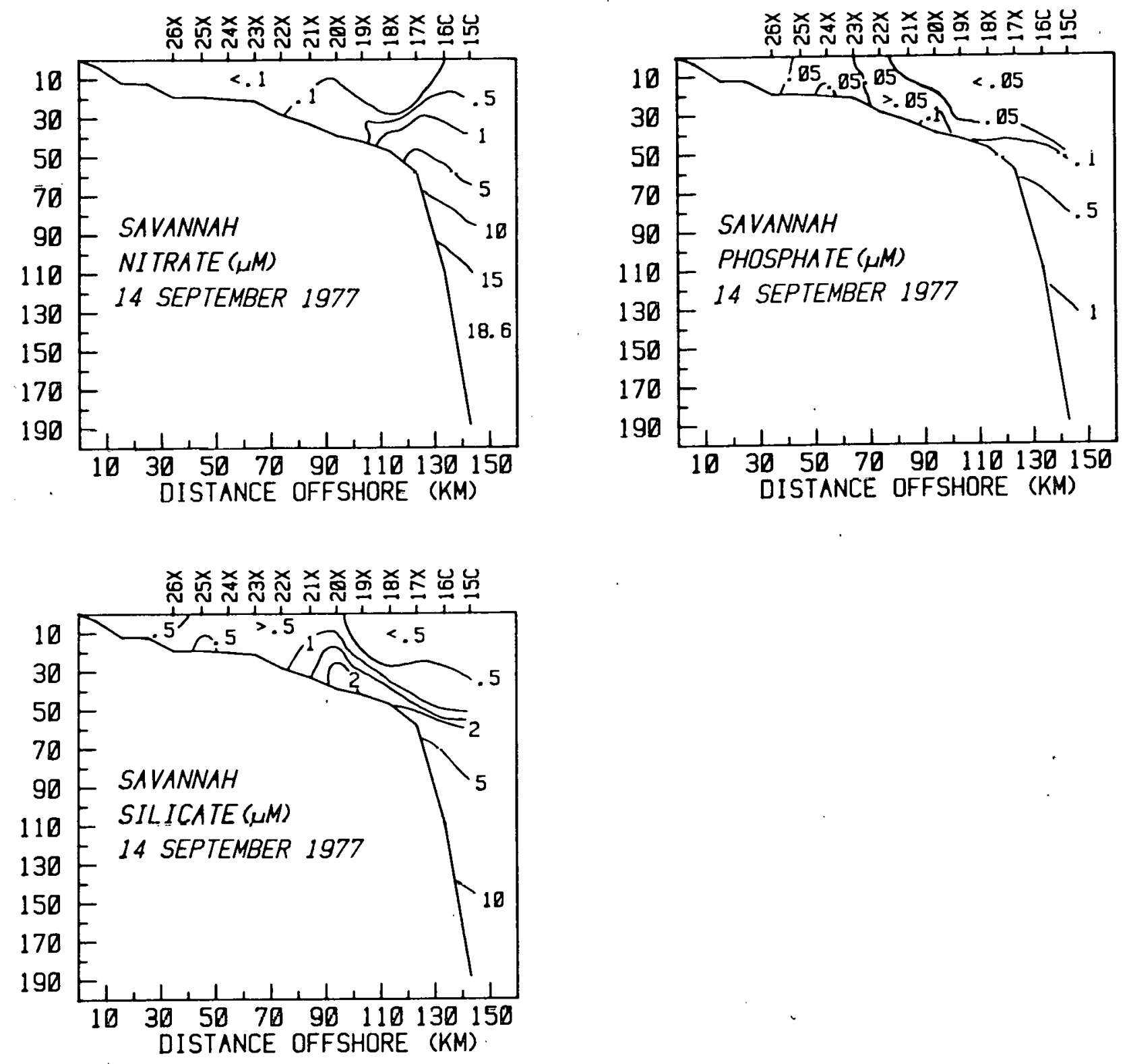

Figure 15. Vertical nitrate, phosphate and silicate structure for the Savannah section, 14 September 1977. 

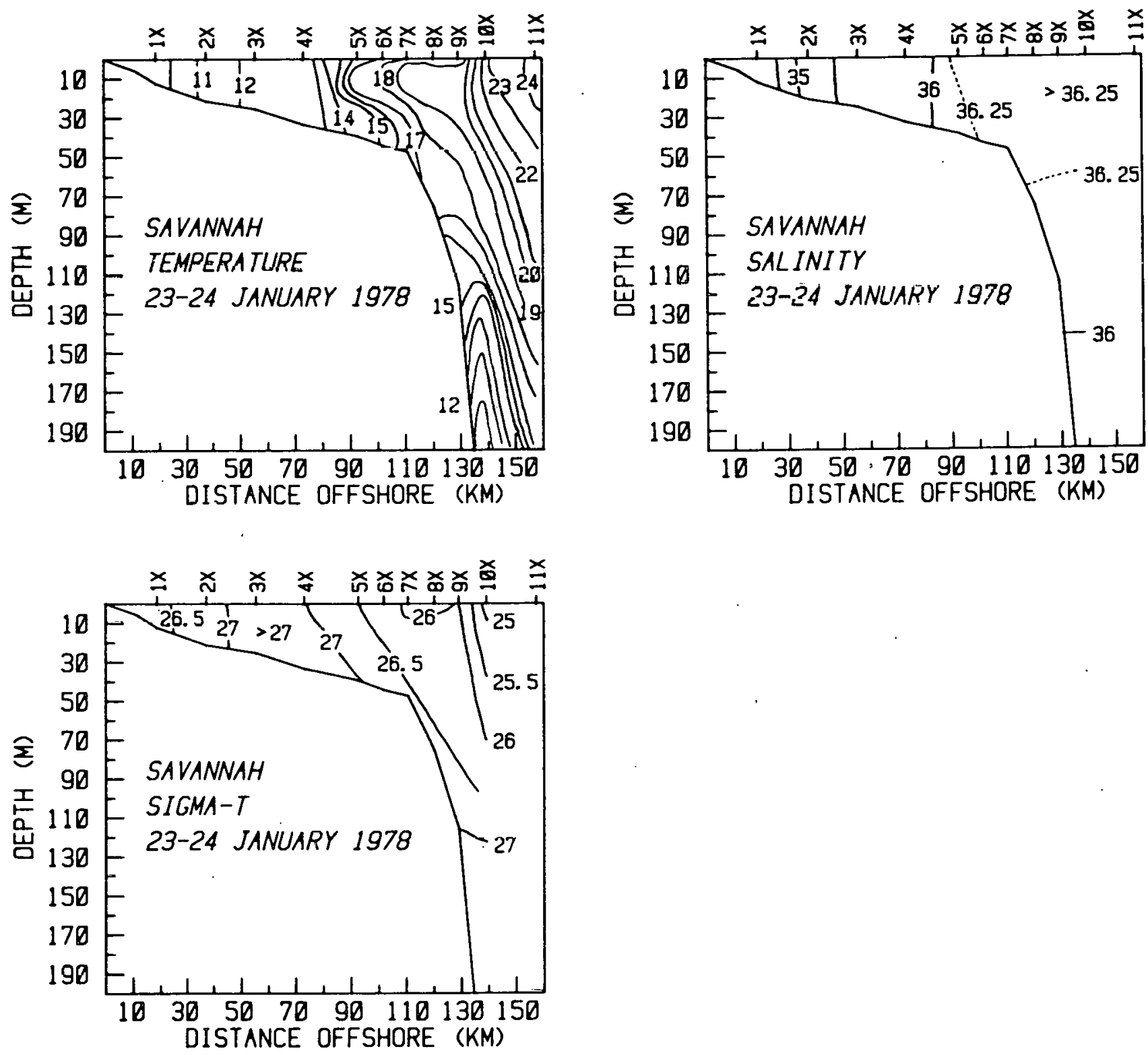

Figure 16. Vertical temperature, salinity and sigma-t structure for the Savannah section, 23-24 January, 1978. 

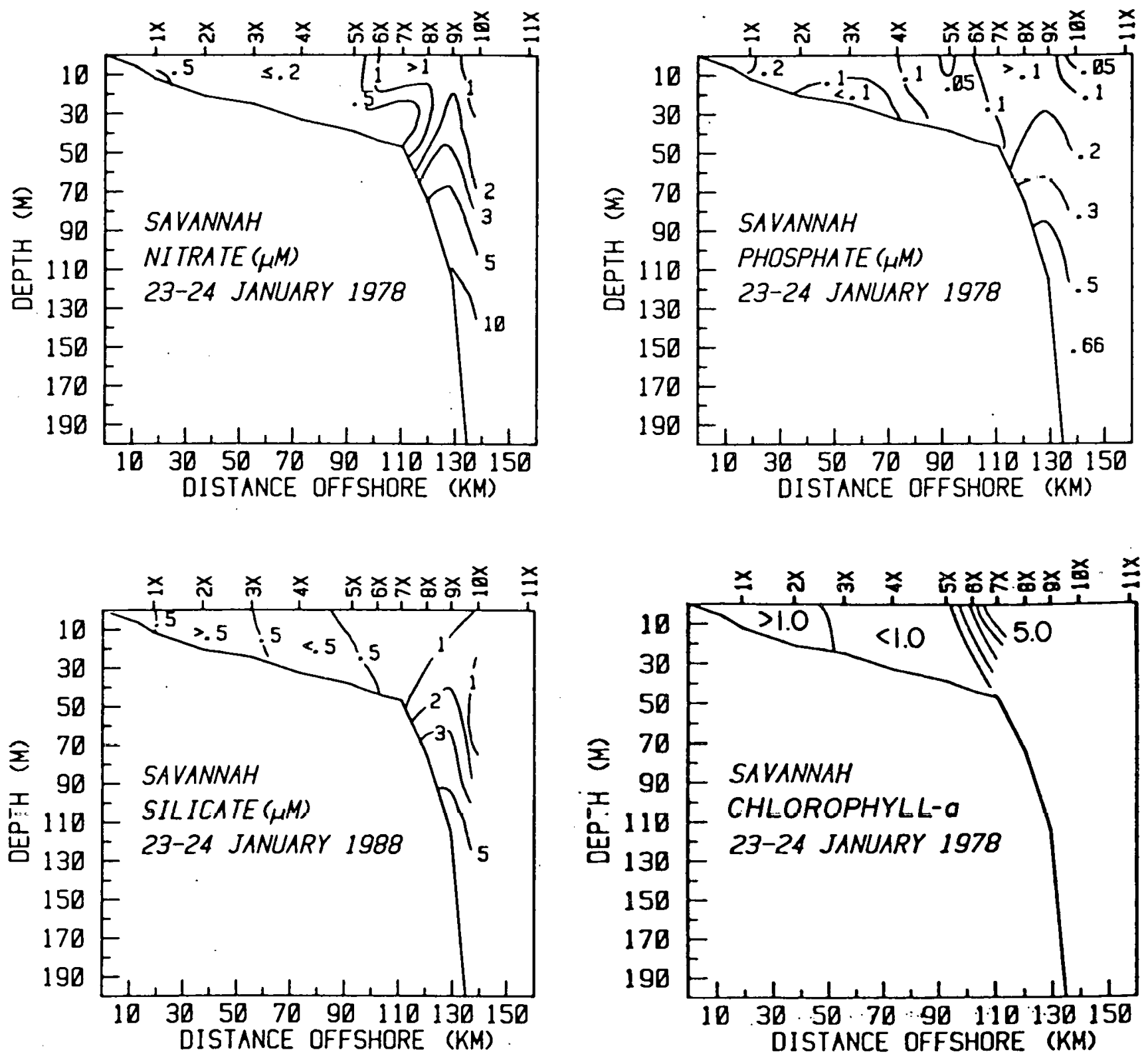

Figure 17. Vertical nitrate, phosphate, silicate and chlorophyll-a structure for the Savannah section, 23-24 January 1978. 

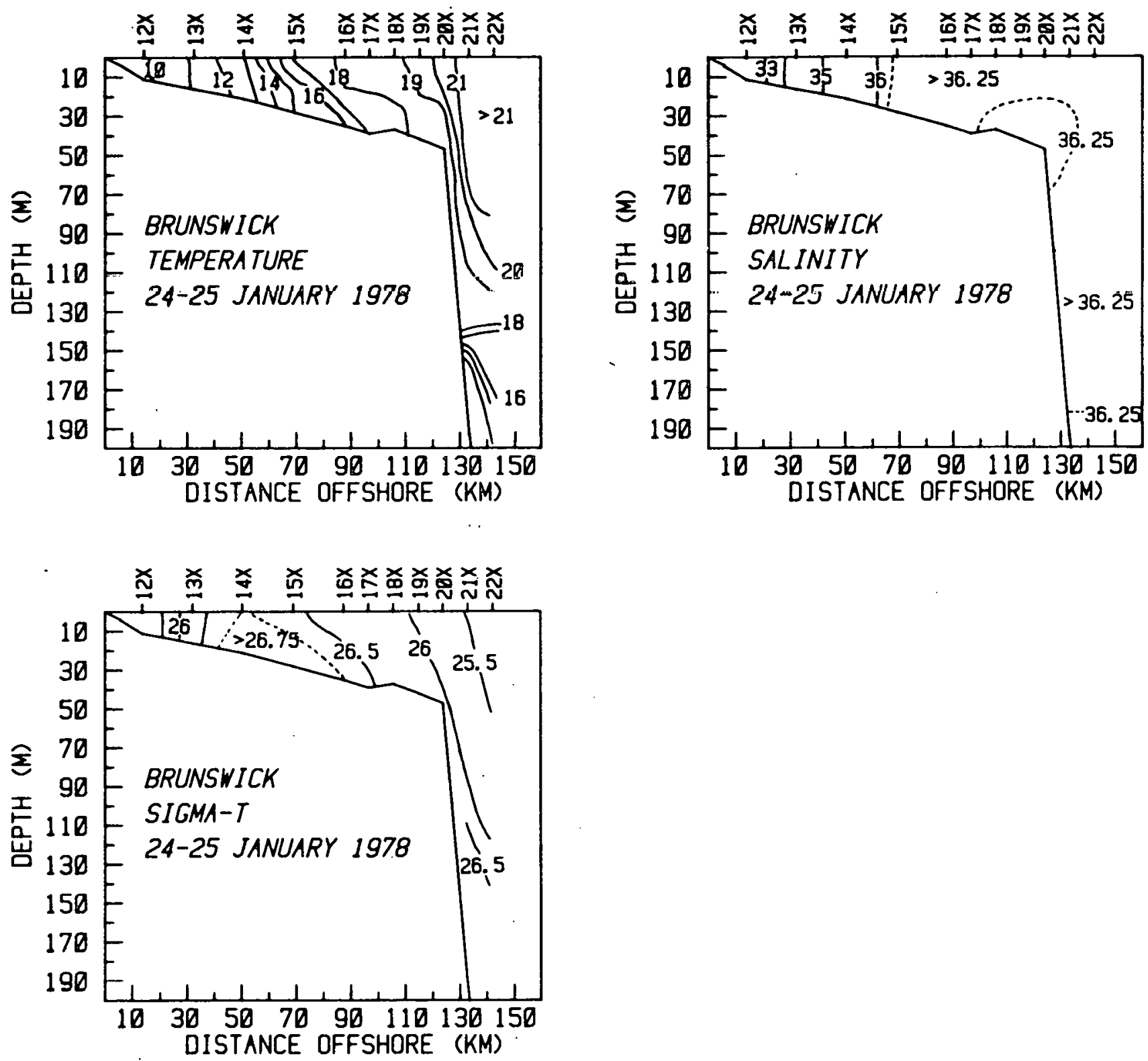

Figure 18. Vertical temperature, salinity and sigma-t structure for the Brunswick section, 24-25 January 1978. 

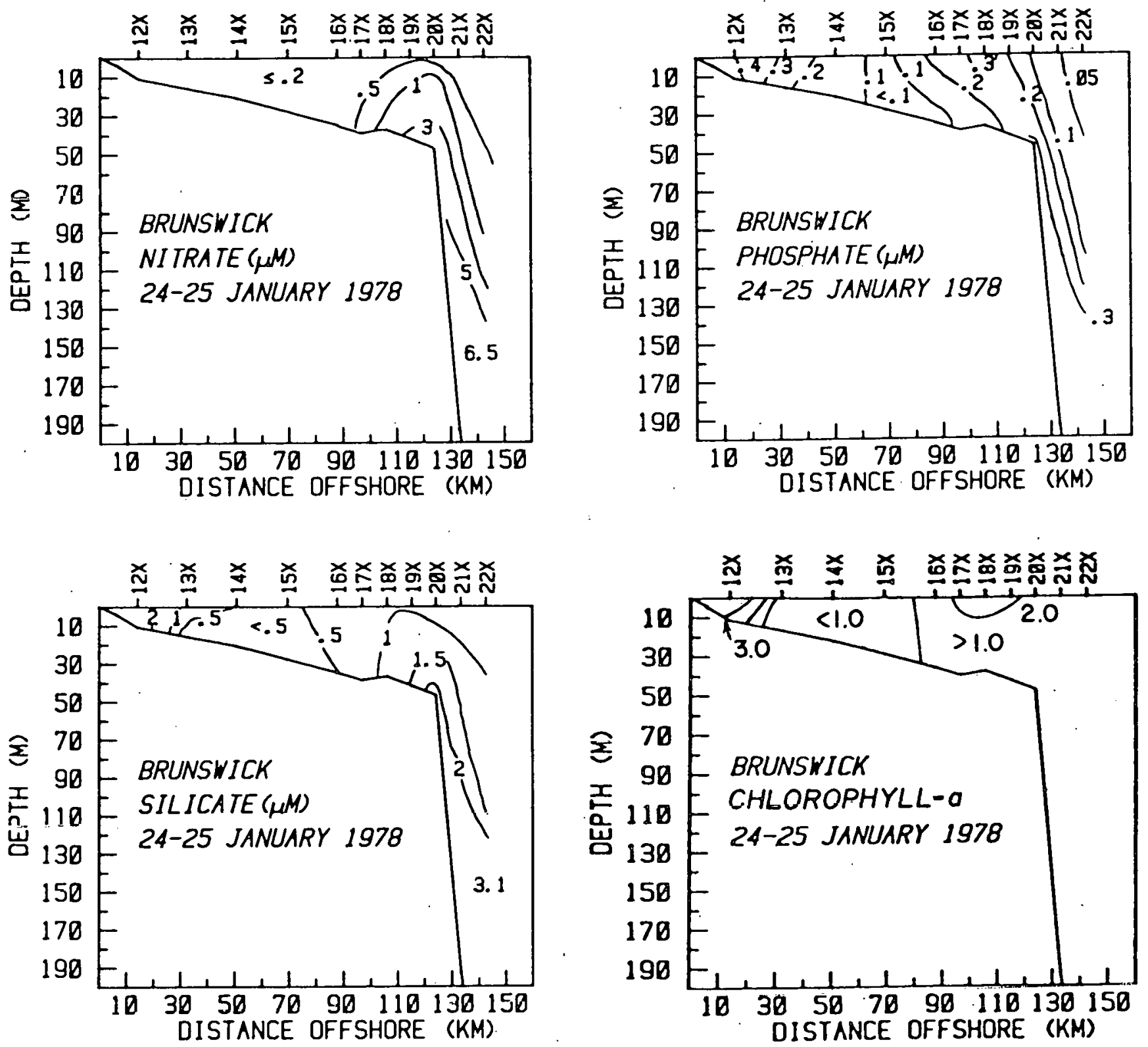

Figure 19. Vertical nitrate, phosphate, silicate and chlorophyll-a structure for the Brunswick section, 24-25 January 1978. 
APPENDIX

Hydrographic Data 
Vertical profiles of salinity, temperature, sigma-t, D0 and nutrients

The symbols used in the following listings are defined as follows:

Header Data:

Weather Data:
Times are GMT (EST + 5 or EDT +4 )

Latitude and Longitude are from Loran $C$

These data are taken from the ship's log.

Wind speed (knots)

Wind direction (degrees)

Air temperature $\left({ }^{\circ} \mathrm{C}\right)$

Weather (WMO code 4501)

Barometric pressure (mb)

Sea state (WM0 3700)

Wave direction (degrees)

Cloud type (not given)

Cloud amount (not given)

Visibility code (not given)

Observations:

$Z=$ Depth in meters

$\mathrm{T}=$ Temperature in ${ }^{\circ} \mathrm{C}$

$S=$ Salinity in $\%$

$D=$ Density in sigma-t units

SVA $=$ Specific volume anomaly $\times 10^{5}$

$\mathrm{O}_{2}=$ Dissolved oxygen in $\mathrm{ml} /$ liter

$\mathrm{O}_{2}{ }^{1}=$ Oxygen saturation in $\mathrm{ml} / \mathrm{liter}$

AOU = Apparent oxygen utilization in ml/liter

$\mathrm{PO}_{4}=$ Phosphate concentration in $\mu$ mole/liter

$\mathrm{NO}_{3}=$ Nitrate concentration in $\mu$ mole/liter

$S_{i}=$ Silicate concentration in $\mu$ mole/liter 


$$
\text { BF-14-77 }
$$

8-9 March 1977 
STATIOH SUAMARY FOR BLUE FIN CRUISE IA

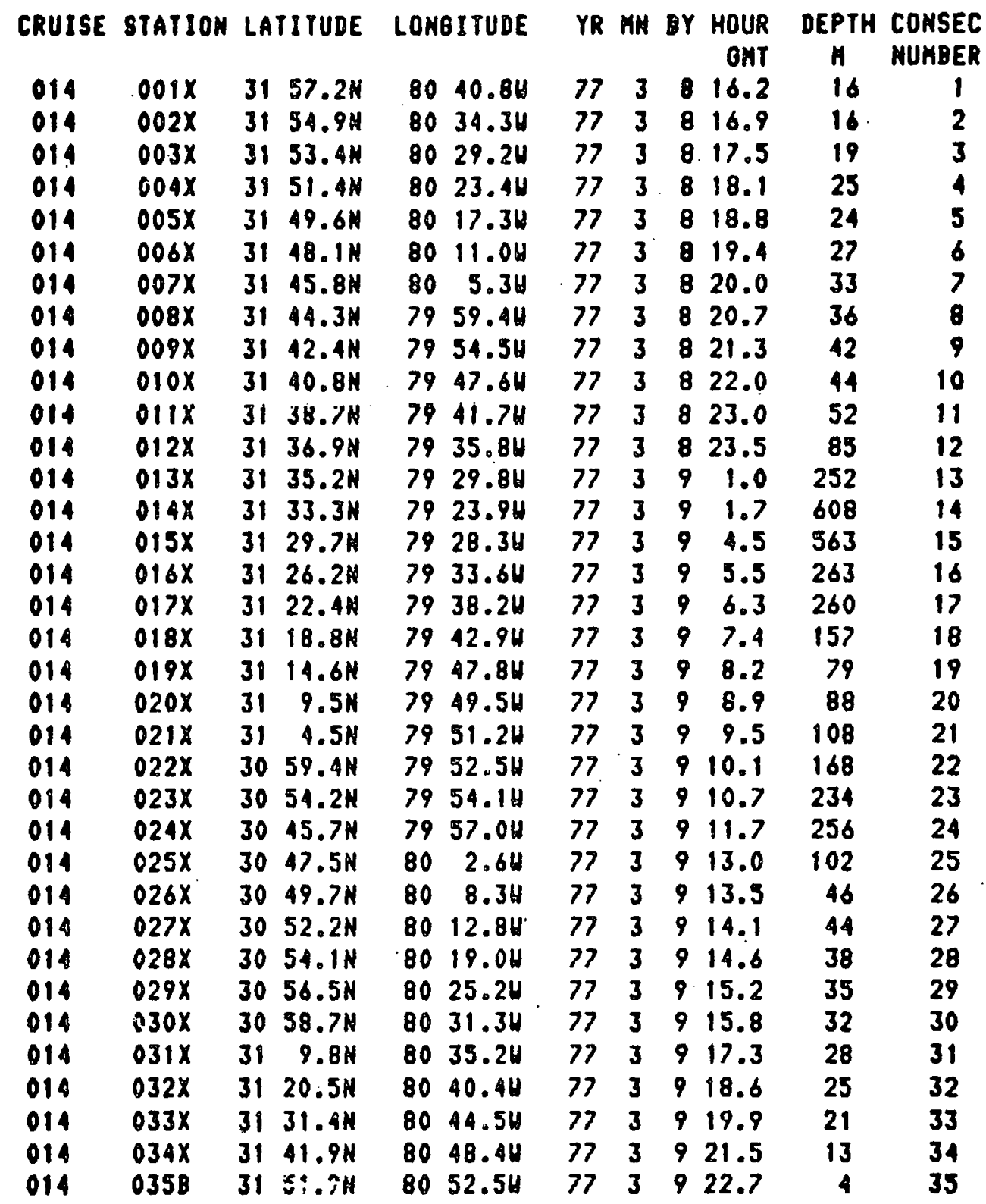


DLUE FIN CKUISE 14 STA IX $8 / 111 / 77$ 16.2 GNI CONSEC STA IAT 3I 57.2W LONG BO 10.8U DEPIH = I6A DISI LAST STA = O.OKA

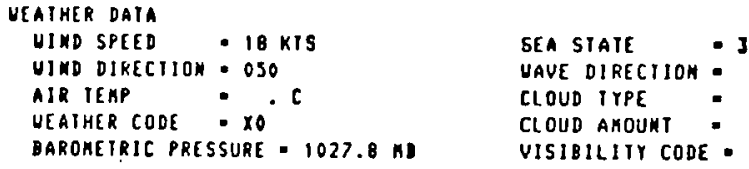

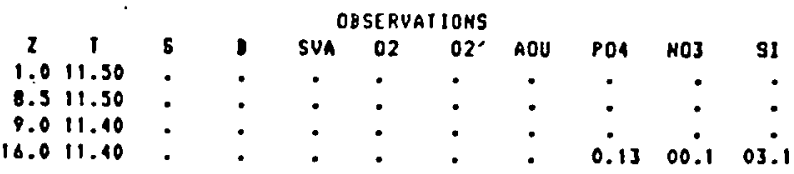

ILUE FIH CRUISE 14 STA $2 \times$ B/ III/77 16.9 GMT CONSEC STA 2 LAT 31 54.9N LOHG 8034.34 DEPTH = 16H DIST LAST STA $=11.1 \mathrm{KM}$

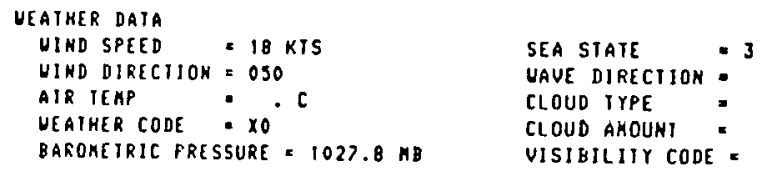

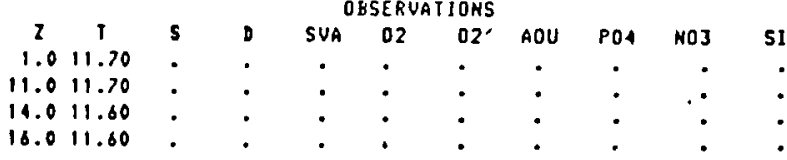

\section{.}

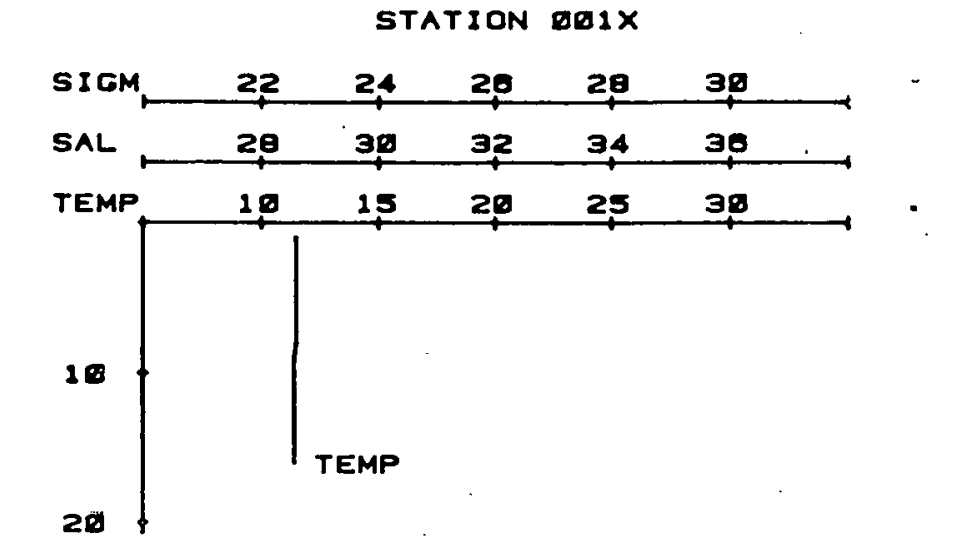




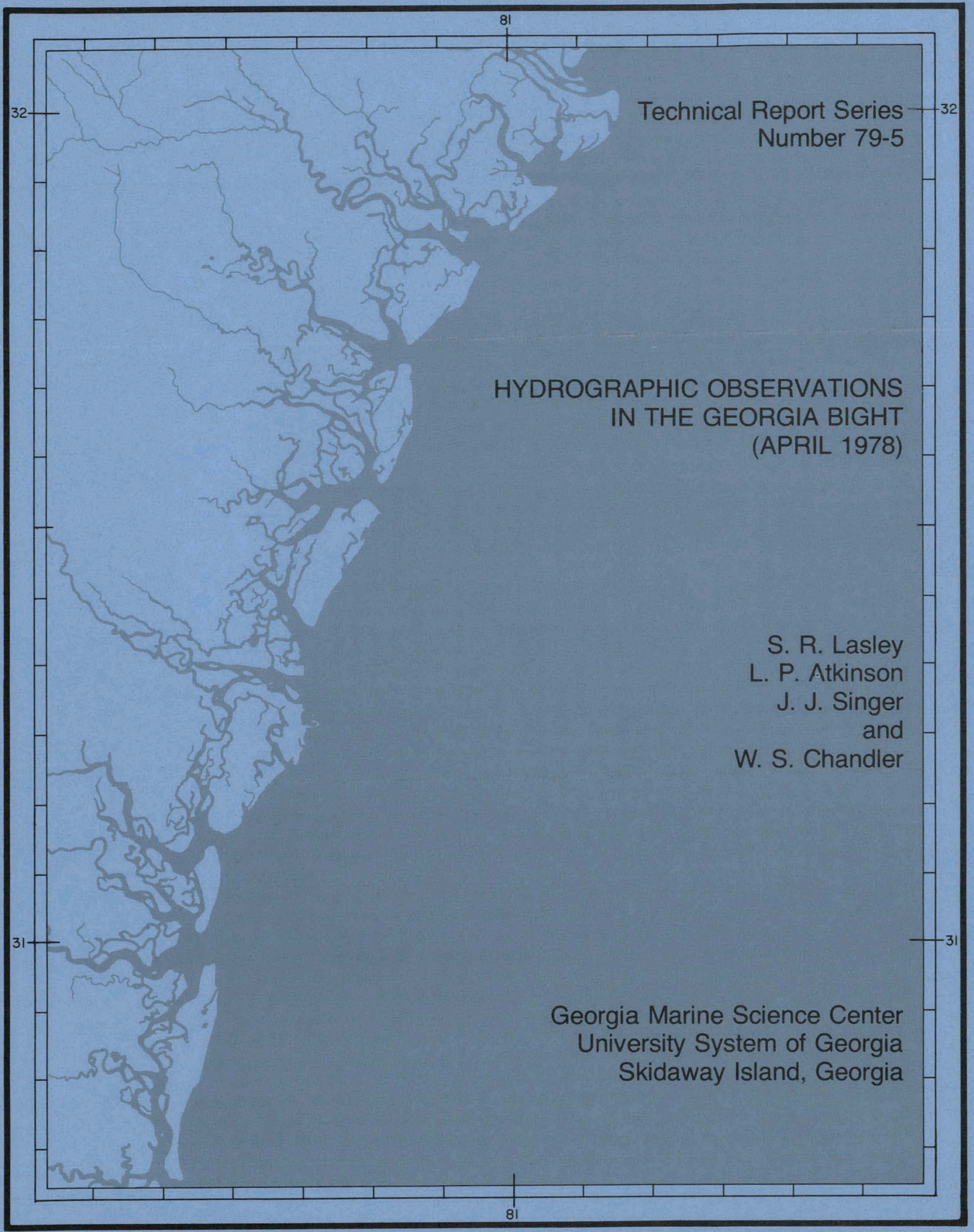


HYDROGRAPHIC OBSERVATIONS IN THE

GEORGIA BIGHT (APRIL 1978)

by

\author{
S.R. Lasley, L.P. Atkinson \\ J.J. Singer and W.S. Chandler
}

Skidaway Institute of Oceanography

P. 0. Box 13687

Savannah, Georgia 31406

July 1979

The Technical Report Series of the Georgia Marine Science Center is issued by the Georgia Sea Grant Program and the Marine Extension Service of the University of Georgia on Skidaway Island (P.0. Box 13687, Savannah, Georgia 31406). It was established to provide dissemination of technical information and progress reports resulting from marinc studies and investigallons malnly by staff and faculty of the University System of Georgia. In addition, it is intended for the presentation of techniques and methods, reduced data and general information of interest to industry, local, regional, and state governments and the public. Information contained in these reports is in the public domain. If this prepublication copy is cited, it should be cited as an unpublished manuscript. 
page

List of Figures ........................ $i$.

List of Tables ........................ i

Acknowledgements ...................... 1

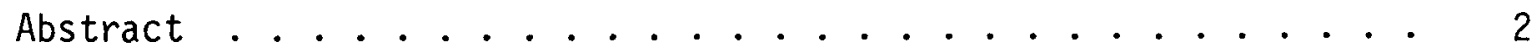

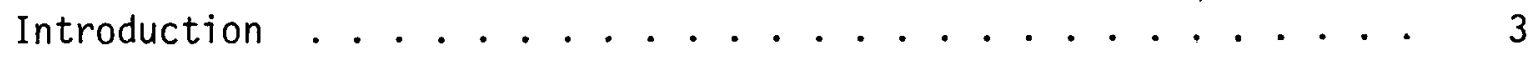

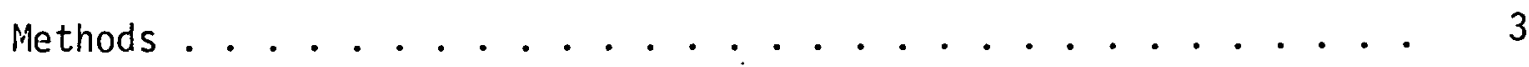

CTD Data Acquisition and Processing . . . . . . . . . . 5

XBT Data Acquisition and Processing . . . . . . . . . . . 13

Physical and Chemical Procedures. . . . . . . . . . 13

Results and Discussions............... 15

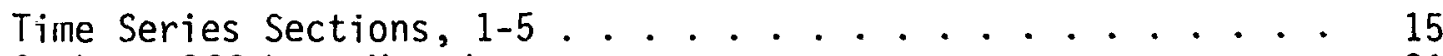

Onshore-Offshore Meanders ............. 21

Vertical Advection. .............. 21

Temperature-Salinity Relationship........... 29

Summary . . . . . . . . . . . . . . . 29

References ................... 30

Appendix I. Calibration Data ............ 31

Appendix II. Hydrographic Data . . . . . . . . . . 34

Appendix III. Chlorophyll and Nutrient Data ......... 91 


\section{LIST OF FIGURES}

Page

1. BLM station grid ................ 4

2. DOE station grid. Onshore-offshore section ........6

3. DOE station grid. Longshore section on shelf break $50 \mathrm{~m}$ isobath. 7

4. CTD data acquisition system ........... 8

5. Broenkow's salinity equation and flow diagram ........11

6. Top: Time-dependent plot of bottle-CTD salinity. Bottom: Depth-dependent plot of bottle-CTD salinity . . . . . 12

7. Brunswick section temperature, salinity and sigma-t, 17 April . 16

8. Brunswick section nitrate, phosphate, silicate and dissolved oxygen, 17 April. Nutrients are in $\mu \mathrm{g}$-at/1 and oxygen in $\mathrm{ml} / 1.17$

9. Temperature profile for stations $47 X-51 X, 18$ April and $62 X-66 X$, 19 April . . . . . . . . . . . . 18

10. Stations $71 \mathrm{C}-75 \mathrm{C}$ temperature, salinity, sigma-t, 20 April . . 19

11. Stations $71 C-75 C$ nitrate, phosphate, silicate and dissolved oxygen, 20 Apri1. Nutrients are in $\mu \mathrm{g}-\mathrm{at} / \mathrm{l}$ and oxygen in $\mathrm{ml} / 1$...................... 20

12. Stations 93C-97C temperature, salinity and sigma-t, 21 April . .22

13. Stations 93C-97C nitrate, phosphate, silicate and dissolved oxygen. Nutrients are in $\mu \mathrm{g}$-at/1 and oxygen in $\mathrm{ml} / 1 \ldots . . . .23$

14. Alongshore section on $50 \mathrm{~m}$ isobath from $87 \mathrm{X}$ (North) to $102 \mathrm{X}$ (South). Station $91 \mathrm{C}$ is on the onshore-offshore time series grid . . . .26

15. Temperature time series at $40 \mathrm{~m}$ station on shelf break, 18-21 April 1978 .................. . 26

16. Temperature-Salinity diagram of all BLM-DOE stations (1C-118C) 10-23 April 1978 . . . . . . . . . . . . . . 28 


\section{LIST OF TABLES}

Page

Table 1. CTD/Data Flow. Shipboard Acquisition to NODC Submission ................. 10

Table 2. Vertical and Onshore-Offshore Velocities of the $190 \mathrm{C}$ Isotherm off Brunswick. (+ down, offshore; up, onshore).................... 24 


\section{ACKNOWLEDGEMENTS}

The following people participated in the cruise and their help was appreciated: T. Lee, C. Pattison, D. Raffo, P. Bedard, T. Tankard, L. Brincko, B. Strahle, J. West, R. Watts, R. Guest, and L. Cunningham. We would also like to thank to Captain and crew of the R/V ISEL IN for their efforts and Lucretia Garrigan for the nutrient analysis. Linda Land is thanked for typing this report.

Funding for thị research and report is provided by the Department of Energy (under Contract EY-76-S-09-0889) and the Bureau of Land Management to L.P. Atkinson.

This report is published as a part of the Georgia Marine Science Center's Technical Report series issued by the Georgia Sea Grant Program under NOAA Office of Sea Grant \#04-7-158-44126. 


\section{ABSTRACT}

During a cruise in the Georgia Bight in Apri1 1978, one onshore-offshore hydrographic section was repeated five times over a five-day period. Temperature, salinity, dissolved oxygen and nutrient $\left(\mathrm{NO}_{3}, \mathrm{PO}_{4}\right.$, and $\left.\mathrm{SiO}_{2}\right)$ data were collected.

The shelf waters were vertically well mixed with horizontal gradients being apparent only for temperature, salinity, and sigma-t. Initially, an upwelling velosity of $-4.3 \times 10^{-3} \mathrm{~cm} \mathrm{sec}^{-1}$ was observed at the shelf break in conjunction with a $10.8 \mathrm{~cm} \mathrm{sec}^{-1}$ offshore meander of the Gulf Stream. By the third day, the Gulf Stream had started to move onshore at velocities as high as $7.9 \mathrm{~cm} \mathrm{sec}^{-1}$. Subsequently, downwelling velocities as high as $8.2 \times 10^{-3}$ $\mathrm{cm} \mathrm{sec} \mathrm{sec}^{-1}$ were observed. 


\section{INTRODUCTION}

This report contains chemical and physical data obtained during Georgia Bight Cruise CI-04-78 (10-23 April 1978) aboard the R/V COLUMBUS ISELIN. The investigation was part of a larger multi-institutional Department of Energy (DOE) program to understand event scale, physical, chemical and biological processes of the South Atlantic Bight, the continental shelf region from Cape Hatteras to Cape Canaveral. The study reported here is concentrated in the Georgia Bight near Brunswick, Georgia. Specifically, the objective was to collect physical and chemical data such that three-dimensional cuasi-synoptic measurements of the interactions of shelf and Gulf Stream waters could be made. In addition, the hydrographic data were used to campare with those of moored instruments deployed by the University of Miami (Or. Tom Lee).

This report also includes background hydrographic data from a Bureau of Land Management (BLM) cruise which occurred in conjunction with the DOE-sponsored Georgia Bight Cruise.

\section{METHODS}

Five onshore-offshore hydrographic sections (Figure 1) were completed as part of the BLM sampling grid. Stations $1 C$ through $43 C$ were occupied from 12-18 April, and stations $105 \mathrm{C}$ to $118 \mathrm{C}$ were completed between 22-23 Apri1. Stations on this grid were sampled using CTD (conductivity/temperature/depth) Rosette casts. An exception was station 35X, and XBT (expendable hathythermngraph) cast.

From 18-21 Apri1, 27 stations were occupied as part of the DOE 


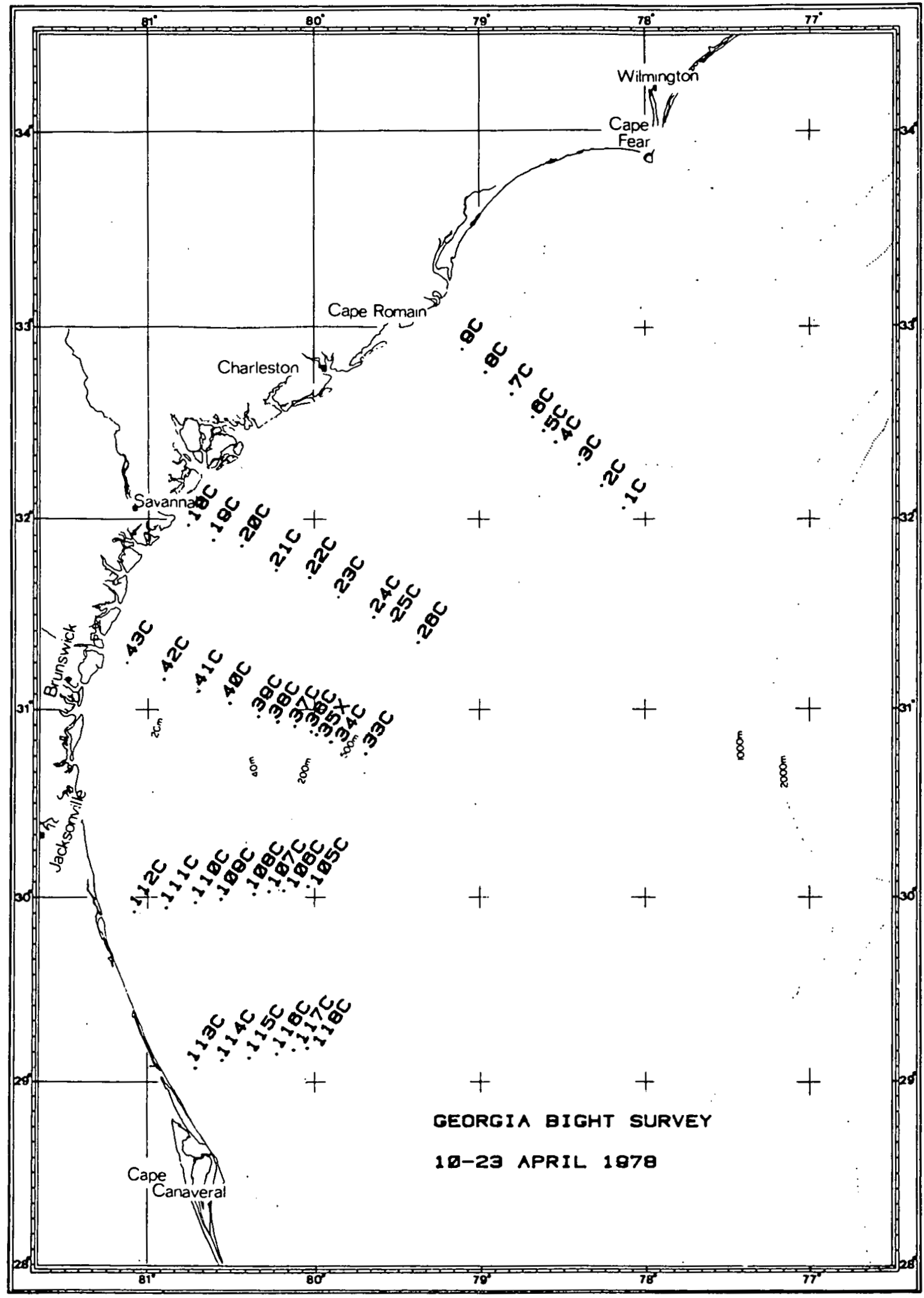

Figure 1. BLM Station Grid. 
sampling grid. One longshore section along the $50 \mathrm{~m}$ isobath and four onshoreoffshore hydrographic sections across the shelf break off of Brunswick, Georgia were completed. On 18 April, stations $47 X-57 X$ were occupied (Figure 2); the next day these stations were reoccupied (stations 62X-66X). A11 stations in these two sections were completed using XBTs. On 20 April, stations $71 C-75 C$ were occupied (Figure 2 ); the next day these stations were reoccupied (stations 93C-97C). All stations in these two sections were completed using CTD casts. The two CTD sections are further offshore than the two XBT sections. On 21 April, a north-south alongshore section was completed along the $50 \mathrm{~m}$ isobath at the shelf break (Figure 3 ). One CTD and 6 XBT stations were occupied in this section. Upon completion of the DOE sampling grid, stations $105 \mathrm{C}$ to $118 \mathrm{C}$ of the BLM grid were then completed.

At CTD stations, a General Oceanics Model 1015 Mark 5 Rosette multi-bottle array with 5-liter Niskin Bottles and a Plessey Model 9400 CTD sensor system were used for water sampling. Niskin sampling depths were determined from the temperature structure obtained from the CTD. Samples were taken near the surface, just above or below the thermocline, at the bottom, and occasionally at other depths. Samples were analyzed for salinily, nitrate, phosphate, silicate, and dissolved oxygen. CTD Data Acquisition and Processing

The CTD Data Acquisition System (Figure 4) consists of a Plessey Model 9400 CTD sensor system, a Model 8400 Digital Logger, and a HewlettPackard 9825A Calculator. Data were stored on cartridge tape and redundant 


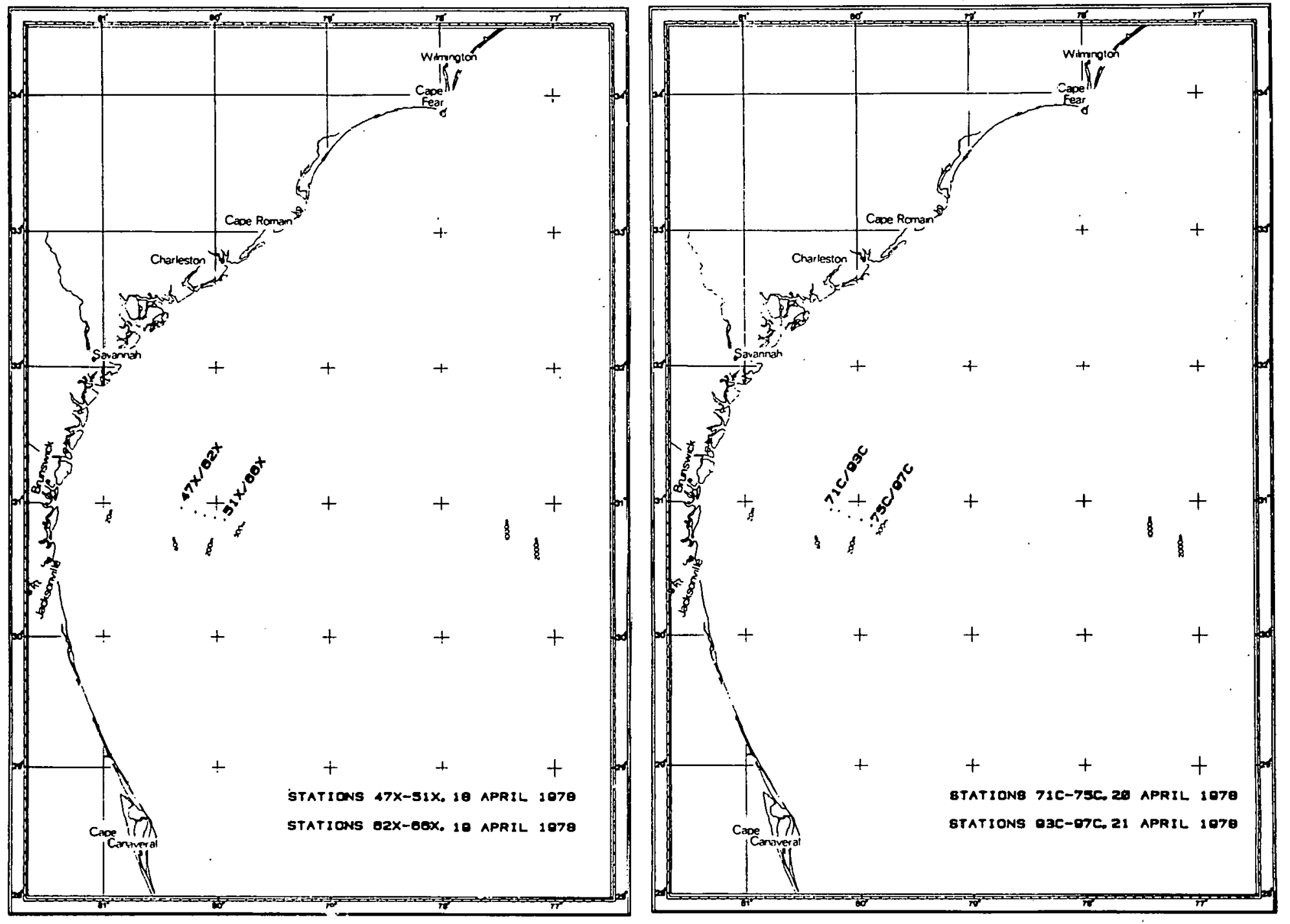

Figure 2. DOE Station Grid. Onshore-offshore Sections. 


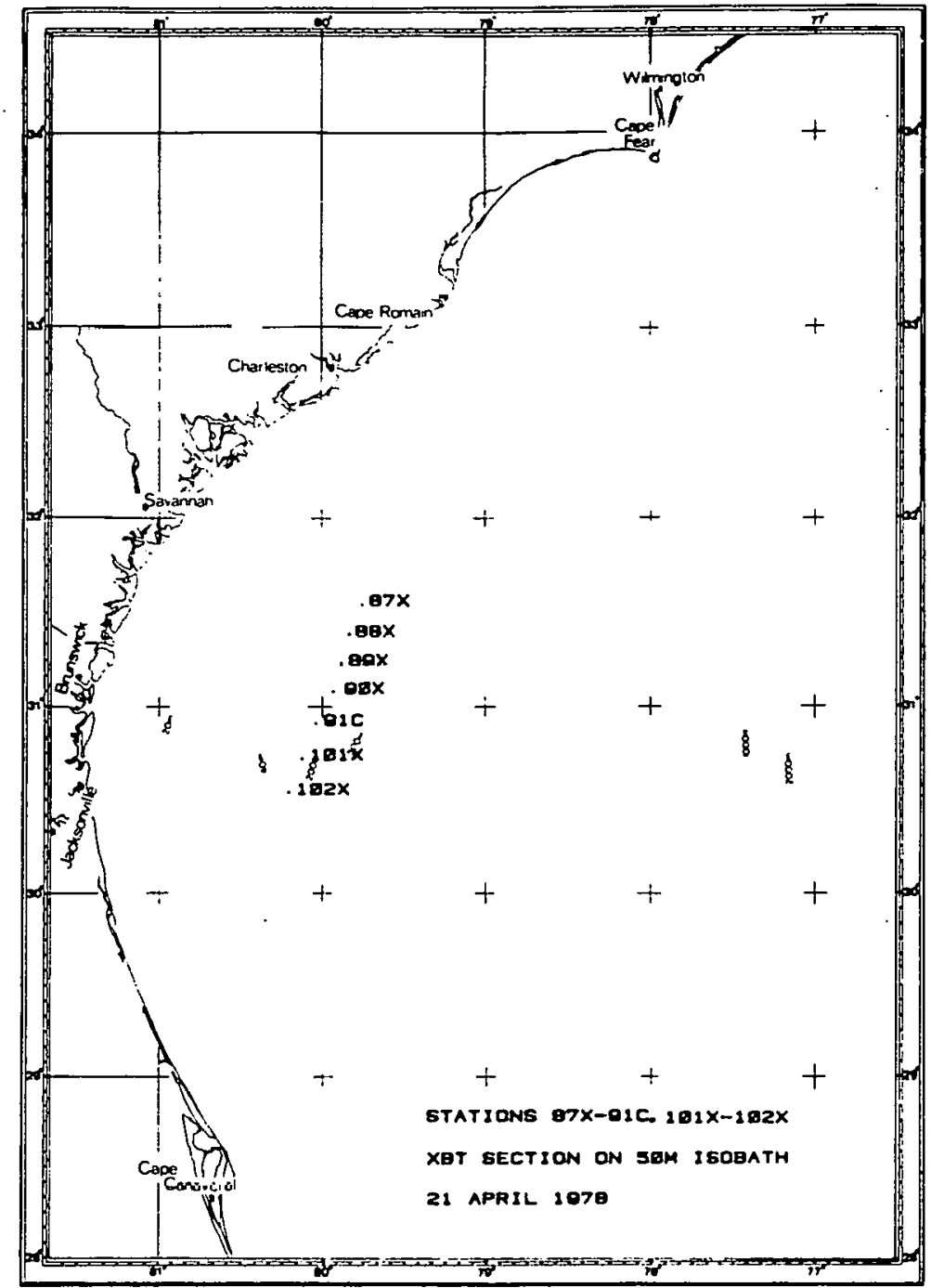

Figure 3. DOE Station Grid. Longshnre Section on Shclf Break 50m Isobath. 


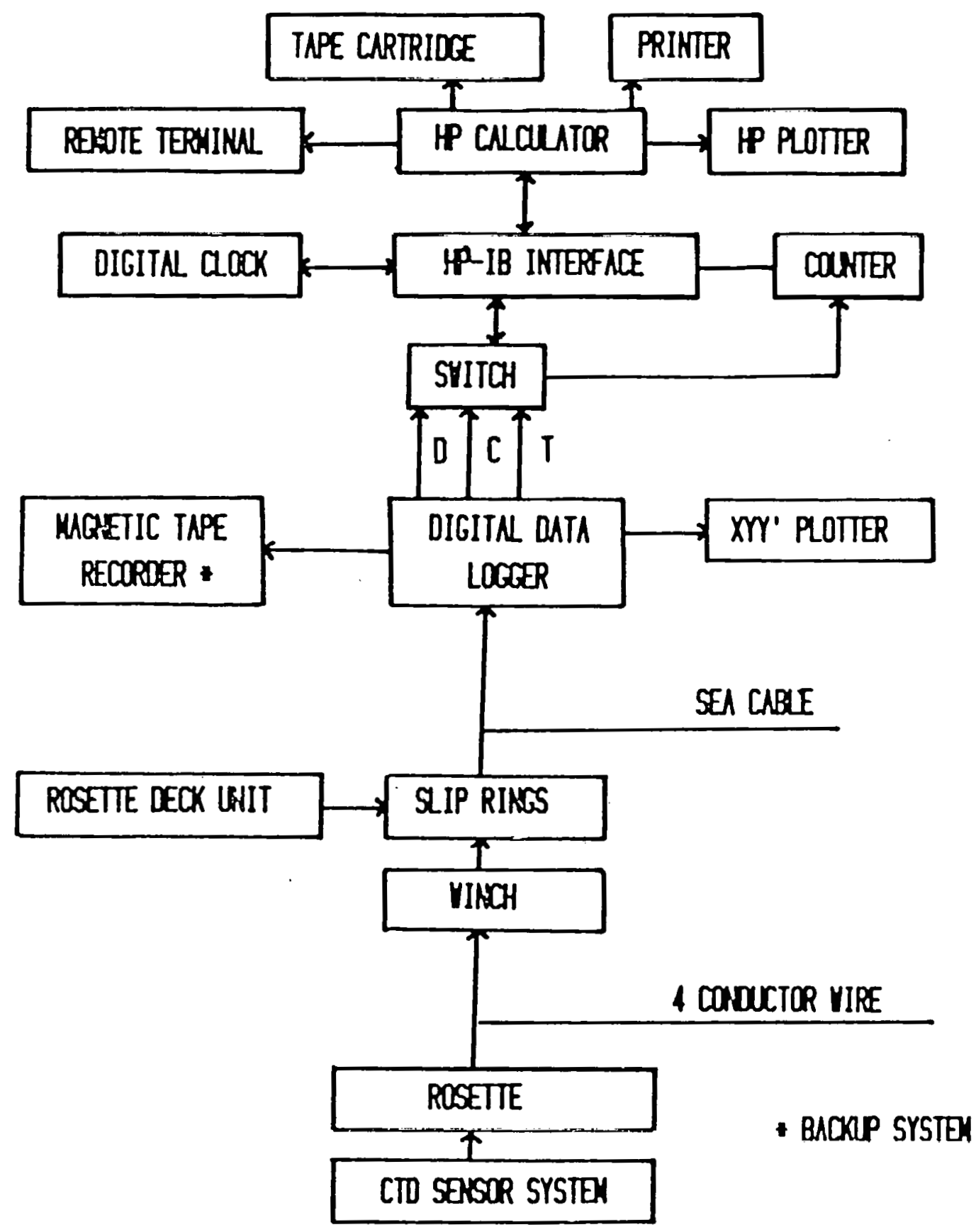

Figure 4. CTD Data Acquisition System. 
plots were produced for each cast on a Hewlett-Packard XYY' Plotter and Model 9862A Plotter.

Digitized data were collected as the CTD sensor unit was lowered at $15 \mathrm{~m} / \mathrm{min}$. on a four conductor cable. All three parameters (C,T, and $D$ ) were sampled once each 405 milliseconds or every $10 \mathrm{~cm}$ at the $15 \mathrm{~m} / \mathrm{min}$. lowering rate. For primary calibration of temperature and salinity, a Niskin Bottle equipped with paired protected deep-sea reversing thermometers was tripped after a four-minute equilibration period at the maximum sample depth in mixed layers. Other water samples were collected during ascent at depths selected after examination of the downcast temperature structure.

All data recorded on HP cartridge tape were processed according to the methods described by Chandler, et al. (1978) in the sequence shown in Table 1. Salinity was calculated from conductivity according to the equations of Broenkow, et al. (1977). Broenkow's equation and a flow diagram showing its use is presented in Figure 5.

The CTD system was calibrated only against bottle samples in mixed layers to insure that the sensors and the bottles were sampling the same water. However, since a mixed layer was not always observed, comparisons could not be made at every station. Salinity and temperature calibration data are included in Appendix $I$.

For the salinity calibration, time-dependent and depth-dependent offsets were determined. The time-dependent plot of bottle-CTD salinity shows no appreciable time-dependent change (Figure 6 ). This constant offset was 
Table 1. CTD/Data Flow. Shipboard Acquisition to NODC Submission.

Data Source/Disposition Program Data File

HP Cartridge Tapes

Primary Calibration from Bottle Casts

Type in Headers on File Head

Submission to NODC
*CTDACQ (CTD sensor controller and data acquisition)

ACQ

*CTDAVE (Raw data processed for temperature lag, depth latch and meter averaging immediately after each cast)

AVE

*HP/CTD (Calculates salinity, converts to NODC format, and transfers the data to Cyber)

$$
N O D C+H E A D
$$

**NUTMERG (Merges NODC data with headers and chemical data)

$$
\text { CI }-04
$$

**CEMLIST (Calculates sigma-t, specific volume anomally, oxygen utilization and prints technical report pages)

and

**STALIST (Prints station list for technical report)

TECHNICAL REPORT

*HP

**Cyber 

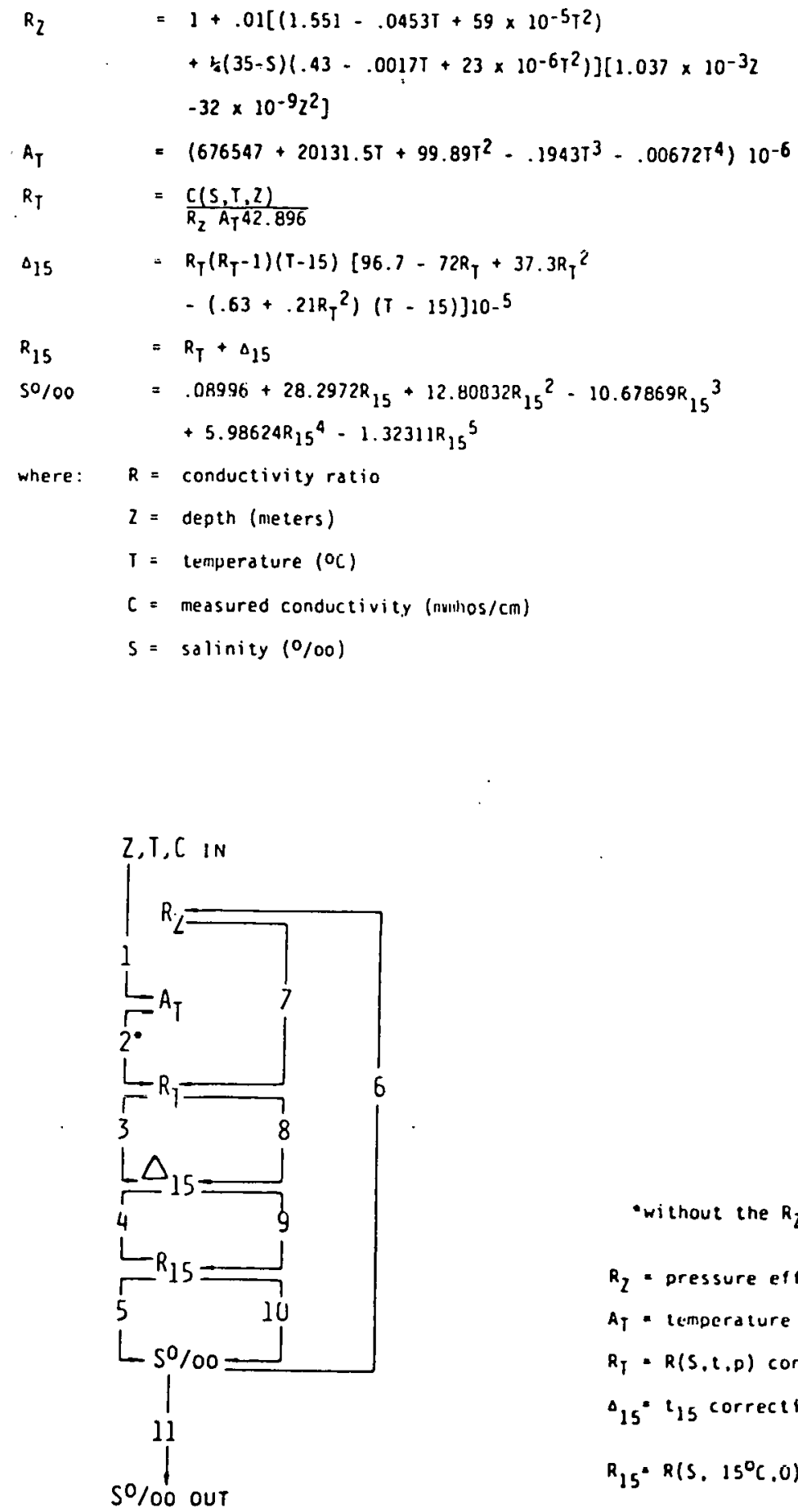

Figure 5. Broenkow Salinity Equation and Flow Diagram. 

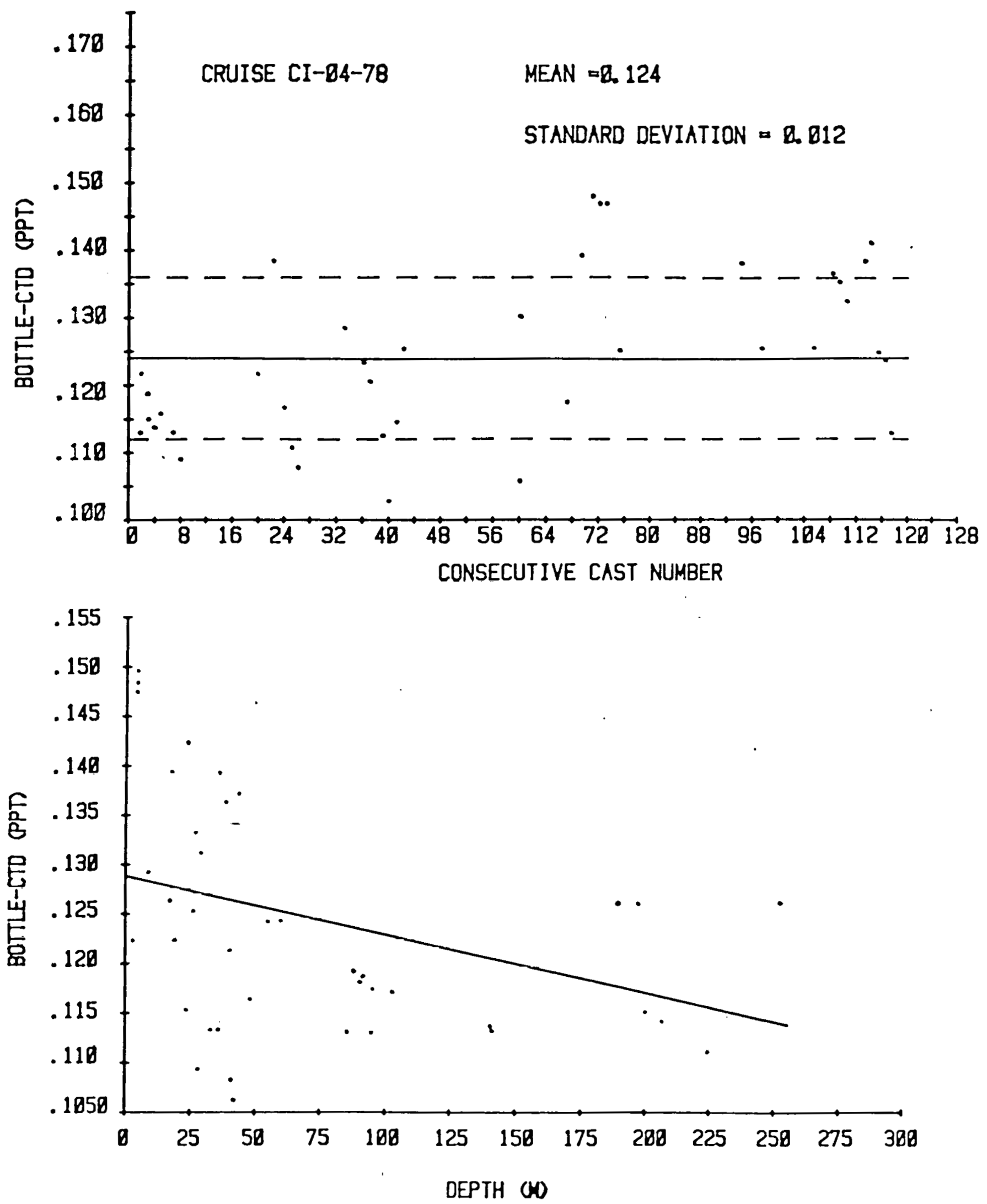

Figure 6. Top: Time-dependent plot of bottle-CTD salinity. Bottom: Depthdependent plot of bottle-CTD salinity. 
determined to be $.124 \%$ with a standard deviation of $0.012 \%$. The depth-dependent plot of bottle-CTD salinity indicates no significant depth-dependent offset (Figure 6).

The mean difference between CTD and reversing thermometers was $+0.020^{\circ} \mathrm{C}$ with a standard deviation of \pm of $0.009^{\circ} \mathrm{C}$. This offset was not considered significant, and no systematic correction was applied to the data.

The CTD depth sensor when compared to wire out under conditions of zero wire angle indicated no offset was necessary. XBT Data Acquisition and Processing

A Sippican Model LM3A handheld launcher and a MK2A-1 recorder were used for XBT casts. The temperature/depth plots were manually digitized, and these data were placed in NODC format and merged with processed CTD data. Depths at which temperature is a whole or half degree are reported as are depths at which a significant mixed layer begins and ends.

During this cruise, the XBT system was not calibrated against CTD casts. Previous comparisons yielded a $0.2^{\circ} \mathrm{C}$ offset which is insignificant compared to the stated accuracies of the XBT system. Physical and Chemical Procedures

Salinity samples collected for calibrating the CTD system were analyzed ashore using a Plessey Model $6230 \mathrm{~N}$ induction salinometer. Dissolved oxygen samples were analyzed during the cruise by the modifled Winkler method outlined by Strickland and Parsons (1965).

The nutrient analysis was performed at Duke University Marine Laboratory 
using Technicon Autoanalyzer procedures. The procedures are based on the manual methods of Murphy and Riley (1962) for reactive phosphate and Armstrong, Stearns, and Strickland (1967) for dissolved silicate, nitrate, and nitrite. The automated methods have been described by Friedrich and Whitledge (1972).

Chlorophyll-a was determined fluorometrically by the methods outlined by Strickland and Parsons (1965). 


\section{RESULTS AND DISCUSSION}

Gulf Stream meandering has been related to upwelling at the she if break with easterly movements of the stream related to lower temperatures at the shelf break. (Atkinson, 1977). Thus, any observed offshore meander should coincide with upwelling. Conversely, the onshore movement of the Gulf Stream would result in downwelling and a rise in lemperature at the shelf break. The five onshore-offshore sections completed off Brunswick clearly show vertical advection in association with the meander of the Gulf Stream. The following is a description of each section:

Section 1, Stations 33C to 43C, 17-18 April. (Figures 7-8).

The shelf waters were well mixed with well-defined horizontal gradients apparent only in the temperature, salinity and sigma-t distributions. The temperature, salinity, nutrient and oxygen distributions all indicated strong upwelling at the shelf break. The isotherm positions showed the Gulf Stream to be offshore of the shelf break.

Section 2, Stations 47X-51X, 18 April. (Figure 9).

The isotherms continued to indicate strong upwelling at the shelf break. The Gulf Stream was still offshore of the shelf.

Section 3, Stations 62X-66X, 19 Apri1. (Figure 9).

Upwelling was apparent at the shelf break but had decreased in intensity. A general lowering of shelf break isotherms indicated downward advections of warmer surface waters.

Section 4, Stations 71C to 75C, 20 April. (Figures 10-11).

The onshore meander of the Gulf Stream, as indicated by the isotherm positions, resulted in downwelling at the shelf break. Warmer, low-nutrient 

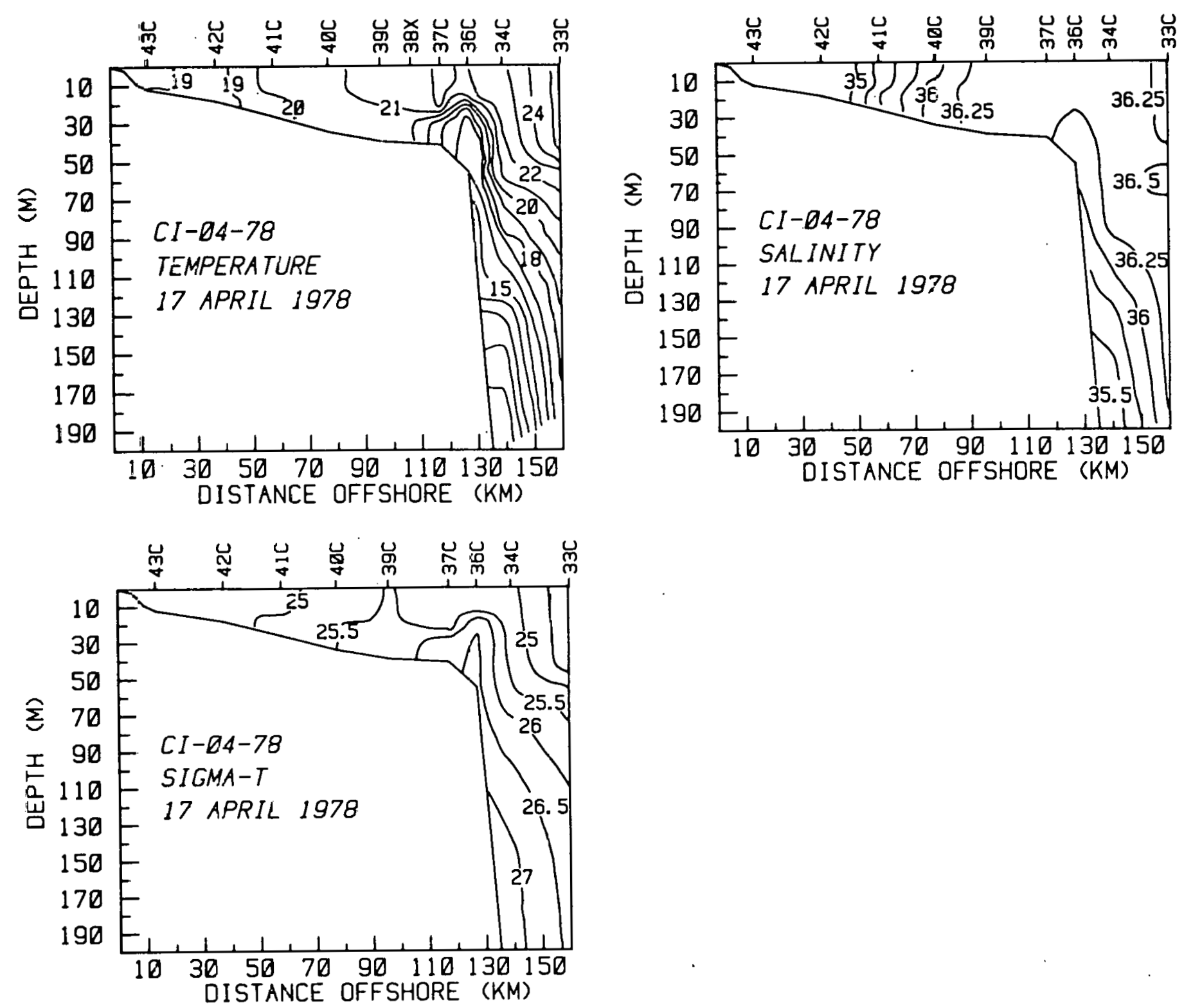

Figure 7. Brunswick section temperature, salinity, and sigma-t, 17 April. 

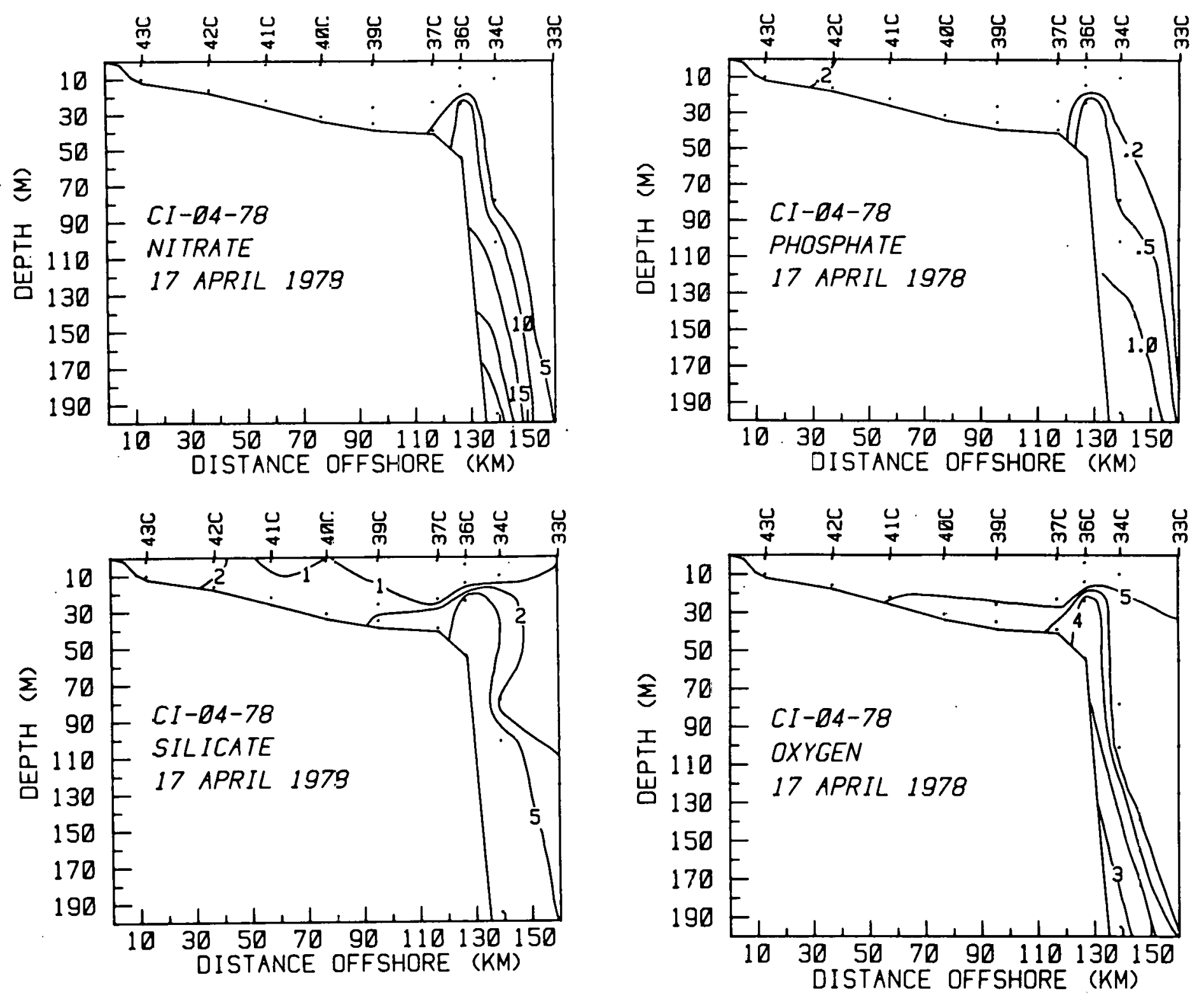

Figure 8. Brunswick section nitrate, phosphate, silicate and dissolved oxygen. 17 April. Nutrients are in $\mu \mathrm{M}$ and oxygen in $\mathrm{ml} / \mathrm{l}$. 

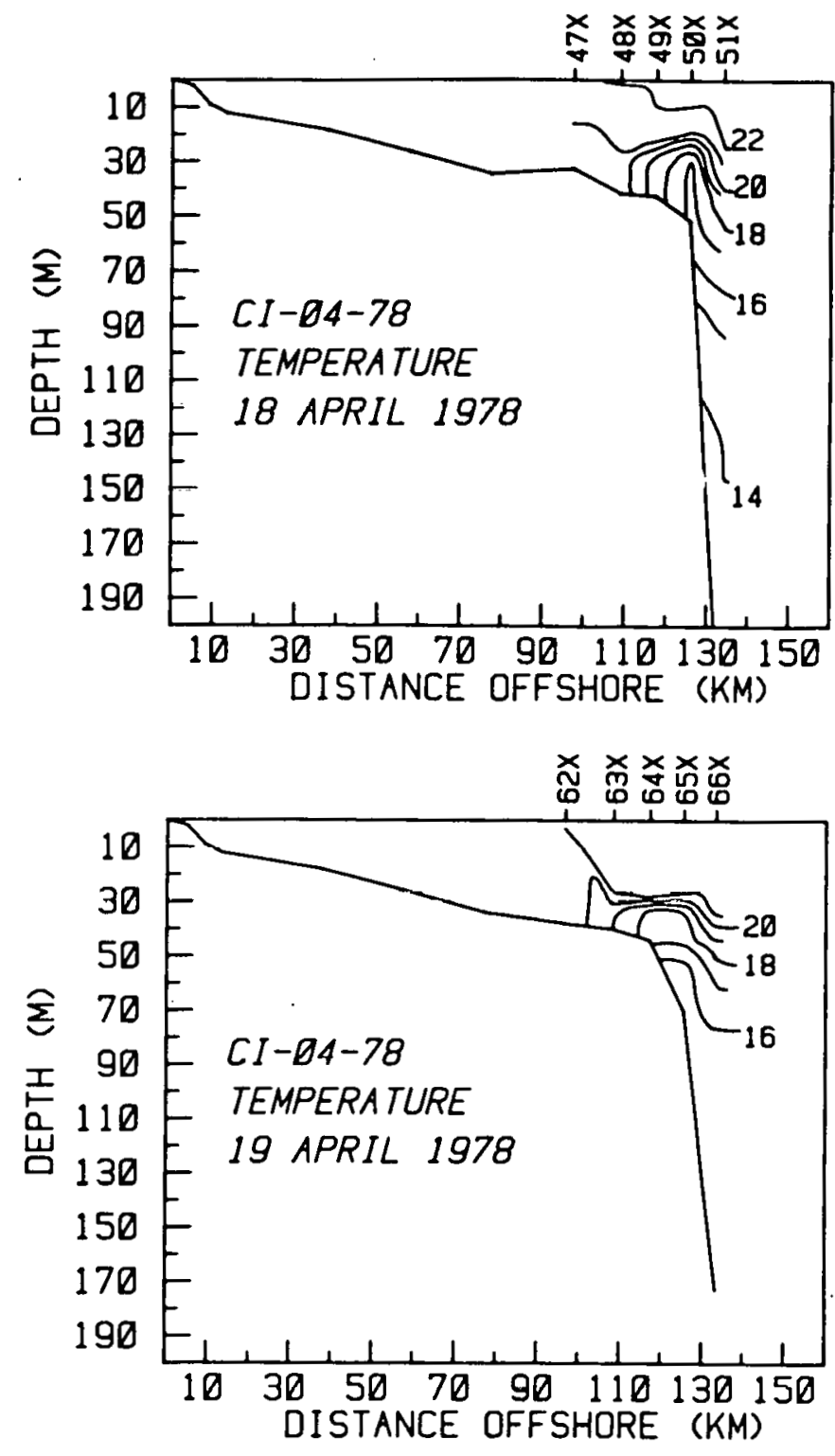

Figure 9. Temperature profile for stations $47 X-51 X, 18$ April and $62 X-66 X$, 19 April. 

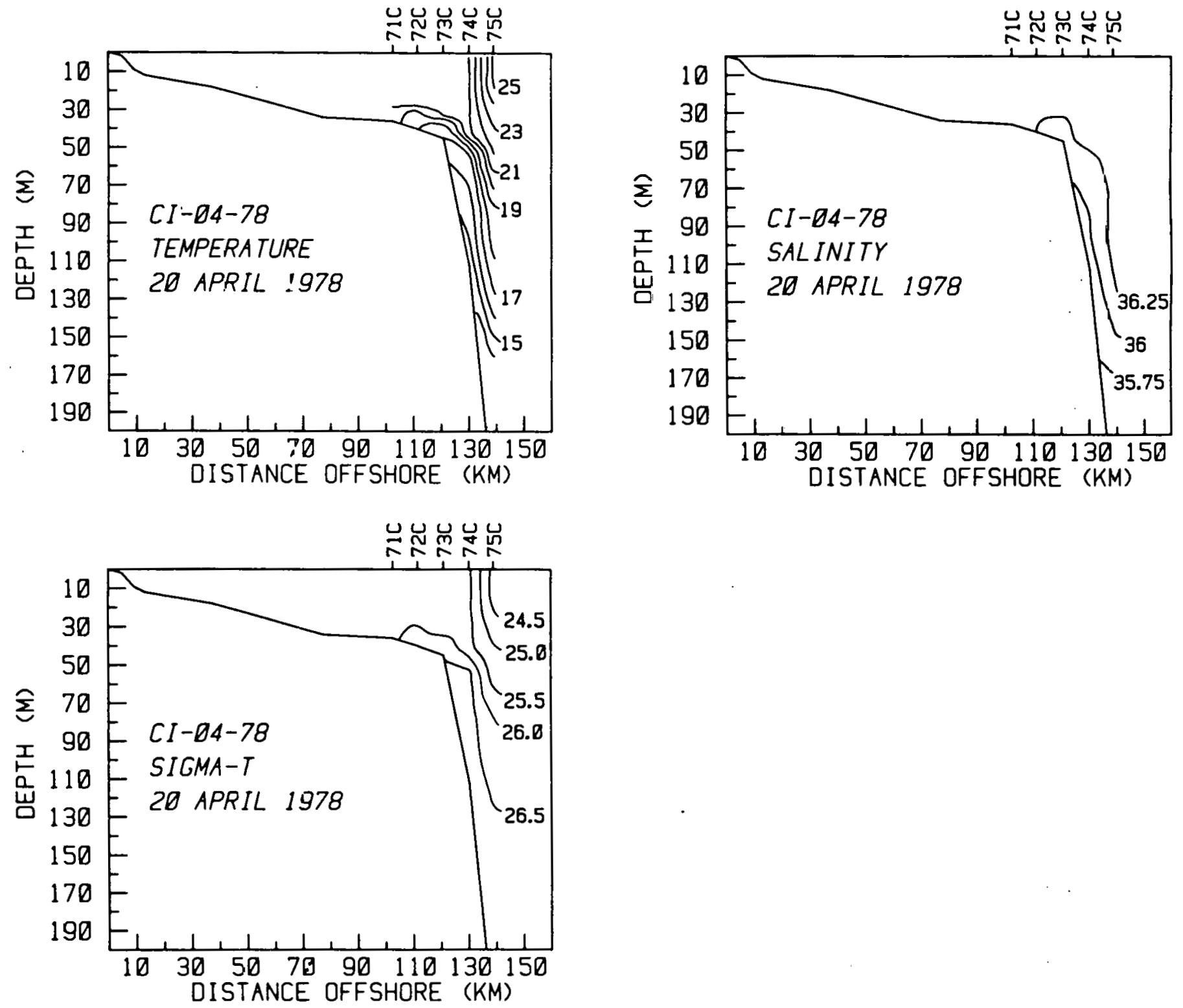

Figure 10. Stations $71 C-75 C$ temperature, salinity, sigma-t, 20 April. 

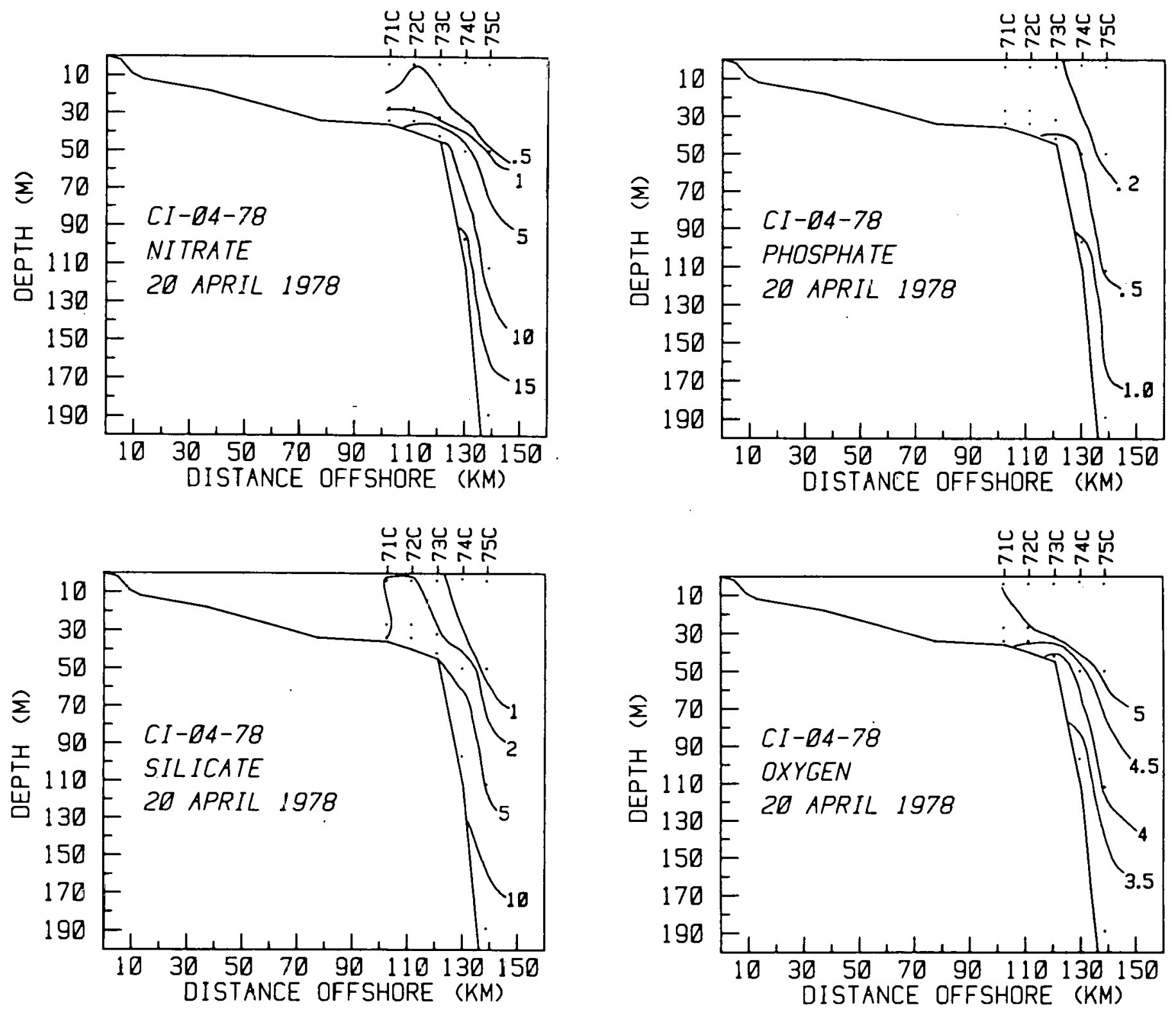

Figure 11. Stations $71 \mathrm{C}-75 \mathrm{C}$ nitrate, phosphate, silicate and aissolved oxygen, 20 April. Nutrients are in $\mu \mathrm{ll}$ and oxygen in $\mathrm{ml} / \mathrm{l}$. 
water dominated at the surface.

Section 5, Stations 93C to 97C, 21 April. (Figures 12-13).

Warm, low-nutrient water continued to be found at the surface at the sheif break. The onshore movement of the $25^{\circ} \mathrm{C}$ isotherm indicated further westward meander of the Gulf Stream.

Onshore-offshore Meanders.

The onshore-offshore velocities were determined from the distance the $19^{\circ} \mathrm{C}$ isotherm moved during the five observation periods (Table 2). Determination of horizontal advection through the first two sections showed an offshore flow of $10.8 \mathrm{~cm} \mathrm{sec}^{-1}$. By the third section, this offshore flow had reversed and the Gulf Stream was moving shoreward at $-7.9 \mathrm{~cm} \mathrm{sec}-1$. This onshore advection or westward meander of the Gulf Stream continued through the remainder of the study.

\section{Vertical Advection.}

Vertical advection at the shelf break was determined from the change in the depth of the $19^{\circ}$ isotherm through the five hydrographic sections (Table 2).

An upwelling velocity of $-4.3 \times 10^{-3} \mathrm{~cm} \mathrm{sec}^{-1}$ was observed through the first two onshore-offshore sections. This period of upwelling corresponded to the observed offshore movement of the Gulf Stream. Downwelling velocities of $2.0 \times 10^{-3}$ and $8.2 \times 10^{-3} \mathrm{~cm} \mathrm{sec}^{-1}$ were observed during the third and fourth sections. This downwelling was associated with the westward meander of the Gulf Stream during the same period.

The final section (Section 5 ) revealed the resumption of upwelling, but at a lesser velocity than in the initial sections. The 

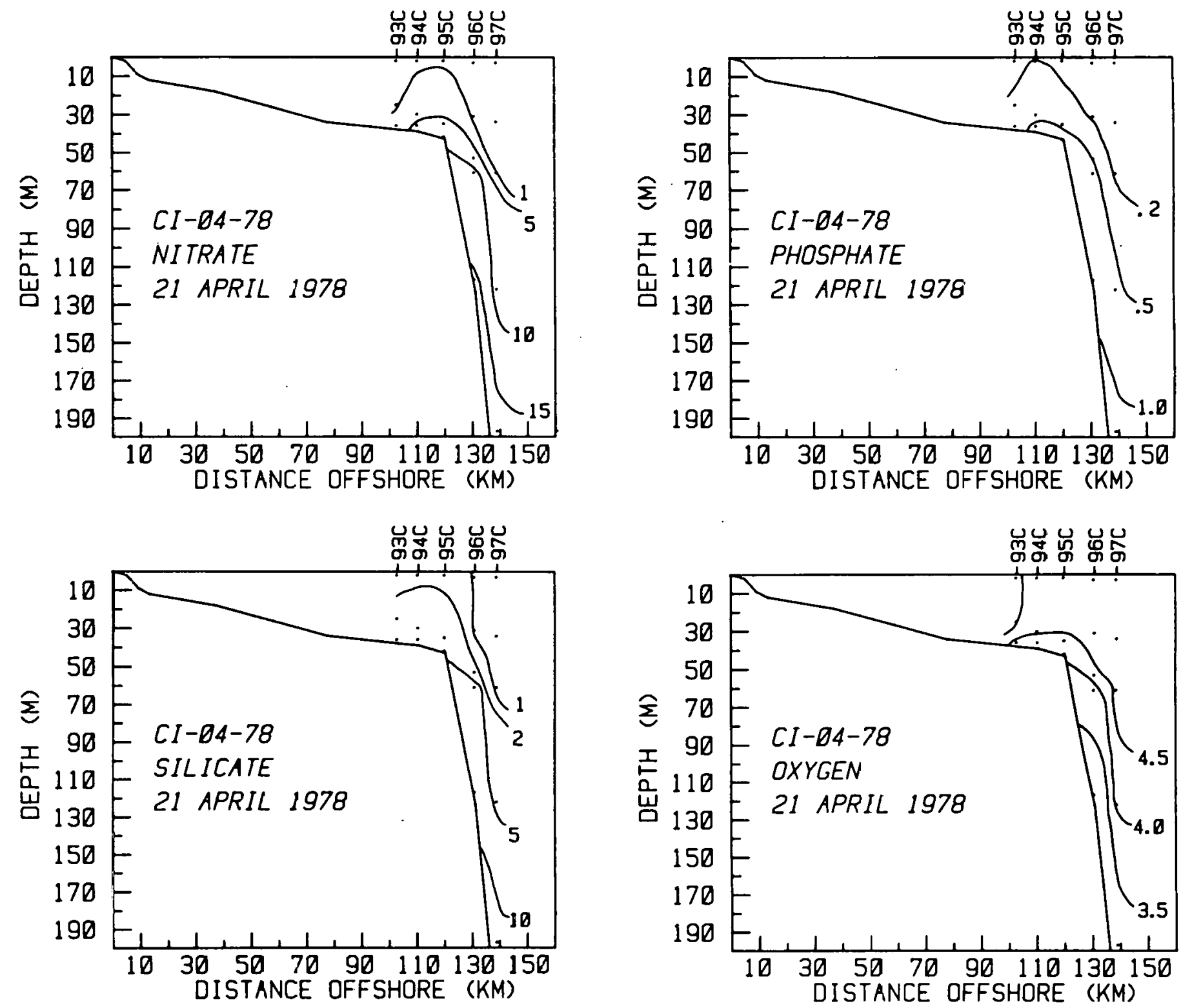

Figure 12. Stations 93C - 97C temperature, salinity and sigma-t, 21 April. 

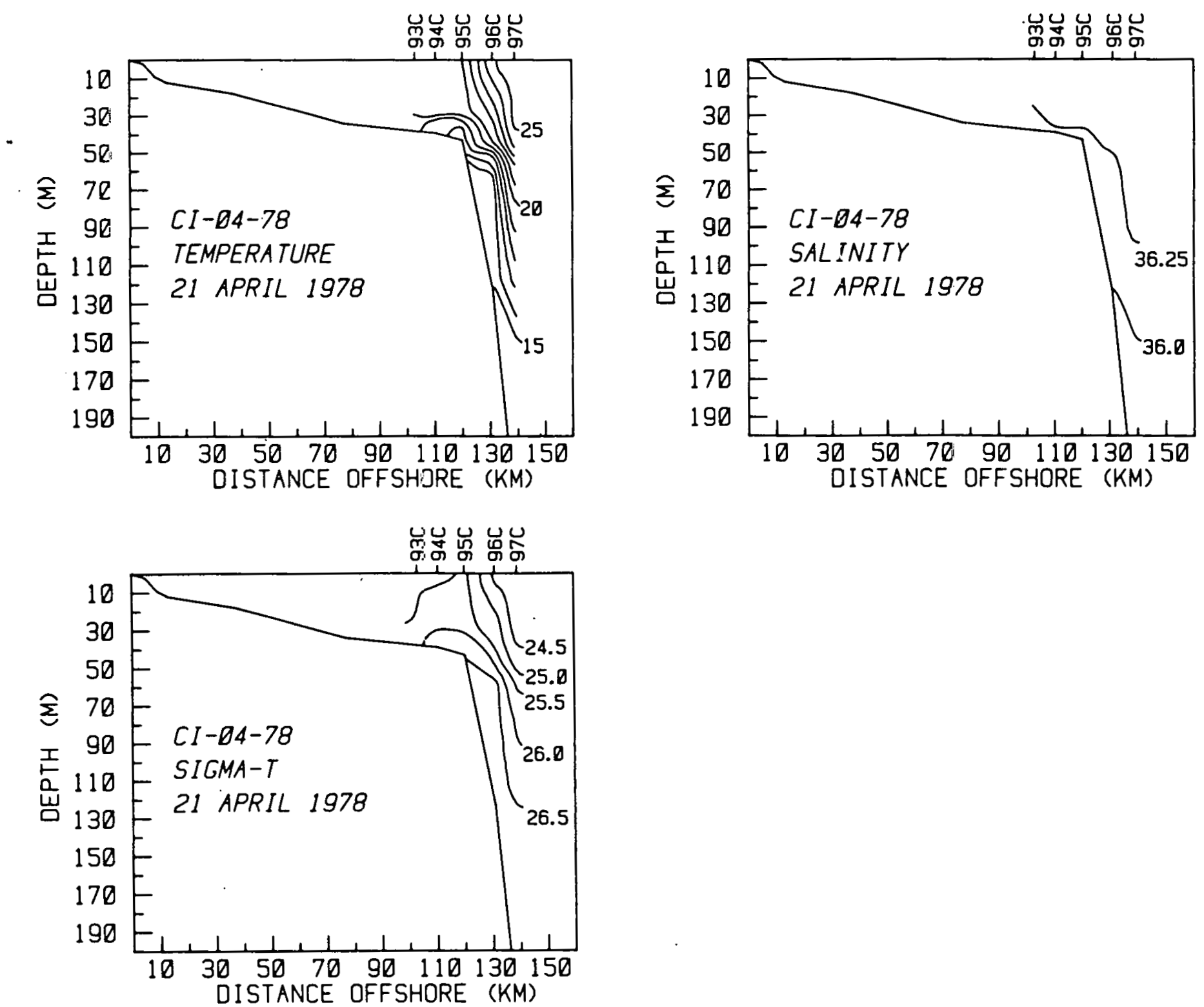

Figure 13. Stations $93 \mathrm{C}-97 \mathrm{C}$ nitrate, phosphate, silicate and dissolved oxygen. Nutrients are in $\mu \mathrm{M}$ and oxygen in $\mathrm{ml} / 1$. 
Table 2. Vertical and onshore-offshore velocities of the 190 isotherm off Brunswick: (+down, offshore; up, onshore).

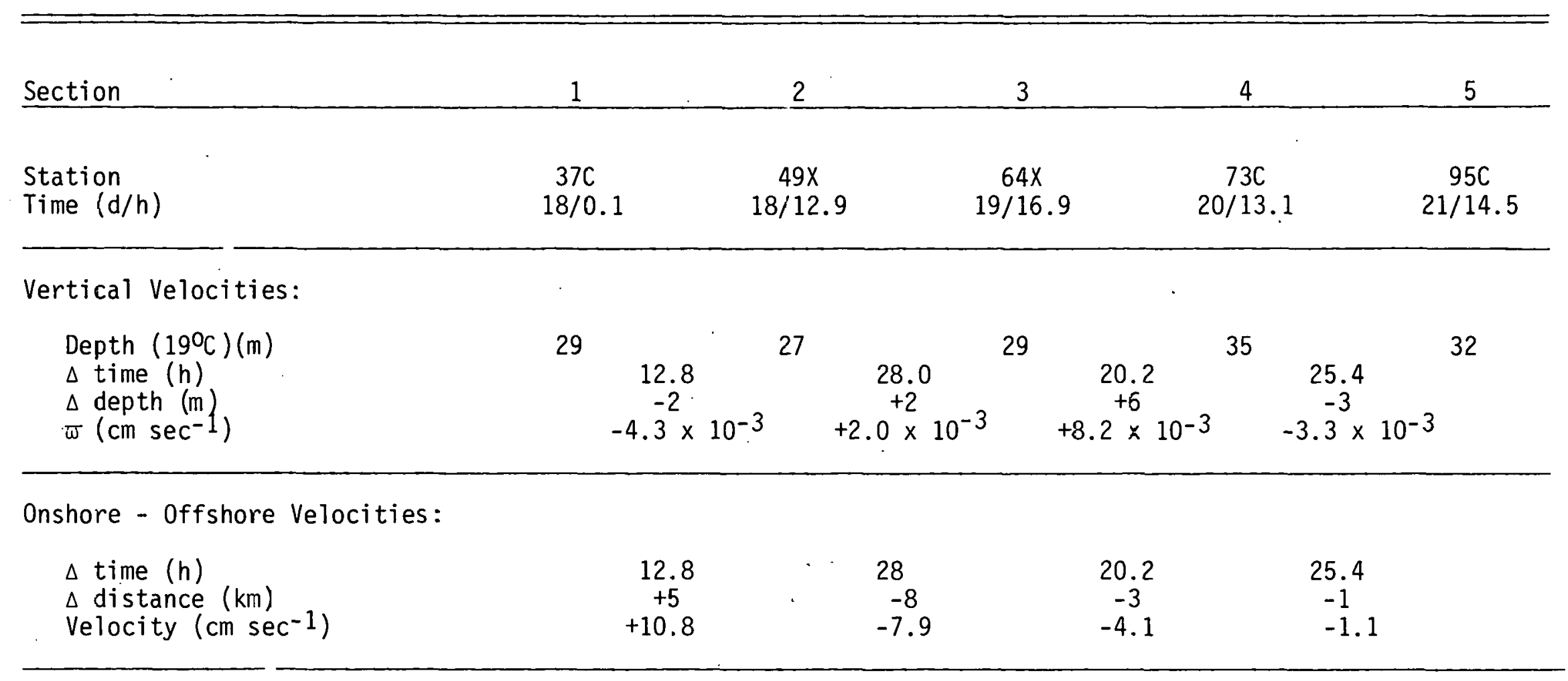


east-west currents were still onshore during the final period but at a considerably reduced rate as compared to the previous sections. The resumption of upwelling and slacking of the westward flow during the fifth section suggests the imminent reversal of the onshore-offshore flow to an eastward direction with the resumption of upwelling.

One alongshore XBT section on the $50 \mathrm{~m}$ isobath was completed on 21 April after section 5 of the onshore-offshore time series grid (Figure 14). This north-south section crossed the onshore-offshore section. Figure 14 reveals a mass of cooler upwelled water north of the time series grid at station $87 X$. This mass of cool water corresponds with the existence of upwelling four days earlier at a position $76 \mathrm{~km}$ south on the time series section. Stations south of $87 X$ showed lower isotherms which slowly moved upward as Station 91C was approached. These depressed isotherms correspond well with the downwelling and onshore flow several days before at the time series grid stations. The elevated isotherms seen at Station $90 x$ generally conform to the observed upwelling seen the day before along the final time series section.

A consideration of temperature at one position on the shelf break (Figure 15) through the five time series sections reflects trends visible in the cross shelf section plots (Figures 7-13). The isotherms were elevated during the upwelling/offshore flow period at the beginning of the study and lowered as downwelling and onshore flow came to dominate the shelf break area. The slight rise of the isotherms on the last days can be attributed to the modest resumption of upwelling. 


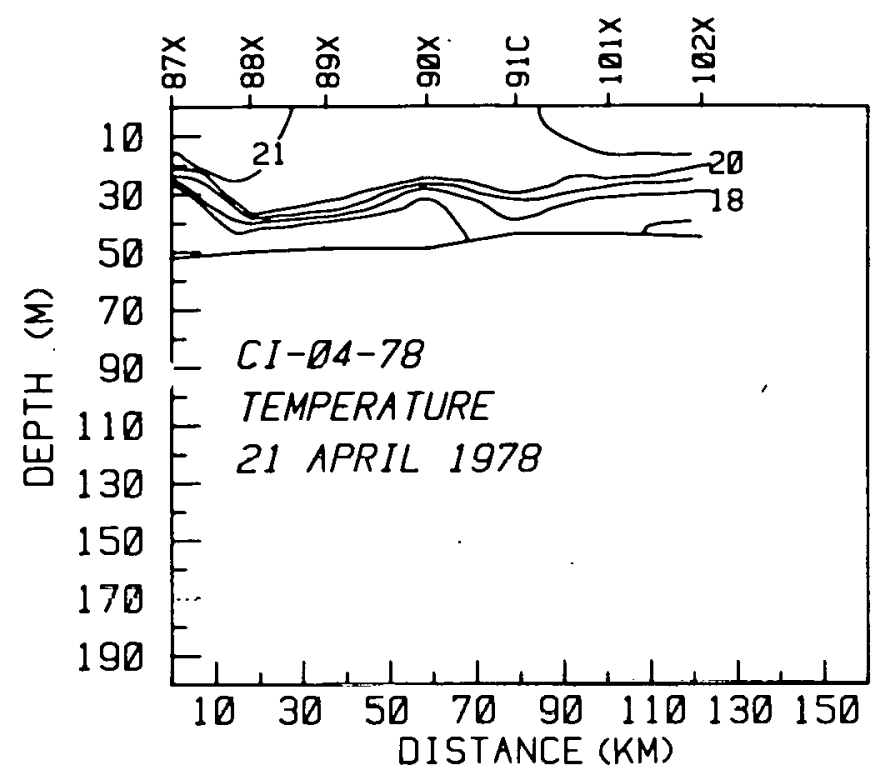

Figure 14. Alongshore section on $50 \mathrm{~m}$ i sobath from $87 \mathrm{X}$ (north) to $102 \mathrm{X}$ (south). Station 91C is on the onshore-offshore time series grid.

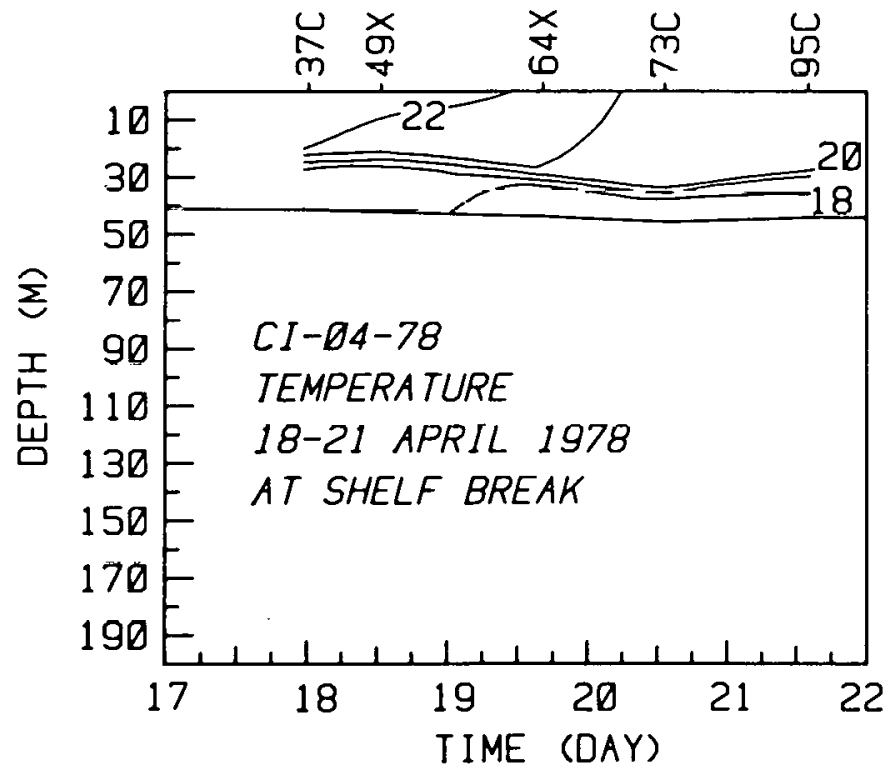

Figure 15. Temperature time series at $40 \mathrm{~m}$ station $L$ on shelf break, 18-21 Apri1, 1978. 
Temperature-Salinity Relationship.

A plot of temperature vs. salinity for all BLM-DOE stations (1C118C) during 10-23 April 1978 revealed two distinctive water masses (Figure 16). Low-salinity, thermally mixed waters can be seen on the shelf, while high-salinity, thermally stratified water was found in the offshore Gulf Stream waters. 


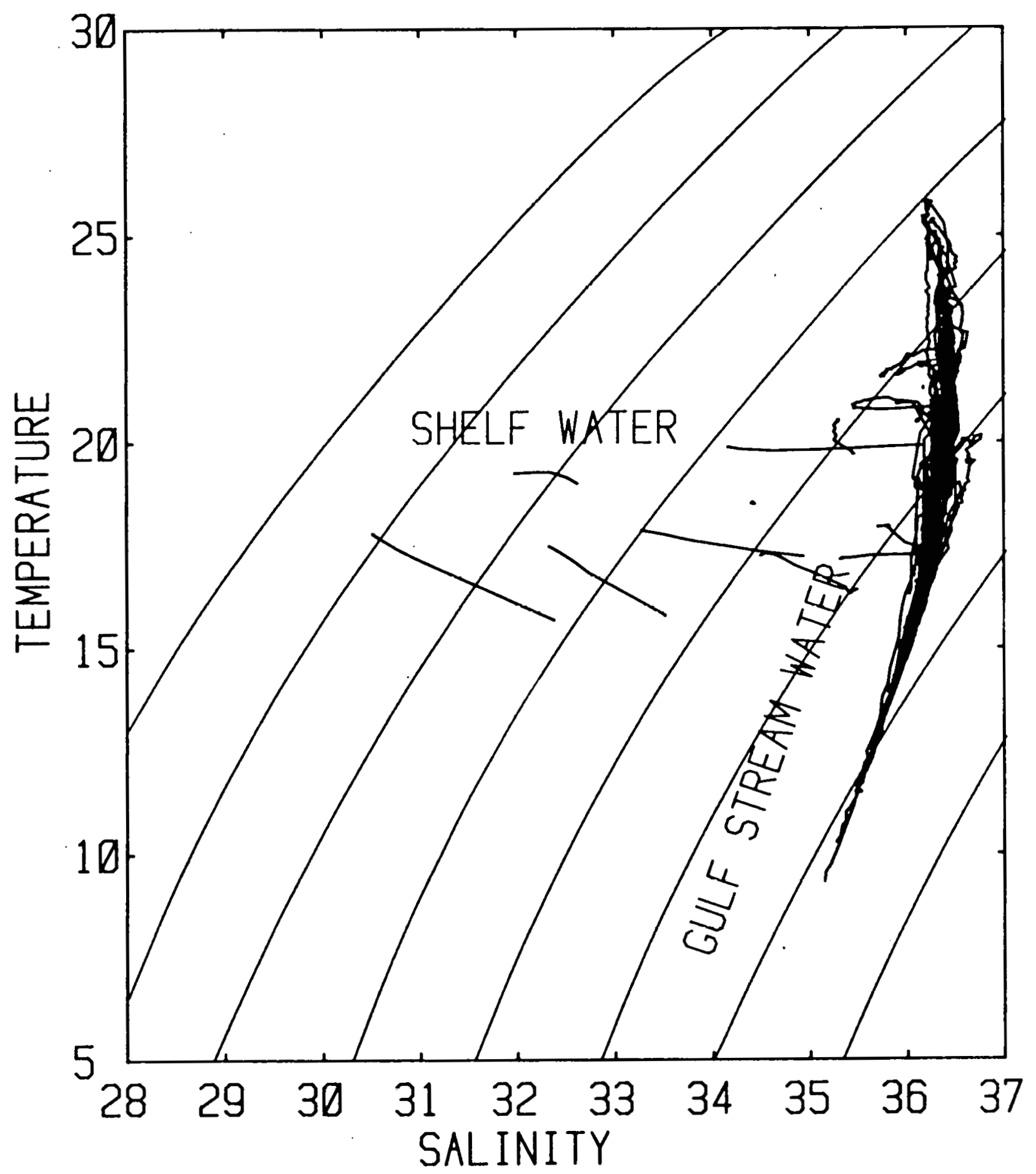

Figure 16. Temperature-salinity diagram of all BLM-DOE stations (1C-118C) 10-23 April 1978. T-S points for each station are connected. 


\section{SUMMARY}

The shelf waters were vertically well mixed with horizontal stratification apparent only in the temperature, salinity, and sigma-t distributions. A Gulf Stream meander was observed at the shelf break which, at first, moved offshore at $10.8 \mathrm{~cm} \mathrm{sec}^{-1}$. The meander then reversed, moving onshore with an initial velocity of $-7.9 \mathrm{~cm} \mathrm{sec}^{-1}$. This shoreward advection continued through the remainder of the study but at a decreasing velocity. An upwelling velocity of $-4.3 \times 10^{-3} \mathrm{~cm} \mathrm{sec}^{-1}$ was observed in association with the offshore meander of the Gulf Stream. The onshore meander resulted in downwelling at the shelf break with vertical velocities as high as $8.2 \times 10^{-3} \mathrm{~cm} \mathrm{sec}^{-1}$. The final day showed weak onshore movement and a resumption of upwelling, though at a lower velocity than observed initially in the study. 


\section{REFERENCES}

Armstrong, F.A.J., C.R. Stearns, and J.D.H. Strickland. 1967. The measurement of upwelling and subsequent biological processes by means of the Technicon Autoanalyzer.

Atkinson, L.P. 1977. Modes of Gulf Stream intrusion into the South Atlantic Bight shelf waters. Geophysical Research Letters, 4(12):583-586.

Broenkow, W.W., W.B. Abrahams, and R.R. McInnis. 1977. A CTD Data Acquisition System for Coastal Applications. Preprint: Proceedings Fourth STD/Ocean Systems Conference, January 19-27, 1977. Plessey Environmental Systems, San Deigo, California.

Chandler, W.S., L.P. Atkinson, J.J. Singer, P.G. O'Malley, and C.V. Baker. 1978. A CTD System: Description, Operation, Data Acquisition and Processing. Georgia Marine Science Center Technical Report 78-7.

Friederich, G.E. and T.E. Whitledge. 1972. Autoanalyzer procedure for nutrients. In Phytoplankton Growth Dynamics: Technical Series 1, Chemostate Methodology and Chemical Analyses. S.P. Pevlou (ed.); Special Report No. 52, Dept. Oceanogr. University of Washington, Seattle, Washington, pp. 38-60.

Murphy, J. and J.P. Riley. 1962. A modified single solution method for the determination of phosphate in natural waters. Anal. Chim. Octa, 27: 31-36.

Strickland, J.D.H. and T.R. Parsons. 1965. A manual of sea water analysis. Fish Res. Bd. Canada, Bu11, No. 125 (2nd ed.), Ottawa. 
APPENDIX I

Calibration Data 
SALINITY CALIBRATION DATA:

\begin{tabular}{|c|c|c|c|c|}
\hline Station & Depth & $\begin{array}{l}\text { Bottle } \\
\text { Salinity }\end{array}$ & $\begin{array}{c}\text { CTD } \\
\text { Salinity }\end{array}$ & Difference \\
\hline $\begin{array}{l}2 C \\
2 C \\
3 C \\
3 C \\
4 C\end{array}$ & $\begin{array}{r}94 \\
2 \\
200 \\
87 \\
206\end{array}$ & $\begin{array}{l}36.384 \\
36.370 \\
35.820 \\
36.350 \\
35.952\end{array}$ & $\begin{array}{l}36.271 \\
36.248 \\
36.705 \\
36.231 \\
35.838\end{array}$ & $\begin{array}{l}+.113 \\
+.122 \\
+.115 \\
+.119 \\
+.114\end{array}$ \\
\hline $\begin{array}{r}5 C \\
7 C \\
8 C \\
20 C \\
22 C\end{array}$ & $\begin{array}{l}47 \\
32 \\
27 \\
18 \\
35\end{array}$ & $\begin{array}{l}36.399 \\
36.185 \\
36.092 \\
34.901 \\
36.280\end{array}$ & $\begin{array}{l}36.283 \\
36.072 \\
35.983 \\
34.779 \\
36.141\end{array}$ & $\begin{array}{l}+.116 \\
+.113 \\
+.109 \\
+.122 \\
+.139\end{array}$ \\
\hline $\begin{array}{l}24 C \\
25 C \\
26 C \\
33 C \\
36 C\end{array}$ & $\begin{array}{r}102 \\
224 \\
40 \\
8 \\
54\end{array}$ & $\begin{array}{l}35.943 \\
35.632 \\
36.202 \\
36.174 \\
36.069\end{array}$ & $\begin{array}{l}35.826 \\
35.521 \\
36.094 \\
36.045 \\
35.945\end{array}$ & $\begin{array}{l}+.117 \\
+.111 \\
+.108 \\
+.129 \\
+.124\end{array}$ \\
\hline $\begin{array}{l}37 C \\
39 C \\
40 C \\
41 C \\
42 C\end{array}$ & $\begin{array}{l}39 \\
35 \\
31 \\
22 \\
16\end{array}$ & $\begin{array}{l}36.272 \\
36.343 \\
36.081 \\
35.442 \\
34.434\end{array}$ & $\begin{array}{l}36.151 \\
36.230 \\
35.978 \\
35.327 \\
34.308\end{array}$ & $\begin{array}{l}+.121 \\
+.113 \\
+.103 \\
+.115 \\
+.126\end{array}$ \\
\hline $\begin{array}{l}60 C \\
60 C \\
67 C \\
69 C \\
71 C\end{array}$ & $\begin{array}{r}41 \\
28 \\
40 \\
4 \\
4\end{array}$ & $\begin{array}{l}36.211 \\
36.235 \\
36.183 \\
36.354 \\
36.253\end{array}$ & $\begin{array}{l}36.105 \\
36.104 \\
36.065 \\
36.207 \\
36.104\end{array}$ & $\begin{array}{l}+.106 \\
+.131 \\
+.118 \\
+.147 \\
+.149\end{array}$ \\
\hline $\begin{array}{l}72 C \\
73 C \\
75 C \\
94 C \\
97 C\end{array}$ & $\begin{array}{r}4 \\
4 \\
189 \\
36 \\
197\end{array}$ & $\begin{array}{l}36.279 \\
36.323 \\
35.679 \\
36.244 \\
35.864\end{array}$ & $\begin{array}{l}36.131 \\
36.175 \\
35.553 \\
36.105 \\
35.738\end{array}$ & $\begin{array}{l}+.148 \\
+.148 \\
+.126 \\
+.139 \\
+.126\end{array}$ \\
\hline $\begin{array}{l}105 C \\
108 C \\
109 C \\
110 C \\
113 C\end{array}$ & $\begin{array}{r}253 \\
43 \\
38 \\
26 \\
17\end{array}$ & $\begin{array}{l}35.975 \\
36.066 \\
36.093 \\
36.312 \\
36.336\end{array}$ & $\begin{array}{l}35.849 \\
35.929 \\
35.957 \\
36.179 \\
36.197\end{array}$ & $\begin{array}{l}+.126 \\
+.137 \\
+.136 \\
+.133 \\
+.139\end{array}$ \\
\hline $\begin{array}{l}114 C \\
115 C \\
116 C \\
117 C\end{array}$ & $\begin{array}{l}23 \\
25 \\
59 \\
85\end{array}$ & $\begin{array}{l}36.289 \\
36.126 \\
35.918 \\
35.827\end{array}$ & $\begin{array}{l}36.147 \\
36.001 \\
35.794 \\
35.714\end{array}$ & $\begin{array}{l}+.142 \\
+.125 \\
+.124 \\
+.113\end{array}$ \\
\hline
\end{tabular}


TEMPERATURE CALIBRATION DATA

\begin{tabular}{|c|c|c|c|c|c|c|}
\hline \multirow[b]{2}{*}{ Station } & \multirow[b]{2}{*}{ Depth } & \multicolumn{3}{|c|}{$\begin{array}{l}\text { Reversing Thermometer } \\
\text { Temperature } \\
\end{array}$} & \multirow{2}{*}{$\begin{array}{c}\text { CTD } \\
\text { Temperature } \\
\end{array}$} & \multirow[b]{2}{*}{ Difference } \\
\hline & & 1 & 2 & Ave & & \\
\hline $\begin{array}{r}7 C \\
8 C \\
36 C \\
39 C \\
40 C\end{array}$ & $\begin{array}{l}32 \\
27 \\
54 \\
35 \\
31\end{array}$ & $\begin{array}{l}17.40 \\
17.29 \\
16.02 \\
20.64 \\
20.50\end{array}$ & $\begin{array}{l}17.41 \\
17.31 \\
16.02 \\
20.63 \\
20.49\end{array}$ & $\begin{array}{l}17.41 \\
17.30 \\
16.02 \\
20.64 \\
20.50\end{array}$ & $\begin{array}{l}17.39 \\
17.27 \\
16.00 \\
20.62 \\
20.47\end{array}$ & $\begin{array}{l}+.02 \\
+.03 \\
+.02 \\
+.02 \\
+.03\end{array}$ \\
\hline $\begin{array}{r}41 C \\
42 C \\
105 C \\
111 C \\
113 C\end{array}$ & $\begin{array}{r}22 \\
16 \\
253 \\
27 \\
17\end{array}$ & $\begin{array}{l}19.73 \\
18.52 \\
14.93 \\
20.85 \\
21.13\end{array}$ & $\begin{array}{l}19.71 \\
18.52 \\
14.94 \\
20.84 \\
21.11\end{array}$ & $\begin{array}{l}19.72 \\
18.52 \\
14.94 \\
20.85 \\
21.12\end{array}$ & $\begin{array}{l}19.70 \\
18.52 \\
14.93 \\
20.83 \\
21.09\end{array}$ & $\begin{array}{l}+.02 \\
0.00 \\
+.01 \\
+.02 \\
+.03\end{array}$ \\
\hline
\end{tabular}


APPENDIX II

Hydrographic Data 
STATION SUMMARY FOR ISELIN CFUISE CI-04

\begin{tabular}{|c|c|c|c|c|c|c|c|c|c|c|c|}
\hline CRUISE & STATION & LAT & I TUDE & LON & GITUNE & YK & KN & IIY & $\begin{array}{l}\text { HOUR } \\
\text { GMI }\end{array}$ & DEFTH & $\begin{array}{l}\text { CONSEC } \\
\text { NUMAER }\end{array}$ \\
\hline 004 & $001 C$ & 32 & $5.2 \mathrm{~N}$ & 78 & $7.7 \mathrm{~W}$ & .78 & 4 & 12 & 5.7 & 515 & 1 \\
\hline 004 & $002 \mathrm{C}$ & 32 & $12.0 \mathrm{~N}$ & 78 & $16.0 \mathrm{~W}$ & 78 & 4 & 14 & 6.7 & 373 & 2 \\
\hline 004 & $003 C$ & 32 & $19.3 N$ & 78 & $24.5 \mathrm{H}$ & 78 & 4 & 14 & 9.8 & 290 & 3 \\
\hline 004 & $004 C$ & 32 & $26.1 \mathrm{~N}$ & 78 & $32.8 W$ & 78 & 4 & 14 & 12.1 & 248 & 4 \\
\hline 004 & $005 C$ & 32 & $29.7 \mathrm{~N}$ & 78 & $37.2 \mathrm{~W}$ & 78 & 4 & 14 & 16.9 & 240 & \\
\hline 004 & $006 C$ & 32 & $33.3 \mathrm{~N}$ & 78 & $41.3 \mathrm{~W}$ & 78 & 4 & 15 & 5.4 & 46 & 6 \\
\hline 004 & $007 C$ & 32 & $40.5 \mathrm{~N}$ & 78 & 49.31 & 78 & 4 & 15 & 6.9 & 35 & 7 \\
\hline 004 & $0 O B C$ & 32 & $47.2 \mathrm{~N}$ & 78 & $58.5 \mathrm{~W}$ & 78 & 4 & 15 & 8.3 & 29 & 8 \\
\hline 004 & $009 C$ & 32 & $54.2 \mathrm{~N}$ & 79 & $6.8 \mathrm{H}$ & 78 & 4 & 15 & 9.7 & 19 & 9 \\
\hline 004 & $018 \mathrm{CU}$ & 31 & $59.1 \mathrm{~N}$ & 80 & 44.84 & 78 & 4 & 16 & 16.0 & 12 & 18 \\
\hline 004 & $019 \mathrm{C}$ & 31 & $54.3 N$ & 80 & $35.6 \mathrm{H}$ & 78 & 4 & 16 & 18.3 & 16 & 19 \\
\hline 004 & $020 C$ & 31 & $49.5 \mathrm{~N}$ & 80 & 24.54 & 78 & 4 & 16 & 20.5 & 20 & 20 \\
\hline 004 & $021 C$ & 31 & $45.0 \mathrm{~N}$ & 80 & $13.0 \mathrm{~W}$ & 78 & 4 & 16 & 22.8 & 25 & 21 \\
\hline 004 & $022 C$ & 31 & $42.4 N$ & 80 & .94 & 78 & 4 & 17 & .7 & 37 & 22 \\
\hline 004 & $023 C$ & 31 & $36.1 \mathrm{~N}$ & 79 & $50.6 \mathrm{~W}$ & 78 & 4 & 17 & 2.7 & 44 & 23 \\
\hline 004 & $024 C U$ & 31 & $30.0 \mathrm{~N}$ & 79 & $38.0 \mathrm{~W}$ & 78 & 4 & 17 & 5.2 & 123 & 24 \\
\hline v04 & $025 \mathrm{C}$ & 31 & $29.0 \mathrm{~N}$ & 79 & $30.5 \mathrm{~W}$ & 78 & 4 & 17 & 6.9 & 337 & 25 \\
\hline 004 & $026 C$ & 31 & $22.5 \mathrm{~N}$ & 79 & $22.0 \mathrm{~W}$ & 78 & 4 & 17 & 9.9 & 460 & 26 \\
\hline 004 & $033 C$ & 30 & $45.8 \mathrm{~N}$ & 79 & $42.0 \mathrm{~W}$ & 78 & 4 & 17 & 23.0 & 525 & 33 \\
\hline 004 & $034 C$ & 30 & $49.6 \mathrm{~N}$ & 79 & $54.4 \mathrm{~L}$ & 78 & 4 & 18 & 1.7 & 280 & 34 \\
\hline 004 & $035 x$ & 30 & $52.0 \mathrm{~N}$ & 79 & $59.4 \mathrm{~W}$ & 78 & 4 & 18 & 3.6 & 117 & 35 \\
\hline 004 & $036 C$ & 30 & $52.7 \mathrm{~N}$ & 80 & $1.2 \mathrm{~W}$ & 78 & 4 & 18 & 4.0 & 55 & 36 \\
\hline 004 & $037 C$ & 30 & $54.6 \mathrm{~N}$ & 80 & 7.04 & 78 & 4 & 18 & 5.1 & 41 & 37 \\
\hline 004 & $038 x$ & 30 & $56.0 \mathrm{~N}$ & 80 & $13.4 \mathrm{H}$ & 78 & 4 & 18 & 5.9 & 39 & 38 \\
\hline 004 & $039 C$ & 30 & $57.6 \mathrm{~N}$ & 80 & $20.0 \mathrm{~V}$ & 78 & 4 & 18 & 6.5 & 39 & 39 \\
\hline 004 & $040 C$ & 31 & $2.0 \mathrm{~N}$ & 80 & $30.5 \mathrm{~W}$ & 78 & 4 & 18 & 7.8 & 34 & 40 \\
\hline 004 & $04 I C U$ & 31 & $6.0 N$ & 80 & $42.0 \mathrm{~W}$ & 78 & 4 & 18 & 9.3 & 26 & 41 \\
\hline 004 & $042 \mathrm{C}$ & 31 & $10.0 \mathrm{~N}$ & 80 & 54.04 & 78 & 4 & 18 & 10.7 & 18 & 42 \\
\hline 004 & $043 C$ & 31 & $15.0 \mathrm{~N}$ & 81 & $8.0 \mathrm{~W}$ & 78 & 4 & 18 & 12.2 & 12 & 43 \\
\hline 004 & $047 x$ & 30 & $57.0 \mathrm{~N}$ & 80 & $19.4 \mathrm{~W}$ & 78 & 4 & 18 & 17.1 & 35 & 47 \\
\hline 004 & $048 x$ & 30 & $55.0 \mathrm{~N}$ & 80 & $12.6 \mathrm{~W}$ & 78 & 4 & 18 & 17.5 & 40 & 48 \\
\hline 004 & $049 X$ & 30 & $54.0 \mathrm{~N}$ & 80 & $7.3 W$ & 78 & 4 & 18 & 17.8 & 42 & 49 \\
\hline 004 & $050 x$ & 30 & $53.0 \mathrm{~N}$ & 80 & $2.2 U$ & 78 & 4 & 18 & 18.5 & 50 & 50 \\
\hline 004 & $051 x$ & 30 & $52.0 \mathrm{~N}$ & 79 & $57.2 W$ & 78 & 4 & 18 & 18.9 & 250 & 51 \\
\hline 004 & $0.5 .3 x$ & 30 & $53.5 \mathrm{~N}$ & 00 & $5.0 \mathrm{~W}$ & 78 & 4 & 18 & 20.6 & 43 & 53 \\
\hline 004 & $057 C$ & 30 & $53.4 \mathrm{~N}$ & 80 & $5.4 \mathrm{U}$ & 78 & 4 & 19 & 1.6 & 44 & 57 \\
\hline 004 & $O B O C$ & 30 & $53.5 \mathrm{~N}$ & 80 & $4.1 \mathrm{H}$ & 78 & 4 & 19 & 13.0 & 44 & 60 \\
\hline 004 & $062 X$ & 30 & $57.7 \mathrm{~N}$ & 80 & 19.54 & 78 & 4 & 19 & 19.9 & 38 & 62 \\
\hline 004 & $063 x$ & 30 & $55.4 \mathrm{~N}$ & 80 & $12.6 \mathrm{H}$ & 78 & 4 & 19 & 21.0 & 40 & 63 \\
\hline 004 & $064 x$ & 30 & $53.5 \mathrm{~N}$ & 80 & 7.54 & 78 & 4 & 19 & 21.8 & 42 & .64 \\
\hline 004 & $065 x$ & 30 & $52.5 \mathrm{~N}$ & 80 & $2.5 \downarrow$ & 78 & 4 & 19 & 22.6 & 68 & 65 \\
\hline
\end{tabular}


ISELIN CRUISE CI-04

\begin{tabular}{|c|c|c|c|c|c|c|c|c|c|c|c|}
\hline RỤ & STATION & LI & $D E$ & $\mathrm{LC}$ & O IIUE & YR & MN & DY & $\begin{array}{c}\text { HOUR } \\
\text { GHT }\end{array}$ & DEPTH & $\begin{array}{l}\text { CONSEC } \\
\text { NUHBER }\end{array}$ \\
\hline 004 & $066 x$ & 30 & $51.8 N$ & 79 & $57.6 \mathrm{~W}$ & 78 & 4 & 19 & 23.0 & 173 & 66 \\
\hline 004 & $067 C$ & 30 & $53.5 \mathrm{~N}$ & 80 & $4.0 \mathrm{U}$ & 78 & 4 & 20 & .9 & 44 & 67 \\
\hline 004 & $069 \mathrm{C}$ & 30 & $53.5 \mathrm{~N}$ & 80 & $4.0 \mathrm{H}$ & 78 & 4 & 20 & 13.0 & 44 & 69 \\
\hline 004 & $071 C$ & 30 & $56.9 N$ & 80 & $15.7 \mathrm{~W}$ & 78 & 4 & 20 & 15.9 & 36 & 71 \\
\hline 004 & $072 \mathrm{CU}$ & 30 & $55.3 N$ & 80 & $10.4 \mathrm{H}$ & 78 & 4 & 20 & 17.0 & 40 & 72 \\
\hline 004 & $073 \mathrm{CU}$ & 30 & $53.3 N$ & 80 & $5.0 \mathrm{U}$ & 78 & 4 & 20 & 18.0 & 45 & 73 \\
\hline 004 & $074 C$ & 30 & $51.7 N$ & 79 & 59.54 & 78 & 4 & 20 & 19.2 & 112 & 74 \\
\hline 004 & $075 C$ & 30 & $49.6 \mathrm{~N}$ & 79 & $54.5 W$ & 78 & 4 & 20 & 20.4 & 244 & 75 \\
\hline 004 & $077 C$ & 30 & $53.4 \mathrm{~N}$ & 79 & $36.8 \mathrm{~W}$ & 78 & 4 & 20 & 23.9 & 44 & 77 \\
\hline 004 & $087 x$ & 31 & $32.1 \mathrm{~N}$ & 79 & $45.8 \mathrm{~W}$ & 78 & 4 & 21 & 10.1 & 52 & 87 \\
\hline 004 & $088 x$ & 31 & $23.4 \mathrm{~N}$ & 79 & $50.5 \mathrm{H}$ & 78 & 4 & 21 & 11.1 & 46 & 88 \\
\hline 004 & $089 x$ & 31 & $14.0 \mathrm{~N}$ & 79 & $54.0 \mathrm{~W}$ & 78 & 4 & 21 & 12.1 & 49 & 89 \\
\hline 004 & $090 x$ & 31 & $3.0 \mathrm{~N}$ & 79 & 57.64 & 78 & 4 & 21 & 13.1 & 49 & 90 \\
\hline 004 & $091 C$ & 30 & $53.5 \mathrm{~N}$ & 80 & 4.04 & 78 & 4 & 21 & 14.6 & 44 & 91 \\
\hline 004 & $093 C$ & 30 & $56.8 \mathrm{~N}$ & 80 & $15.5 \mathrm{~W}$ & 78 & 4 & 21 & 17.5 & 38 & 93 \\
\hline 004 & $094 C$ & 30 & $55.5 \mathrm{~N}$ & 80 & $11.0 \mathrm{~W}$ & 78 & 4 & 21 & 18.3 & 39 & 94 \\
\hline 004 & $095 \mathrm{C}$ & 30 & $53.5 \mathrm{~N}$ & 80 & $5.4 \mathrm{H}$ & $78^{\circ}$ & 4 & 21 & 19.5 & 43 & 95 \\
\hline 004 & $096 \mathrm{C}$ & 30 & $51.5 \mathrm{~N}$ & 79 & $59.0 \mathrm{~W}$ & 76 & 4 & 21 & 20.6 & 123 & 96 \\
\hline 004 & $097 \mathrm{C}$ & 30 & $49.5 N$ & 79 & $54.5 \mathrm{H}$ & 78 & 4 & 21 & 21.6 & 245 & 97 \\
\hline 004 & 0990 & 30 & $55.3 \mathrm{~N}$ & 80 & $2.1 \mathrm{H}$ & 78 & 4 & 21 & 23.9 & 46 & 99 \\
\hline 004 & $101 x$ & 30 & $42.8 \mathrm{~N}$ & 80 & $9.0 \mathrm{~W}$ & 78 & 4 & 22 & 4.5 & 44 & 101 \\
\hline 004 & $102 x$ & 30 & $32.0 \mathrm{~N}$ & 80 & $13.8 \mathrm{H}$ & 78 & 4 & 22 & 5.5 & 45 & 102 \\
\hline 004 & $103 C$ & 30 & $53.0 \mathrm{~N}$ & 80 & $5.0 \mathrm{H}$ & 78 & 4 & 22 & 12.5 & 44 & 103 \\
\hline 004 & $105 C$ & 30 & $4.0 N$ & 80 & $2.2 \mathrm{H}$ & 78 & 4 & 22 & 19.9 & 430 & 105 \\
\hline 004 & $106 \mathrm{C}$ & 30 & $2.5 N$ & 80 & $11.0 \mathrm{~W}$ & 78 & 4 & 22 & 21.8 & 240 & 106 \\
\hline 004 & $107 C$ & 30 & $2.1 \mathrm{~N}$ & BO & $16.0 \mathrm{~W}$ & 78 & 4 & 22 & 23.2 & 55 & 107 \\
\hline 004 & $108 \mathrm{CU}$ & 30 & $1.5 \mathrm{~N}$ & 80 & $22.0 \mathrm{H}$ & 78 & 4 & 23 & .1 & 45 & 108 \\
\hline 004 & $109 C$ & 30 & $0.0 N$ & 80 & $33.1 \mathrm{H}$ & 78 & 4 & 23 & 1.3 & 41 & 109 \\
\hline 004 & $110 \mathrm{C}$ & 29 & $58.2 \mathrm{~N}$ & 80 & $43.0 \mathrm{~W}$ & 78 & 4 & 23 & 2.4 & 28 & 110 \\
\hline 004 & $111 C$ & 29 & $56.8 \mathrm{~N}$ & 80 & $53.9 \mathrm{~W}$ & 78 & 4 & 23 & 3.7 & 29 & 111 \\
\hline 004 & $112 \mathrm{C}$ & 29 & $55.2 \mathrm{~N}$ & 81 & $5.0 \mathrm{H}$ & 78 & 4 & 23 & 4.8 & 19 & 112 \\
\hline 004 & $113 C$ & 29 & $6.0 \mathrm{~N}$ & 80 & $42.7 \mathrm{~W}$ & 78 & 4 & 23 & 9.6 & 19 & 113 \\
\hline 004 & $114 C$ & 29 & $8.0 \mathrm{~N}$ & 80 & 33.04 & 78 & 4 & 23 & 10.7 & 26 & 114 \\
\hline 004 & $115 c$ & 29 & $8.8 \mathrm{~N}$ & 80 & $23.0 \mathrm{H}$ & 78 & 4 & 23 & 11.8 & 26 & 115 \\
\hline 004 & $116 C$ & 29 & $9.9 \mathrm{~N}$ & 80 & $12.9 \mathrm{~W}$ & 78 & 4 & 23 & 13.0 & 63 & 116 \\
\hline 004 & 1170 & 29 & $11.2 \mathrm{~N}$ & 80 & $7.0 \mathrm{H}$ & 78 & 4 & 23 & 14.2 & 130 & 117 \\
\hline 004 & $118 \mathrm{CU}$ & 29 & $11.9 \mathrm{~N}$ & 80 & $2.1 \mathrm{~W}$ & 78 & 4 & 23 & 15.7 & 350 & 118 \\
\hline
\end{tabular}


HYDROGRAPHIC DATA

Vertical profiles of salinity, temperature, sigma-t, Do, and nutrients

The symbols used in the following listings are defined as follows:

Header Data: $\quad$ Times are GMT (EST + 5)

Latitude and Longitude are from Loran $C$

Weather Data: These data are taken from the ship's log.

Wind speed (knots)

Wind direction (degrees)

Air temperature $\left({ }^{\circ} \mathrm{C}\right)$

Weather (WMO code 4501)

Barometric pressure (mb)

Sea State (WMO 3700)

Wave direction (degrees)

Cloud type (not given)

Cloud amount (not given)

Visibility code (not given)

Observations: $\quad Z=$ Depth in meters

$\mathrm{T}=$ Temperature in ${ }^{\circ} \mathrm{C}$

$S=$ Salinity in $\%$

$D=$ Density in sigma-t units

SVA $=$ Specific volume anomaly $\times 10^{5}$

$\mathrm{O}_{2}=$ Dissolved oxygen in $\mathrm{ml} / \mathrm{liter}$

$0_{2}^{\prime}=$ Oxygen saturation in $\mathrm{ml} / \mathrm{liter}$

AOU = Apparent oxygen utilization in ml/liter

$\mathrm{PO}_{4}=$ Phosphate concentration in umole/liter

$\mathrm{NO}_{3}=$ Nitrate concentration in $\mu$ mole/liter

Si $=$ Silicate concentration in $\mu$ mole/liter 
LGT 32 5.2N LONG 78 7.TU UEFTH $=515 N$ IIST LAST SIA = O.OKN

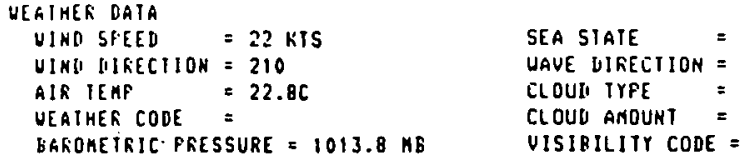

BGFOREIEIC PRESSURE $=1013.8 \mathrm{~KB}$

OESERVATIONS

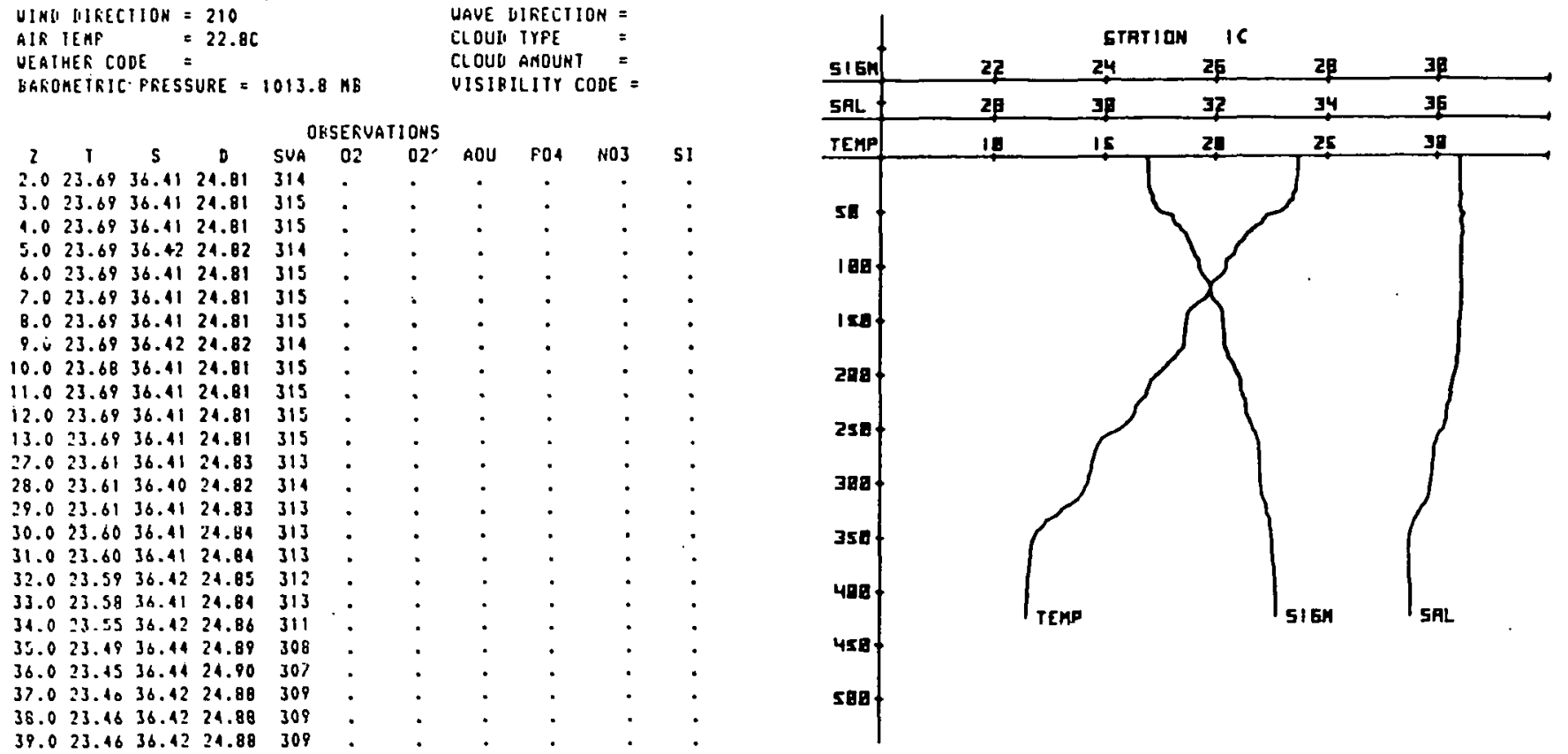

$94.0 \quad 20.63 \quad 36.4325 .69 \quad 234$ $95.020 .5536 .1325 .71 \quad 232$ $\begin{array}{lllll}86.0 & 20.51 & 36.43 & 25.72 & 231\end{array}$ $97.0 \quad 20.48 \quad 36.43 \quad 25.73 \quad 230$ $98.0 \quad 20.4836 .1325 .73230$ $99.020 .49 \quad 36.12 \quad 25.72 \quad 231$ $100.020 .45 \quad 36.4225 .72 \quad 231$ $101.020 .48 \quad 36.4225 .7223$

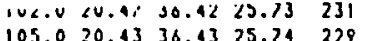
$110.0 \quad 20.21 \quad 36.43 \quad 25.80 \quad 225$ $115.019 .94 \quad 36.4425 .88 \quad 216$ $120.019 .75 \quad 36.41 \quad 25.93 \quad 212$ $126.018 .7036 .4125 .95 \quad 211$ $130.0 \quad 19.60 \quad 36.41 \quad 25.97 \quad 208$ $\begin{array}{llllll}135.0 & 19.25 & 36.43 & 26.06 & 201\end{array}$ $140.018 .93 \quad 36.4426 .15 \quad 192$ $\begin{array}{llllll}145.0 & 18.77 & 36.41 & 26.17 & 191\end{array}$ $151.018 .72 \quad 36.4026 .17 \quad 190$ $\begin{array}{lllll}156.0 \quad 18.68 & 36.10 \quad 26.18 \quad 189\end{array}$ $161.0 \quad 18.68 \quad 36.42 \quad 26.20 \quad 188$ $185.0 \quad 18.66 \quad 36.40 \quad 26.19 \quad 189$ $171.0 \quad 18.63 \quad 36.39 \quad 26.19 \quad 190$ $\begin{array}{lllll}175.0 & 18.61 \quad 36.41 \quad 26.21 \quad 188\end{array}$ $\begin{array}{llllll}180.0 & 16.36 & 36.40 & 26.26 & 183\end{array}$ $\begin{array}{llllll}185.0 & 18.17 & 36.37 & 26.29 \quad 180\end{array}$ $\begin{array}{llllll}190.0 & 17.90 & 36.37 & 26.35 & 174\end{array}$ $195.0 \quad 17.69 \quad 36.35 \quad 26.39 \quad 171$ $200.0 \quad 17.43 \quad 36.33 \quad 26.44 \quad 166$ $\begin{array}{llllll}205.0 & 17.16 & 36.30 & 26.18 & 162\end{array}$ $\begin{array}{llllll}211.0 & 17.03 & 36.27 & 26.19 & 162\end{array}$ $215.0 \quad 16.94 \quad 36.25 \quad 26.50 \quad 161$ $220.016 .83 \quad 36.2426 .51 \quad 160$ $225.0 \quad 16.60 \quad 36.23 \quad 26.56 \quad 155$ $\begin{array}{llllll}230.0 & 16.40 \quad 36.18 & 26.57 & 154\end{array}$ $236.0 \quad 16.35 \quad 36.17 \quad 26.57 \quad 154$ $\begin{array}{llllll}241.0 & 16.21 & 36.19 & 26.62 & 150\end{array}$ $245.0 \quad 16.02 \quad 36.1526 .64 \quad 149$ $251.015 .86 \quad 36.12 \quad 26.69 \quad 143$ $255.0 \quad 15.7436 .0426 .73 \quad 140$ $260.0 \quad 14.84 \quad 35.99 \quad 26.78 \quad 135$ $265.0 \quad 14.88 \quad 35.97 \quad 26.80 \quad 133$ $270.0 \quad 14.80 \quad 35.94 \quad 26.79 \quad 134$ $275.014 .5435 .9426 .81 \quad 133$ $280.0 \quad 14.48 \quad 35.93 \quad 26.81 \quad 132$ $285.0 \quad 14.4435 .91 \quad 26.80 \quad 133$ $\begin{array}{lllll}291.0 & 14.40 & 35.91 & 26.81 & 132\end{array}$ $295.014 .2935 .9026 .83 \quad 131$ $300.0 \quad 14.25 \quad 35.89 \quad 26.83 \quad 131$ $\begin{array}{llllll}305.0 & 14.13 \quad 35.88 & 26.85 & 129\end{array}$ $311.0 \quad 13.99 \quad 35.85 \quad 26.86 \quad 129$ $316.013 .7735 .83 \quad 26.89 \quad 126$ $321.013 .4135 .7926 .92 \quad 122$ 


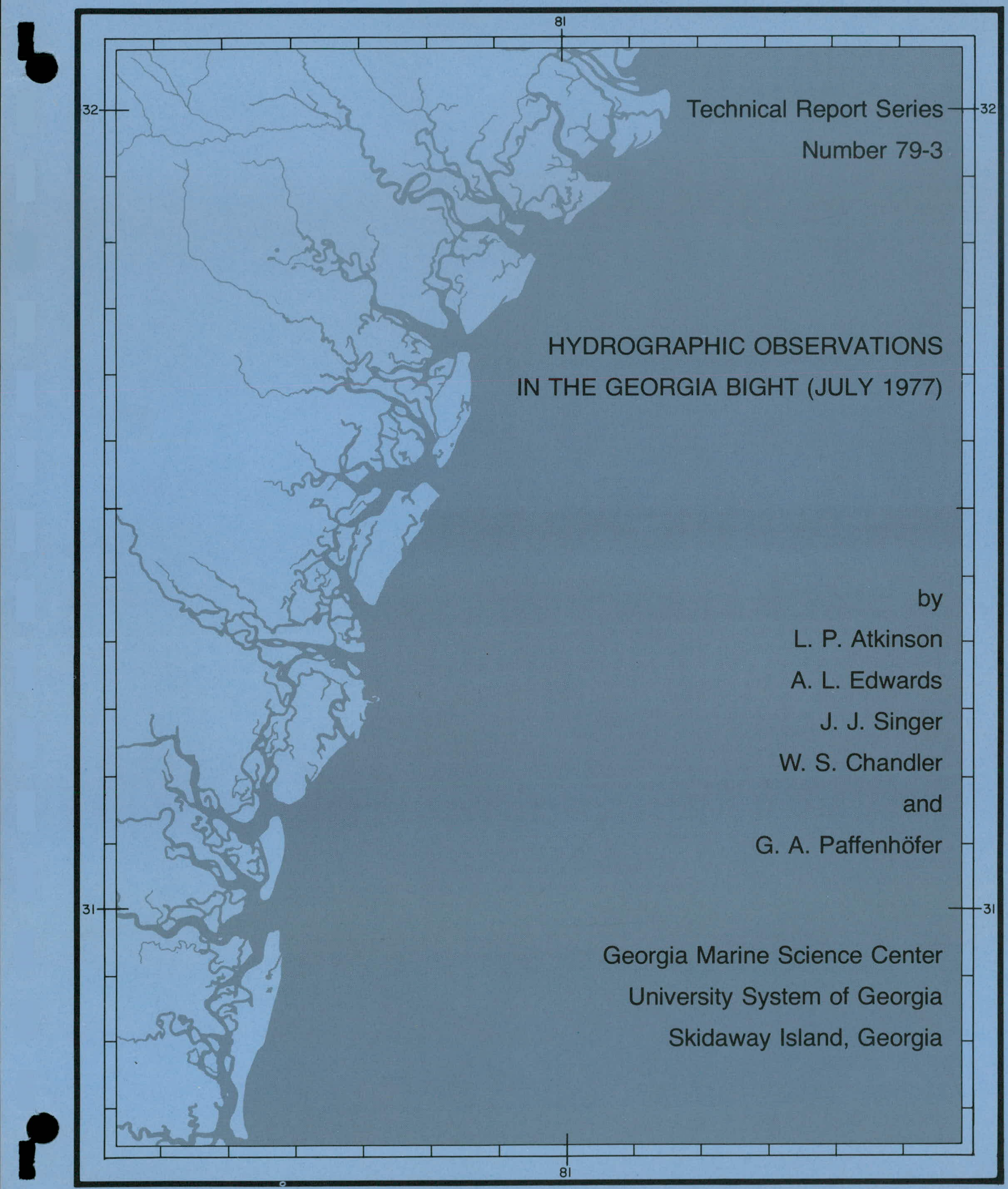


HYDROGRAPHIC OBSERVATIONS IN THE

GEORGIA BIGHT (JULY 1977)

\author{
L. P. Atkinson \\ A. L. Edwards \\ J. J. Singer \\ W. S. Chandler \\ G. -A. Paffenhöfer
}

\author{
Skidaway Institute of Oceanography \\ P. 0 . Box 13687
}

Savannah, Georgia 31406

February 1979

The Technical Report Series of the Georgia Marine Science Center is issued by the Georgia Sea Grant Program and the Marine Extension Service of the University of Georgia on Skidaway Island (P. 0. Box 13687, Savannah, Georgia 31406). It was established to provide dissemination of technical information and progress reports resulting from marine studies and investigations mainly by staff and faculty of the University System of Georgia. In addition, it is intended for the presentation of techniques and methods, reduced data, and general information of interest to industry, local, regional, and state governments and the public. Information contained in these reports is in the public domain. If this prepublication copy is cited, it should be cited as an unpublished manuscript. 
páge

List of Tables................... . . $i$. .

List of figures ...................... . . . . . .

Acknowledgements................... 1

Abstract. .................. 2

Introduction. ................. 3

Methods ...................... 3

Chemical and Physical Procedures............. 3

XBT Data Acquisition and Processing. .......... 5

CTD Data Acquisition and Processing. . . . . . . . . . 5

CTD Calibration and Error Analysis . . . . . . . . . 5

Meteorological Conditions.............. 7

Results and Discussion. ............... 7

Horizontal Distributions . . . . . . . . . 7

Vertical Distributions ......................... 11

Nutrient Relationships. . . . . . . . . . . . 11

Temperature-Salinity .............. . 12

Oxygen Anomaly .................. . . 12

Drogue observations .................... 12

Summary . . . . . . . . . . . . . . . 13

References................... 14

Figures ....................... 15

Appendix I: Hydrographic Data ............. 59

Appendix II: Chlorophyll with Nutrient Data. . . . . . . . 125 


\section{LIST OF TABLES}

page

Table 1. Sampling Events. .................. . 4

Table 2. Data Flow. Shipboard Acquisition to NODC Submitted. . . . 6

Table 3. Salinity Calibration of Hewlett-Packard data

(Cruise CI-03-77). . . . . . . ......... 8

Table 4. Salinity Calibration of magnetic tape data (Cruise CI-03-77)................. 10

Table 5. Station Summary for Isel in Cruise CI-03-77 ....... . 60 


\section{LIST OF FIGURES}

page

1. Current/Temperature/Pressure moorings designated A-G. . . . . . . 16

2. Station locations, Cruise CI-03-77, hydrographic leg. . . . . 17

3. Drogue tract. In 8 July 23,7 GMT, out 10 July 18.8 GMT, samples taken every 90 minutes ............. 18

4. Schematic of CTD acquisition system . . . . . . . . . . . 19

5. Salinity offset versus depth, regression analysis, cruise CI-03-77 stations $1 \mathrm{C}-13 \mathrm{C} . . . . . . . . . . . . .20$

6. Salinity offset versus depth, regression analysis, cruise CI-03-77 stations $14 \mathrm{C}-53 \mathrm{C} . . . . . . . . . . . .$.

7. Wind data, Savannah Navigational Light Tower, 4-8 July 1977, at one hour intervals (Blanton, Bailey and Hayes (1978)). . . . 21

8. Air temperature $\left({ }^{\circ} \mathrm{C}\right)$ data, Savannah Navigational Light Tower, 4-8 July 1977, at one hour intervals (Blanton, Bailey and Hayes (1978)).................. 22

9. Horizontal surface temperature $\left({ }^{\circ} \mathrm{C}\right)$ distribution. . . . . . . . 23

10. Horizontal bottom temperature $\left({ }^{\circ} \mathrm{C}\right)$ distribution . . . . . . . 24

11. Horizontal surface salinity $(\% / 00)$ distribution . . . . . . . 25

12. Horizontal bottom salinity $(\% / 00)$ distribution. . . . . . . 26

13. Horizontal surface sigma-t distribution . . . . . . . . . . 27

14. Horizontal bottom sigma-t distribution. . . . . . . . . . . 28

15. Horizontal bottom nitrate $(\mu M)$ distribution . . . . . . . . 29

16. Horizontal bottom phosphate ( $\mu \mathrm{M})$ distribution . . . . . . . . 30

17. Horizontal bottom silicate $(\mu M)$ distribution. . . . . . . . . 31

18. Horizontal surface silicate $(\mu M)$ distribution . . . . . . . 32

19. Horizontal surface chlorophyll-a $(\mu \mathrm{g} / 1)$ distribution. . . . . . 33

20. Horizontal bottom chlorophyll-a $(\mu \mathrm{g} / 1)$ distribution . . . . . 34 
21. Vertical distribution of temperature $\left({ }^{0} \mathrm{C}\right)$, salinity $(0 / 00)$, sigma-t, and oxygen (m1/1), Savannah section, 4-5 July 1977. . .

22. Vertical distribution of nutrients ( $\mu$ iM) and chlorophyll-a $(\mu \mathrm{g} / 1)$, Savannah section 4-5 July 1977 ........... 36

23. Vertical distribution of temperature $\left({ }^{\circ} \mathrm{C}\right)$, salinity $\left({ }^{0} / 00\right)$, sigma-t, and oxygen $(m l / 1)$, Ossabaw section, 5 July $1977 . . .37$

24. Vertical distribution of nutrients ( $\mu M)$, Ossabaw section, 5 July 1977...................... 38

25. Vertical distribution of temperature $\left({ }^{\circ} \mathrm{C}\right)$, salinity $(0 / 00)$, sigma-t, and oxygen (ml/1), Sapelo section, 6 July 1977.....

26: Vertical distribution of nutrients $(\mu M)$, Sapelo section, 6 July 1977......................

27. Vertical distribution of temperature $\left({ }^{\circ} \mathrm{C}\right)$, salinity $\left({ }^{0} / 00\right)$, sigma-t, and oxygen (m1/7), St. Simons section, 6-7 July 1977. .

28. Vertical distribution of nutrients $(\mu M)$ and chlorophyli-a $(\mu \mathrm{g} / 1)$, St. Simons section, 6-7 July 1977. . . . . . . . . .

29. Vertical distribution of temperature $\left({ }^{\circ} \mathrm{C}\right)$, salinity $\left({ }^{\circ} / 00\right)$, sigma-t, and oxygen (ml/l), Jacksonville section, 7-8 July 1977 .

30. Vertical distribution of nutrient $(\mu \mathrm{M})$ and chloropinyll-a $(\mu \mathrm{g} / 1)$ Jacksonville section, 7-8 July 1977.

31. Vertical distribution of temperature $\left({ }^{\circ} \mathrm{C}\right)$, St. Simons section, 8 July 1977...................... 45

32. Station locations for comparative section plots. . . . . . . 46

33. Temperature $\left({ }^{\circ} \mathrm{C} \ldots \ldots\right) /$ ivitrate $(\mu M \ldots---)$ comparative section plots.......................

34. Temperature $\left({ }^{\circ} \mathrm{C} \ldots\right.$ __ $/$ Chlorophyll-a $(\mu \mathrm{g} / 1---)$ comparative section plots.

35. Nitrate $(\mu M-) / C h$ lorophyl1-a ( $\mu \mathrm{g} / 1---)$ comparative section plots. . . . . . . . . . . . . . . . . . . . 
36. Nitrate $(\mu M)$ versus phosphate $(\mu M)$ plot. . . . . . . . 50

37. Silicate $(\mu M)$ versus nitrate $(\mu M)$ plot ........... . 51

38. Nitrate $(\mu \mathrm{M})$ versus temperature $\left({ }^{\circ} \mathrm{C}\right)$ plot. . . . . . . . . 52

39. Phosphate $(\mu M)$ versus temperature $\left({ }^{\circ} \mathrm{C}\right)$ plot. . . . . . . . 53

40. Silicate $(\mu M)$ versus temperature $\left({ }^{\circ} \mathrm{C}\right)$ plot.......... 54

41. Temperature $\left({ }^{\circ} \mathrm{C}\right)$ versus salinity $(\%$ ) plot, cruise CI-03-77. . 55

42. Oxygen (ml/1) versus sigma-t plot, cruise CI-03-77. Concentration of oxygen in fully saturated Sargasso Sea type water (---).

Curve for actual Sargasso Sea water (_). . . . . . . . . 56

43. Drogue tract. In 8 July 23.7 GMT, out 10 July 18.8 GMT, samples taken every 90 minutes............ . 57

44. Time series of parameters measured during the drogue drift.

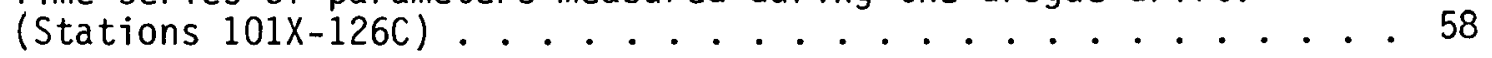


The authors thank Dr. Jack Blanton, Pat O'Malley, Lee Bailey, Eileen Hofmann, and Lynn Rubicam for their participation in the study. We also thank the Captain, mates and crew of the R/V COLUMBUS ISELIN. Dan McIntosh provided graphics assistance and Cindy Miller typed the text.

Funding for this research and report preparation was provided by the Department of Energy, under contracts EY-76-S-09-0889 to Dr. Atkinson and EY-76-S-09-0936 to Dr. Paffenhofer.

This report is publitshed as a part of the Georgia Marine Science Center's Technical Report series issued by the Georgia Sea Grant Program under NOAA Office of Sea Grant \#04-7-158-44126. 


\section{ABSTRACT}

From 4 to 8 July, 1977, five hydrographic sections and one temperature section were made in the Georgia Bight between Savannah, Georgia and Jacksonville, Florida. Salinity, temperature, dissolved oxygen, nutrient $\left(\mathrm{NO}_{3}, \mathrm{PO}_{4}, \mathrm{SiO}_{2}\right)$ and chlorophyll data were collected. Nutrient rich intrusions of cold, deep Gulf Stream waters were observed off Savannah and Jacksonville. 


\section{INTRODUCTION}

This report covers Georgia Bight cruise CI-03-77 (4 to 10 July 1977) aboard the R/V COLUMBUS ISELIN. Geographically, the cruise included the continental shelf region from Savannah, Georgia south to Jacksonville, Florida. The objective was to collect physical and chemical data for correlation with biological data and current/ temperature/pressure data from moored instruments deployed by the University of Miami (Dr. Tom Lee) (Fig. 1). In addition, temperature and conductivity data from the hydrographic work are used to intercompare with the moored instruments. Correlation of the hydrographic/chemical observations with the current meter data will be made at a later time. The data will provide information about the Georgia Bight for intrusion studies and frontal mappings.

Five onshore-offshore Conductivity/Temperature/Depth (CTD) sections and one Expendable Bathythermograph (XBT) section were completed during the cruise (Fig. 2). The XBT section repeated the Brunswick CTD section (stations 29X-37X). The Jacksonville section included three XBT stations (50X, 51X, and 52X) and eleven CTD stations.

The St. Simons XBT section was taken to locate sites for drogues which were to be deployed by the biological group. During drogue tracking, XBT and CTD stations al ternated at 90 minute intervals (Fig. 3). After the drogues were retrieved a final XBT section $(A X, B X, C X, D X)$ was run. Table 1 summarizes the events.

The processed hydrographic data are available from the National Oceanographic Data Center (NODC).

\section{METHODS}

At CTD stations a General Oceanics Model 1015 Mark 5 Rosette Multi-Bottle Array (equipped with 1.7 liter Niskin Bottles) and a Plessey CTD Sensor System were used. Bottle sampling depths were determined by examination of the downcast temperature profile. During the upcast, samples were taken near surface, just above or below the thermocline, at the bottom and at other selected depths. The samples were analyzed for salinity, nitrate, phosphate, silicate, dissolved oxygen, and chlorophyll.

\section{Chemical and Physical Procedures}

In the lab, salinity samples were analyzed conductometrically using a Plessey Model 6230N Lab Salinometer. These samples were used to calibrate the CTD system. A separate section of this report deals with the CTD calibration procedure. Temperature was determined with deep sea reversing thermometers, XBT's, and the CTD system.

oxygen samples were analyzed within 24 hours of collection using a modification of the Strickland and Parsons (1965) method. Nutrient samples were frozen in polyethylene bottles and stored in the dark until thawed for analysis onshore. Colorimetric 
Table 1. Sampling Events.

\begin{tabular}{|c|c|c|c|}
\hline Event & $\begin{array}{c}\text { Station } \\
\text { Designation }\end{array}$ & $\underset{\#}{\text { Consecutive }}$ & Time (GMT) $(h / d / m / y)$ \\
\hline Savannah Section & $1 C-13 C$ & $1-13$ & $18.8 / 4 / 7 / 77-10.2 / 5 / 7 / 77$ \\
\hline Ossabaw Section & $14 C-19 C$ & $14-19$ & $14.7 / 5 / 7 / 77-23.3 / 5 / 7 / 77$ \\
\hline Sapelo Section & $21 C-26 C$ & $20-25$ & $1.5 / 6 / 7 / 77-8.5 / 6 / 7 / 77$ \\
\hline St. Simons Section & $27 C-37 C$ & $26-36$ & $13.0 / 6 / 7 / 77-5.3 / 7 / 7 / 77$ \\
\hline Station 37 & $38 \mathrm{C}$ & 37 & $9.0 / 7 / 7 / 77$ \\
\hline Jacksonville Section & $40 C-53 C$ & $38-51$ & $11.8 / 7 / 7 / 77-6.2 / 8 / 7 / 77$ \\
\hline St: Simons Section & $29 x-37 x$ & $52-59$ & $14.2 / 8 / 7 / 77-17.9 / 8 / 7 / 77$ \\
\hline Drogue Location XBT's & $D 1 X-D 2 X$ & $60-61$ & $22.1 / 8 / 7 / 77-22.8 / 8 / 7 / 77$ \\
\hline Drogue Tracking Stations & $101 x-126 x$ & $62-87$ & $23.7 / 8 / 7 / 77-13.8 / 10 / 7 / 77$ \\
\hline XBT Section (Drogue to Savannah) & $A X-D X$ & $88-91$ & $15.5 / 10 / 7 / 77-18.5 / 10 / 7 / 77$ \\
\hline
\end{tabular}


determinations of the nutrient concentrations were made using a Bausch and Lomb Spectronic 88 Spectrophotometer. Silicate was determined by the method of Mullin and Riley (1955) as modified by Strickland and Parsons (1965), phosphate by the method of Murphy and Riley (1962) and nitrate by the cadmium column reduction technique of Gardner, et al. (1976).

\section{XBT Data Acquisition and Processing}

A Sippican Model LM3A Handheld Launcher equipped with T10 (for $200 \mathrm{~m}$ casts) or T6 (for $450 \mathrm{~m}$ casts) probes and Model MK2A-1 Recorders were used for XBT casts. The temperature versus depth plots were digitized on a Hewlett-Packard (H-P) Model 9864A Digitizer interfaced with an H-P Model 9825A Calculator. The digitized data was stored on $H-P$ cartridge tapes, transferred to Texas Instruments cassette tapes, entered into the University of Georgia Cyber 70 computer, formatted for NODC, and merged with the CTD data, producing a final tape copy and printout for this report.

\section{CTD Data Acquisition and Processing}

The CTD system consists of: 1) a Plessey Model 9400 Conductivity/ Temperature/Depth System; 2) a Plessey Model 8400 Digital Data Logger (DDL); 3) an H-P 9825A Calculator, to control the casts and record the data; 4) a Kennedy Model 1600 Incremental Magnetic Tape Recorder for data storage; 5) an H-P 7046 XYY' Recorder, to plot temperature and conductivity versus depth; and 6) an H-P 9862A Plotter, to plot temperature versus depth and other plots. The use of this system, and copies of the Hewlett-Packard prograris can be found in Chandler, et al. (1978). A diagram of this system and general data flow are presented in Figure 4.

Plots from both the H-P $9862 \mathrm{~A}$ and H-P $7046 \mathrm{~A}$ plotters were logged and stored with their respective station sheets. The H-P system was still in an experimental stage during this cruise; subsequently, $\mathrm{H}-\mathrm{P}$ data are reported only for stations $1 \mathrm{C}-13 \mathrm{C}$, where the data recorded on the Kennedy magnetic tape was inaccurate, due to a faulty temperature board in the DDL. The remainder of the data were extracted from data stored on the magnetic tape. Further computation and data manipulation were performed on a CDC Cyber 70 computer. The extraction and processing was done according to the methods described by Chandler, et al. (1978), as summarized in Table 2. Upcasts data from the CTD sensor are reported for stations $1 \mathrm{C}-13 \mathrm{C}, 32 \mathrm{C}$ and $126 \mathrm{C}$, where the downcast data was faulty.

\section{CTD Calibration and Error Analysis}

The CTD system was calibrated against samples taken in mixed layers. Because the conductivity sensor is affected by increased pressure at depth, regression analyses were performed (Fig. 5 for 
Table 2. Data Flow. Shipboard Acquisition to NODC Submitted.

\begin{tabular}{|c|c|}
\hline Data Source/Disposition & Data File \\
\hline $\begin{array}{l}\text { Station } 14 C-53 C \\
\text { Tape from data logger }\end{array}$ & $\begin{array}{c}\text { CTDRUN (Copies tape data to computer } \\
\text { file) }\end{array}$ \\
\hline & $\begin{array}{l}\text { MAGREAD (Converts binary coded data } \\
\text { to decimal) }\end{array}$ \\
\hline Enter depth offset & $\begin{array}{l}\text { CTDUNIT (Converts decimal units to } \\
\text { engineering units; eliminates } \\
\text { upcast data) }\end{array}$ \\
\hline $\begin{array}{l}\text { Readdition of upcast } \\
\text { data Stations } 32 \mathrm{C}, 49 \mathrm{C}, 126 \mathrm{C}\end{array}$ & LAGFILT (Coarse filters and temperature lag) \\
\hline $\begin{array}{l}\text { From HP9825A data cassette } \\
\text { Station } 1 \mathrm{C}-13 \mathrm{C}\end{array}$ & $\begin{array}{l}\text { SWITCH (Turns upcast data around for } \\
\text { station } 1 C-13 C, 32 C, 49 C, 126 C \text { ) } \\
\text { LATCH } \\
\text { DLATCH (Removes decreasing and repeated } \\
\text { depths) }\end{array}$ \\
\hline & $\begin{array}{r}\text { CTDATA } \\
\text { CTDAVE5 (One meter average data) } \\
\text { AVE }\end{array}$ \\
\hline $\begin{array}{l}\text { Primary calibration from } \\
\text { bottle casts and enter } \\
\text { salinity offset }\end{array}$ & $\begin{array}{l}\text { BROENK (Calculates salinity and sigma-t) } \\
\text { SGSA }\end{array}$ \\
\hline & NODCFO (Converts to NODC format) \\
\hline $\begin{array}{l}\text { Type in headers on file } \\
\text { HEAD }\end{array}$ & $\begin{array}{l}\text { XBTMERG (Merges headers and XBT data) } \\
\text { NODC + HEAD } \\
\text { NUTMERG (Merges headers, NODC data } \\
\text { and chemical data) }\end{array}$ \\
\hline Submitted to NODC & $\begin{array}{l}\text { FINAL } \\
\text { CEMBELL (Calculates specific volume } \\
\text { anomaly, oxygen utilization } \\
\text { and creates technical report } \\
\text { pages) }\end{array}$ \\
\hline & $\begin{array}{c}\text { STABELL (Creates station list) } \\
\text { TECHNICAL REPORT }\end{array}$ \\
\hline
\end{tabular}


$\mathrm{H}-\mathrm{P}$ data and Fig. 6 for magnetic tape data) and the resulting expressions $\left(S=S_{0}+0.102-3.67 \times 10^{-4} D\right.$ and $S=S_{0}+.101-3.05$ $x 10^{-4} D$ where $S$ is the corrected salinity, $S_{0}$ is the salinity without calibration offset and $D$ is the depth of the sample) were applied to generate corrected salinities for both forms of collected data. These expressions have a $0.012 \%$ difference at a depth of $200 \mathrm{~m}$. due to differences in the number of deep data points available for comparison. The calibration data used to generate both the original offsets and the formulated expressions for the effect of depth are listed in Tables 3 and 4. CTD salinities for the same stations may vary in these tables due to slight differences in the acquisition systems.

A depth offset of +2.29 meters was applied to zero the depth sensor. The temperature sensor agreed with protected reversing thermometers within the range of accuracy $\left( \pm 0.02^{\circ} \mathrm{C}\right)$; therefore, no temperature offset was applied.

The composite maximum error of the conductivity, temperature, and depth sensors rated accuracy, resolution, and time constants and the Broenkow (1977) equations for salinity is approximately $\pm 0.06 \%$. However, the standard deviation of a 11 mixed layer samples taken for salinity calibration after offset is .02 .

\section{METEOROLOGICAL CONDITIONS}

Wind data from the Savannah Navigational Light Tower (31057'N, $80^{\circ} 41^{\prime} \mathrm{W}$ ) are presented in Figure 7 . Winds were mostly from the south with increasing strength and there was no precipitation.

Air temperature ( $\mathrm{Fig} .8$ ) ranged from $29.2^{\circ} \mathrm{C}$ to $31.5^{\circ} \mathrm{C}$ and averaged $30.5^{\circ} \mathrm{C}$. The daily highs and nightly lows increased $0.8^{\circ} \mathrm{C}$ and $1.2^{\circ} \mathrm{C}$, respectively, during the 5-day period.

Additional data collected by the ship's personnel at each station are presented with the data (Appendix I).

\section{RESULTS AND DISCUSSION}

\section{Horizontal Distributions}

Surface temperatures (Fig. 9) varied from 28 to $29^{\circ} \mathrm{C}$ with warmest waters at the shelf break. There were no significant horizontal gradients. Near bottom temperatures (Fig. 10) decreased towards offshore with strongest gradients between $20-23^{\circ} \mathrm{C}$. The near bottom isotherms trended southwest indicating a large subsurface intrusion to the south of the observation area.

Surface salinity (Fig. 11) was lowest off the Savannah River and maximums were found mid-shelf and to the south. Near-bottom salinity (Fig. 12) was similar in trend but higher than surface salinity.

Surface density (Fig. 13) reflected the rather chaotic thermal distribution; however, near-bottom density (Fig. 14) increased offshore in response to the decreasing temperature. 
Table 3. Salinity calibration of Hewlett Packard data (Cruise CI-03-77).

\begin{tabular}{|c|c|c|c|c|c|}
\hline $\begin{array}{c}\text { Consecutive } \\
\text { Cast No. }\end{array}$ & $\begin{array}{l}\text { Station } \\
\text { No. }\end{array}$ & $\begin{array}{l}\text { Depth } \\
(m)\end{array}$ & $\begin{array}{c}\text { Bottle } \\
0 / 00\end{array}$ & $\begin{array}{l}\text { CTD } \\
0 \% 00\end{array}$ & $\begin{array}{c}\text { Difference } \\
\text { Bottle-CTD } \\
0 / 00\end{array}$ \\
\hline $\begin{array}{l}2 \\
3 \\
4 \\
5 \\
7\end{array}$ & $\begin{array}{l}2 \mathrm{CU} \\
3 \mathrm{CU} \\
4 \mathrm{CU} \\
5 \mathrm{CU} \\
7 \mathrm{CU}\end{array}$ & $\begin{array}{l}13 \\
17 \\
18 \\
21 \\
34\end{array}$ & $\begin{array}{l}34.910 \\
35.136 \\
35.353 \\
35.693 \\
36.150\end{array}$ & $\begin{array}{l}34.832 \\
35.001 \\
35.231 \\
35.579 \\
36.078\end{array}$ & $\begin{array}{l}+.078 \\
+. .135 \\
+.122 \\
+.114 \\
+.078\end{array}$ \\
\hline $\begin{array}{r}8 \\
9 \\
12 \\
14 \\
15\end{array}$ & $\begin{array}{l}8 C U \\
9 C U \\
12 C U \\
14 C \\
15 C\end{array}$ & $\begin{array}{r}38 \\
40 \\
113 \\
274 \\
63\end{array}$ & $\begin{array}{l}36.200 \\
36.220 \\
35.784 \\
35.096 \\
36.117\end{array}$ & $\begin{array}{l}36.138 \\
36.148 \\
35.742 \\
35.069 \\
36.034\end{array}$ & $\begin{array}{l}+.062 \\
+.072 \\
+.042 \\
+.027 \\
+.083\end{array}$ \\
\hline $\begin{array}{l}16 \\
17 \\
18 \\
19 \\
20\end{array}$ & $\begin{array}{l}16 C \\
17 C \\
18 C \\
19 C \\
21 C\end{array}$ & $\begin{array}{l}41 \\
33 \\
23 \\
19 \\
17\end{array}$ & $\begin{array}{l}36.274 \\
36.162 \\
35.988 \\
35.477 \\
35.803\end{array}$ & $\begin{array}{l}36.196 \\
36.067 \\
35.888 \\
35.380 \\
35.706\end{array}$ & $\begin{array}{l}+.078 \\
+.095 \\
+.0100 \\
+.097 \\
+.097\end{array}$ \\
\hline $\begin{array}{l}21 \\
22 \\
23 \\
24 \\
25\end{array}$ & $\begin{array}{l}22 C \\
23 C \\
24 C \\
25 C \\
26 C\end{array}$ & $\begin{array}{r}25 \\
40 \\
43 \\
45 \\
232\end{array}$ & $\begin{array}{l}36.027 \\
36.202 \\
36.300 \\
36.196 \\
34.938\end{array}$ & $\begin{array}{l}35.908 \\
36.103 \\
36.217 \\
36.128 \\
34.901\end{array}$ & $\begin{array}{l}+.119 \\
+.099 \\
+.083 \\
+.068 \\
+.037\end{array}$ \\
\hline $\begin{array}{l}28 \\
29 \\
30 \\
31 \\
32\end{array}$ & $\begin{array}{l}29 C \\
30 C \\
31 C \\
32 C \\
33 C\end{array}$ & $\begin{array}{l}58 \\
38 \\
34 \\
33 \\
32\end{array}$ & $\begin{array}{l}36.216 \\
36.281 \\
36.267 \\
36.304 \\
36.294\end{array}$ & $\begin{array}{l}36.105 \\
36.202 \\
36.183 \\
36.218 \\
36.218\end{array}$ & $\begin{array}{l}+.111 \\
+.079 \\
+.084 \\
+.086 \\
+.076\end{array}$ \\
\hline $\begin{array}{l}33 \\
34 \\
36 \\
37 \\
39\end{array}$ & $\begin{array}{l}34 C \\
35 C \\
37 C \\
38 C \\
41 C\end{array}$ & $\begin{array}{l}27 \\
28 \\
18 \\
22 \\
27\end{array}$ & $\begin{array}{l}36.282 \\
36.271 \\
36.132 \\
36.343 \\
36.306\end{array}$ & $\begin{array}{l}36.197 \\
36.191 \\
36.031 \\
36.247 \\
36.217\end{array}$ & $\begin{array}{l}+.085 \\
+.080 \\
+.0101 \\
+.096 \\
+.089\end{array}$ \\
\hline $\begin{array}{l}40 \\
41 \\
42 \\
43 \\
47\end{array}$ & $\begin{array}{l}42 C \\
43 C \\
44 C \\
45 C \\
49 C\end{array}$ & $\begin{array}{r}28 \\
28 \\
31 \\
36 \\
206\end{array}$ & $\begin{array}{l}36.289 \\
36.255 \\
36.265 \\
36.254 \\
34.987\end{array}$ & $\begin{array}{l}36.205 \\
36.161 \\
36.171 \\
36.145 \\
34.933\end{array}$ & $\begin{array}{r}+.084 \\
+.094 \\
+.094 \\
+.0109 \\
+.054\end{array}$ \\
\hline $\begin{array}{l}65 \\
67 \\
71 \\
73 \\
75\end{array}$ & $\begin{array}{l}104 C \\
106 C \\
110 C \\
112 C \\
114 C\end{array}$ & $\begin{array}{l}36 \\
38 \\
40 \\
41 \\
41\end{array}$ & $\begin{array}{l}36.273 \\
36.268 \\
36.250 \\
36.253 \\
36.260\end{array}$ & $\begin{array}{l}36.177 \\
36.183 \\
36.158 \\
36.168 \\
36.173\end{array}$ & $\begin{array}{r}+.096 \\
+.085 \\
+.092 \\
+.085 \\
+.087\end{array}$ \\
\hline
\end{tabular}


Table 3. Continued

\begin{tabular}{cccccc}
\hline $\begin{array}{c}\text { Consecutive } \\
\text { Cast No. }\end{array}$ & $\begin{array}{c}\text { Station } \\
\text { No. }\end{array}$ & $\begin{array}{c}\text { Depth } \\
(\mathrm{m})\end{array}$ & $\begin{array}{c}\text { Bottle } \\
0 \% 00\end{array}$ & $\begin{array}{c}\text { CTD } \\
\% \text { \%o }\end{array}$ & $\begin{array}{c}\text { Difference } \\
\text { Bottle-CTD } \\
\% / 00\end{array}$ \\
\hline 79 & $118 \mathrm{C}$ & 43 & 36.213 & 36.130 & +.083 \\
81 & $120 \mathrm{C}$ & 43 & 36.213 & 36.124 & +.089 \\
83 & $122 \mathrm{C}$ & 39 & 36.227 & 36.150 & +.077 \\
85 & $124 \mathrm{C}$ & 43 & 36.249 & 36.166 & +.083 \\
87 & $126 \mathrm{C}$ & 45 & 36.222 & 36.147 & +.075 \\
\hline
\end{tabular}


Table 4. Salinity calibration of magnetic tape data (Cruise CI-03-77).

\begin{tabular}{|c|c|c|c|c|c|}
\hline $\begin{array}{c}\text { Consecutive } \\
\text { Cast No. }\end{array}$ & $\begin{array}{l}\text { Station } \\
\text { No. }\end{array}$ & $\begin{array}{l}\text { Depth } \\
(m)\end{array}$ & $\begin{array}{c}\text { Bottle } \\
0 / 00\end{array}$ & $\begin{array}{l}\text { CTD } \\
0 / 00\end{array}$ & $\begin{array}{c}\text { Difference } \\
\text { Bottle-CTD } \\
0 / 00\end{array}$ \\
\hline $\begin{array}{l}14 \\
15 \\
16 \\
17 \\
18\end{array}$ & $\begin{array}{l}14 C \\
15 C \\
16 C \\
17 C \\
18 C\end{array}$ & $\begin{array}{r}274 \\
63 \\
41 \\
33 \\
23\end{array}$ & $\begin{array}{l}35.096 \\
36.117 \\
36.274 \\
36.162 \\
35.988\end{array}$ & $\begin{array}{l}35.062 \\
36.035 \\
36.191 \\
36.060 \\
35.886\end{array}$ & $\begin{array}{l}+.034 \\
+.082 \\
+.083 \\
+.0102 \\
+.102\end{array}$ \\
\hline $\begin{array}{l}19 \\
20 \\
21 \\
22 \\
23\end{array}$ & $\begin{array}{l}19 C \\
21 C \\
22 C \\
23 C \\
24 C\end{array}$ & $\begin{array}{l}19 \\
17 \\
25 \\
40 \\
43\end{array}$ & $\begin{array}{l}35.477 \\
35.803 \\
36.027 \\
36.202 \\
36.300\end{array}$ & $\begin{array}{l}35.375 \\
35.708 \\
35.927 \\
36.109 \\
36.227\end{array}$ & $\begin{array}{r}+.102 \\
+.095 \\
+.100 \\
+.093 \\
+.073\end{array}$ \\
\hline $\begin{array}{l}24 \\
25 \\
28 \\
29 \\
30\end{array}$ & $\begin{array}{l}25 C \\
26 C \\
29 C \\
30 C \\
31 C\end{array}$ & $\begin{array}{r}45 \\
232 \\
58 \\
33 \\
34\end{array}$ & $\begin{array}{l}36.196 \\
34.938 \\
36.216 \\
36.281 \\
36.267\end{array}$ & $\begin{array}{l}36.126 \\
34.905 \\
36.103 \\
36.199 \\
36.174\end{array}$ & $\begin{array}{l}+.070 \\
+.033 \\
+. .113 \\
+.082 \\
+.093\end{array}$ \\
\hline $\begin{array}{l}31 \\
32 \\
33 \\
34 \\
36\end{array}$ & $\begin{array}{l}32 C \\
33 C \\
34 C \\
35 C \\
37 C\end{array}$ & $\begin{array}{l}33 \\
32 \\
27 \\
28 \\
18\end{array}$ & $\begin{array}{l}36.304 \\
36.294 \\
36.282 \\
36.271 \\
36.132\end{array}$ & $\begin{array}{l}36.215 \\
36.210 \\
36.195 \\
36.180 \\
36.028\end{array}$ & $\begin{array}{l}+.089 \\
+.084 \\
+.087 \\
+.091 \\
+.0104\end{array}$ \\
\hline $\begin{array}{l}37 \\
39 \\
40 \\
41 \\
42\end{array}$ & $\begin{array}{l}38 C \\
41 C \\
42 C \\
43 C \\
44 C\end{array}$ & $\begin{array}{l}22 \\
27 \\
28 \\
28 \\
31\end{array}$ & $\begin{array}{l}36.343 \\
36.306 \\
36.289 \\
36.255 \\
36.265\end{array}$ & $\begin{array}{l}36.243 \\
36.218 \\
36.204 \\
36.157 \\
36.173\end{array}$ & $\begin{array}{l}+.100 \\
+.088 \\
+.085 \\
+.098 \\
+.092\end{array}$ \\
\hline $\begin{array}{l}43 \\
47 \\
65 \\
67 \\
71\end{array}$ & $\begin{array}{l}45 C \\
49 C \\
104 C \\
106 C \\
110 C\end{array}$ & $\begin{array}{r}36 \\
206 \\
36 \\
38 \\
40\end{array}$ & $\begin{array}{l}36.254 \\
34.987 \\
36.273 \\
36.268 \\
36.250\end{array}$ & $\begin{array}{l}36.139 \\
34.934 \\
36.181 \\
36.181 \\
36.153\end{array}$ & $\begin{array}{l}+.115 \\
+.053 \\
+.092 \\
+.087 \\
+.097\end{array}$ \\
\hline $\begin{array}{l}73 \\
75 \\
79 \\
81 \\
83\end{array}$ & $\begin{array}{l}112 C \\
114 C \\
118 C \\
120 C \\
122 C\end{array}$ & $\begin{array}{l}41 \\
41 \\
42 \\
42 \\
40\end{array}$ & $\begin{array}{l}36.253 \\
36.260 \\
36.213 \\
36.213 \\
36.227\end{array}$ & $\begin{array}{l}36.163 \\
36.170 \\
36.131 \\
36.120 \\
36.154\end{array}$ & $\begin{array}{r}+.090 \\
+.090 \\
+.082 \\
+.093 \\
+.073\end{array}$ \\
\hline $\begin{array}{l}85 \\
87\end{array}$ & $\begin{array}{l}124 C \\
126 C\end{array}$ & $\begin{array}{l}44 \\
43\end{array}$ & $\begin{array}{l}36.249 \\
36.222\end{array}$ & $\begin{array}{l}36.152 \\
36.141\end{array}$ & $\begin{array}{l}+.097 \\
+\quad .081\end{array}$ \\
\hline
\end{tabular}


Near-bottom nutrient concentrations (Figs. 15-17) were very high in outer shelf waters in response to the assumed influx of deeper Gulf Stream waters. Low surface silicate concentrations (Fig. 18), which indicate runoff distribution, were generally low.

Surface chlorophyll concentrations (Fig. 19) were highest nearshore off Jacksonville while near-bottom concentrations (Fig, 20) were high nearshore off Savannah. A mid-shelf maximum of $4 \mu \mathrm{g} 1^{-1}$ was found off Jacksonville.

Vertical Distributions

The vertical sections (Figs. 21-31) clearly show the apparent active advection of deeper Gulf Stream water onto the shelf. These waters are characteristically colder, saltier and contain high nutrient concentrations and low oxygen.

The core of high density water $(>36.50 \%$, 00 , which indicates the Gulf Stream core, was further offshore off Savannah (Fig. 21) and Jacksonville (Fig. 29) relative to the area between (Figs. 23, 25, and 27). This observation is confirmed in the lower temperatures at the shelf break off Savannah and Jacksonville.

Mid-shelf upwelling appeared to be occurring mid-shelf at all sections except Jacksonville. The result was a lower temperature, higher salinity band that isolated a lens of warm lower salinity water over the outer shelf. One result was a maximum in pyncocline strength over that outer shelf. Off Jacksonville no outer shelf low salinity band was observed although the density section indicates slight erosion of the thermocline.

The only time series observations made, excluding the drogue tracking experiment, were the $S t$. Simons section which was run on 6-7 July (Fig. 27-28) and again on 8 July (Fig. 31). As stated previously, the St. Simons section was between the two zones of Gulf Stream intrusion. On 6-7 July the Gulf Stream was near the shelf break and the $24^{\circ} \mathrm{C}$ water was apparently stranded on the outer shelf. On 8 July the inner shelf waters appeared to be unchanged but $18^{\circ} \mathrm{C}$ water invaded the outer shelf waters replacing the $24-25^{\circ} \mathrm{C}$ water previously there. This observation confirms the hypothesis of northerly propagation of Gulf Stream meanders and eddies.

To place the hydrographic situation in relation to nutrient distribution and chlorophyll concentrations composite plots were made (Figs. 32-35). Fig. 32 shows the relative position of the sections. The temperature-nitrate composite (Fig. 33) shows the greatest intrusion of $2 \mu \mathrm{M} \mathrm{NO} 3$ water off Savannah and Jacksonville and the least penetration off St. Simons. Temperature-chlorophyll comparisons (Fig. 34) suggest that chlorophyll production occurs at the "leading edge" of the intruding water.

\section{NUTRIENT RELATIONSHIPS}

The relationships between nutrient, temperature and salinity are useful for data quality assessment and elucidation of certain biological and physical interactions. 
The nitrate-phosphate plot (Fig. 36) shows the typical 16:1 nitrate to phosphate ratio. At low concentrations phosphate was disproportionately higher than nitrate possibly because of faster release of phosphate in surface and shelf waters.

The silicate-nitrate plot (Fig. 37) shows direct correlation between the two.

The nutrient-temperature plots (Figs. 38-40) show the linear relation that exists in these waters. The nitrate-temperature and phosphate-temperature plots (Figs. 38-39) are quite Tinear up to $23^{\circ} \mathrm{C}$ above which non-conservative processes prevail. The silicatetemperature plot (Fig. 40) is not linear but does behave similarly to nitrate and phosphate above $23^{\circ} \mathrm{C}$. The non-linearity is a result of mixing of several water types in the $5-15^{\circ} \mathrm{C}$ temperature range (Stefánsson and Atkinson, 1971).

\section{Temperature-Salinity}

The composite T-S plot for all samples (Fig. 41) is typical of summer conditions in the Bight. There were considerable amounts of water between 15 and $23^{\circ} \mathrm{C}$ that were slightly lower in salinity than normal Gulf Stream waters and represent mixtures of shelf and Gulf Stream waters. Waters greater than $27^{\circ} \mathrm{C}$ varied in salinity from 33.8 to $36.4 \%$ with lower values from nearshore off Savannah.

A T-S analysis of each section indicated that the shelf was flooded with waters of dominant Gulf Stream characteristics except nearshore off Savannah.

The salinity maximum appeared at station 53C, Jacksonville section, with values of $36.80 \%$ (see data in Appendix and Fig. 29).

\section{Oxygen Anomaly}

The oxygen anomaly (Richards and Redfield, 1955) (Fig. 42) indicates whether the observed Gulf Stream waters are of Caribbean or Antilles origin. Waters of Caribbean origin generally have anomalies

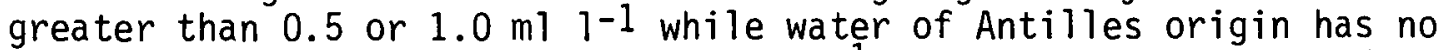
anomally. Anomalies less than $0.5 \mathrm{ml} 1^{-1}$ are not significant and those in waters less dense than $\sigma_{T}=25$ are not included because of non-conservative processes. The largest anomalies ( 0.99 to 1.32 ) were found mid-depth at station $26 \mathrm{C}$ in the Sapelo section and stations $27 \mathrm{C}$ and $28 \mathrm{C}$ in the St. Simons section. These sections are also where the Gulf Stream was furthest west.

Since essentially all samples greater than $\sigma_{T}=25$ had a significant anomaly, we conclude that the sampled waters were of Caribbean rather than Antilles origin.

\section{DROGUE OBSERVATIONS}

A drogue was launched at 23.7 (GMT) on 8 July and tracked until 13.8 on 10 July. The drogue sail was placed at a depth of 24-26 meters which was below the thermocline. During the drogue tracking experiment, XBT and CTD samples were taken alternately every 90 minutes. CTD casts 
also included nutrient and chlorophyll samples. These data are included in Appendix II.

The drogue track (Fig. 43) was to the northeast with a tidal onshore/offshore drift. The net drogue movement coincided with the mean wind.

Figure 44 is a time series of parameters measured during the drogue drift. The 3 hour wave feature noticeable in the thermocline is partly due to different response times of the CTD and XBT'S. The drogue apparently did not track the same water mass. Bottom temperatures decreased from $23^{\circ} \mathrm{C}$ to $21^{\circ} \mathrm{C}$ and then warmed again towards the end of the sampling period. The presence of water approaching $21^{\circ} \mathrm{C}$ is critical since at that temperature, nitrate concentrations increase dramatically. With the increase in nutrients, chlorophyll increased.

\section{SUMMARY}

1. During the sampling period subsurface intrusions of Gulf Stream water penetrated partly across the shelf off Sivannah; however, off Jacksonville the intrusion of nutrient rich water extended across the shelf to within ca. $20 \mathrm{~km}$ of the coast. Between the Savannah and Jacksonville sections, the Gulf Stream was nearer shore and relatively warmer water was found in that area. It is concluded that either a Gulf Stream meander or eddy was present north of Savannah and likewise off Jacksonville. There are not sufficient data to determine whether a meander or eddy was present.

2. Off St. Simons $23.5^{\circ} \mathrm{C}$ water was apparently stranded on the shelf by a shoreward migration of the Gulf Stream.

3. Chlorophyll concentrations were generally high in nearshore areas and at the leading edge of subsurface Gulf Stream intrusions. 


\section{REFERENCES}

Atkinson, L. P. 1976. Oceanographic observations in the Georgia Bight, R/V EASTWARD cruise E-3-74 and E-12-74. Technical Report 76-1.

Atkinson, L. P. 1977. Modes of Gulf Stream intrusion into the South Atlantic Bight shelf waters. Geophys. Res. Let., 4: 583-586.

Blanton, J., L. Bailey, and D. Hayes. 1978. Data Report II, Ocean and Meteorological Data $15 \mathrm{~km}$ off the Coast of Georgia. Technical Report. (in press)

Broenkow, W. W., W. B. Abrahams, and R. R. McInnis. 1977. A CTD data acquisition system for coastal applications. Proceedings, Fourth STD/Ocean Systems Conference, San Diego, CA.

Chandler, W. S., L. P. Atkinson, J. J. Singer, P. G. O'Malley and C. V. Baker. 1978. A CTD System: Description, Operation, Data Acquisition and Processing. Georgia Marine Science Center Technical Report 78-7.

Gardner, W. S., D. S. Wynne and W. M. Dunstan. 1976. Simplified procedure for the manual analysis of nitrate in sea water. Mar. Chem., 4: 393-396.

Lee, T. 1975. Florida Current Spin-off Eddies. Deep-Sea Res., 22: $753-765$.

Mullin, J. B. and J. P. Riley. 1955. The colorimetric determination of silicate with special reference to sea and natural waters. Ana 1. Chim. Acta, 12: 162-176.

Murphy, J. and J. P. Riley. 1962. Modified singlé solution method for the determination of phosphate in natural waters. Anal. Chim. Acta, 27: 31-36.

Richards, F. A. and A. C. Redfield. 1955. Oxygen-density relationships in the Western Atlantic. Deep-Sea Res., 2: 182-199.

Stefánsson, U. and L. P. Atkinson. 1971. Relationship of potential temperature and silicate in the deep waters between Cape Lookout, North Carolina and Bermuda. J. Marine Research, 29(3): 306-318.

Strickland, J. D. H. and T. R. Parsons. 1965. A manual of sea water analysis. Fish Res. Bd. Canada, Bull. No. 125 (2nd ed.), Ottawa. 
FIGURES 


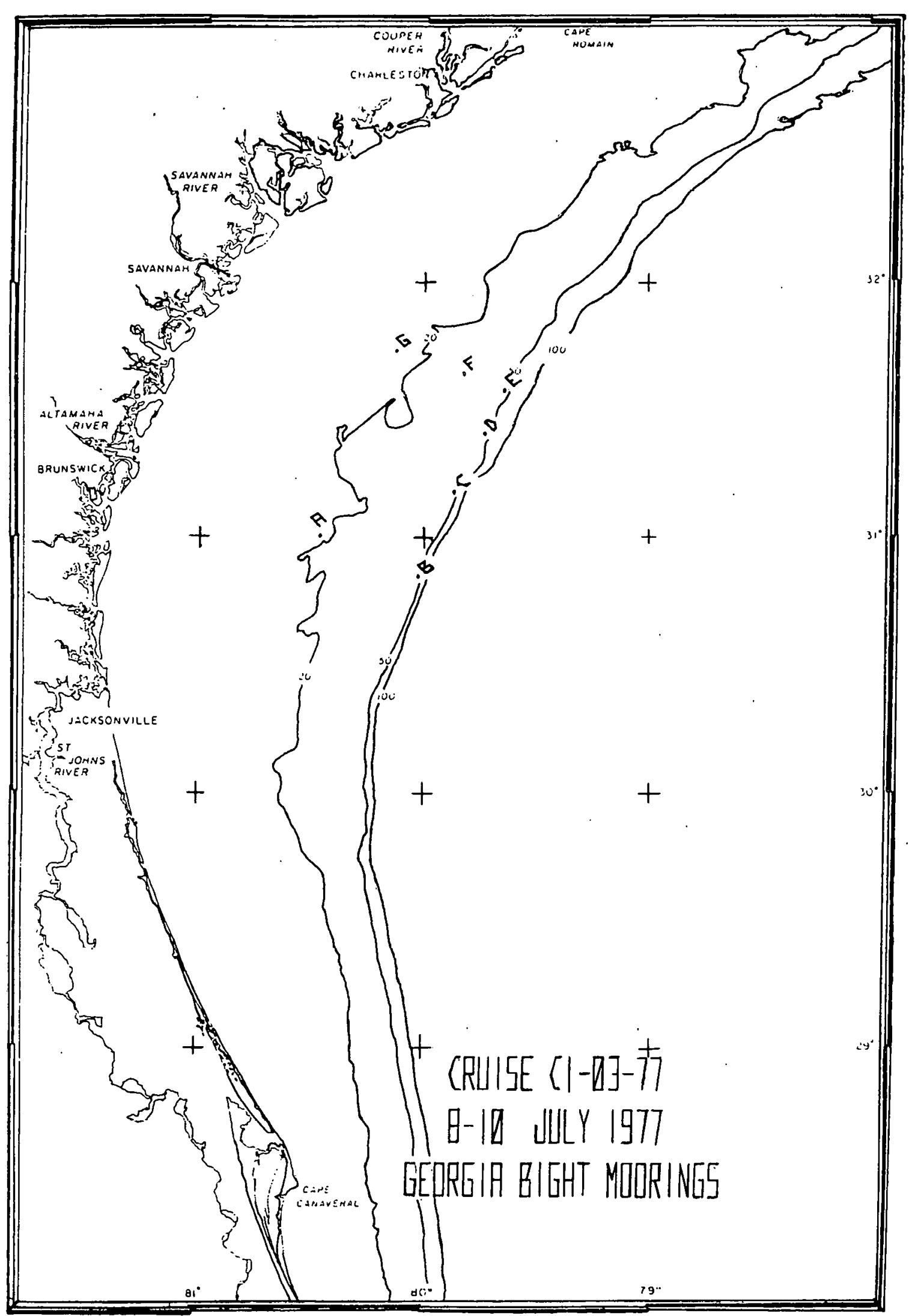

Fiǵ. 1. Georgia Bight, Current/Temperature/Pressure moorings designated $A-G$. 


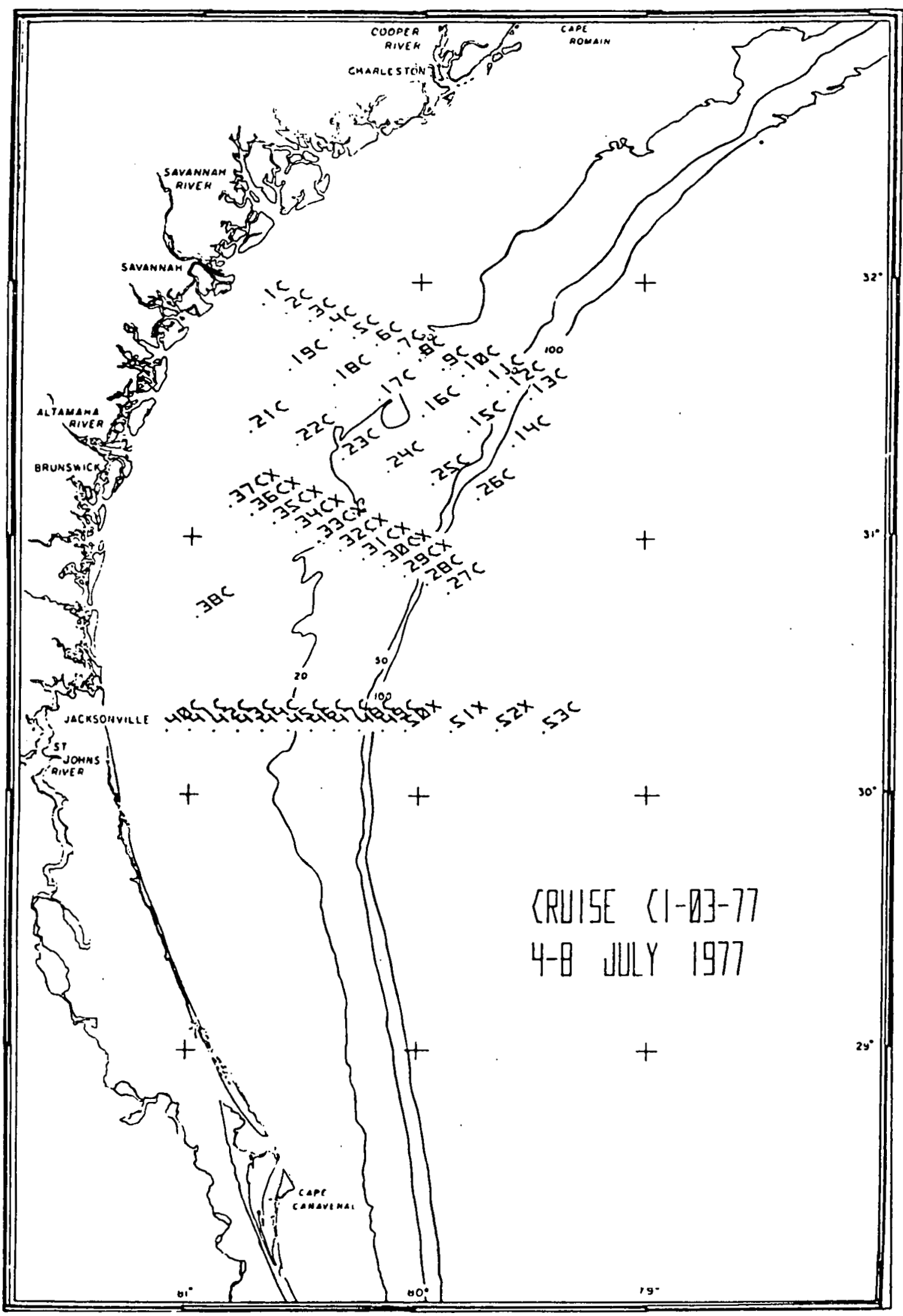

Fig. 2. Georgia Bight, station locations, Cruise CI-03-77, hydrographic leg. 


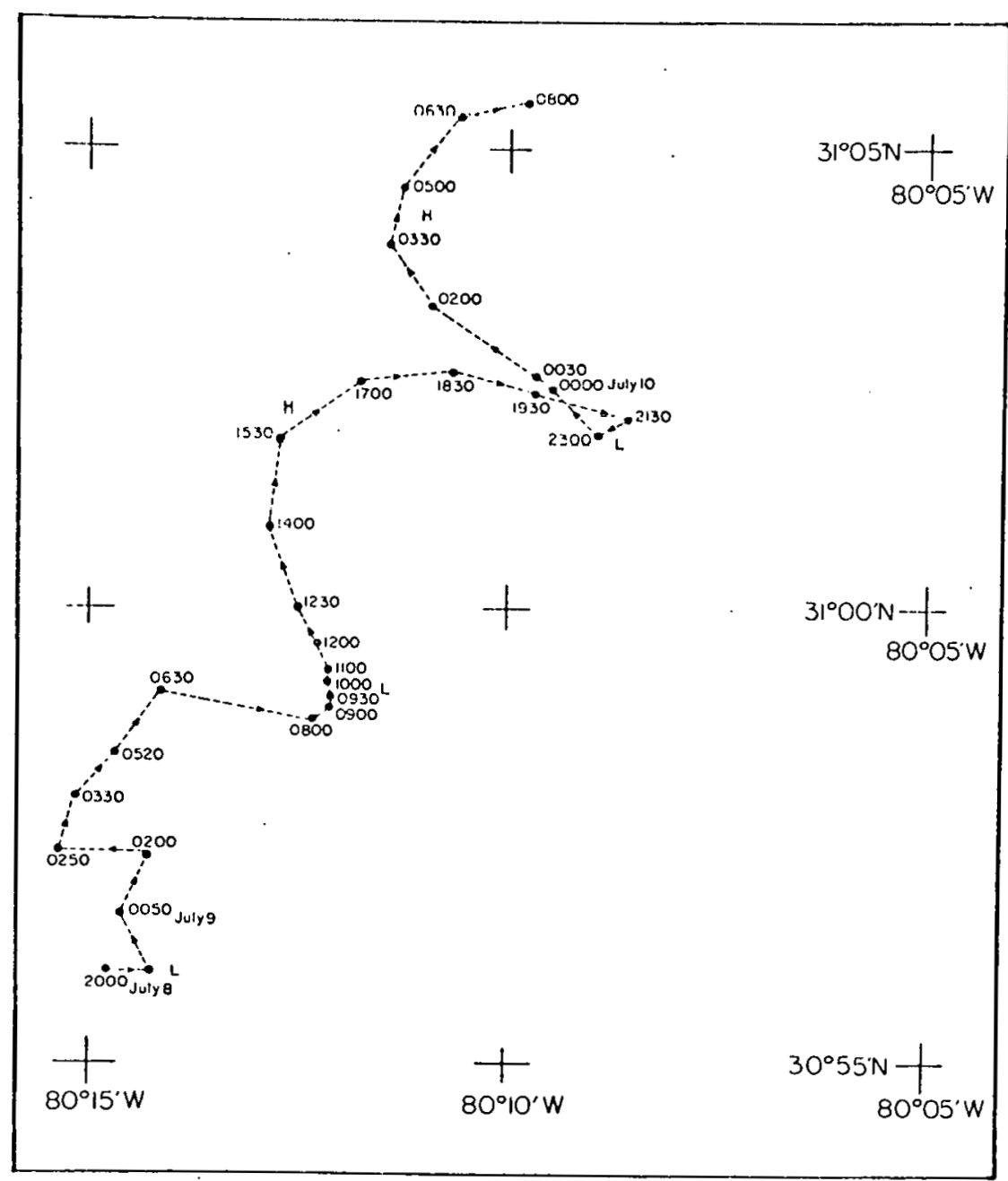

Fig. 3. Drogue tract. In 8 July 23.7 GMT, out 10 July 18.8 GMT, samples taken every 90 minutes. 


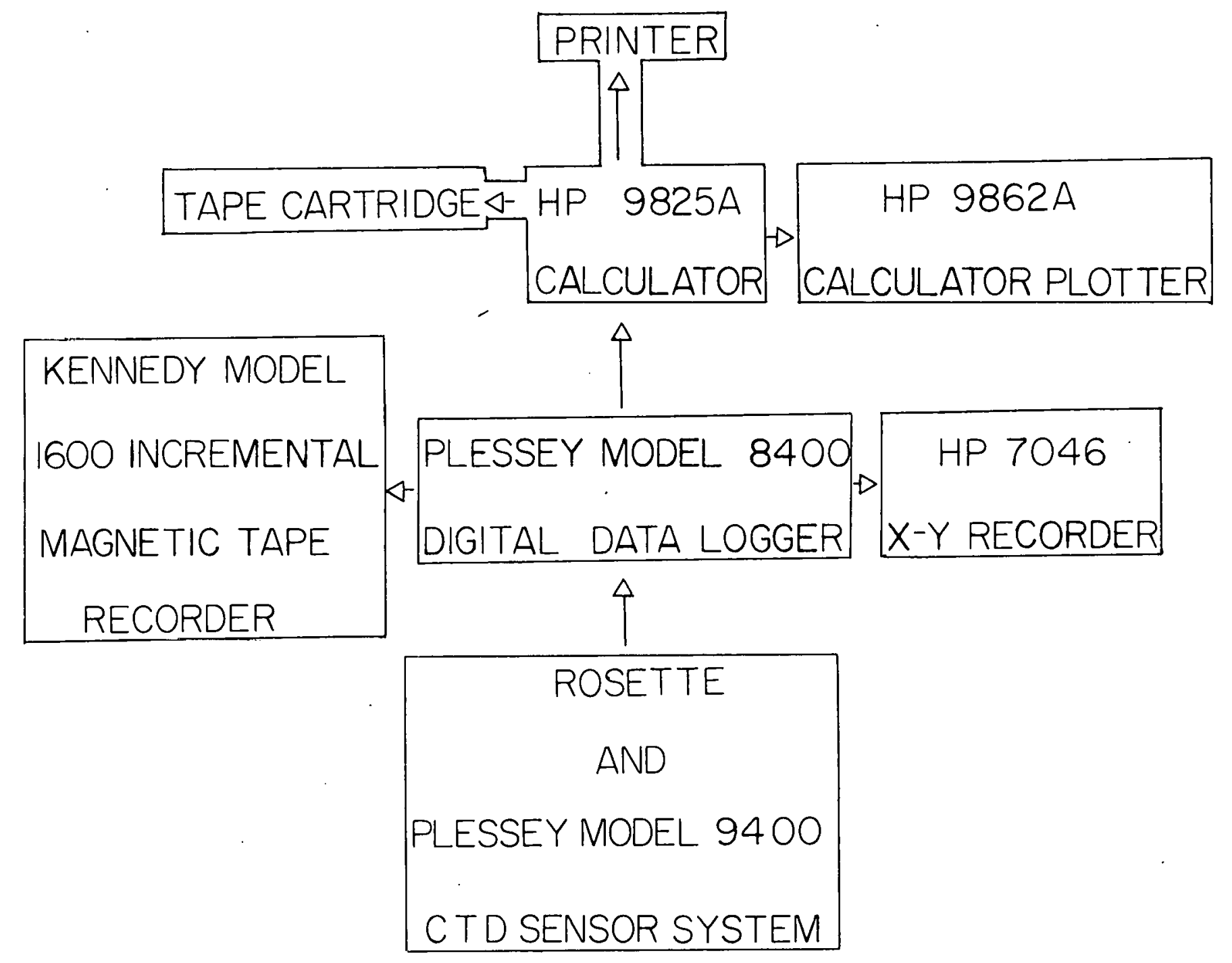

KENNEDY MODEL 1600 INCREMENTAL MAGNETIC TAPE RECORDER

Fiq. 4. Schematic of CTD acquisition system. 


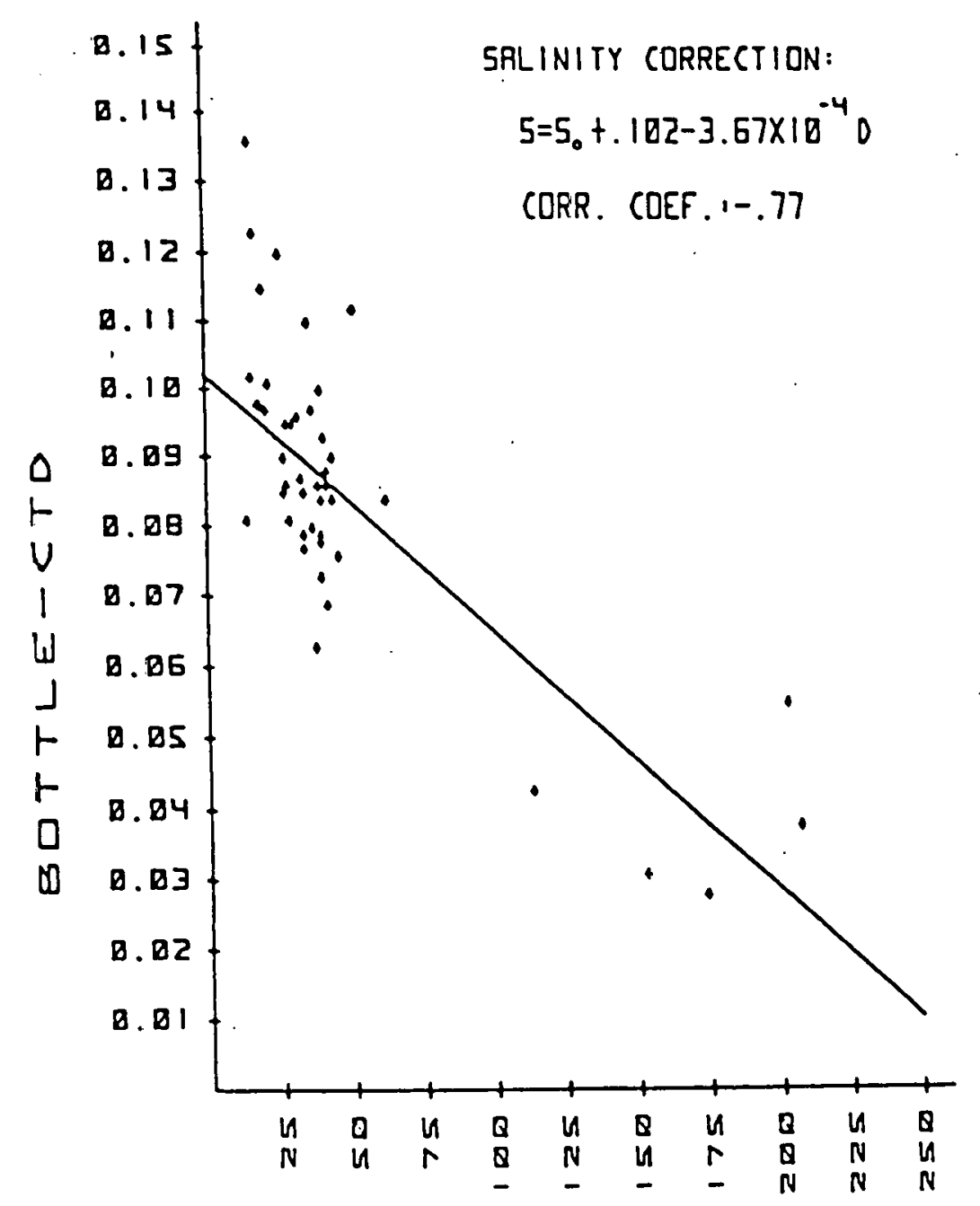

Fig. 5. Salinity offset versus depth, regression analysis, cruise CI-03-77 stations $1 \mathrm{C}-13 \mathrm{C}$.

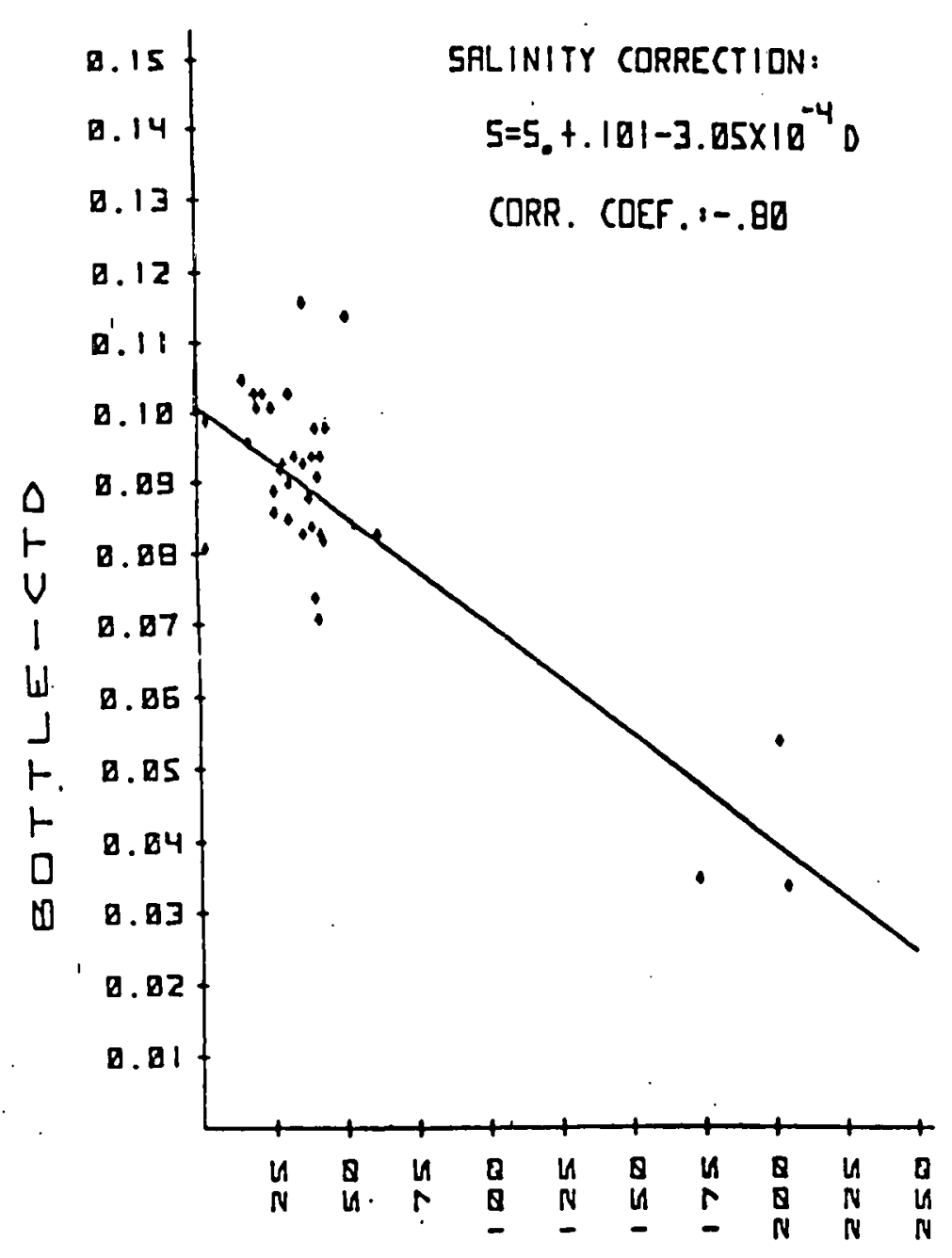

Fig. 6. Salinity offset versus depth, regression analysis, cruise CI-03-77 stations 14C-53C. 


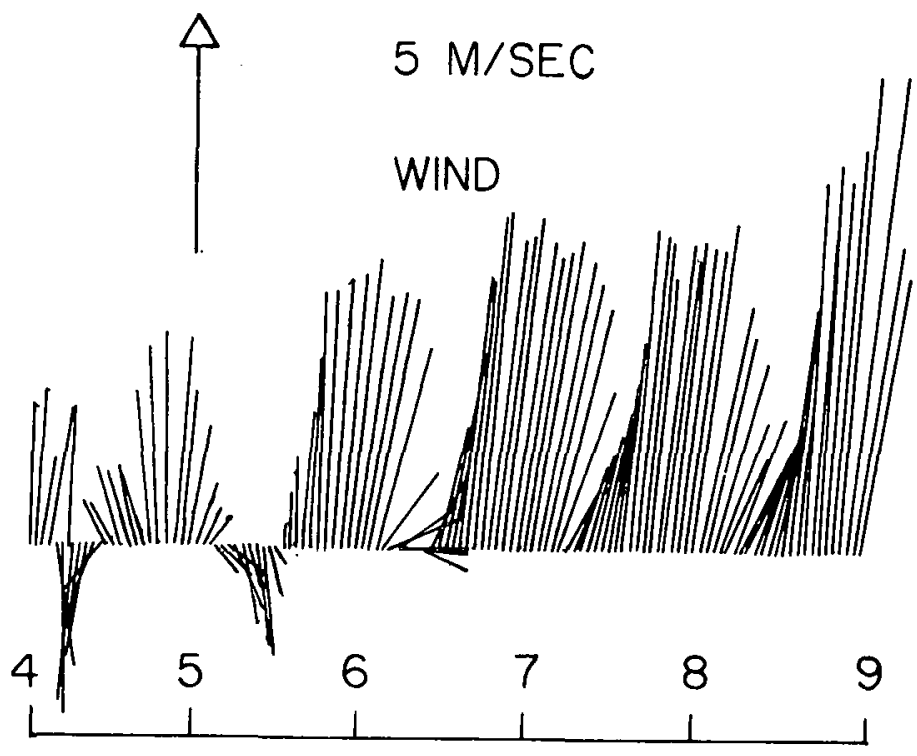

4-8 JULY 1977

Fig. 7. Wind data, Savannah Navigational Light Tower, 4-8 July 1977, at one-hour intervals (Blanton, Bailey and Hayes (1978)). 


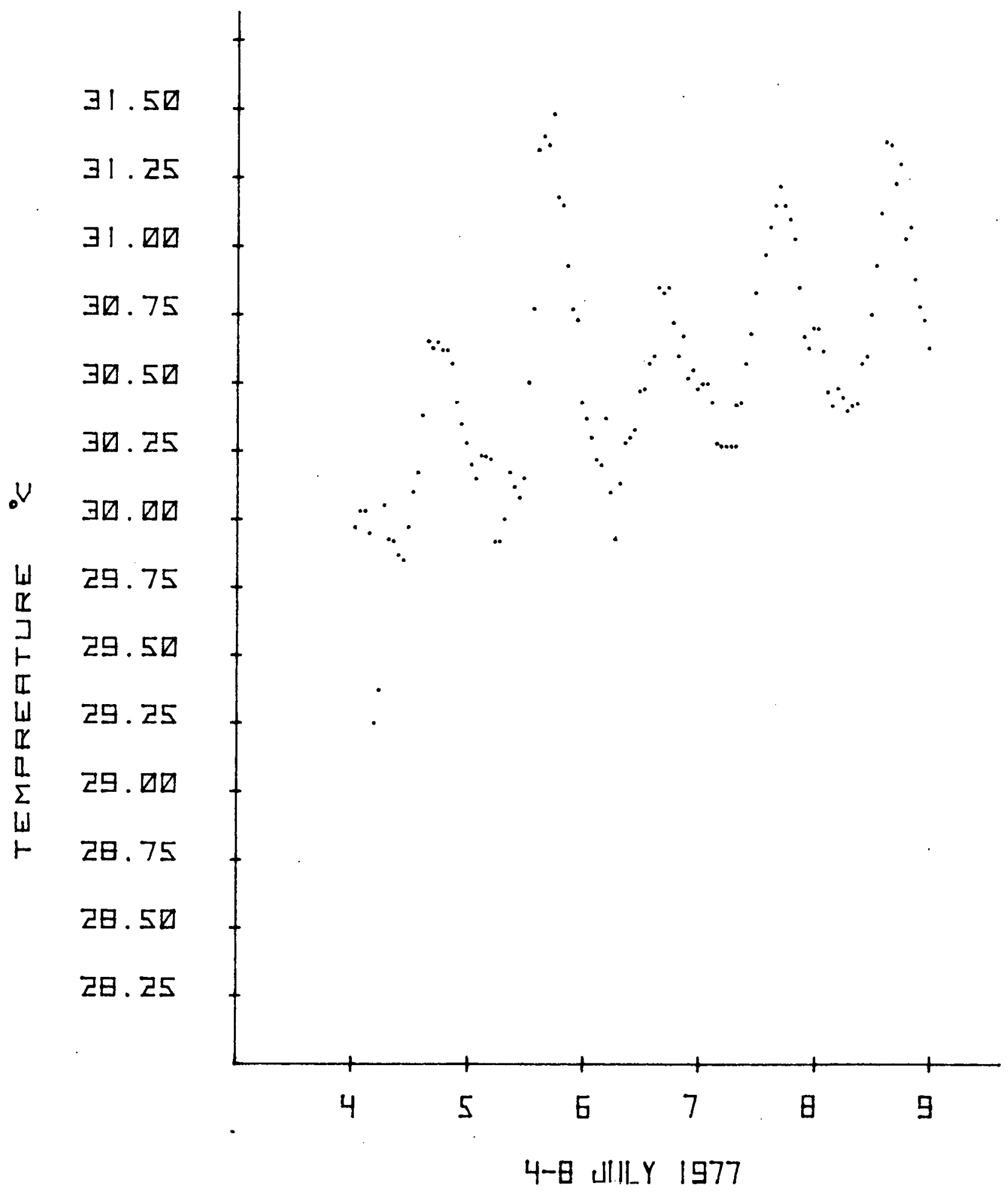

Fig. 8. Air temperature $\left({ }^{\circ} \mathrm{C}\right)$ data, Savannah Navigational Light Tower, 4-8 July 1977, at one hour intervals (Blanton, Bailey and Hayes, 1978)). 


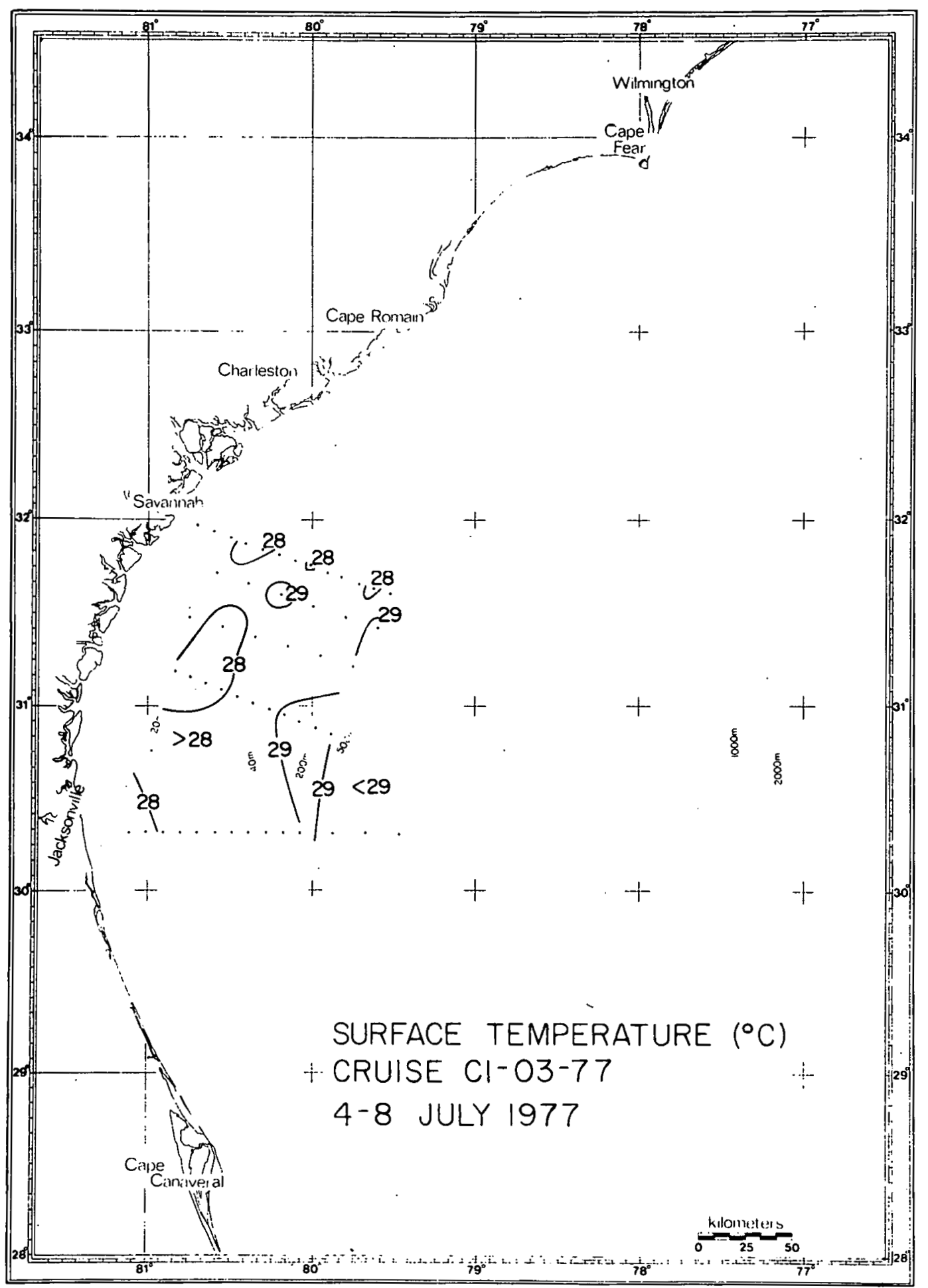

Fig. 9. Horizontal surface temperature $\left({ }^{\circ} \mathrm{C}\right)$ distribution. 


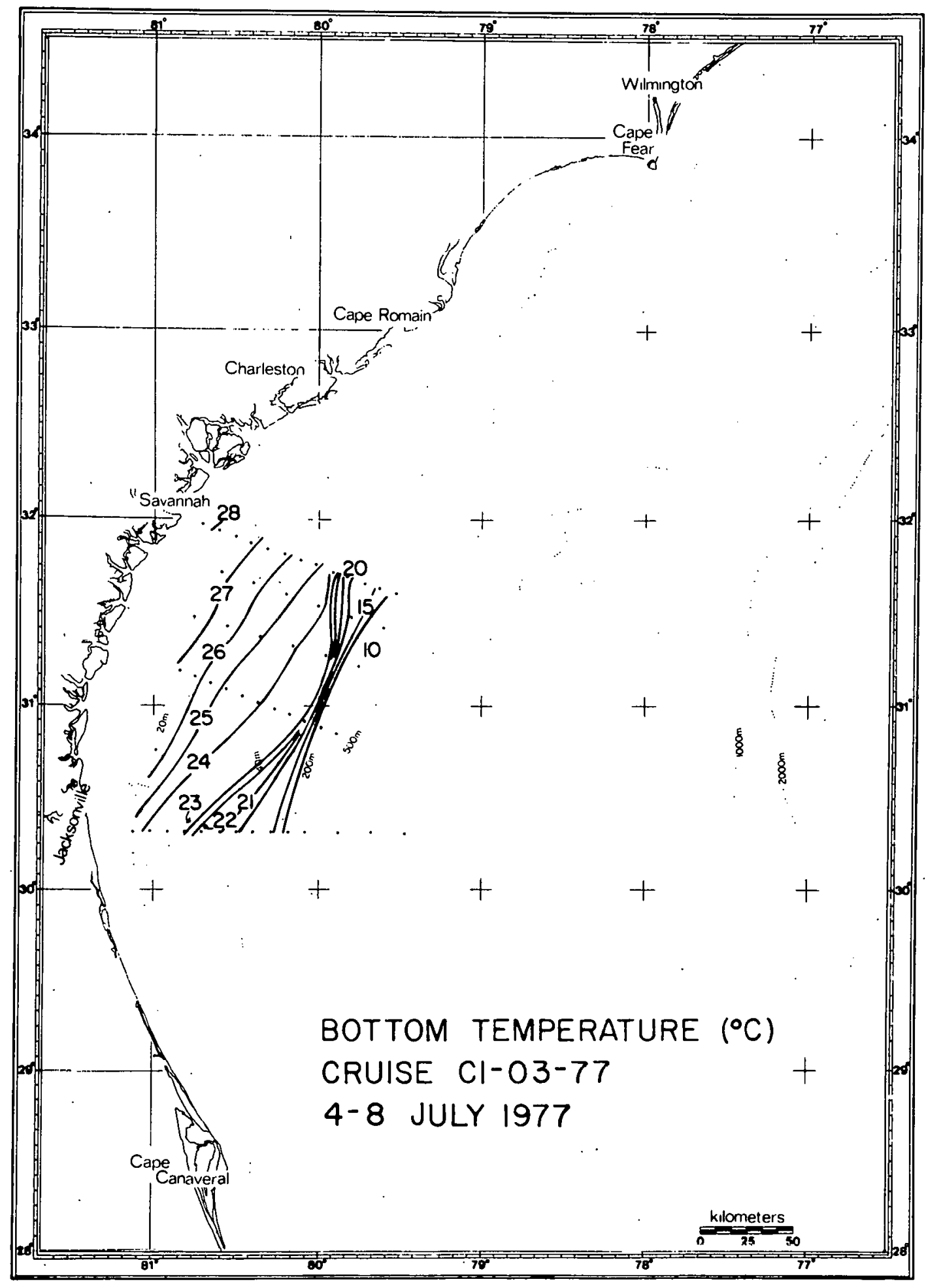

Fig. 10, Horizontal bottom temperature $\left({ }^{\circ} \mathrm{C}\right)$ distribution. 


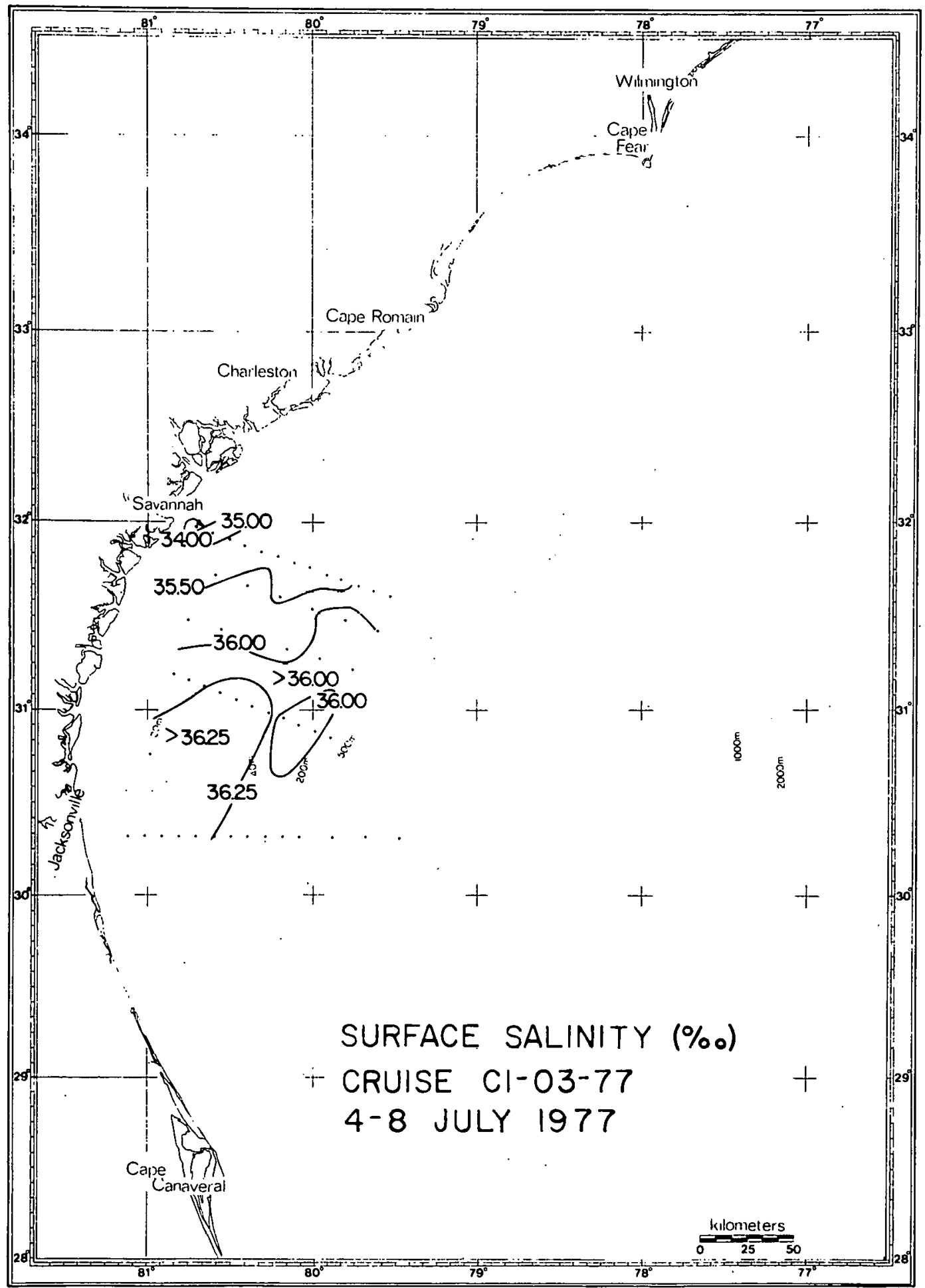

Fig. 11. Horizontal surface salinity $(\% / 00)$ distribution. 


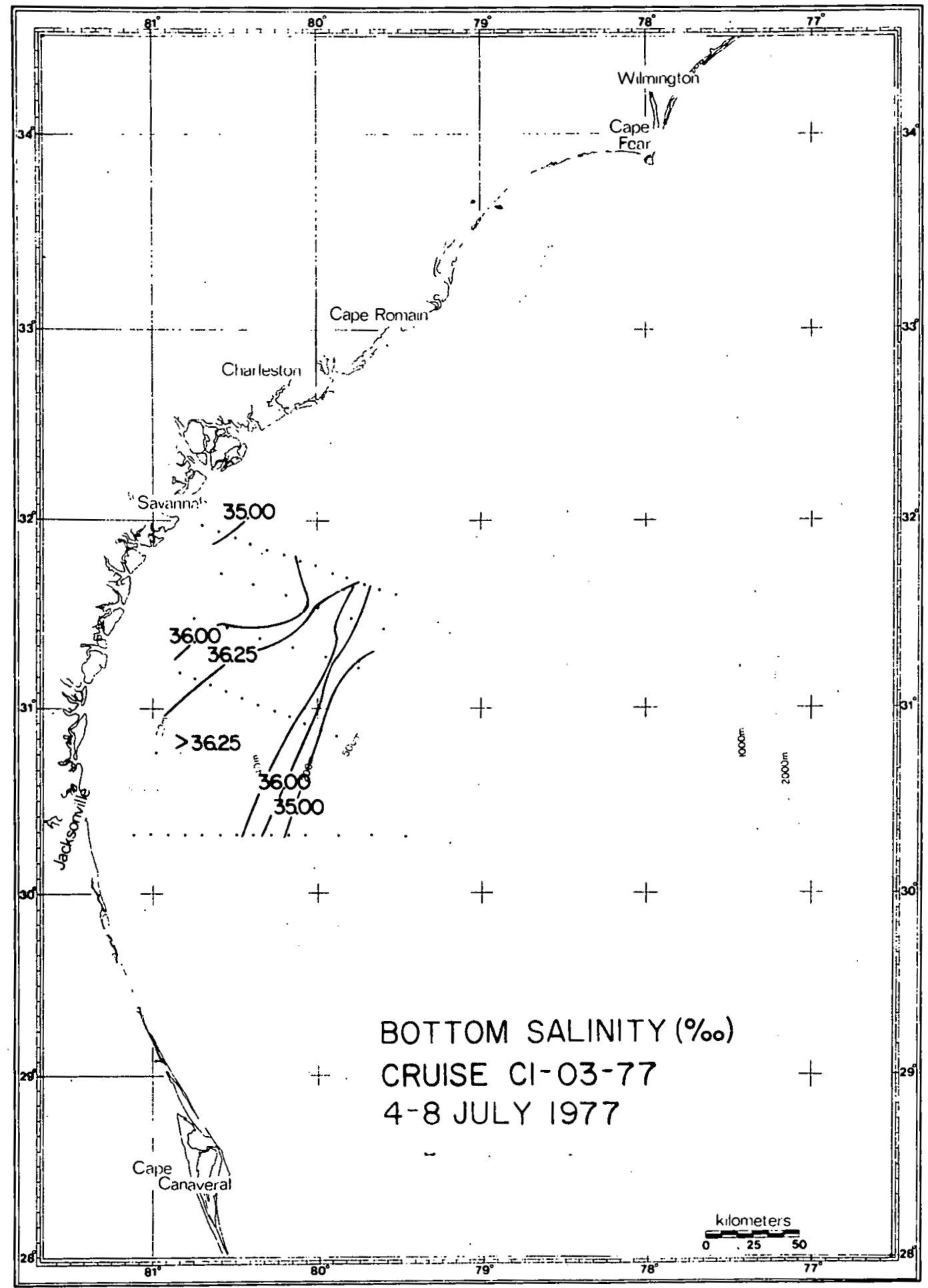

Fig. 12. Horizontal bottom salinity $(\% / 00)$ distribution. 


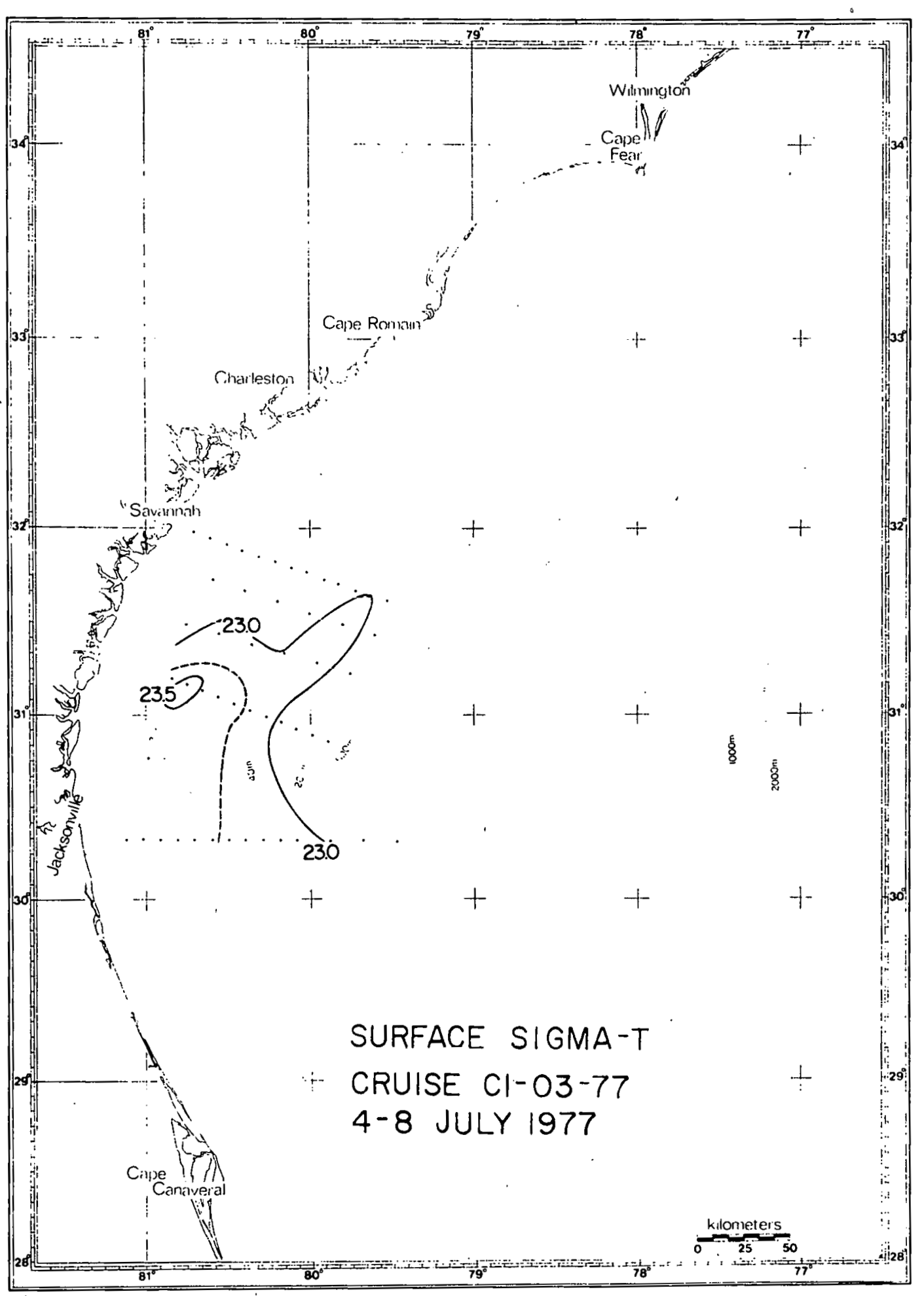

Fig. 13. Horizontal surface sigma-t distribution. 


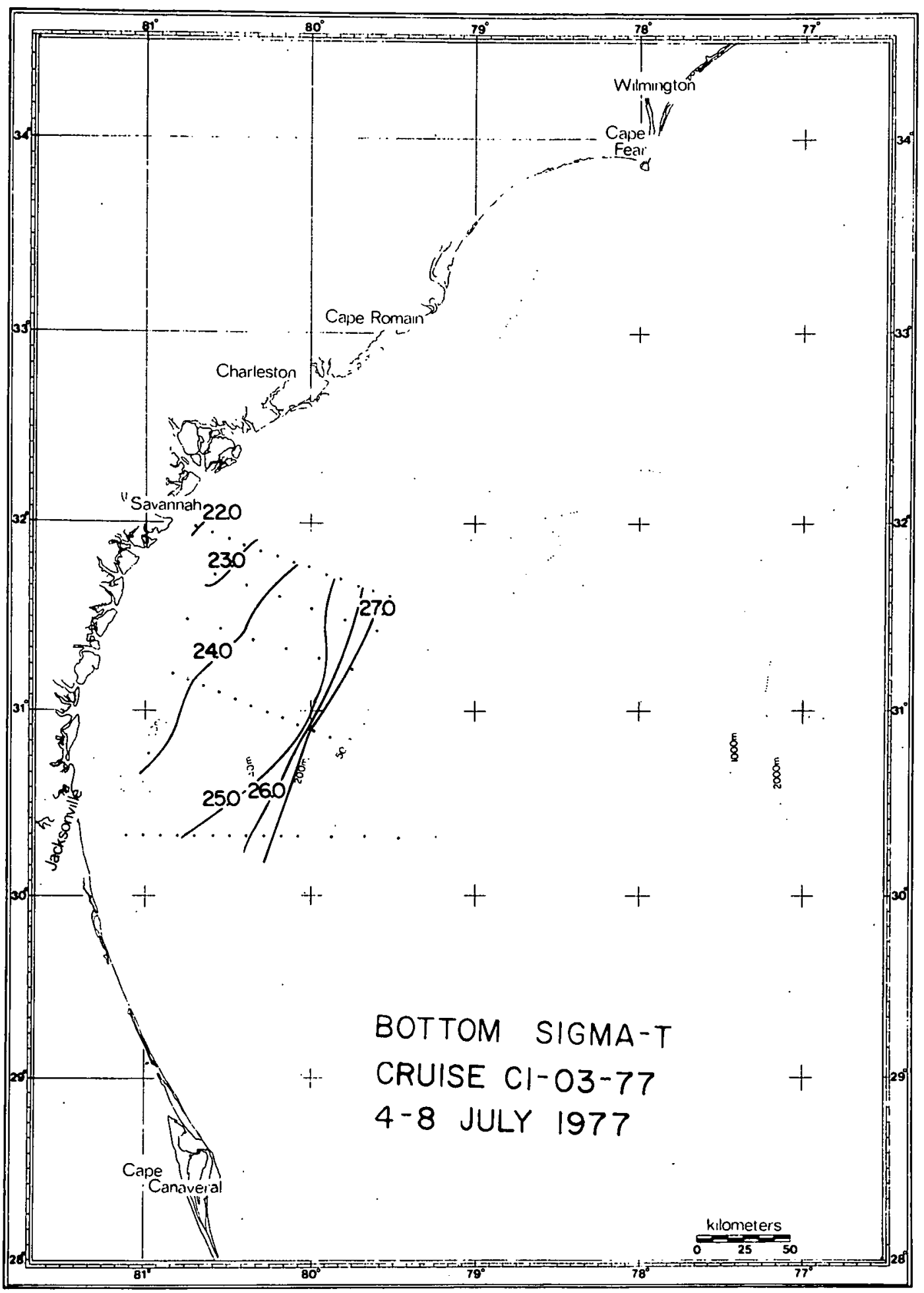

Fig. 14. Horizontal bottom sigma-t distribution. 


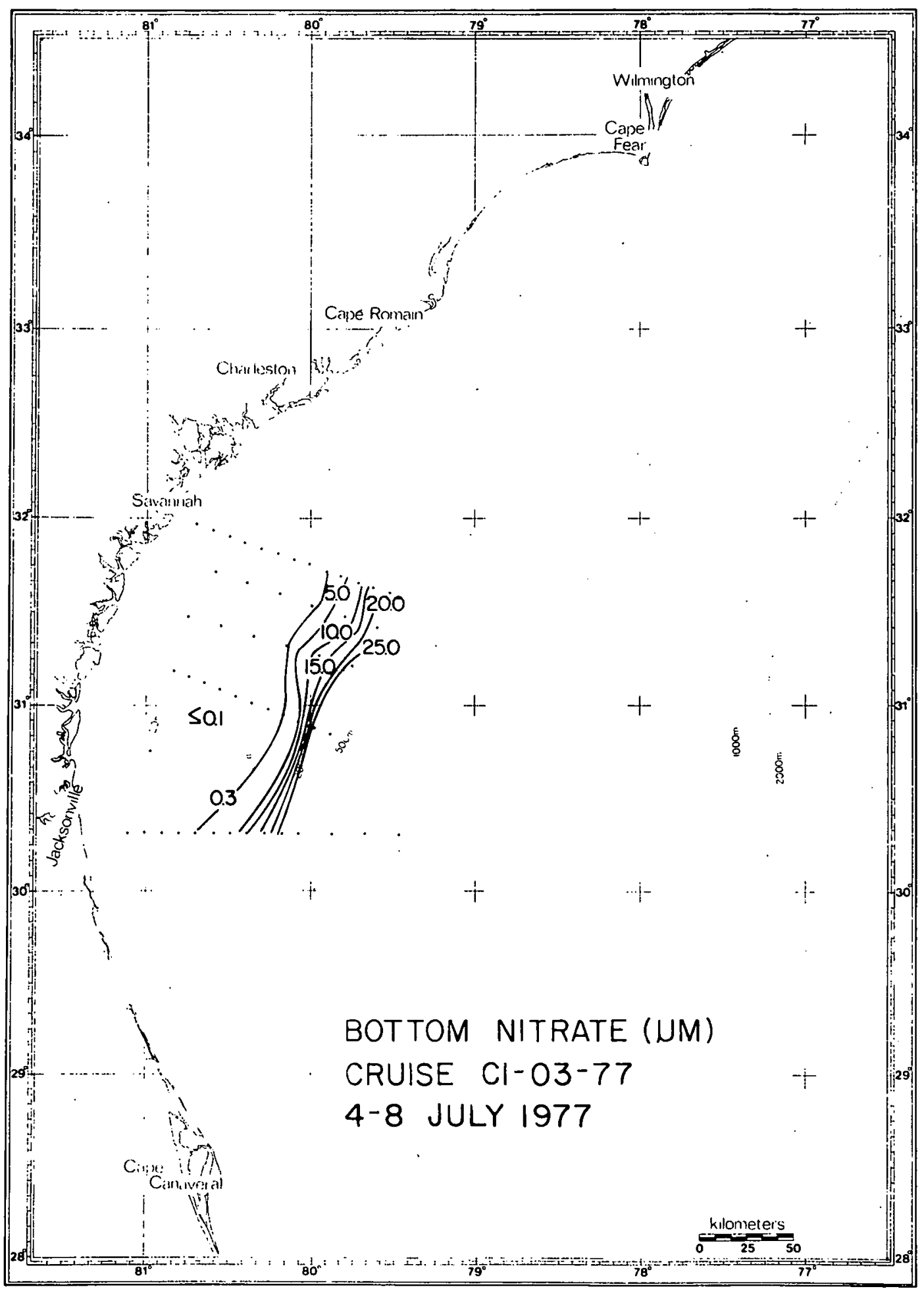

Fig. 15. Horizontal bottom nitrate ( $\mu M)$ distribution. 


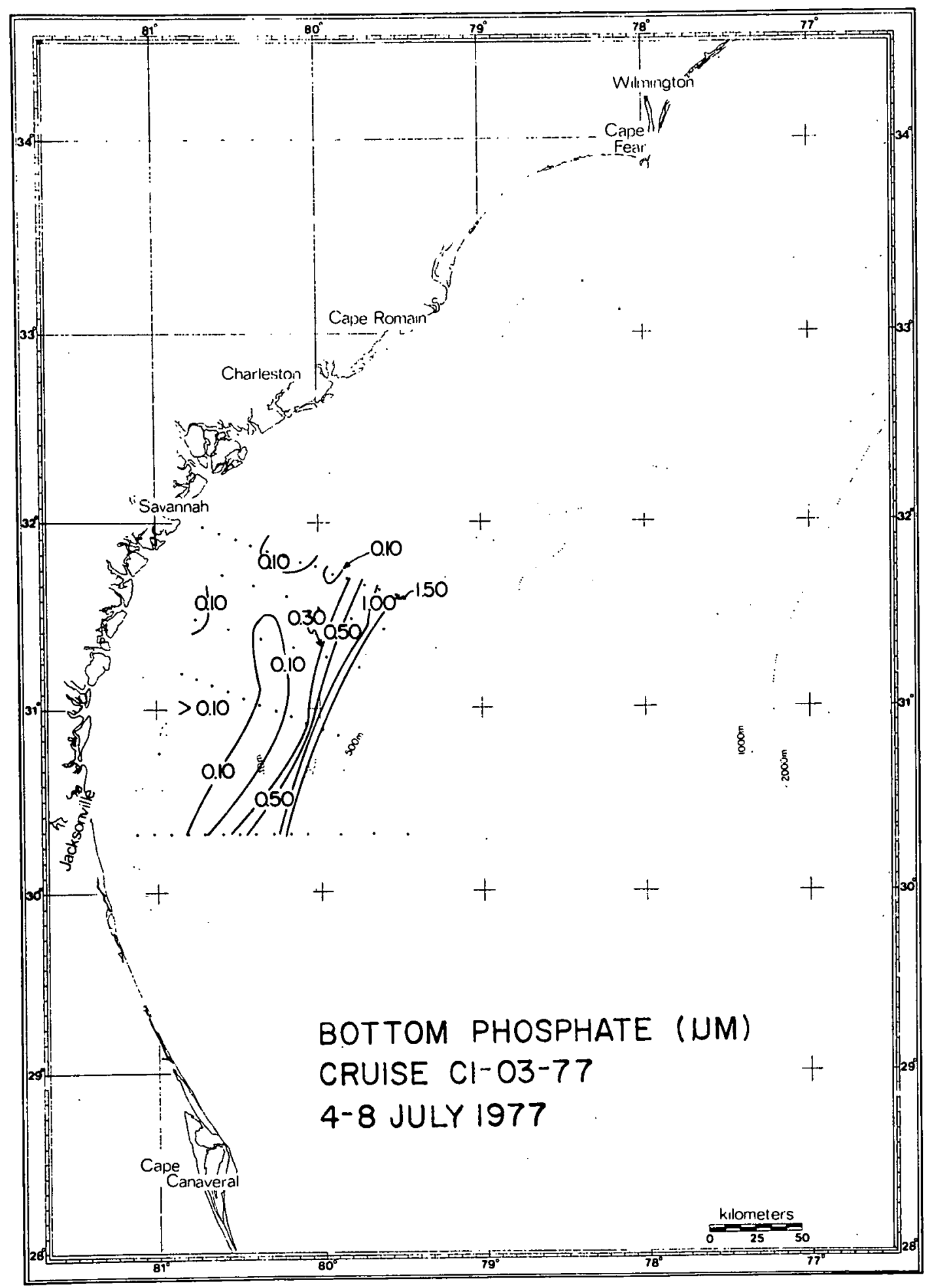

Fig. 16. Horizontal bottom phosphate $(\mu \mathrm{M})$ distribution. 


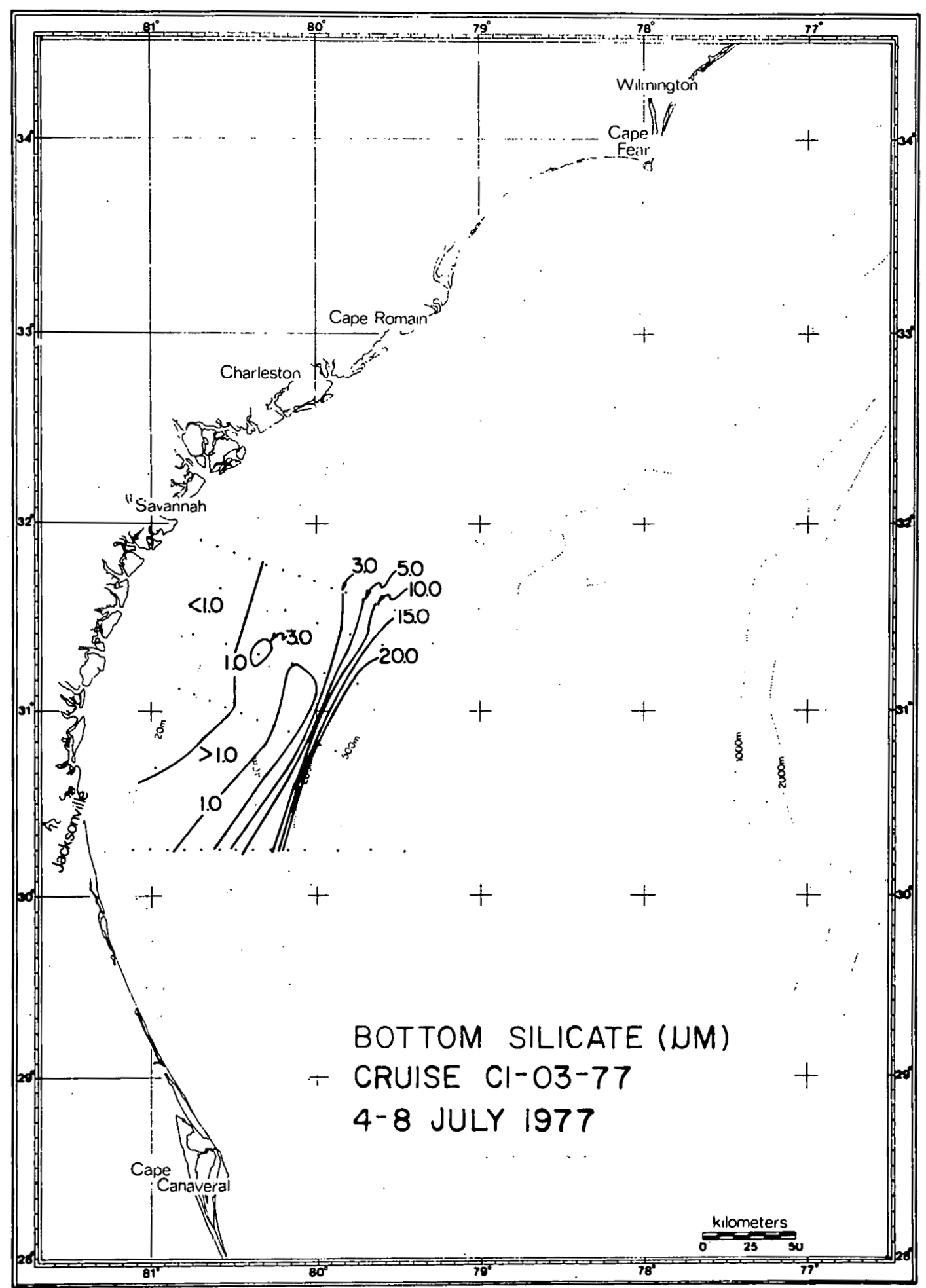

Fig. 17. Horizontal bottom silicate ( $\mu M)$ distribution. 


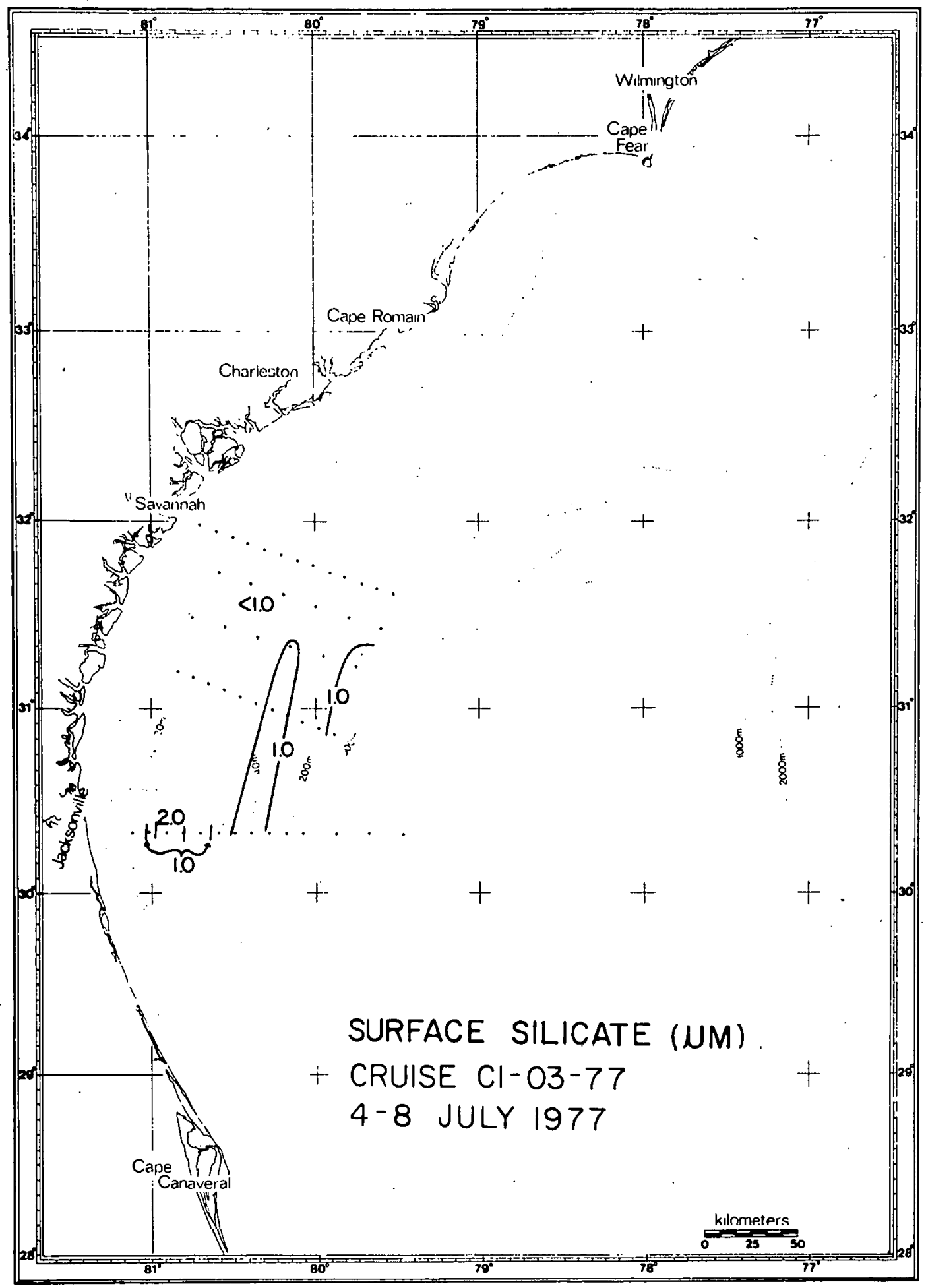

Fig. 18. Horizontal surface silicate ( $\mu \mathrm{M})$ distribution. 


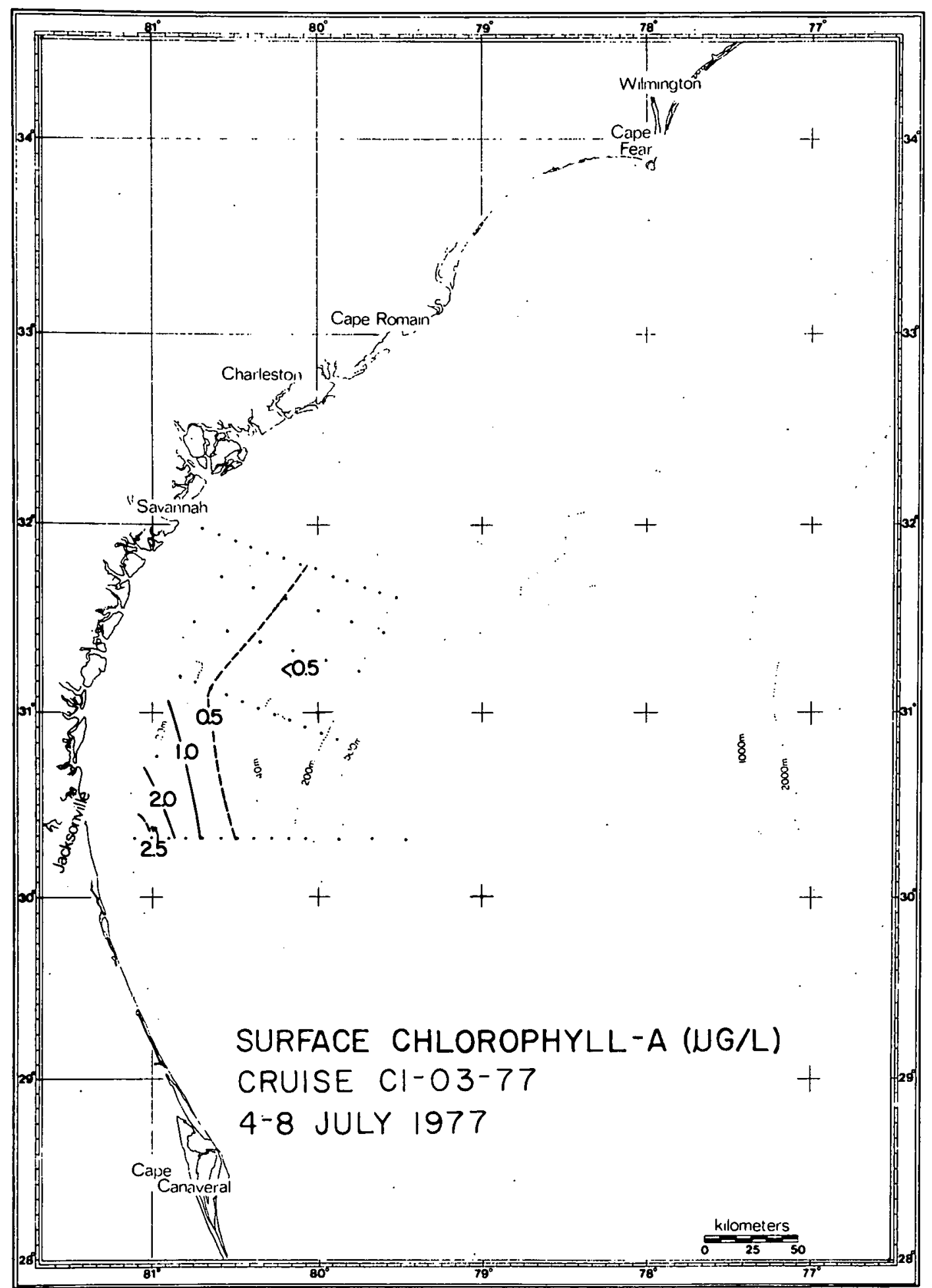

Fig. 19. Horizontal surface chlorophyll-a $(\mu \mathrm{g} / 1)$ distribution. 


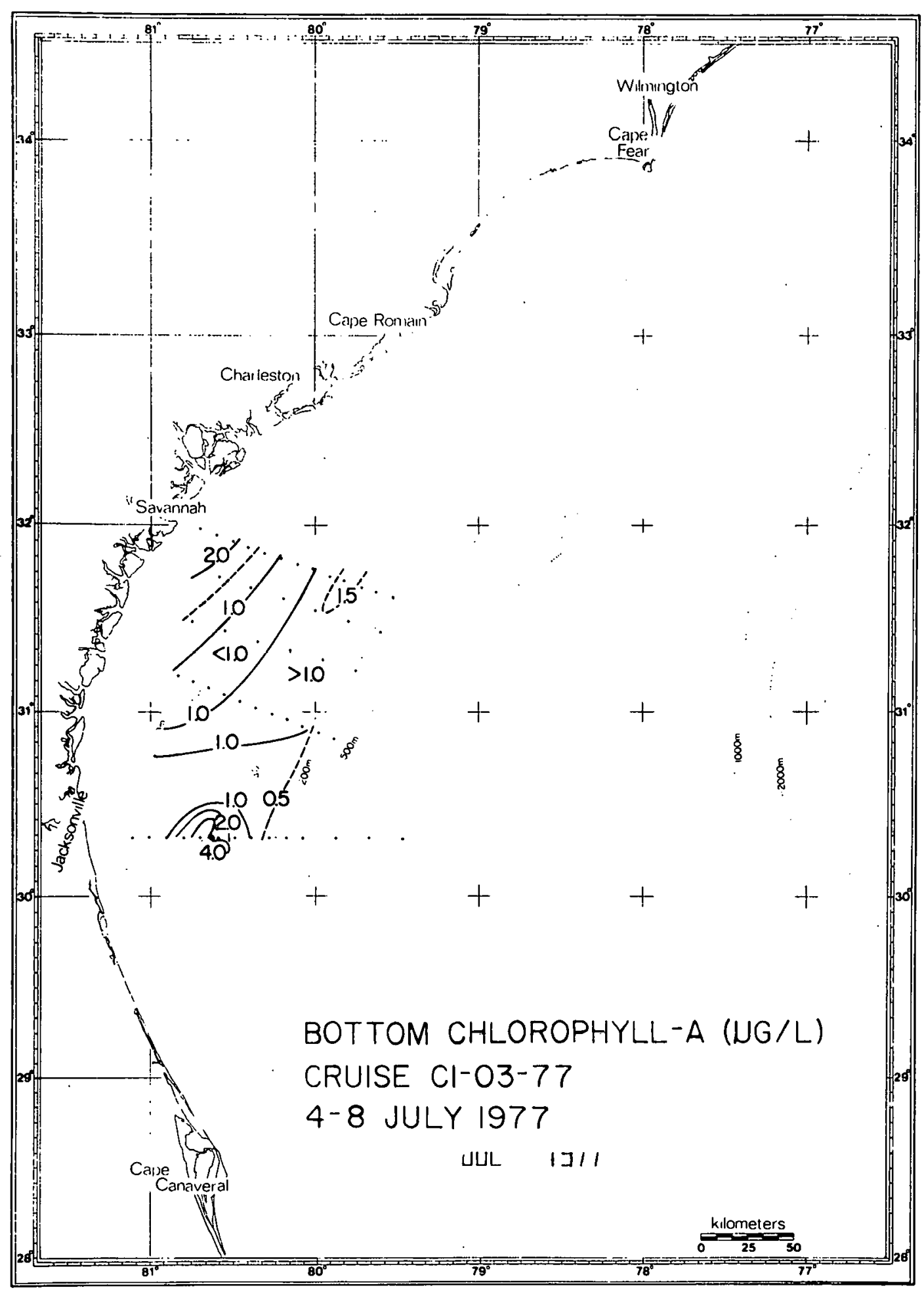

Fig. 20. Horizontal bottom chlorophyll-a $(\mu \mathrm{g} / 1)$ distribution. 

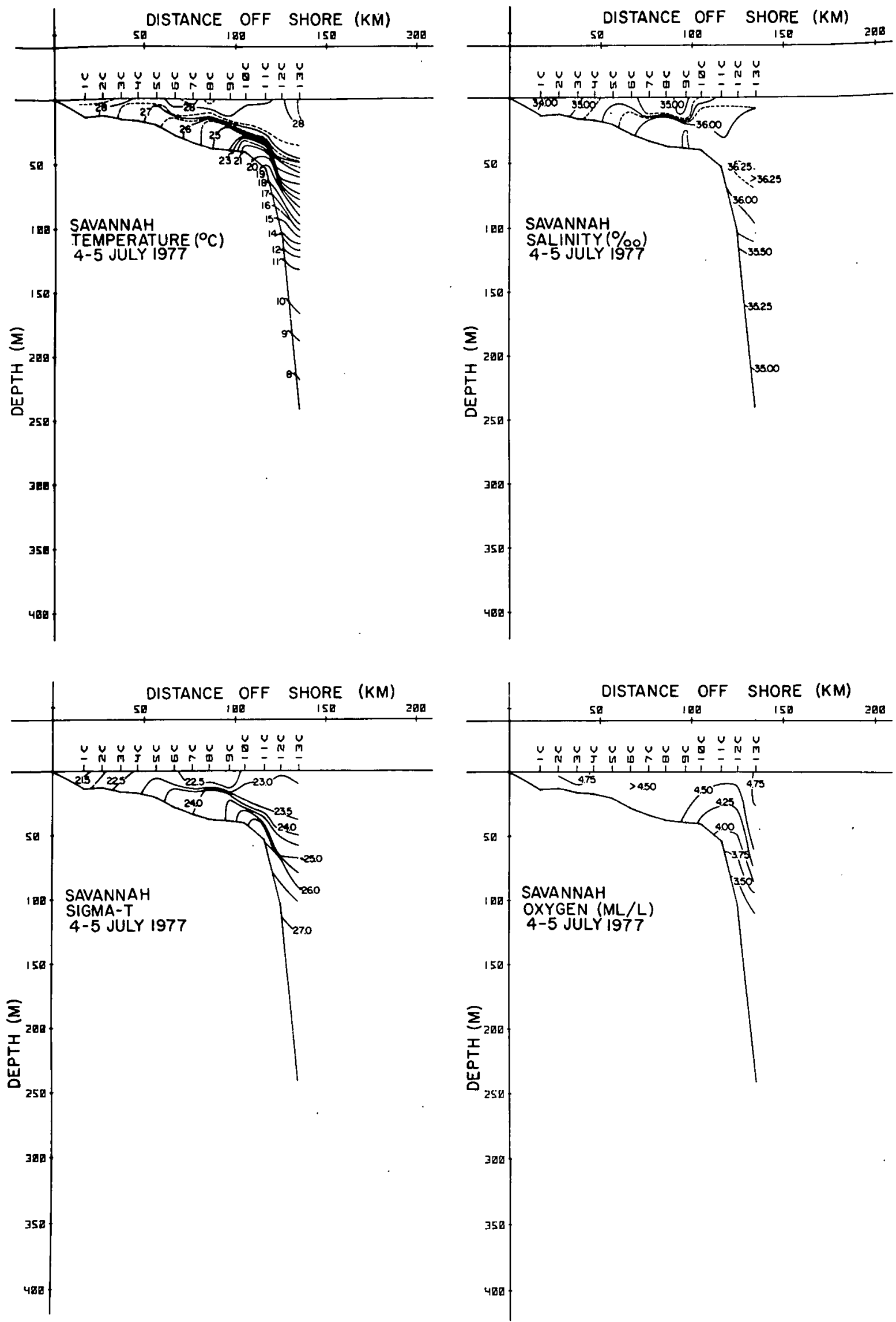

Fig. 21. Vertical distribution of temperature $\left({ }^{0} \mathrm{C}\right)$, salinity $\left({ }^{0} / 00\right)$, sigma-t, and oxygen (ml/l), Savannah section, 4-5 july 1977. 

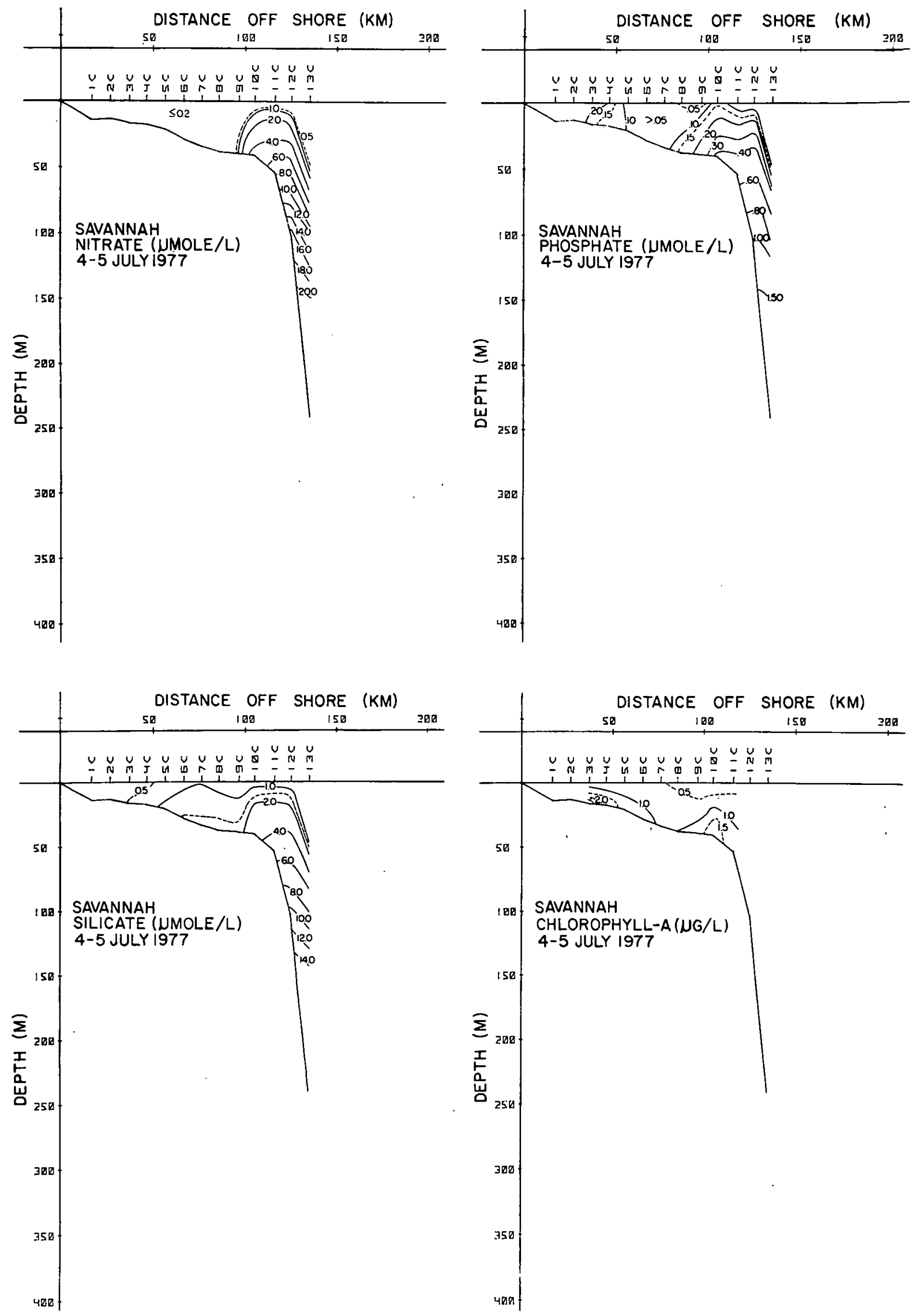

Fig. 22. Vertical distribution of nutrients ( $\mu M)$ and chlorophyll-a $(\mu \mathrm{g} / 1)$, Savarimalı seccliun 2-5 Juty 1977. 

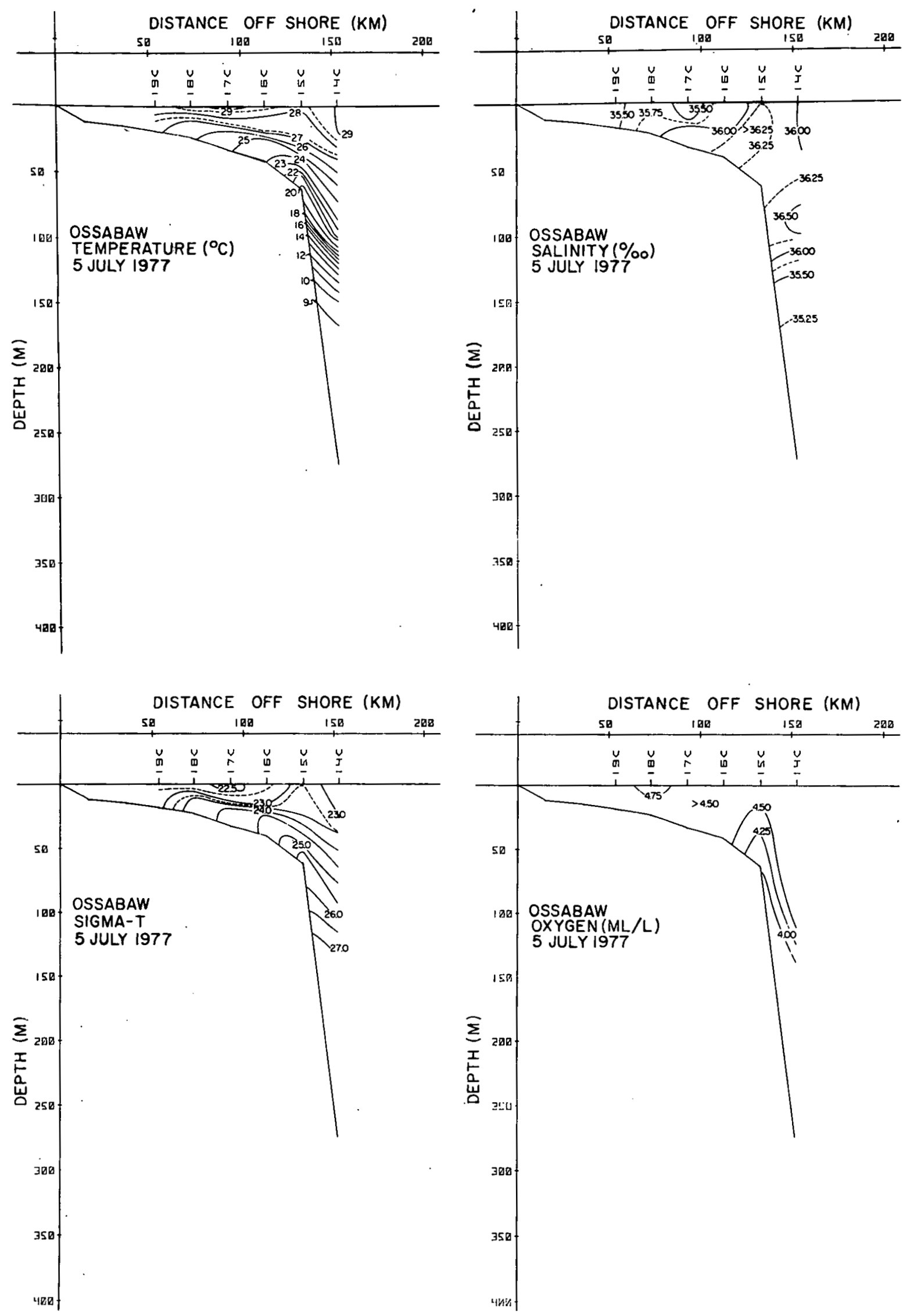

Fig. 23. Vertical distribution of temperature $\left({ }^{\circ} \mathrm{C}\right)$, salinity $(\% / 00)$, sigma-t, and oxygen (ml/1), Ossabaw section, 5 July 1977. 

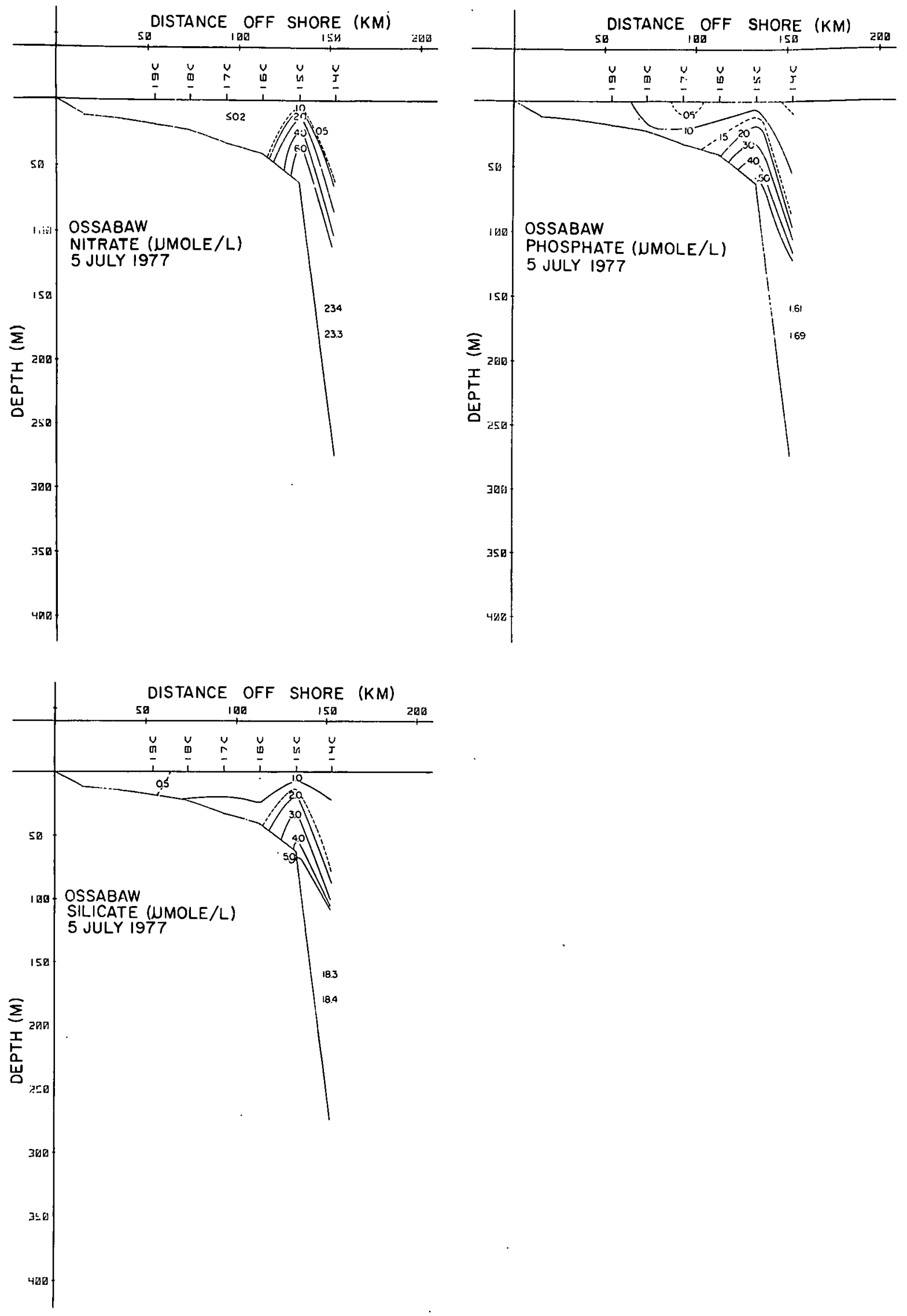

Fig. 24. Vertical distribution of nutrients ( $\mu M)$, Ossabaw section, 5 July 1977. 

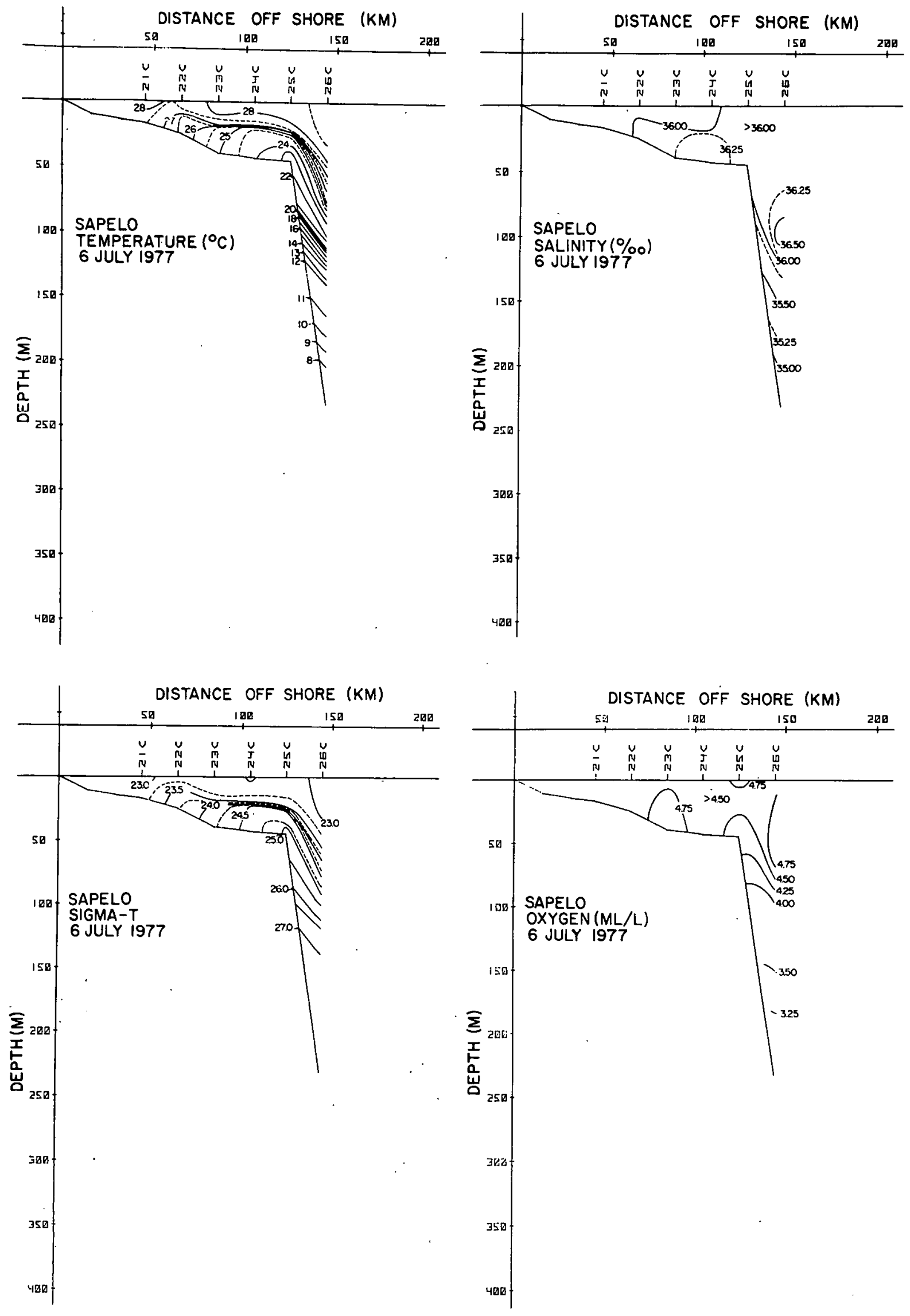

Fig. 25. Vertical distribution of temperature $\left({ }^{\circ} \mathrm{C}\right)$, salinity $(0 / 00)$, sigma-t, and uxyyen (ml/l), Sapelo section, $b$ July $\mid y / /$. 
40
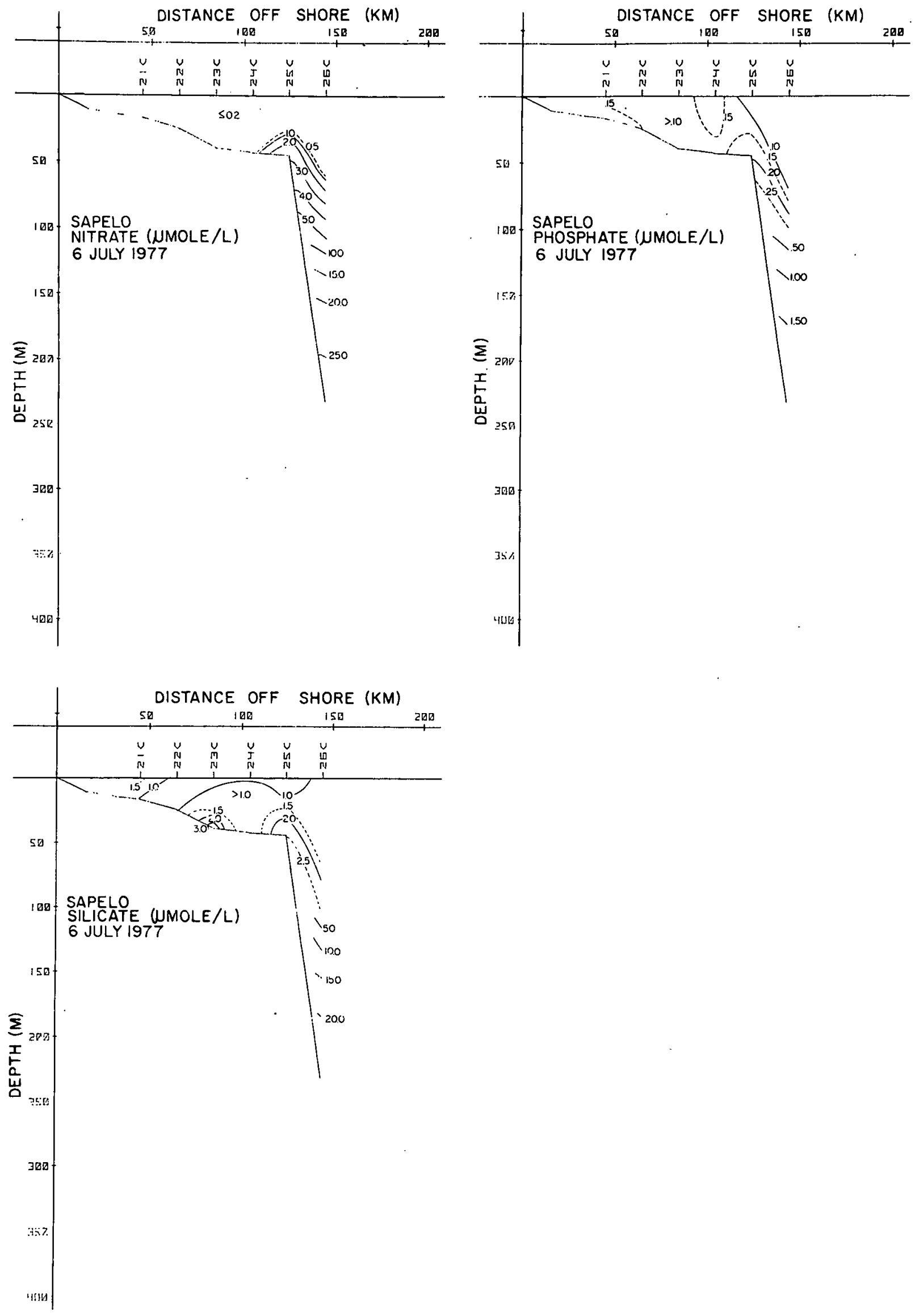

Fig. 26. Vertical distribution of nutriente (iM), japelu section, 6 July $197 \%$. 

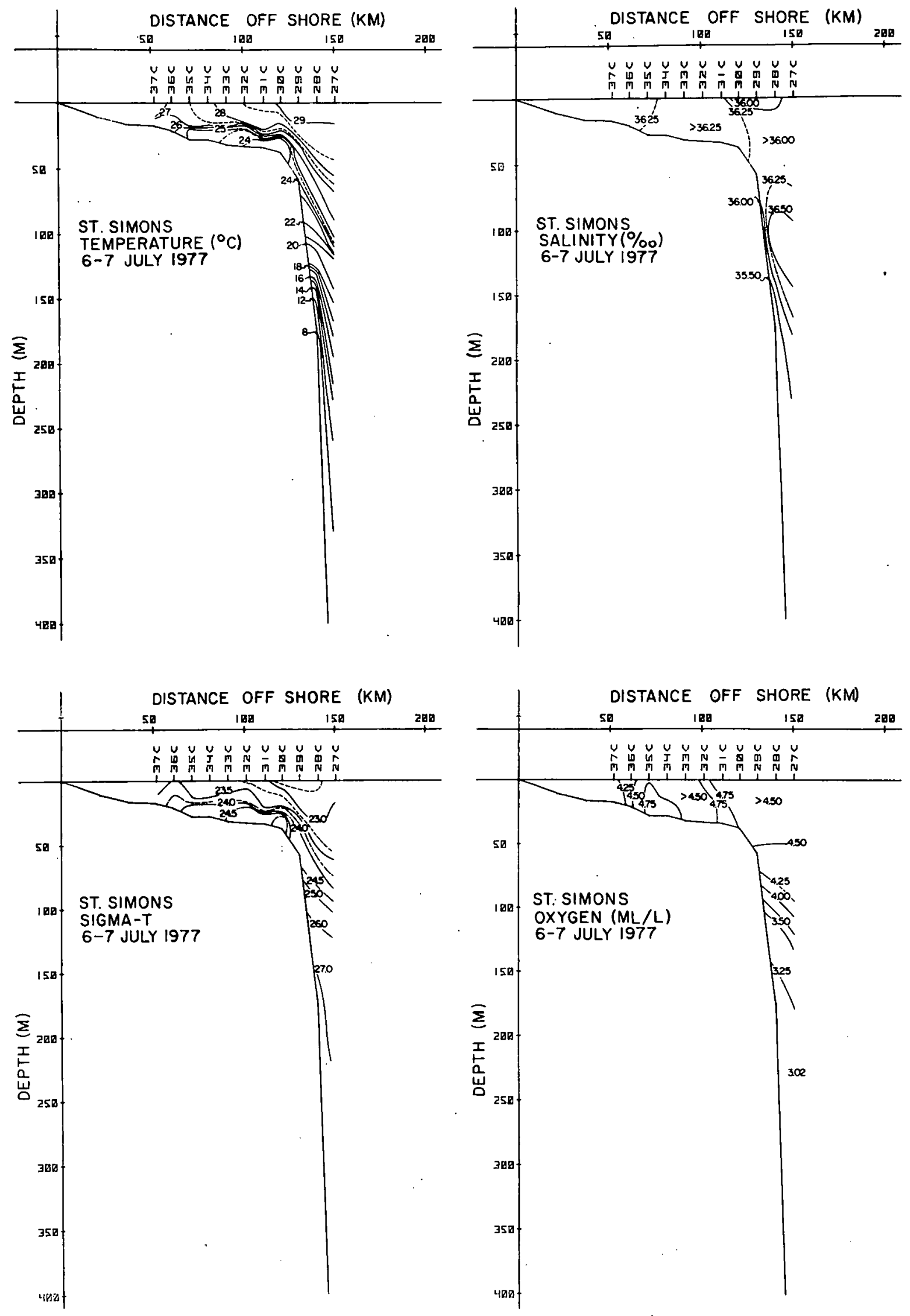

Fig. 27. Vertical distribution of temperature $\left({ }^{\circ} \mathrm{C}\right)$, salinity $\left({ }^{0} / 00\right)$, sigma-t, and oxygen $(\mathrm{ml} / 1)$, St. Simons section, 6-7 July 1977. 

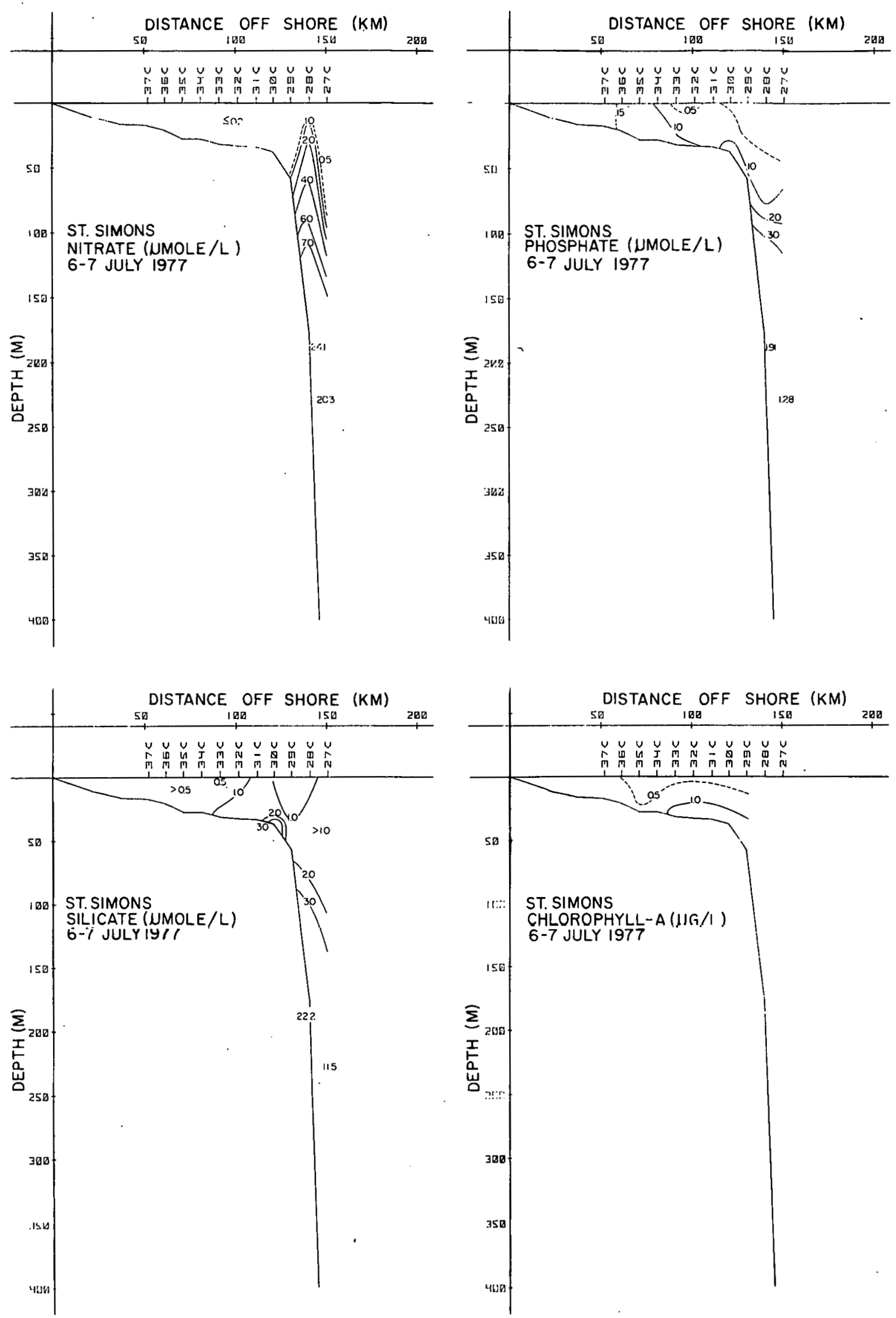

Fig. 28. Vertical distribution of nutrients $(\mu M)$ and chlorophyll-a ( $\mu \mathrm{g} / 1)$, St. Simons section, 6-7 July 1977. 

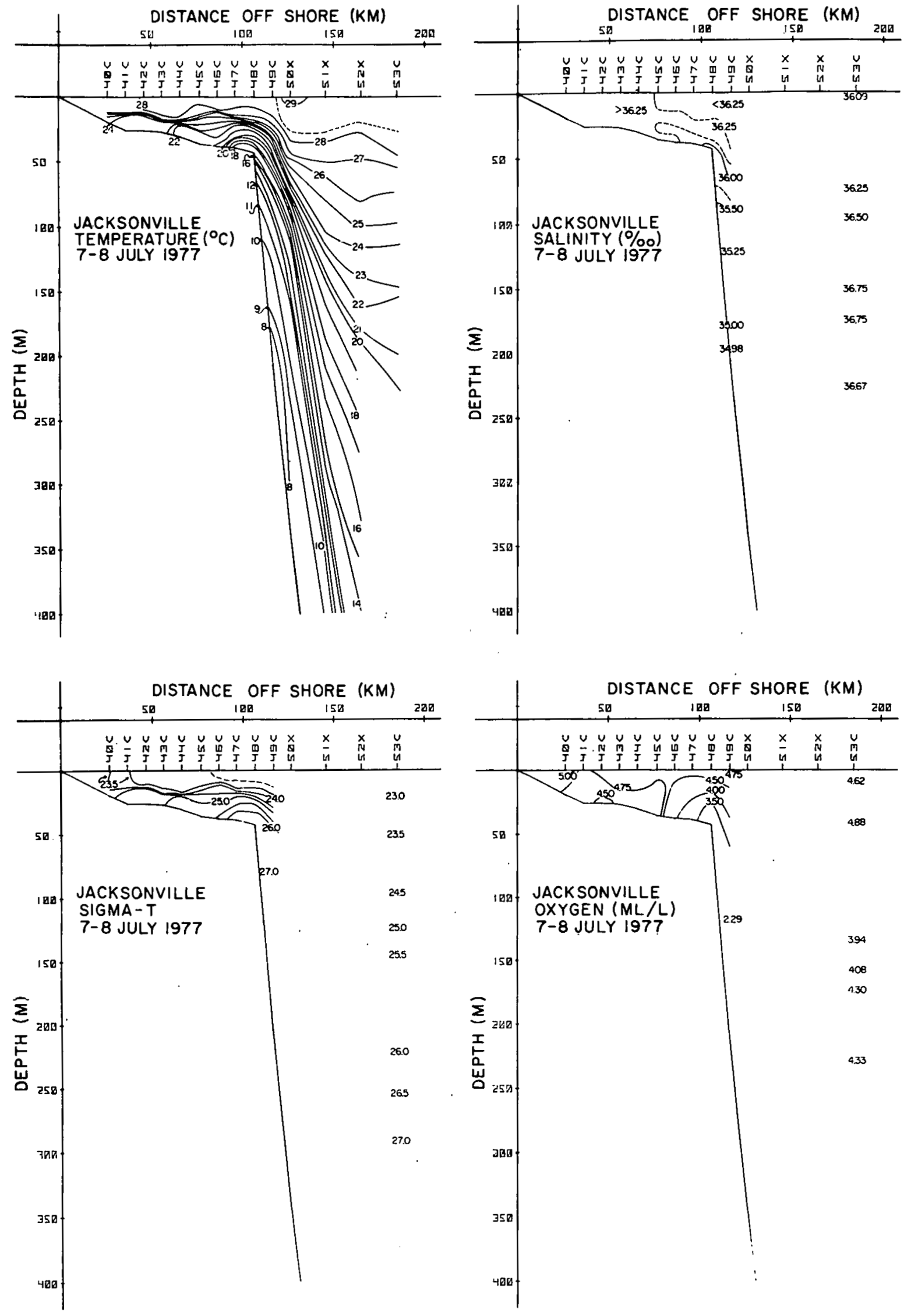

Fig. 29. Vertical distribution of temperature $\left({ }^{0} \mathrm{C}\right)$, salinity $\left({ }^{0} / 00\right)$, sigma-t, and oxygein (iiil/1), Jacksurville secclun, 7-8 July 1977 . 

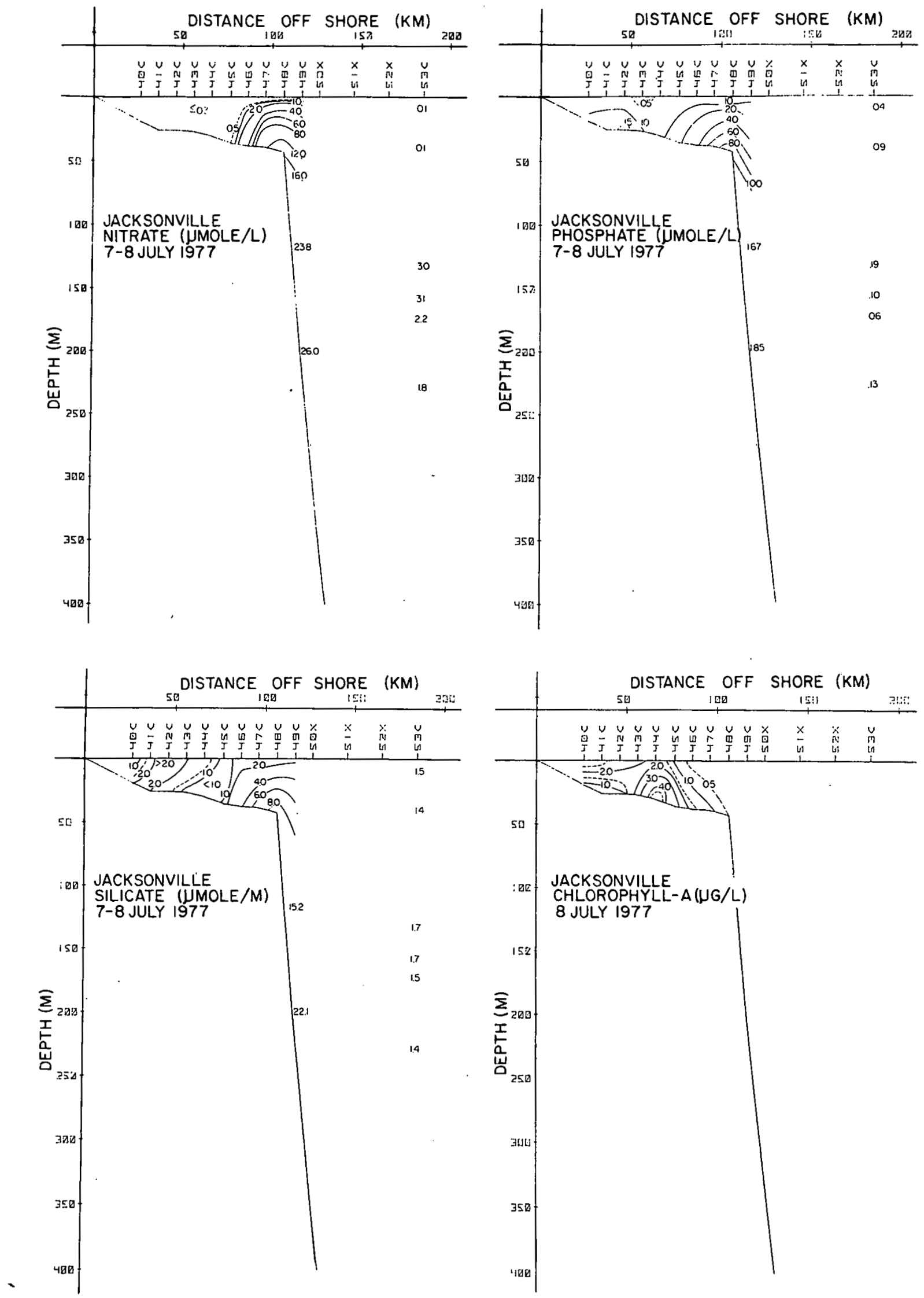

Fig. 30. Vertical distribution of nutrient ( $\mu M$ ) and chlorophyll-a $(\mu y / 1)$, Jdcksunvllie section, /-y July 1977. 


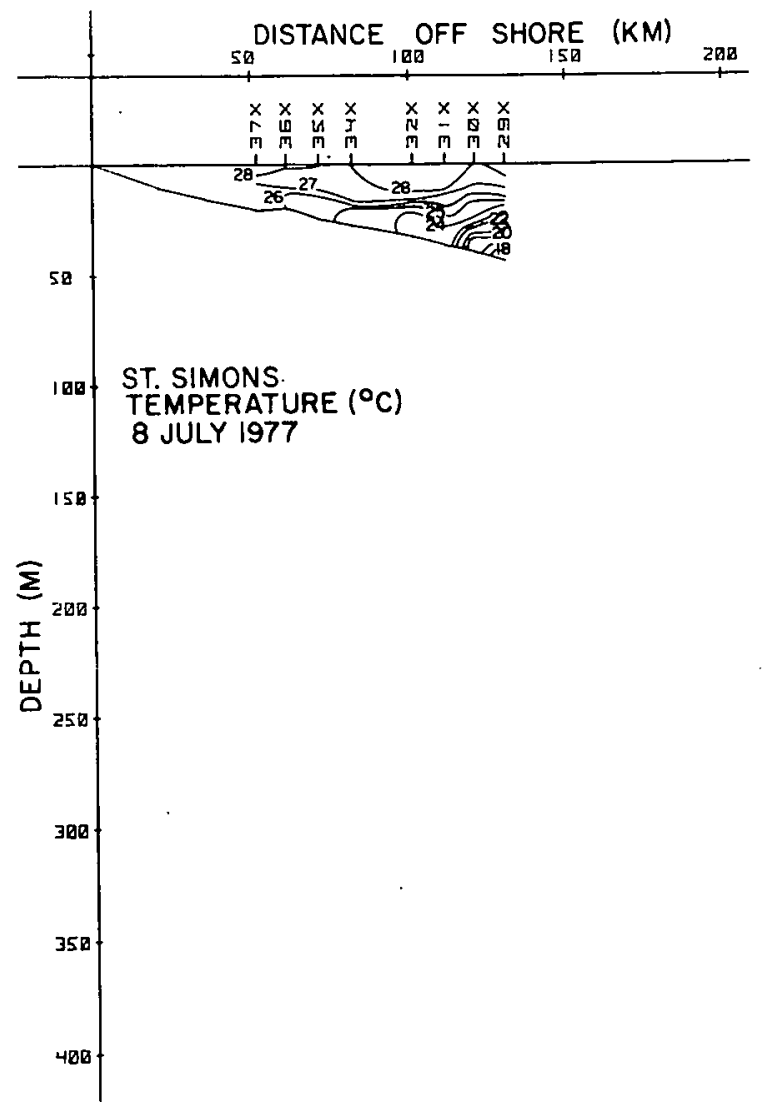

Fig. 31. Vertical distribution of temperature $\left({ }^{\circ} \mathrm{C}\right)$, St. Simons section, 8 Juty 1977. 


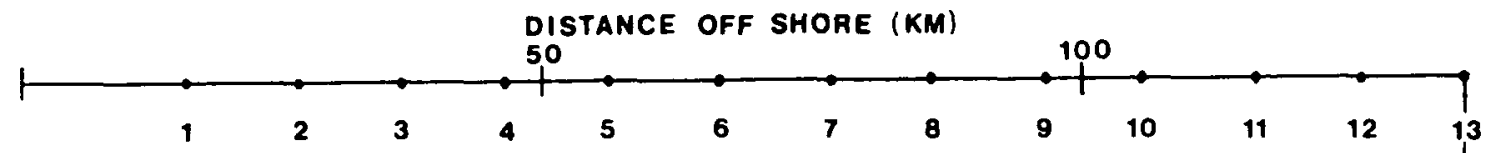

SAVANNAH

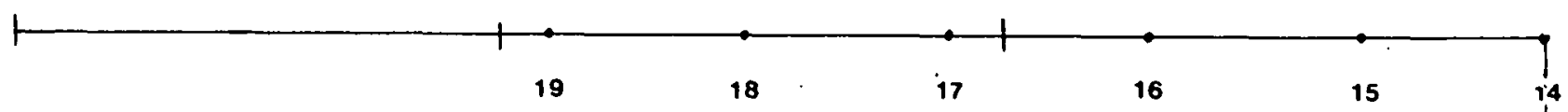

OS SABAW

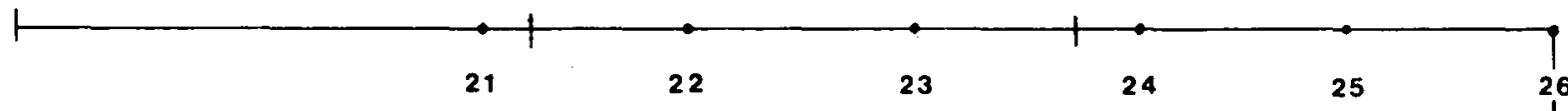

SAPELO

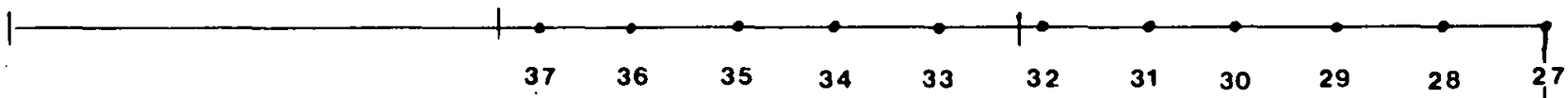

ST. SIMONS

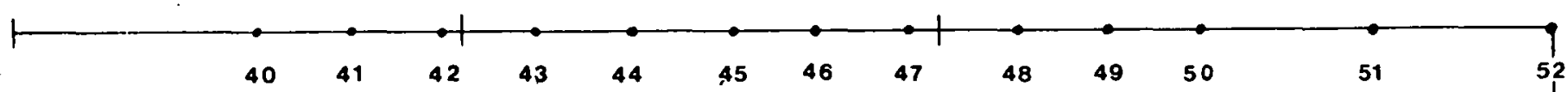

JACKSONVILLE

Fig. 32. Station locations for comparative section plots. 

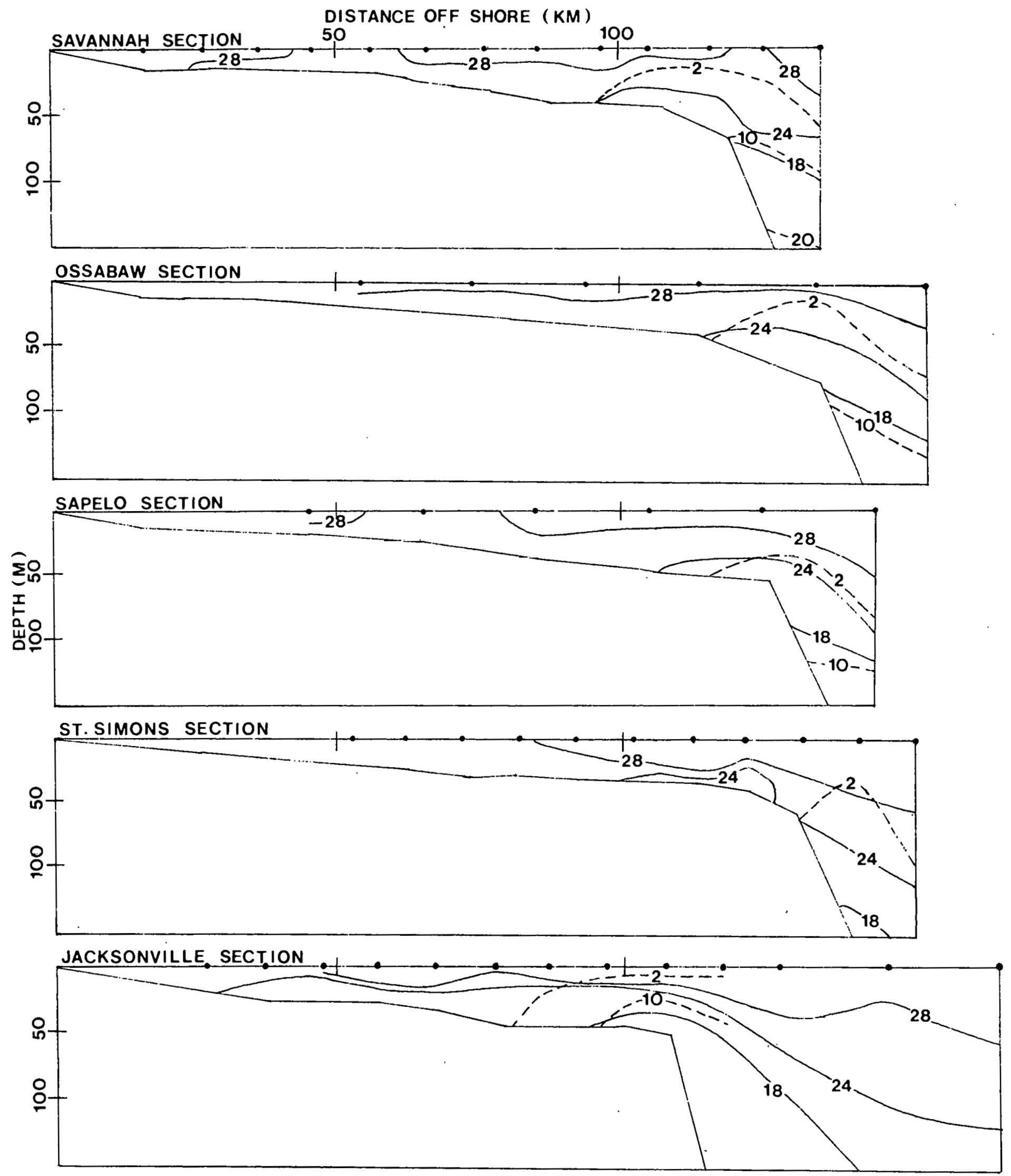

Fig. 33. Temperature $\left({ }^{\circ} \mathrm{C}-\right) /$ Nitrate $(\mu M-)$ comparative section plots. 


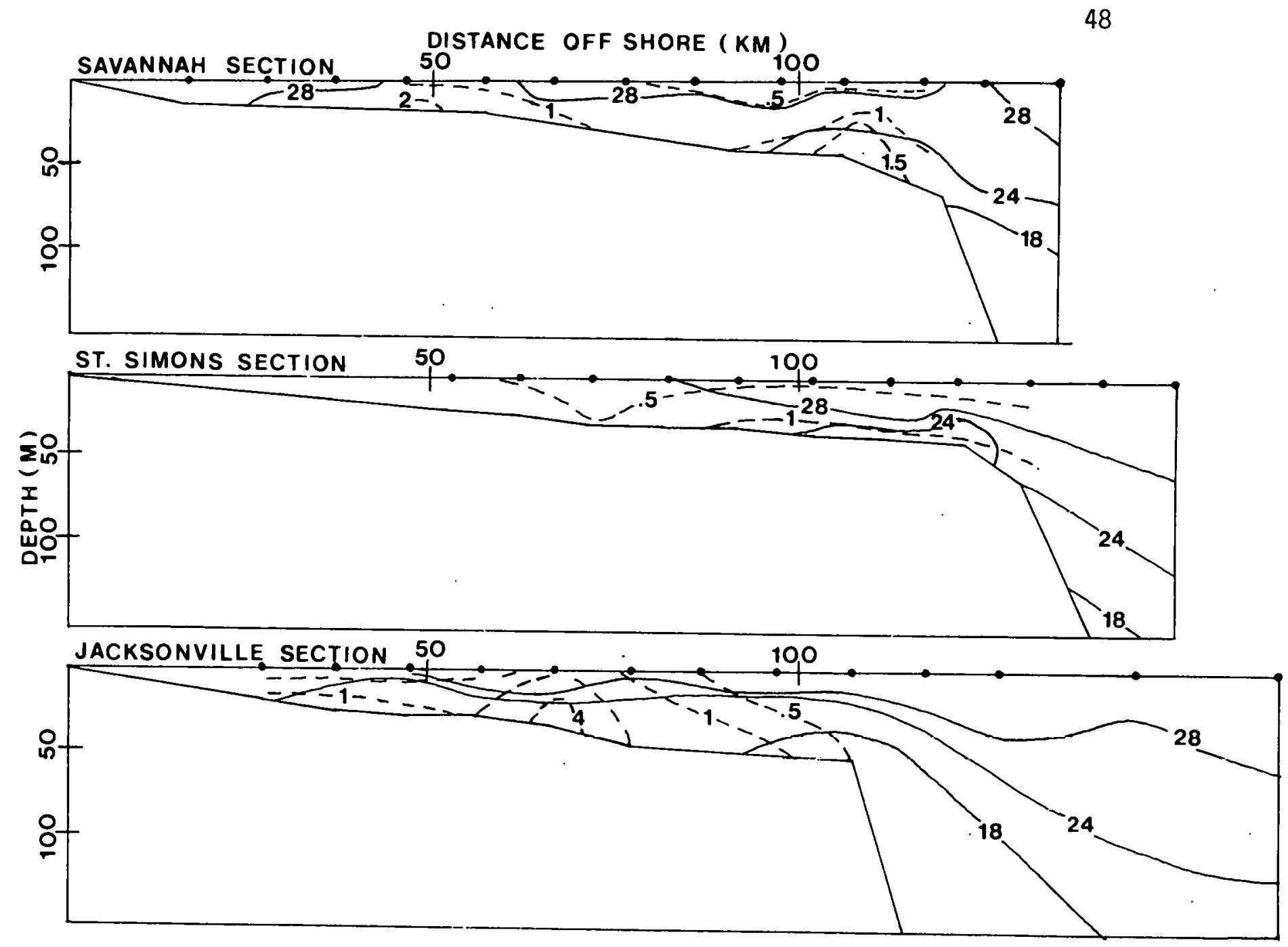

Fig. 34. Temperature $\left({ }^{\circ} \mathrm{C}-\right) / \mathrm{Ch}$ lorophyll-a $(\mu \mathrm{g} / 1--)$ comparative section plots. 


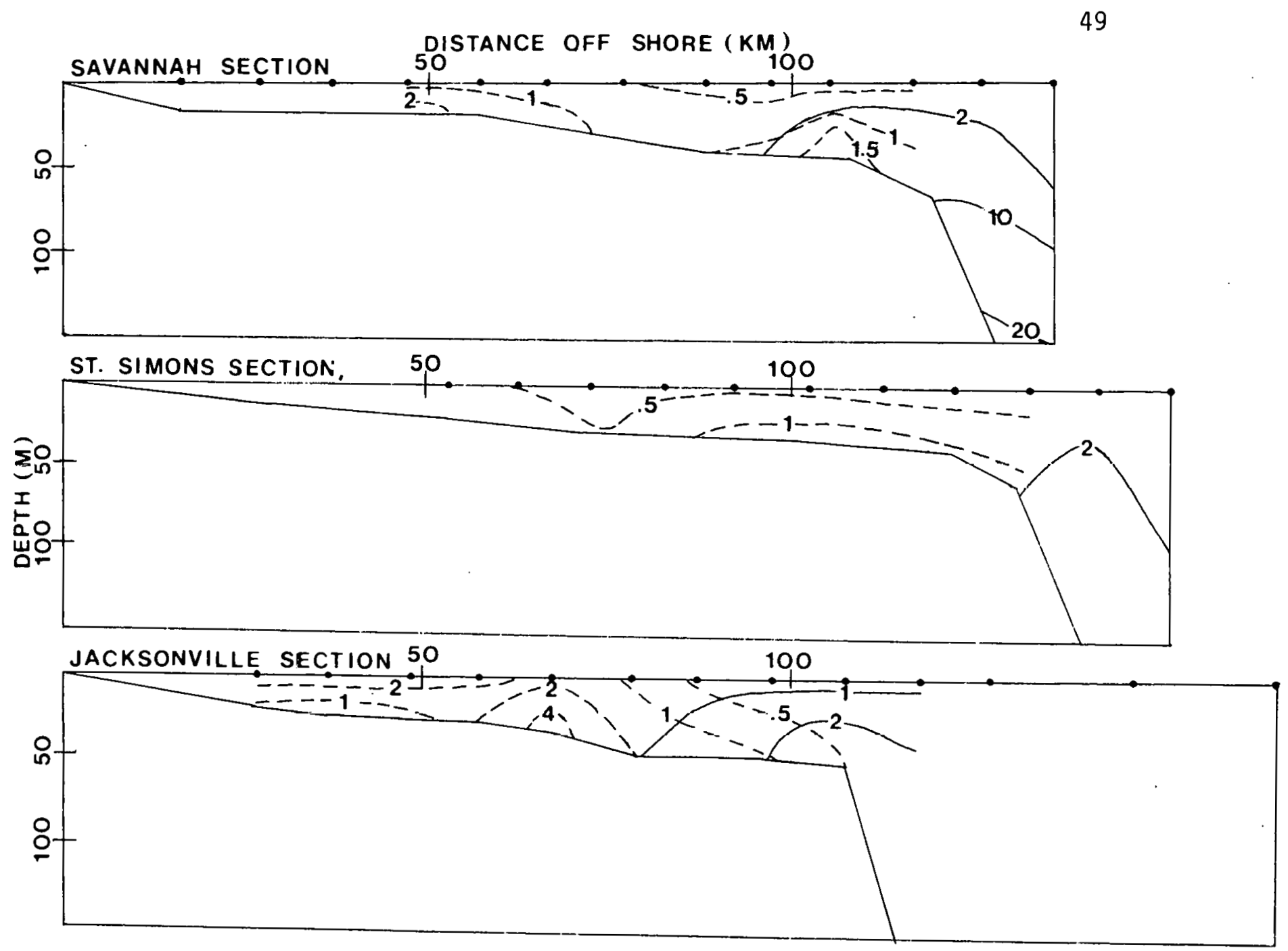

Fig. 35. Nitrate $(\mu M-) /$ Chlorophyll-a $(\mu \mathrm{g} / 1--)$ comparative section plots. 


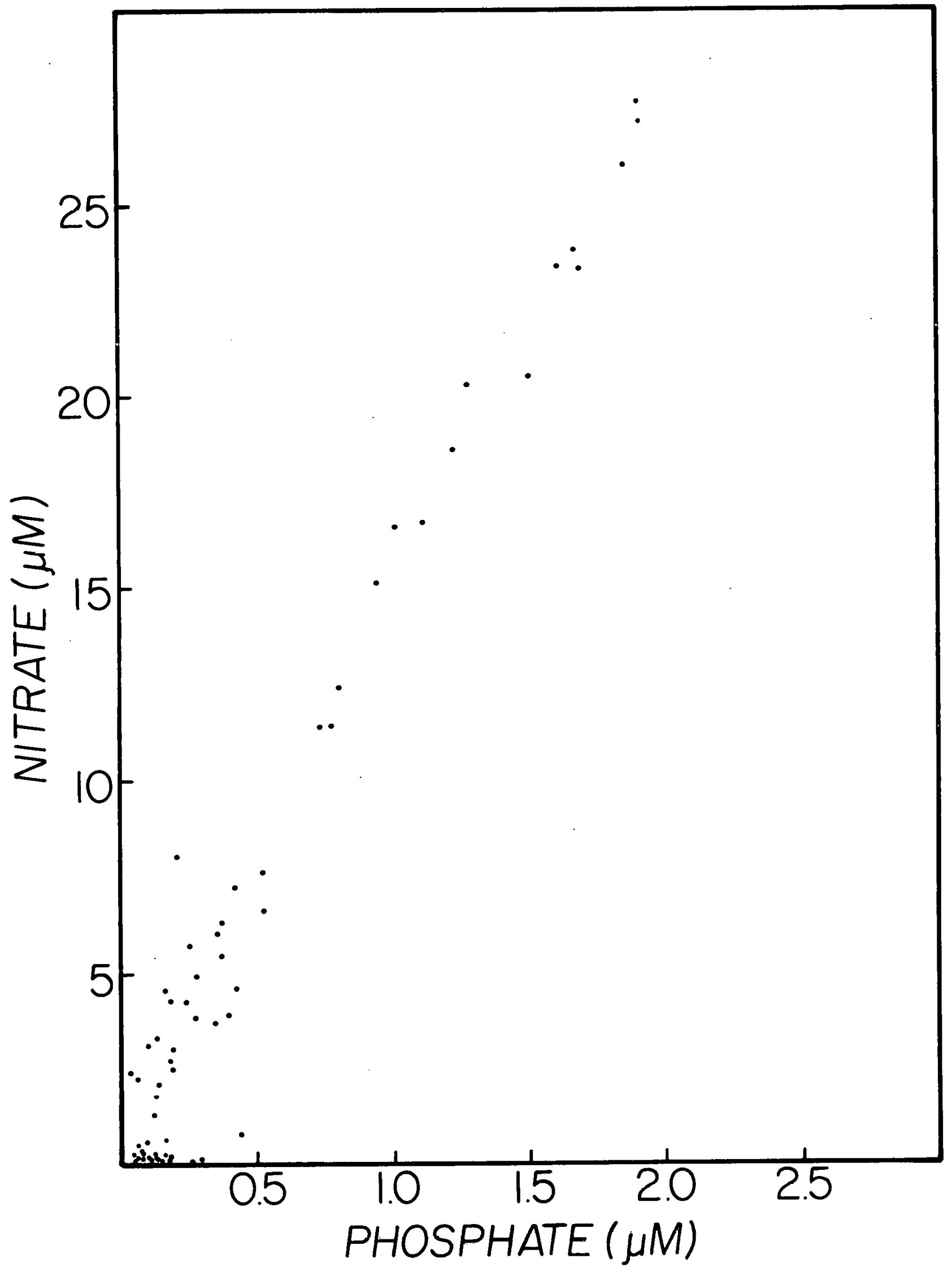

Fig. 36. Nitrate ( $\mu M)$ versus phosphate ( $\mu M)$ plot. 


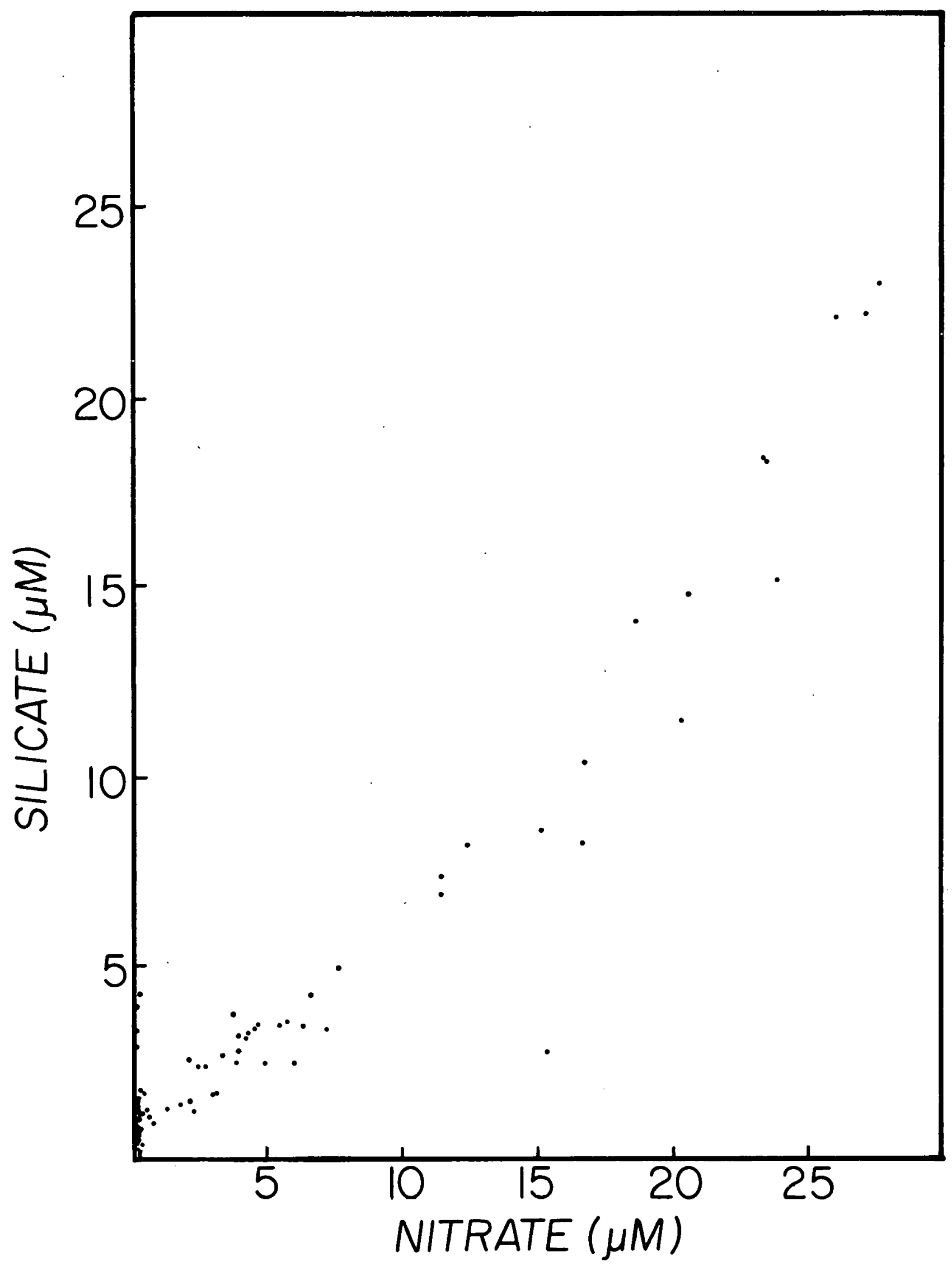

Fig. 37. Silicate ( $\left.{ }_{\mu M}\right)$ versus nitrate $(\mu M)$ plot. 


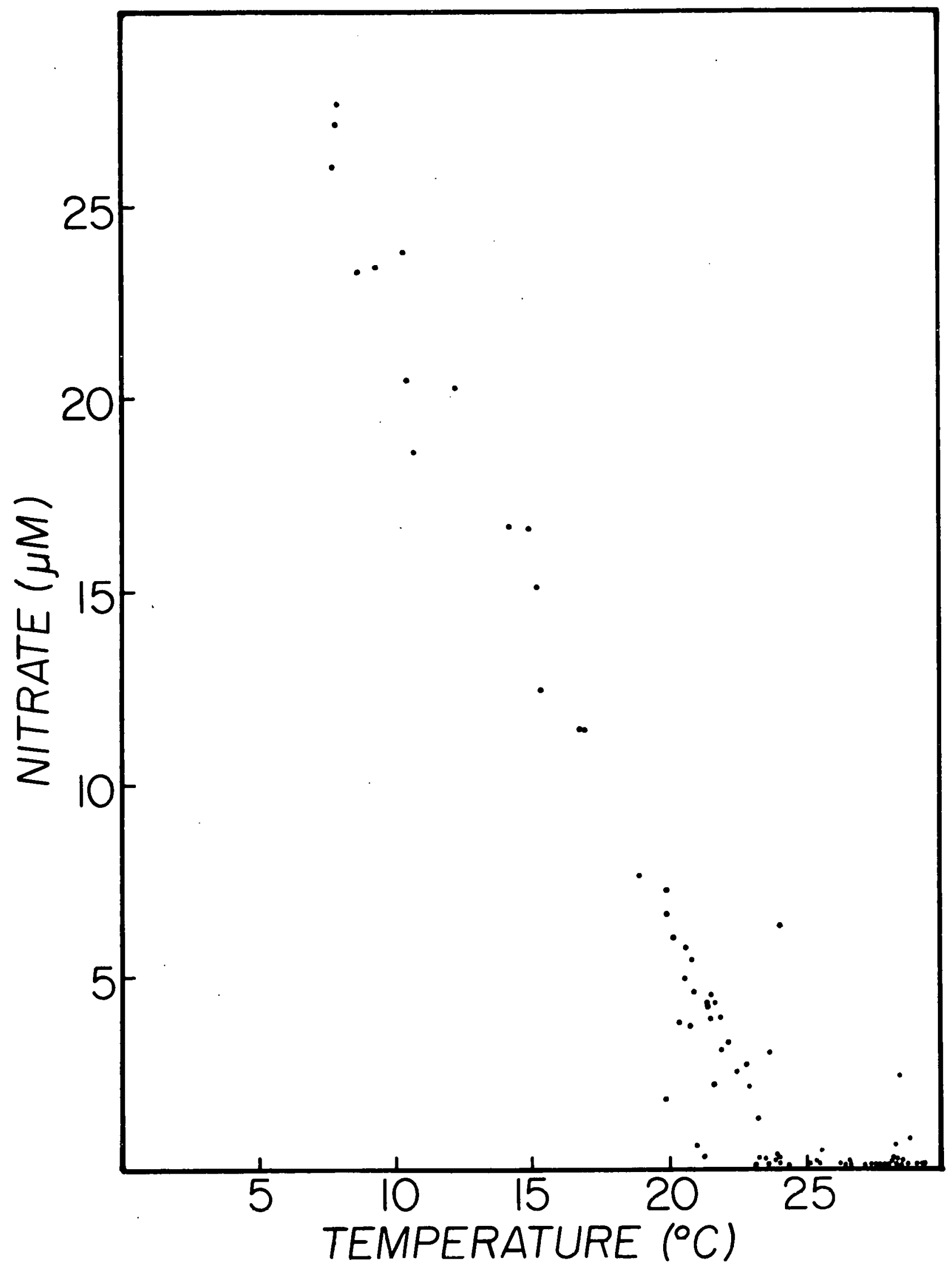

Fig. 38. Nitrate ( $\mathrm{\mu M})$ versus temperature $\left({ }^{\circ} \mathrm{C}\right)$ plot. 


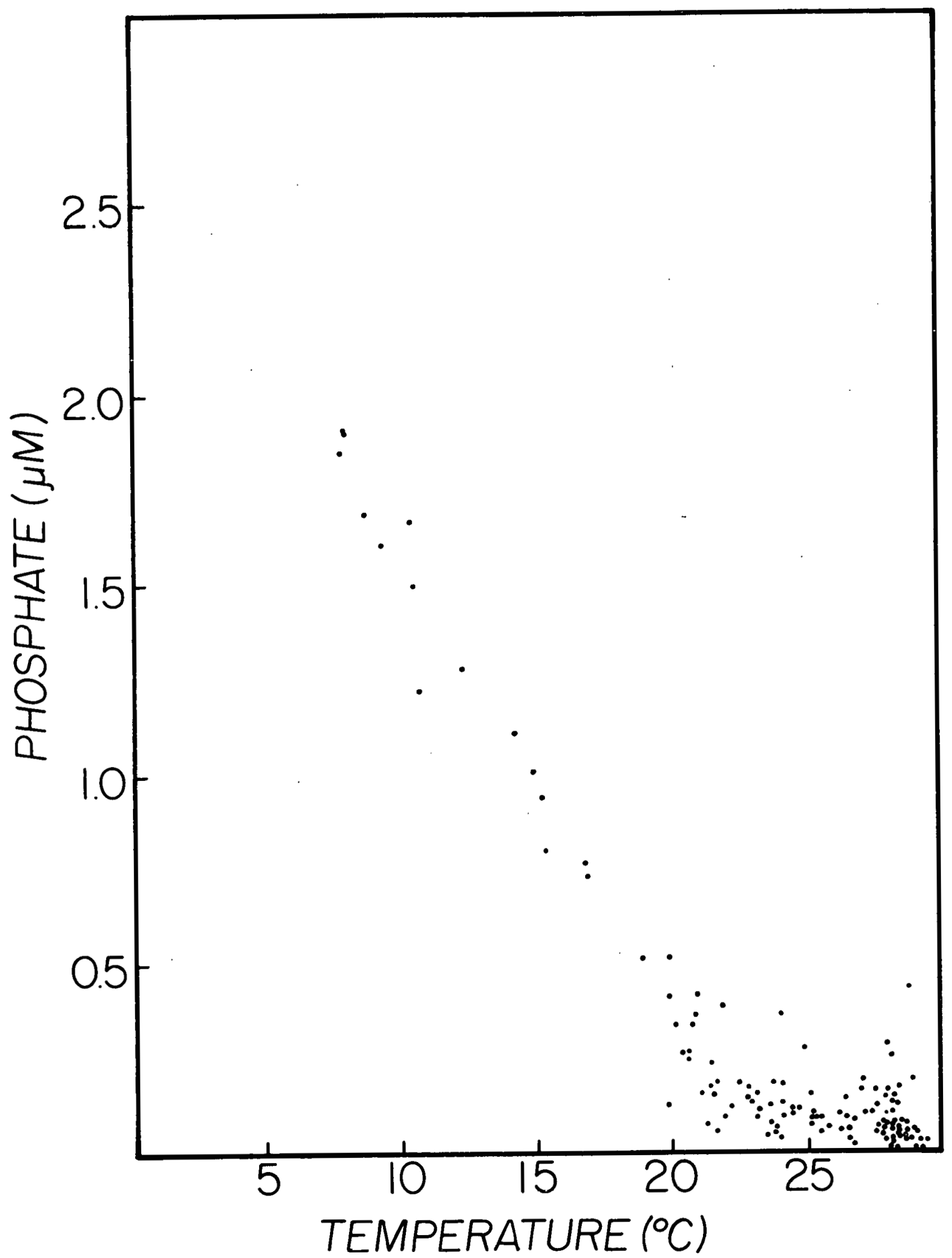

rig. 39. Phosphate $(\mu M)$ versus temperature $\left({ }^{0}(i)\right.$ plot. 


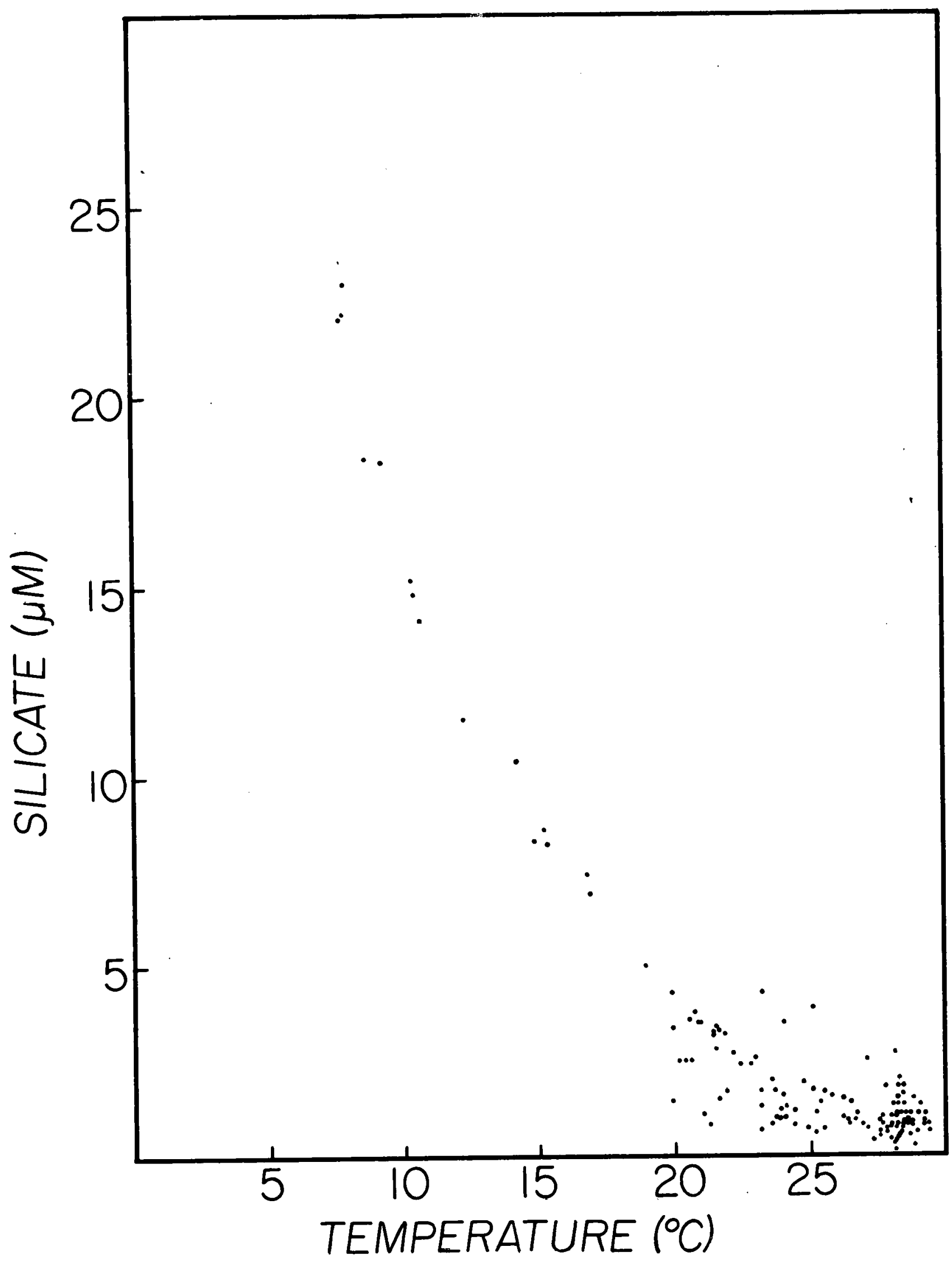

Fig. 40. Silicate $(\mu \mathrm{M})$ versus temperature $\left({ }^{\circ} \mathrm{C}\right)$ plot. 


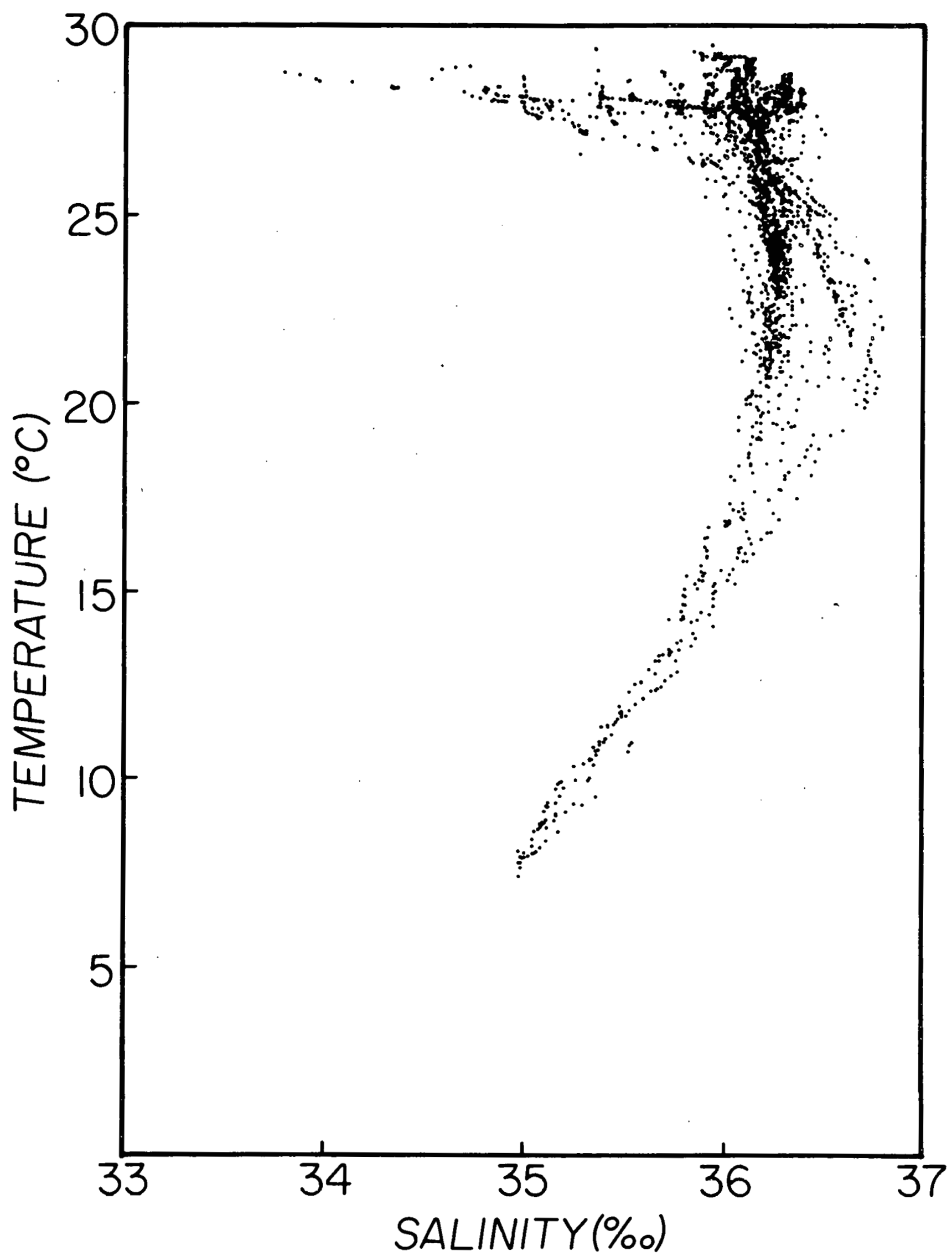

Fig. 41. Temperature $\left({ }^{\circ} \mathrm{C}\right)$ versus salinity $(\% / 00)$ plot, cruise CI-03-77. 


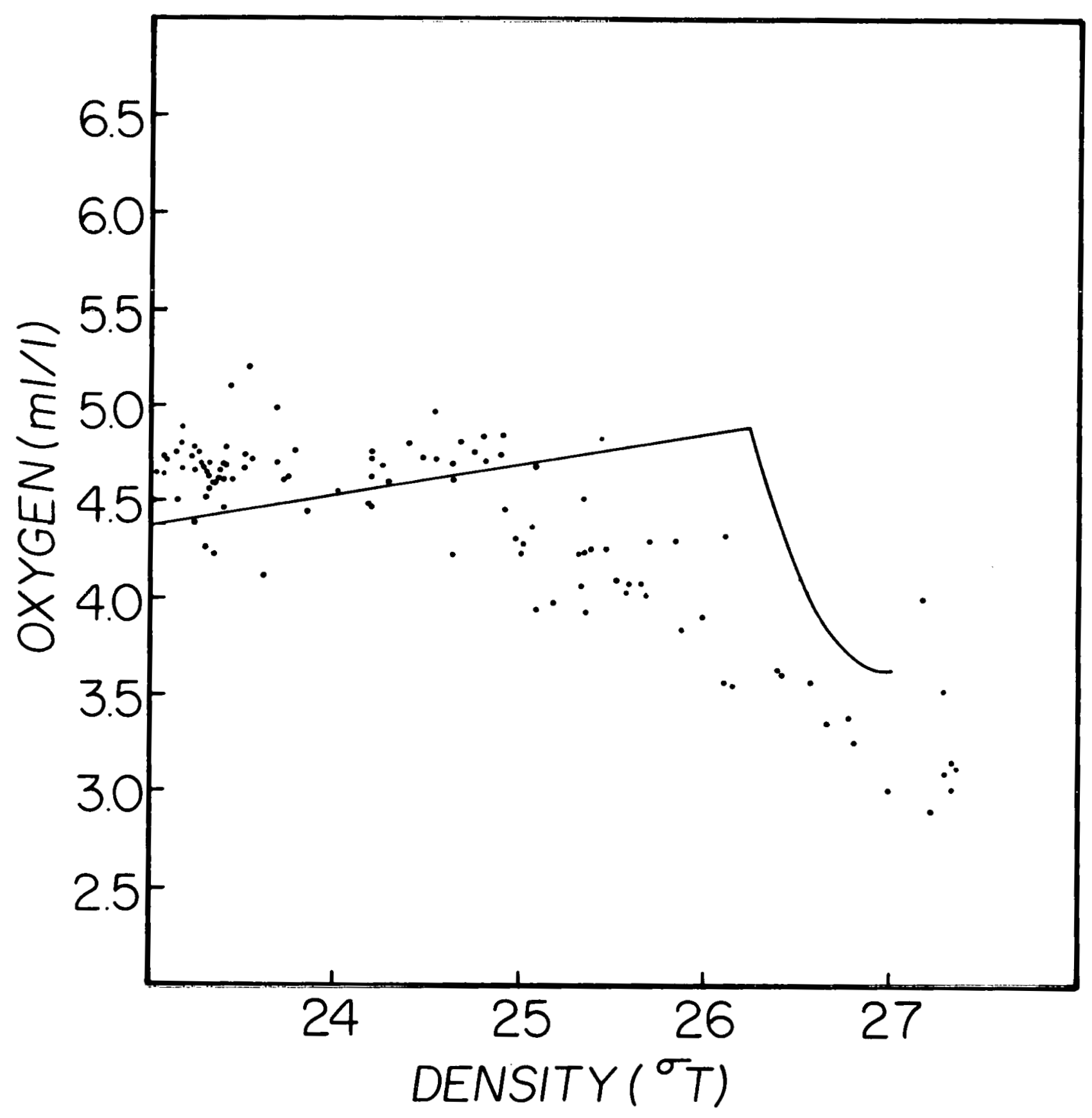

Fig. 42. Oxygen (m7/1) versus sigma-t plot, cruise CI-03-77. Concentration of oxygen in fully saturated Sargasso Sea type water (---). Curve for actual Sargasso Sea water $(-)$. 


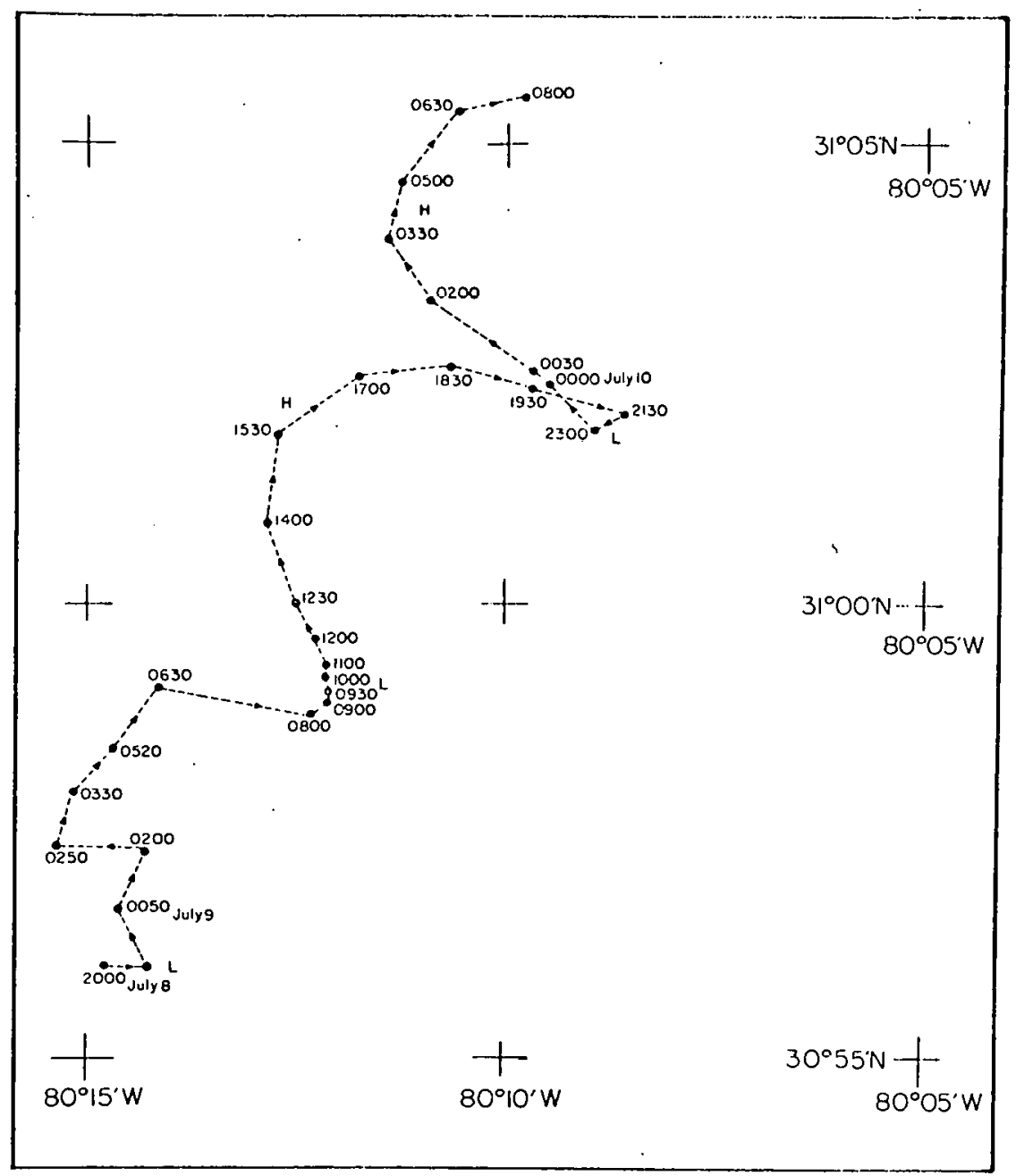

Fig. 43. Drogue tract. In 8 July 23.7 GMT, out 10 July 18.8 GMT, samples taken every 90 minutes. 

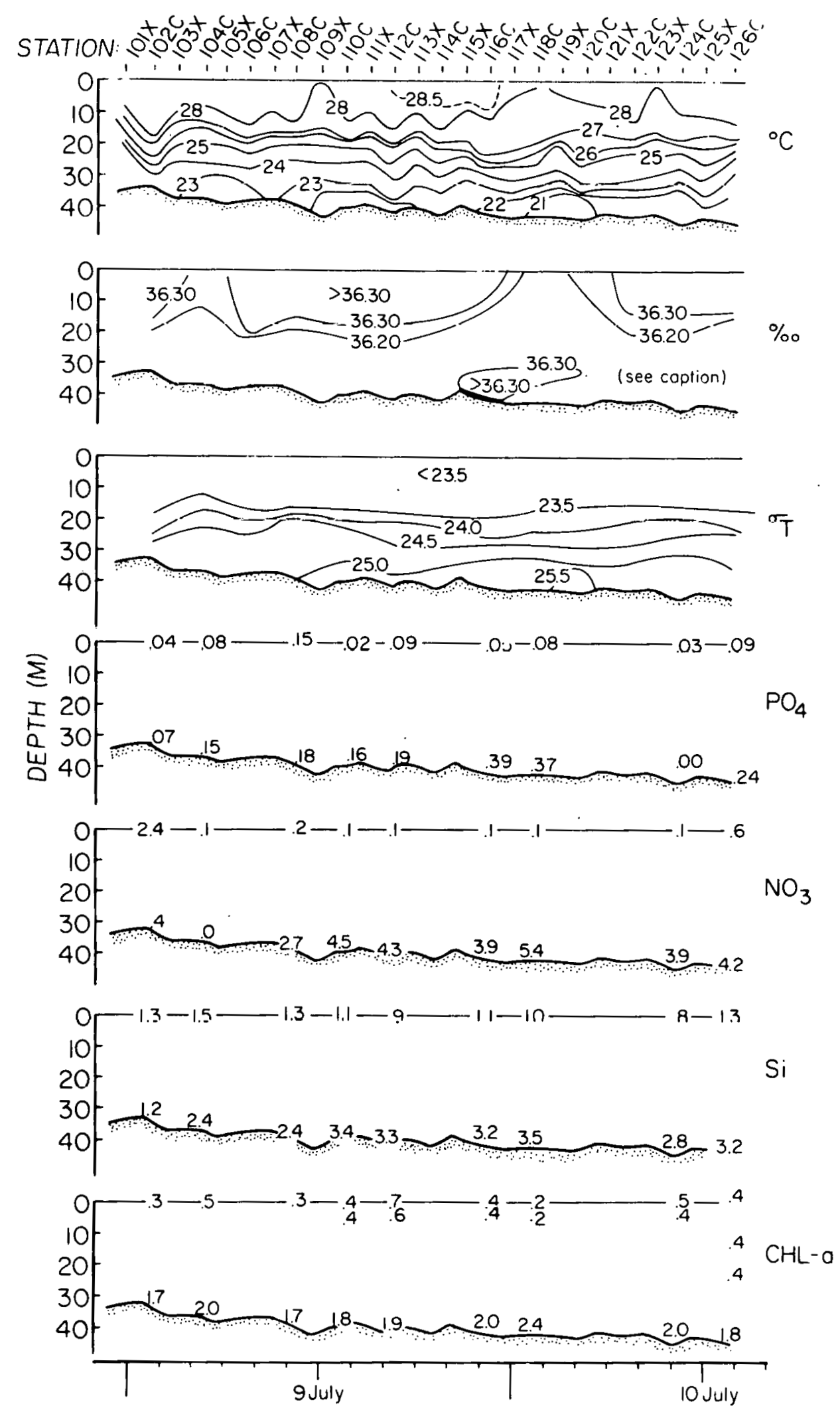

Fig. 44. Time series of parameters measured during the drogue drift. (stations $107 x-126 \mathrm{C}$ ). In the same area marked "see caption," salinities are not contoured because of extreme scatter. 
APPENDIX I :

Hydrographic Data 
STATION SUAMARY FOR ISELIN CRUISE CI-OJ

\begin{tabular}{|c|c|c|c|c|c|c|c|c|c|}
\hline UIS & STATION & & I TUDE & LOH & GITUDE & $Y R$ & MN & & $\begin{array}{r}\text { HOUR } \\
\text { GH }\end{array}$ \\
\hline 003 & $001 C U$ & 31 & $55.0 \mathrm{~N}$ & 80 & 12.04 & 77 & 7 & 4 & 18.8 \\
\hline 03 & $002 \mathrm{CU}$ & 31 & $53.0 \mathrm{~N}$ & 80 & 36.14 & 77 & 7 & 4 & 19.8 \\
\hline 003 & $003 \mathrm{CU}$ & 31 & $31.0 \mathrm{~N}$ & 80 & 30.04 & 77 & 7 & 1 & 20.8 \\
\hline 003 & $004 C U$ & 31 & $19.0 \mathrm{H}$ & 80 & 24.54 & 77 & 7 & 1 & 22.1 \\
\hline 003 & $005 \mathrm{CU}$ & 31 & $17.0 \mathrm{~K}$ & Bo & $18.5 \mathrm{~V}$ & 77 & 7 & 4 & 23.3 \\
\hline 003 & $006 \mathrm{CU}$ & 31 & $45.4 \mathrm{~N}$ & 80 & 12.40 & 77 & 7 & 5 & 1.0 \\
\hline 003 & $007 \mathrm{CU}$ & 31 & $43.5 \mathrm{~N}$ & 80 & 6.50 & 77 & $?$ & 5 & 2.3 \\
\hline 003 & OOBCU & 31 & $12.0 \mathrm{~N}$ & 80 & .84 & 77 & 7 & 5 & 4.1 \\
\hline 003 & $009 C U$ & 31 & $39.6 \mathrm{~N}$ & 79 & 54.64 & 77 & 7 & 5 & 5.0 \\
\hline 003 & $010 C U$ & 31 & $38.2 \mathrm{H}$ & 29 & 19.44 & 77 & 7 & 5 & 6.7 \\
\hline 003 & $011 C U$ & 31 & $36.0 \mathrm{~N}$ & 79 & 43.04 & 7 & 7 & 5 & 7.6 \\
\hline 003 & $2 \mathrm{CU}$ & 31 & $34.5 \mathrm{~N}$ & 79 & 37.54 & 77 & $?$ & 5 & 9.0 \\
\hline 003 & $013 \mathrm{CU}$ & 31 & $32.8 \mathrm{~N}$ & 79 & 31.50 & 77 & 7 & 5 & 10.2 \\
\hline 003 & $014 C$ & 31 & $21.6 \mathrm{~N}$ & 79 & 35.94 & 37 & 7 & 5 & 14.7 \\
\hline 003 & 150 & 31 & $25.0 \dot{H}$ & 79 & $47.7 \mathrm{~W}$ & 77 & 7 & 5 & 17.2 \\
\hline 003 & 160 & 31 & $28.6 \mathrm{H}$ & 79 & $59.8 \mathrm{H}$ & 77 & 7 & 5 & 18.6 \\
\hline 003 & 170 & 31 & $32.5 \mathrm{~N}$ & 80 & $11.5 \mathrm{~W}$ & 77 & 7 & 5 & 20.5 \\
\hline 003 & $8 C$ & 31 & $36.0 \mathrm{~N}$ & 80 & 23.50 & 77 & 7 & 5 & 21.9 \\
\hline 003 & 9C & 31 & $39.5 \mathrm{~K}$ & 80 & $35.0 \mathrm{~V}$ & 77 & 7 & 5 & 23.3 \\
\hline 003 & 110 & 31 & $25.0 \mathrm{~N}$ & 80 & 41.94 & 77 & 7 & 6 & 1.5 \\
\hline 003 & c & 31 & $21.9 \mathrm{~N}$ & 80 & 32.94 & 77 & 7 & 6 & 3.0 \\
\hline 003 & $3 i$ & 31 & $18.5 \mathrm{~N}$ & 80 & 21.04 & 77 & 7 & 6 & 1.4 \\
\hline 003 & $24 C$ & 31 & $15.5 \mathrm{~N}$ & 80 & 9.04 & 77 & 7 & 6 & 5.9 \\
\hline 003 & $025 C$ & 31 & $12.5 \mathrm{~N}$ & 79 & 57.04 & 77 & 7 & 6 & 7.2 \\
\hline 003 & $26 C$ & 31 & $9.0 \mathrm{~N}$ & 79 & $45.0 \mathrm{~W}$ & 77 & 7 & 6 & 8.5 \\
\hline 003 & $7 c$ & 30 & $47.0 \mathrm{~N}$ & 9 & $52.6 \mathrm{H}$ & 77 & 7 & 6 & 13.0 \\
\hline 003 & & 30 & $49.0 \mathrm{~K}$ & 29 & 58.54 & 77 & 7 & $\delta$ & 16.6 \\
\hline 003 & $9 C$ & 30 & $51.0 \mathrm{~N}$ & 80 & $4.5 \mathrm{H}$ & 77 & 7 & 6 & 18.4 \\
\hline 003 & 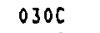 & 30 & $53.3 \mathrm{H}$ & 80 & 10.06 & 77 & 7 & 6 & 20.7 \\
\hline 003 & 316 & 30 & ON & 10 & 15.54 & 77 & 7 & 6 & 21.9 \\
\hline 003 & SU & 30 & 57 & 0 & 21.54 & 77 & 7 & 6 & 23.3 \\
\hline 00 & & 30 & $59.2 \mathrm{~K}$ & 0 & 27.34 & 77 & 7 & 7 & .2 \\
\hline 003 & 0 & 31 & $1.4 \mathrm{~N}$ & 0 & 3 & 77 & 7 & 7 & 1.8 \\
\hline 003 & 0 & 31 & $3.5 \mathrm{H}$ & 0 & 38.84 & 77 & 7 & 7 & 2.8 \\
\hline 003 & 0 & 31 & $5.5 \mathrm{H}$ & 0 & 14.54 & 77 & 7 & 7 & 4.2 \\
\hline 003 & & 31 & $7.4 \mathrm{~K}$ & 80 & $50.0 \mathrm{~V}$ & 77 & 7 & 7 & 5.3 \\
\hline 003 & $03 B C$ & 30 & $41.5 \mathrm{~N}$ & 80 & 58.54 & 77 & 7 & 7 & 9.0 \\
\hline 003 & $040 C$ & 30 & $15.0 \mathrm{~K}$ & 81 & 6.54 & 77 & 7 & 7 & 11.8 \\
\hline 003 & $041 C$ & 30 & $15.2 \mathrm{H}$ & 1 & .40 & 77 & 7 & 7 & 13.2 \\
\hline 003 & $042 C$ & 30 & $15.0 \mathrm{~N}$ & 0 & 54.10 & 77 & $?$ & 7 & 14.2 \\
\hline 003 & & 30 & 15 & 0 & 47.91 & 77 & 7 & 7 & 15. \\
\hline & & 30 & & 80 & 41.74 & 77 & 7 & 7 & 16.8 \\
\hline 003 & 0456 & 30 & 15. & 80 & $35.0 \mathrm{~W}$ & 77 & 7 & 7 & 19.8 \\
\hline 003 & $0\{d c$ & 30 & $15.0 \mathrm{H}$ & 80 & 29.04 & 77 & 7 & 7 & 21.0 \\
\hline 003 & $047 \mathrm{C}$ & 30 & $15.0 \mathrm{~K}$ & 80 & 23.04 & 77 & 7 & 7 & 22.5 \\
\hline 003 & $048 C$ & 30 & $15.0 \mathrm{~N}$ & 80 & $16.5 \mathrm{~d}$ & 7 & $?$ & 7 & 23.8 \\
\hline $00 \mathrm{~J}$ & 0496 & 30 & $14.9 N$ & 80 & 10.24 & 77 & 7 & $\theta$ & 1.1 \\
\hline
\end{tabular}

ISELIN CRUISE CI-OJ

CRUISE SIATIOH LATITUDE LONGITUDE YR NN DY HOUR WEFTH CONSEC

\begin{tabular}{|c|c|c|c|c|c|c|c|c|c|c|c|}
\hline 03 & $050 x$ & 30 & $14.9 \mathrm{~N}$ & 80 & 4.14 & 77 & 7 & 8 & 2.8 & 347 & 48 \\
\hline 03 & $051 x$ & 30 & $14.7 \mathrm{H}$ & 78 & $52.0 \mathrm{H}$ & 77 & 7 & 8 & 3.9 & 570 & 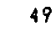 \\
\hline 03 & $052 x$ & 30 & $15.0 \mathrm{H}$ & 78 & 39.94 & 77 & 7 & 8 & 4.8 & 826 & \\
\hline 003 & $053 C$ & 30 & $14.5 \mathrm{H}$ & 79 & 27.64 & 77 & $?$ & 8 & 6.2 & 734 & \\
\hline 003 & $029 x$ & 30 & $51.0 \mathrm{H}$ & 80 & $4.5 v$ & 17 & 7 & 8 & 14.2 & 14 & \\
\hline 003 & $030 x$ & 30 & $53.3 \mathrm{H}$ & 80 & 10.04 & 77 & 7 & 8 & 14.7 & 40 & \\
\hline 003 & $031 x$ & 30 & $55.0 \mathrm{~K}$ & 80 & $15.5 \mathrm{~V}$ & 77 & 7 & 8 & 15.1 & 37 & \\
\hline 003 & $032 x$ & 30 & $57.0 \mathrm{H}$ & 80 & 21.56 & 77 & 7 & $a$ & 15.6 & 33 & \\
\hline 003 & $034 x$ & 31 & $1.5 \mathrm{H}$ & 80 & 32.44 & 77 & 7 & 8 & 16.5 & 29 & \\
\hline 003 & $035 x$ & 31 & $3.5 \mathrm{H}$ & 80 & 38.56 & 77 & 7 & 8 & 17.0 & 26 & \\
\hline 003 & $036 x$ & 31 & $5.7 \mathrm{H}$ & 80 & 14.5H & 77 & 7 & 8 & 17.5 & 21 & \\
\hline 003 & $037 x$ & 31 & $7.5 \mathrm{H}$ & 80 & $50.0 \mathrm{~W}$ & 77 & 7 & 8 & 17.8 & 20 & \\
\hline 003 & $001 x$ & 30 & $59.2 \mathrm{H}$ & 80 & 27.36 & 77 & 7 & 8 & 22.1 & 34 & \\
\hline 003 & $002 x$ & 31 & $1.1 \mathrm{H}$ & 80 & 33.16 & 77 & 7 & 8 & 22.8 & 28 & \\
\hline 003 & $101 x$ & 30 & $56.3 \mathrm{~N}$ & 80 & $14.9 v$ & 77 & $?$ & 8 & 23.7 & 34 & \\
\hline 003 & $102 \mathrm{C}$ & 30 & $36,2 \mathrm{H}$ & 80 & $14.4 \mathrm{~W}$ & 77 & 7 & 9 & 1.5 & 33 & \\
\hline 003 & $103 x$ & 30 & $56.2 \mathrm{~N}$ & 80 & 14.46 & 77 & 7 & 9 & 3.0 & 3) & \\
\hline 003 & $104 C$ & 30 & $56.7 \mathrm{H}$ & 80 & 14.94 & 77 & 7 & 9 & $4 . i$ & 37 & \\
\hline 003 & $105 x$ & 30 & $57.5 \mathrm{H}$ & 80 & 15.04 & 77 & 7 & 9 & 6.0 & 39 & \\
\hline 003 & $106 C$ & 30 & $57.5 \mathrm{k}$ & $B O$ & 15.10 & 77 & 7 & 9 & 7.5 & 38 & 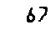 \\
\hline 003 & $107 x$ & 30 & 58.411 & 80 & 14.70 & 77 & 7 & 9 & 9.0 & 39 & 8 \\
\hline 203 & $10 a c$ & 30 & 59.11 & 80 & 14.04 & 77 & 7 & 9 & 10.4 & 39 & 99 \\
\hline 003 & $109 x$ & so & $58.0 \mathrm{H}$ & $B O$ & 12.58 & 77 & $?$ & 9 & 12.0 & 43 & \\
\hline 003 & $110 C$ & 30 & $59.3 \mathrm{H}$ & 0 & $12.5 \mathrm{~J}$ & 77 & 7 & 9 & 13.5 & 10 & \\
\hline 003 & $112 C$ & 30 & $58.1 \mathrm{~N}$ & 80 & 12.70 & $\eta$ & 7 & 9 & 16.5 & 12 & 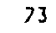 \\
\hline 003 & $113 x$ & 31 & $.9 \mathrm{H}$ & 80 & $13.4 \mathrm{~W}$ & 77 & 7 & 9 & 18.0 & 41 & 74 \\
\hline 003 & $114 C$ & 31 & $2.0 \mathrm{H}$ & 0 & 13.04 & 77 & 7 & 9 & 19.5 & 12 & 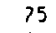 \\
\hline 003 & $115 x$ & jo & 50.111 & 80 & 12.04 & 7 & 7 & 9 & 21.0 & 10 & 8 \\
\hline 003 & 1160 & 31 & . SH & 60 & 12.54 & 77 & 7 & 9 & 22.5 & 43 & \\
\hline 003 & $117 x$ & 31 & $2.5 \mathrm{H}$ & 80 & 9.415 & 77 & 71 & 10 & 0.0 & 44 & \\
\hline 003 & $118 C$ & 31 & $2.2 \mathrm{H}$ & 80 & 8.74 & 77 & 71 & 10 & 1.5 & 13 & \\
\hline 003 & $119 x$ & 31 & $2.1 \mathrm{H}$ & 80 & 9.84 & 77 & 71 & 10 & 3.0 & 43 & 80 \\
\hline $0 \dot{3}$ & 1200 & 31 & $3.0 \mathrm{~N}$ & 80 & $10.0 \mathrm{H}$ & 77 & 71 & 10 & 4.5 & 14 & 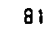 \\
\hline 003 & $121 x$ & 31 & $1.4 \mathrm{~N}$ & 80 & $10.7 \mathrm{~W}$ & 77 & 71 & 10 & 5.0 & 12 & 82 \\
\hline $\begin{array}{l}003 \\
003\end{array}$ & $\begin{array}{l}1220 \\
123 x\end{array}$ & $\begin{array}{l}31 \\
31\end{array}$ & $\begin{array}{l}3.3 \mathrm{H} \\
4.5 \mathrm{H}\end{array}$ & $\begin{array}{l}30 \\
80\end{array}$ & $\begin{array}{l}11.2 \mathrm{~W} \\
10.3 \mathrm{v}\end{array}$ & $\begin{array}{l}77 \\
77\end{array}$ & $\begin{array}{ll}7 & 1 \\
7 & 1\end{array}$ & $\begin{array}{l}10 \\
10\end{array}$ & $\begin{array}{l}7.5 \\
9.0\end{array}$ & $\begin{array}{l}43 \\
43\end{array}$ & 93 \\
\hline 003 & $121 C$ & 31 & $1.9 \mathrm{~N}$ & 80 & 11.00 & 77 & 7 & 10 & 10.5 & 46 & 85 \\
\hline 003 & $125 x$ & 31 & $3.7 \mathrm{~N}$ & 80 & 12.00 & 77 & 7 & 10 & 12.0 & 14 & 86 \\
\hline $00 \mathrm{~J}$ & $12 \mathrm{dCU}$ & 31 & $3.7 \mathrm{~N}$ & 80 & $12.0 \mathrm{H}$ & 77 & 7 & 10 & 13.8 & 45 & 8) \\
\hline 003 & OOAX & 31 & $18.0 \mathrm{H}$ & 80 & $18.3 \mathrm{H}$ & 77 & 7 & 10 & 15.5 & 36 & 88 \\
\hline 003 & $005 x$ & 31 & $28.0 \mathrm{~N}$ & 80 & 25.00 & 77 & 7 & 10 & 16.5 & 29 & 89 \\
\hline 003 & $00 c x$ & 31 & $38.7 \mathrm{~N}$ & 80 & $32.0 \mathrm{~V}$ & 77 & ? & 10 & 12.7 & 21 & \\
\hline & 000 & & 49 & 80 & $38 . ?$ & 77 & 71 & 10 & 18 & 7 & \\
\hline
\end{tabular}

Table 5. Station Summary for Isel in Cruise CI-03-77. 
Vertical profiles of salinity, temperature, sigma-t, D0, and nutrients

The symbols used in the following listings are defined as follows:

Header Data: $\quad$ Times are CMT (EDT + 4)

Latitude and Longitude are from Loran C

Weather Data: These data are taken from the ship's log.

Wind speed (knots)

Wind direction (degrees)

Air temperature $\left({ }^{\circ} \mathrm{C}\right)$

Weather (WMO code 4501)

Barometric pressure (mb)

Sea State (WMO code 3700)

Wave direction (degrees)

Cloud type (not given)

Cloud amount (not given)

Visibility code (not given)

Observations: $\quad Z=$ Depth in meters

$\mathrm{T}=$ Temperature in ${ }^{\circ} \mathrm{C}$

$S=$ Salinity in $\%$

$D=$ Density in sigma-t units

SVA $=$ Specific volume anomaly $\times 10^{5}$

$\mathrm{O}_{2}=$ Dissolved oxygen in $\mathrm{ml} / \mathrm{liter}$

$0_{2}=$ =xygen saturation in ml/liter

$\mathrm{A} 0 \mathrm{O}=$ Apparent oxygen utilization in $\mathrm{ml} / \mathrm{i}$ iter

$\mathrm{PO}_{4}=$ Phosphate concentration in $\mu \mathrm{mole} / \mathrm{liter}$

$\mathrm{NO}_{3}=$ Nitrate concentration in $\mu$ rinole/liter

$\mathrm{Si}^{3}=$ Silicate concentration in $\mu$ mole/liter 


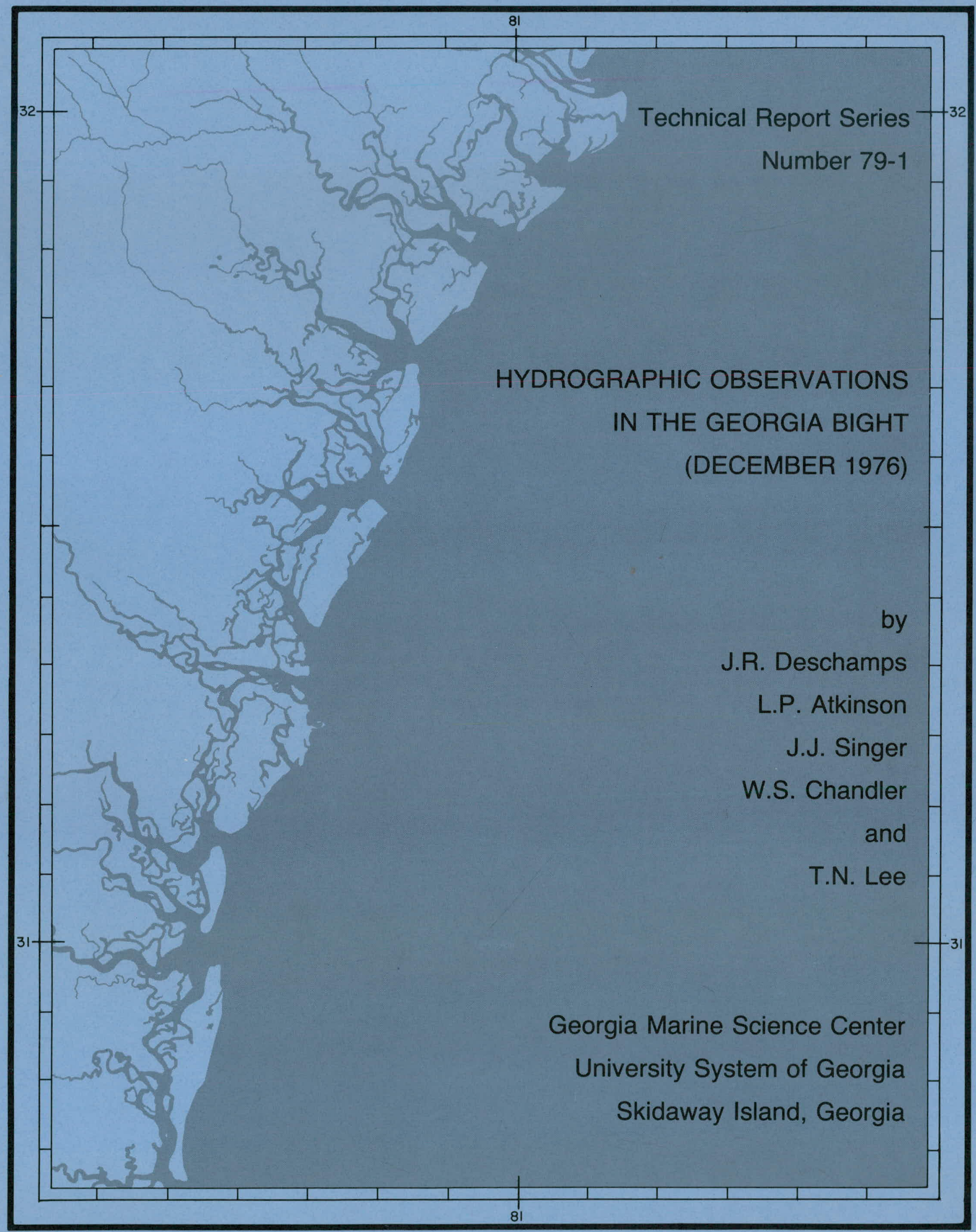


HYDROGRAPHIC OBSERVATIONS IN THE

GEORGIA BIGHT (DECEMBER 1976)

by

J. R. Deschamps, L. P. Atkinson,

J. J. Singer, W. S. Chandler, and T. N. Lee

Skidaway. Institute of Oceanography

P. 0. Box 13687

Savannah, Georgia 31406

January 1979

The Technical Report Series of the Georgia Marine Science Center is issued by the Georgia Sea Grant Program and the Marine Extension Service of the University of Georgia on Skidaway Island ( $P$. 0. Box 13687, Savannah, Georgia 31406). It was established to provide dissemination of technical information and progress reports resulting from marine studies and investigations mainly by staff and faculty of the University System of Georgia. In addition, it is intended for the presentation of techniques and methods, reduced data and general information of interest to industry, local, regional, and state governments and the public. Information contained in these reports is in the public domain. If this prepublication copy is cited, it should be cited as an unpublished manuscript. 
TABLE OF CONTENTS

page

List of Figures. ....................... . . . . . .

List of Tables..................

Acknowledgements ................. . 1

Abstract .................... 2

Introduction .................. 3

Methods. . . . . . . . . . . . . . . . 3

Chemical and Physical Procedures............ 3

XBT Data Acquisition and Processing.......... 5

CTD Data Acquisition. . . . . . . . . . . . 5

CTD Data Processing. . . . . . . . . . . . . . 5

CTD Calibration ................ . . . 5

CTD Error Analysis. . . . . . . . . . . . . 7

Meteorological Conditions. . . . . . . . . . . . 14

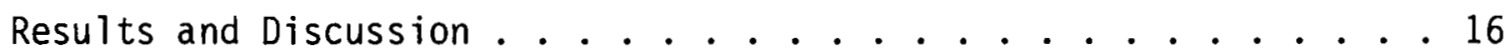

Surface Temperature Distributions .......... . 16

Subsurface Distributions. . . . . . . . . . 16

Savannah Section, 10-11 December 1976. . . . . . . 16

Savannah Section, 12 December 1976 . . . . . . . . . 16

Savannah Section, 14 December 1976 . . . . . . . . . 16

Brunswick Section, 11-12 December 1976 . . . . . . 16

Brunswick Section, 13 December 1976. . . . . . . . . . 11

Brunswick Section, 14-15 December 1976 . . . . . . 17

Onshore/Offshore Motions. . . . . . . . . . 17

Vertical Motions............... 17

Propagation Rate............... 18

T-S Relationship............... . 18

Nitrate-Phosphate-Silicate-Temperature Relationships. . . . . 19

0xygen-Density Correlation. . . . . . . . . . 19 
TABLE OF CONTENTS (cont'd)

page

Summary. . . . . . . . . . . . . . . . . . . . . . . 20

References ............................ 21

Figures (5-29) . . . . . . . . . . . . . . . . . 22

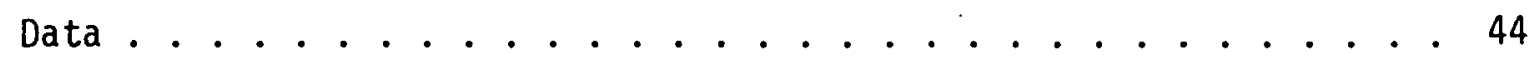




\section{LIST OF FIGURES}

page

1. Location of Stations on Cruise CI-12-76. . . . . . . . . 4

2. Mean offset for salinities at stations at which the maximum sampling depth was less than 50 m (—- mean offset; -....standard deviation............... 8

3. Regression analysis of salinity offset versus depth of sample. 9

4. Wind speed and direction recorded at Savannah Airport. , . . 15

5. Surface temperature distribution. The 9 December data are from a Coast Guard Airborn Radiation Thermometer flight. Dashed line is cruise track. . . . . . . . . . . . . 23

6. Savannah section temperature, salinity and signa-t, 10-11 December 1976. . . . . . . . . . . . . . . . 24

7. Savannah section nitrate, phosphate, silicate and dissolved oxygen, 10-11 December 1976. . . . . . . . . . 25

8. Savannah section temperature, salinity and sigma-t, 12 December 1976 . . . . . . . . . . . . . . 26

9. Savannah section nitrate, phosphate, silicate and oxygen, 12 December 1976 . . . . . . . . . . . . 27

10. Savannah section temperature, salinity and sigma-t, 14 December 1976 . . . . . . . . . . . . . . 28

11. Savannah section nitrate, phosphate, silicate and dissolved oxygen, 14 December 1976 ............. 29

12. Brunswick section temperature, salinity and sigma-t, 11-12 December 1976. . . . . . . . . . . . . . 30

13. Brunswick section nitrate, phosphate, silicate and dissolved oxygen, 11-12 December 1976............ 31

14. Brunswick section salinity and sigma-t, 13 December 1976 . . 32

15. Brunswick section nitrate, phosphate, silicate and dissolved oxygen, 13 December 1976............ 33

16. Brunswick section temperature, 14-15 December 1976 . . . . 34

17. Time series of the $21^{\circ} \mathrm{C}$ and $24^{\circ} \mathrm{C}$ isotherms (-10-12 December, -----12-13 December, -....-14-15 December) . . . . . . . 35 


\section{LIST OF FIGURES (cont'd)}

page

18. Temperature-salinity diagram, Cruise CI-12-76, December 1976.36

19. Savannah section, 10-11 December 1976. . . . . . . . . 37

20. Brunswick section, 10-11 December 1976 . . . . . . . . . 37

21. Savannah section, 12 December 1976 . . . . . . . . . . 38

22. Brunswick section, 13 December 1976. . . . . . . . . . 38

23. Savannali secliun, 14 Uecember $19 / 6$. . . . . . . . . . . . . . .

24. Nitrate vs. phosphate with line representing the $16: 1(\mathrm{~N}: \mathrm{P})$

ratio....................... . 40

25. Nitrate vs. temperature. . . . . . . . . . . . . 40

26. Phosphate vs. temperature................ . 41

27. Silicate vs. temperature .................... 41

28. Silicate vs. salinity. . . . . . . . . . . . . . 42

29. Oxygen vs. sigma-t with line representing normal Sargasso Sea water. ......................43 
page

Table 1. CTD/Data Flow. Shipboard Acquisition to NODC submission. ............... 6

Table 2. Cruise CI-12-76 Salinity Calibration Data . . . . . . 10

Table 3. Specifications for Plessey Model 9400 CTD System. . . . 7

Table 4. Broenkow's Salinity Equations ............ 11

Table 5. Flow Using Broenkow's Salinity Equations. . . . . . . 12

Table 6. Onshore/offshore velocities off Savannah and Brunswick. . 17

Table 7. Vertical velocities off Savannah and Brunswick. . ... 18

Table 8. Station summary for Iselin Cruise CI-12 ....... 45 


\section{Acknowledgements}

The authors thank Drs. J. 0. Blanton and D. W. Menzel for critically reading the manuscript.

The following people participated in the cruise and their help was appreciated: D. Gregory, R. Findley, 0. Guest, L. Quad, D. Huntley, A. Brinko, N. Chalker, P. Thompson, and M. Kelley. We would also like to thank the Captain and crew of the R/V ISELIN for their efforts. Dan McIntosh and Cindy Miller are thanked for graphics and typing, respectively.

Funding for this research and report is provided by the Department of Energy, under contract EY-76-S-09-0889 to L. P. Atkinson, and contract EY-76-S-05-51,63 to T. N. Lee.

This report is published as a part of the Georgia Marine Science Center's Technical Report series issued by the Georgia Sea Grant Program under NOAA Office of Sea Grant \#04-7-158-44126. 


\section{Abstract}

During a cruise in the Georgia Bight in December 1976 two onshore-offshore hydrographic sections were repeated three times over a four-day period. Temperature, salinity, dissolved oxygen, and nutrient $\left(\mathrm{NO}_{3}, \mathrm{PO}_{4}\right.$, and $\mathrm{SiO}_{2}$ ) data were collected.

The shelf waters were vertically well mixed with horizontal gradients typical of winter conditions. A Gulf Stream meander was observed near the shelf break with upwelling velocities as high as $2.8 \times 10^{-2} \mathrm{~cm} \mathrm{sec}^{-1}$ and an along stream propagation of $31 \mathrm{~cm} / \mathrm{sec}(26.8 \mathrm{~km} /$ day $)$. 


\section{Introduction}

This report contains chemical and physical data obtained during Georgia Bight cruise CI-12-76 (9-15 December 1976) aboard the $\mathrm{R} / \mathrm{V}$ COLUMBUS ISELIN. The investigation was part of a larger multi-institutional Department of Energy program to understand event scale, physical, chemical, and biological processes of the South Atlantic Bight, the continental shelf region from Cape Hatteras to Cape Canaveral. The study reported here is concentrated in the Georgia Bight near Savannah, Georgia. Specifically, the objective was to collect physical and chemical data such that 3-dimensional, quasi-synoptic measurements of .the interactions of shelf and Gulf Stream waters could be made. In addition, the hydrographic data were used to compare with moored instruments deployed by the University of Miami (Dr. Tom Lee). The hydrographic data sets are available from the National Oceanographic Data Center (NODC).

\section{Methods}

Two onshore-offshore hydrographic sections were repeated three times (Figure 1) between 10 and 14 December. Between stations a thermosalinograph was operated to obtain a detailed map of surface temperatures and salinities.

A typical hydrographic section consisted of alternate CTD (conductivity/temperature/depth) Rosette casts and XBT (expendable bathythermograph) casts at approximately 10 kilometer intervals. The Brunswick section (14-15 December) consisted exclusively of XBT stations 10 kilometers apart.

At CTD stations, a General Oceanics Model 1015 Mark 5 Rosette multi-bottle array with 1.7 liter Niskin Bottles and a Plessey Model 9400 CTD sensor system were used for water sampling. Niskin sampling depths were determined from the temperature structure obtained from the CTD. Samples were taken near the surface, just above or below the thermocline, at the bottom, and occasionally at other depths. Samples were analyzed for salinity, nitrate, phosphate, silicate, and dissolved oxygen.

\section{Chemical and Physical Procedures}

Salinity samples were analyzed conductometrically using a Plessey Model 6230N salinometer. Values obtained were used to calibrate the Plessey Model 9400 CTD system. A separate section of this report details the CTD calibration procedure. Temperature was determined with deep sea reversing thermometers, XBT's, and the CTD system.

Dissolved oxygen analyses were performed within 24 hours of collection using a modified Winkler procedure (Strickland and Parsons, 1965).

Nutrient samples were immediately frozen in polyethylene bottles and stored in the dark until thawed and analyzed ashore. Colorimetric 


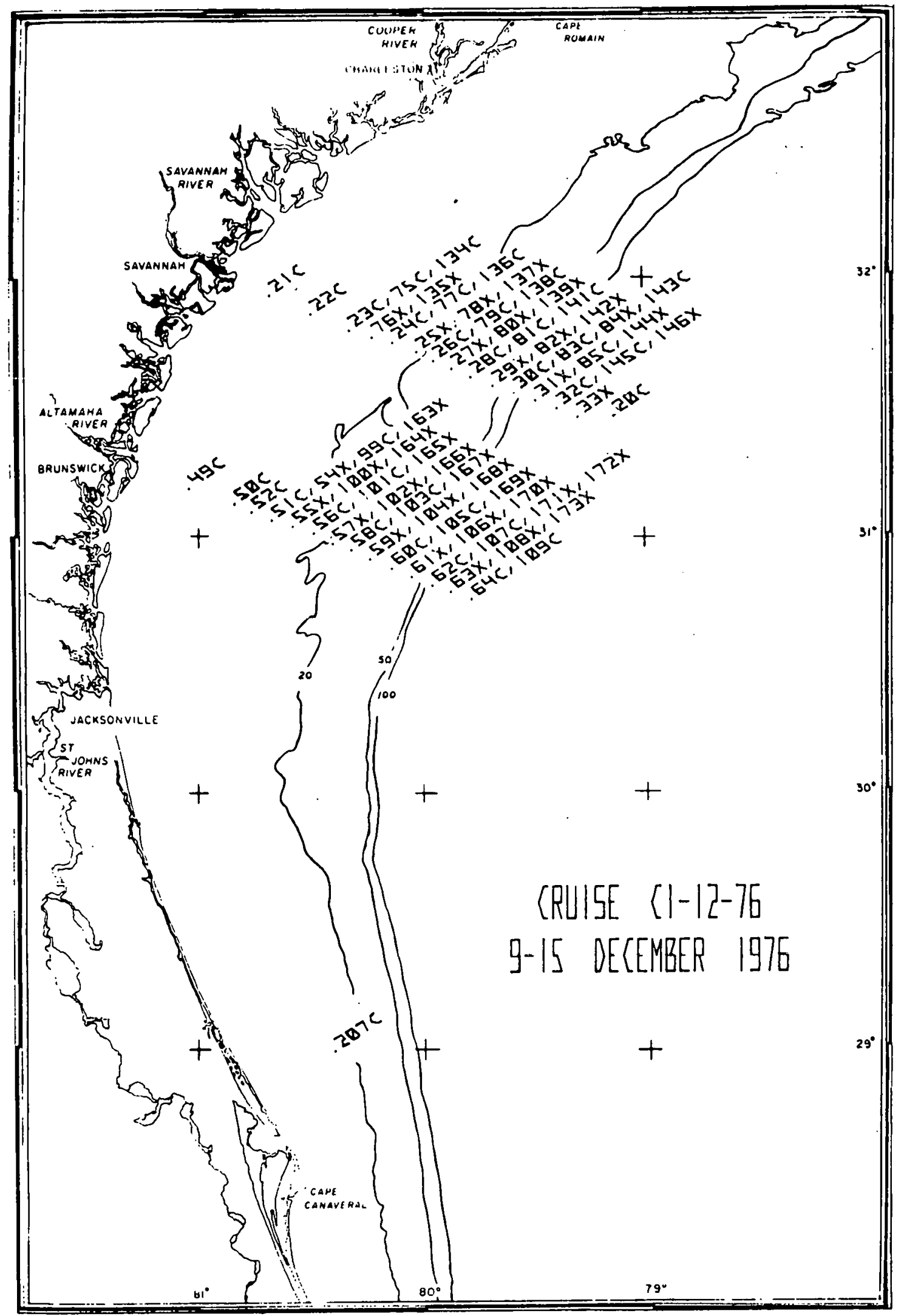

Figure 1. Location of Stations on Cruise CI-12-76. 
determinations of nutrient concentrations were made utilizing a Bausch and Lomb Spectronic 88 spectrophotometer with a sample sipper. Silicate was determined by the method of Mullin and Riley (1955) as modified by Strickland and Parsons (1965), phosphate by the method of Murphy and Riley (1962), and nitrate by the cadmium column reduction technique as modified by Gardner, et al. (1976).

\section{XBT Data Acquisition and Processing}

A Sippican Model LM3A handheld launcher and an MK2A-1 recorder were used for XBT casts. The temperature/depth plots were manually digitized and these data were placed in NODC format and merged with processed CTD data. Depths at which temperature is a whole or half degree are reported as are depths at which a significant mixed layer begins or ends.

\section{CTD Data Acquisition}

The CTD unit consists of a Plessey Model 9400 CTD sensor system with a Model 8400 digital data logger and Kennedy Model 1600 incremental magnetic tape recorder for data acquisition and storage. A redundant $X Y Y^{\prime}$ plot was made of all casts using a Hewlett-Packard Model $7046 X-Y-Y$ recorder which was calibrated with a precision 1OVDC source.

Digitized data were collected as the CTD sensor unit was lowered at $15 \mathrm{~m} / \mathrm{min}$ on a two conductor cable. All three parameters (C, T, and D) were sampled once each 229 milliseconds or every $6 \mathrm{~cm}$ at the $15 \mathrm{~m} / \mathrm{min}$ lowering rate. For primary calibration of temperature and salinity, a Niskin bottle equipped with paired protected deep sea reversing thermometers was tripped after a four minute equilibration period at the maximum sample depth in mixed layers. Other water samples were collected during ascent at depths selected after examination of the downcast temperature structure. The average time for stations less than 100 meters in depth was 25 minutes; for those greater than 100 meters, average time was 48 minutes, with a maximum of 65 minutes at station $20 \mathrm{C}$.

\section{CTD Data Processing}

CTD plots were logged and stored with their respective station sheets. All data recorded on magnetic tape were extracted and processed according to the flow scheme shown in Table 1. Computation and data manipulation were performed on a CDC Cyber 70/74 computer. All CTD data were acquired and processed according to the methods described by Chandler, et al. (1978).

\section{CTD Calibration}

The CTD system was calibrated only against bottle samples in mixed layers to insure that the sensors and the bottles were sampling 
Table 1. CTD/Data Flow. Shipboard Acquisition to NODC Submission.

\begin{tabular}{|c|c|c|}
\hline Data Source/Disposition & Program & Data File \\
\hline \multirow[t]{8}{*}{ Tape from Data Logger } & MAGREAD & $\begin{array}{c}\text { (Converts binary coded data to decimal) } \\
\text { BIRANG }\end{array}$ \\
\hline & CTDUNIT & $\begin{array}{l}\text { (Converts decimal units to engineering } \\
\text { units) }\end{array}$ \\
\hline & & LAG \\
\hline & LAGFILT & (Course filters and temperature lag) \\
\hline & & LATCH \\
\hline & DLATCH & $\begin{array}{l}\text { (Removes decreasing and repeated depths) } \\
\text { CTDATA }\end{array}$ \\
\hline & CTDAVE5 & $\begin{array}{l}\text { (One meter average data less than } 100 \\
\text { meters and } 5 \text { meter average data after } \\
100 \text { meters) }\end{array}$ \\
\hline & & AVE \\
\hline \multirow[t]{6}{*}{$\begin{array}{l}\text { Primary Calibration from } \\
\text { Bottle Casts }\end{array}$} & BROENK & $\begin{array}{c}\text { (Calculates salinity and sigma-t) } \\
\text { SGSA }\end{array}$ \\
\hline & NODCFO & (Converts to NODC format) \\
\hline & & $N O D C+H E A D$ \\
\hline & NUTMERG̈ & $\begin{array}{l}\text { (Merges NODC data with headers and } \\
\text { chemical data) }\end{array}$ \\
\hline & & FINAL (CTD) \\
\hline & STAMERG & (Merges CTD and XBT data) \\
\hline \multirow[t]{3}{*}{ Submission to NODC } & & CI012 \\
\hline & CEMLIST & $\begin{array}{l}\text { (Calculates specific volume anomally, } \\
\text { oxygen utilization, etc.) }\end{array}$ \\
\hline & & TECHNICAL REPORT \\
\hline
\end{tabular}


the same water. However, since a mixed layer was not always observed, comparisons could not be made at every station. The resulting mean offset, $+0.020^{\circ} / 00$ (Figure 2) was applied to all stations at which the maximum sampling depth was less than $50 \mathrm{~m}$. At depths greater than $50 \mathrm{~m}$, it was found that the effects of pressure could not be neglected. For these stations a regression analys is was performed (Figure 3 ) and an expression ( $S=S_{0}+0.023-1.57 \mathrm{x}$ $10^{-4} D$ where $S$ is the corrected salinity, $S_{0}$ is the calculated salinity without a calibration offset and $D$ is the depth of the sample) was obtained. This expression was applied to generate corrected salinities at all CTD stations at which the maximum depth was greater than $50 \mathrm{~m}$.

After the entire data set was treated with the derived offset equation, $+0.10 \%$ was added to the salinities from casts $49 \mathrm{C}$, $64 \mathrm{C}$, and $99 \mathrm{C}$. It is thought that powering up operations may be the cause of these higher offsets as 2 of the 3 problem casts (49C and 99C) were at the beginning of sections. The calibration data used to generate both the original offset and the subsequent expression for the depth effect are listed in Table 2. (Station numbers are discontinuous since thermosalinograph stations were established at intervals between hydrographic sections). Calibration data for stations $49 \mathrm{C}, 64 \mathrm{C}$, and $99 \mathrm{C}$ were rejected in establishing the original offset equations.

No depth offset was necessary, and no temperature offset was applied since the CTD temperature sensor agreed with protected reversing thermometers within the range of accuracy $\left( \pm 0.02^{\circ} \mathrm{C}\right)$.

\section{CTD Error Analysis}

The Plessey Model 9400 CTD system has the following rated accuracy, resolution, and time constants (Table 3 ).

Table 3. Specifications for Plessey Model 9400 CTD System.

\begin{tabular}{lrrr} 
& Conductivity & Temperature & Depth \\
\hline Accuracy & $\pm 0.03 \mathrm{mmho} / \mathrm{cm}$ & $\pm 0.02^{\circ} \mathrm{C}$ & $\pm 1.5 \mathrm{~m}$ \\
Resolution & $0.0001 \mathrm{mmho} / \mathrm{cm}$ & $0.0001^{\circ} \mathrm{C}$ & $0.0012 \mathrm{~m}$ \\
Time Constant & $0.1 \mathrm{sec}$ & $0.35 \mathrm{sec}$ & $0.1 \mathrm{sec}$ \\
\hline
\end{tabular}

Since salinity is not measured directly, it must be calculated from the above parameters, resulting in the composite errors of the $C, T$, and $D$ sensors and the salinity equation.

By varying "real" C, T, and D by the rated sensor accuracies in the salinity equation (Tables 4 and 5 ), the maximum error 


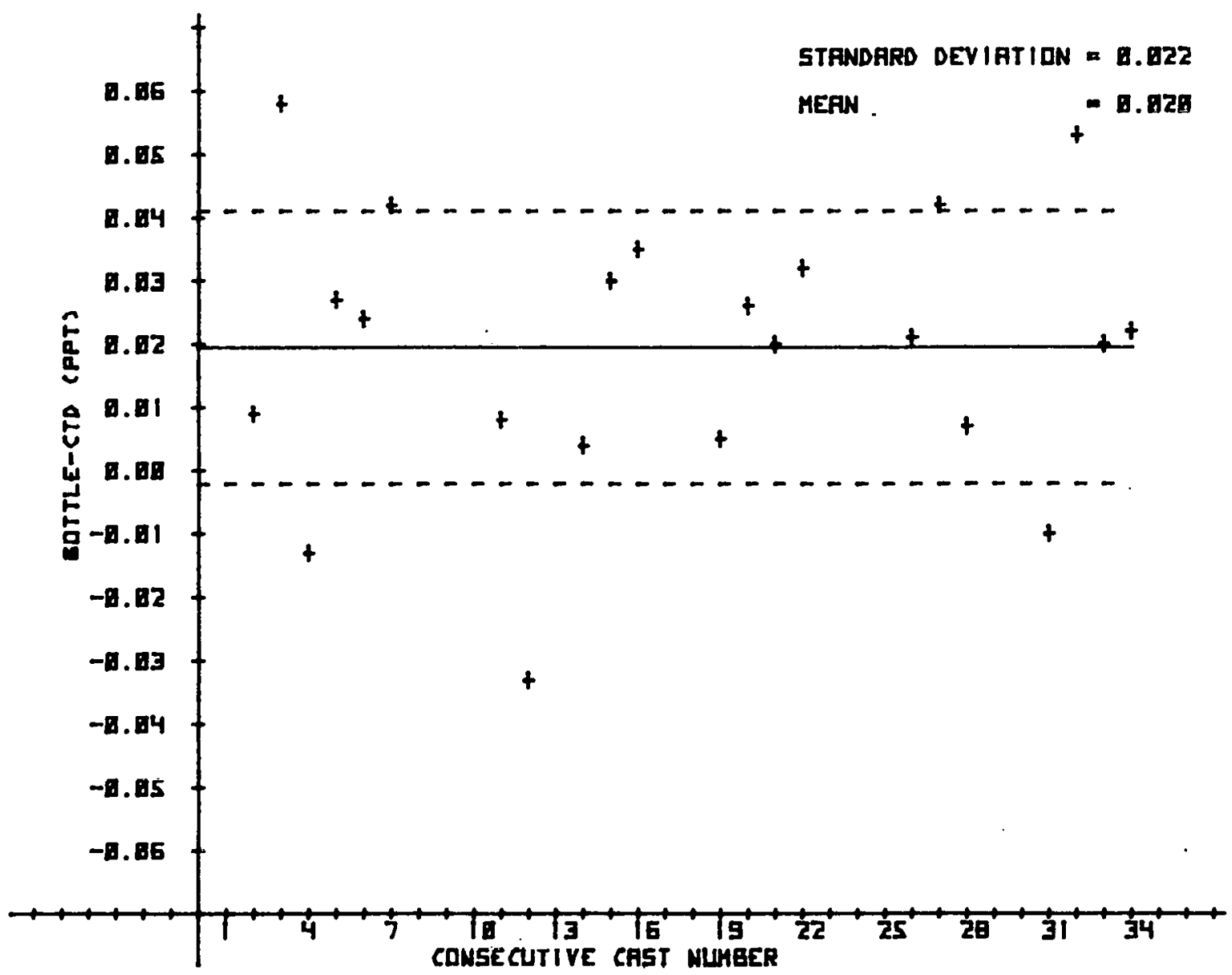

Figure 2. Mean offset for salinities at stations at which the maximum sampling depth was less than $50 \mathrm{~m}$ (— mean offset;-----standard deviation). 


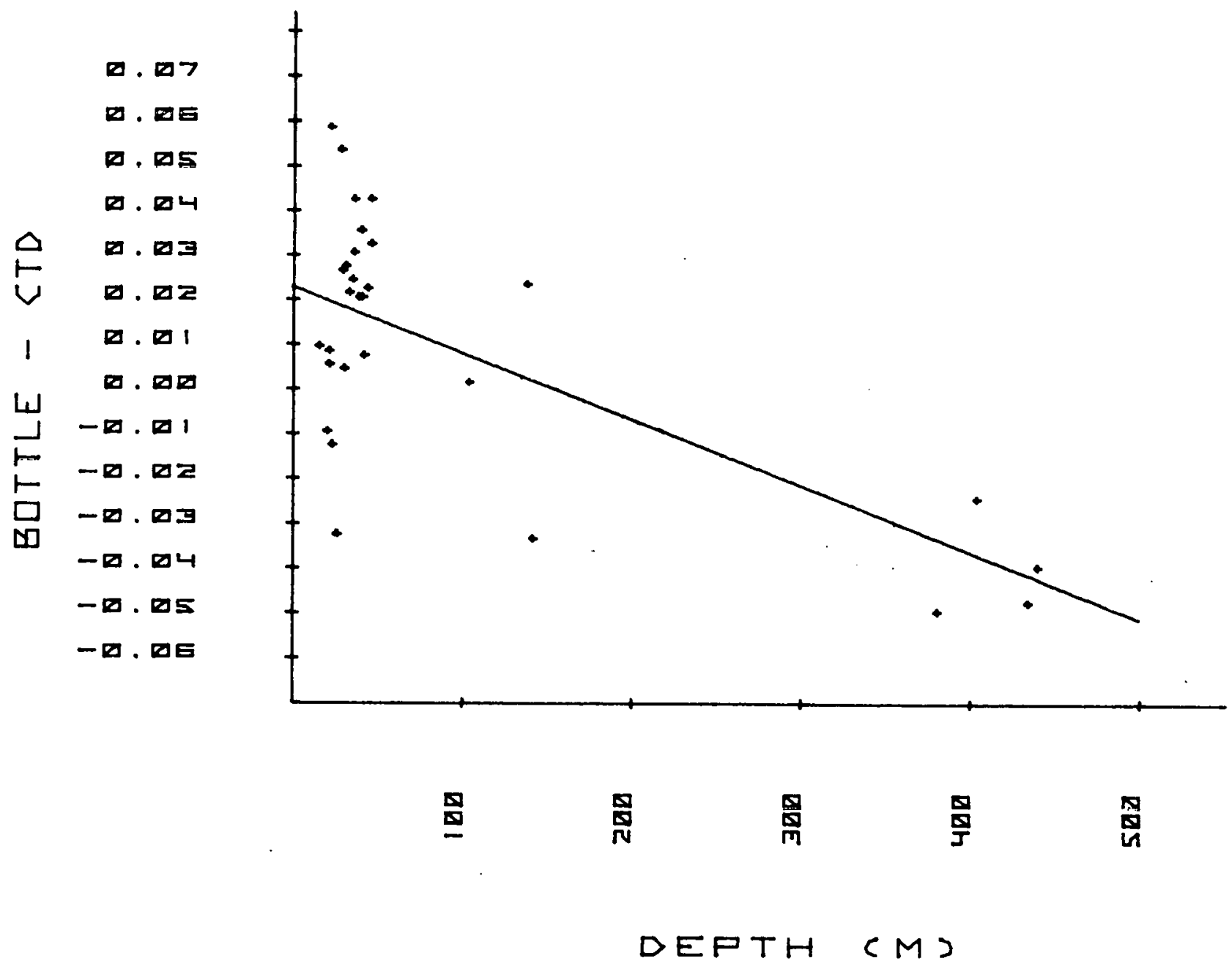

Figure 3. Regression analysis of salinity offset versus depth of sample. 
Table 2. Cruise CI-12-76 Salinity Calibration Data.

\begin{tabular}{|c|c|c|c|c|c|}
\hline $\begin{array}{c}\text { Consecutive } \\
\text { Cast No. }\end{array}$ & $\begin{array}{l}\text { Station } \\
\text { No. }\end{array}$ & $\begin{array}{l}\text { Depth } \\
(\mathrm{m})\end{array}$ & $\begin{array}{c}\text { Bottle } \\
0 / 00\end{array}$ & CTD $\%$ & $\begin{array}{c}\text { Difference } \\
\text { Bottle-CTD }(\% / 00)\end{array}$ \\
\hline $\begin{array}{l}1 \\
2 \\
3 \\
4 \\
5\end{array}$ & $\begin{array}{l}20 C \\
21 C \\
22 C \\
23 C \\
24 C\end{array}$ & $\begin{array}{r}402 \\
13 \\
20 \\
21 \\
29\end{array}$ & $\begin{array}{l}35.163 \\
33.878 \\
35.020 \\
35.894 \\
36.103\end{array}$ & $\begin{array}{l}35.188 \\
33.869 \\
34.962 \\
35.907 \\
36.076\end{array}$ & $\begin{array}{r}-.025 \\
+.009 \\
+.058 \\
-.013 \\
+.027\end{array}$ \\
\hline $\begin{array}{r}6 \\
7 \\
8 \\
9 \\
11\end{array}$ & $\begin{array}{l}26 C \\
28 C \\
30 C \\
32 C \\
50 C\end{array}$ & $\begin{array}{r}38 \\
44 \\
136 \\
438 \\
19\end{array}$ & $\begin{array}{l}36.094 \\
36.129 \\
36.162 \\
34.969 \\
35.585\end{array}$ & $\begin{array}{l}36.070 \\
36.087 \\
36.139 \\
35.012 \\
35.577\end{array}$ & $\begin{array}{r}+.024 \\
+.042 \\
+.023 \\
-.043 \\
+.008\end{array}$ \\
\hline $\begin{array}{l}12 \\
14 \\
15 \\
16 \\
19\end{array}$ & $\begin{array}{l}51 C \\
56 C \\
58 C \\
60 C \\
75 C\end{array}$ & $\begin{array}{l}24 \\
28 \\
34 \\
38 \\
19\end{array}$ & $\begin{array}{l}35.878 \\
36.066 \\
36.109 \\
36.100 \\
35.672\end{array}$ & $\begin{array}{l}35.911 \\
36.062 \\
36.079 \\
36.065 \\
35.667\end{array}$ & $\begin{array}{r}-.033 \\
+.004 \\
+.030 \\
+.035 \\
+.005\end{array}$ \\
\hline $\begin{array}{l}20 \\
21 \\
22 \\
23 \\
24\end{array}$ & $\begin{array}{l}77 C \\
79 C \\
81 C \\
83 C \\
85 C\end{array}$ & $\begin{array}{r}27 \\
39 \\
44 \\
140 \\
379\end{array}$ & $\begin{array}{l}36.081 \\
36.107 \\
36.146 \\
36.123 \\
34.997\end{array}$ & $\begin{array}{l}36.055 \\
36.087 \\
36.114 \\
36.157 \\
35.047\end{array}$ & $\begin{array}{l}+.026 \\
+.020 \\
+.032 \\
-.034 \\
-.050\end{array}$ \\
\hline $\begin{array}{l}26 \\
27 \\
28 \\
30 \\
31\end{array}$ & $\begin{array}{l}101 C \\
103 C \\
105 C \\
109 C \\
134 C\end{array}$ & $\begin{array}{r}31 \\
34 \\
40 \\
432 \\
18\end{array}$ & $\begin{array}{l}36.048 \\
36.098 \\
36.076 \\
34.995 \\
35.675\end{array}$ & $\begin{array}{l}36.027 \\
36.056 \\
36.069 \\
35.043 \\
35.685\end{array}$ & $\begin{array}{r}+.021 \\
+.042 \\
+.007 \\
-.048 \\
-.010\end{array}$ \\
\hline $\begin{array}{l}32 \\
33 \\
34 \\
35\end{array}$ & $\begin{array}{l}136 C \\
138 C \\
141 C \\
143 C\end{array}$ & $\begin{array}{r}26 \\
37 \\
42 \\
102\end{array}$ & $\begin{array}{l}36.099 \\
36.096 \\
36.115 \\
36.096\end{array}$ & $\begin{array}{l}36.046 \\
36.076 \\
36.093 \\
36.097\end{array}$ & $\begin{array}{r}+.053 \\
+.020 \\
+.022 \\
-.001\end{array}$ \\
\hline
\end{tabular}


Table 4. Broenkow's Salinity Equations.

$$
\begin{aligned}
R_{Z}= & 1+.01\left\{\left(1.551-.0453 T+59 \times 10^{-5} T^{2}\right)\right. \\
& \left.+\frac{3}{4}(35-S)\left(.043-.0017 T+23 \times 10^{-6} T^{2}\right)\right\}\left\{1.037 \times 10^{-3} Z\right. \\
& \left.-32 \times 10^{-9} Z^{2}\right\} \\
A_{T}= & \left(676547+20131.5 T+99.89 T^{2}-.1943 T^{3}-.00672 T^{4}\right) 10^{-6} \\
R_{T}= & \frac{C(S, T, Z)}{R_{Z} A_{T} 42.896} \\
\Delta_{15}= & R_{T}\left(R_{T}-1\right)(T-15)\left\{96.7-72 R_{T}+37.3 R_{T}^{2}\right. \\
& \left.-\left(.63+.21 R_{T}^{2}\right)(T-15)\right\} 10^{-5} \\
R_{15}= & R_{T}+\Delta 15 \\
S^{0} / 00= & .08996+28.2972 R_{15}+12.80832 R_{15}^{2}-10.67869 R_{15}^{3} \\
& +5.98624 R_{15}^{4}-1.32311 R_{15}^{5}
\end{aligned}
$$

where: $R=$ conductivity ratio

$$
\begin{aligned}
& Z=\text { depth (meters) } \\
& T=\text { temperature }\left({ }^{\circ} \mathrm{C}\right) \\
& \mathrm{C}=\text { measured conductivity (mmhos } / \mathrm{cm}) \\
& \mathrm{S}=\text { salinity }(\% / 00)
\end{aligned}
$$


Table 5. Flow Using Broenkow's Salinity Equations.

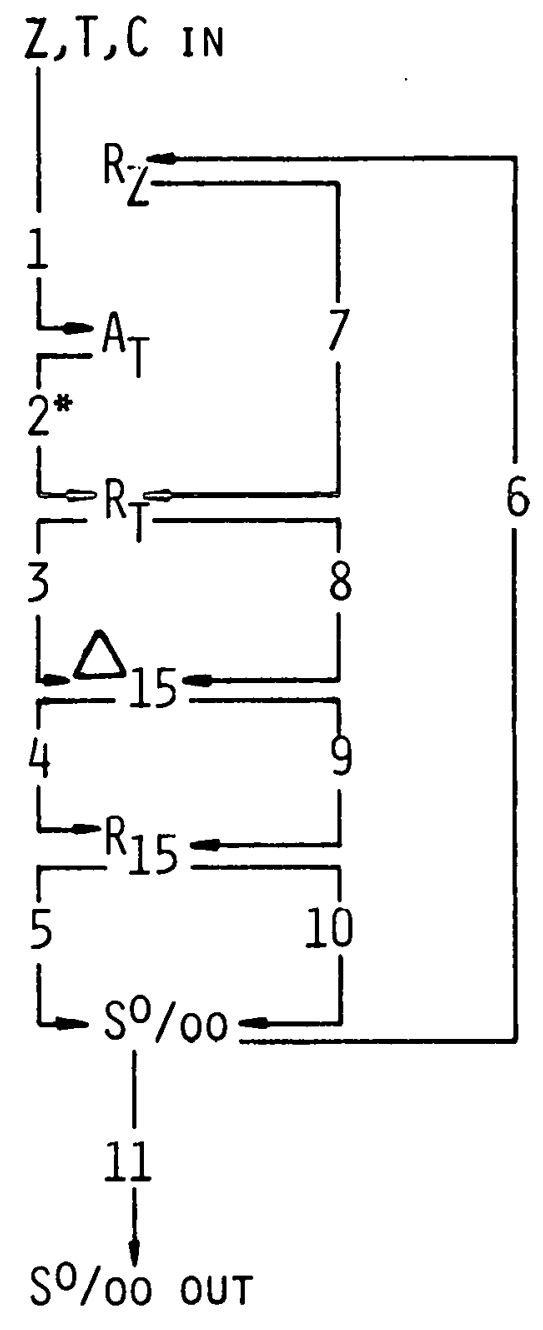

*wi thout the $R_{Z}$ term

$R_{Z}=$ pressure effect on conductivity

$A_{T}=$ temperature effect

$R_{T}=R(S, t, p)$ conductivity ratio

$\Delta_{15}=t_{15}$ correction (International Oceanographic

$R_{15}=R\left(S, 15^{\circ} \mathrm{C}, 0\right)$ 
attributable to each sensor can be determined. The composite maximum error is approximately $\pm 0.06^{\circ} / 00$ for "real" data sets. However, the standard deviation of all mixed layer samples taken for salinity calibration purposes implies greater accuracy, namely $\pm 0.02 \%$ after offset for this data set. We believe this value is a more realistic measure of the quality of the data set. 


\section{Meteorological Conditions}

Wind data from Savannah, Georgia are presented in Figure 4. These data are derived from the monthly summary for December 1976 (U.S. Department of Commerce, December 1976) and are plotted in GMT at three-hour intervals.

Winds were generally northeasterly from 9-15 December with a southerly interruption on 11 and 12 December. The strongest winds were observed on 13 December averaging 9.0 knots.

Air temperature at the Savannah station ranged from $9^{\circ} \mathrm{C}$ to $22^{\circ} \mathrm{C}$ during the cruise period. Additional meteorological data, collected by the ship's personnel, are presented with the data. 


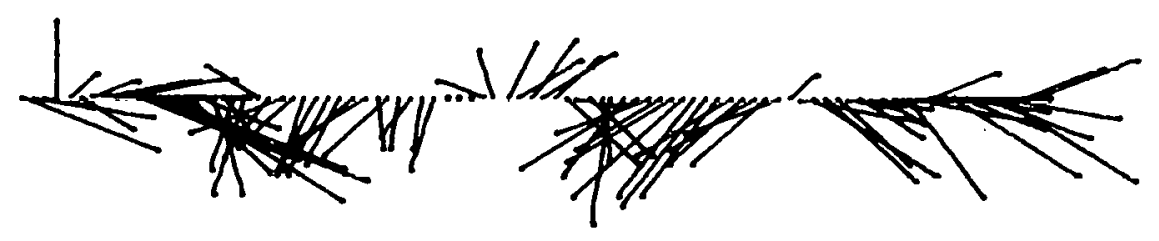

\begin{tabular}{|c|c|c|c|c|}
\hline 日 & 10 & 12 & 14 & 15 \\
\hline
\end{tabular}

Figure 4. Wind speed and direction recorded at Savannah Airport. 
The results of the synoptic mapping are shown in Figures 5-16 in both horizontal and vertical planes.

\section{Surface Temperature Distributions}

Included with the three surface temperature maps is the map obtained by the Coast Guard Airborne Radiation Thermometer flight on 9 December 1976 (Figure 5). Surface temperature over the time period increased towards the offshore with isotherms paralleling the coast. The Stream was, as determined by the $21-24^{\circ} \mathrm{C}$ isotherm, meandering with the maximum offshore position in the southern part of the area on 10-11 December, and, with time, migrating north until the 14th when the offshore meander was apparently north of the observation area. The ART flight data indicates that on 9 December the Stream was relatively far to the west. The strongest thermal gradients were observed on 12-13 December when the Stream was advancing again to the west.

\section{Subsurface Distributions}

Gulf Stream meandering has been related to upwelling at the shelf break with easterly movements of the stream related to lower temperatures at the shelf break (Atkinson, 1977). Thus the observed offshore meander should coincide with observed upwelling. The vertical sections (Figures 6-16) clearly show upwelling and downwelling associated with the meander. Following is a description of each section:

Savannah Section, 10-11 December 1976. (Figures 6-7) The shelf water was well mixed vertically with horizontal gradients. Offshore, upwelling can be seen in the isotherms positions as well as the distribution of nitrate and phosphate. Upwelling in this region is typical when the Gulf Stream is offshore of the shelf break.

Savannah Section, 12 December 1976. (Figures 8-9) The shelf waters were well mixed with horizontal gradients and once again upwelling can be seen in the temperature, nitrate and oxygen data. Elevated nutrient concentration at the shelf break indicate that upwelling reach the surface. The Gulf Stream was closer to shore than on 10-11 December.

Savannah Section, 14 December 1976. (Figures 10-11) The shelf waters were unstratified with high nitrate and phosphate waters at the shelf break indicative of recent upwelling. The Gulf Streall was further onshore $\left(24^{\circ} \mathrm{C}\right.$ isotherm).

Brunswick Section, 11-12 December 1976. (Figures 12-13) Typical winter conditions persisted on the shelf. The isotherms indicate some upwelling, but as the Savannah section on these dates, this feature is weak. Nitrate, phosphate, and silicate plots also indicate upwelling. 
Brunswick Section, 13 December 1976. (Figures 14-15) Typical winter conditions persisted over the shelf. The Gulf Stream moved onshore a distance of approximately $12 \mathrm{~km}$ and downwelling occurred along the slope to a depth of ca. $175 \mathrm{~m}$.

Brunswick Section, 14-15 December 1976. (Figure 16) There was little change from the profile made on 13 December. The Gulf Stream moved offshore (compare with $24^{\circ} \mathrm{C}$ isotherm for 13 December; Figure 14) and some upwelling was present as shown by the positions of the $20^{\circ} \mathrm{C}$ and $21^{\circ} \mathrm{C}$ isotherms. No salinity or nutrient data are available.

\section{Onshore/0ffshore Motions}

The onshore-offshore velocities were determined from the distance the $21^{\circ} \mathrm{C}$ and $24^{\circ} \mathrm{C}$ isotherms moved during the three observation periods. The isotherm positions are summarized in Figure 17 and the calculations are as follows:

Table 6. Onshore/offshore velocities off Savannah and Brunswick ( + offshore, - onshore).

\begin{tabular}{|c|c|c|c|c|c|}
\hline & & \multicolumn{2}{|c|}{$21^{\circ} \mathrm{C}$} & \multicolumn{2}{|c|}{$24^{\circ} \mathrm{C}$} \\
\hline & Grid & 1 & 3 & 1 & 2 \\
\hline \multirow[t]{3}{*}{ Savannah } & Distance $(\mathrm{km})$ & -15 & +11 & +4 & -17 \\
\hline & Elapsed Time $(h)$ & 40 & 42 & 39 & 29 \\
\hline & Velocity $\left(\mathrm{cm} \mathrm{sec}^{-1}\right)$ & -10.4 & +7.3 & +2.8 & -16.3 \\
\hline \multirow[t]{3}{*}{ Brunswick } & Distance $(\mathrm{km})$ & +3 & +3 & -6 & +7 \\
\hline & Elapsed Time $(h)$ & 33 & 42 & 33 & 44 \\
\hline & Vclocity $(\mathrm{cm} \mathrm{sec}-1)$ & +2.5 & +2.0 & -5.0 & 14.4 \\
\hline
\end{tabular}

The $24^{\circ} \mathrm{C}$ isotherm appears to be a better indicator of the meander motion. Onshore velocities were first observed off Brunswick between the first two grids and then off Savannah between the second and third grids.

\section{Vertical Motions}

Vertical motions were determined from the variation in the minimum depth of the $19^{\circ} \mathrm{C}$ isotherm. The calculation and results are given in Table 7 . 
Table 7. Vertical velocities off Savannah and Brunswick (+ down).

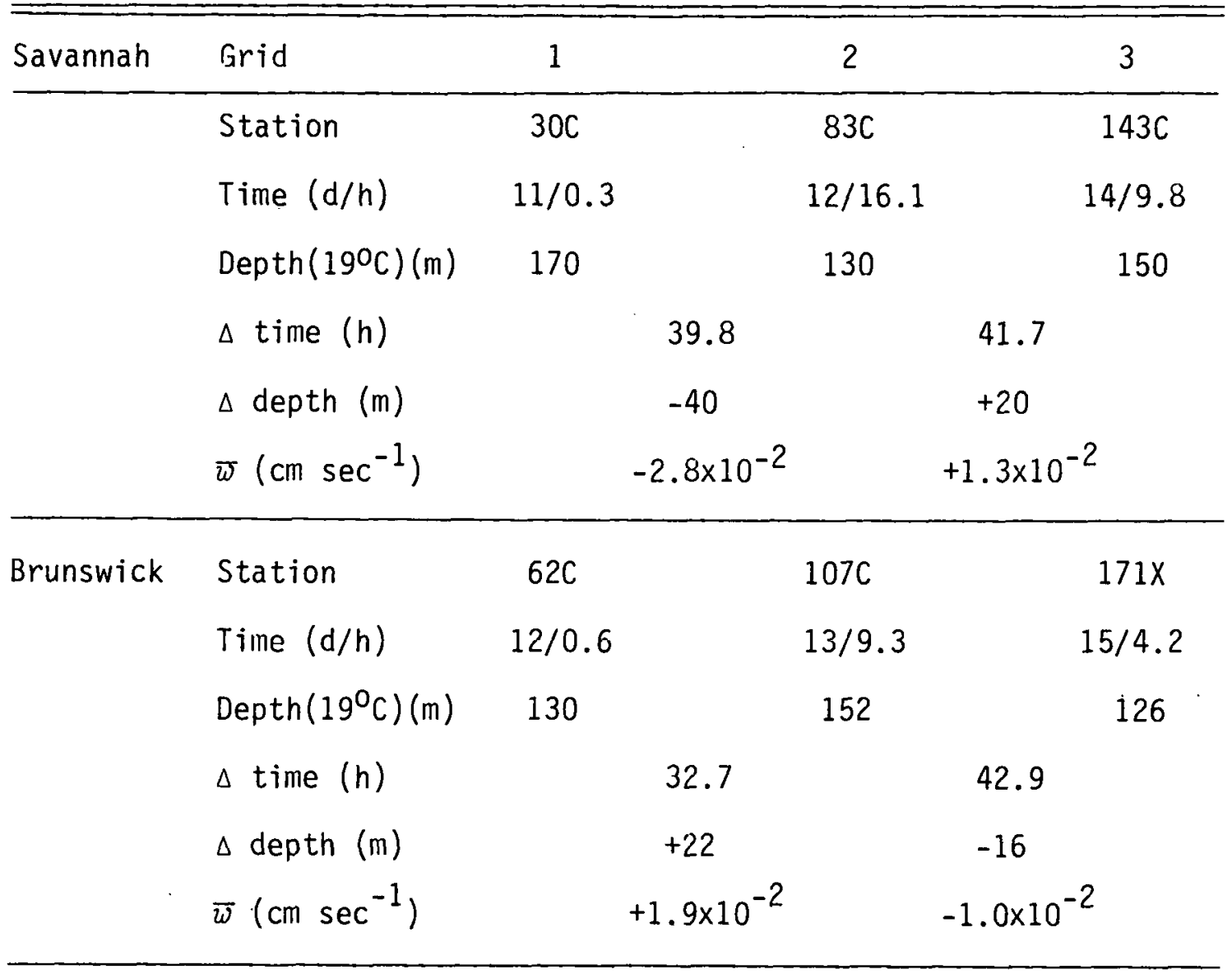

These velocities are typical of upwelling situations. Interestingly, the upwelling occurred first off Savannah leading the offshore motion.

Propagation Rate

The rate at which the meander moves downstream can be estimated from the surface isotherm positions. The amplitude of the meander was ca. $15 \mathrm{~km}$ and typical onshore/offshore velocities were $10 \mathrm{~cm}$ $\mathrm{sec}^{-1}$ thus the period is 3.4 days. The observed length is $93 \mathrm{~km}$ so the phase speed would be $31 \mathrm{~cm} \mathrm{sec}-1$ ( $0.6 \mathrm{knot})$. This rate is similar to the $39 \mathrm{~cm} \mathrm{sec}^{-1}$ observed by Legeckis (1975).

\section{T-S Relationship}

The T-S plot for all data is in Figure 18. The group of points at ca. $20^{\circ} \mathrm{C} / 34 \%$ are from Station 207 which is considerably south of the existing hydrogrid (see Figure 1).

Figures 19-23 are T-S plots for each individual section. They show the transition from shelf to Gulf Stream water in each of the onshore-offshore sections. At some deep stations (i.e., 54-62) mixing of shelf waters with Gulf Stream water is apparently active. 
Nitrate-Phosphate-Silicate-Temperature Relationships

Various relationships between nitrate, phosphate, silicate and temperature are useful to assess the quality of the data and to elucidate some of the chemical, biological, and physical processes.

For deeper waters the ratio of nitrate to phosphate is typically 16:1 and is derived from the decomposition of organic matter. All nitrate and phosphate data for this cruise appear in Figure 24 with a line representing the $16: 1 \mathrm{~N}: \mathrm{P}$ ratio.

At low nutrient concentrations, an excess of phosphate over nitrate is observed. Stations with excess phosphate are generally in shallow areas where any free nitrogen is released more quickly than nitrate, leading to an apparent excess of phosphate.

Temperature-nutrient plots (Figures 25-27) show the inverse relationship between temperature and nutrient concentration.

The scatter at low concentrations represents samples taken over the shelf with temperature decreasing towards shore.

A plot of silicate versus salinity is presented in Figure 28. Higher salinity and silicate concentrations are representative of Gulf Stream waters. Other values correspond to shelf waters.

\section{Oxygen-Density Correlation}

Figure 29 plots oxygen versus sigma-t. The curve is typical of normal Sargasso Sea water. Points above the curve are from surface Gulf Stream and shelf waters. Points below the curve with a sigma- $t$ of 25 to 26 are a Caribbean component of the Gulf Stream (Richards and Redfield, 1955). 
In summary, the following observations were made:

1. The shelf waters were well mixed with horizontal stratification, typical of winter conditions.

2. A meander was observed at the shelf break and passed through the area of this study.

3. The vertically induced component of velocity (upwelling) associated with this meander was as high as $2.8 \times 10^{-2} \mathrm{~cm} \mathrm{sec}^{-1}$.

4. The meander moved northward at a rate of $31 \mathrm{~cm} \mathrm{sec}^{-1}$, a velocity comparable to the $39 \mathrm{~cm} \mathrm{sec}^{-1}$ reported by Legeckis (1975). 
Atkinson, L. P. 1977. Modes of Gulf Stream intrusion into the South Atlantic Bight shelf waters. Geophysical Research Letters, 4(12): 583-586.

Chandler, W. S., L. P. Atkinson, J. J. Singer, P. G. 0'Malley, and C. V. Baker. 1978. A CTD System: Description, Operation, Data Acquisition and Processing. Georgia Marine Science Center Technical Report 78-7.

Gardner, W. S., D. S. Wynne, and W. M. Dunstan. 1976. Simplified procedure for the manual analysis of nitrate in sea water. Mar. Chem., 4: 393-396.

Lee, Thomas N. 1978. Measurement of Gulf Stream and wind induced shelf circulation in the South Atlantic Bight. A Progress Report submitted to U.S. Department of Energy, Contract EY-76-S-05-5163.

Legeckis, R. 1975. Application of synchronous meteorological satellite data to the study of time dependent sea surface temperature changes along the boundary of the Gulf Stream. Geophysical Research Letters, 2: 435-438.

Mullin, J. B. and J. P. Riley. 1955. The colorimetric determination of silicate with special reference to sea and natural waters. Anal. Chim. Acta, 12: 162-176.

Murphy, J. and J. P. Riley. 1962. Modified single solution method for the determination of phosphate in natural waters.

Ana1. Chim. Acta, 27: 31-36.

Richards, F. A. and A. C. Redfield. 1955. 0xygen-density relationships in the western North Atlantic. Deep-Sea Research, 2: 182-199.

Strickland, J. D. H. and T. R. Parsons. 1965. A manual of sea water analysis. Fish. Res. Bd. Canada, Bull. No. 125 (2nd ed.), Ottawa.

U. S. Department of Commerce, NOAA, eds. 1976. Local climatological data, monthly summary, Savannah, Georgia, December 1976. National Climatic Center, Asheville, North Carolina. 
FIGURES

$(5-29)$ 


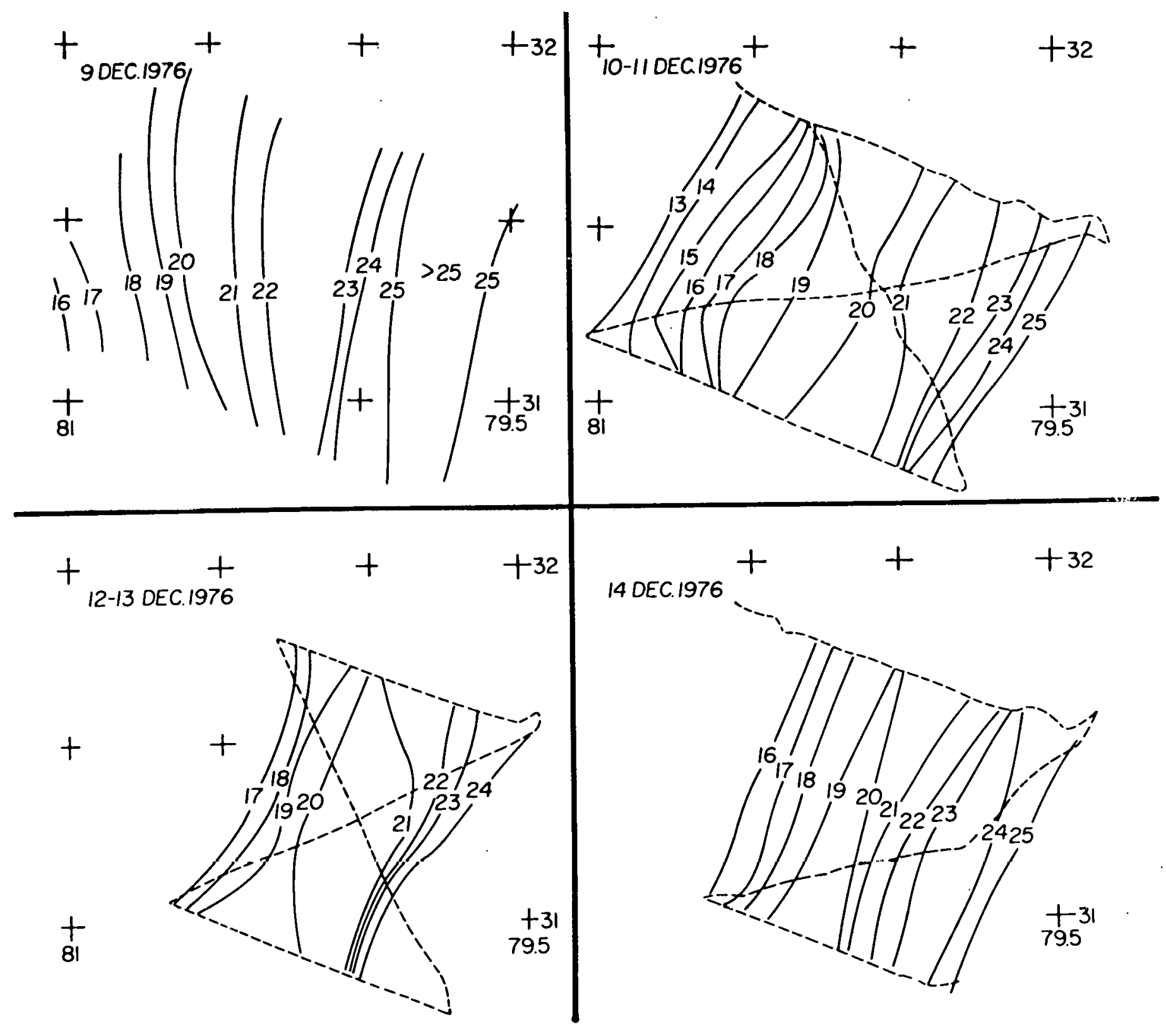

Figure 5. Surface temperature distribution. The 9 December data are from a Coast Guard Airborn Radiation Thermometer flight. Dashed line is cruise track. 

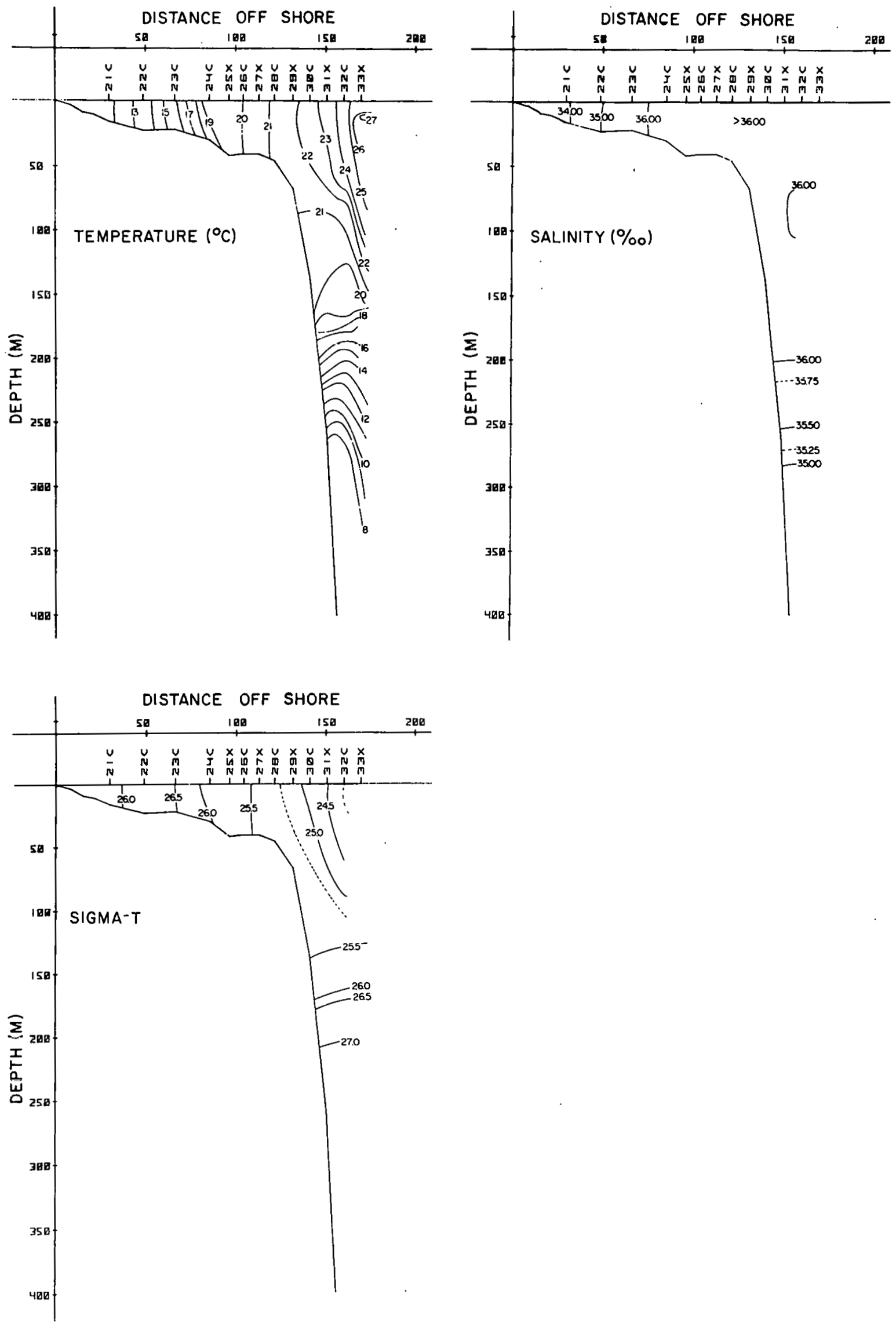

Figure 6. Savannah section temperature, salinity and sigma-t, 10-11 December. 

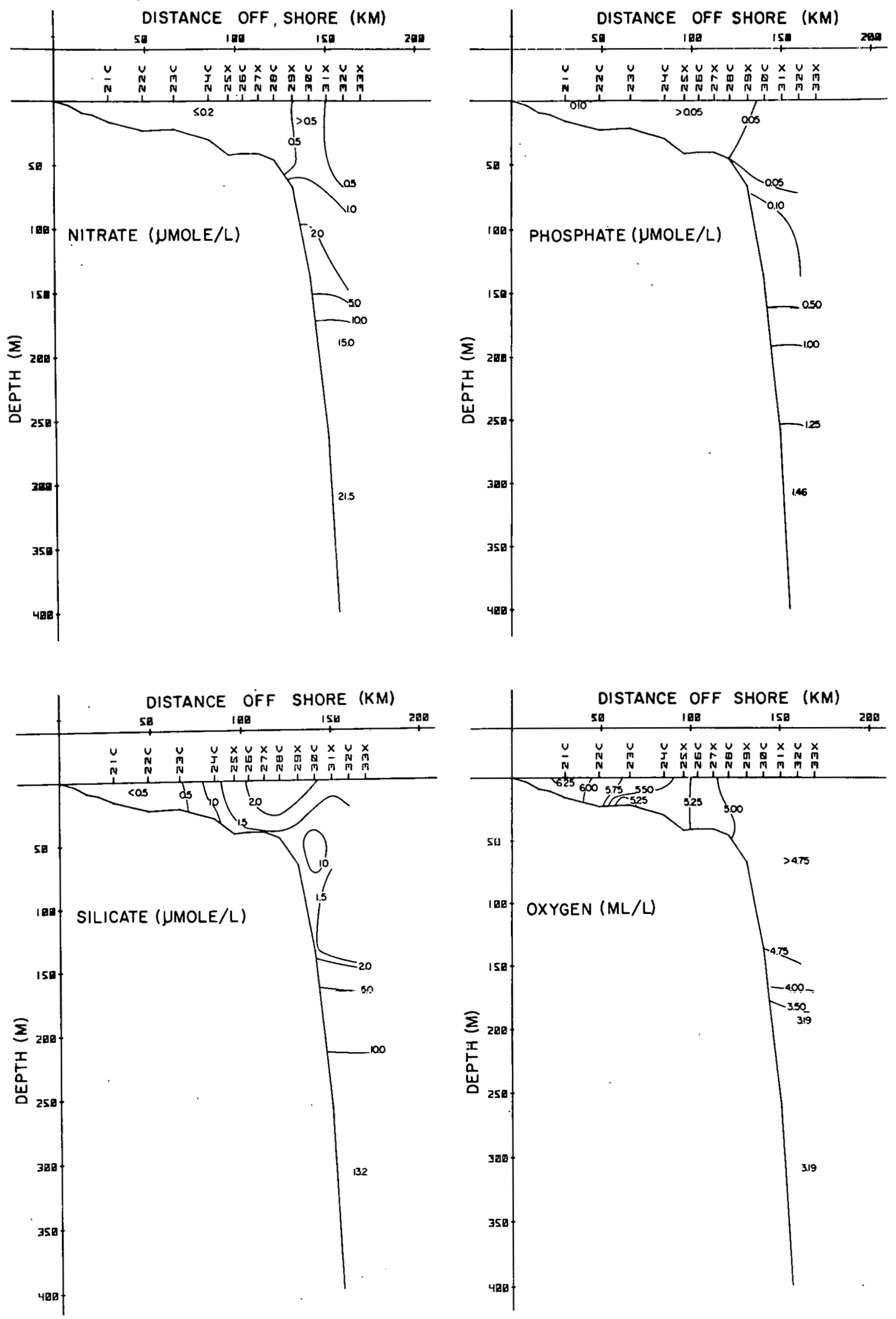

Figure 7. Savannah section nitrate, phosphate, silicate and dissolved oxygen, 10-11 December. 


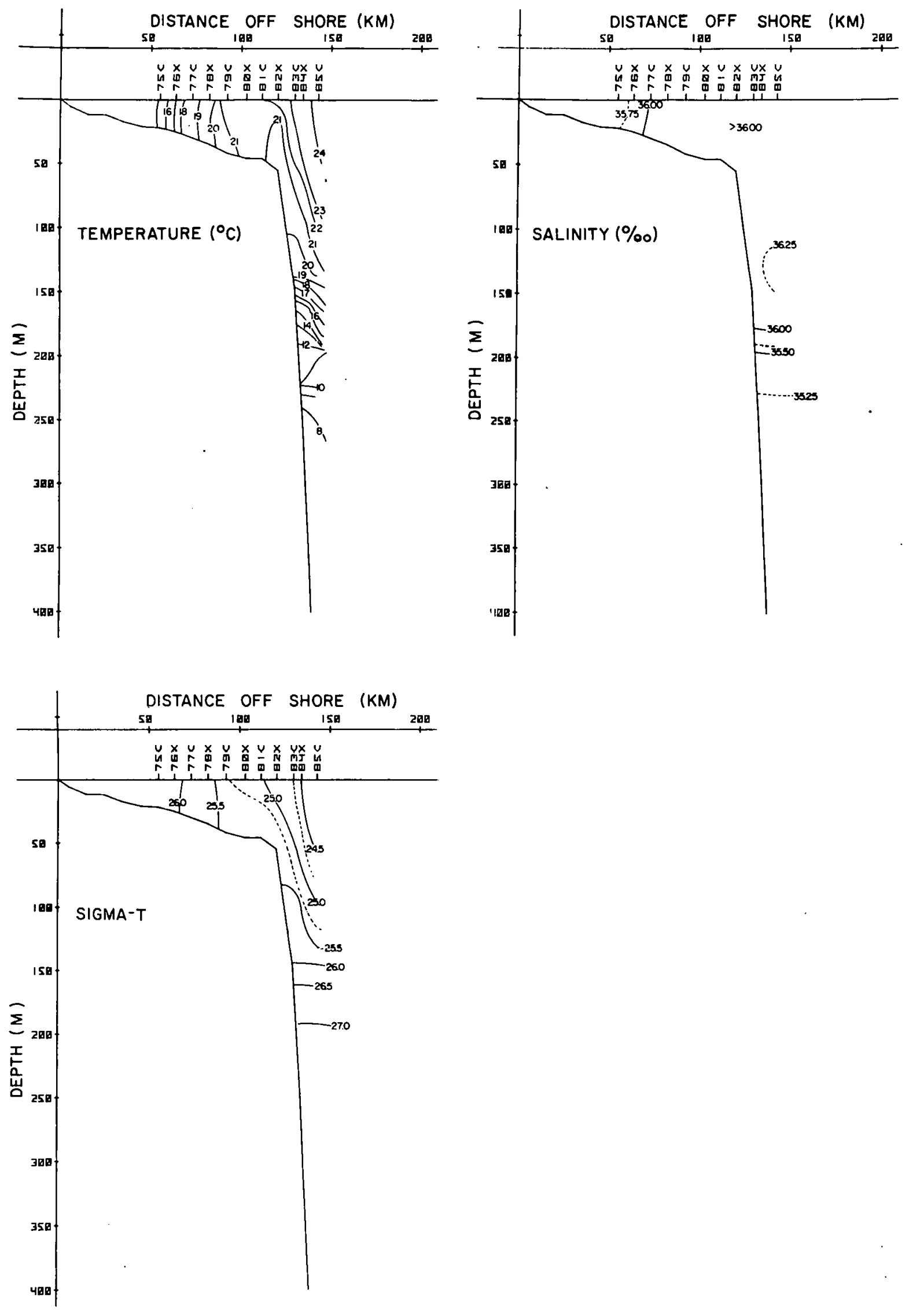

Figure 8. Savannah section temperature, salinity, and sigma-t, 12 December. 

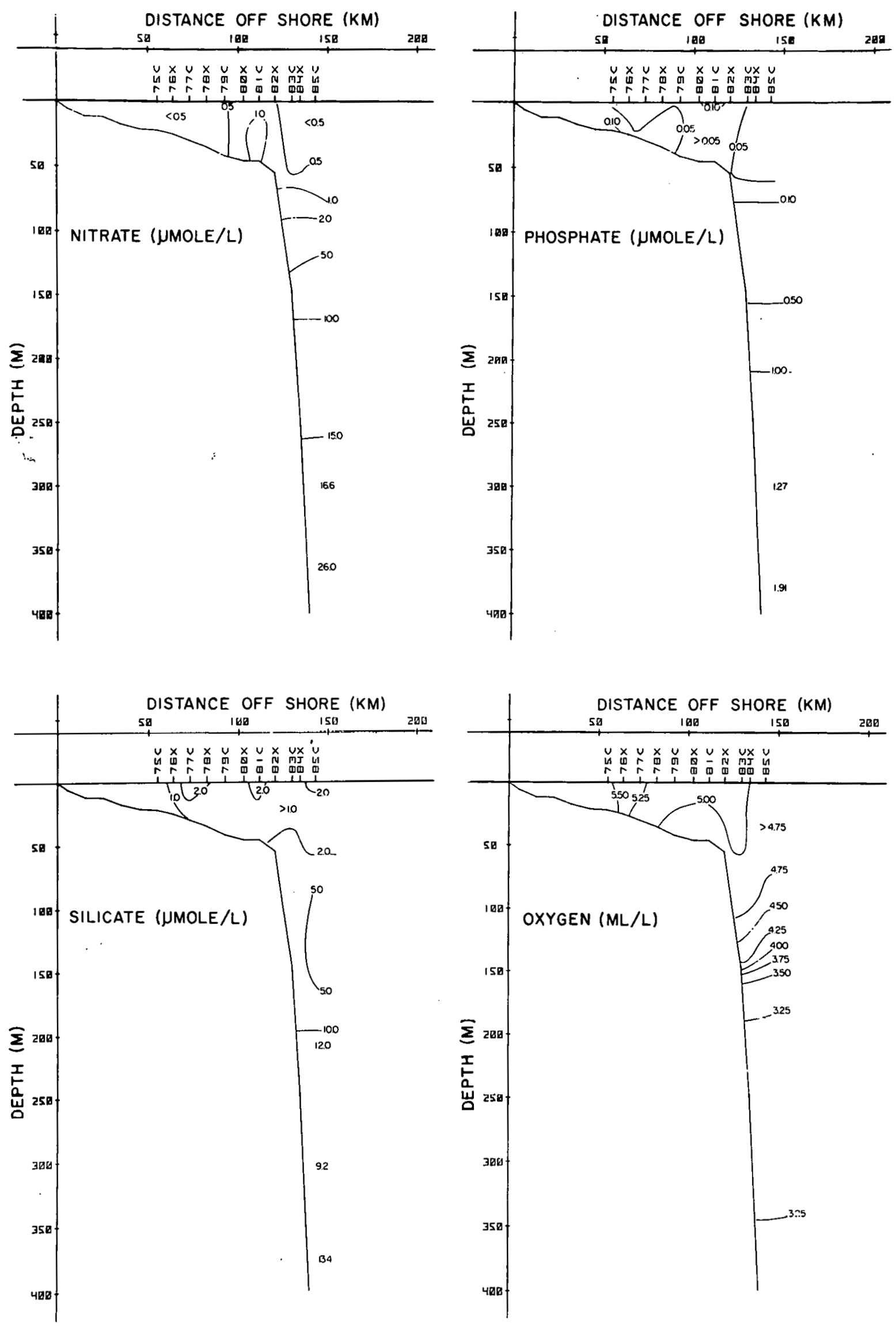

Figure 9. Savannah section nitrate, phosphate, silicate and dissolved oxygen, 12 December. 

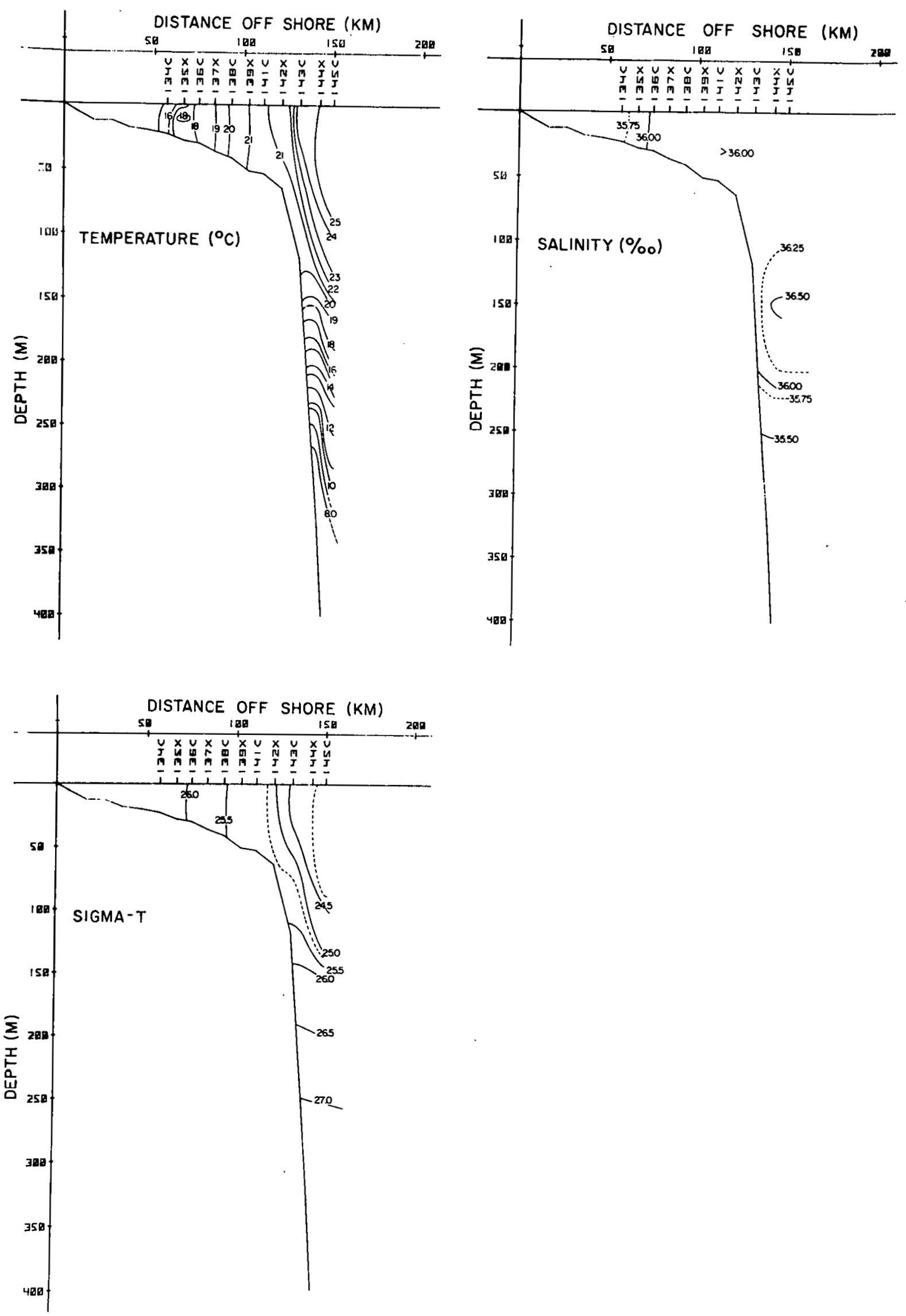

Figure 10. Savannah section temperature, salinity and sigma-t, 14 December. 

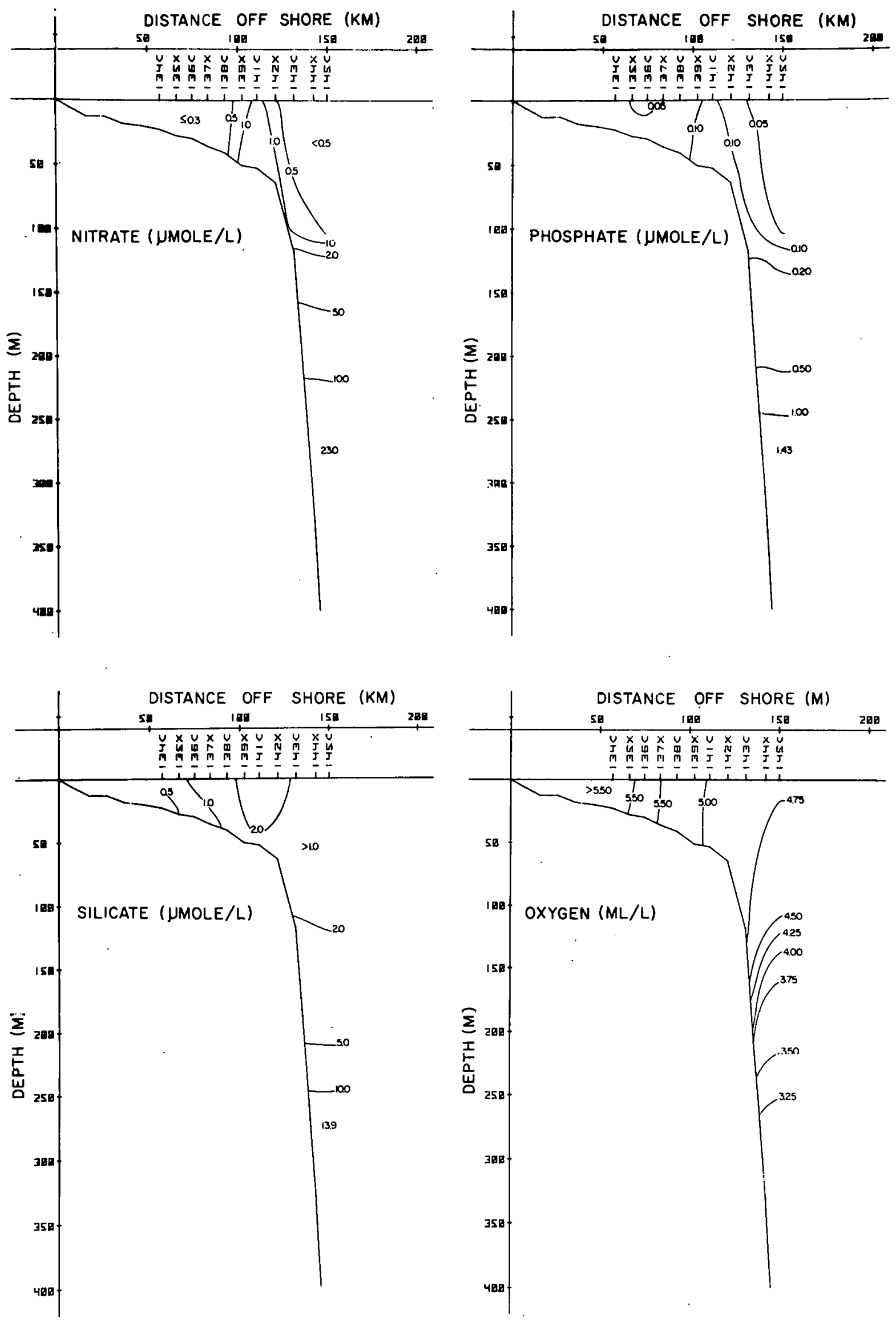

Figure 11. Savannah section nitrate, phosphate, silicate and dissolved oxygen, 14 December. 

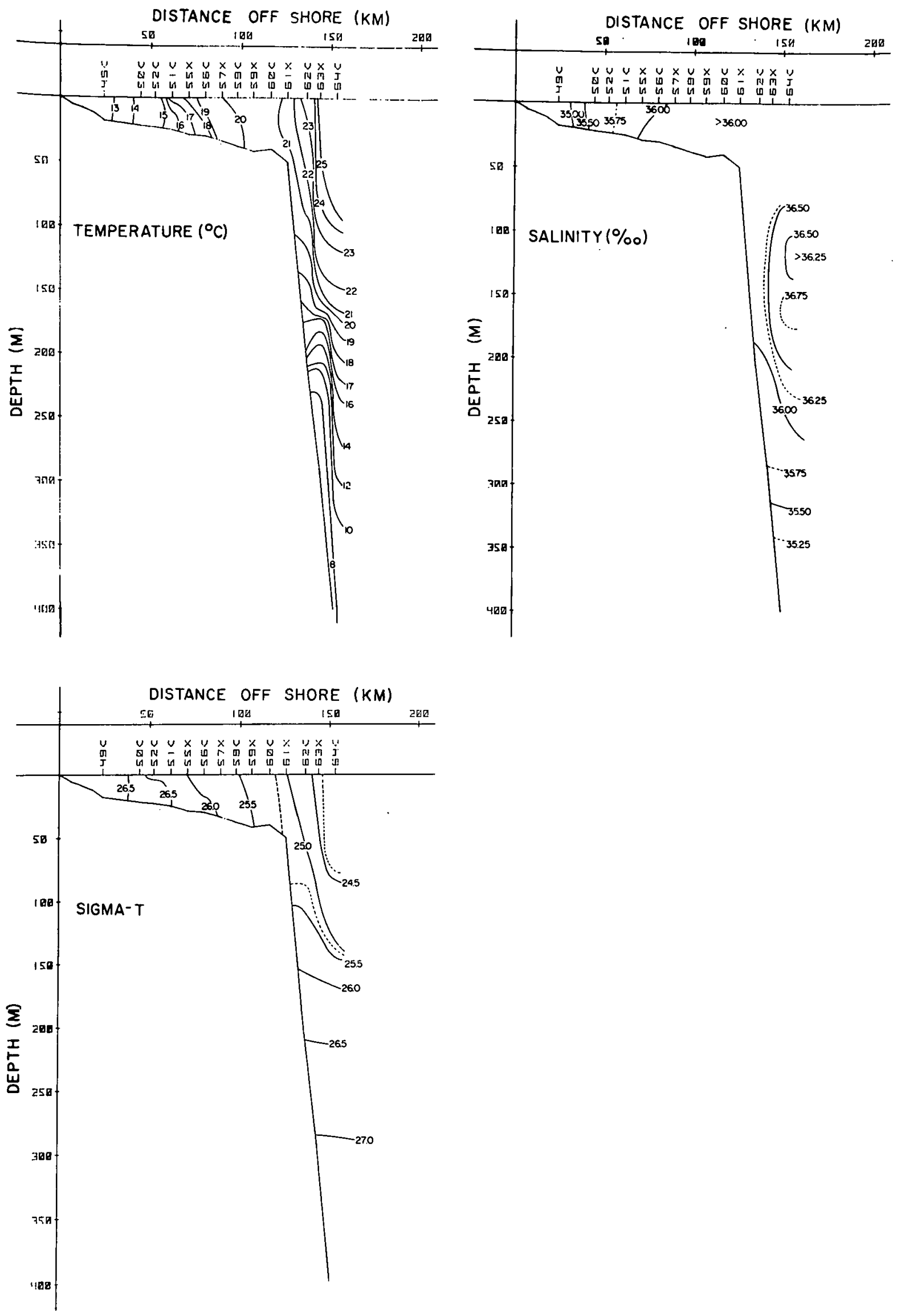

Figure 12. Brunswick section temperature, salinity and sigma-t, 11-12 December. 


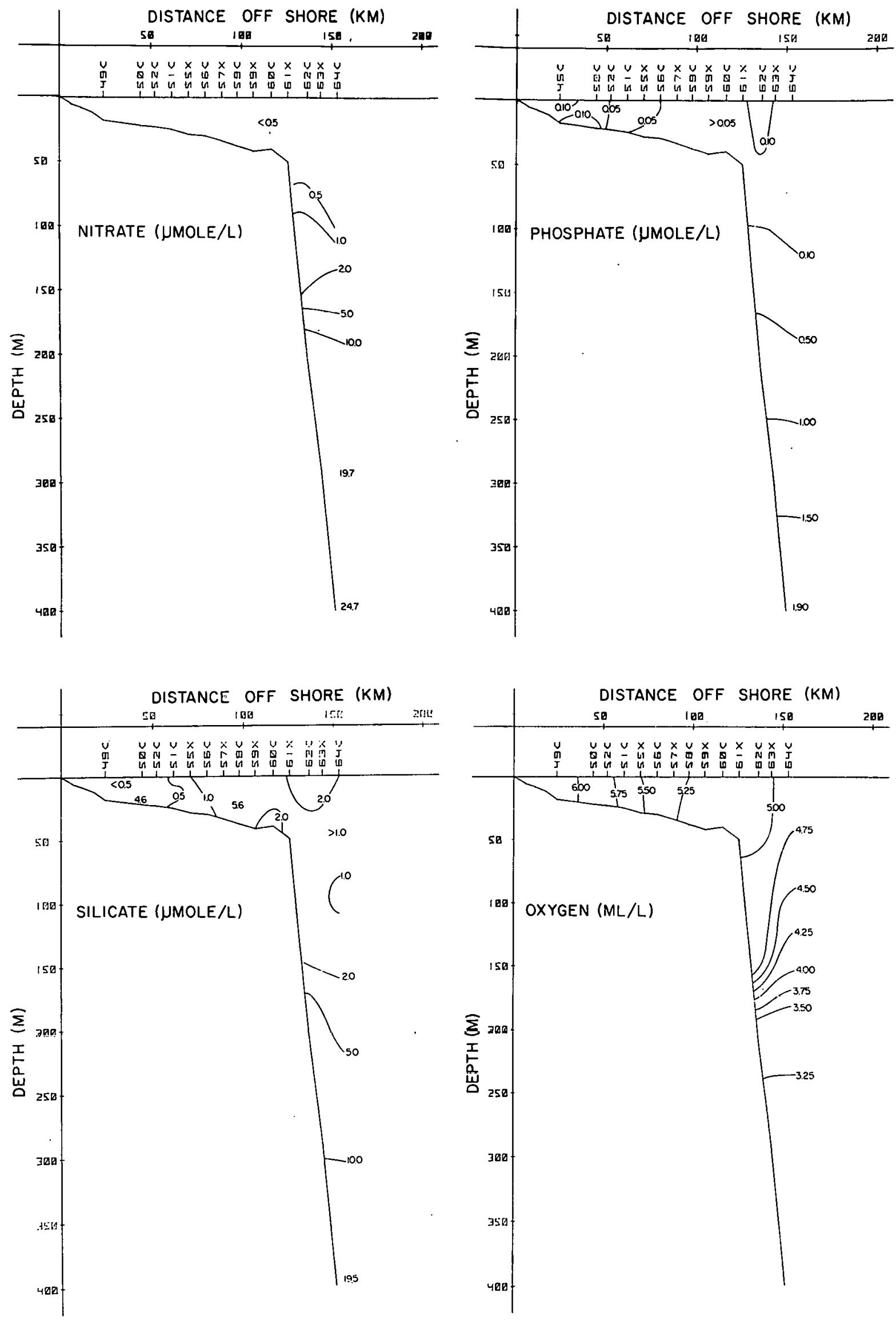

Figure 13. Brunswick section nitrate, phosphate, silicate and dissolved oxygen, 11-12 December. 

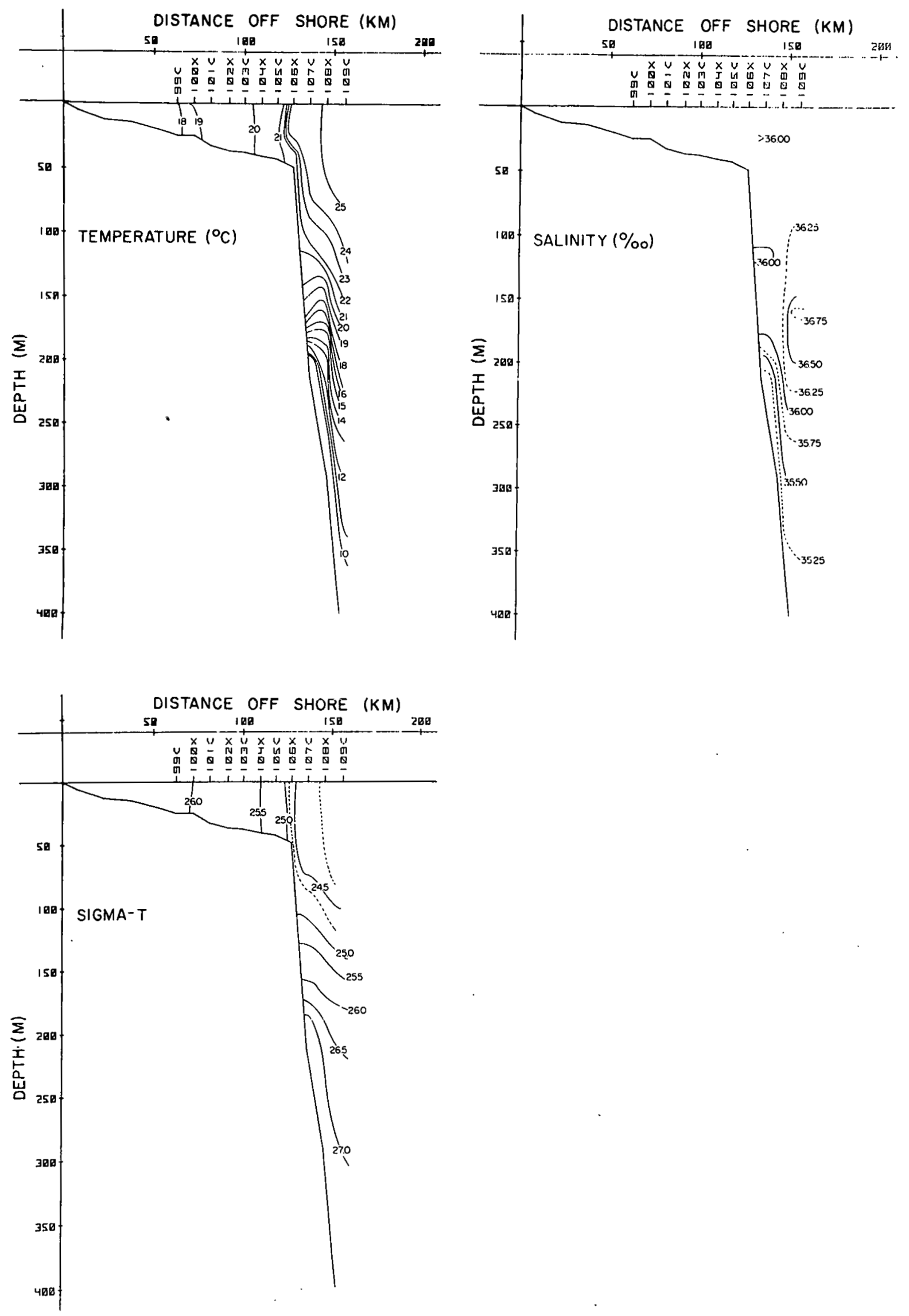

Figure 14. Brunswick section salinity and sigma-t, 13 December. 

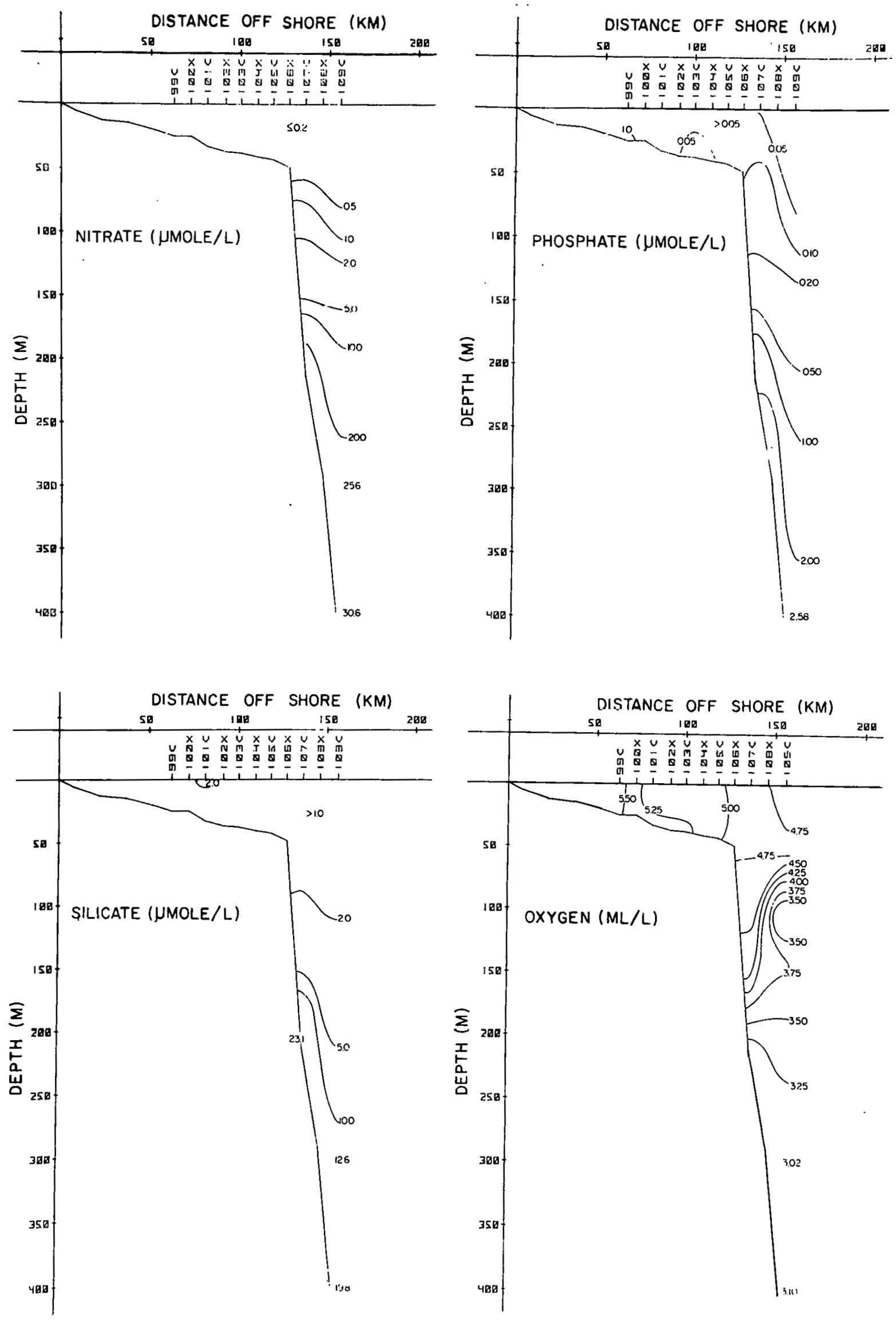

Figure 15. Brunswick section nitrate, phosphate, silicate and dissolved oxygen, 13 December. 


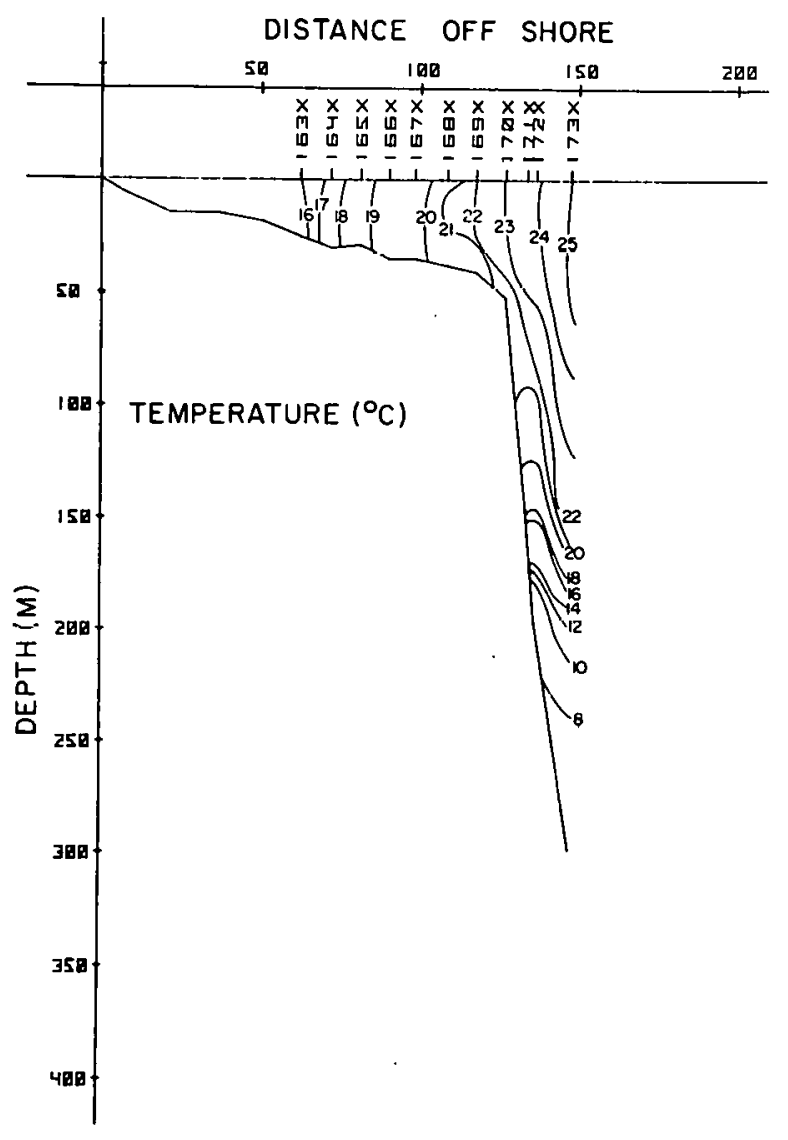

Figure 16. Bruriswick section temperature, 14-15 vecember. 

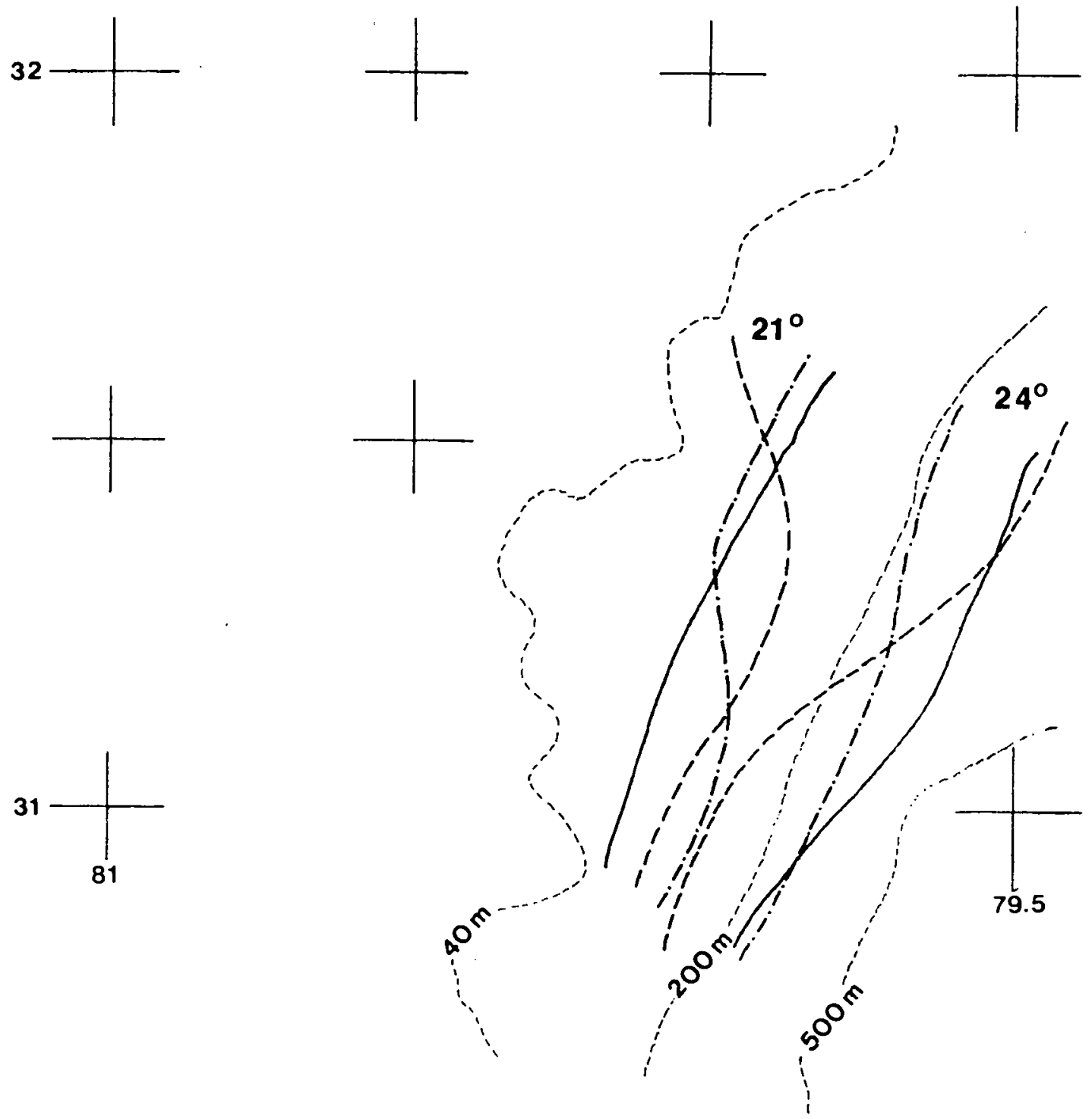

Figure 17 . Time series of the $21^{\circ} \mathrm{C}$ and $24^{\circ} \mathrm{C}$ isotherms $10-12$ December, -..--12-13 December, -...-14-15 December. 


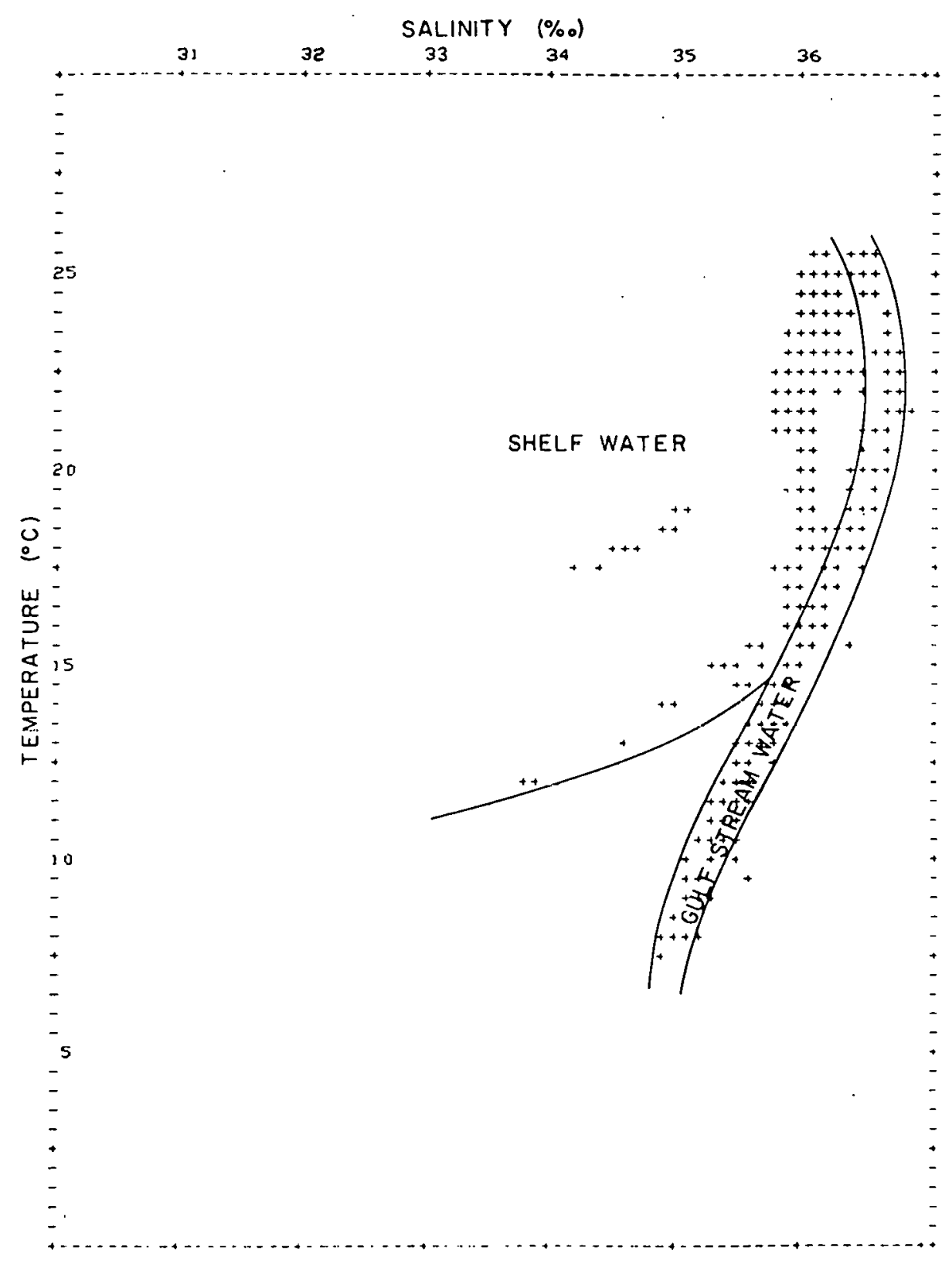

Figure 18. Temperature-salinity diagram, Cruise CI-12-76, December 1976. 


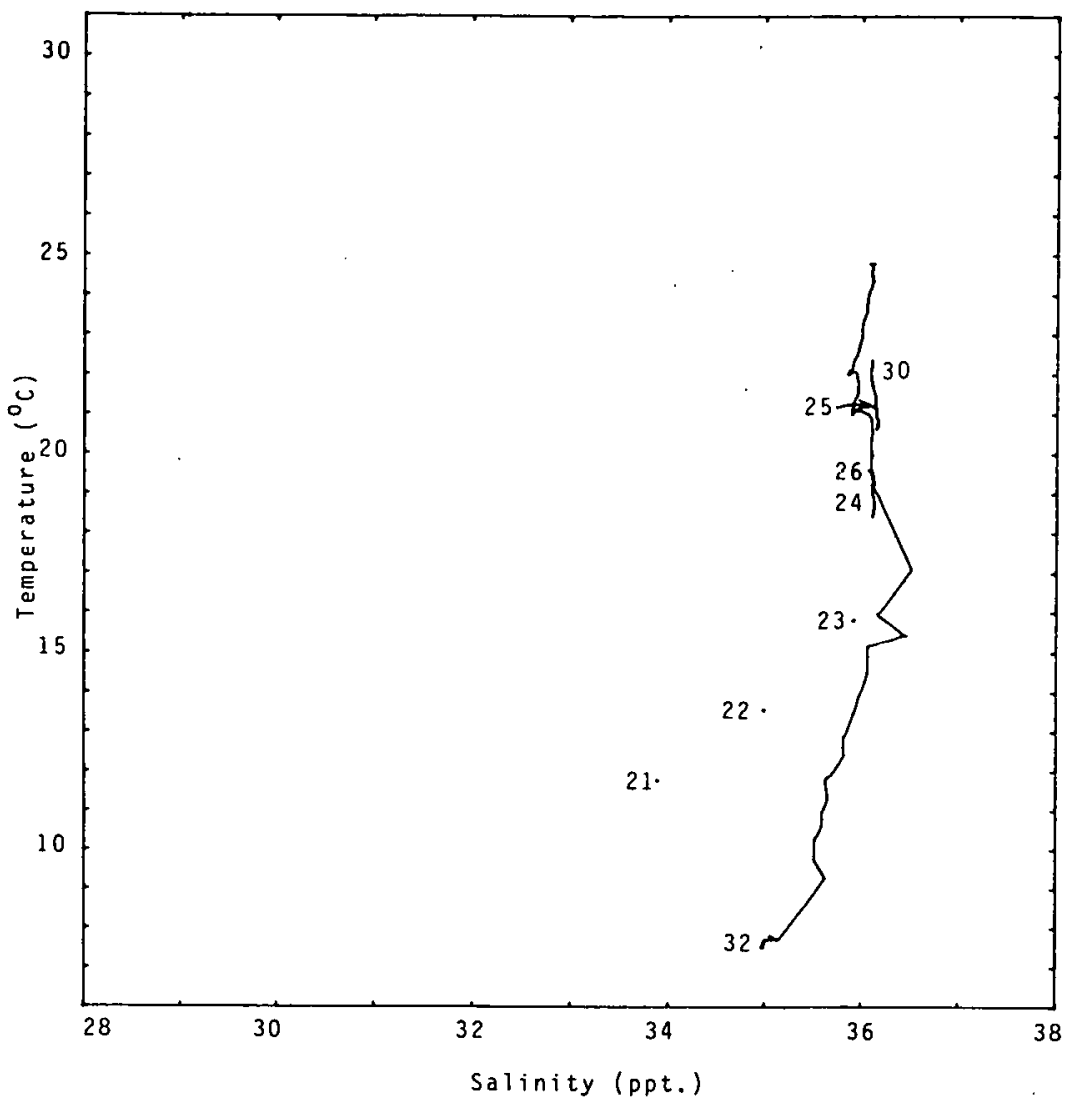

Figure 19. Savannah Section, 10-11 December.



Figure 20. Brunswick Section, 10-11 December. 


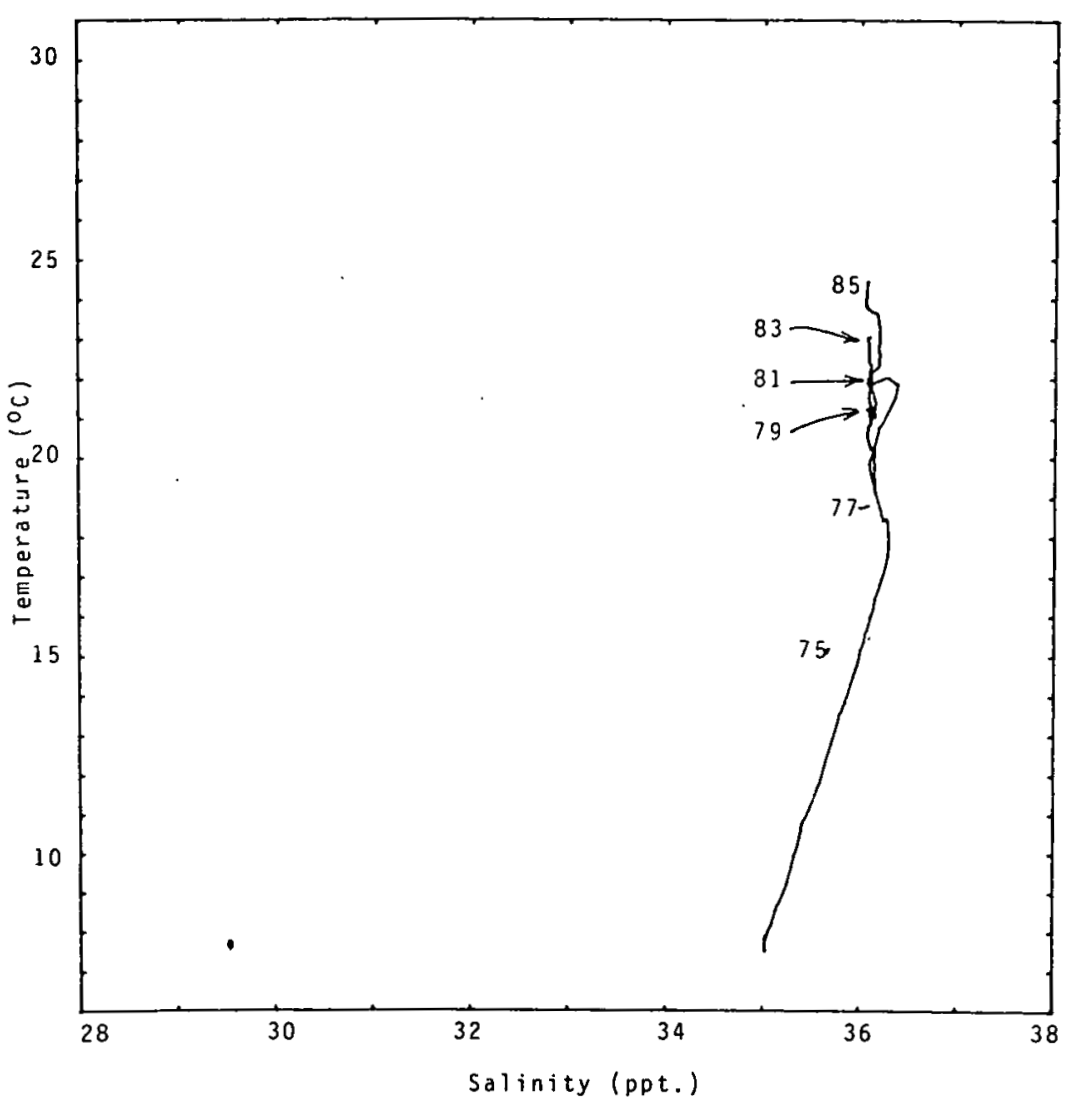

Figure 21. Savannah Section, 12 December.

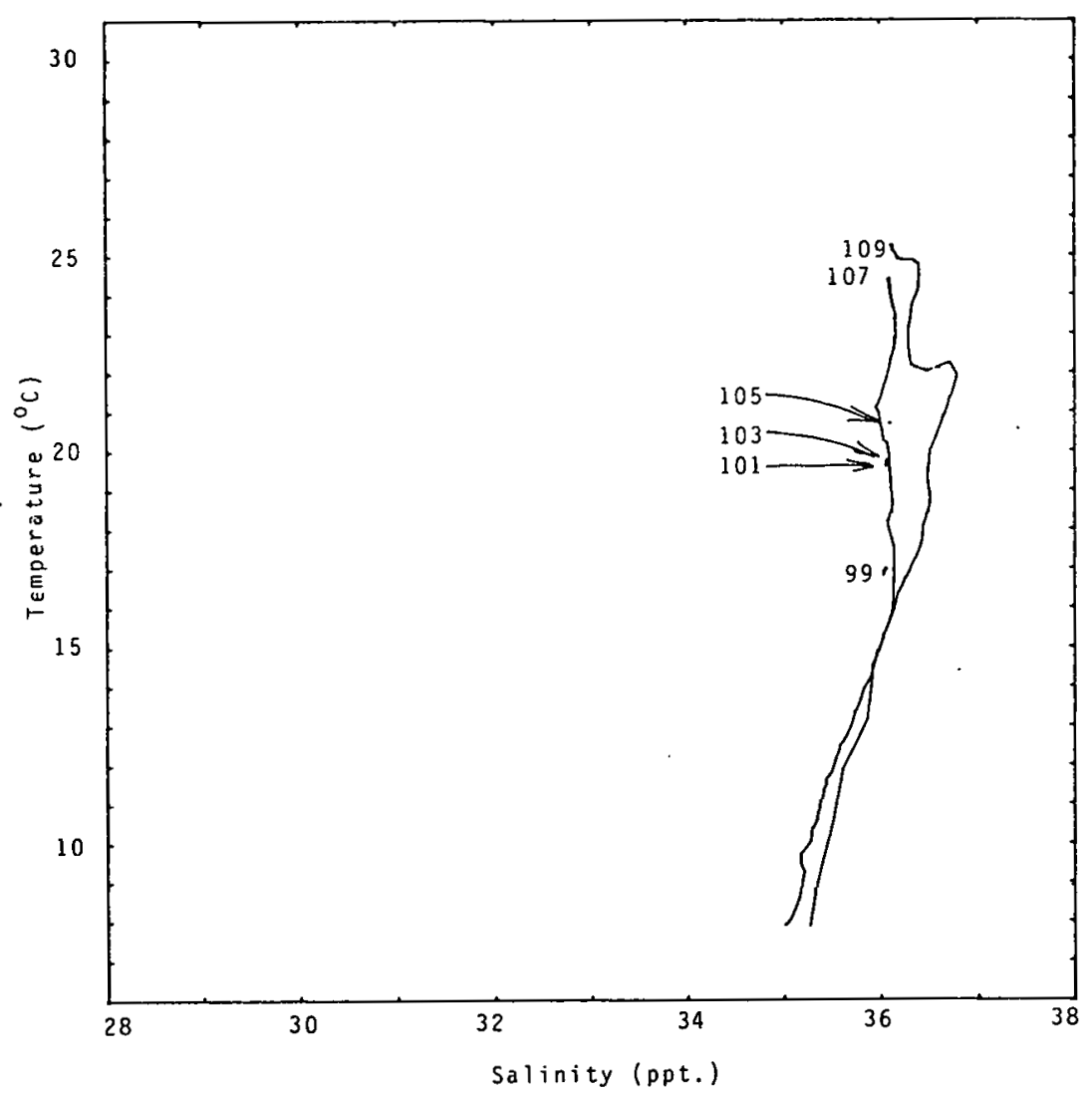

Figure 22. Brunswick Section, 13 December. 


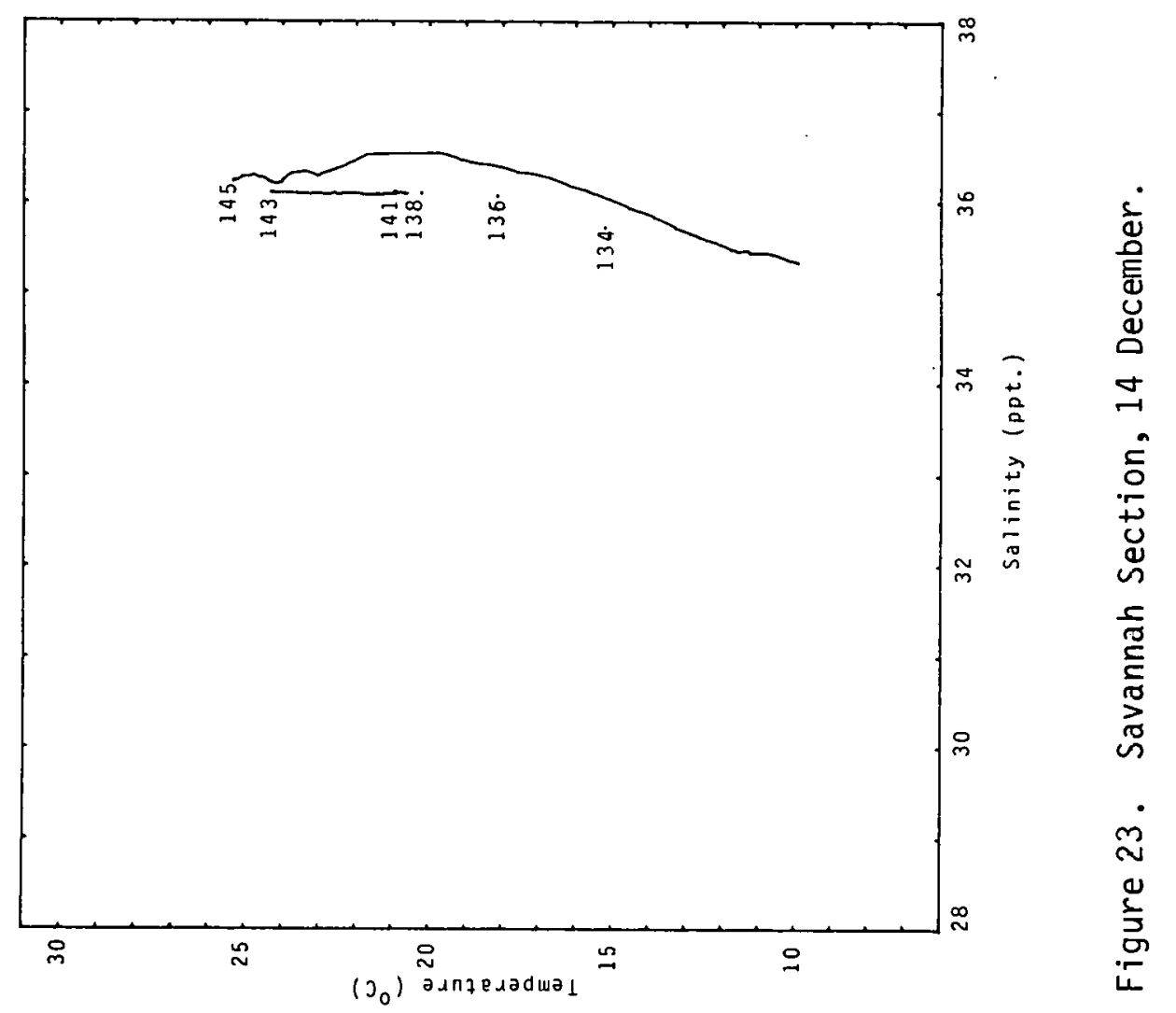




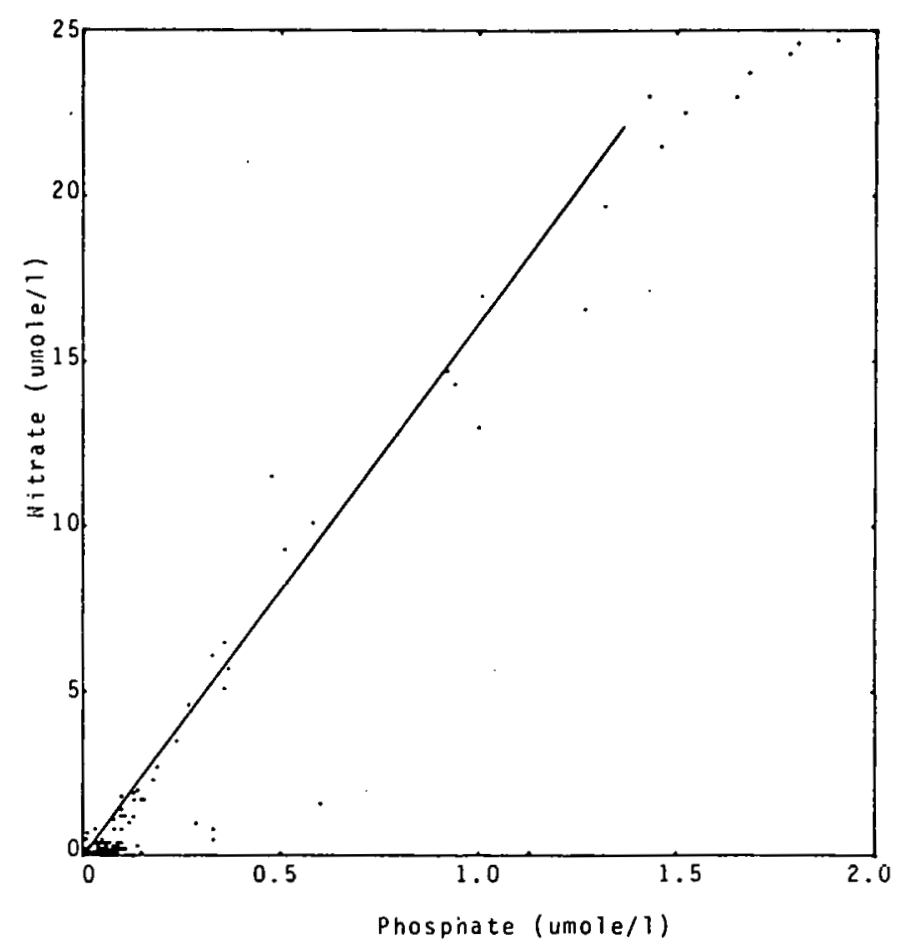

Figure 24 . Nitrate vs, phosphate with line representing the $16: 1(\mathrm{~N}: \mathrm{P})$ ratio.

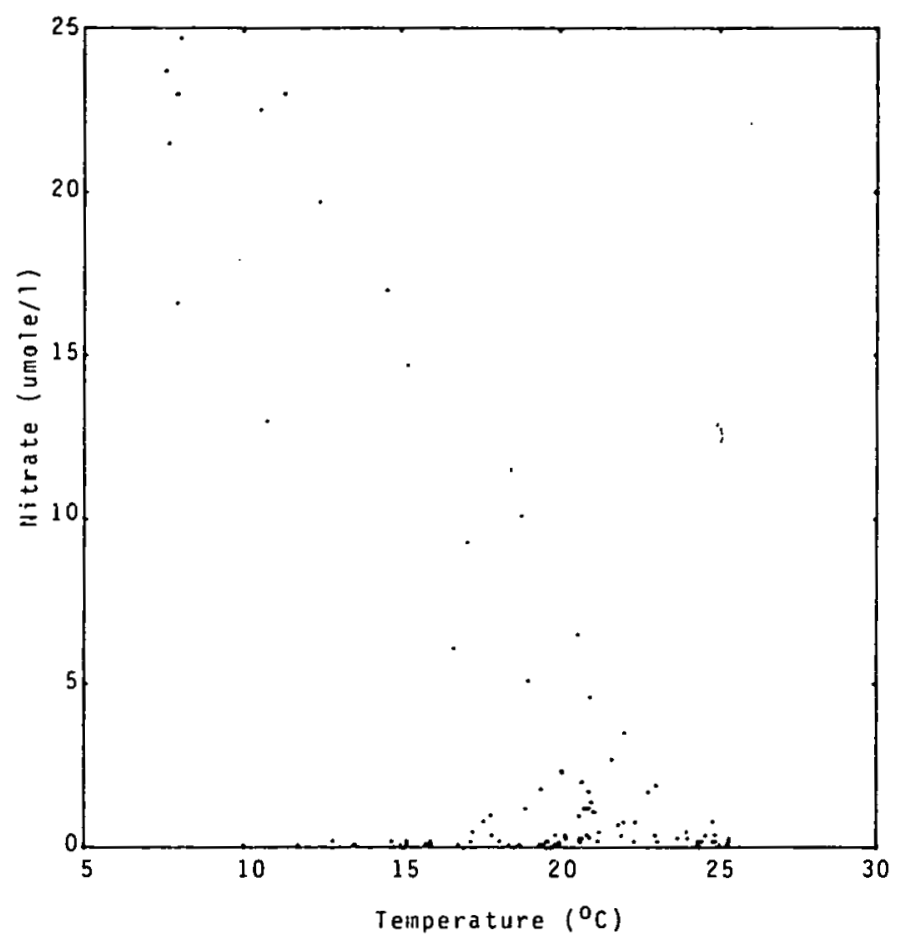

Figure 25. Nitrate vs. temperature. 


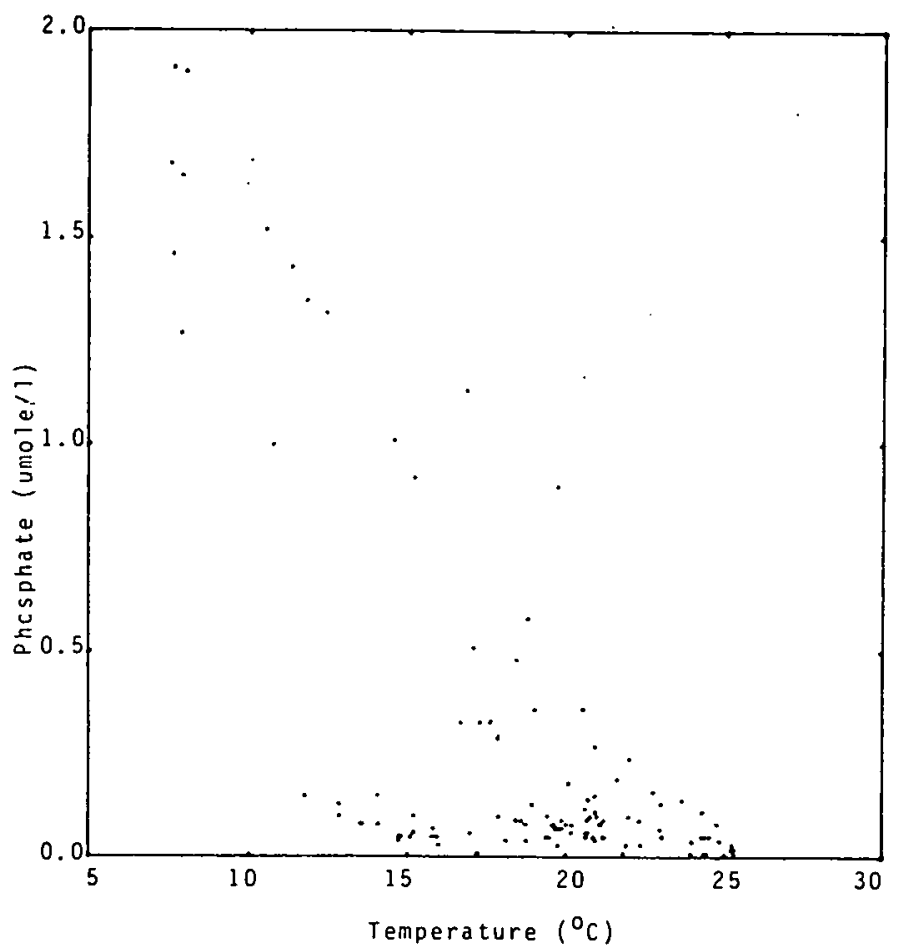

Figure 26. Phosphate vs, temperature.

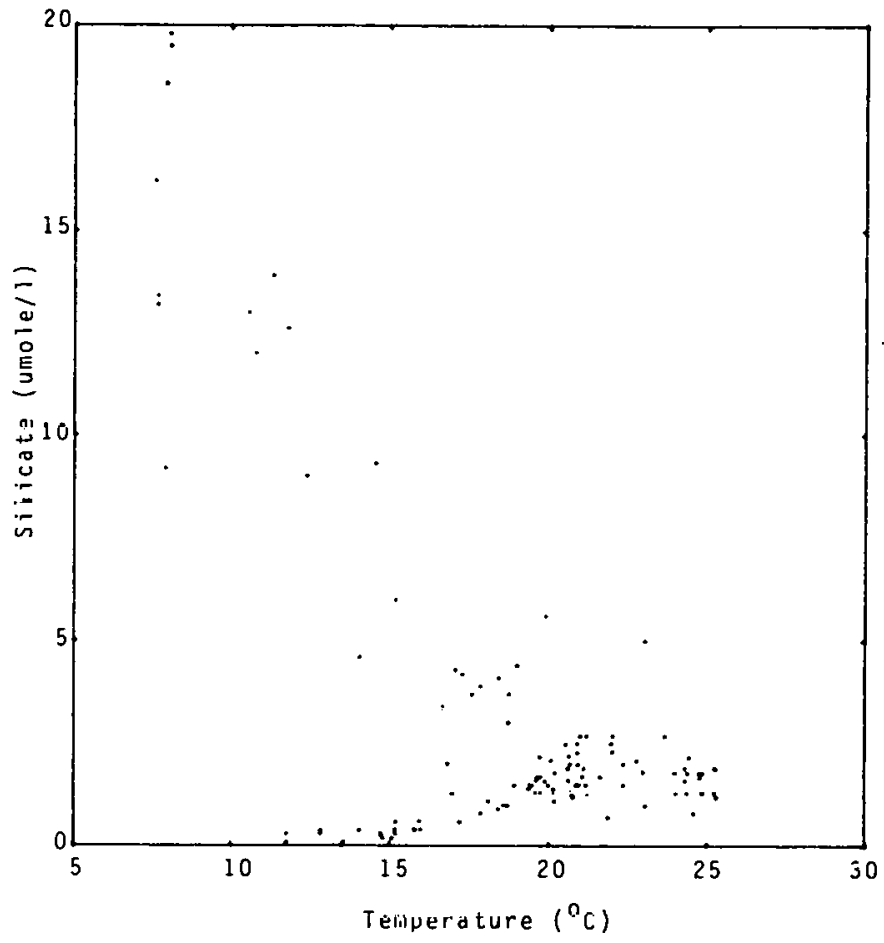

Figure 27. Silicate vs. temperature. 


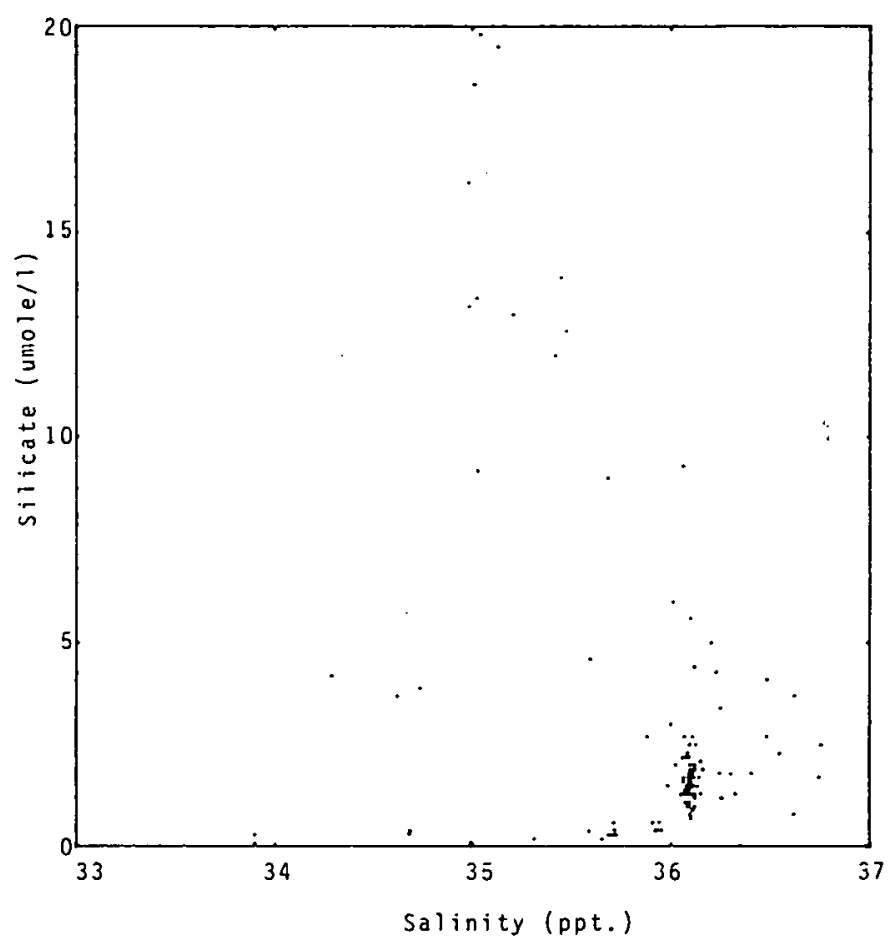

Figure 28. Silicate vs. salinity. 


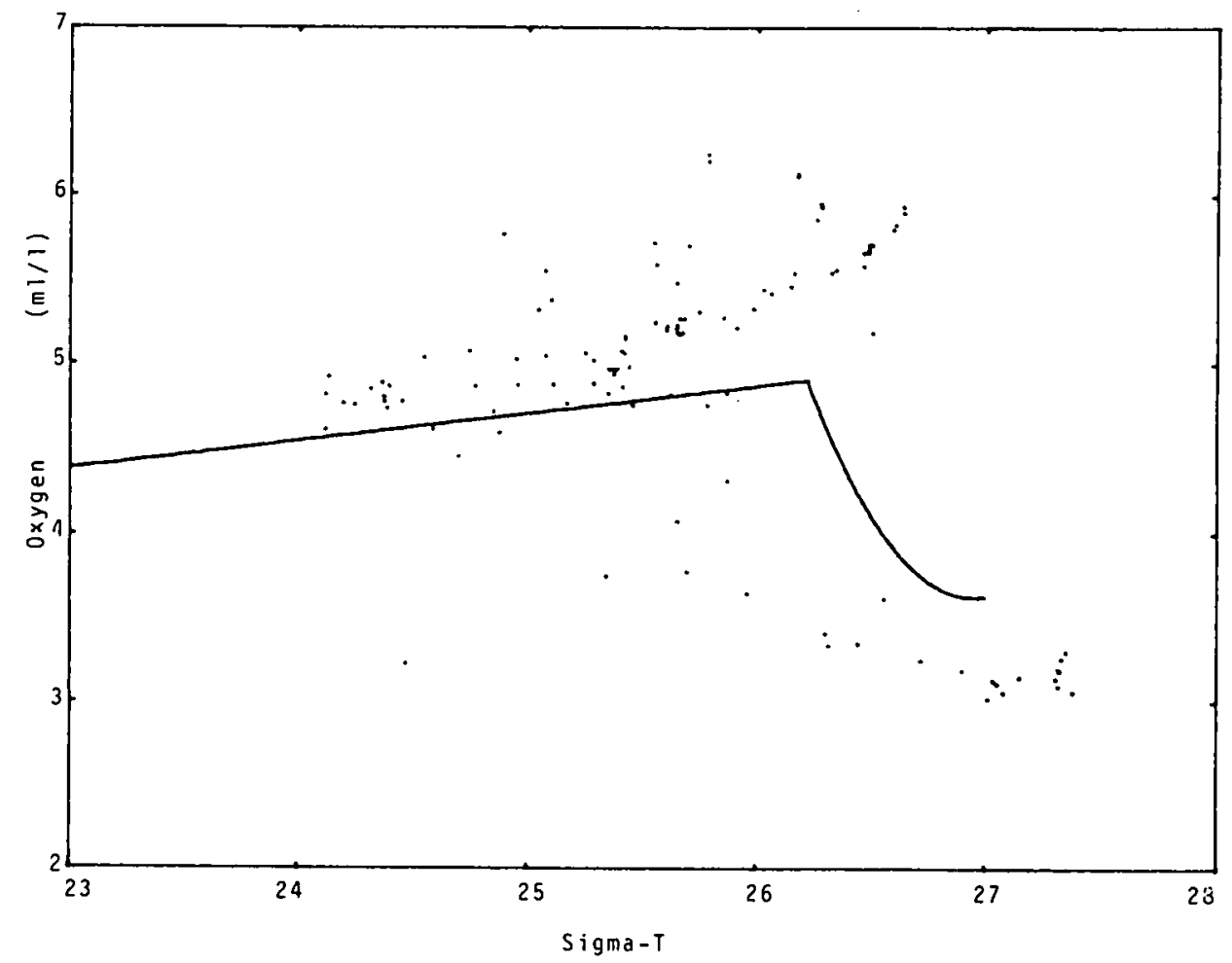

Fiyure 29. Oxygen versus sigma-t with line representing norma? Sargasso Sea water. 
DATA

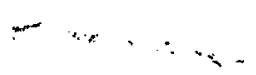


Table 8. STATION SUMMARY FOR ISELIN CRUISE CI-12

\begin{tabular}{|c|c|c|c|c|c|c|c|c|c|c|}
\hline KUISE & STA & LA & $\mathrm{L}$ & GI TUIIE & $Y R$ & $M N$ & DY & $\begin{array}{c}\text { HOUF } \\
\text { GMT }\end{array}$ & $\underset{\text { MEFTH }}{\text { M }}$ & $\begin{array}{l}\text { CONSEC } \\
\text { NUMBER }\end{array}$ \\
\hline 012 & $020 \mathrm{C}$ & $3128.1 \mathrm{~N}$ & 79 & 7. OW & 76 & 12 & 9 & 4.0 & 500 & 20 \\
\hline 012 & $021 \mathrm{C}$ & $3156.4 \mathrm{~N}$ & 80 & $41.0 \mathrm{~W}$ & 76 & 12 & 10 & 14.7 & 16 & 21 \\
\hline 012 & $022 \mathrm{C}$ & $3152.0 \mathrm{~N}$ & 80 & $30.1 \mathrm{~W}$ & 76 & 12 & 10 & 15.7 & 23 & 22 \\
\hline 012 & $623 C$ & $3148.2 N$ & 80 & $20.0 \mathrm{~W}$ & 76 & 12 & 10 & 17.3 & 22 & 23 \\
\hline 012 & $024 C$ & $3145.2 N$ & 80 & $8.4 W$ & 76 & 12 & 10 & 18.7 & 30 & 24 \\
\hline 012 & $025 x$ & $3143.0 \mathrm{~N}$ & 80 & $2.0 \mathrm{~W}$ & 76 & 12 & 10 & 20.0 & 42 & 25 \\
\hline 012 & $026 \mathrm{C}$ & $3140.9 \mathrm{~N}$ & 79 & $57.5 \mathrm{H}$ & 76 & 12 & 10 & 20.5 & 41 & 26 \\
\hline 012 & $027 x$ & $3139.0 \mathrm{~N}$ & 79 & JL. JW & 76 & 12 & 10 & 21.2 & 41 & 27 \\
\hline 012 & $028 \mathrm{C}$ & $3137.1 \mathrm{~N}$ & 79 & $47.5 \mathrm{~W}$ & 76 & 12 & 10 & 22.0 & 46 & 28 \\
\hline 012 & $029 x$ & $3135.0 \mathrm{~N}$ & 79 & $41.6 \mathrm{~W}$ & 76 & 12 & 10 & 23.5 & 67 & 29 \\
\hline 012 & $030 C$ & $3133.5 \mathrm{~N}$ & 79 & $36.0 \mathrm{~W}$ & 76 & 12 & 11 & .3 & 136 & 30 \\
\hline 012 & $031 x$ & $3131.6 \mathrm{~N}$ & 79 & $30.3 \mathrm{~W}$ & 76 & 12 & 11 & 1.6 & 259 & 31 \\
\hline 012 & $032 \mathrm{C}$ & $3129.8 \mathrm{~N}$ & 79 & $24.6 \mathrm{~W}$ & 76 & 12 & 11 & 2.5 & 510 & 32 \\
\hline 012 & $033 x$ & $3127.8 \mathrm{~N}$ & 79 & $19.1 \mathrm{H}$ & 76 & 12 & 11 & 3.0 & 480 & 33 \\
\hline 012 & $049 \mathrm{C}$ & $3111.5 \mathrm{~N}$ & 81 & 2.JW & 76 & 12 & 11 & 14.0 & 18 & 47 \\
\hline 012 & 0500 & $317.9 N$ & 80 & $50.5 \mathrm{~W}$ & 76 & 12 & 11 & 15.3 & 22 & 50 \\
\hline 012 & $051 C$ & $314.0 \mathrm{~N}$ & 80 & $40.6 \mathrm{~W}$ & 76 & 12 & 11 & 16.8 & 25 & 51 \\
\hline 012 & $052 \mathrm{C}$ & $6.0 \mathrm{~N}$ & 80 & $46.0 \mathrm{~W}$ & 76 & 12 & 11 & 17.8 & 23 & 52 \\
\hline 012 & $054 x$ & $314.5 \mathrm{~N}$ & 80 & $42.0 \mathrm{~W}$ & 76 & 12 & 11 & 19.1 & 25 & 54 \\
\hline 012 & $055 x$ & $31 \quad 2.6 \mathrm{~N}$ & 80 & $35.0 \mathrm{~W}$ & 76 & 12 & 11 & 19.6 & 27 & 55 \\
\hline 012 & $056 \mathrm{C}$ & $31 \quad 1.0 N$ & 80 & $29.5 \mathrm{~W}$ & 76 & 12 & 11 & 20.2 & 30 & 56 \\
\hline 012 & $057 x$ & $3058.5 \mathrm{~N}$ & 80 & $24 . J W$ & 76 & 12 & 11 & 21.0 & 34 & 57 \\
\hline 012 & $058 \mathrm{C}$ & $3057.0 \mathrm{~N}$ & 80 & $19.5 \mathrm{~W}$ & 76 & 12 & 11 & 21.6 & 38 & 58 \\
\hline 012 & $059 x$ & $3054.9 \mathrm{~N}$ & 80 & $14.5 \mathrm{~W}$ & 76 & 12 & 11 & 22.4 & 42 & 59 \\
\hline 012 & $066 C$ & $3052.7 \mathrm{~N}$ & 80 & $8.8 \mathrm{~W}$ & 76 & 12 & 11 & 23.0 & 40 & 60 \\
\hline 012 & $061 x$ & $3050.7 N$ & 80 & $3.5 \mathrm{~W}$ & 76 & 12 & 12 & 0.0 & 50 & 61 \\
\hline 012 & $062 \mathrm{C}$ & $3049.0 \mathrm{~N}$ & 79 & $57.0 \mathrm{~W}$ & 76 & 12 & 12 & .6 & 206 & 62 \\
\hline 012 & $063 x$ & $3 \mathrm{C} \quad 47.2 \mathrm{~N}$ & 79 & $52.9 \mathrm{~W}$ & 76 & 12 & 12 & 2.6 & 291 & 63 \\
\hline 012 & $064 C$ & $30 \quad 45.4 \mathrm{~N}$ & 79 & $47.4 \mathrm{w}$ & 76 & 12 & 12 & 3.2 & 429 & 64 \\
\hline 012 & $0 \%$ & $31 \quad 48.2 \mathrm{~N}$ & 80 & $19.0 \mathrm{~W}$ & 76 & 12 & 12 & 9.9 & 22 & 75 \\
\hline 012 & $076 x$ & $3146.5 \mathrm{~N}$ & 80 & 13 & 76 & 12 & 12 & 11.0 & 2 & 76 \\
\hline 01: & 0776 & $3145.0 \mathrm{~N}$ & 80 & 8. & 76 & 12 & 12 & 11.5 & 30 & 77 \\
\hline 012 & $078 x$ & $3143.0 \mathrm{~N}$ & 80 & $2.8 \mathrm{~W}$ & 76 & 12 & 12 & 12.4 & 35 & 78 \\
\hline 012 & $079 \mathrm{C}$ & $3141.1 \mathrm{~N}$ & 79 & $56.9 \mathrm{~W}$ & 76 & 12 & 12 & 13.2 & 42 & 79 \\
\hline 012 & $080 x$ & $3139.1 \mathrm{~N}$ & 79 & $50.6 \mathrm{~W}$ & 76 & 12 & 12 & 14.2 & 46 & 80 \\
\hline 012 & $081 \mathrm{C}$ & $3137.5 \mathrm{~N}$ & 79 & $45.4 w$ & 76 & 12 & 12 & 14.8 & 46 & 81 \\
\hline 012 & $082 x$ & $3135.8 \mathrm{~N}$ & 79 & $40.3 \mathrm{~W}$ & 76 & 12 & 12 & 15.6 & 55 & 82 \\
\hline 012 & $083 \mathrm{C}$ & $3134.1 \mathrm{~N}$ & 79 & $34.6 \mathrm{~W}$ & 76 & 12 & 12 & 16.1 & 146 & 83 \\
\hline 012 & $084 x$ & $3133.0 \mathrm{~N}$ & 79 & $32.1 \mathrm{~W}$ & 76 & 12 & 12 & 17.0 & 247 & 84 \\
\hline & $085 \mathrm{C}$ & $3132.0 \mathrm{~N}$ & 79 & $26.8 \mathrm{~W}$ & 76 & 12 & 12 & 17.5 & 507 & 85 \\
\hline 011 & $099 \mathrm{C}$ & $314.1 \mathrm{~N}$ & 80 & $40.8 \mathrm{~W}$ & 76 & 12 & 13 & 3.7 & 25 & 99 \\
\hline
\end{tabular}


Table 8. ISELIN CRUISE CI-12

[CONTINUE[I]

\begin{tabular}{|c|c|c|c|c|c|c|c|c|c|c|c|}
\hline CFUISE & STATION & LA & $D E$ & LO & IE & $Y F$ & MN & IIY & $\begin{array}{l}\text { HOLH } \\
\text { GMT }\end{array}$ & $\underset{M}{\text { UEFF } T H}$ & $\begin{array}{l}\text { CONSEC } \\
\text { NUMBER }\end{array}$ \\
\hline 012 & $100 x$ & 31 & $2.0 \mathrm{~N}$ & 80 & $35.3 \mathrm{~W}$ & 76 & 12 & 13 & 4.6 & 25 & 100 \\
\hline 012 & $101 \mathrm{C}$ & 31 & $0.0 \mathrm{~N}$ & 80 & $30.0 \mathrm{~W}$ & 76 & 12 & 13 & 5.2 & 33 & 101 \\
\hline 012 & $102 x$ & 30 & $58.0 \mathrm{~N}$ & 80 & $24.0 \mathrm{~W}$ & 76 & 12 & 13 & 6.0 & 37 & 102 \\
\hline 012 & $103 \mathrm{C}$ & 30 & $56.0 \mathrm{~N}$ & 80 & $19.2 \mathrm{~W}$ & 76 & 12 & 13 & 6.6 & 38 & 103 \\
\hline 012 & $104 x$ & 30 & $54.4 N$ & 80 & $13.5 \mathrm{~W}$ & 76 & 12 & 13 & 7.5 & 41 & 104 \\
\hline 012 & $105 C$ & 30 & $52.5 \mathrm{~N}$ & 80 & $8.5 \mathrm{~W}$ & 76 & 12 & 1.3 & 8.0 . & 43 & 105 \\
\hline 012 & $106 x$ & 30 & $50.5 \mathrm{~N}$ & 80 & $3.4 W$ & 76 & 12 & 13 & 8.8 & 49 & 106 \\
\hline 012 & $107 C$ & 30 & N8.7 & 79 & $58.0 \mathrm{~W}$ & 76 & 12 & 13 & 9.3 & 214 & 107 \\
\hline 012 & $108 x$ & 30 & $46.6 \mathrm{~N}$ & 79 & $52.5 \mathrm{~W}$ & 76 & $\cdot 12$ & 13 & 10.7 & 292 & 108 \\
\hline 012 & $109 C$ & 30 & $44.5 \mathrm{~N}$ & 79 & $46.6 \mathrm{~W}$ & 76 & 12 & 13 & 11.3 & 443 & $10 \%$ \\
\hline 012 & $134 \mathrm{C}$ & 31 & $48.2 N$ & 80 & $19.0 \mathrm{~W}$ & 76 & 12 & 14 & 1.6 & 23 & 134 \\
\hline 012 & $135 x$ & 31 & $46.4 \mathrm{~N}$ & 80 & $13.5 \mathrm{~W}$ & 76 & 12 & 14 & 2.7 & 28 & 135 \\
\hline 012 & $13 \delta \mathrm{C}$ & 31 & $44.9 \mathrm{~N}$ & 80 & $8.4 \mathrm{~W}$ & 76 & 12 & 14 & 3.7 & 30 & 136 \\
\hline 012 & $137 x$ & 31 & $43.0 N$ & 80 & $3.4 \mathrm{~W}$ & 76 & 12 & 14 & 4.9 & 36 & 137 \\
\hline 012 & $138 \mathrm{C}$ & 31 & $41.4 N$ & 79 & $57.8 \mathrm{~W}$ & 76 & 12 & 14 & 5.9 & 41 & 138 \\
\hline 012 & $139 x$ & 31 & $37.6 \mathrm{~N}$ & 79 & 52.06 & 76 & 12 & 14 & 7.1 & 51 & 139 \\
\hline 012 & $141 \mathrm{C}$ & 31 & $38.0 \mathrm{~N}$ & 79 & $47.0 \mathrm{~W}$ & 76 & 12 & 14 & 8.1 & 5.3 & 141 \\
\hline 012 & $142 X$ & 31 & $36.0 \mathrm{~N}$ & 79 & $41.0 \mathrm{~W}$ & 76 & 12 & 14 & 9.0 & 64 & 142 \\
\hline 012 & $143 C$ & 31 & $34.0 \mathrm{~N}$ & 79 & 35.04 & 76 & 12 & 14 & 9.8 & 118 & 143 \\
\hline 012 & $144 x$ & 31 & $32.5 \mathrm{~N}$ & 79 & $28.2 W$ & 70 & 12 & 14 & 11.5 & 330 & 144 \\
\hline 012 & $145 \mathrm{C}$ & 31 & $30.5 \mathrm{~N}$ & 79 & $24.0 \mathrm{~W}$ & 76 & 12 & 14 & 12.2 & 520 & 145 \\
\hline 012 & $146 x$ & 31 & $30.3 \mathrm{~N}$ & 79 & $23.8 \mathrm{~W}$ & 76 & 12 & 14 & 14.2 & 485 & 146 \\
\hline 012 & $163 x$ & 31 & $4.5 \mathrm{~N}$ & 80 & $40.5 \mathrm{~W}$ & 76 & 12 & 14 & 22.2 & 25 & 163 \\
\hline 012 & $164 x$ & 31 & $2.5 \mathrm{~N}$ & 80 & $35.0 \mathrm{~W}$ & 76 & 12 & 14 & 23.0 & 30 & 164 \\
\hline 012 & $165 x$ & 31 & $.5 \mathrm{~N}$ & 80 & $29.6 \mathrm{~W}$ & 76 & 12 & 14 & 23.6 & 29 & 165 \\
\hline 012 & $166 x$ & 30 & $58.5 \mathrm{~N}$ & 80 & $24.5 \mathrm{~W}$ & 76 & 12 & 15 & .3 & 35 & 166 \\
\hline 012 & $167 x$ & 30 & $57.2 \mathrm{~N}$ & 80 & $19.6 \mathrm{~W}$ & 76 & 12 & 15 & .9 & 35 & 167 \\
\hline 012 & $168 x$ & 30 & $54.6 \mathrm{~N}$ & 80 & $13.9 \mathrm{~W}$ & 76 & 12 & 15 & 1.7 & 38 & 168 \\
\hline 012 & $169 x$ & 30 & $52.9 \mathrm{~N}$ & 80 & 8.64 & 76 & 12 & 15 & 2.6 & 41 & 169 \\
\hline 012 & $170 x$ & 30 & $51.0 \mathrm{~N}$ & 80 & $3.1 \mathrm{~W}$ & 76 & 12 & 15 & 3.4 & 52 & 170 \\
\hline 012 & $171 x$ & 30 & $50.0 \mathrm{~N}$ & 79 & $59.0 \mathrm{~W}$ & 76 & 12 & 15 & 4.2 & 147 & 171 \\
\hline 012 & $172 x$ & 30 & $49.2 \mathrm{~N}$ & 79 & $57.4 \mathrm{~W}$ & 76 & 12 & 15 & 4.6 & 198 & 172 \\
\hline 012 & $173 x$ & 30 & $49.5 \mathrm{~N}$ & 79 & $50.5 \mathrm{~W}$ & 76 & 12 & 15 & 5.6 & 300 & 173 \\
\hline 012 & $207 C$ & 28 & $59.3 \mathrm{~N}$ & 80 & $24.6 \mathrm{~W}$ & 76 & 12 & 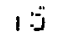 & 21.3 & 26 & 207 \\
\hline
\end{tabular}


Vertical profiles of salinity, temperature, sigma-t, D0, and nutrients

The symbols used in the following listings are defined as follows:

Header Data: $\quad$ Times are GMT (EST + 5)

Latitude and Longitude are from Loran C

Weather Data: These data are taken from the ship's log.

Wind speed (knots)

Wind direction (degrees)

Air temperature $\left({ }^{\circ} \mathrm{C}\right)$

Weather (WMO code 4501)

Barometric pressure (mb)

Sea State (WMO code 3700)

Wave direction (degrees)

Cloud type (not given)

Cloud amount (not given)

Visibility code (not given)

Observations: $\quad Z=$ Depth in meters

$\mathrm{T}=$ Temperature in ${ }^{\circ} \mathrm{C}$

$\mathrm{S}=$ Salinity in $\%$

$D=$ Density in sigma-t units

SVA $=$ Specific volume anomaly $\times 10^{5}$

$\mathrm{O}_{2}=$ Dissolved oxygen in $\mathrm{ml} / \mathrm{liter}$

$\mathrm{O}_{2}^{2}=$ oxygen saturation in $\mathrm{ml} / \mathrm{liter}$

AOU = Apparent oxygen utilization in $\mathrm{ml}<$ liter

$\mathrm{PO}_{4}=$ Phosphate concentration in $\mu$ mole/liter

$\mathrm{NO}_{3}^{4}=$ Nitrate concentration in $\mu$ mole/liter

$\mathrm{Si}^{3}=$ Silicate concentration in umole/liter 


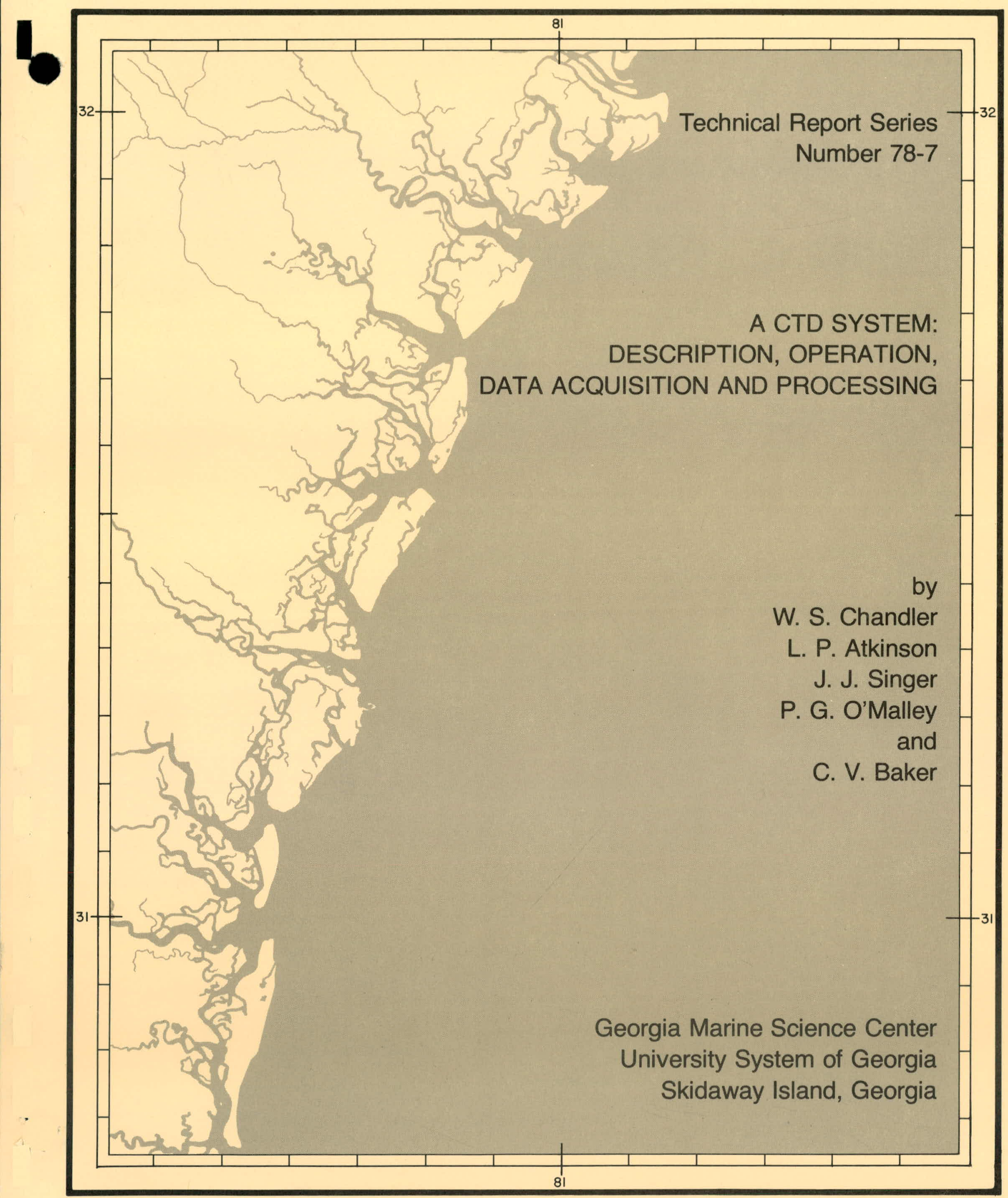


This report was prepared as an account of work sponsored by the United States Government. Neither the United States nor the United States Department of Energy, nor any of their employees, nor any of their contractors, subcontractors, or their employees, makes any warranty, express or implied, or assumes any legal liability or responsibility for the accuracy, completeness or usefulness of any information, apparatus, product or process disclosed, or represents that its use would not infringe privately-owned rights. 
A CTD SYSTEM: DESCRIPTION,

OPERATION, DATA ACQUISITION AND PROCESSING

\author{
W. S. Chandler \\ L. P. Atkinson \\ J. J. Singer \\ P. G. O'Malley \\ C. V. Baker
}

Skidaway Institute of Oceanography

P. 0. Box 13687

Savannah, Georgia 31406

October 1978

The Technical Report Series of the Georgia Marine Science Center is issued by the Georgia Sea Grant Program and the Marine Extension Service of the University of Georgia on Skidaway Island (P. 0. Box 13687, Savannah, Georgia 31406). It was established to provide dissemination of technical information and progress reports resulting from marine studies and investigations mainly by staff and faculty of the University System of Georgia. In addition, it is intended for the presentation of techniques and methods, reduced data and general information of interest to industry, local, regional, and state governments and the public. Information contained in these reports is in the public doma in. If this prepublication copy is cited, it should be cited as an unpublished manuscript. 


\section{TABLE OF CONTENTS}

Page

List of Tables...................... . $i$. .

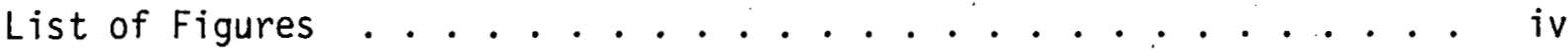

Acknowledgements .................. . . . . .

Introduction . . . . . . . . ........... I

Description of the System ................ 1

The CTU Sensor System . . . . . . .......... . 1

The Winch and Rosette Multi-Bottle Array .......... 4

The Deck Unit and Data Processing System .......... . 5

CTD Assembly . . . . . . . . . . . . . 8

Operating Procedure ...................... 8

Cyber Processing ................ 12

Temperature Lag .................. 12

Offsets and Course Filter ............ 14

Depth Latch and Averaging ............ . 14

Salinity ....................... 16

CTD Calibration .................. 16

Upcasts ..................... 16

CTD Error Analysis . . . . . . . . . . . . 16

Hewlett-Packard System ............... 19

Summary ...................... 23

References................... . . 24 24

Appendix I-Troubleshooting . . . . . . . . . . . 25

Appendix II-Cruise Supplies . . . . . . . . . . . 31

Appendix III - Cyber Programs . . . . . . . . . . . . . . 38

Appendix IV - HP Programs . . . . . . . . . . . . . . . 58

Appendix $V$-Sample HP-CTD Cast Printout . . . . . . . . 71

Appendix VI-Data Logging Forms . . . . . . . . . . . . . 75 


\section{LIST OF TABLES}

Table

Page

1. Component List of the CTD System . . . . . . . . . . 3

2. Parameters Measured and Sensor Ranges . . . . . . . . . . 4

3. Analog Characteristics ............... 7

4. CTD Operating Procedure . . . . . . . . . . . . 10

5. Suggested Sampling Depths . . . . . . . . . . . . 12

6. Ryher reTn nata Flow: Shipboard Acquisition to NODC Submission................... 13

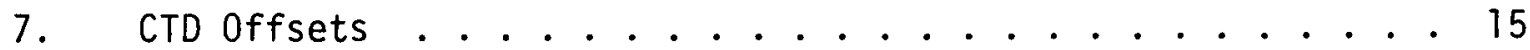

8. Broenkow's Salinity Equations . . . . . . . . . . 17

9. Flow Using Broenkow's Salinity Equations . . . . . . . . 18

10. Specifications for Plessey Model 9400 CTD System . . . . . . 19

11. Jaeger Pressure, Conductivity, Temperature, Salinity Table................... 20

12. HP-CTD Data Acquisition Scheme . . . . . . . . . . 22 


\section{LIST OF FIGURES}

\section{Figure}

Page

1. Schematic of CTD System ................ 2

2. Underwater Assembly ................. . . 6

3. Station Sheet ................... . 11 


\section{ACKNOWLEDGEMENTS}

The development of this system is the result of the cooperation of many people. The initial effort was inspired by the success of Dr. William W. Broenkow, Moss Landing Laboratories, Moss Landing, California, and his assistance is appreciated. We also thank $\mathrm{Mr}$. Lee Knight, engineer, Skidaway Institute, for his assistance in the development. Others who assisted through direct effort or helpful comments included Drs. Tom Curtin and T. N. Lee. Mrs. Cindy Miller typed the manuscript. Funding support for the system was and is provided by the Department of. Energy (Contract No. EY-76-S-09-0889) to Dr. L. P. Atkinson.

This report is published as a part of the Georgia Marine Science Center's Technical Report series issued by the Georgia Sea Grant Program under NOAA Office of Sea Grant \#04-8-M0-175. 


\section{INTRODUCTION}

The level of sophistication of today's marine research dictates the need for a rapid, reliable and accurate system for acquiring and processing temperature and salinity data.

In order to meet these needs, we at the Skidaway Institute of Oceanography have acquired a conductivity/temperature/depth (CTD) system. With principal support from the U. S. Department of Energy, we have developed the software and made numerous modifications to the hardware of the system, facilitating the principal task of investigating and explaining the chemical and physical processes in the South Atlantic Bight.

The purpose of this report is to describe our CTD system, document the developments and improvements we have made thus far, and relate our practical experience. It is hoped this report will be useful to oceanographers who now have, or will in the future have, a CTD system. The system is in a continual state of upgrading and modification, so this report represents the state of our system as of May 1978. Recent additions to the system are an HP Flexible Disk Unit (0.5 megabyte) and an HP-BCD Interface Bus. The $X B T$ has also been interfaced to the HP $9825 \mathrm{~A}$.

\section{DESCRIPTION OF THE SYSTEM}

The CTD system, shown schematically in Figure 1, has four major components: 1) the underwater unit, consisting of the depth, conductivity, and temperature sensors, and a mixer that powers the sensors and multiplexes the signals; 2) the winch, conductor wire, and Rosette Multi-Bottle Array fitted with a variety of Niskin sampling bottles; 3 ) the deck unit that powers the rosette and the CTD sensors and filters and digitizes the multiplexed CTD signal; and 4) the data processing system. The data processing system is actually two separate systems, one which records the raw data digitally on magnetic tape and another that performs real-time data processing and stores and displays the data in a variety of ways (i.e., Hewlett-Packard (HP) tape cartridge, calculator plotter, printer and analog plotter). All components of the CTD system are listed in Table 1. In the following discussion, the hardware components, the shipboard operating procedure, and the software of the system will be described, some in more detail than others. Troubleshooting problems, causes, and repairs for those problems that we have encountered are listed in Appendix I.

\section{The CTD Sensor System}

The CTD unit consists of the three sensors powered by a 120 ma constant current supply in the mixer. The sensors output AC signals of frequencies that are proportional to the parameters being sensed (Table 2). The AC signals from these sensors are multiplexed by the mixer and transmitted through a single conductor to the deck unit. Thus, only one conductor is required by the CTD for input power and an output multiplexed signal. To 


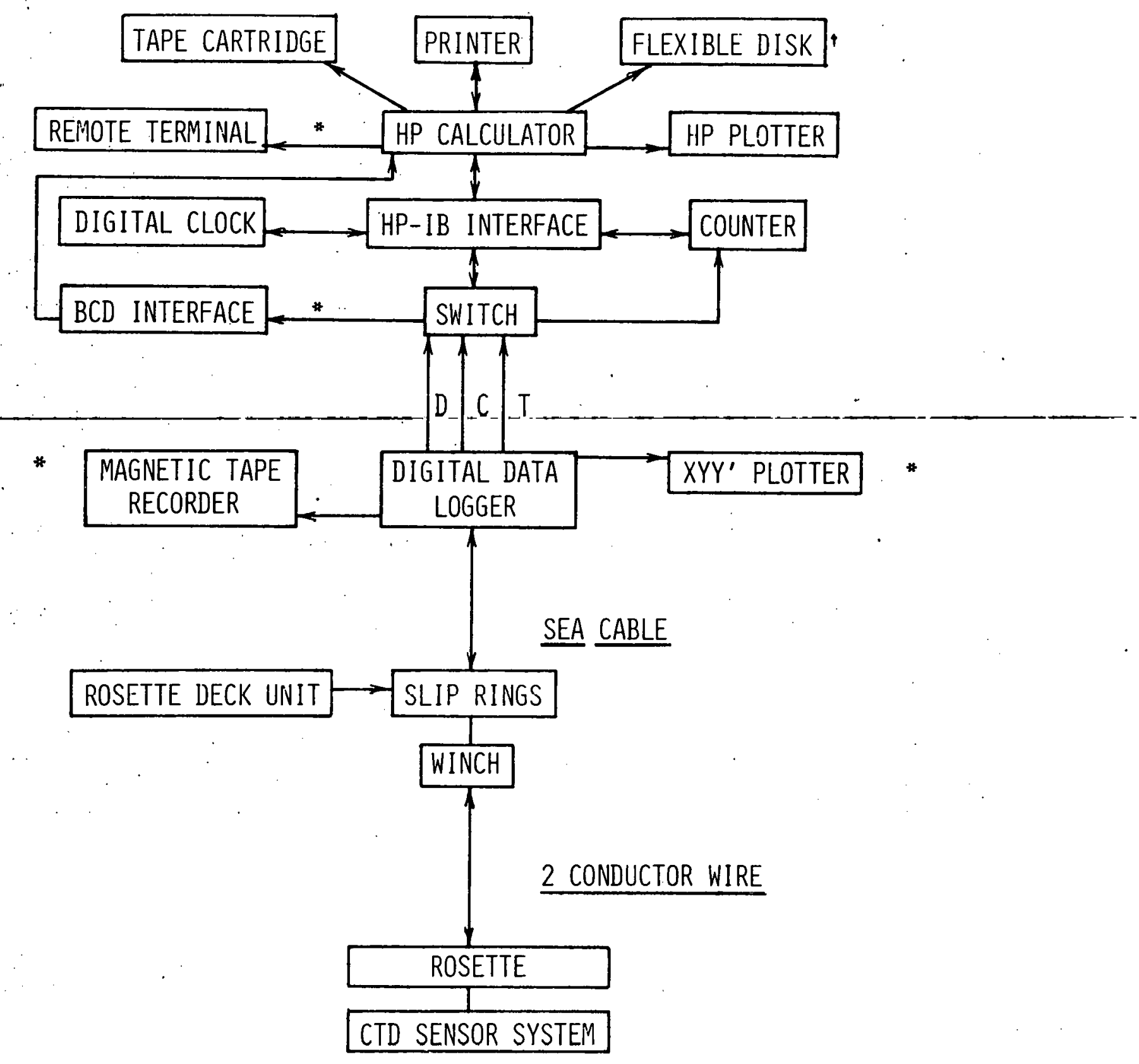

* OPTIONAL

+ RECENT ADDITION

Figure 1. Schematic of CTD System. 
Table 1. Component List of the CTD System.

Plessey Model 9400 System

Plessey Model 6500 Conductivity Sensor

Plessey Mode1 4500 Temperature Sensor

Plessey Model 4600 Pressure Sensor

Plessey Model 4400 Mixer

General Oceanics Rosette Multi-Bottle Array Model 1015 Mark V

Plessey Model 7400 Winch

Plessey Model 8400 Digital Data Logger

HP 7046A X-Y Recorder

Kennedy Model 1600 Incremental Magnetic Tape Recorder

HP 59307A VHF Switch

HP $98034 \mathrm{~A}$ HP-IB Interface

HP 5328A Universal Counter

HP 59309A HP-IB Digital Clock

HP 9825A Calculator

HP 9862A Calculator Plotter

Texas Instruments Silent 700 ASR Electronic Data Terminal 
guard against applying reverse voltage to the CTD sensors, a reverse biased diode is installed on the input power line to the mixer. Our system is dismantled and reassembled frequently and such protection is good insurance against damaging the sensors.

Table 2. Parameters Measured and Sensor Ranges.

\begin{tabular}{lll}
\hline \hline Parameter & Frequency Range & Sensor Range \\
\hline Temperature & $2127-4193 \mathrm{hz}$ & $-2-35^{\circ} \mathrm{C}$ \\
Conductivity & $4995-7901 \mathrm{hz}$ & $0-60 \mathrm{mmhos} / \mathrm{cm}$ \\
Depth & $9712-11288 \mathrm{hz}$ & $0-600 \mathrm{~m}$
\end{tabular}

The pressure vessels housing the sensors protect the sensors to 600 meters; however, flooding of the vessels, even at shallow depths, has been a problem. According to Plessey, Inc., replacing the plastic endcaps with stainless steel endcaps has solved the flooding problem. When our system is not furctioning properly and flooding is suspected, the sensors are disassembled and dried out. Pins in the connectors are also examined and dried out when wet. Care should be exercised when handling the 0-ring seals for the connectors. Silicone grease is used to seal the connections. It should be used sparingly to avoid insulating the electrical connecting pins.

We have spare C, T, and D sensors, connectors, Scotchcast electrical splicing kits, and wire harnesses so that any malfunctioning part can be replaced on board, allowing sampling to proceed after repairs are made.

The Winch and Rosette Multi-Bottle Array

The winch should be equipped with at least two conductor oceanographic electromechanical cables and the appropriate slip rings. One conductor is for the CTD and the other for the rosette. The winch should be capable of lowering and raising at rates of $15 \mathrm{~m} / \mathrm{min}$ or 1 ess. This 10 winch speed is necessary so that enough data points are collected to average over one meter increments, especially in strong thermoclines such as those encountered in the South Atlantic Bight.

Most oceanographic ships are equipped with conductor winches. However, the wire and/or slip rings are often in disrepair and should be checked out beforehand. We bring a portable winch for backup. Our portable winch (Plessey Model 7400 ) has $250 \mathrm{~m}$ of 4 -conductor wire and runs on 110 Volts AC power at a constant speed of $15 \mathrm{~m} / \mathrm{min}$. It handles a maximum load of 200 pounds, which is of minimum acceptable capability. Changes have been made to improve the operation of the winch. The operating switch installed by Plessey, Inc. burned out after very little use, so a heavy duty switching 
relay was installed. The new switch also increases safety since a spring returns it to the off position upon release; therefore, the operator cannot leave the switch unattended while the CTD is being raised or lowered. Solid state relays will be installed soon in order to minimize the electrical noise that spikes the data signals. An occasional overhaul and repainting of the winch housing is necessary due to corrosion from salt spray. It should also be disassembled, cleaned, and lubricated regularly.

The Rosette Multi-Bottle Array is manufactured by General Oceanics, Inc. as are the Niskin bottles mounted on it. The rosette is mounted on a frame which encloses the CTD sensor system (Figure 2). Reference to the "Fish" includes the sensors and rosette as one unit. The sensors are located beneath the rosette so that they are not in the wake of the rosette as the Fish is lowered through the water column. Conversely, during the upcast the sensors are in the wake of the rosette, degrading the data. During the upcast, the Niskin bottles are triggered serially on command from the deck unit at desired depths:

Plessey, Inc. had designed the system so that the sea cable from the. winch's single slip ring entered the rosette deck unit, then continued on to the digital data logger (DDL). The wire harness connected to the winch wire went through the rosette, then to the sensors. With only one path as such, powering the rosette with the high voltage required to trip a bottie interrupted the connection to the sensors.

We have modified the system and now use multi-conductor wire, allowing separate rosette and sensor operation. A branching cable connects the slip ring wires to the rosette deck unit and the DDL. An underwater harness branches from the winch wire connector to the rosette and to the CTD sensors.

The rosette requires continual mantenance to perform reliably. After every cast the cam/trip mechanism should be washed with fresh water and sprayed with a penetrating lubricant such as CRC. Recommended spare parts are appropriate relays for the winch, rosette, and rosette deck unit and SCR for the rosette deck unit.

A Helle pinger is mounted on the frame of the Fish to aid in recovery if the Fish becomes severed from the conductor wire. A buoy, chain, and anchor are also kept ready to use to mark a lost instrument.

The Deck Unit and Data Processing System

The Plessey Model 8400 Digital Data Logger (DDL) provides power to the CTD sensors, receives and demultiplexes the CTD signal, and determines the frequencies for depth, conductivity, and temperature for output to recording devices.

Several modifications were made to the DDL that make control of the system more convenient. An on-off switch for power to the Fish, as well as voltage and current meters, were installed in the front panel of the DDL. that readily indicate the power status of the Fish. Thus, an opened, closed, or shorted circuit in the system can easily be detected. One input 


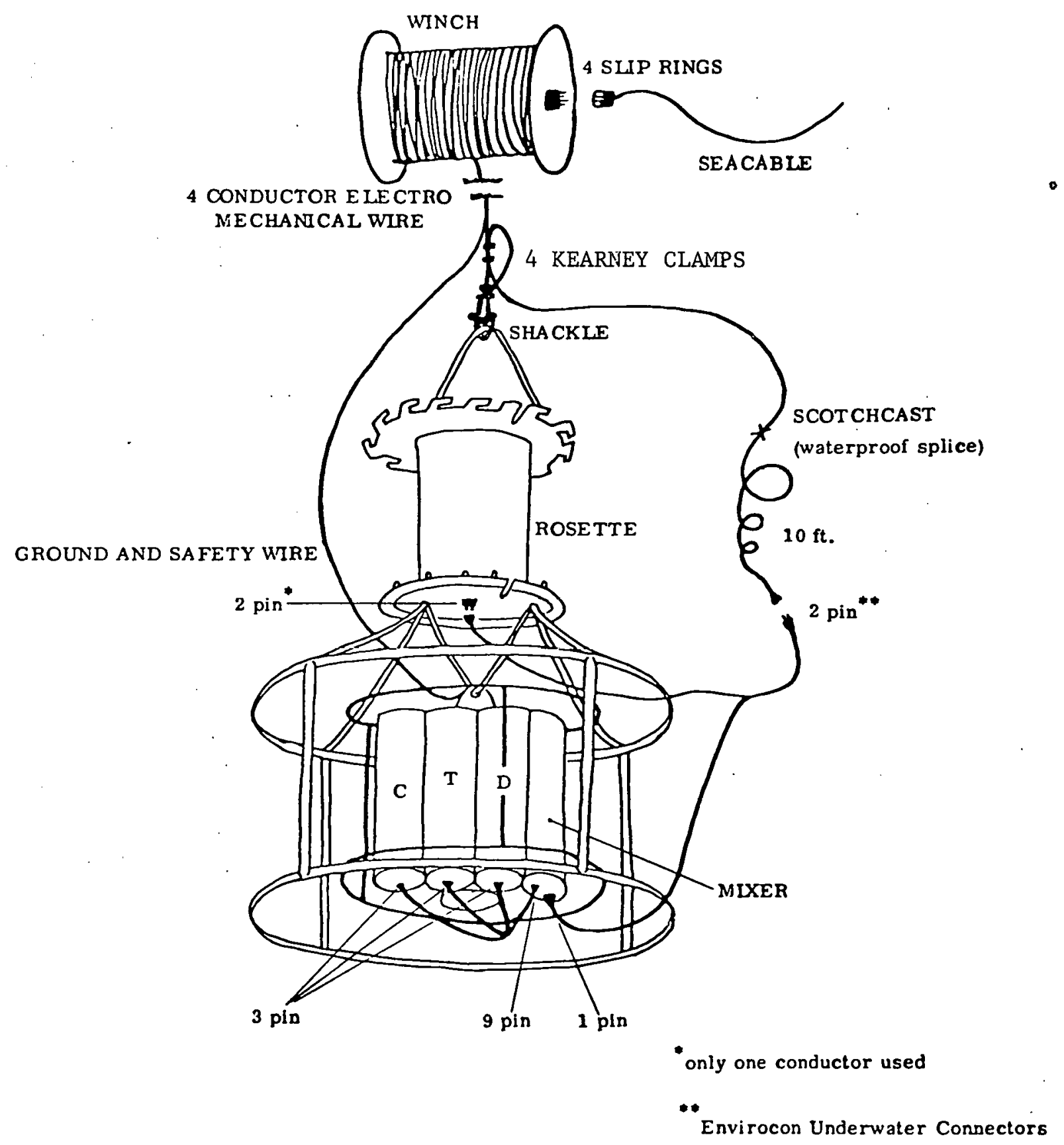

Figure 2. Underwater Assembly. 
and two outputs may be connected to one of the three channels, and a switch and porter LEDs for selecting a channel also were installed in the front panel of the DDL. The two outputs allow an oscilloscope and frequency counter to monitor any one channel at a time. A signal generator can be attached to the input. When using a winch with a short wire, a capacitor is put on the DDL input line to attenuate the signal, simulating a longer wire, and thus preventing interference of one channel with another. Another modification was the replacement of the 741 operational amplifier in the DDL with a higher grade ultra-linear operational amplifier.

Spare parts for the DDL include spare counting and digitizing boards. $D, C$, or $T$ counting and digitizing boards are essentially interchangeable. The plastic integrated circuits (ICs) that Plessey, Inc. used on our unit are less reliable than ceramic ICs and do not stand up to the humid, saltair environment. Consequently, our boards have been sprayed with a sealer to reduce failure. The newer Plessey, Inc. units, however, are equipped with ceramic ICs.

The digital signal output from the DDL is recorded on a Kennedy Model 1600 Incremental Magnetic Tape Recorder. The digital-to-analog converter in the DDL outputs an analog voltage proportional to the input range which drives an HP-XYY' Recorder (Model 7046A). The DDL folds the signals proportional to 0 to 10 Volts full scale (Table 3 ). We have found that shipboard generators are not stable, therefore, a line conditioner is required. The greatest problem caused by a power failure is that the magnetic tape must be started up again and the lack of continuity will cause tape reading errors when it is played back.

Table 3. Analog Characteristics.

\begin{tabular}{lccc}
\hline \hline & $\mathrm{D}$ & $\mathrm{C}$ & $\mathrm{T}$ \\
\hline Full Scale & $0-600$ & $0-80 \mathrm{mmhos} / \mathrm{cm}$ & $-5-35^{\circ} \mathrm{C}$ \\
Ranges & 4 & 8 & 8 \\
Folded Range Scale & $0.06666 \mathrm{v} / \mathrm{m}$ & $1 \mathrm{v} / \mathrm{mmhos} / \mathrm{cm}$ & $2 \mathrm{v} /{ }^{\circ} \mathrm{C}$ \\
Scale on Paper & $0.25 \mathrm{~cm} / \mathrm{m}$ & $2.5 \mathrm{~cm} / \mathrm{mmhos} / \mathrm{cm}$ & $5.0 \mathrm{~cm} /{ }^{\circ} \mathrm{C}$ \\
Finest Line Reading & $0.4 \mathrm{~m}$ & $0.2 \mathrm{mmhos} / \mathrm{cm}$ & $0.02^{\circ} \mathrm{C}$ \\
\hline
\end{tabular}

After this CTD system was in use for one year, an HP 9825A Calculator and peripherals were added which decreased the time and cost of data acquisition. The HP recording devices are the 9862A Plotter and the tape cartridge and printer in the $9825 \mathrm{~A}$ Calculator. 
CTD Assembly

Loading and assembling the components of the CTD system aboard various ships can become routine, as it has for us. The deck unit must be situated in a dry, preferably air-conditioned lab. Most of the HP components are rack-mounted, and the racks are bolted to lab tables. Everything that is not in a rack is secured with rope or tape.

A full complement of tools and spare electronic parts is necessary (see Appendix II for a complete list). If the ship does not have adequate communications between the lab, deck, and bridge, a portable intercom system is placed so that the deck unit operator can talk with the winch operator. The CTD sea cable must reach the deck, where it is affixed to the slip rings on the winch. Enough conductor wire is unspooled from the winch to reach the Fish after it is put through a block or metering wheel on an A-frame or boom that can be extended away from the ship. A splice must be made to join the Envirocon underwater connectur that mates the two pin connectors on the wire harness of the Fish to the conductor wire used on most ships' winches. Using Scotchcast over the spliced wire is a convenient method of waterproofing underwater connections. Scotchcast is mechanically and electrically sound because of its rigidity, unlike underwater tape that can bend and break. Our small winch is equipped with the connector that joins the conductor wire and Fish.

Niskin bottles appropriate for the anticipated sampling are mounted on the rosette. Invariably, a rack to hold three reversing thermometers (two of the protected type and one unprotected) is put on the bottle that will be tripped at the deepest sampling depth. Expendable Bathythermograph (XBT) pins (one ground to a point and another to a flat blade) are convenient tools to cock the bottles on the rosette and to rotate the cam/trip mechanism. While not in use, the Fish should be secured in a shaded place to protect the rosette's rubber pressure-compensating diaphram and reversing thermometers.

Early CTD tests indicated that the pendulum motion of the Fish while in the air between the deck and the water should be dampened by weight suspended from a rope harness beneath the Fish. In practice, the pendulum motion ceases as the weight enters the water. In calm-to-moderate seas, a 10-pound weight is used. In heavy seas more weight is added in accordance with the capacity of the winch. Our winch can support 30 pounds in addition to the weight of the Fish.

\section{OPERATING PROCEDURE}

To utilize ship time to the fullest, the CTD should be ready for a cast before arriving on station. The sensors are powered up for a short time on deck, and the frequencies for $D$ and $C$ are recorded to use as offsets from the manufacturer's zero $D$ and $C$ frequencies during the ensuing cast. In order to prevent accidents, power to the Fish is on only during a cast. The rest of the deck unit has power to it throughout the cruise to insure electronic stability. 
The HP plotter is programmed for 5 to $30^{\circ} \mathrm{C}$ and 0 to 400 meters full scale and the XYY' recorder plots conductivity and temperature-versus-depth proportional to the analog voltage output by the DOL (Table 3). The XYY' recorder must be calibrated often with a precision 10 Volt source to check the 0 to 10 Volts full scale. Both plotters are made ready before arriving on station.

Operating the CTD recording devices requires a complex system of button-pushing. Explicit instructions are displayed on the front of the deck unit (Table 4). Any deviation from this procedure produces a nonstandardized tape recording, making processing costly and time consuming. The standard tape recording for the Kennedy should have an identification (header) for each station cast followed by a file gap (blank mark of a specific length) and the cast data followed by a file gap. Missing or extra file gaps must be reported so that tape errors can be found and corrected.

A minimum of two people can operate the CTD. One person on deck runs the winch and guides the Fish into the water while the second person in the lab operates the data acquisition system and fills in the station sheets (Figure 3). Prior to lowering the Fish, the depth at a station should be determined by a depth sounding device, either on the bridge or in the lab. The data acquisition operator instructs the winch operator when to put the Fish in the water and when to lower and raise it. At the beginning of a cast, all of the data-recording devices should be simultaneously set into action. During the downcast, the HP Calculator is programmed to display depth so that the data acquisition operator can tell the winch operator when to stop lowering the Fish. Then the plotter pens are raised, and the programming is switched to a soak routine. After four minutes (to allow the reversing thermometers to equilibrate), the bottom sample bottles are tripped from the rosette deck unit. During the upcast, new plotter paper is used or the pens are raised to trace over the downcast plot. The vertical temperature plot is used to decide where to stop and trip bottles on the upcast (Table 5). While the Fish is stopped at the predetermined sampling depths, the rate of data acquisition is slowed down by using a mid-depth soak program.

After the surface sample bottles are tripped, power to the Fish is turned off, and the Fish is brought on deck and secured. The rest of the CTD operation may be carried out while the ship is steaming towards the next station. Dissolved oxygen, nutrient, salinity and other samples are drawn from the Niskin bottles into appropriate collecting bottles, treated, and stored as needed. The data acquisition operator records the bottle numbers for the samples taken on the station sheets. The reversing thermometers are read, and temperatures are recorded on the station sheets for calibration of the CTD temperature sensor. After the samples are taken, the rosette cam/trip mechanism should be rinsed with fresh water and spraycd with a marine lubricant. Then the cam must be reset and the Niskin bottles cocked in preparation for the next cast. The station sheets and plots are filed, and all data acquisition devices are made ready for the next station.

Examples of other forms we use are in Appendix VI. 
Table 4. CTD Operating Procedure.

1. Determine the depth of the water column.

2. Turn Rosette ON (Smal1 button under "8400 DIGITAL").

3. Set heading data. $(10(00))$ for upcasts; $00(00)$ for downcasts).

*4. Push "ENTER" five times; push "FILE GAP" once.

5. Set up HP programming (trk1, 1df0, RUN). Try to time the readiness of the HP to receive data so that steps 6 and 7 can immediately be completed.

6. When ready to begin cast push "START" on recording control (tape should begin moving in short increments). Turn on recorder "SERVO" and -put pen-on-"RECORD"

7. Lower CTD (stop 2-3 meters from the bottom).

8. Change to scan 10 at bottom of cast. LIFT PEN.

9. Follow the 4 minute soak instructions on the HP.

10. Push "STOP" after soak. Change back to scan 0.

11. Push "FILE GAP" once.

12. Follow steps 3-6 for upcast.

13. Raise CTD to desired depths and "FIRE" Niskin bottles. (Change to scan 1 while firing bottles).

14. Turn Rosette off (small button under "8400 DIGITAL").

15. For the next cast, repeat procedure with step 1.

16. When tape is completed change header to 9999 and push "ENTER" five times, then push "FILE GAP" three times, rewind and remove tape.

*IF "FILE GAP" IS PUSHEd TWICE IN A ROW OR NEGLECTED AT ANY TIME, PLEASE NOTE THIS ON THE RESPECTIVE STATION SHEET. DO NOT "ENTER" A HEADER AND "FILE GAP" MORE THAN ONCE. JUST NOTE THE ERRONEOUS HEADER NUMBER. 
STATION SHEET

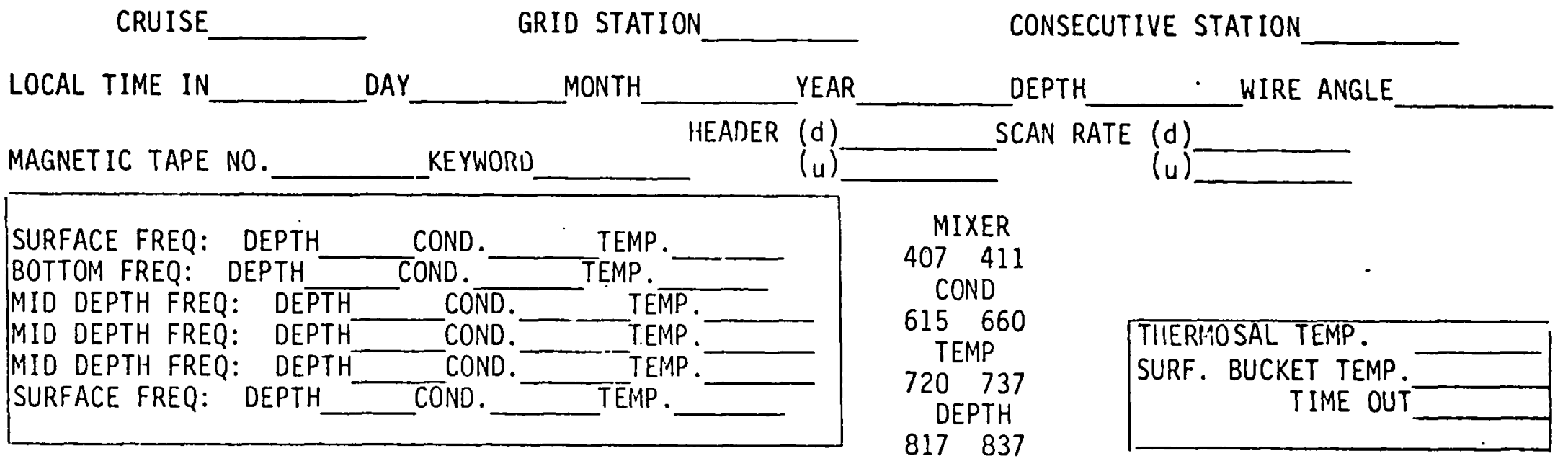

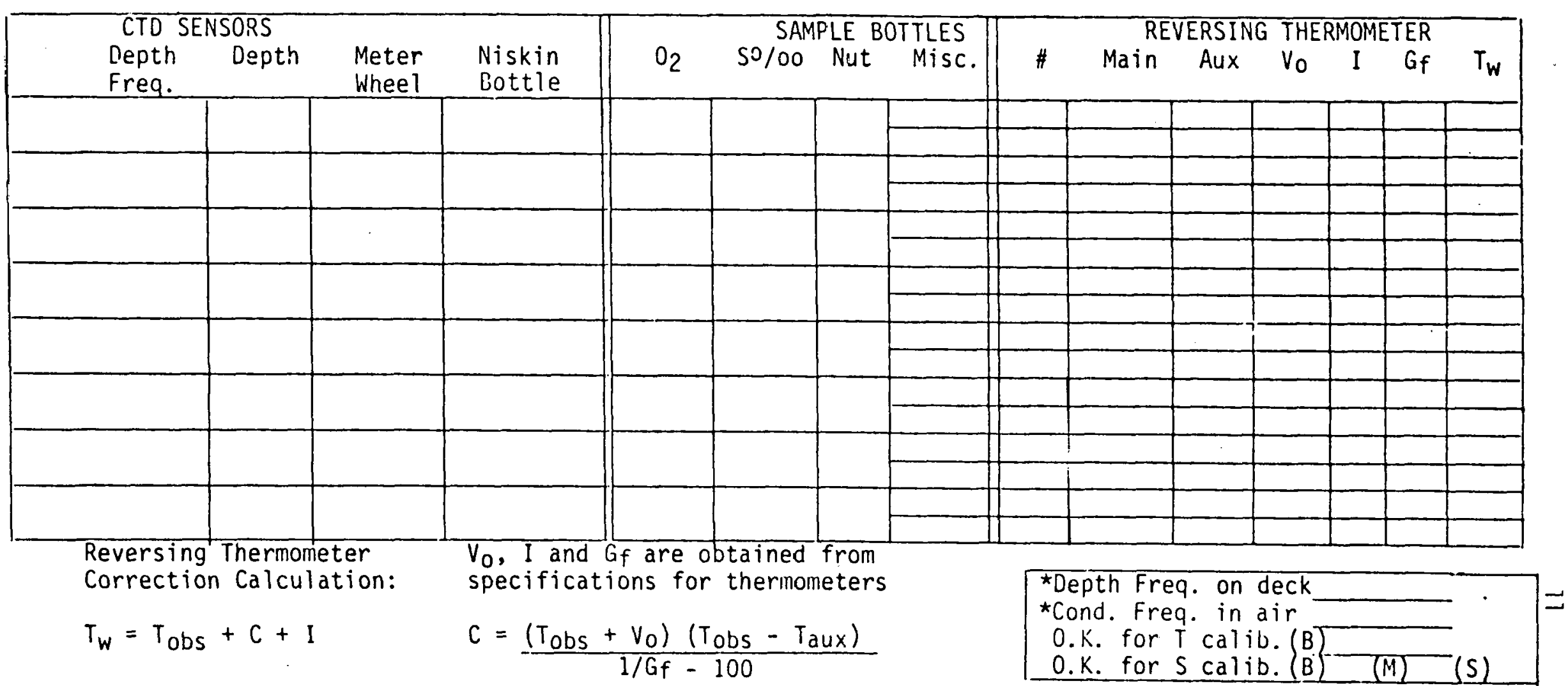

Figure 3. Station sheet. 
Table 5. Suggested Sampling Depths.

Depth less than $50 \mathrm{~m}$ :

Mixed - Surface and bottom

Two-Layer - Surface, above or below the thermocline and bottom

Depth greater than $50 \mathrm{~m}$ and less than $100 \mathrm{~m}$ :

$0,25,50,75,100$ (or bottom)

Depth greater than $100 \mathrm{~m}$ :

$0,50,100,150,200,300,400$ (or bottom)

\section{Cyber Processing}

After a cruise, the magnetic tape is sent to the University of Georgia Computer Center and stored in their tape 1 ibrary. The tape is then processed at Skidaway where there is access to interactive time-sharing of the University's Control Data Corporation Cyber 70 through a telephone link.

During the shipboard CTD operations, binary coded frequencies are recorded on 7-track magnetic tapes by the Kennedy recorder. The processing of tape data has been adapted from that described by Scarlet (1975). Table 6 shows the basic data flow, though program modifications are necessary for the special situations that arise for each new data set. The programs are listed in Appendix III. The final programming step, NUTMERG, merges additional station data, i.e., nutrients, weather, latitude, longitude, etc., to the CTD data for submission to the NODC. This final product is stored on magnetic tape in our computer system and all data, i.e., CTD, XBT, chemical, etc., are available from the NODC.

Another program, CEMLIST, calculates specific volume anomally, oxygen saturation and apparent oxygen utilization (from the International 0ceanographic Tables, 1966), and the distance between successive stations from the NODC formatted data. CEMLIST reformats the NODC data for presentation in a technical report.

Temperature Lag. The Plessey temperature sensor time constant is reported to be 0.35 seconds. The depth and conductivity sensors each have a reported 0.1 second time constant, so that temperature lags behind depth and conductivity. Therefore, the "real" T at the time that D and $C$ are sampled must be calculated from the "indicated" T. From Scarlet, 1975: 
Table 6. Cyber CTD Data Flow: Shipboard Acquisition to NODC Submission.

Data Source/Disposition Program Data File

Digital Data Logger to Tape CTDRUN (Copies tape data to a computer file)

KEYWORD

MAGREAD (Converts binary coded data to decimal)

BIRANG

CTDUNIT (Converts decimal units to engineering units)

LAGFILT (Temperature lag and course filter)

CAL

Primary Calibration from BROENK (Calculates salinity and sigma-t) Bottle Casts

LATCH

DLATCH (Removes decreasing and repeated depths)

CTDATA

CTDAVE (One meter averaged data)

AVE

NODCFO (Converts to NODC format)

NODC + HEAD

NUTMERG (Merges NODC data with headers and chemical data)

Submission to NODC

FINAL

CEMLIST (Calculates specific volume anomaliy, oxygen utilization, etc.)

TECHNICAL REPORT 


$$
\begin{aligned}
T_{R(n)}= & T_{I(n)}+\frac{\tau\left(T_{I(n+1)}-T_{I(n-1)}\right)}{2 \sigma} \\
\text { where: } & T_{R}=\text { real } T \\
T_{I} & =\text { indicated } T \\
\tau & =\text { sensor time constant } \\
\sigma & =\text { sampling rate } \\
n & =1,2,3 \ldots \text { (each CTD scan) }
\end{aligned}
$$

The sensor with the slowest time constant determines the fastest rate at which a CTD scan can be updated by the digital-to-analog converter in the DDL. The T time constant of 0.229235 seconds governs the fastest rate for this system. Setting the scan interval to 00 provides the fastest rate. The scan interval can be set as high as 99 , with each of the 100 increments slowing the sampling rate down by multiples of 0.229235 seconds. The temperature lag of this sytem can be calculated from:

$$
T_{R(n)}=T_{I(n)}+\frac{0.35\left(T_{I(n+1)}-T_{I(n-1)}\right)}{(2)(0.229235)(\operatorname{Scan}+1)}
$$

Offsets and Course Filter. Depth and temperature offsets (Table 7), determined by the on-deck frequencies for depth and temperature, are applied in program CTDUNIT. The offsets correct for the deviation of the zero depth and temperature frèquency readings from the frequencies preset by the manufacturer. Our temperature sensor has shown no signs of drift or offset with age when compared with protected reversing thermometer readings, so no offset has been applied. In addition, no offset is determined for conductivity though it, like depth, has been observed to drift slightly with age. This drift is compensated for in BROENK by a salinity offset from a comparison of bottle salinity with CTD salinity. This salinity offset may be depth dependent due to the effect of pressure on the conductivity sensor. A simple test for this is a linear regression analys is of bottle salinity less CTD salinity versus depth. When sampling at depths less than 50 meters or when no pressure effect is apparent, the mean offset from bottle salinities less CTD salinities for all stations is most appropriate.

LAGFILT course filters electronic, slip ring, and winch noise. The windows for the filter are $\pm 5 \mathrm{~m}, \pm 0.8 \mathrm{mmhos} / \mathrm{cm}$ and $\pm 0.5^{\circ} \mathrm{C}$.

Depth Latch and Averaging. The normal descent rate of 0.25 meters/second and scan rate of 0.229 seconds should provide 17 scans/meter. The number of scans/meter varies because the motion of the Fish reflects ship roll. Repeated depths are removed by the DLATCH program. The average number of scans (remaining) through a 1 meter interval is $10 \pm 7$. Scans of data 0.5 meters above and below each 1 meter are averaged for depths less than 100 meters and data 2.5 meters above and below each 5 meters are averaged for depths greater than 100 meters. 
Table 7. CTD Offsets.

\begin{tabular}{|c|c|c|c|c|c|c|}
\hline Cruise & $D(m)$ & $\begin{array}{c}T\left({ }^{0} \mathrm{C}\right) \\
S / N 720\end{array}$ & $\begin{array}{l}S(\%)(\text { Bottle-CTD }) \\
\quad \text { or equation }\end{array}$ & $\begin{array}{l}\text { Sal. Eq. } \\
\text { (from) }\end{array}$ & $\begin{array}{l}\text { Data } \\
\text { Source }\end{array}$ & $\begin{array}{c}\text { Deepest } \\
\text { Calib. depth }\end{array}$ \\
\hline $\begin{array}{l}\text { ObIS V (July-Aug. 1976): } \\
\text { Hydro } 1 \\
\text { Bio } 1 \\
\text { Hydro/Bio } 2 \\
\text { Aborted Hydro } 3 \\
\text { Bio } 3 \\
\text { Hydro } 4 \\
\text { Bio } 4 \\
\text { Hydro } 5\end{array}$ & $\begin{array}{l}\text { None } \\
\text { None } \\
\text { None } \\
\text { None } \\
\text { None } \\
\text { None } \\
\text { None } \\
\text { None }\end{array}$ & $\begin{array}{l}\text { None } \\
\text { None } \\
\text { None } \\
\text { None } \\
\text { None } \\
\text { None } \\
\text { None } \\
\text { None }\end{array}$ & $\begin{array}{l}+.138 \pm .030 \\
+.033 \pm .023 \\
+.099 \pm .008 \\
+.090 \pm .017 \\
+.0101 \pm .022 \\
+.073 \pm .025 \\
+.064 \pm .021 \\
+.019 \pm .008 \\
+.068 \pm .009\end{array}$ & $\begin{array}{l}\text { Knowles } \\
\text { Knowles } \\
\text { Knowles } \\
\text { Knowles } \\
\text { Knowles } \\
\text { Knowles } \\
\text { Knowles } \\
\text { Knowles } \\
\text { Knowles }\end{array}$ & $\begin{array}{l}X Y Y \\
X Y Y \\
X Y Y \\
X Y Y \\
\text { Mag tape } \\
\text { Mag tape } \\
\text { Mag tape } \\
\text { Mag tape } \\
\text { Mag tape }\end{array}$ & $\begin{array}{l}55 \mathrm{~m} \\
55 \mathrm{~m} \\
55 \mathrm{~m} \\
55 \mathrm{~m} \\
55 \mathrm{~m} \\
55 \mathrm{~m} \\
55 \mathrm{~m} \\
55 \mathrm{~m} \\
55 \mathrm{~m}\end{array}$ \\
\hline CI 12 (December, 1976) & None & None & $S=S_{0}+0.023-1.57 \times 10^{-4}$ & Broenkow & Mag tape & $438 \mathrm{~m}$ \\
\hline AD 477 (ApriT, 197?) & +1.714 & Hone & $S=S_{0}+.007-4.97 \times 10^{-4} \mathrm{D}$ & Bennett & Mag tape & $192 m$ \\
\hline BF 38 (Miay, 1977) & +2.29 & None & $+.06 \pm .015$ & Broenkow & $\mathrm{HP}$ & $74 m$ \\
\hline CI 03 (July, 1977) & +2.29 & None & $S=S_{0}+.101-3.05 \times 10^{-4} \mathrm{D}$ & Broenkow & Mag tape & $204 m$ \\
\hline BF 57 (September, 1977! & +2.29 & None & $S=S_{0}+.113-5.19 \times 10^{-4} \mathrm{D}$ & Broenkow & Mag tape & $196 \mathrm{~m}$ \\
\hline CI 07 (November, 1977) & +3.24 & None & Not determined* & Broenkow & $X Y Y^{\circ}$ & \\
\hline BF 07 (February, 1978) & & None & $-.003 \pm .004$ & Broenkow & HP & $209 m$ \\
\hline PIERCE (March, 197.3) & $+4.57(-1.14) * \star$ & None & $+.042 \pm .013$ & Broenkow & $4 P$ & $398 m$ \\
\hline CI 01 (Apri], 1978) & & None & $+.125 \pm .013$ & Broenkow & HP & $253 m$ \\
\hline BF 21 (May, 1978) & & None & $+.136 \pm .011$ & Broenkow & $H P(\& X Y Y)$ & $15 m$ \\
\hline
\end{tabular}

${ }^{*}$ Change $C$ sensor (S/N 615 replaced with S/N 660); **change D sensor (S/N 817 replizced with S/N 837) 
Salinity. Salinity is calculated from CTD scans using shortened equations adapted from those of Bradshaw and Schleicher (1965) and Cox et al. (1967) by Broenkow (1977) (Table 8). To determine the effects of pressure and temperature on the conductivity sensor, uncorrected and then corrected salinity calculations are required according to the steps in Table 9.

CTD Calibration. The CTD system is calibrated against water samples from rosette bottles tripped in mixed layers to insure that the sensors and the bottles are both sampling the same water. When a mixed layer is not observed, a comparison cannot be made at that station. Consequently, an offset equation is derived from the available data and applied to the entire cruise (Table 7). A Plessey Model 6230N Lab Salinometer is used to determine the salinity of water samples from the rosette bottles.

The Onslow Bay 1976 project was an exception. Each leg of the project had its nwn offset. At times, more than one offset was necessary during a single leg because of repairs to the CTD system. "Many problems were encountered during this initial break-in period. Modifications to the system, as described on pages 1-7 of this report, overcame many of the problems.

Upcasts. Our original Plessey CTD system was set up using a oneconductor wire that would carry the multiplexed C, T, and D and rosette bottle tripper signals. Sending the signal to trip a bottle interrupted the data reception from the CTD (actually sending spiked signals). For this reason, only downcast data was recorded on tape, and bottles were tripped on the upcasts.

The system has since been modified. Two wires and the shield (used for a ground wire) of a four-conductor wire are used, separating the CTD and rosette signals. Upcast data is recorded, unaffected by bottle tripping. However, the sensors lie in the wake of the rosette during upcasts and this causes turbulent disturbance of the water being sampled; therefore, the data reported to NODC and in technical reports are the downcasts oniy, except were downcast data is lost or incomplete.

CTD Error Analysis. The Plessey Model 9400 CTD system has the following rated accuracy, resolution, and time constants (Table 10). Since salinity is not measured directly, it has to be calculated from the parameters indicated in Table 10, resulting in the composite errors of the $C, T$, and $D$ sensors and the salinity equation. 
Table 8. Broenkow's Salinity Equations.

$$
\begin{aligned}
R_{Z}= & 1+.01\left\{\left(1.551-.0453 T+59 \times 10^{-5} T^{2}\right)\right. \\
& \left.+\frac{1}{4}(35-S)\left(.043-.0017 T+23 \times 10^{-6} T^{2}\right)\right\}\left\{1.037 \times 10^{-3} Z\right. \\
& \left.-32 \times 10^{-9} Z^{2}\right\} \\
A_{T}= & \left(676547+20131.5 T+99.89 T^{2}-.1943 T^{3}-.00672 T^{4}\right) 10^{-6} \\
R_{T}= & \frac{C(S, T, Z)}{R_{Z} A_{T} 42.896} \\
\Delta_{15}= & R_{T}\left(R_{T}-1\right)(T-15)\left\{96.7-72 R_{T}+37.3 R_{T}{ }^{2}\right. \\
& \left.-\left(.63+.21 R_{T}{ }^{2}\right)(T-15)\right\} 10^{-5} \\
R_{15}= & R_{T}+\Delta_{15} \\
S^{0} / 00= & .08996+28.2972 R_{15}+12.80832 R_{15}{ }^{2}-10.67869 R_{15}{ }^{3} \\
& +5.98624 R_{15}{ }^{4}-1.32311 R_{15}{ }^{5}
\end{aligned}
$$

where: $\mathrm{R}=$ conductivity ratio

$$
\begin{aligned}
& Z=\text { depth (meters) } \\
& T=\text { temperature }\left({ }^{\circ} \mathrm{C}\right) \\
& \mathrm{C}=\text { measured conductivity (mrahos } / \mathrm{cm}) \\
& \dot{S}=\text { salinity }(\% / 00)
\end{aligned}
$$


Table 9. Flow Using Broenkow's Saḷinity Equations.

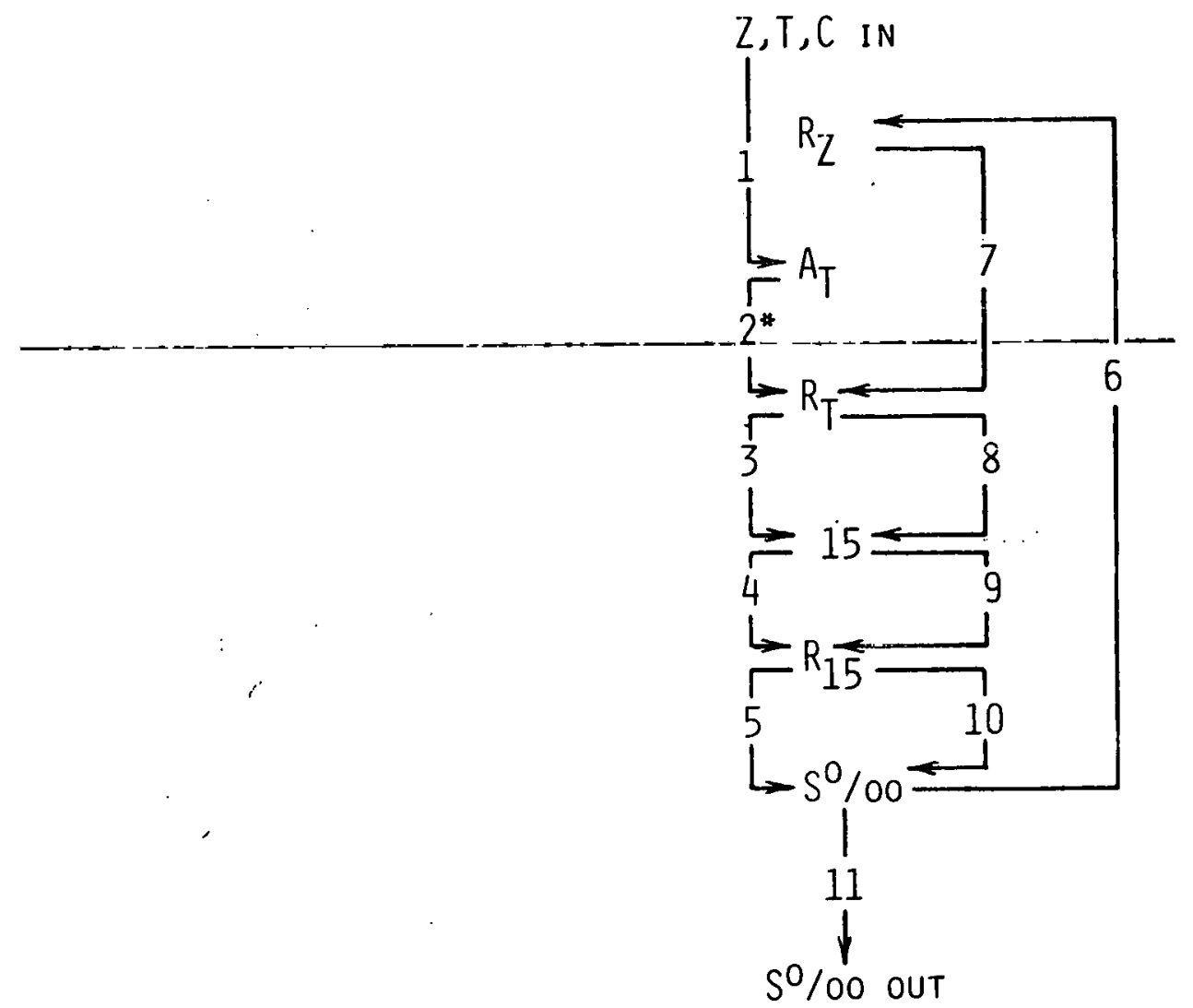

*without the $\mathrm{R}_{Z}$ term

$R_{Z}=$ pressure effect on conductivity

$A_{T}=$ temperature effect

$R_{T}=R(S, t, p)$ conductivity ratio

$\Delta_{15}=t_{15}$ correction (International 0ceanographic Tables, 1966)

$R_{15}=R\left(S, 15^{\circ} C, 0\right)$ 
Table 10. Specifications for Plessey Model 9400 CTD System.

\begin{tabular}{lccc}
\hline & Conductivity & Temperature & Depth \\
\hline Accuracy & $\pm 0.03 \mathrm{mmho} / \mathrm{cm}$ & $\pm 0.02^{\circ} \mathrm{C}$ & $\pm 1.5 \mathrm{~m}$ \\
Resolution & $0.0002 \mathrm{mmho} / \mathrm{cm}$ & $0.0001^{\circ} \mathrm{C}$ & $0.0012 \mathrm{~m}$ \\
Time Constant & $0.1 \mathrm{sec}$ & $0.35 \mathrm{sec}$ & $0.1 \mathrm{sec}$ \\
\hline
\end{tabular}

We have progressively used several different compact sets of salinity equations in the HP calculator, going from Knowles (1973) to Bennett (1976) to Broenkow (1977). The knowles equation does not consider the influence of depth on the calculation of salinity and, therefore, is not recommended. Both Bennett and Broenkow include depth dependence. The Bennett equations apparently have received considerable acceptance and use (Lewis and Perkin, 1978). We have gravitated further, now using the equations of Broenkow (1977). These equations give a better fit to Jaeger's (1973) table of salinities calculated from experimental conductivities, temperatures, and depths than Bennett for the temperature, depth, and salinity ranges we experience in our work (Table 11). This in turn gives a better real time look at the salinity structure before introducing the salinity calibration data.

By varying "real" $C, T$, and $D$ by the rated sensor accuracies in the salinity equation, the maximum error attributable to each sensor can be determined. Those stations with deep casts that have a low conductivity and temperature have been found to cause the maximum error, therefore, those "real" data are used to determine each parameters' effect on the salinity equation. The composite maximum error has been approximately $\pm 0.06 \%$ for the "real" data sets. However, the standard deviation of all mixed layer samples taken for salinity calibration purposes implies greater accuracy, namely $\pm 0.03 \%$ after offset. We believe this value is a more realistic measure of the quality of the data set, except in strong thermoclines $\left(\Delta T>1^{\circ} \mathrm{C} / \mathrm{m}\right)$.

\section{Hewlett-Packard System}

The previously described digital magnetic tape recording has many advantages. However, there are several serious disadvantages. The principal weaknesses are the lack of onboard confirmation of data acquisition, no real time presentation of data, and costly computer analysis. In an effort to avoid these disadvantages and provide a more redundant system, we have assembled a data acquisition system based on a HewlettPackard 9825A calculator.

Present7y, our HP-CTD data acquisition system is in the final developmental stages. The remaining problems are principally with software. Our intentions are to use the HP tape cartridge or flexible disk as a primary 
Table 11. Jaeger Pressure, Conductivity, Temperature, Salinity Table.

\begin{tabular}{|c|c|c|c|c|c|c|c|}
\hline $\begin{array}{l}\text { Depth } \\
\mathrm{m} \\
\end{array}$ & $\begin{array}{c}\text { Pressure } \\
\text { dbar }\end{array}$ & $\begin{array}{c}\text { Conductivity } \\
\text { mmhos } / \mathrm{cm}^{2}\end{array}$ & $\begin{array}{l}\text { Temperature } \\
{ }^{\circ} \mathrm{C} \\
\end{array}$ & $\begin{array}{c}\text { Experimental } \\
\text { Salinity } \\
\text { ppt }\end{array}$ & $\begin{array}{c}\text { Knowles } \\
\text { Salinity } \\
\text { ppt }\end{array}$ & $\begin{array}{c}\text { Bennett } \\
\text { Salinity } \\
\text { ppt }\end{array}$ & $\begin{array}{c}\text { Broenkow } \\
\text { Salinity } \\
\text { ppt }\end{array}$ \\
\hline $\begin{array}{l}0.00 \\
0.00 \\
0.00 \\
0.00 \\
0.00\end{array}$ & $\begin{array}{l}0.00 \\
0.00 \\
0.00 \\
0.00 \\
0.00\end{array}$ & $\begin{array}{l}25.381 \\
29.267 \\
33.340 \\
37.582 \\
41.977\end{array}$ & $\begin{array}{r}0.00 \\
5.00 \\
10.00 \\
15.00 \\
20.00\end{array}$ & $\begin{array}{l}30.200 \\
30.200 \\
30.200 \\
30.200 \\
30.200\end{array}$ & $\begin{array}{l}30.163 \\
30.177 \\
30.184 \\
30.187 \\
30.189\end{array}$ & $\begin{array}{l}30.186 \\
30.188 \\
30.187 \\
30.188 \\
30.188\end{array}$ & $\begin{array}{l}30.183 \\
30.186 \\
30.192 \\
30.196 \\
30.197\end{array}$ \\
\hline $\begin{array}{r}0.00 \\
0.00 \\
1714.00 \\
1714.00 \\
0.00\end{array}$ & $\begin{array}{r}0.00 \\
0.00 \\
1723.00 \\
1723.00 \\
0.00\end{array}$ & $\begin{array}{l}46.510 \\
51.149 \\
39.146 \\
43.629 \\
38.606\end{array}$ & $\begin{array}{l}25.00 \\
30.00 \\
15.00 \\
20.00 \\
15.00\end{array}$ & $\begin{array}{l}30.200 \\
30.200 \\
31.000 \\
31.000 \\
31.118\end{array}$ & $\begin{array}{c}30.193 \\
30.188 \\
- \\
- \\
31.105\end{array}$ & $\begin{array}{l}30.187 \\
30.186 \\
30.989 \\
30.988 \\
31.105\end{array}$ & $\begin{array}{l}30.199 \\
30.197 \\
31.003 \\
31.004 \\
31.113\end{array}$ \\
\hline $\begin{array}{r}0.00 \\
0.00 \\
0.00 \\
0.00 \\
1714.00\end{array}$ & $\begin{array}{r}0.00 \\
0.00 \\
0.00 \\
0.00 \\
1723.00\end{array}$ & $\begin{array}{l}38.094 \\
44.580 \\
50.571 \\
29.021 \\
29.779\end{array}$ & $\begin{array}{r}13.80 \\
20.90 \\
27.20 \\
0.00 \\
0.00\end{array}$ & $\begin{array}{l}31.619 \\
31.619 \\
31.619 \\
35.000 \\
35.000\end{array}$ & $\begin{array}{c}31.610 \\
31.610 \\
31.611 \\
34.976 \\
-\end{array}$ & $\begin{array}{l}31.611 \\
31.608 \\
31.605 \\
34.992 \\
34.993\end{array}$ & $\begin{array}{l}31.619 \\
31.618 \\
31.618 \\
35.000 \\
35.007\end{array}$ \\
\hline $\begin{array}{r}3427.99 \\
5141.99 \\
6855.98 \\
0.00 \\
0.00\end{array}$ & $\begin{array}{r}3446.00 \\
5169.00 \\
6892.00 \\
0.00 \\
0.00\end{array}$ & $\begin{array}{l}30.451 \\
31.035 \\
31.541 \\
33.443 \\
38.073\end{array}$ & $\begin{array}{r}0.00 \\
0.00 \\
0.00 \\
5.00 \\
10.00\end{array}$ & $\begin{array}{l}35.000 \\
35.000 \\
35.000 \\
35.000 \\
35.000\end{array}$ & $\begin{array}{c}- \\
- \\
34.987 \\
34.989\end{array}$ & $\begin{array}{l}34.996 \\
34.995 \\
34.993 \\
34.995 \\
34.990\end{array}$ & $\begin{array}{l}35.023 \\
35.040 \\
35.069 \\
34.998 \\
34.999\end{array}$ \\
\hline $\begin{array}{r}0.00 \\
1714.00 \\
3427.99 \\
5141.99 \\
0.00\end{array}$ & $\begin{array}{r}0.00 \\
1723.00 \\
3446.00 \\
5169.00 \\
0.00\end{array}$ & $\begin{array}{l}42.896 \\
43.623 \\
44.269 \\
44.838 \\
47.891\end{array}$ & $\begin{array}{l}15.00 \\
15.00 \\
15.00 \\
15.00 \\
20.00\end{array}$ & $\begin{array}{l}35.000 \\
35.000 \\
35.000 \\
35.000 \\
35.000\end{array}$ & $\begin{array}{c}34.990 \\
- \\
- \\
- \\
34.989\end{array}$ & $\begin{array}{l}34.991 \\
34.987 \\
34.988 \\
34.993 \\
34.989\end{array}$ & $\begin{array}{l}35.000 \\
35.004 \\
35.012 \\
35.025 \\
34.998\end{array}$ \\
\hline $\begin{array}{r}0.00 \\
1714.00 \\
0.00 \\
0.00 \\
1714.00\end{array}$ & $\begin{array}{r}0.00 \\
1723.00 \\
0.00 \\
0.00 \\
1723.00\end{array}$ & $\begin{array}{l}53.046 \\
53.746 \\
58.324 \\
47.186 \\
48.020\end{array}$ & $\begin{array}{l}25.00 \\
25.00 \\
30.00 \\
15.00 \\
15.00\end{array}$ & $\begin{array}{l}35.000 \\
35.000 \\
35.000 \\
38.951 \\
39.000\end{array}$ & $\begin{array}{c}34.993 \\
- \\
34.989 \\
38.944 \\
-\end{array}$ & $\begin{array}{l}34.988 \\
34.985 \\
34.988 \\
38.945 \\
38.989\end{array}$ & $\begin{array}{l}35.000 \\
35.000 \\
34.999 \\
38.956 \\
39.008\end{array}$ \\
\hline $\begin{array}{r}1714.00 \\
0.00 \\
0.00 \\
0.00 \\
0.00\end{array}$ & $\begin{array}{r}1723.00 \\
0.00 \\
0.00 \\
0.00 \\
0.00\end{array}$ & $\begin{array}{l}53.495 \\
46.290 \\
54.130 \\
61.369 \\
32.880\end{array}$ & $\begin{array}{r}20.00 \\
13.80 \\
20.90 \\
27.20 \\
0.00\end{array}$ & $\begin{array}{l}39.000 \\
39.333 \\
39.333 \\
39.333 \\
40.196\end{array}$ & $\begin{array}{c}- \\
39.319 \\
39.321 \\
39.322 \\
40.178\end{array}$ & $\begin{array}{l}38.989 \\
39.320 \\
39.320 \\
39.315 \\
40.192\end{array}$ & $\begin{array}{l}39.009 \\
39.330 \\
39.331 \\
39.331 \\
40.205\end{array}$ \\
\hline $\begin{array}{l}0.00 \\
0.00 \\
0.00 \\
0.00 \\
0.00\end{array}$ & $\begin{array}{l}0.00 \\
0.00 \\
0.00 \\
0.00 \\
0.00\end{array}$ & $\begin{array}{l}37.869 \\
43.090 \\
48.524 \\
54.151 \\
59.961\end{array}$ & $\begin{array}{r}5.00 \\
10.00 \\
15.00 \\
20.00 \\
25.00\end{array}$ & $\begin{array}{l}40.196 \\
40.196 \\
40.196 \\
40.196 \\
40.196\end{array}$ & $\begin{array}{l}40.192 \\
40.194 \\
50.192 \\
40.188 \\
40.193\end{array}$ & $\begin{array}{l}40.198 \\
40.194 \\
40.193 \\
40.188 \\
40.187\end{array}$ & $\begin{array}{l}40.203 \\
40.205 \\
40.203 \\
40.199 \\
40.202\end{array}$ \\
\hline 0.00 & 0.00 & 65.911 & 30.00 & 40.196 & 40.190 & 40.186 & 40.201 \\
\hline
\end{tabular}


data storage device, with the Kennedy tape recorder and HP XYY' recorder available as backup units. The expanded scale of the HP XYY' recorder $(0.20 / \mathrm{cm}, 0.4(\mathrm{mmhos} / \mathrm{cm}) / \mathrm{cm}, 4 \mathrm{~m} / \mathrm{cm})$ still makes it valuable for determining at which depths to trip Niskin bottles on the upcast, having plotted $T$ and $C$ versus $D$ during the downcast.

A single HP tape cartridge, which is structured with two parallel tracks, contains programs for the CTD acquisition on one track and has space for data storage for as many as 30 stations on the other. The programs are listed in Appendix IV. The master program instructs the operator how to initiate a CTD cast. Special function keys are defined by this program that enable interactive control of data acquisition modes, i.e., downcast, upcast, soak routines. All subsequent programs prompt the operator on procedures and ask for the necessary variable entries, i.e., offsets, data storage, file numbers. An example of the internal printer output is shown in Appendix $V$.

The data acquired by the HP is treated using a software scheme similar to the Cyber programming but is real time (Table 12). While the CTD is on the deck of the ship the frequencies for $D$ and $C$ are entered following the station number. These variables are used in the frequency to engineering unit conversion as the frequencies for zero $D$ and $C$.

Three scans of CTD are acquired and the temperature lag is calculated similar to the Cyber programming:

$$
T_{R(n)}=T_{I(n)}+\frac{0.35\left(T_{\left.I(n+1)-T_{I(n-1)}\right)}\right.}{2(0.405)}
$$

The difference is the sampling rate; 0.405 seconds are required for the HP to acquire and process a CTD scan. The length and complexity of the HP data acquisition program governs the sampling rate. Further data processing is done after data is acquired and recorded on preliminary tape cartridge files at this fastest sampling rate. A T-versus-D plot is done in real time.

After the CTD Fish is lowered to within 3 meters of the bottom, data collection is stupped dnd a soak routine begins. Depth, temperature, and salinity are displayed and printed during the four minutes that the reversing thermometers remain at a constant depth for equilibration. $T$ and $S$ printed during the soak are used to calibrate the CTD against the reversing thermometers and salinity bottle samples taken at that depth.

The preliminary down cast data is then averaged for each meter and recorded permanently on the HP tape cartridge. Data collection during upcasts is taken in the same manner. If calibration is to be done at depths other than the deepest sample depth, a mid-depth soaking routine is used to print $D, T$, and $S$ while a rosette bottle is being tripped. The middepth soak can be used at any time the CTD Fish is stopped, so that excessive data is not recorded. At the end of the upcast the preliminary data is averaged to meter increments and recorded on a permanent file. 
Table 12. HP-CTD Data Acquisition Scheme.

ENTER HEADER \& C AND D ON DECK FREQ.

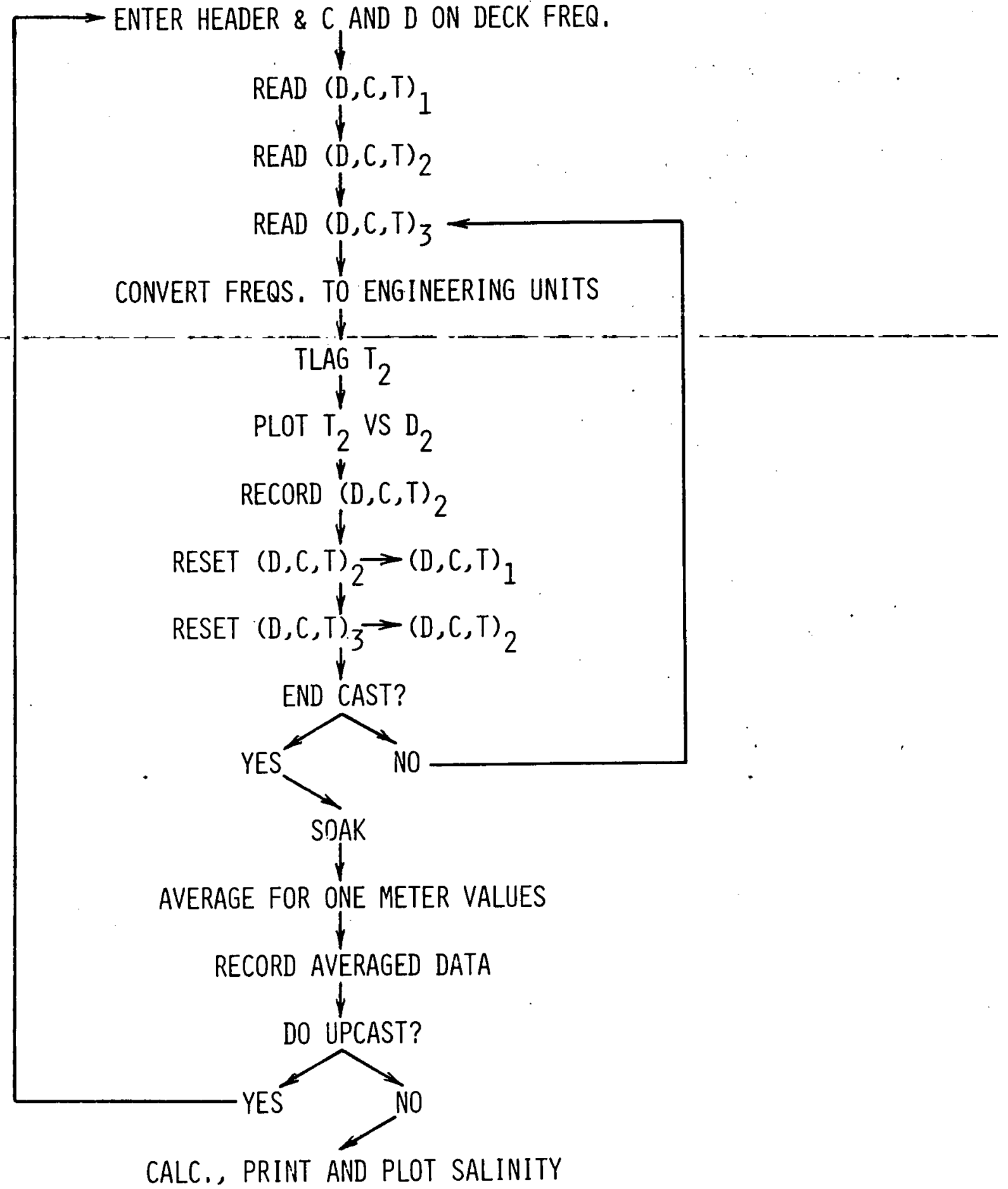


Our HP calculator was purchased with $8 k$ bytes of core memory. With the program taking up one-fourth of the core, only 100 CTD scans could be input before the array had to be recorded on a preliminary file. The core was then free to receive 100 more CTD scans. As much as two meters of data were missed while the calculator stopped to record each 100 scans. Sixteen $k$ bytes of memory were recently added. Initial tests indicate that $80 \mathrm{~m}$ can be stored in an array before copying to the tape cartridge. Use of disk would eliminate this problem.

Further data processing is done aboard ship. Salinity (preferably from downcast data) is plotted versus depth. Until calibration data becomes available, plots are made using uncorrected salinity values. Temperature and salinity onshore-offshore transects are plotted in vertical cross section as well as horizontal plots and station locations. The HP software for this was developed at Skidaway Institute.

\section{SUMMARY}

The system described herein is a powerful tool for hydrographic data collection and reduction. Over 900 vertical CTD profiles and 45 hours of horizontal profiling (pumping water over the sensors in a bucket on deck) have been successfully completed in the two years since purchasing the initial system components. Through the first year, a $96 \%$ success rate was achieved while the system was being tried and upgraded. The success rate improved in the second year and continues to do so.

The portability of the system has allowed us to work from many of the ships available for research in the South Atlantic Bight. We take part in cooperative cruises and can operate on a minimum of manpower.

Real time data processing aboard ship has been achieved. The HP programmed plotter provides immediate visual presentation of the data. The sensors show drift with time; therefore, an extension calibration scheme is performed for every cruise. Once calibrated and formatted for NODC, cruise data is presented in technical report form. 


\section{REFERENCES}

Bennett, A. S. 1976. Conversion of in situ measurements of conductivity to salinity. Deep-Sea Res., 23: $757-165$.

Bradshaw, A. and K. E. Schleicher. 1965. The effect of pressure on the electical conductance of sea water. Deep-Sea Res., 12: 151-162.

Broenkow, W. W., W. B. Abrahams, and R. R. McInnis. 1977. A CTD Data Acquisition System for Coastal Applications. Preprint: Proceedings Fourth STD/Ocean Systems Conference, January 19-27, 1977. Plessey Environmental Systems, San Diego, California.

Cox, R. A., F. Culkin, and J. P. Riley. 1967. The electrical conductivity/ chlorinity relationship in natural sea water. Deep-Sea Res., 14: 203-220.

Jaeger, J. E. 1973. The determination of salinity from conductivity, temperature, and pressure measurements. Proceedings of the Second STD Conference and Workshop, January 24-26, 1973. P1 essey Environmental Systems, San Diego, California.

Knowles, C. E. 1973. CTD sensors, specific conductance and the determination of salinity. University of North Carolina Sea Grant Program, Sea Grant Publications UNC-SG-73-16.

Lewis, E. L. and R. G. Perkin. 1978. Salinity: Its Definition and Calculation. Journal of Geophysical Research, 83: 466-478.

National Institute of Oceanography of Great Britain and UNESCO. 1966. International Oceanographic Tables, Wormley, Godalming, Surrey, England.

Scarlet, R. I. 1975. A data processing method for salinity, temperature, depth profiles. Deep-Sea Res., 22: 509-515. 
APPENDIX I.

Troubleshooting 
This section summarizes some of our problems and cures in a troubleshooting chart. This is not an attempt to list every possible problem nor the probable remedy. 
CTD TROUBLESHOOTING

PROBLEM

* No $C, T$, and $D$ signals in air

PROBABLE CAUSE

1) Have not made all connections (DDLslip rings - CTD)

2) Bad ground

3) Short in armored cable

4) Bad mixer

5) Bad connection to $C, T$, and $D$ sensors from mixer
CORRECTION

1) Check connections

2) Check ground

3) Cut off bad part of cable and re-scotchcast

4) Replace or repair mixer

5) Check connection for too much dielectric grease Loss of $C, T$, or D signal
in air
1) Bad counter or digitizing board in $\mathrm{DDL}$

2) Bad connection to sensor
1) Replace or repair board

2) Check connection for too much dielectric grease
Loss of $C, T$, or $D$ signal or some combination of signals in air but recovery of signal with depth
1) Too much silicone dielectric grease in connection
1) Clean connector pins and sleeves
Loss of all signals as

Fish enters water
1) Bad ground
1) Check ground
2) Leak in C, T, D, or mixer pressure housings containing electronics
2) Disassemble and dry with alcohol and Q-tips
3) Leak in 9 pin or 3 pin plugs to sensors
3) Dry and seal with silicone dielectric grease
Loss of $C, T$, and $D$ signals at depth but recovery with return to ship

1) Wire crimped and wedged in pressure housing of mixer
1) Replace or repair wire 1) Replace or repair wire

*See "Volt-Amp Meter Readings" for troubleshooting problems (page 30). 


\section{Occasional spiking \\ (blinking) in $C, T$, and \\ $D$ signals}

1) Fluctuation in $A C$ system

2) Wet or bad connection to slip rings

3) Loose ground

4) Some stress on a connector (on ship or on Fish)

5) Wet 9 pin or 3 pin connectors on sensors
1) Use different wall sockets for power cords

2) Check slip ring wiring

3) Check ground

4) Check all connectors

5) Dry pins

1) Relays to winch

Spiking of $C, T$, and $D$ signals when winch is turned on or off
Occasional D spiking beginning at a particular depth from one cast to the next
1) Bad armored conductor cable
Spiking (blinking) of $\mathrm{C}$ signal in high salinity water but $0 . K$. in air or in low salinity water. Also note on $X Y Y^{\prime}$ that while signal occasionally spikes, conductivity remains too constant (false reading)
1) Defective frequency plug on $C$ board in DDL (Changes the limit of acceptable frequencies which it will allow to pass into DDL for processing)
Blinking $C$ and analog $\left(X Y Y^{\prime}\right)$ spikes
1) Capacitor to attenuate Fish power to DDL when using a short conductor wire is not in place
1) Inspect cable and cut off bad section
1) Replace plug or capacitor on plug

\section{1) Connect capacitor}

1) Solid state relays would be an improvement 
PROBLEM

Good signals to DDL but nothing to $X Y Y^{\prime}$ plotter

Good signals to DDL but nothing to frequency counter

Not tripping bottles

in air
PROBABLE CAUSE

1) S3 switch on back of DDL in wrong position

1) Bad conductor between the two
CORRECTION

1) Flick switch to proper position

1) Repair or replace conductor
1) Incorrect armored cable hookup

2) Bad ground

3) Loose or wet connection on Fish

4) Bad relays in deck box

5) Bad step motor

6) Bad cold solders in deck unit
1) Check hookup

2) Check ground

3) Check connections

4) Replace relays

5) Repair or replace step motor

6) Check solders
Bottles trip in air but not in water
1) Leakage in armored conductor cable
1) Cut off bad cable and re-scotchcast (entire cable may be bad) 
Our Plessey 8400 Digital Data Logger, which also powers the CTD, was modified to indicate sea cable voltage and amperage on the front panel. The following table is very useful for troubleshooting.

\section{Volt-Amp Meter Readings}

CTD on Deck:

Open Circuit high voltage, low amperage*

Short Circuit:

Short is in deck unit

Short is in Fish low voltage, correct amperage

$$
2 \text { Volts }
$$

5 Volts

During CTD cast:

Short Circuit

Corrosion voltage decrease

voltage increase

* For our 250 meter, 4-conductor wire the normal readings are 30 Volts and 135 milliamps. 
APPENDIX II.

Cruise Supplies 
CRUISE SUPPLIES

General

Drafting supplies

Ruler

Dividers

10 point dividers

Rubber station stamp and ink pad

Stop watch

HP-55 hand held calculator and power cord

Meter-fathoms-feet disc

2 boxes of pencils (\#2)

2 magic markers (black)

Graph paper for XYY' and $9862 A$ plotters $(25 \times 38 \mathrm{~cm})$

15 legal size white envelopes

2 clip boards

10 large plastic bags

Spare tubing for Niskin Bottles

2 spare Niskin end caps (tops)

Spare landyards and micro-press clamps for Niskin Bottles

Pair of stainless steel wing bolts for each Niskin Bottle (in tool box)

2 scotch cast (type 82-A1) (2 others in electronics box)

1 box scotch auto-electric sealing compound (1ive rubber tape)

5 G.0. messengers (for Niskins in case of CTD failure)

Inclinometer (wire angle)

Bicycle stretch straps

3 - radiator specialty straps (black rubber) for CTD

1 pair of gloves

$50^{\prime} 1 / 8^{\prime \prime}$ nylon line (for tying down)

$50^{\prime}$ ' $1 / 4^{\prime \prime}$ clothes line (for tying down)

2 cans of CRC spray

4 nutrient freezing boxes

2 ice chests (if entering another port)

Nutrient Bottles

Large dissolved oxygen (B.0.D. Bottles)

2 boxes of large salinity bottles ( 70 total)

1 box of small salinity bottles (50 total)

2 black pails with attached rope

Bucket thermometer and spare thermometer $\left(0.1^{\circ} \mathrm{C}\right.$ increments)

Weather radio

Anchor, $500 \mathrm{ft}$. of line and buoy

Desk lamp

Lab stool

Lawn chairs

2 unprotected thermometers

4 protected thermometers ( 7715 and 7718 are best)

10 and $30 \mathrm{lb}$. weights

CTD weight harness

Thermometer reader-magnifier

7 small Niskin Bottles ( 1.7 liter) - 3 with thermometer racks

2 large (5.0 liter) Niskin Bottles

NODC sheets

Ringbinder reinforcers 
Cruise Supplies - General (cont'd)

"Cruise Log" ring-binder notebook with: cruise plan, cruise log, data cassette logs (10), cruise section logs (10), station sheets (120), XBT event log (15), CTD procedure, D, C, T frequency conversion tables, protected and unprotected thermometer calibration sheets (copies), oxygen analysis procedure (3), oxygen data sheets (15)

XBT Tester

XBT test canister

XBT chart paper $(0-200 \mathrm{~m}$ roll)

$X B T$ 's

XBT recorder

$X B T$ gun

Plessey Lab Salinometer

Standard seawater

CTD-Rosette with Helle Pinger

CTD Winch +3 welding brackets

CTD par.ts box

ELECTRONIC GEAR

EQUIPMENT MANUALS

OXYGEN ANALYSIS SUPPLIES

TOOL BOX 


\section{CRUISE SUPPLIES}

\section{ELECTRONIC GEAR}

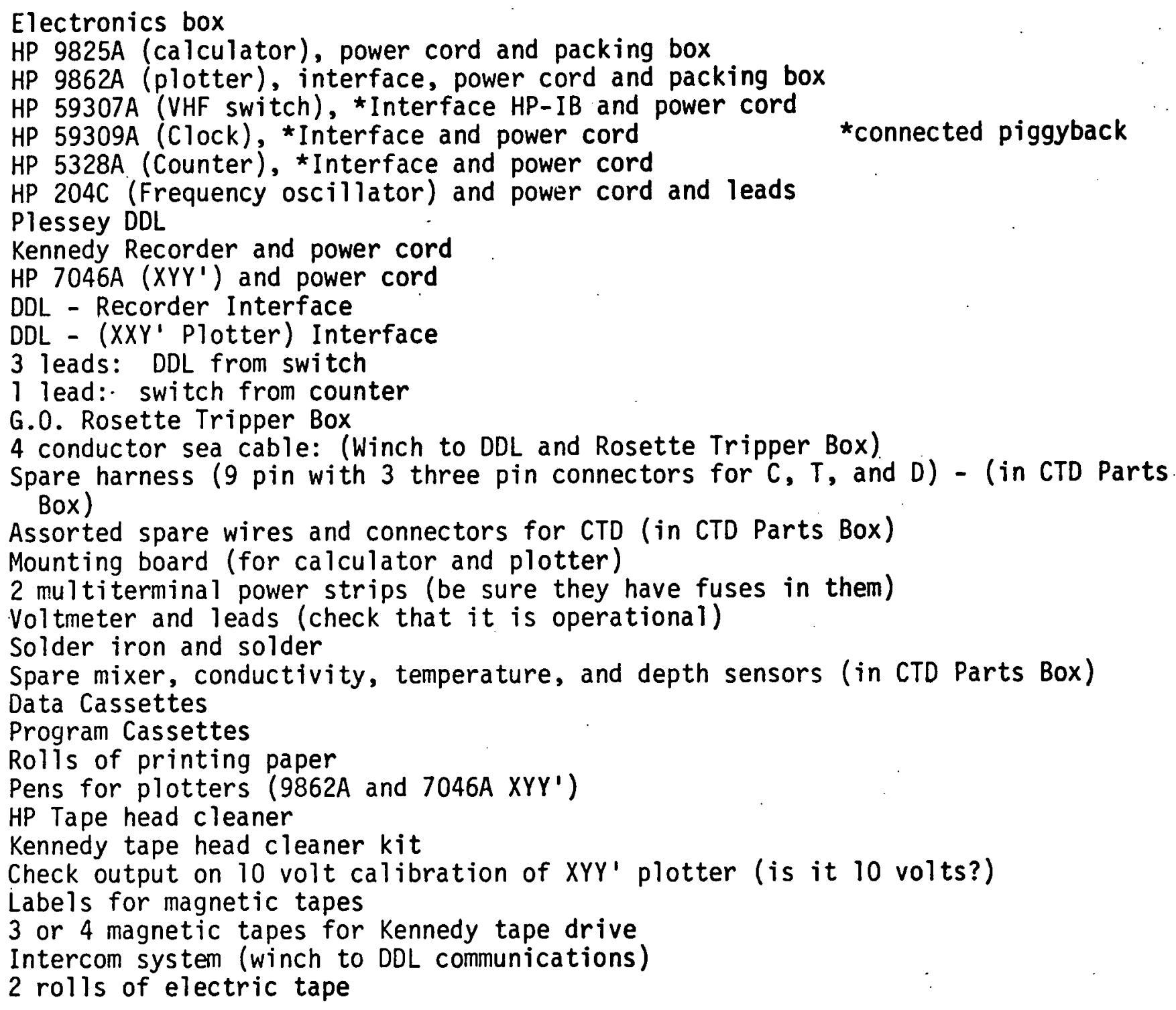




\title{
CRUISE SUPPLIES
}

\section{EQUIPMENT MANUALS}

\author{
HP 9825A Calculator: Operating and Programming \\ HP 9825A Calculator: System Test Booklet and Test Cartridge 09825-90035 \\ HP 9825A Calculator: Quick Reference Guide \\ HP 9825A Calculator: General I/0 Programming \\ HP 9825A Calculator: Extended I/0 Programming \\ HP 9825A Calculator and Plotter: Plotter Programming \\ HP 9825A Calculator: Advanced Programming \\ HP 9825A Calculator: String Variable Programing \\ HP 9825A Calculator: Systems Programming \\ HP 98034A HP-IB Interface: Installation and Service Manual \\ HP 59307A VHF Switch: Operating and Service Manual \\ HP 59309A ASCII Digital Clock: Operating and Service Manual \\ HP 7046A X-Y Recorder: Operating and Service Manual \\ HP 5328A Universal Counter: User and Service Manual \\ HP 204C/204D Oscillator: Operation and Service Manual \\ HP Option 020 Digital Voltmeter: Installation and Service Manual \\ HP Software General Statistics Binder with 3-tapes \\ Kennedy Model 1600 Incremental Tape Recorder: Operation and Maintenance Manual \\ G.0. Model 1015 Rosette: Instruction Manual \\ G.0. Mode1 $3070 \mathrm{Film}$ Recording Thermograph: Instruction Manual \\ Plessey Model 7400 Winch: Instruction Manual \\ Plessey Model 9400 CTD System: Instruction Manual \\ Plessey Model 8400 DDL: Instruction Manual \\ Sippican Model R-603 XBT System: Instruction Manual \\ Plessey Model 6230N Laboratory Salinometer.
}




\section{OXYGEN ANALYSIS SUPPLIES}

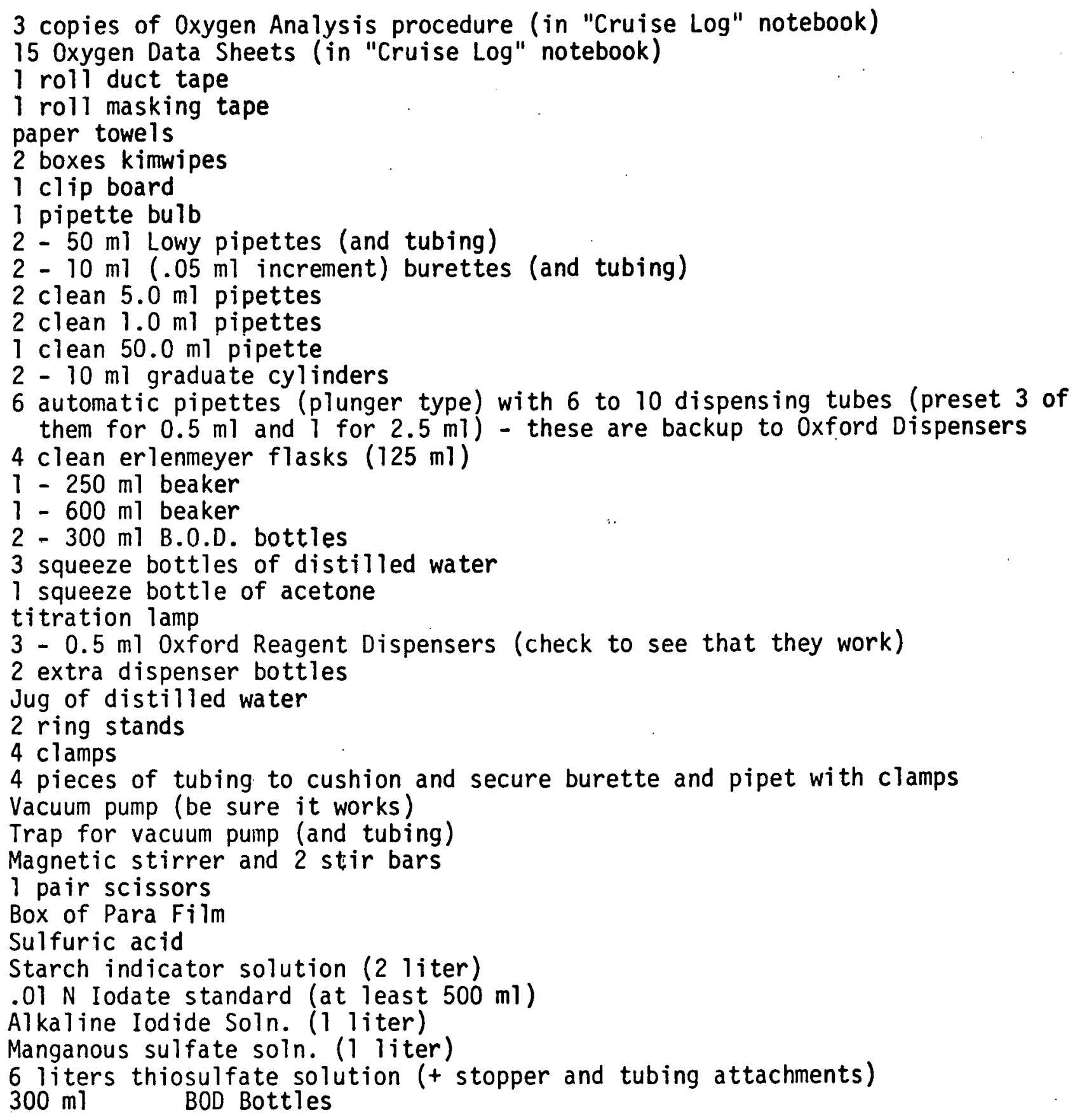


CRUISE SUPPLIES

TOOL BOX

1 roll masking tape

1 roll duct tape

1 roll electric tape

1 tube silicone lubricant, 1 tube silicone glue

1 can PVC cement

1 magic marker (black)

1 hammer

3 screw drivers

2 phillips screw drivers (large and small handled)

6 jewelers screw drivers

Channel lock pliers

Needle nose pliers

Regular pliers

Cutting pliers

Vise grips

Cable cutters (that don't fit in Tool Box)

Allen wrenches

Tape measure

Small ratchet set

$\star 1$ knife or cutting tool

Triangle file for Copenhagen water

Niskin bottle cocker and screw driver

Electric drill (Separate from box)

Drill bits

* $]$ pair scissors

8" adjustable wrench

$2-1 / 2^{\prime \prime}-9 / 16^{\prime \prime}$ open end wrenches

1 - 1/2" wrench $0 / \mathrm{c}$

1 - 9/16" wrench o/c

$2-3 / 8^{\prime \prime}-7 / 16^{\prime \prime}$ open end wrenches

1 - 3/8" wrench $0 / \mathrm{c}$

1 - $7 / 16^{\prime \prime}$ wrench $0 / \mathrm{c}$

1 - 1/4"-5/16" open end wrench

1 - 5/16" wrench $0 / \mathrm{c}$

1 - 3/4" chisel

Wire strippers

ACCESSORIES TO TOOL BCX

2 - 1/8" thimbles

2 - 3/16" thimbles

2 - 7/16" thimbles

Pair of stainless wing bolts for each Niskin bottle Nuts and bolts for securing DDL and XYY' plotter

2 shackles

Hard wire (for securing shackles)

Wire clamps (U-bolts)

2" C-clamps

Assorted bolts, wood screws, and screw eyes 
APPENDIX III.

Cyber Programs

7 
The following programs are written in CDC Fortran IV extended time sharing (FTNTS). The language is identical to Fortran IV except for the addition line numbers and the relaxed column requirements. These programs are stored and run in compiled (binary) form. 
PROGRAM CTDRUN

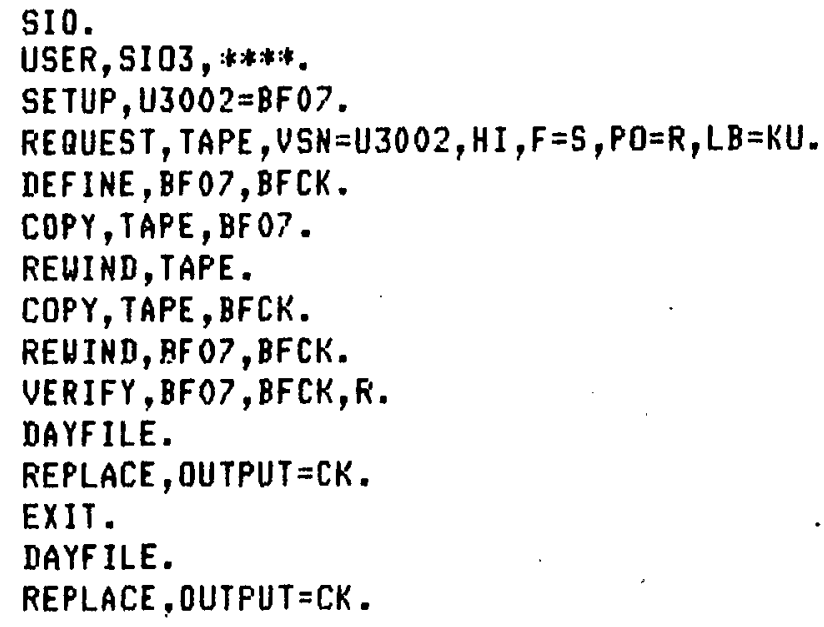


FROGRAA MAGREAD

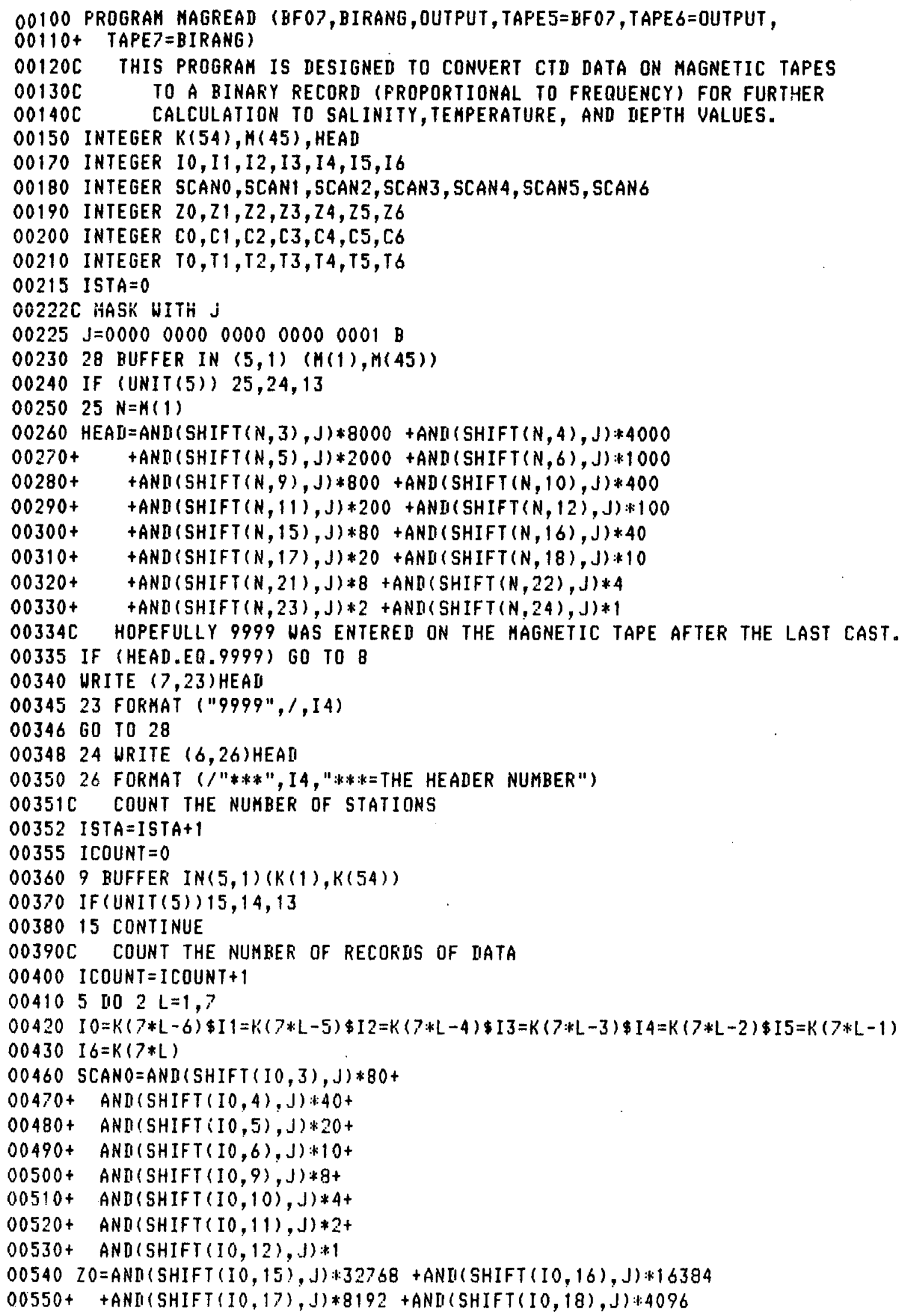


$00560+$ +ANI $($ SHIFT $(I 0,21), J) * 2048+$ AND $(\operatorname{SHIFT}(I 0,22), J) * 1024$

$00570++A N D(\operatorname{SHIFT}(I 0,23), J) * 512+\operatorname{ANM}(\operatorname{SHIFT}(10,24), \mathrm{J}): 256$

$00580+$ + ANI $(S H I F T(I 0,27), J) * 128+$ ANI $(S H I F T(I 0,28), J) * 64$

$00590++$ AND $(S H I F T(I 0,29), J) * 32+$ ANI $($ SHIFT $(I 0,30), J) * 16$

$00600++$ ANI (SHIFT $(I 0,33), J) * 8+$ AND $(\operatorname{SHIFT}(I 0,34), J): 4$

$00610+$ + AND(SHIFT $(I 0,35), J) * 2$ +AND $(\operatorname{SHIFT}(I 0,36), J): 1$

00620 CO=AND(SHIFT $(I 0,39), J) * 32768+A N D(S H I F T(I 0,40), J) * 16384$

$00630++A N D(S H I F T(I 0,41), J) * 8192+\operatorname{AND}(\operatorname{SHIFT}(I 0,42), J) * 4096$

$00640+$ + AND $(S H I F T(I 0,45), J) * 2048+$ AND $(S H I F T(I 0,46), J): k 1024$

$00650++A N D(S H I F T(10,47), J) * 512+A N D(\operatorname{SHIFT}(10,48), J) * 256$

$00660++$ ANI $(\operatorname{SHIFT}(I 0,51), \mathrm{J}) * 128+$ AND $(\operatorname{SHIFT}(I 0,52), \mathrm{J}) * 64$

$00670++A N D(S H I F T(I 0,53), J) * 32+A N D(S H I F T(10,54), J) * 16$

$00680++A N D(S H I F T(I 0,57), J) * 8$ +AND $(\operatorname{SHIFT}(I 0,58), J) * 4$

$00690++$ AND $(S H I F T(10,59), J) * 2+A N D(S H I F T(10,60), J) * 1$

00700 TO=AND $(S H I F T(I 1,3), J) * 32768$ + ANIISHIFT $(I 1,4), J) * 16384$

$00710++\operatorname{AND}(S H I F T(11,5), J) * 8192+$ ANM $(S H I F T(I 1,6), J) * 4096$

$00720++$ +AND(SHIFT $(I 1,9), J) * 2048+$ AND $(\operatorname{SHIFT}(I 1,10), J) * 1024$

$00730++$ AND $(S H I F T(11,11), J) * 512+A N D(\operatorname{SHIFT}(I 1,12), J): 256$

$00740++$ AND $(S H I F T(I 1,15), J) * 128+A N D(\operatorname{SHIFT}(I 1,16), J) * 64$

$00750++A N D(S H I F T(11,17), J) * 32+A N D(S H I F T(I 1,18), J) * 16$

$00760++A N D(S H I F T(I 1,21), J) * 8+A N D(\operatorname{SHIFT}(I 1,22), J): 4$

$00770+$ +AND(SHIFT $(11,23), J) * 2$ + AND(SHIFT $(I 1,24), J) * 1$

00780 SCAN $1=A N D(S H I F T(I 1,27), J) * 80+A N D(\operatorname{SHIFT}(I 1,28), J) * 40$

$00790++A N D(S H I F T(I 1,29), J) * 20+\operatorname{ANI}(S H I F T(I 1,30), J) * 10$

$00800+$ +AND $(S H I F T(I 1,33), J) * 8+$ AND $(S H I F T(I 1,34), J): * 4$

$00810+$ + AND(SHIFT $(I 1,35), J) * 2$ + AND $(\operatorname{SHIFT}(I 1,36), J) * 1$

$00820 \quad 21=A N D(S H I F T(I 1,39), J) * 32768+A N D(S H I F T(I 1,40), J) * 16384$

$00830+$ +AND(SHIFT $(I 1,41), J) * 8192+$ AND(SHIFT $(I 1,42), J): 4096$

$00840+$ +AND(SHIFT $(I 1,45), J) * 2048+$ AND $(\operatorname{SHIFT}(I 1,46), J) * 1024$

$00850+$ +ANI $(\operatorname{SHIFT}(I 1,47), J) * 512+$ ANII $(\operatorname{SHIFT}(I 1,48), J) * 256$

$00860+$ +ANI(SHIFT $(I 1,51), J) * 128+$ AND $(S H I F T(I 1,52), J): 64$

$00870++\operatorname{ANI}(S H I F T(I 1,53), J) * 32+\operatorname{AND}(\operatorname{SHIFT}(I 1,54), J) * 16$

$00880++A N D(S H I F T(I 1,57), J) * 8+A N D(S H I F T(I 1,58), J) * 4$

$00890+$ +AND $(S H I F T(I 1,59), J) * 2$ + AND $(S H I F T(I 1,60), J) * 1$

$00900 \mathrm{Cl}=\operatorname{AND}(\operatorname{SHIFT}(12,3), J) * 32768+\operatorname{AND}(\operatorname{SHIFT}(12,4), J): 16384$

$00910+$ +AND $(\operatorname{SHIFT}(I 2,5), \mathrm{J}) * 8192+\operatorname{AND}(\operatorname{SHIFT}(I 2,6), \mathrm{J}) * 4096$

$00920++$ AND $(S H I F T(I 2,9), J) * 2048+$ AND $(S H I F T(I 2,10), J) * 1024$

$00930++\operatorname{AND}(\operatorname{SHIFT}(12,11), J) * 512+\operatorname{AND}(\operatorname{SHIFT}(I 2,12), J) * 256$

$00940+$ +AND(SHIFT $(I 2,15), J) * 128+$ AND (SHIFT $(I 2,16), J) * 64$

$00950++$ ANM $(S H I F T(I 2,17), J) * 32+A N D(S H I F T(12,18), J) * 16$

$00960++\operatorname{AND}(S H I F T(I 2,21), J) * 8+A N D(\operatorname{SHIFT}(I 2,22), J) * 4$

$00970++$ AND $(S H I F T(12,23), J) * 2$ + AND $(S H I F T(12,24), J) * 1$

$00980 T 1=A N D(S H I F T(I 2,27), J) * 32768+A N I(S H I F T(12,28), J) * 16384$

$00990+$ +AND $(S H I F T(I 2,29), J) * 8192+$ AND $(S H I F T(I 2,30), J): * 4096$

$01000+$ +AND(SHIFT $(12,33), J) * 2048+$ ANIS SHIFT $(I 2,34), J) * 1024$

$01010++$ AND $(S H I F T(12,35), J) * 512+\operatorname{AND}(\operatorname{SHIFT}(12,36), J) * 256$

$01020+$ +AND(SHIFT $(I 2,39), J) * 128+$ AND $(S H I F T(I 2,40), J): 64$

$01030++\operatorname{AND}(\operatorname{SHIFT}(12,41), J) * 32+\operatorname{AND}(\operatorname{SHIFT}(12,42), J) * 16$

$01040++A N D(S H I F T(I 2,45), J) * 8+A N D(\operatorname{SHIFT}(I 2,46), J) * 4$

$01050+$ +AND $(\operatorname{SHIFT}(12,47), \mathrm{J}) * 2+\operatorname{ANI}(\operatorname{SHIFT}(I 2,48), \mathrm{J}) * 1$

01060 IF (L.EQ.7) 6.12

0107012 CONTINUE

01080 SCAN2=ANI $($ SHIFT $(12,51), J) * 80+$ ANO $($ SHIFT $(I 2,52), J) * 40$

$01090+$ +ANU(SHIFT $(I 2,53), J) * 20$ + ANII $(S H I F T(I 2,54), J) * 10$

$01100++\operatorname{AND}(\operatorname{SHIFT}(12,57), J): 8+\operatorname{AND}(\operatorname{SHIFT}(I 2,58), J): \leqslant 4$

$01110++\operatorname{AND}(\operatorname{SHIFT}(12,59), J) * 2+\operatorname{AND}(\operatorname{SHIFT}(12,60), J) * 1$ 
$01120 Z 2=\operatorname{AND}(\operatorname{SHIFT}(I 3,3), J) * 32768+\operatorname{AND}(\operatorname{SHIFT}(I 3,4), J) * 16384$

$01130+$ +AND $(S H I F T(13,5), J) * 8192+$ ANII $(S H I F T(I 3,6), J) * 4096$

$01140+$ + AND $(S H I F T(13,9), J) * 2048+$ AND $(S H I F T(I 3,10), J) * 1024$

$01150+$ + AND(SHIFT $(I 3,11), J) * 512+$ AND $(\operatorname{SHIFT}(I 3,12), J) * 256$

$01160++$ AND $(S H I F T(13,15), J) * 128+$ AND $(\operatorname{SHIFT}(13,16), J) * 64$

$01170+$ + ANI $(S H I F T(13,17), J) * 32$ + AND $(\operatorname{SHIFT}(I 3,18), J) * 16$

$01180++$ AND $(\operatorname{SHIFT}(13,21), J) * 8+$ AND $(\operatorname{SHIFT}(13,22), J) * 4$

$01190++A N D(S H I F T(I 3,23), J) * 2+A N I(\operatorname{SHIFT}(13,24), J): k 1$

01200 C2 $=$ AND $(S H I F T(13,27), J) * 32768$ +ANI $(\operatorname{SHIFT}(13,28), J): 16384$

$01210+$ +AND $(\operatorname{SHIFT}(13,29), \mathrm{J}) * 8192+$ AND $(\operatorname{SHIFT}(I 3,30), \mathrm{J}): 4096$

$01220+$ +AND $(S H I F T(I 3,33), J) * 2048+$ AND $(S H I F T(I 3,34), J) * 1024$

$01230+$ +AND $(\operatorname{SHIFT}(13,35), J) * 512+$ AND $(S H I F T(I 3,36), J): 256$

$01240+$ + AND $(\operatorname{SHIFT}(I 3,39), \mathrm{J}) * 128+$ AND $(\operatorname{SHIFT}(I 3,40), \mathrm{J}): 64$

$01250+$ ANB $(S H I F T(13,41), J) \approx 32$ +AND (SHIFT $(13,42), J) * 16$

$01260+$ +ANI $(S H I F T(13,45), J) * 8+$ AND $(S H I F T(13,46), J) * 4$

$01220+$ + ANI $(\operatorname{SHIFT}(I 3,47), J) * 2+$ AND $(\operatorname{SHIFT}(I 3,48), J) * 1$

01280 T2=AND (SHIFT $(I 3,51), J): 32768+$ ANI $(S H I F T(I 3,52), J) * 16384$

$01290+$ +ANM(SHIFT $(I 3,53), J) * 8192+$ ANI $(S H I F T(I 3,54), J) * 4096$

$01300+$ +ANI $(S H I F T(I 3,57), J) * 2048+A N D(S H I F T(I 3,58), J) * 1024$

$01310++$ ANI $(S H I F T(I 3,59), J) * 512+$ AND $(\operatorname{SHIFT}(I 3,60), J): 256$

$01320++\operatorname{AND}(S H I F T(I 4,3), J) * 128+A N D(\operatorname{SHIFT}(I 4,4), J) * 64$

$01330++\operatorname{AND}(\operatorname{SHIFT}(I 4,5), J) * 32+\operatorname{AND}(\operatorname{SHIFT}(I 4,6), J) * 16$

$01340+$ +AND(SHIFT $(I 4,9), J) * 8$ + ANIS(SHIFT $(I 4,10), j): 4$

$01350+$ +ANISSHIFT $(I 4,11), \mathrm{J}) * 2+\operatorname{AND}(\operatorname{SHIFT}(I 4,12), \mathrm{J}) * 1$

01360 SCAN3 $=$ AND $(S H I F T(14,15), J) * 80+$ AND (SHIFT $(14,16), J) * 40$

$01370+$ +AND(SHIFT $(14,17), J) * 20+$ ANI $(S H I F T(14,18), J) * 10$

$01380++\operatorname{AND}(\operatorname{SHIFT}(I 4,21), J) * 8+\operatorname{AND}(\operatorname{SHIFT}(14,22), J): * 4$

$01390+$ +ANI $(\operatorname{SHIFT}(I 4,23), \mathrm{J}) * 2+$ AND $(S H I F T(I 4,24), \mathrm{J}) * 1$

$01400 Z 3=$ AND (SHIFT $(I 4,27), J) * 32768$ +ANI $(\operatorname{SHIFT}(I 4,28), J) * 16384$

$01410++\operatorname{AND}(\operatorname{SHIFT}(14,29), J) * 8192+\operatorname{AND}(\operatorname{SHIFT}(I 4,30), J) * 4096$

$01420++$ AND $(S H I F T(14,33), J) * 2048+$ AND $(S H I F T(I 4,34), J) * 1024$

$01430++$ AND(SHIFT $(I 4,35), J) * 512+$ AND $($ SHIFT $(I 4,36), J) * 256$

$01440+$ +AND(SHIFT $(I 4,39), J) * 128+$ AND $(S H I F T(I 4,40), J) * 64$

$01450+$ + AND(SHIFT $(14,41), J): 32$ + AND $(\operatorname{SHIFT}(14,42), J) * 16$

$01460++A N D(S H I F T(14,45), J) * 8+A N D(\operatorname{SHIFT}(14,46), J) * 4$

$01470+$ +AND(SHIFT $(I 4,47), J): 2$ +AND(SHIFT $(I 4,48), J) * 1$

01480 C3=AND (SHIFT $(I 4,51), J) * 32768+$ AND(SHIFT $(I 4,52), J) * 16384$

$01490+$ +AND $(\operatorname{SHIFT}(14,53), J) * 8192+$ ANI $(\operatorname{SHIFT}(I 4,54), J): 14096$

$01500++$ AND(SHIFT $(I 4,57), J) * 2048+$ ANI $(S H I F T(I 4,58), J) * 1024$

$01510++$ AND $($ SHIFT $(14,59), J): 5512+$ ANU $($ SHIFT $(14,60), J): 256$

$01520+$ +ANM(SHIFT $(I 5,3), J) * 128+$ AND $(S H I F T(I 5,4), J) * 64$

$01530+$ +ANI $(S H I F T(I 5,5), J) * 32$ + AND $(S H I F T(I 5,6), J) * 16$

$01540+$ +AND $(S H I F T(I 5,9), J) * 8$ +ANIISHIFT $(I 5,10), J) * 4$

$01550+$ +AND(SHIFT $(I 5,11), J) * 2$ +AND $(S H I F T(I 5,12), J) * 1$

01560 T $3=$ ANI $(S H I F T(I 5,15), J) \geqslant 32768$ +ANI SHIFT $(I 5,16), J) * 16394$

$01570+$ +ANI (SHIFT $(I 5,17), J) * 8192$ +ANI $(S H I F T(I 5,18), J): 4096$

$01580+$ +ANIISHIFT(IS,21),J)*2048 +ANI (SHIFT $(I 5,22), .1) * 1024$

$01590+$ +AND(SHIFT $(I 5,23), J) * 512+$ AND $(S H I F T(I 5,24), J) * 256$

$01600+$ +ANISSHIFT $(I 5,27), J) * 128+$ AND $(S H I F T(I S, 28), J) * 64$

$01610+$ +AND(SHIFT $(I 5,29), J) * 32+$ AND(SHIFT $(I 5,30), J) * 16$

$01620+$ +ANISSHIFT $(I 5,33), J) * 8$ +ANIISHIFT $(I 5,34), J) * 4$

$01630+$ +ANI(SHIFT $(I 5,35), J) * 2$ +ANIISHIFT $(I 5,36), J) * 1$

01640 SCAN4 $=$ AND $($ SHIFT $(15,39), J) * 80$ +ANII SHIFT $(I 5,40), J) * 40$

$01650+$ +ANIS(SHIFT $(15,41), J): 20$ +ANI $(S H I F T(I 5,42), J): 10$

$01660++\operatorname{ANI}(5 H I F T(I 5,45), J) * 8+\operatorname{AND}(\operatorname{SHIFT}(I 5,46), J): 4$ 


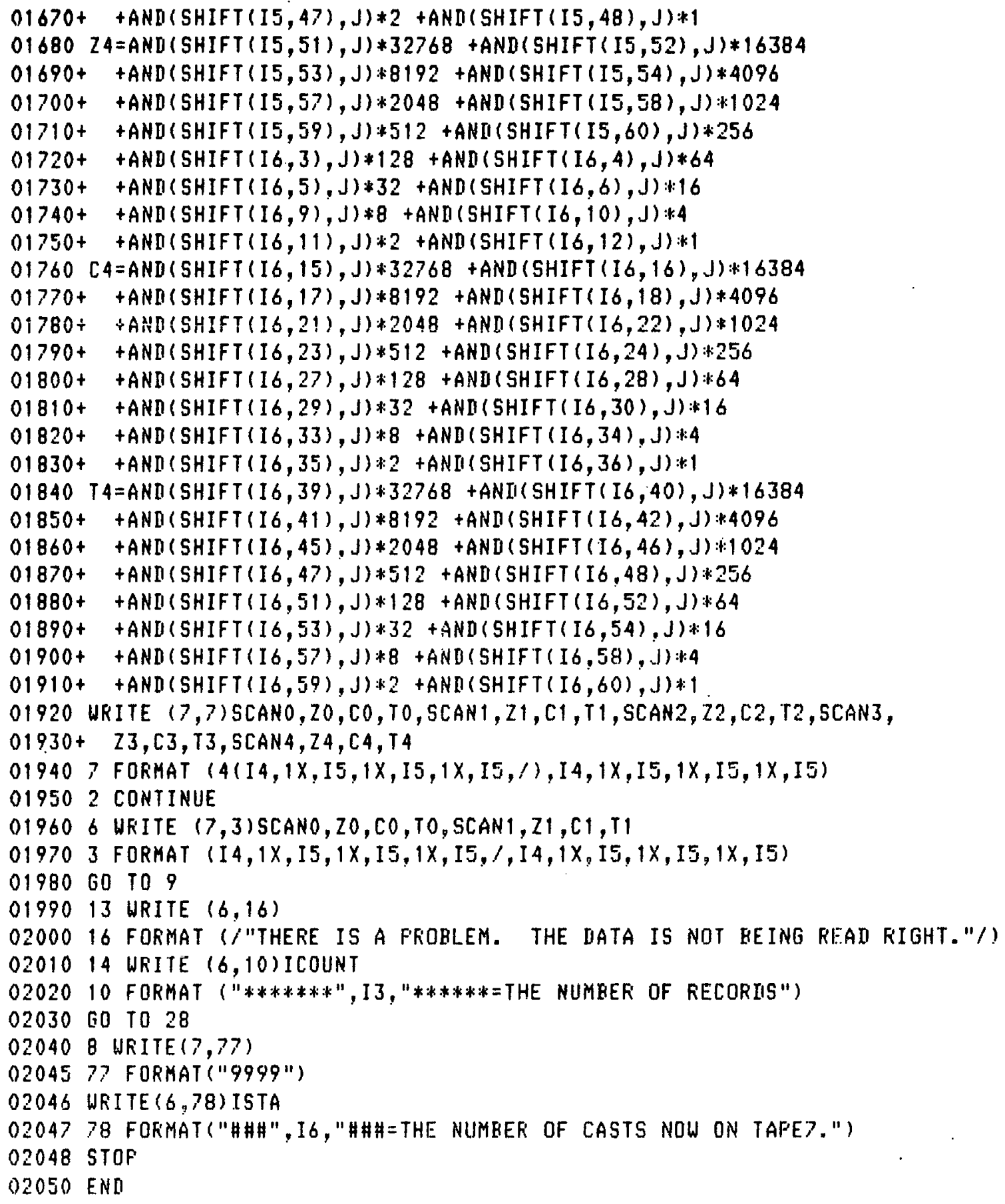


PROGRAM CTDUNIT

00100 PROGRAM CTDUNIT (INPUT, BIRANG, OUTPUT, LAG, TAPES=BIRANG, TAPE $7=L A G$, $00110+$ TAPE $4=$ INPUT, TAFE $6=$ OUTPUT)

O0120C THIS PROGRAM REAIS FREQUENCIES (BINARY RANGE,BR) FROM BIRANG, O0130C CONUERTS THEN TO DEPTH, CONDUCTIUITY, ANI TEMPERATURE, AND O0140C WRITES THE NEW DATA SET ON A FILE IESIGNATED BY TAPE?.

00150 INTEGER HEAD, SCAN, W

00160 INTEGER ZBR, CAR, TBR

00170 REWIND 5

$00180 \quad I=0$

00185 URITE $(6,8)$

00187 READ $(4,9)$ COR

O0190C W IS THE FRE-HEADER WRITTEN ONTO BIRANG TO IDENTIFY NEN CASTS. O0200C W=9999. THE HEADER NUHBER FOLLOUS.

0021010 REAI $(5,11) \mathrm{W}$

0022012 READ $(5,13)$ HEAI

00230 IF (EOF (5))6,16

0023516 CONTINUE

00240 WR ITE $(7,14)$ HEAI

OO250C I COUNTS THE NUMBER OF CASTS.

$00260 \quad I=I+1$

$00270 \mathrm{~J}=0$

002802 IF (EOF (5)) 6,7

002907 READ $(5,3)$ SCAN, ZBR, CER, TER

00300 IF (SCAN.EQ.9999) GO TO 12

OO310C J COUNTS THE NUMBER OF LINES PER CAST.

$00320 \quad J=J+1$

$00330 \quad Z=0.036621094 k Z \mathrm{BR}$

$00335 Z=Z+\operatorname{COR}$

$00340 \quad C=0.002441406 * C B R$

$00350 T=0.001220679 * T B F-4.999208208$

00360 WRITE $(7,5) \mathrm{J}, \mathrm{SCAN}, Z, \mathrm{C}, \mathrm{T}$

00370 GO TO 2

003806 WRITE $(6,4)$ I

00390 WRITE $(7,1)$

OO400C THE FORMAT SECTION FOLLOWS

OO410 1 FORHAT("9999")

004203 FORMAT $(14,1 X, I 5,1 X, 15,1 X, I 5)$

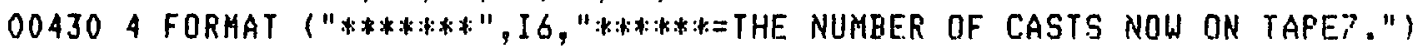

004405 FORMAT (I $4,1 X, I 2,1 X, F 6.2,1 X, F 6.3,1 X, F 5.2)$

004458 FORIMAT("ENTER THE IIEPTH CORRECTION FACTOF FOR THE CTD".,

$00446+$ "IN THF FRRMAT + X.XXX OF $-X . X X X ")$

004479 FORMAT (F6.3)

DO450 11 FIRMAT (I2)

0046013 FORMAT (I4)

00470 14 FORHAT ("9999", 1,14 )

00480 STOF

00490 ENI 
00100 FROGRAM LGFILT (LAG, OUTPUT, LATCH, TAFES=LAG, TAPE $6=0 U T F U T$, $00110+$ TAFE $7=$ LATCH)

00120C THIS PROGRAM READS D, C, AND T FROM LAG, COURSE FILTERS THE IIATA,

00130C CALCULATES THE TEMPERATURE SENSOR LAG, ANI WRITES THE NEW IATA

O0140C SET ONTO A FILE DESIGNATED BY TAPET.

00150 INTEGER W,HEAD

00160 REWINI 5

$00170 \quad I=0$

00180 READ(5, 10)W

00190 GO TO 1

002002 WRITE $(6,19)$ HEAII, M

00210 I READ $(5,10)$ HEAI

00220 IF (EOF (5)) 4,5

002305 WRITE $(7,15)$ HEAD

$00240 \quad M=0$

$00250 \mathrm{C}$ I COUNTS THE NUMBER OF CASTS.

$00260 \quad I=I+1$

00290 REAII $(5,12) \mathrm{J} 1, \mathrm{S1},[11, \mathrm{C1}, \mathrm{T} 1$

00300 REAII $(5,12) \mathrm{J} 2, \mathrm{S2}, \mathrm{D2}, \mathrm{C} 2, \mathrm{~T} 2$

003103 IF (EOF (5)) 4,23

0032023 REAI $\{5,12) \mathrm{J3}, 53,113, \mathrm{C3}, \mathrm{T3}$

00325 IF (EOF (5)) 4,28

$0033028 \mathrm{~L}=0$

00340 IF ( J3,ER.9999)GO TO 2

00350 IF (D3.GE. D2+5.0F. I13.LE.D2-5)GO TO 30

00360 IF (C3.GE.C2+0.8.OR.C3.LE.C2-0.8)GO TO 30

00370 IF $(T 3 . G E . T 2+0.5 .0 R . T 3 . L E . T 2-0.5) G 0$ TO 30

$00380 T=.76341 *(T 3-T 1) /(S 2+1)+T 2$

00390 URITE( 7,12$) \mathrm{J} 2,52,[12, \mathrm{C} 2, \mathrm{~T}$

$00400 \mathrm{~J} 1=\mathrm{J} 2 \$ \mathrm{~J} 2=\mathrm{J} 3 \$ S 1=S 2 \$ S 2=S 3 \$ D 1=\mathrm{I} / 2 \$ D 2=\mathrm{I} 3 \$ \mathrm{Cl}=\mathrm{C} 2 \$ \mathrm{C} 2=\mathrm{C} 3 \$ \mathrm{~T} 1=\mathrm{T} 2 \$ \mathrm{~T} 2=\mathrm{T} 3$

00410 GO TO 3

0042030 REAII $(5,12) J 4,54,[14,[4, T 4$

00423 IF (J4.EQ.9999)GO TO 2

00425 IF (EOF $(5)) 4,26$

OO430C M COUNTS THE NUMBER OF LINES OF IIATA REMOUED BY THE COURSE FILTER.

$0044026 \quad M=M+1$

$00445 \mathrm{~L}=\mathrm{L}+1$ \$IF (L.EQ.5)GO T0 33

00460 IF $([14 . G E .[12+5.0 R$. B4.LE. II2-5)G0 TO 30

00470 IF (C4.GE.C2+0.8.DR.C4.LE.C.2-0.8)G0 TO 30

00480 IF (T4.GE.T2+0.5.OF.T4.LE.T2-0.5)GO TO 30

0049031 REAII $(5,12) J 5, S 5,115, C 5, T 5$

00495 IF (J5.EQ.9999)50 TO 2

00497 IF (EOF (5)) 4,27

0050027 IF (115.GE.I14+5.0R. [15.LE. (14-5)G0 TO 32

00510 IF (C5.GE.CA+0.8.0K.C5.LE.CA-0.8)GO TO 32

00520 IF (T5.GE.T4+0.5.OF. TS.LE.T4-0.5)GO TO 32

$00530 \mathrm{J1}=\mathrm{J} 4 \$ \mathrm{~J} 2=\mathrm{J} 5 \$ 51=54 \$ S 2=55 \$[11=I 14 \$ 112=I 15 \$ C 1=C 4 \$ C 2=C 5 \$ T 1=T 4 \$ T 2=T 5$

00540 GO TO 23

$0054232 \quad L=0 \quad$ GO TO 30

0054433 IF( I14.GE.[12+20.0K. II4.LE.[12-20)G0 TO 32

00546 G0 T0 31

005504 WFITE $(7,16)$

00560 UFITE $(6,17) I$

O0570C FORMATS ARE AS FOLI.0US:

0058010 FOFIATIII4)

0059012 FORIATT(I4,1X, I2, 1X,F6.2.1X,F6.3.1X,F5.2)

0060015 FOKMAT("9999\%, $/, 14)$

00610 16 FOFRATS"9999")

0062017 FORMATY" "k:" Ib." $*:=$ THE NUMBEF OF CASTS NOU ON TAFE?."?

O0630 19 FOEMAT("CAST", 14," LOST", 14," IATA FTS. THRU COUFSE FILTERING.")

00640 STOF

00650 ENII 
O0100 FROGRAM BROE (INPUT, AVE, OUTPUT, SGSA, TAPEA=INPUT,

$00110+$ TAFES $=$ AUE, TAFE $6=0 U T P U T$, TAPE $7=S G S A$ )

00120C THIS PROGRAM READS II, C, AND T FROM AUE, CALCULATES SALINITY

O0130C AND SIGMAT, AND WRITES THOSE PARAMETERS ONTO A FILE

DO140C IIESIGNATED BY TAFE7. THE SALINITY CALCULATION IS FROK

OO141C BROENKOH.

00150 INTEGER H,HEAI

$00160 \quad C 1=.03895414$

$00170 \quad C 2=-2.2584586$

00180 REWINI 5

00190 URITE $(6,37)$

00210 REAII $(4,36)$ COR

$00230 \quad I=0$

00240 READ $(5,12) \mathrm{W}$

0025013 READ $(5,12)$ HEAD

00260 IF (EOF (5)) 5,4

OO27OC I CQUNTS THE NUMBER OF CASTS.

$00280 \& I=I+1$

00290 WRITE (7,21)HEAI

$00300>$ IF (EOF (5)) 5,9

003109 READ $(5,10)$ J, SCAN, B2, CSTP,T, M

00320 IF (J.EQ.9999) GO TO 13

$00330 \mathrm{~K}=0$

00332 AT $=(676547+20131.5 * T+99.89 * T * 2-0.1943 * T * * 3-0.00672 * T * k * 4) * 1.0 E-6$

00340 RT $=$ CSTP $/(A T * 42.896)$

$00420100 \quad D 15=R T *(R T-1) *(T-15) *(96.7-72.0 * R T+37.3 * R T * * 2-$

$00430+(0.63+0.21 * R T * * 2) *(T-15)) * 1.0 E-5$

$00440 R 15=R T+D 15$

$00450 \quad S=-0.08996+28.29720 * R 15+12.80832 * R 15 * 2-10.67869 * R 15 * * 3+$

$00460+5.98624 * R 15 * 4-1.32311 * R 15 * 5$

00462 IF(K.EQ.1)G0 TO 101

$00464 R Z=1.0+0.01 *(1.551-0.0453 * T+0.00059 * T * * 2+0.25 *(35-S) *(0.043-0.0017 * T$

$00465++2.3 E-5 * 1 * * 2)) *(1.037 E-3 * 12-3.2 E-8 * D 2 * * 2)$

$00466 R T=C S T F /(R Z * A T * 42.896)$

$00467 \mathrm{~K}=1$ \&OO TO 100

00470C. A CORRECTION FACTOR FOR SALINITY(BOTTLE)-SALINITY(CTD) IS ADIED

00480C TO ALL SALINITY VALUES.

O0490C (IT MUST BE CALCULATED FOR EVERY CRUISE)

$00500101 S=S+C O R$

$00510 F 1=((T-3.98) * * 2) *(T+283) /.((503.57) *(T+67.26))$

$00520 F 2=(T * 3) *(1.0843 F-h)-(T * T) *(9.8185 E-5)+T * 4.7867 E-3$

$00530 \mathrm{~F} 3=(T * 3) *(1.667 \mathrm{E}-8)-(T * T) *(8.164 \mathrm{E}-7)+T * 1.803 \mathrm{E}-5$

$00540 \mathrm{FS}=(S * * 3) *(6.76786136 E-6)-(S * S) *(4.8249614 E-4)+5 * .814876577$

$005505 I G=-F 1+(F S+C 1) *(1 .-F 2+(F 3) *(F S+C 2))$

00560 WRITE $(7,20) \mathrm{J}$, SCAN, D2, CSTP, T, H, S, STG

005706 G0 TO 7

005805 WRITE $(6,38)$ I

00590 WRITE $(7,39)$

DO6OOC THE FORMAT SECTION FOLLOHS

006103 FORMAT $(3 X, 14,2 X, F 6.2,6 X, F 6.3,8 X, F 5.2,6 X, F 6.3)$

0062010 FORMAT $(14,1 X, 12,1 X, F 6.2,1 X, F 6.3,1 X, F 5.2,1 X, I 4)$

0063012 FORMAT (I4)

0064015 FORHAT (/, "HEAIIER NUMBER=", I 4,/)

0065021 FORHAT ("9999",/,I4)

0066020 FORMAT $(14,1 \times, 12,1 \times, F 6.2,1 X, F 6.3,1 X, F 5.2,1 X, 14,2 X, F 6.3,1 X, F 5.2)$

0067036 FOKMAT (F6.3)

0068037 FORMAT("A SALINITY CORFECTION FACTOR FOR SAL(BOTTLE)-SAL(CT(1)",',

$00690+$ "SHOULD BE ENTERED IN THE FORMAI + X.XXX OR - X.XXX")

0070038 FORMAT("***",16,"***=THE NUMBER OF CASTS NOW ON TAFE?.")

O0710 39 FORMAT( ("9999")

$0072050 \mathrm{STOF}$

00730 ENI 


\section{PROGRAM ILATCH}

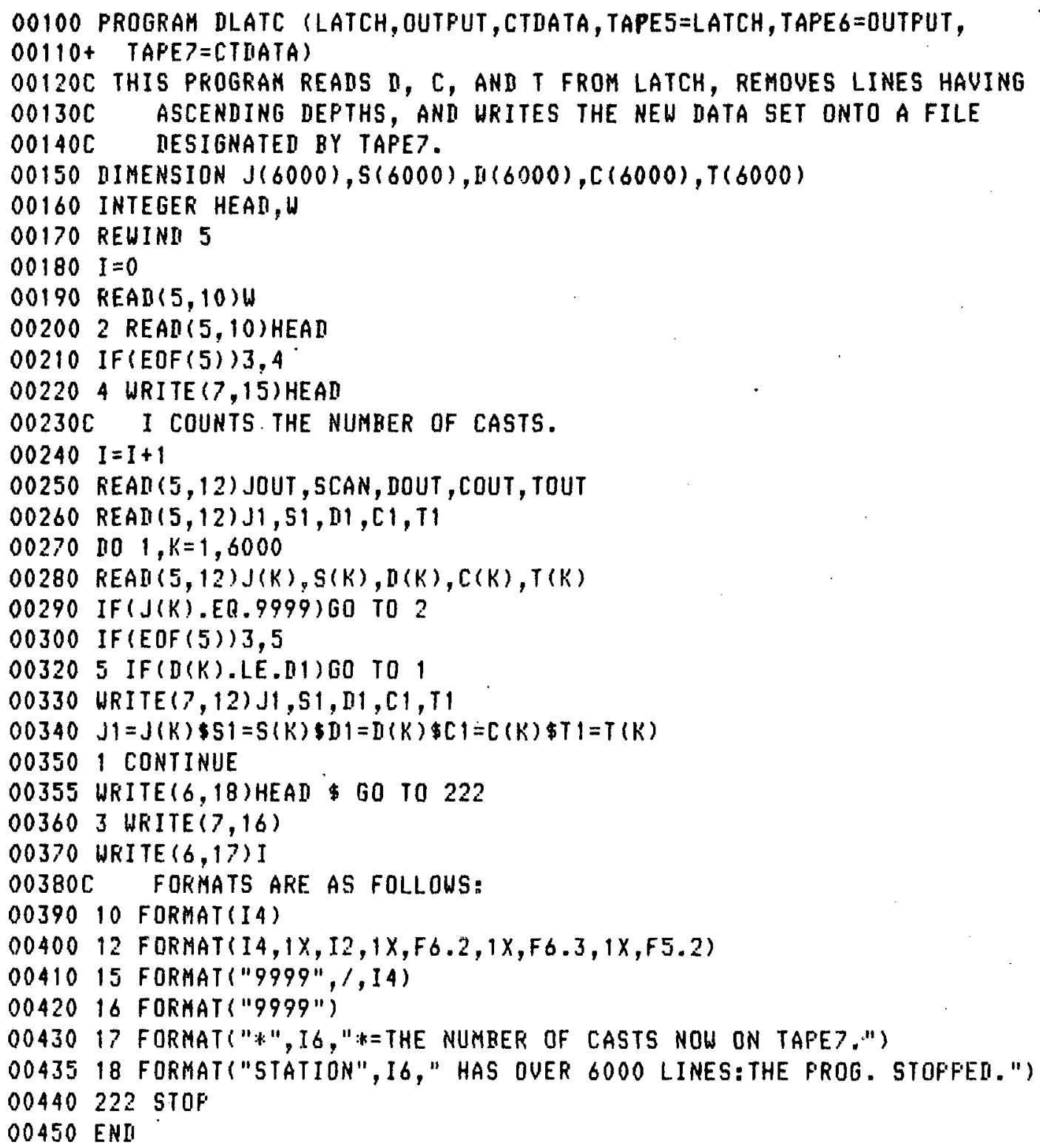




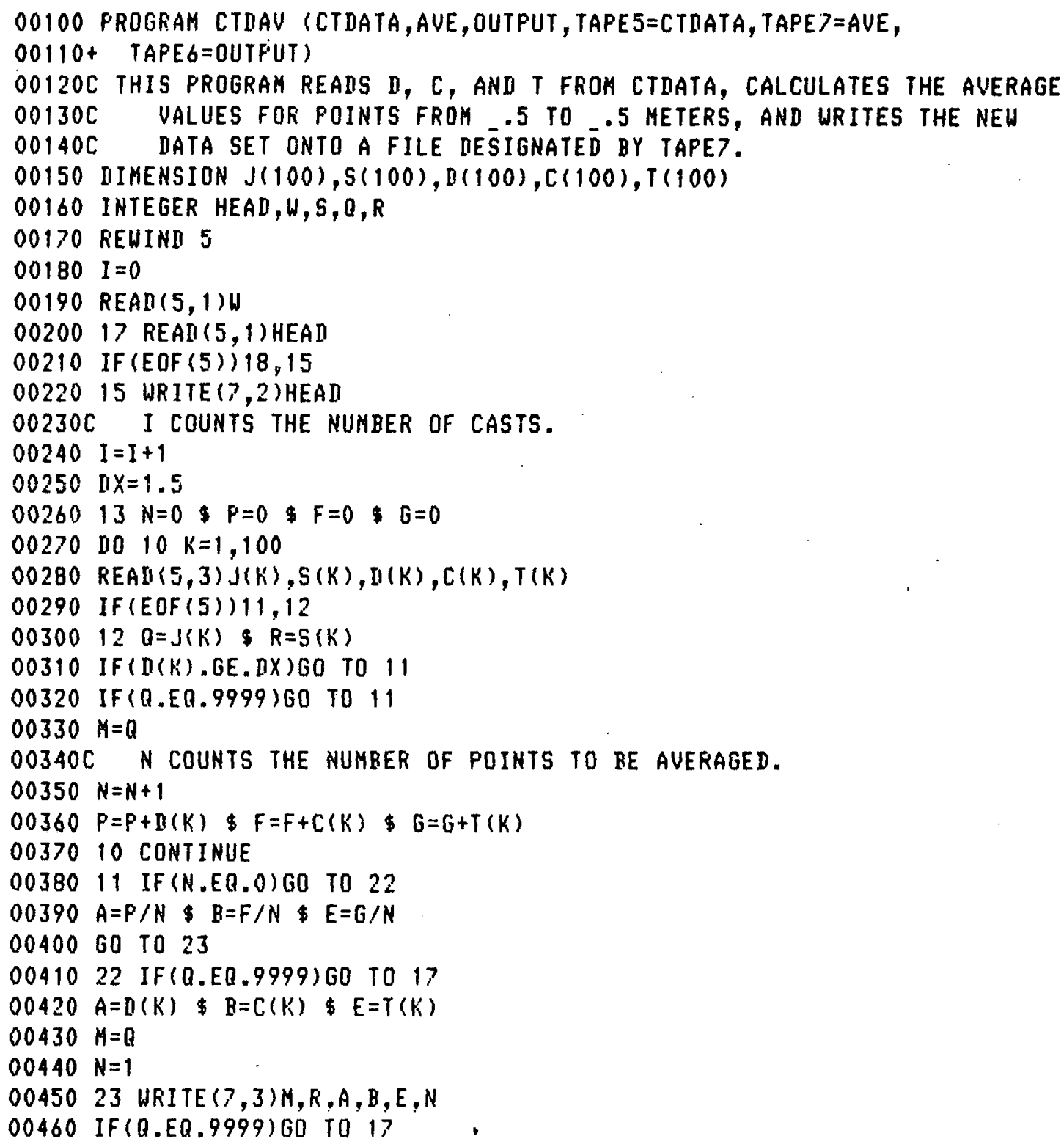




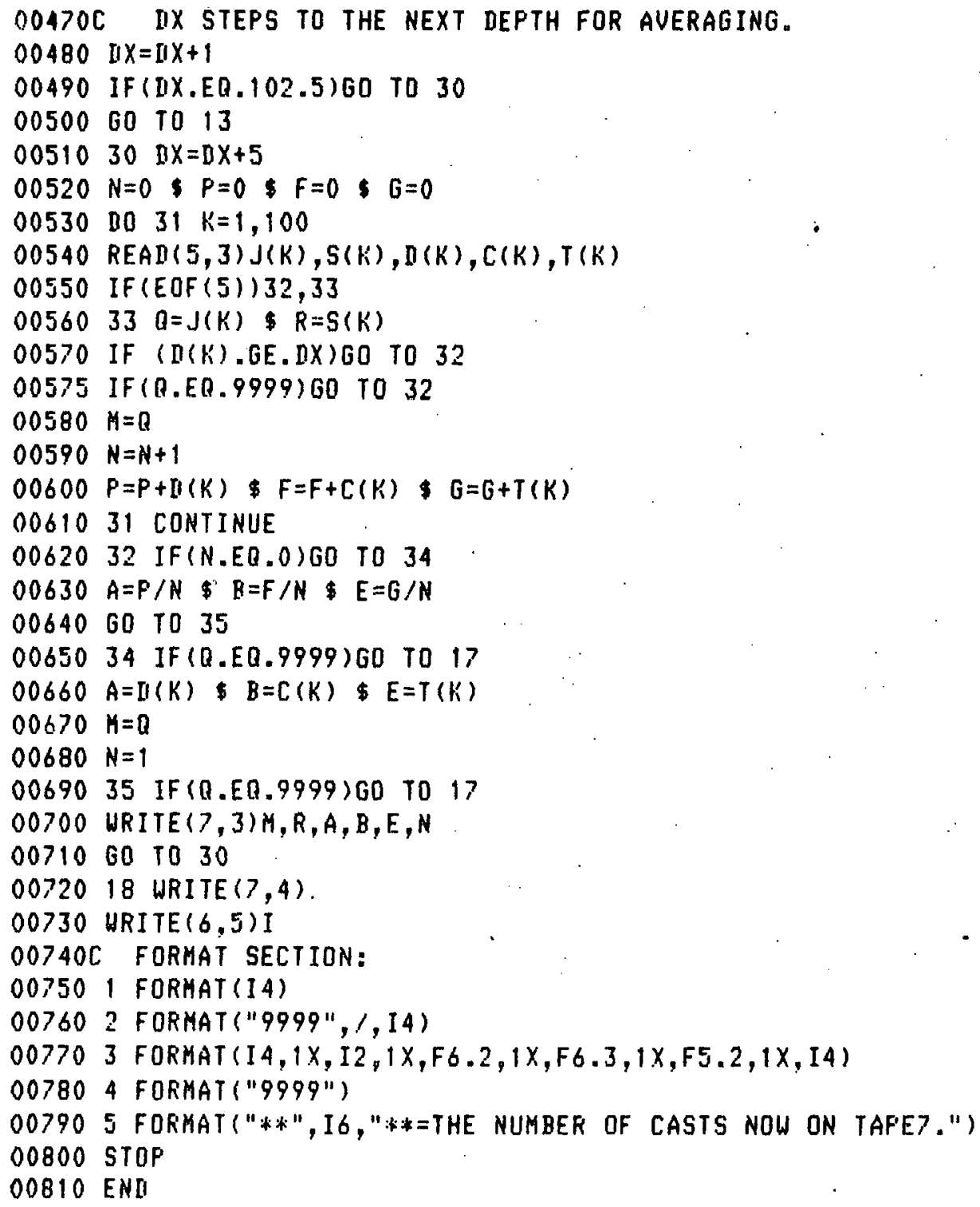




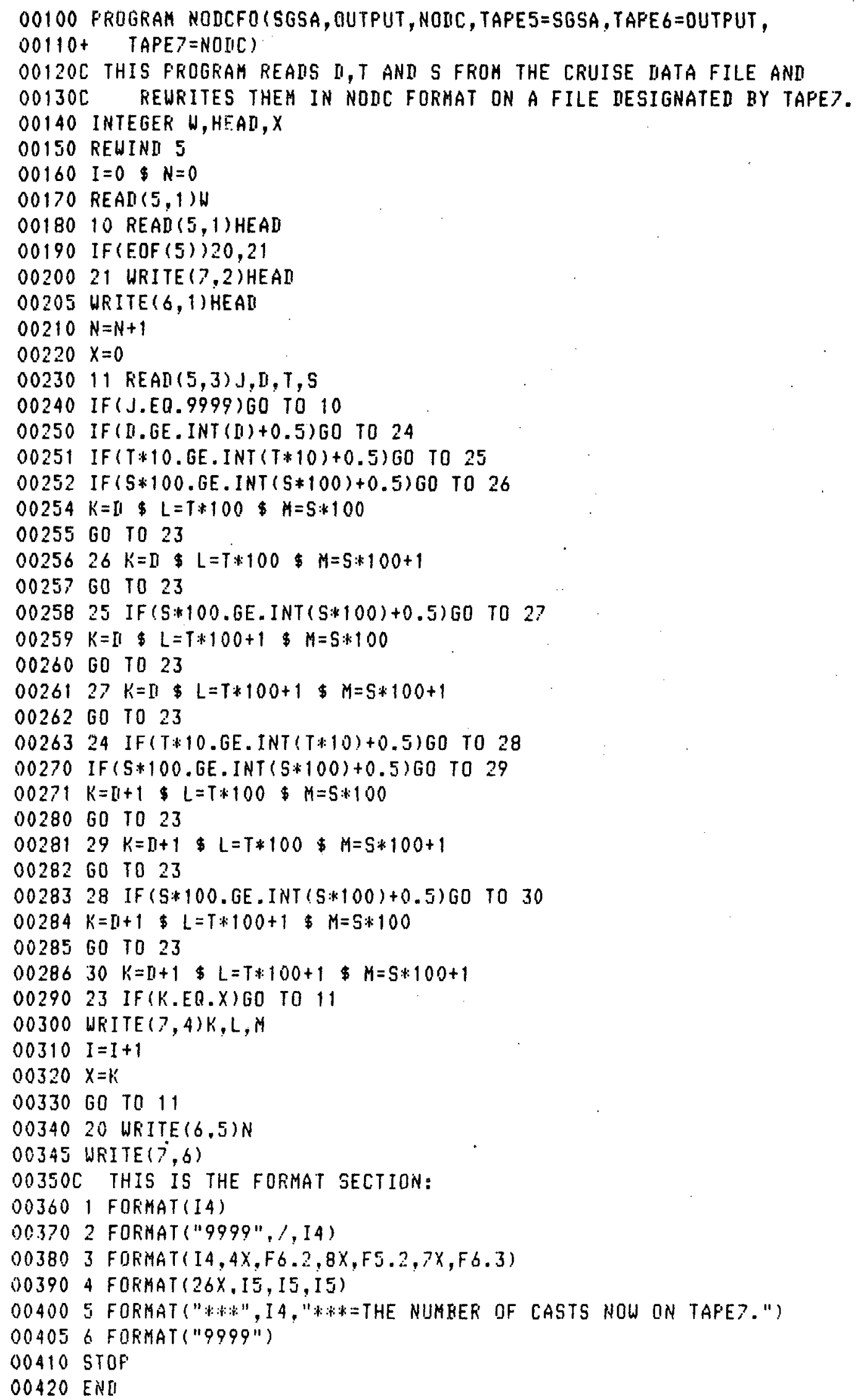


00100 PROGRAM MERGEIT (INFUT, NOD, HEA, OUTFUT, FINAL, TAFE 4:=INFUT,

$00110+$ TAFES $=$ NOI, TAFE $6=0 U T P U T, T A P E 7=F I N A L, T A F E B=H E A)$

00115+ THIS FROGKAM MERGES HEADER ANI NUTRIENT DATA TO CAST IIATA IN NOIIC FORHAT.

00120 DIMENSION IH(10)

O0130 INTEGER $H, H E A D ; X, C T, Z$

00140 REHINDS \$ REUINII8

$00150 \quad I=0 \$ N=0$

00160 READ $(5,1) \mathrm{W}$

0017041 BACKSPACE 8

0018010 READ $(5,1)$ HEAD

00185 IF (EOF (5)) 20,21

0018721 REAII $(8,6)($ IH (I), I 1,9$)$, IP, IHEAD, IR

00190 IF (EOF (8)) 20,29

0020029 CONTINUE

0021022 WRITE $(7,6)(I H(I), I=1,9)$, IP, IHEAD, IR

$00219 \mathrm{~N}=\mathrm{N}+1$

0022112 READ $(8,9) Z$

00222 IF (EOF (8)) 13,14

0022314 IF (Z.EQ.31)GO TO 13

00224 BACKSFACE 8

O0230 READ (8,7)KK, ISAL, 02,P04,N03,SI03,CT

00232 GO TO 11

$0023413 \quad K K=999$

$0024011 \operatorname{READ}(5,3) \mathrm{J}, K, L, 14$

00250 IF (J.EQ.9999)G0 TO 40

00255 IF (K.GT.100.)G0 T0 60

00257 IF (KK.EQ.2)GO TO 43

00260 IF (KK.LE.K) GO TO 43

00263 GO TO 44

0026560 IF (KK.LT.K+2.5)G0 T0 43

0028244 WRITE $(?, 4) K, L, M$

00283 G0 TO 11

0028543 IF (I.SAL.EQ.0)GO TO 48

00287 WFITE $(7,51) \mathrm{K}, \mathrm{L}, \mathrm{ISAL}, 02, \mathrm{FO4,N03,SI03,CT}$

00288 GO TO 12

0029048 WRITE $(7,8) K, L, M, 02, P 04, N 03, S I O 3, C T$

$00300 \quad 60 \quad T 0 \quad 12$

0031040 IF (KK.EQ.999)GO TO 41

O0315 IF (J.EQ.9999)URITE (7,8)KK,L, M, 02,P04,N03,SI03,CT

00317 GO TO 47

0032045 WRITE $(7,7) K K, I S A L, 02, P 04, N 03, S I 03, C T$

0032347 CONTINUE

00330 REAL $(8,9) Z$

00335 IF (EDF (8)) 10,46

0034046 IF (Z.EQ.31)G0 TO 41

00345 BACKSPACE $B$

00347 READ (8,?)KK, ISAL, 02,P04,N03,5I03,CT

00350 GO TO 45

0036020 WRITE $(6,5) \mathrm{N}$

O0370C THIS IS THE FORMAT SECTION:

00380 I FORMAT(14)

003902 FOFIMAT("9999", /, I4)

004003 FOFMAT (I 4,22X, IS, A.5, A5)

004104 FORMAT(26X, I5, A5, A5, 38X, "3")

004205 FOKMAT("***",I4,"***=THE NUMBEF OF CASTS NDW ON TAFE?.")

004306 FOFMAT (9A8, A4, I3, A1)

004407 FORHAT (26X, 15, 5X,15,9X,A3,A.3, 6X,A.3,A3,11X,11)

OOA50 8 FORAAT (26X, I5,A5,A5,9X,A3,A3,6X,A3,A3,11X,11)

00452 ? FOFMAT(I2)

0045351 FQRMAT $(26 X, I 5, A 5, I 5,9 X, A 3, A 3,6 X, \hat{A} 3, A 3,11 X, 11)$

004555 . FOFHAT $(30 X, I 3)$

00460 STOF

00470 ENII 
FROGRAN CEMLIST

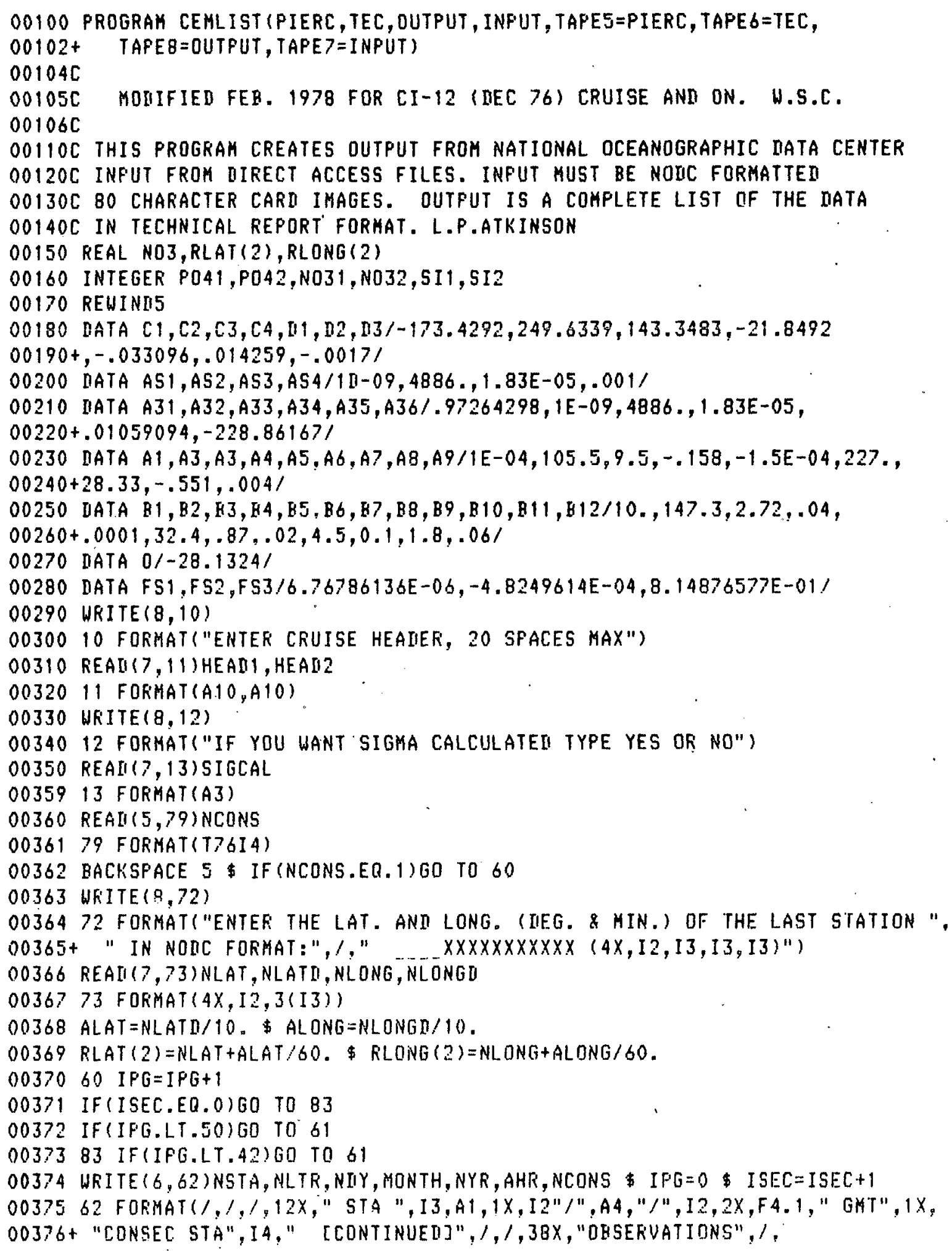




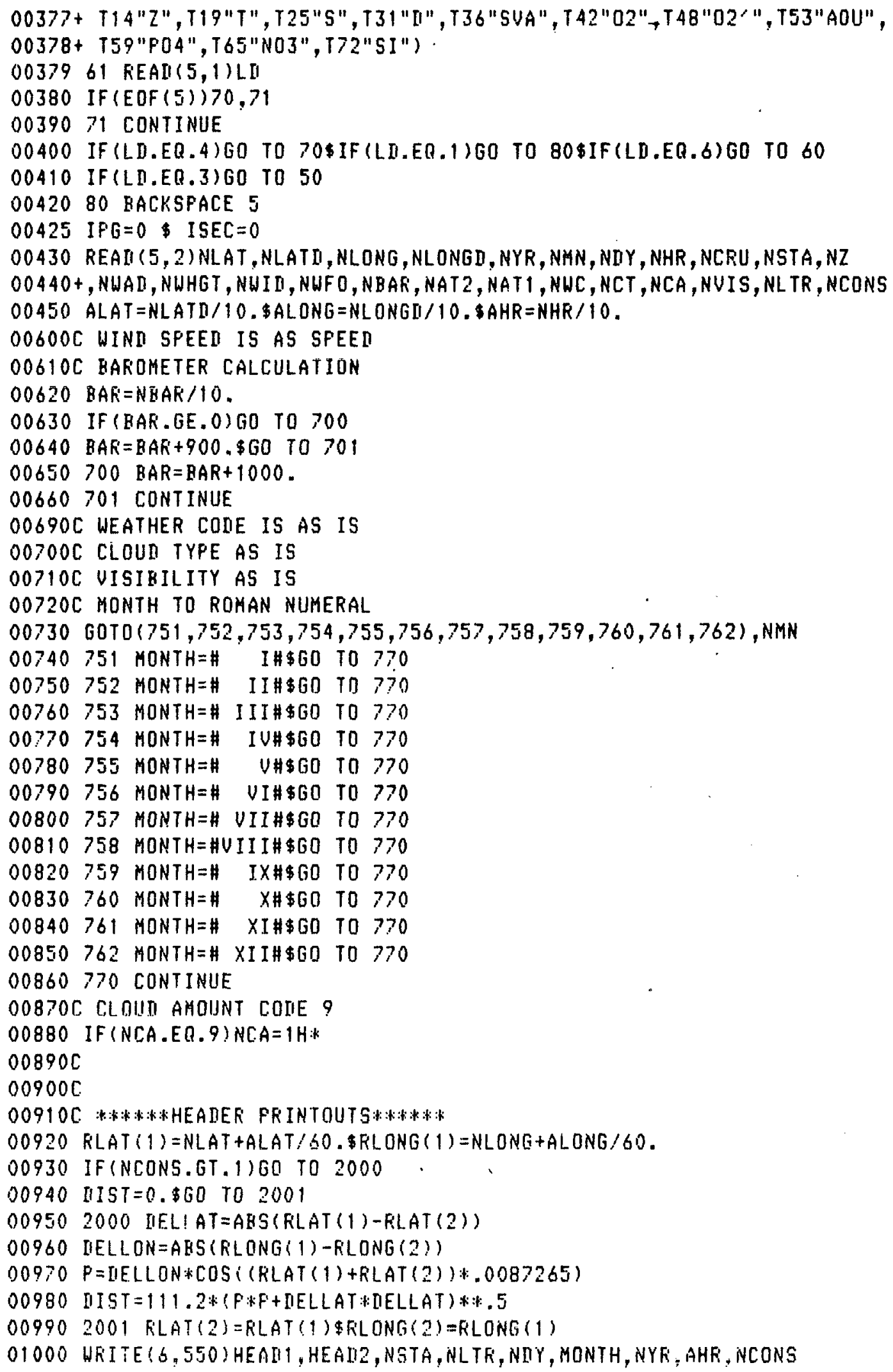




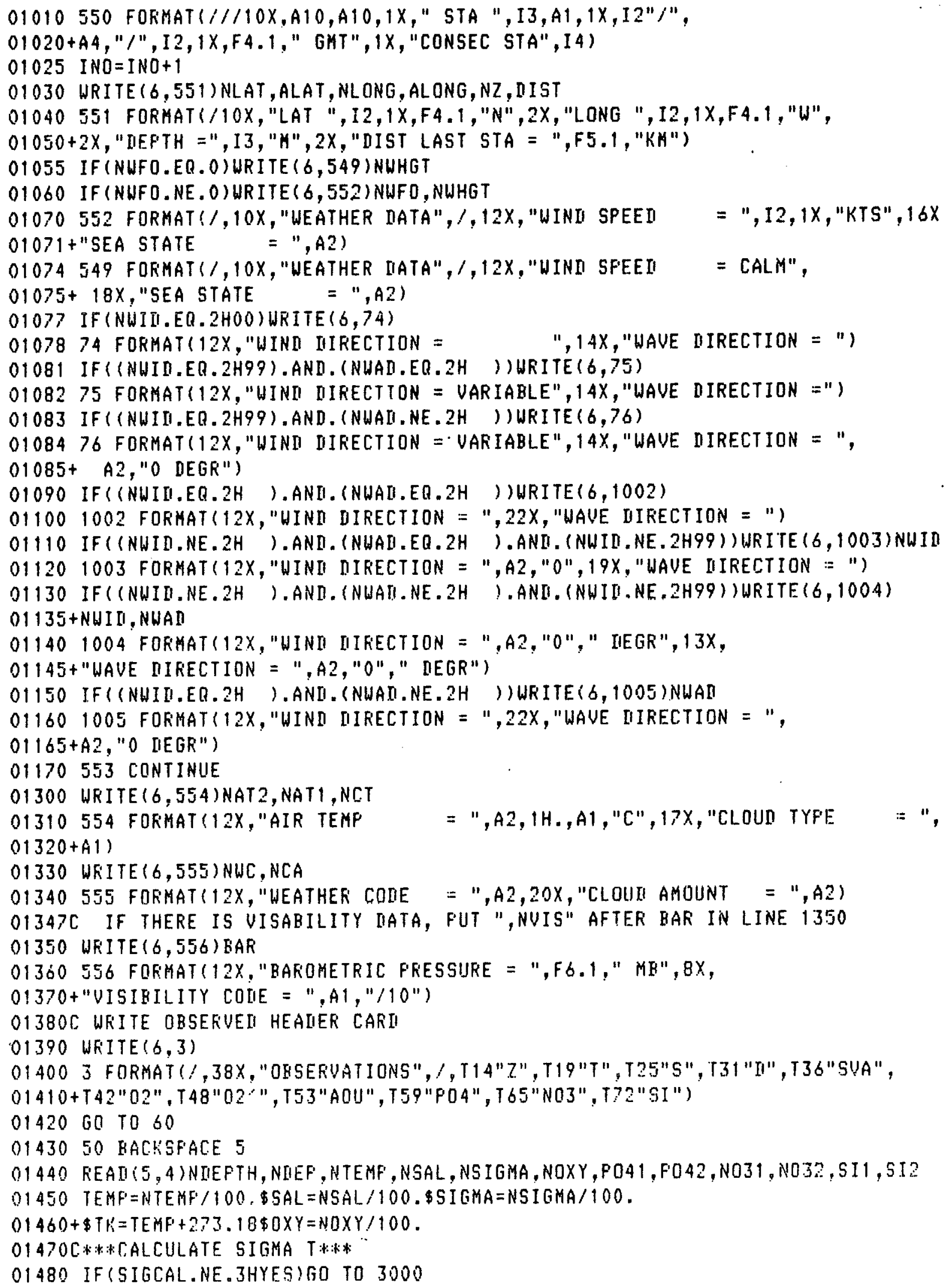




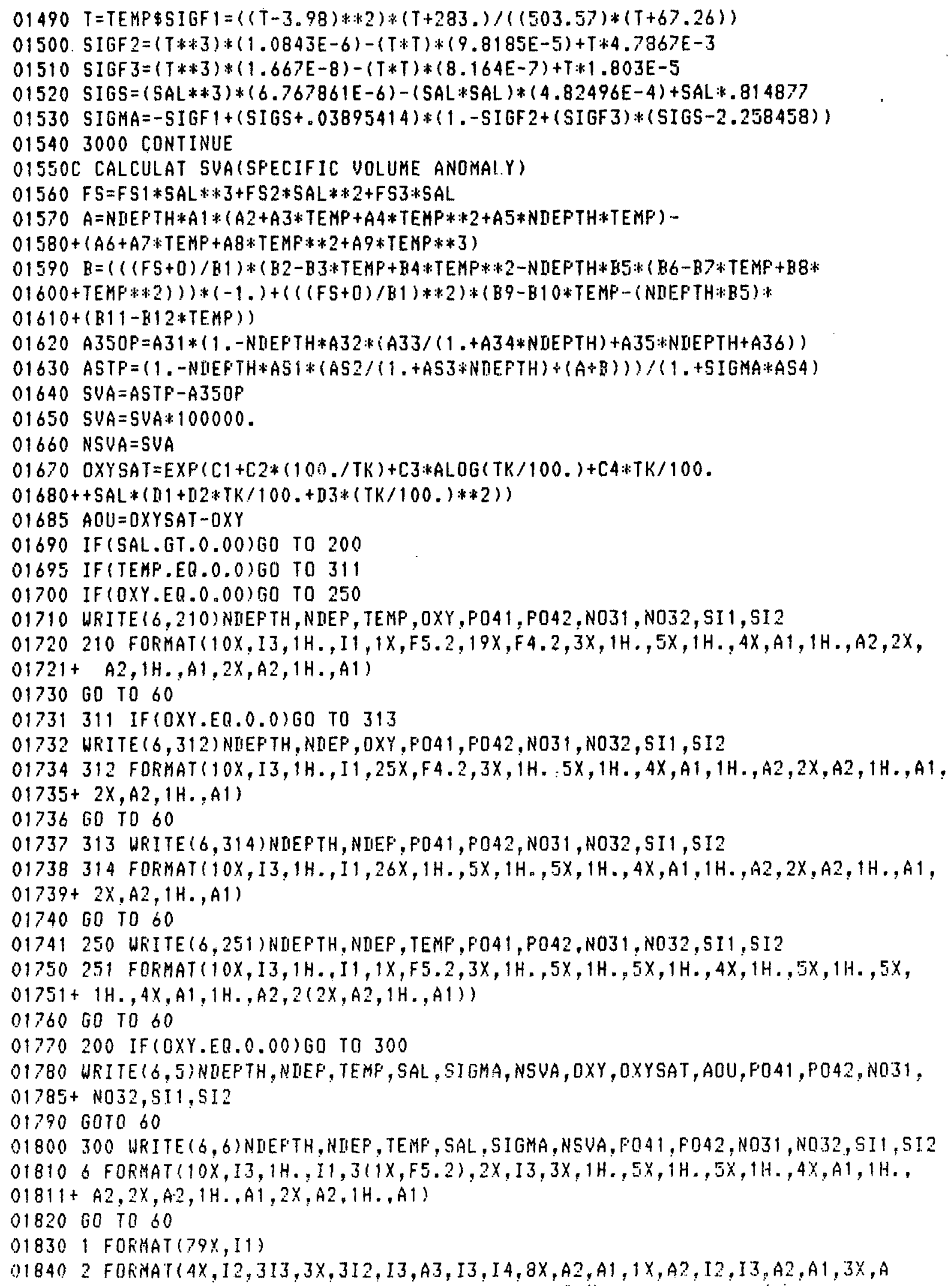


$01850+2, A 1, A 1, A 1, A 1,7 X, 14)$

01860 4 FORMAT $(28 X, 13, I 1, I 4,1 X, I 4,1 X, I 4,4 X, 13, A 1, A 2,6 X, A 2, A 1, A 2, A 1)$

018705 FORMAT(10X,13,1H., I , 3(1X,FF.2), 2X,I3,2X,F4.2,2(1X,F5.2), 2X,A1,1H., $01880+A 2,2 X, A 2,1 H ., A 1,2 X, A 2,1 H ., A 1)$

0189070 URITE $(8,77)$ INO

0189577 FORMAT("\#\#\#", I4, "\#\#\#=THE NUMBER OF CASTS NOW ON TAPE).")

01898 STOF

01900 END 
APPENDIX IV.

HP Programs 
The following programs are written for the HP 9825A desktop conputer with the following options:

93214A 9862A Plotter - General I/0 Extended I/O ROM

98210A String-Advanced Programming ROM

98324A Systems Programming ROM

and

$24 \mathrm{~K}$ core

The $9825 \mathrm{~A}$ internal printer is 16 characters wide. Using a RS-232C interface to a T.I. Silent 700 ASR terminal provides an 80 character printout. Some characters are not the same, such as:

$\begin{array}{cc}\stackrel{\text { HP }}{\rightarrow} & \frac{\text { T.I. }}{\}} \\ \text { Lower case } & \text { Little caps. } \\ \uparrow & \wedge\end{array}$


The programs are stored by file on the internal cassette and are as follows:

File

0

1

2

3

4

5

6

7

8
Name

Master File

Special Function Keys

Taking a Cast

List D, C, T

Bottom Soak

Downcast Average

Mid-depth Soak

Upcast Average

Salinity Plot

The programs are stored on track 1, files 0-8. The preliminary data are stored on track 1 from file $10 \mathrm{on}$. The final data (filtered and meter averaged) is stored on track 0 , file 0 on.

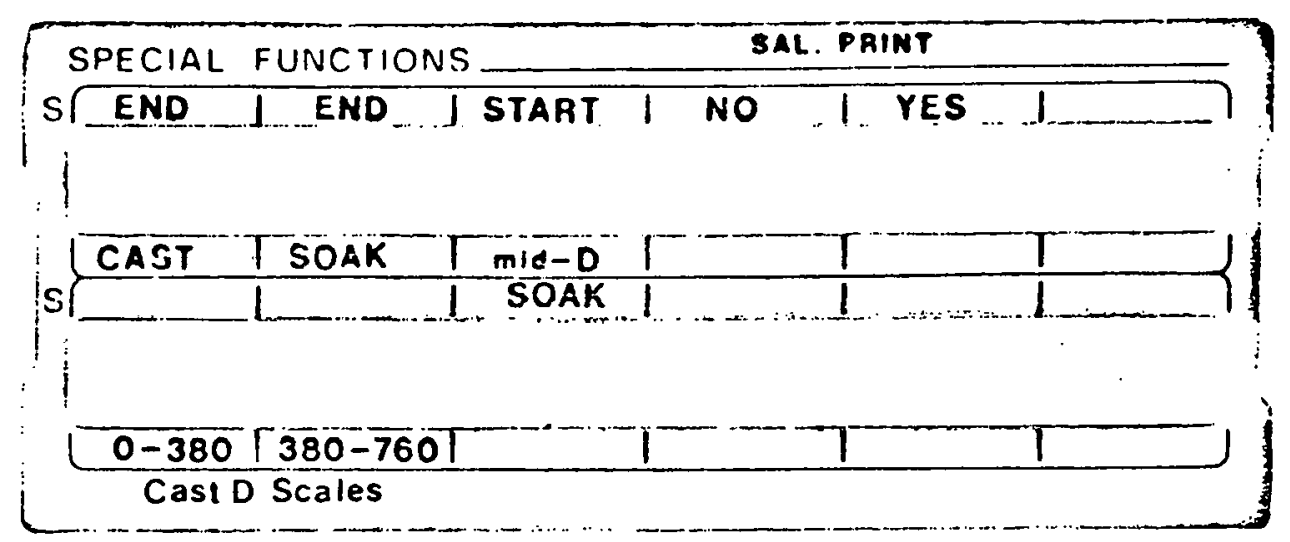

Overlay used for Special Function Keys 


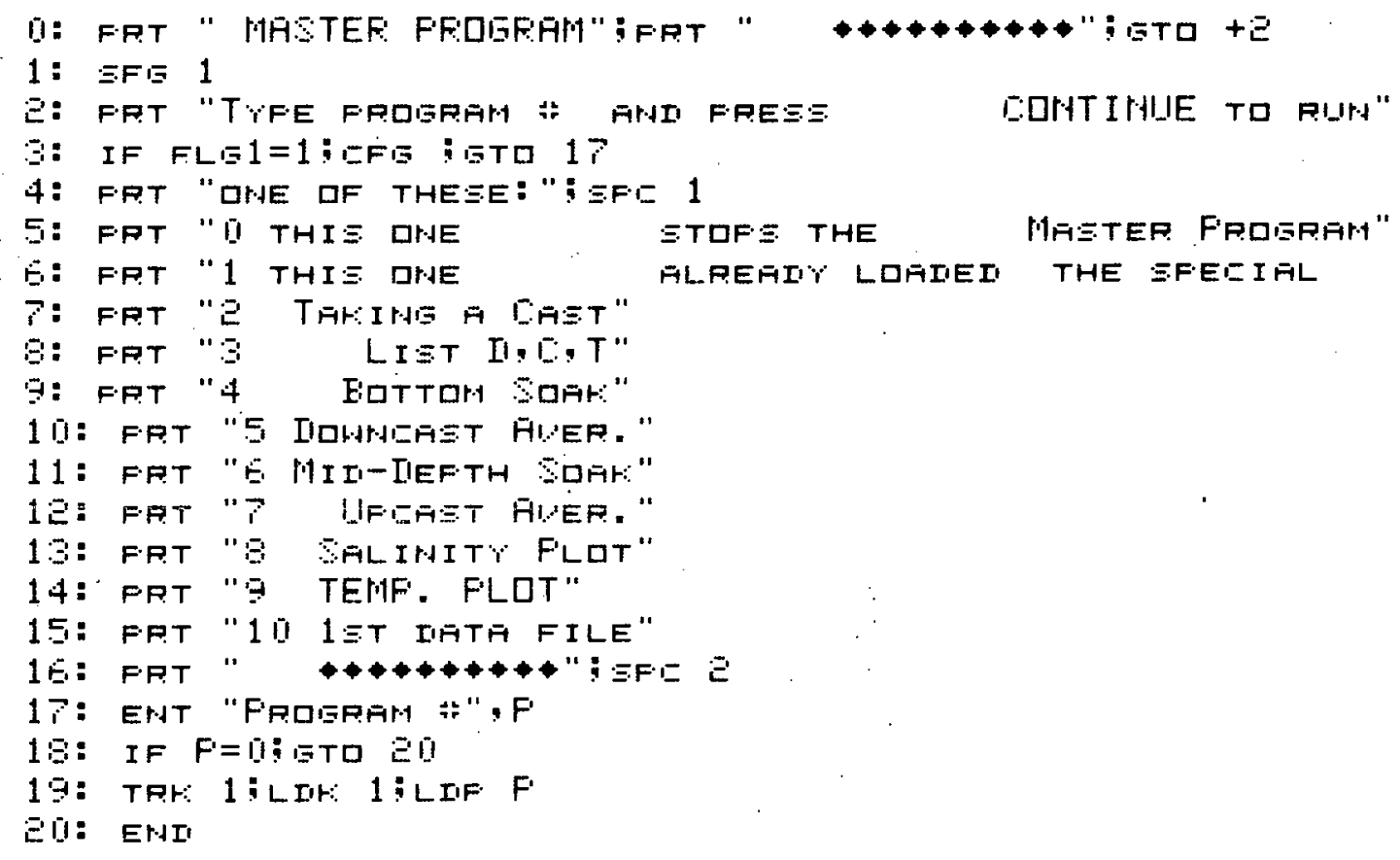
FLIHETI I RH FEY 


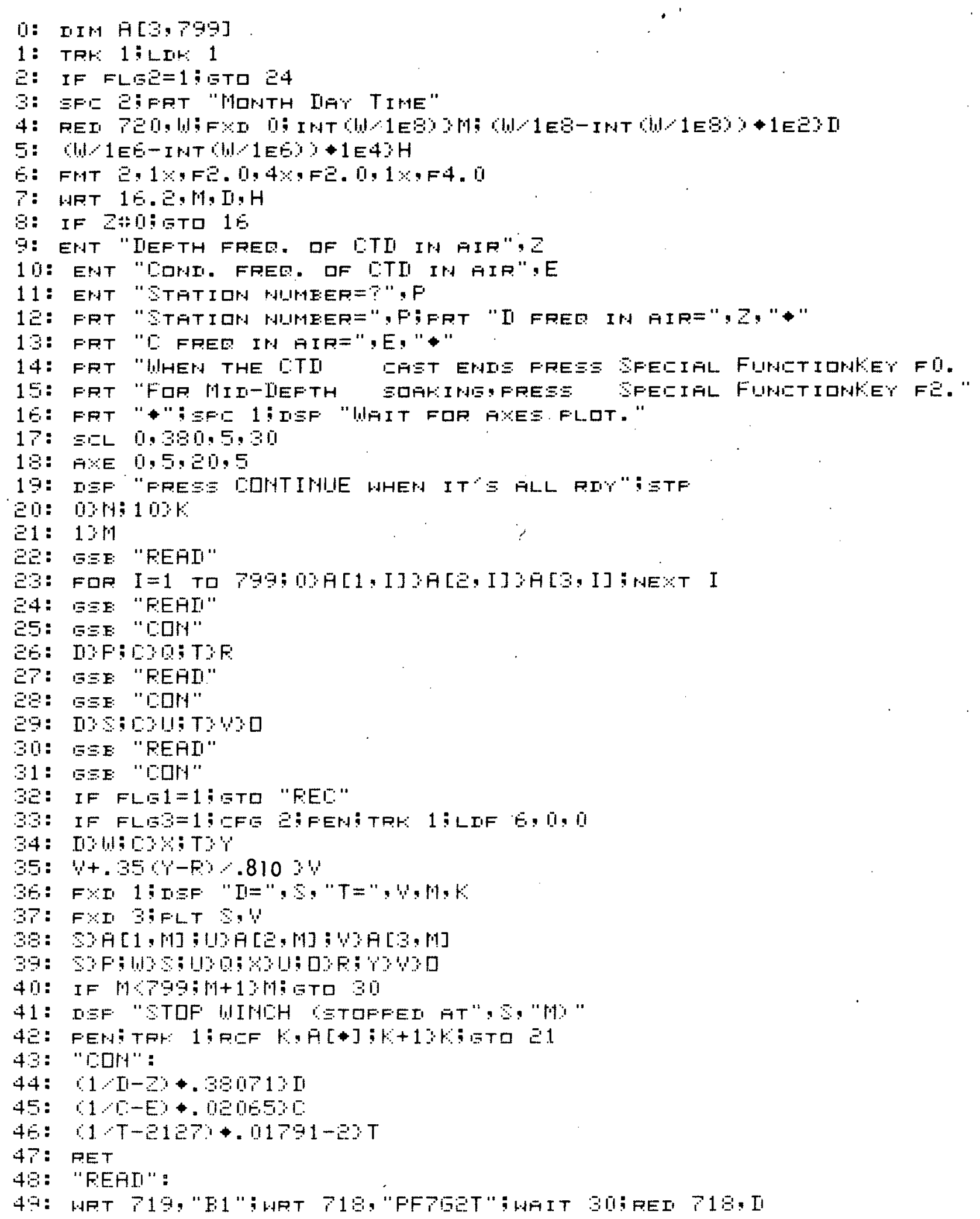




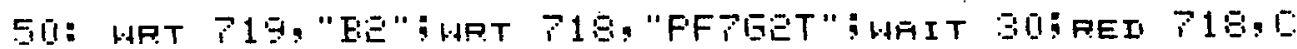

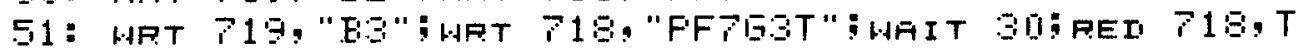

SE: RET

5: "FEL":

54: FEH: TPH: 1 : REF KOA $[*]$

55: IF FLEE=1 वR IIS5:BTD 57

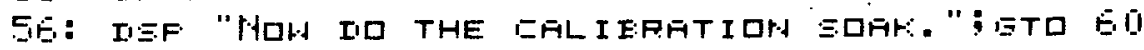

5P: FOI DIFRT "THE FIPET FHA LAET FILES DF THIEIAET FPE

1 II $\mathrm{AHI}, \mathrm{K}$

SE: FPT :

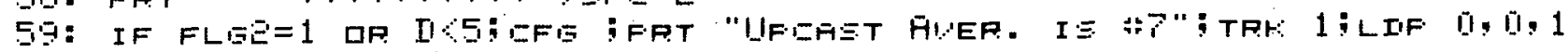

EI: TRR: 1 illof 4:0, II

E1: EHII 


\section{LIST II,COT}

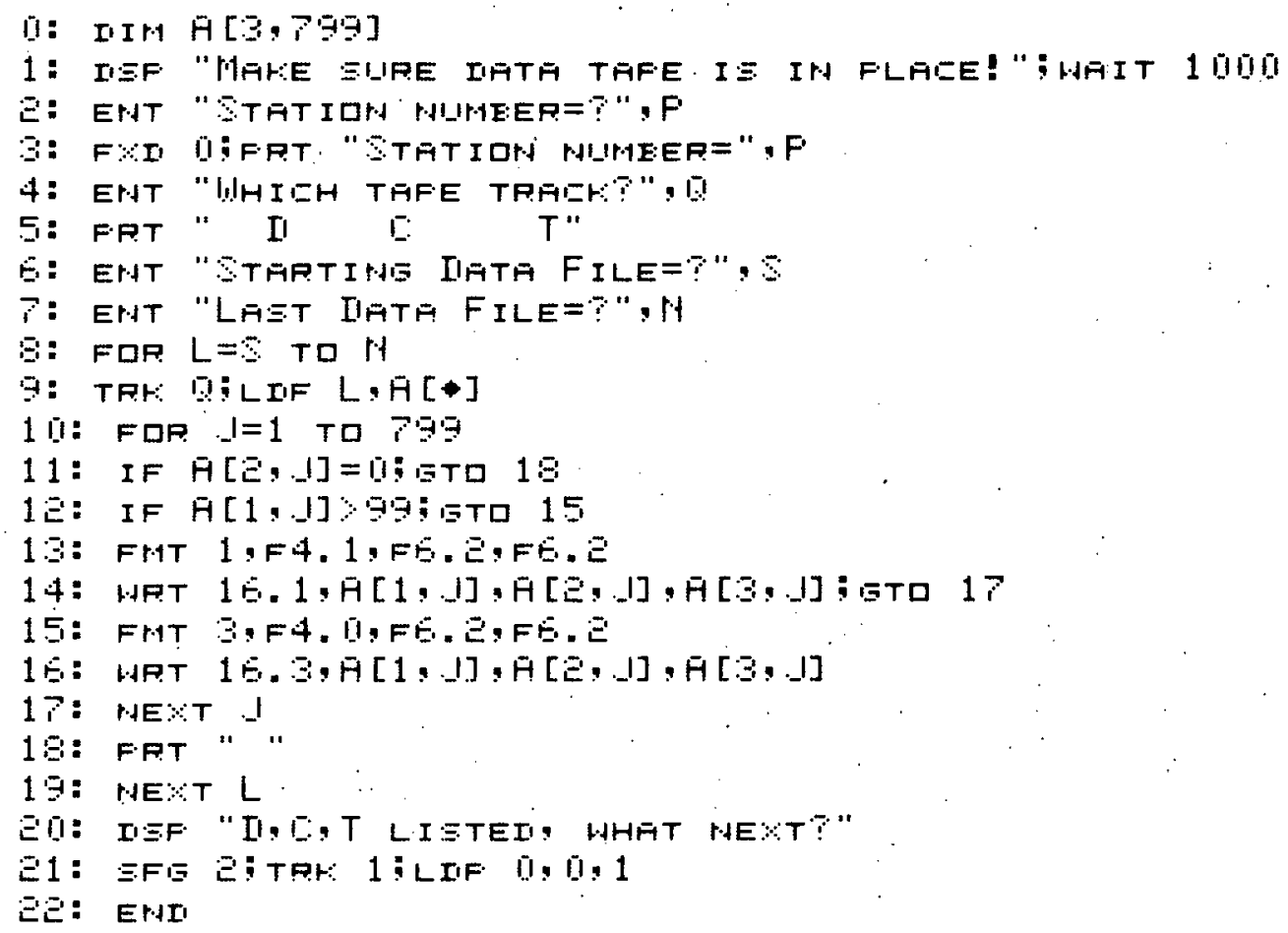


EDTTOM SOAK:

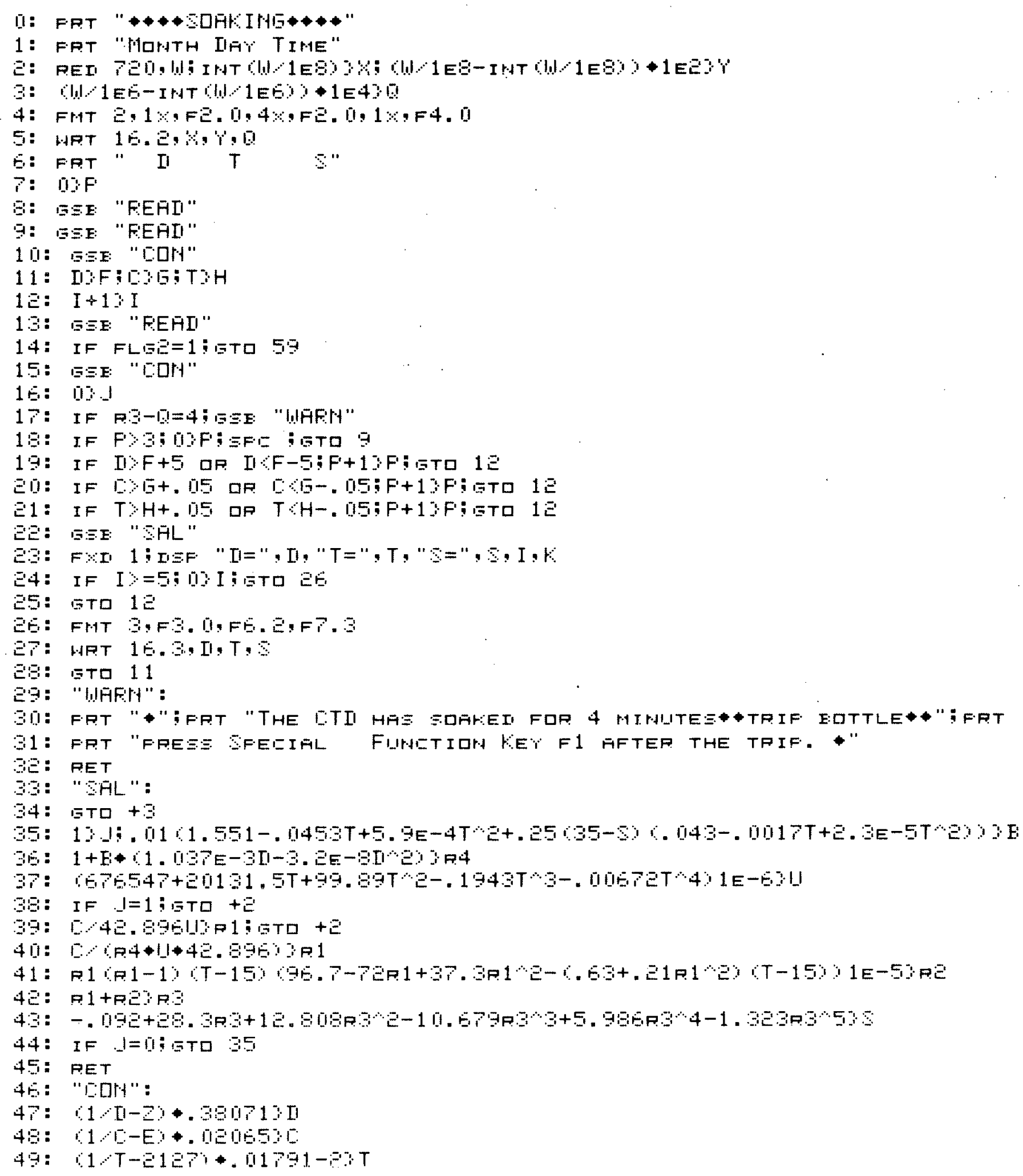




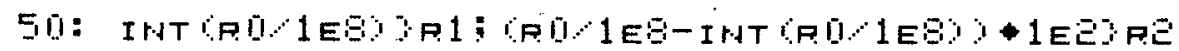

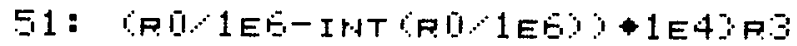

SE: PETT

E: "F:EHII":

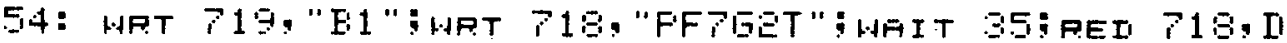

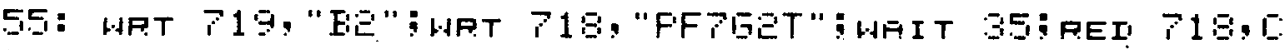

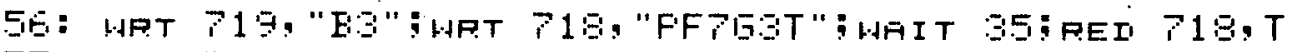

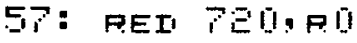

SE: PET

5I: FRT"

EI: FRT "THE FIP:T AHI LAST FILES DF THIEIAET FPE

B1: TRH 13 LIF $5,0,0$

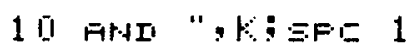

EE: EHI 


\section{IDUHEAST AWEFHEIHE}

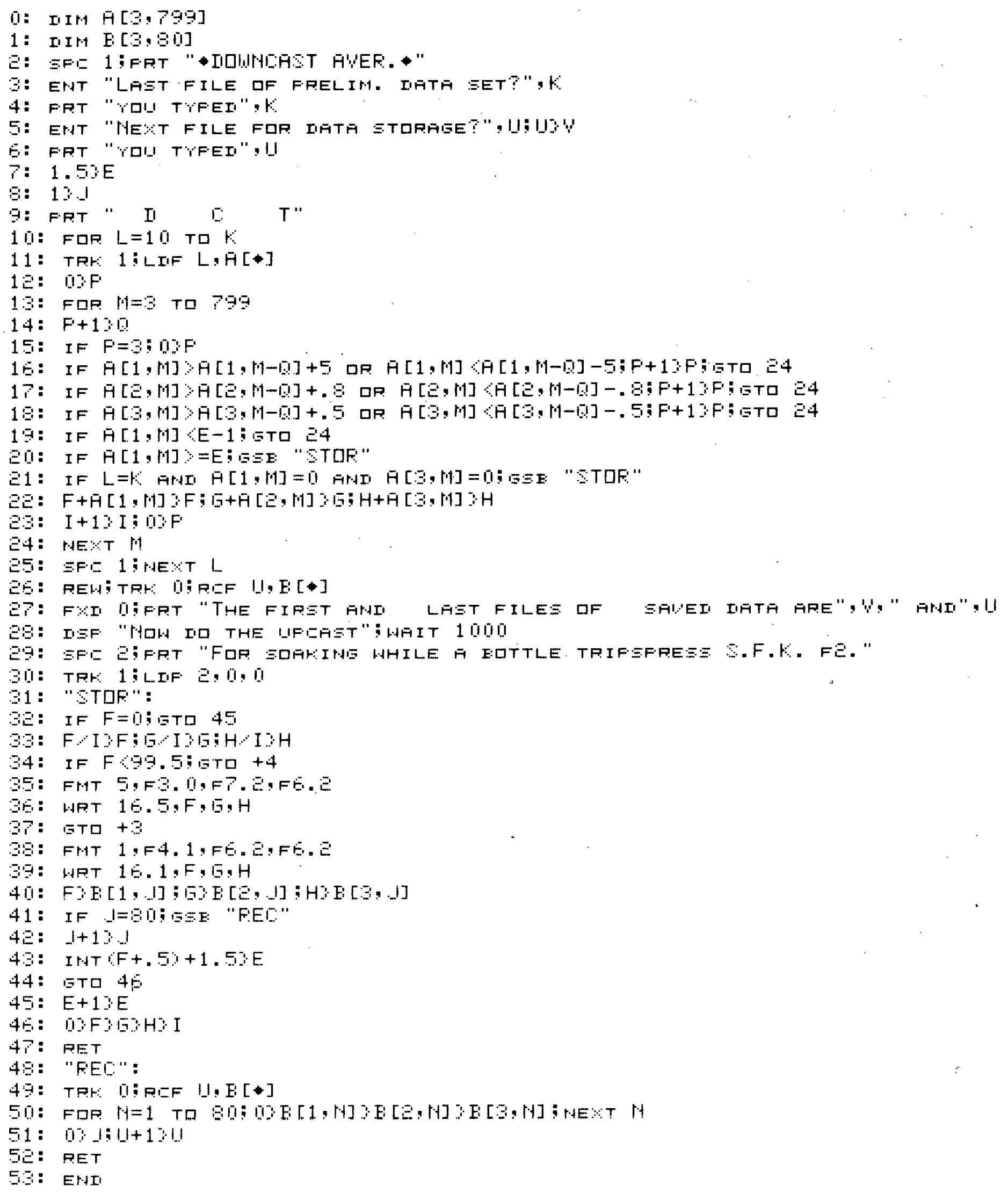


MII-IEFTH SDAK:

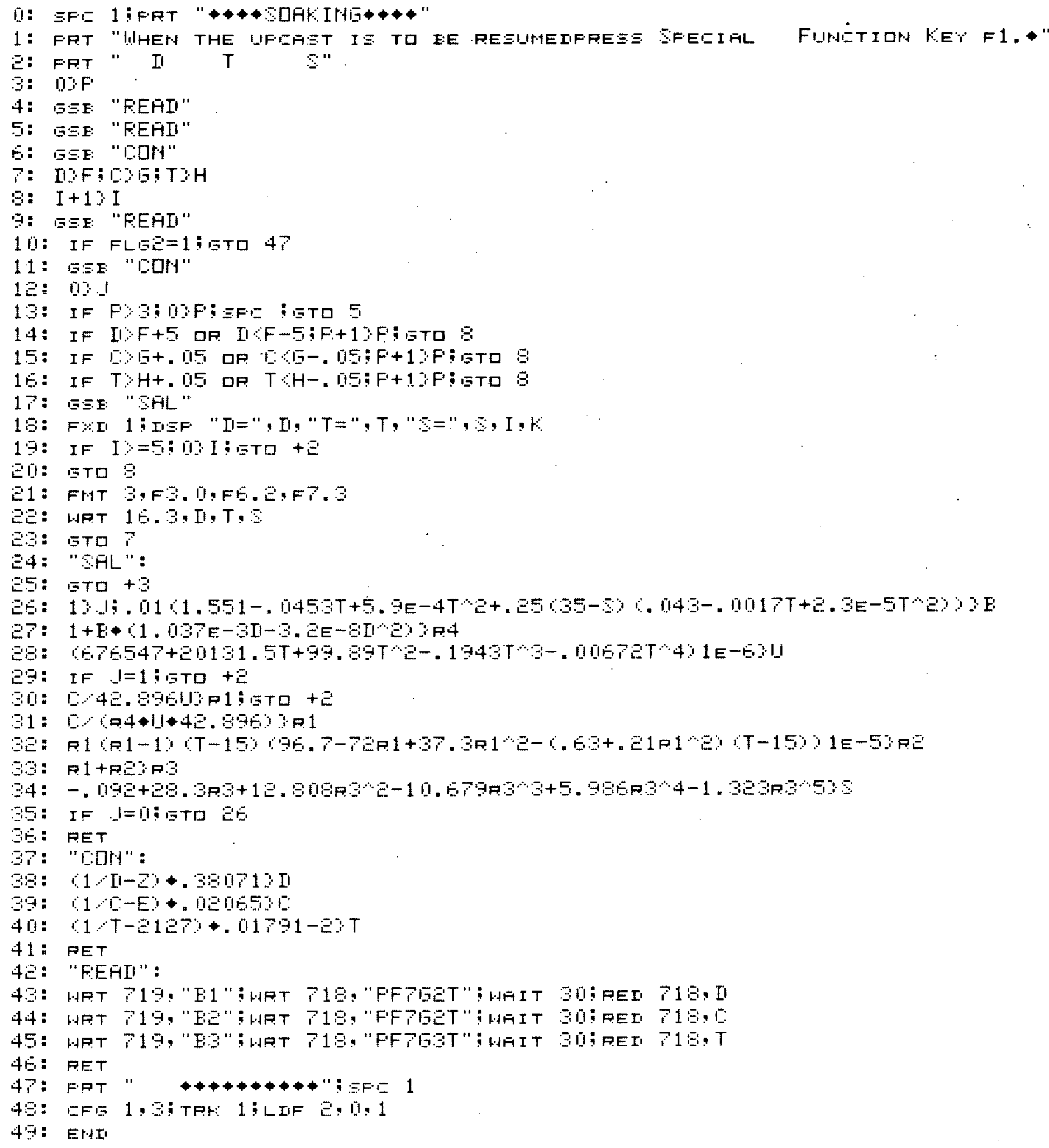


UPEAST AWERAEIHE

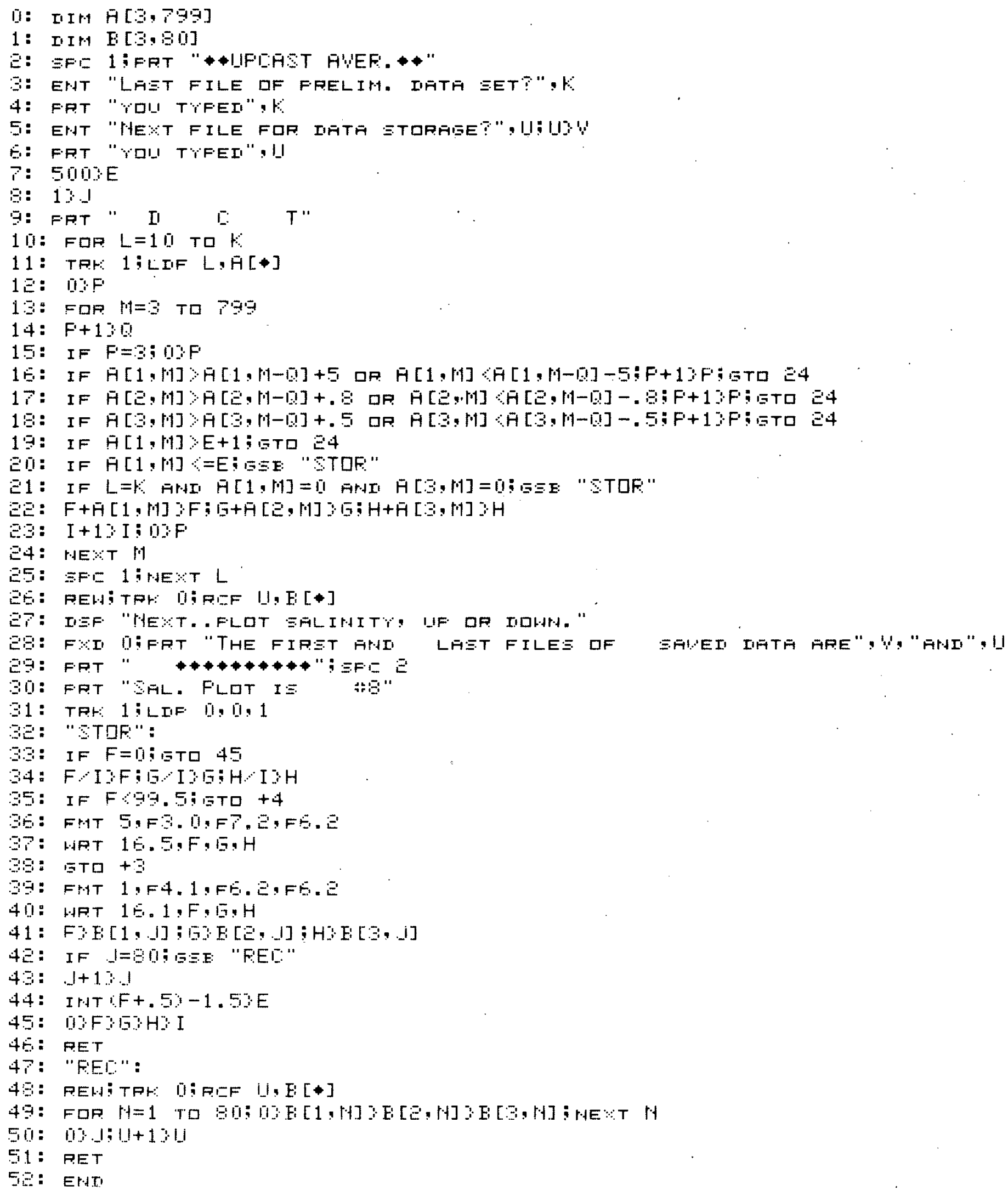




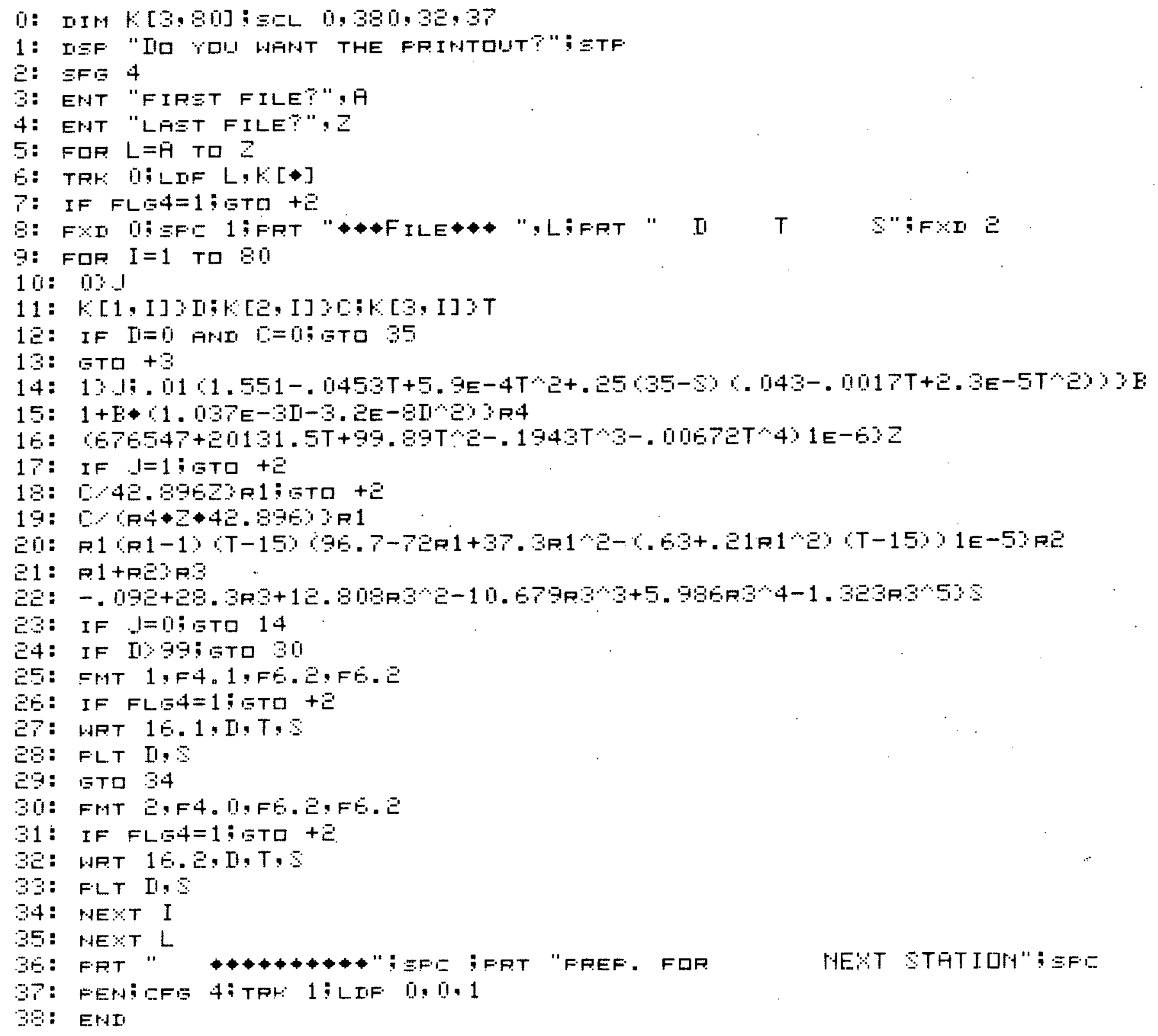


APPENDIX $V$.

Sample HP-CTD Cast Printout 
The following is a sample listing of an HP-CTD cast. The various sections of the printout are as follows:

1. The Master Program (TRK1, FILE 0) provides access to the other programs. It also loads the special function keys.

2. Program 2 reads the clock and prints the month, day, and hour. It then asks for the station number followed by depth and conductivity zero frequencies.

*During the cast, both depth and temperature are displayed on the LED display. Special function key fo ends the cast and puts the $9825 \mathrm{~A}$ into a soak routine. The $9825 \mathrm{~A}$ times the soak and after 4 minutes prints the time and continues. During the soak, 5 consecutive temperature values are averaged and printed unless one of the values varies by more than $0.05^{\circ} \mathrm{C}$ from others, in which. case a space is printed. This visually displays the quality of the soak for calibration purposes.

*After the soak, program 4 prints the first and last preliminary data files, in this case files 10 and 13 .

3. Program 4 loads and runs program 5 which prints the downcast one meter averaged data and asks where to store that data (files 8 and 9 in this case).

4. The upcast is similar to the downcast with final data stored on files 10 and 11 .

5. Program 8 simultaneously prints and plots salinity values for the up and down cast if requested. 


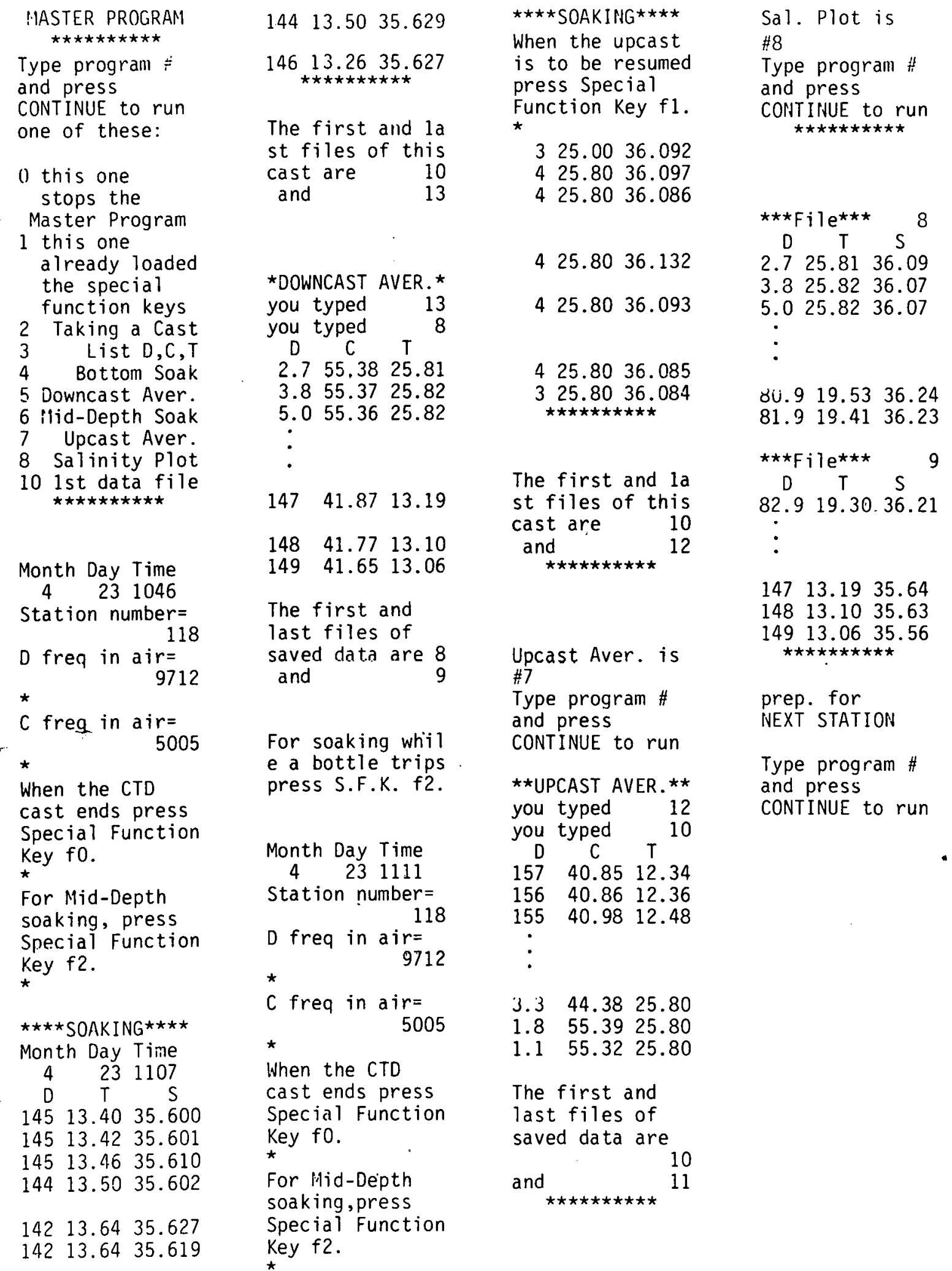




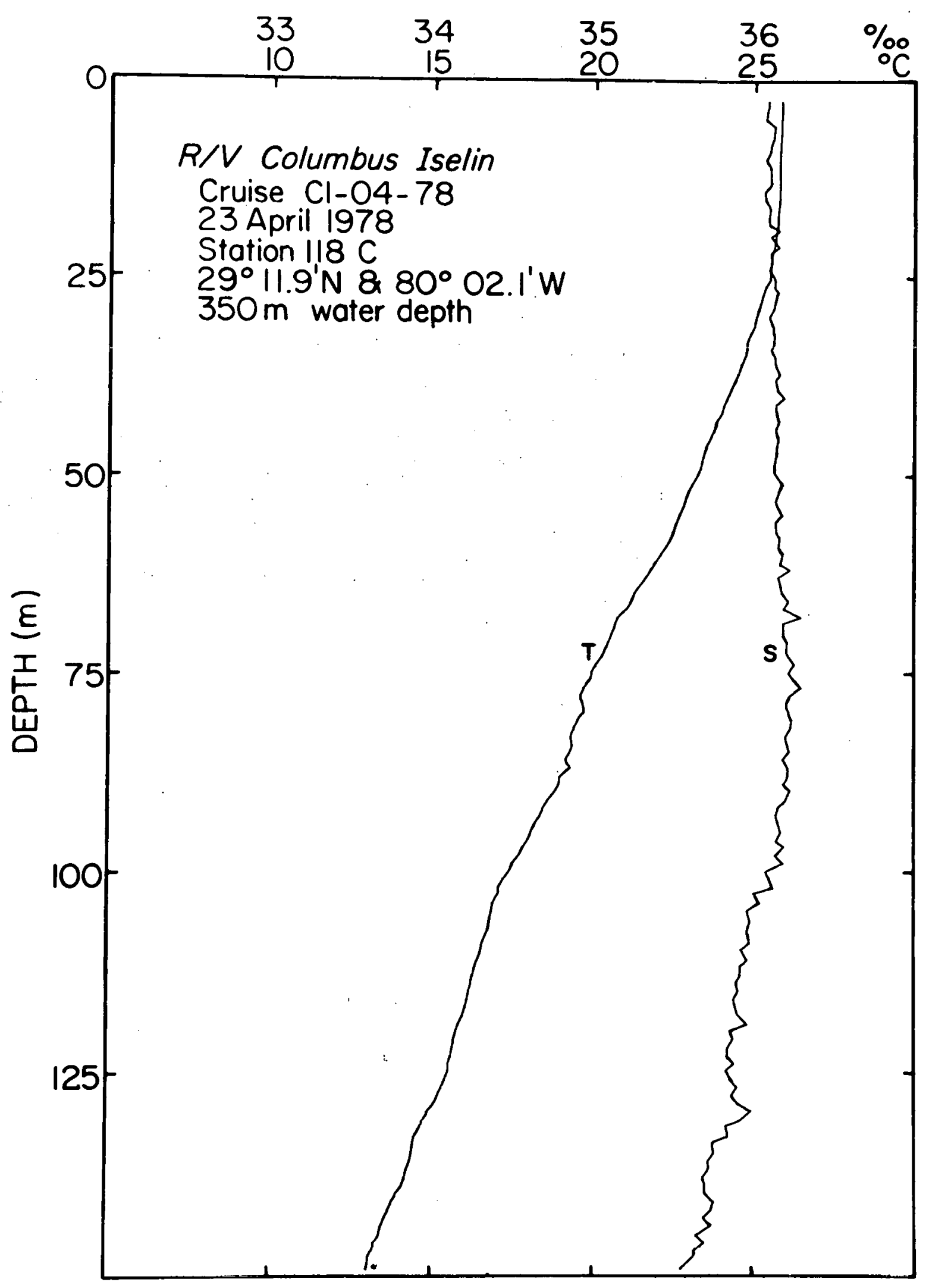


APPENDIX VI.

Data Logging Forms 
DATA CASSETTE LOG

Cruise__ Date

\begin{tabular}{|c|c|c|c|c|}
\hline Station & Time & $\begin{array}{c}\text { Data Acquiring } \\
\text { Program }\end{array}$ & *Data Files* & Remarks \\
\hline & & & & \\
\hline & & & & \\
\hline & & & & \\
\hline & & & & \\
\hline & & & & \\
\hline & & & & \\
\hline & & & & \\
\hline & & & & \\
\hline & & & & \\
\hline & & & & \\
\hline & & & & \\
\hline & & & & \\
\hline & & . & & \\
\hline & & & & \\
\hline & & & & \\
\hline & & & & \\
\hline & & & & \\
\hline & & & & \\
\hline & & & & \\
\hline & & & & \\
\hline & & & & \\
\hline & & & & \\
\hline
\end{tabular}




\section{CRUISE SECTION LOG}

Cruise

Date

Section

\begin{tabular}{|c|c|c|c|c|c|c|c|}
\hline \multicolumn{4}{|c|}{ Distance Offshore to 1st Station $=$} & \multicolumn{3}{|c|}{ Nautical Miles $\times 1.853=$} & KM \\
\hline Station & Depth & Latitude & Longitude & Data Files & Time & Date & Remarks \\
\hline & & & & & & & \\
\hline & & & & & & & \\
\hline & & & & & & & \\
\hline & & & & & & & \\
\hline & & & & & & & \\
\hline & & & & & & & \\
\hline & & & & & & & \\
\hline & . & & & & & & \\
\hline & & & & & & & \\
\hline & & & & & & & \\
\hline & & & & & & & \\
\hline & & & & & & & \\
\hline & & & & & & & \\
\hline & & & & & & & \\
\hline & & & & & & & \\
\hline & & & & & & & \\
\hline & & & & & & & \\
\hline & & & & & & & \\
\hline & & & & & & & \\
\hline & & & & & & & \\
\hline & & & & & & & \\
\hline & & & & & . & & \\
\hline & & & & & & & \\
\hline & & & & & & & \\
\hline
\end{tabular}


Country $=31$

Ship = CI

$\mathrm{C}=\mathrm{CTD}$

$X=X B T$

\begin{tabular}{|c|c|c|c|c|c|c|c|c|c|c|c|c|}
\hline Station\# & Lat. & Long. & Loran C & Day & Time & Depth & $\begin{array}{l}\text { Wlav } \\
\text { Dir. }\end{array}$ & Ht. & Dir. Wind Spd. & $\begin{array}{l}\text { Bar. } \\
\text { Pres. }\end{array}$ & $\begin{array}{l}\text { Air } \\
\text { Temp. }\end{array}$ & $\begin{array}{r}\text { WMO } 4501 \\
\text { Weather }\end{array}$ \\
\hline & & & & & & & & & & & & $x$ \\
\hline & & & & & & & & & & & & $x$ \\
\hline & & & & & & & & & & & & $x$ \\
\hline & & & & & & & & & & & & $x$ \\
\hline & & & & & & & & & & & & $x$ \\
\hline & & & & & & & & & & & & $x$ \\
\hline & & & & & & & & & & & & $x$ \\
\hline & & & & & & & & & & & & $x$ \\
\hline & & & & & & & & & & & & $x$ \\
\hline & & & & & & & & & & & & $x$ \\
\hline & & & & & & & & & & & & $x$ \\
\hline & & & & & & & & & & & & $x$ \\
\hline & & & & & & & & & & & & $x$ \\
\hline & & & & & & & & & & & & $x$ \\
\hline & & & & & & & & & & & & $x$ \\
\hline & & & & & & & & & & & & $x$ \\
\hline & & & & & & & & & & & & $x$ \\
\hline & & & & & & & & & & & & $x$ \\
\hline & & & & & & & & & & & & $x$ \\
\hline
\end{tabular}

CRUISE:

Page of

XBT - CTD BRIDGE LOG 
PINGER LOG

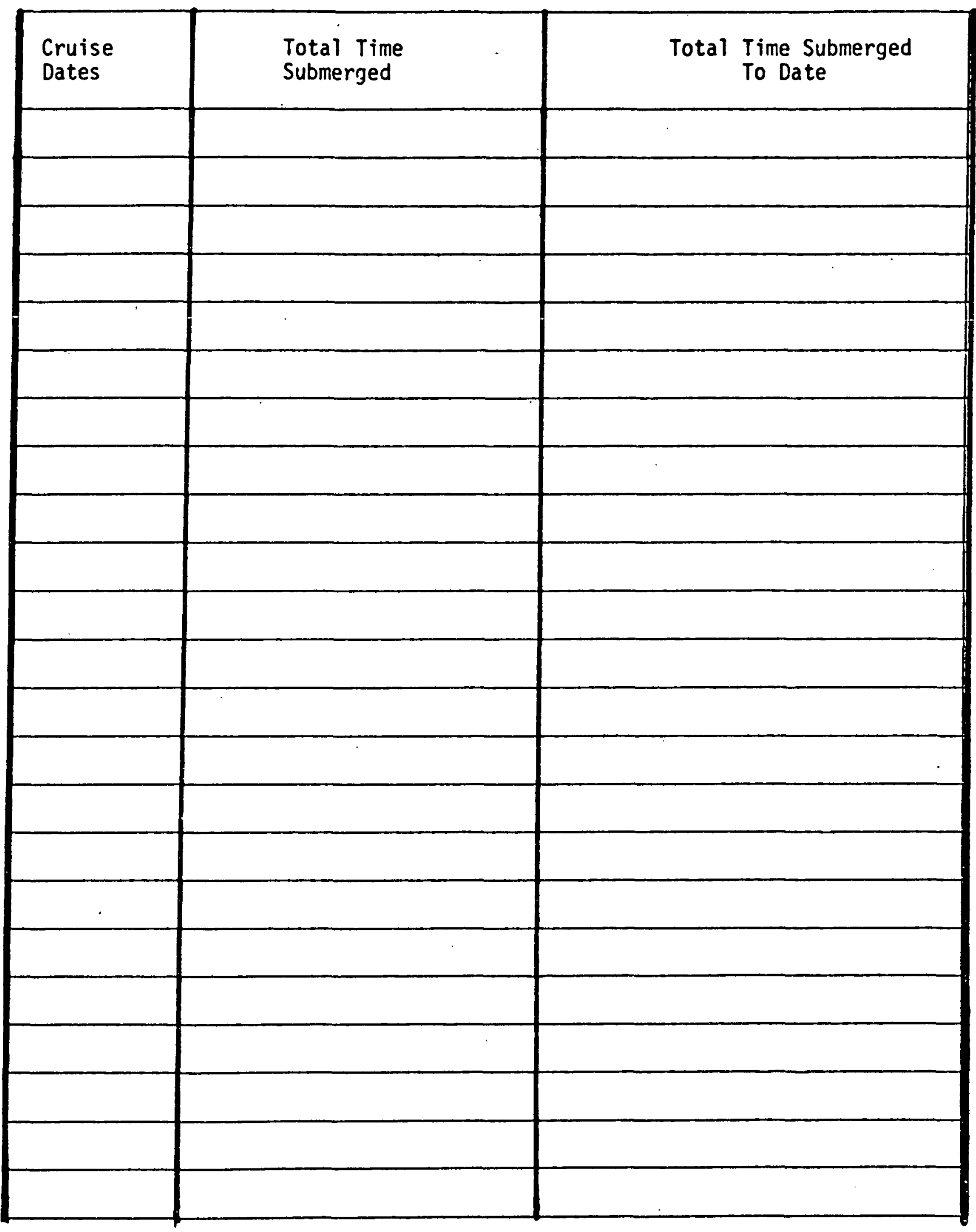




\section{SALINITY LOG SHEET}

\begin{tabular}{|l|l|l|l|}
\hline Cruise & Operators Name & Analys is Date & STANDARD Sea water Stock \# and Year \\
\hline & & & \\
\hline
\end{tabular}

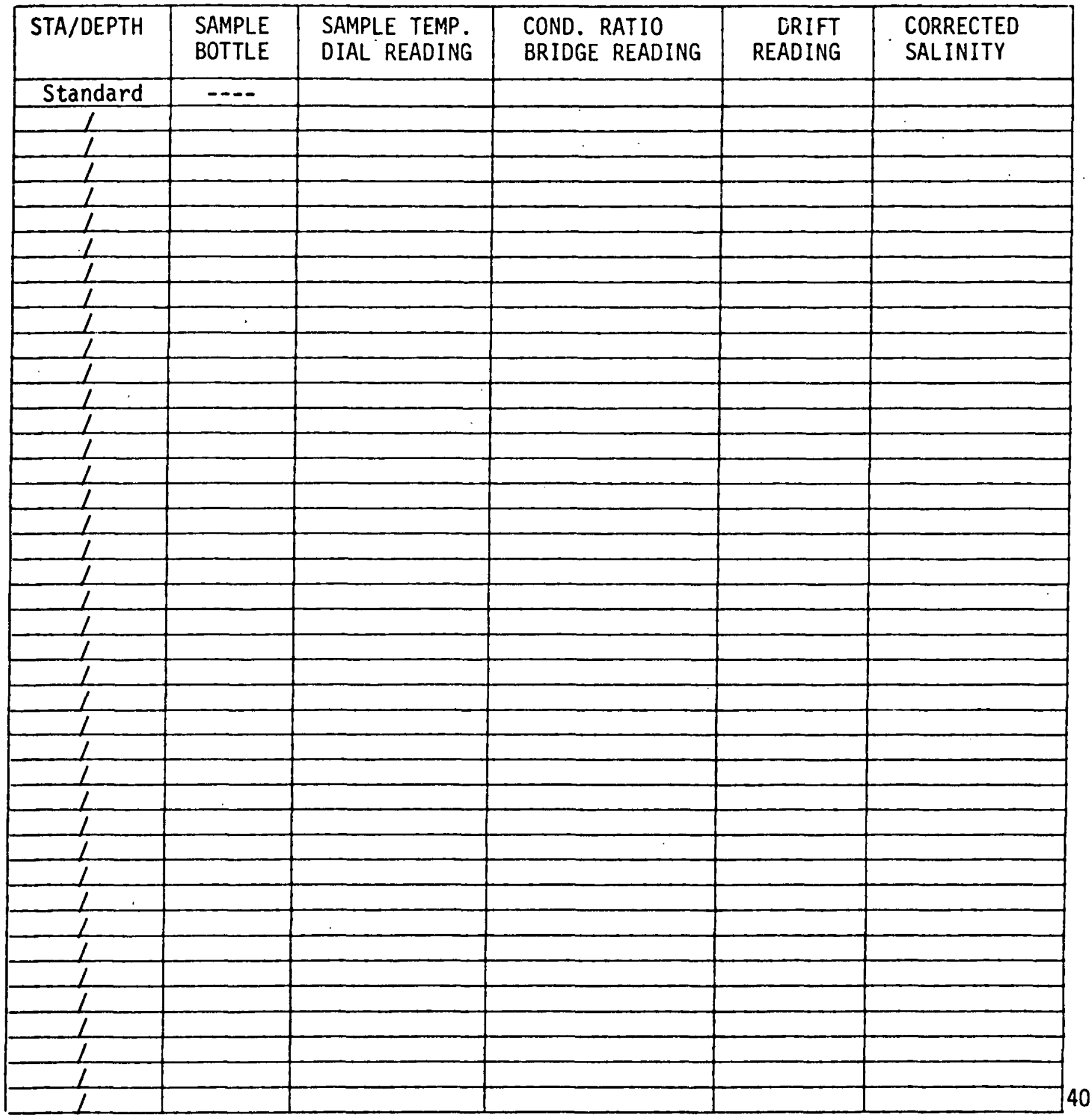




\section{CTO - SALINITY AND TEMPERATURE \\ CALIBRATION DATA}

CRUISE

DATES
DATA SOURCE:

Mag Tape
HP
$X Y Y$

\begin{tabular}{|c|c|c|c|c|c|c|c|}
\hline $\begin{array}{l}\text { Consec. } \\
\text { Sta. Number }\end{array}$ & $\begin{array}{l}\text { Station } \\
\text { Number }\end{array}$ & $\begin{array}{l}\text { Bottle } \\
0 \% 00\end{array}$ & $\begin{array}{c}615 \text { 660 } \\
\text { CTD } \\
\text { \% }\end{array}$ & Diff. & Therm(Rev.) & $\begin{array}{c}720737 \\
\text { CTD } \\
{ }^{\circ} \mathrm{C}\end{array}$ & Diff. \\
\hline & 1 & & & & & & \\
\hline . & 1 & & & & & & \\
\hline & 1 & & & & & & \\
\hline & 1 & & & & & & \\
\hline & 1 & & & * & & & \\
\hline & 1 & & & & & & \\
\hline & 1 & & & & & & \\
\hline & $L$ & & & & & & \\
\hline & 1 & & & & & & \\
\hline & 1 & & & & & & \\
\hline & 1 & & & & & & \\
\hline & 1 & & & & & & \\
\hline & 1 & & & & & & \\
\hline & 1 & & & & & & \\
\hline & L & & & & & & \\
\hline & $L$ & & & & & & \\
\hline & $L$ & & & & & & \\
\hline & 1 & & & & & & \\
\hline & 1 & & & & & & \\
\hline & 1 & & & & & & \\
\hline
\end{tabular}

CTD - SALINITY EQUATION USED :

MEAN $\%$ DIFFERENCE

MEAN OC DIFFERENCE

STANDARD DEV.

STANDARD DEV. 


\begin{tabular}{|c|c|c|}
\hline SENSOR (Accuracy) & \multicolumn{2}{|c|}{ Maximum $\%$ Error } \\
\hline & Shallow & Deep \\
\hline Conductivity $( \pm .03 \mathrm{mmho} / \mathrm{cm})$ & & \\
\hline Temperature $\left( \pm .02{ }^{\circ} \mathrm{C}\right)$ & & \\
\hline Depth $( \pm 1.5 \mathrm{~m})$ & & \\
\hline \%oo Equation: & & \\
\hline Total & & \\
\hline
\end{tabular}

\begin{tabular}{|l|l|l|}
\hline DIGITIZING (RESOLUTION) & Maximum \% $/ 00$ Error \\
\hline Conductivity $( \pm .01 \mathrm{mmho} / \mathrm{cm})$ & & \\
\hline Temperature $\left( \pm .005^{\circ} \mathrm{C}\right)$ & & \\
\hline Depth $\pm .10 \mathrm{~m})$ & & \\
\hline Total & & \\
\hline
\end{tabular}

\begin{tabular}{|l|r|}
\hline \multicolumn{2}{|c|}{$\begin{array}{c}\text { (Values used for error analysis) } \\
\text { SHALLOW }\end{array}$} \\
\hline Cond. & Cond. \\
Temp. & Temp. \\
Depth & Depth \\
\hline
\end{tabular}




\begin{tabular}{|c|c|c|c|c|c|c|c|c|c|c|c|c|c|c|c|c|c|c|c|c|c|c|c|c|c|c|c|c|c|c|c|c|c|c|c|c|c|c|c|c|}
\hline \multirow[b]{4}{*}{$\mathrm{COI}$} & & \multirow{3}{*}{\multicolumn{2}{|c|}{ SHIP }} & \multirow{3}{*}{\multicolumn{6}{|c|}{$\frac{\text { LAYITUDE }}{S=\times 8}$}} & \multirow{3}{*}{\multicolumn{7}{|c|}{$\begin{array}{l}\text { IONGITUDE } \\
E=x 14\end{array}$}} & ENVIR & DNME & NIAL & INFOR & aAtic & & (MASI & ER C & RDD) & & & & & & & & & & & & & & & \\
\hline & \multirow{2}{*}{ COUntar } & & & & & & & & & & & & & & & & \multirow{2}{*}{\multicolumn{3}{|c|}{$\begin{array}{l}\text { MARSDEN } \\
\text { SOUARE }\end{array}$}} & \multicolumn{6}{|c|}{ DATE } & \multicolumn{3}{|c|}{ IIME GMI } & \multirow{2}{*}{\multicolumn{3}{|c|}{$\begin{array}{c}\text { SHIP'S } \\
\text { CRUISE NO. }\end{array}$}} & \multirow{2}{*}{\multicolumn{3}{|c|}{$\begin{array}{c}\text { SHIP S } \\
\text { STAYION NO. }\end{array}$}} & \multirow{2}{*}{\multicolumn{4}{|c|}{$\begin{array}{l}\text { DEPTH 10 } \\
\text { BOTOM (M) }\end{array}$}} & \multirow{2}{*}{\multicolumn{2}{|c|}{$\max _{\text {SMAPLE }}$}} \\
\hline & & & & & & & & & & & & & & & & & & & & \multicolumn{2}{|c|}{ VEAR } & \multicolumn{2}{|c|}{ MONTH } & \multicolumn{2}{|c|}{ DAY } & \multicolumn{2}{|c|}{ HR. } & \multirow{2}{*}{\begin{tabular}{|c|}
$1 / 10$ \\
27 \\
\end{tabular}} & & & & & & & & & & & & \\
\hline & 1 & 3 & 4 & 3 & 0 & 7 & 8 & 9 & NS & 10 & 11 & 12 & 13 & 14 & is & $E \mathbf{E}$ & 10 & 17 & 18 & 19 & 20 & 21 & 22 & 23 & 24 & 25 & 26 & & 28 & 20 & 30 & 31 & 32 & 33 & 34 & $\sqrt{35}$ & 36 & 37 & 38 & 39 \\
\hline & & & & & & & & $1 / 10$ & & & & & & & $1 / 10$ & & & & & & & & & & & & & & & & & & $\cdots$ & $\infty$ & $\pi$ & 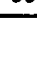 & re & 0 & 50 & 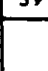 \\
\hline & \multirow{2}{*}{$\begin{array}{c}100 \\
\text { OAS } \\
\text { CODE }\end{array}$} & \multicolumn{4}{|c|}{ WATER } & \multicolumn{4}{|c|}{ wave } & \multicolumn{4}{|c|}{ WINO } & & & & \multicolumn{6}{|c|}{ AIR temperatuafe $c$} & WEA & HER & \multicolumn{2}{|c|}{ CIOUD } & \multirow{2}{*}{\multicolumn{6}{|c|}{ SPECIAL OBS }} & & & PROC & $5 s i$ & 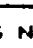 & & & $c$ \\
\hline & & & & TRA & & D & & 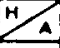 & 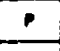 & & & SPEED & oxCE & & C. IMt & & & Der & & & VET & & & & 7 & $A$ & & & & & & & & 10 & mo & & $\mathrm{COI}$ & $\overline{C N}$ & & I \\
\hline cor & 41 & 42 & 43 & 44 & 43 & 40 & 47 & 48 & 49 & so & 51 & 52 & 53 & 54 & 55 & so & 37 & 38 & 59 & 80 & 61 & 62 & 63 & 84 & 65 & 66 & 67 & 68 & 09 & 70 & 71 & 72 & 73 & 74 & 75 & 70 & $\pi$ & 78 & 79 & 80 \\
\hline & & & & & & & & & & & & & & & & & & & & & & & & & & & & & & & & & & & & & & & & \\
\hline
\end{tabular}

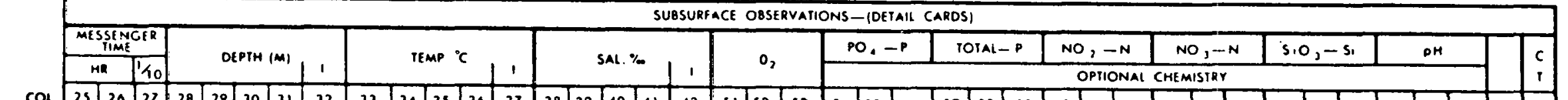

\begin{tabular}{|l|l|l|l|l|l|l|l|l|l|l|l|l|l|l|l|l|l|l|l|l|l|l|l|l|l|l|l|l|l|l|l|l|l|l|l|l|l|l|l|l|}
\hline 25 & 20 & 27 & 28 & 29 & 30 & 31 & 32 & 33 & 34 & 35 & 30 & 37 & 38 & 39 & 10 & 11 & 42 & 31 & 32 & 53 & 54 & 55 & 50 & 57 & 58 & 59 & 60 & 01 & 62 & 03 & 04 & 05 & 60 & 67 & 08 & 69 & 70 & 31 & 72 & 80 \\
\hline
\end{tabular}

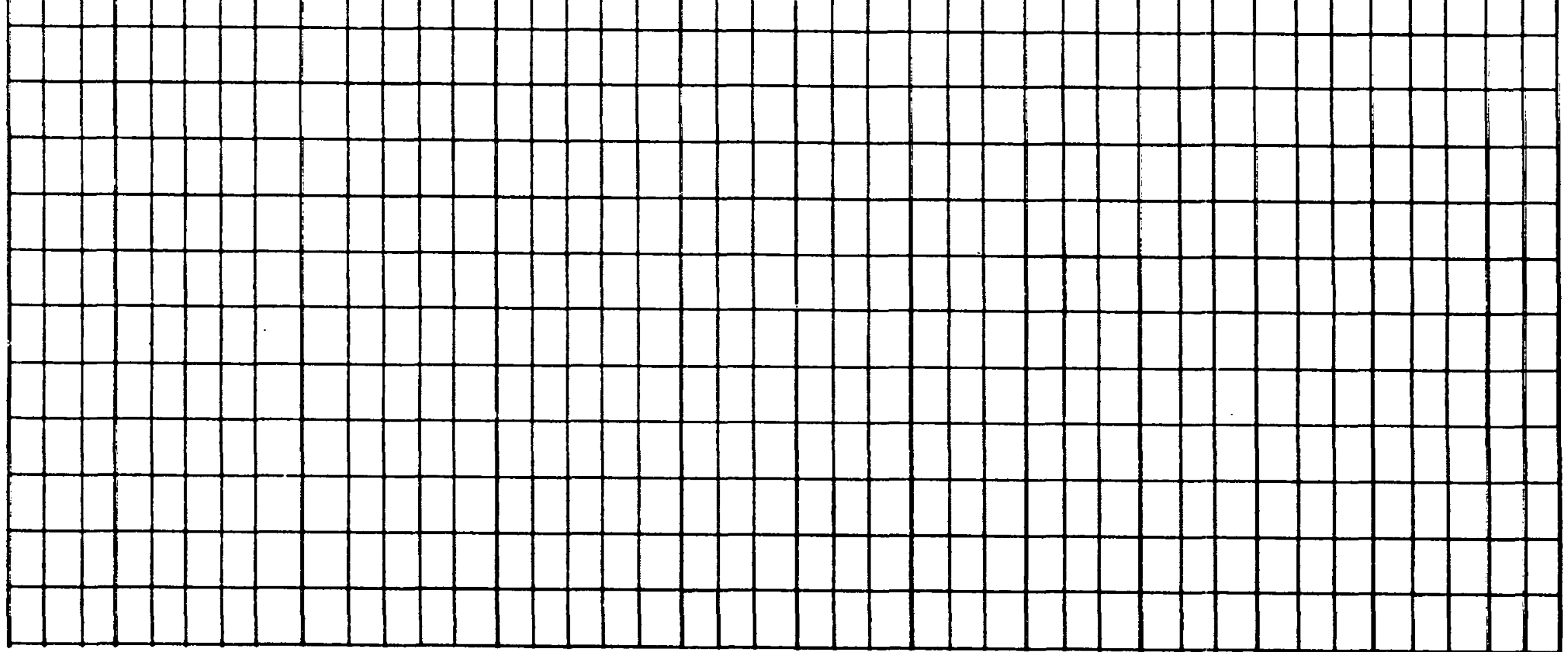


MAGNETIC TAPE LOG

\begin{tabular}{|c|c|c|c|c|c|c|c|}
\hline Tape No. & Date Used & Where Used & $\begin{array}{l}\text { Keyword } \\
\text { VSN }\end{array}$ & Date Mailed & Date Returned & $\begin{array}{l}\text { Cleaned/Inspect } \\
\text { Yes/No }\end{array}$ & Comments \\
\hline & & & & & & & \\
\hline & & & & & & & \\
\hline & & & & & & & \\
\hline & & & & & & & \\
\hline & & & & & & & \\
\hline & & & & & & & \\
\hline & & & & & & & \\
\hline & & & & & & & \\
\hline & & & & & & & \\
\hline & & & & & & & \\
\hline & & & & & & & \\
\hline & & & & & & & \\
\hline & & & & & & & \\
\hline & & & & & . & & \\
\hline & & & & & & & \\
\hline & & & & & & & \\
\hline & & & & & & & $\stackrel{\infty}{\infty}$ \\
\hline & & & & & & & \\
\hline
\end{tabular}




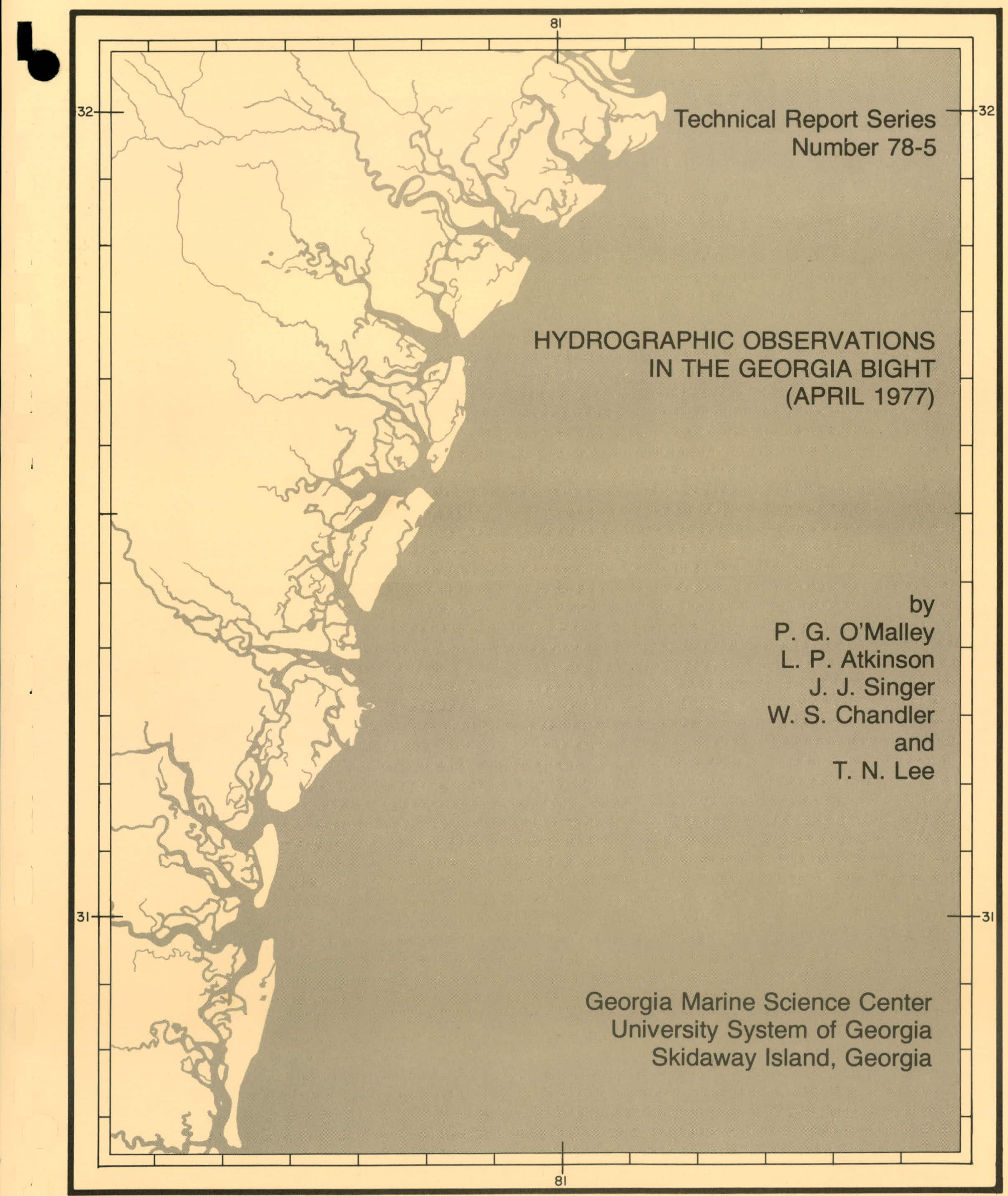


This report was prepared as an account of work sponsored by the United States Government. Neither the United States nor the United States Department of Energy, nor any of their employees, nor any of their contractors, subcontractors, or their employees, makes any warranty, express or implied, or assumes any legal liability or responsibility for the accuracy, completeness or usefulness of any information, apparatus, product or process disclosed, or represents that its use would not infringe privately-owned rights. 
HYDROGRAPHIC OBSERVATIONS IN THE

GEORGIA BIGHT (APRIL 1977)

\author{
by \\ P. G. O'Malley, L. P. Atkinson,
}

J. J. Singer, W. S. Chandler, and T. N. Lee

Skidaway Institute of Oceanography

P. 0. Box 13687

Savannah, Georgia 37406

Ju7y 1978

The Technical Report Series of the Georgia Marine Science Center is issued by the Georgia Sea Grant Program and the Marine Extension Service of the University of Georgia on Skidaway Island ( $P$. 0 . Box 13687, Savannah, Georgia 31406). It was established to provide dissemination of technical information and progress reports resulting from marine studies and investigations mainly by staff and faculty of the University System of Georgia. In addition, it is intended for the presentation of techniques and methods, reduced data and general information of interest to industry, local, regional, and state governments and the public. Information contained in these reports is in the public domain. If this prepublication copy is cited, it should be cited as an unpublished manuscript. 
List of Tables................... . i i

List of figures ....................... . . . . .

Acknowledgements. .................. . v

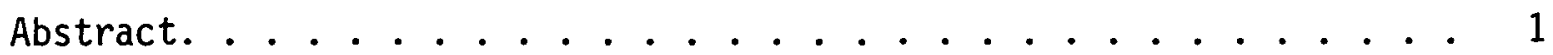

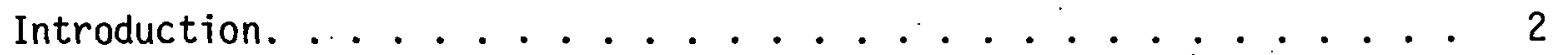

Methods ...................... 2

Chemical and Physical Procedures............ 5

XBT Data Acquisition and Processing. . . . . . . . . . 6

CTD Data Acquisition . . . . . . . . . . . . . . . 6

CTD Data Processing. . . . . . . . . . . . . . . . . 8

CTD Calibration. ....................... 11

CTD Error Analysis . . . . . . . . . . . . . 12

Meteorological Conditions . . . . . . . . . . . . 17

Results and Discussion................ 19

The Vertical Distribution of Physical and Chemical Properties. . 19

Savannah Section, 8-9 April 1977. . . . . . . . . . 19

St. Simons Section, 10 April 1977......... 20

Savannah Section, 11-12 April 1977. . . . . . . . . . 20

Jacksonville Section, 13-14 April 1977. ........ 21

St. Augustine (South) Section, 14 April 1977. . . . . . . 21

Ormond Beach Section, 15 April 1977 . . . . . . . . . 21

St. Augustine (North) Section, 15 Apri1 1977. . . . . . . 22

Jacksonville (North) Section, 15 April 1977 : . . . . . . 22

St. S1mons Section, 16 Apr17 $1977 \ldots . . ., \ldots, \ldots 22$

Savannah Section, 16 April 1977 ........... 22

Savannah Section, 19 April 1977 . . . . . . . . . 23

The Horizontal Distribution of Temperature . . . . . . 23

T-S Relationship................ 24

Summary ........................ . . . 24

Figures ........................... 25

References................... . . 48

Appendix I. Hydrographic Data. . . . . . . . . . . . 49 


\section{LIST OF TABLES}

Page

1. CTO/Data Flow. Shipboard acquisition to NODC submission. . . 9

2. Stations at which Hewlett-Packard $9825 \mathrm{~A}$ was used as the . . 10 primary data acquisition system

3. Cruise AD-4-77 Salinity Calibration Data. . . . . . . 15

4. Specifications for Plessey Mode1 9400 CTD system. . . . . . 13

5. Sources of salinity error due to the reported accuracy. . . . 17 of the sensors and the salinity equation 
1. The Georgia Bight. Current/Temperature/Pressure moorings are designated A through G. . . . . . . . . . 3

2. The study area showing station locations for cruises AD-4-77 (numbered stations) and BF-29-77 (lettered stations.................. 4

3. Salinity offset for cruise AD-4-77 (—- mean offset; -...- standard deviation) . . . . . . . . 12

4. Regression analysis of salinity offset versus depth of sensor, cruise AD-4-77. . . . . . . . . . . 14

5. Wind data, Jacksonville, Florida, 1-20 Apri1, 1977 at three hour intervals (U.S. Depart. of Comm. April, 1977) . . . 18

6. Vertical distribution of temperature, salinity, and sigma-t, Savannah section, 8-9 April 1977. . . . . . . . . 26

7. Vertical distribution of nutrients and oxygen, Savannah section, 8-9 April 1977............ . 27

8. Vertical distribution of temperature, salinity, and sigma-t, St. Simons section, 10 April 1977 . . . . . . . . 28

9. Vertical distribution of nutrients and oxygen, St. Simons section, 10 April 1977. . . . . . . . . . . 29

10. Vertical distribution of temperature, salinity, and sigma-t, Savannah section, 11 April 1977 .......... 30

11. Vertical distribution of nutrients and oxygen, Savannah section, 11 April 1977................ 31

12. Vertical distribution of temperature, salinity, and sigma-t, Savannah section, 12 April $1977 \ldots . . . . . . .32$

13. Vertical distribution of nutrients and oxygen, Savannah section

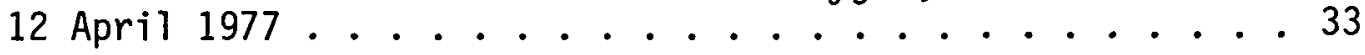

14. Vertical distribution of temperature, salinity, and sigma-t, Jacksonville section, 13-14 April 1977. . . . . . . 34

15. Vertical distribution of nutrients and oxygen, Jacksonville section, 13-14 April 1977 . . . . . . . . . 35

16. Vertical distribution of temperature, salinity, and sigma- $t$, St. Augustine (South) section, 14 April 1977....... 36

17. Vertical distribution of nutrients and oxygen, St. Augustine (South) section, 14 Apr11 1977............. 37 


\section{LIST OF FIGURES (Cont'd)}

Page

18. Vertical distribution of temperature, salinity, and sigma-t, Ormond Beach section, 15 April 1977. . . . . . . . . . 38

19. Vertical distribution of nutrients and oxygen, Ormond Beach

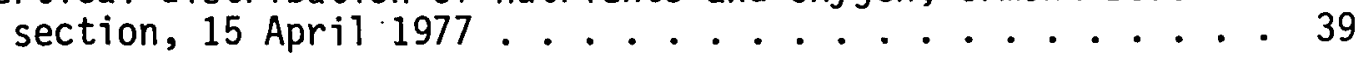

20. Vertical distribution of temperature, salinity, and sigma-t, St. Augustine (North) section, 15 April 1977....... 40

21. Vertical distribution of nutrients and oxygen, St. Augustine (North) section, 15 ApriT 1977 ............. 41

22. Vertical distribution of temperature, salinity, and sigma-t, Savannah section, 16 April 1977............ 42

23. Vertical distribution of nutrients and oxygen, Savannah section, 16 April 1977 ........................ 43

24. Vertical distribution of temperature, (a) Jacksonville (North) section, 15 April 1977, (b) St. Simons section, 16 April 1977, and (c) cruise BF-29-77 (Savannah) 19 Apri1 1977 . . . . 44

25. Horizontal surface temperature distribution, 12-14 April 1977. 45

26. Horizontal surface temperature distribution, 14-16 Apri] 1977. 46

27. Temperature-Sal inity plot, cruise AD-4-77, April 1977. . . . 47 


\section{ACKNOWLEDGEMENTS}

The authors thank Alex Brincko, Rich Findley, Dave Gregory, 0. C. Guest and Dave Leach for their participation in the study. We also thank the Captains, mates, crew and students of the S/S ADVANCE II and the R/V BLUE FIN. Dan McIntosh provided graphics assistance and Cindy Miller typed the text.

Funding for this research and report preparation is provided by the Department of Energy, under Contract EY-S-76-09-0889.

This report is published as a part of the Georgia Marine Science Center's Technical Report series issued by the Georgia Sea Grant Program under NOAA Office of Sea Grant \# 04-7-158-44126. 


\section{ABSTRACT}

During two cruises in the Georgia Bight in April 1977, nine hydrographic and three XBT transects were conducted. Temperature, salinity, dissolved oxygen, and nutrient $\left(\mathrm{NO}_{3}, \mathrm{PO}_{4}\right.$, and $\left.\mathrm{SiO}_{2}\right)$ data were collected.

Generally, the continental shelf water was well mixed vertically and characterized by low nutrient concentrations and oxygen saturation. However, bottom and interlayering intrusions of Gulf Stream water onto the shelf were observed. Satellite thermal images revealed a Gulf Stream spin-off eddy which was subsequently mapped and intensively sampled. Strong upwelling of dense, cold, nutrient-rich, and oxygen depleted water was associated with the eddy event. It is likely that the regular occurrence of spin-off eddies provides a mechanism for significant nutrient enrichment of the continental shelf. 


\section{INTRODUCTION}

This report contains chemical and physical data obtained during Georgia Bight cruises AD-4-77 and BF-29-77 aboard the S/S ADVANCE II and the R/V BLUE FIN from 8 to 20 Apri1 1977. The investigation was part of a larger multi-institutional DOE program to describe and explain the physical, chemical, and biological processes of the South Atlantic Bight, the continental. shelf region from Cape Hatteras to Cape Canaveral. The study reported here was concentrated in the Georgia Bight from Savannah, Georgia, south to Ormond Beach, Florida (Fig. 1).

Our object was to collect temperature and chemical data to correlate with other data from box arrays of current/temperature/pressure recording instruments (deployed by the University of Miami) concurrently operative in the study area (Fig. 1). Additionally, our temperature and conductivity data are used to calibrate the moored instruments. No attempt is made here to correlate the hydrographic/chemical observations with the current meter data. The latter will appear in a separate report edited by Dr. T. Lee of the University of Miami.

The processed hydrographic data set is available from the National Oceanographic Data Center (NODC).

\section{METHODS}

Nine onshore-offshore hydrographic transects and two XBT transects were conducted during the ADVANCE II cruise (Fig. 2). The first four transects were selected to provide chemical and physical data during recovery, servicing, and deployment of the current/temperature/pressure instruments of the box array off Savannah and St. Simons, Georgia. Later, we proceeded south to locate what appeared, in satellite thermal images, to be a Gulf Stream spin-off eddy (Lee, 1975). 


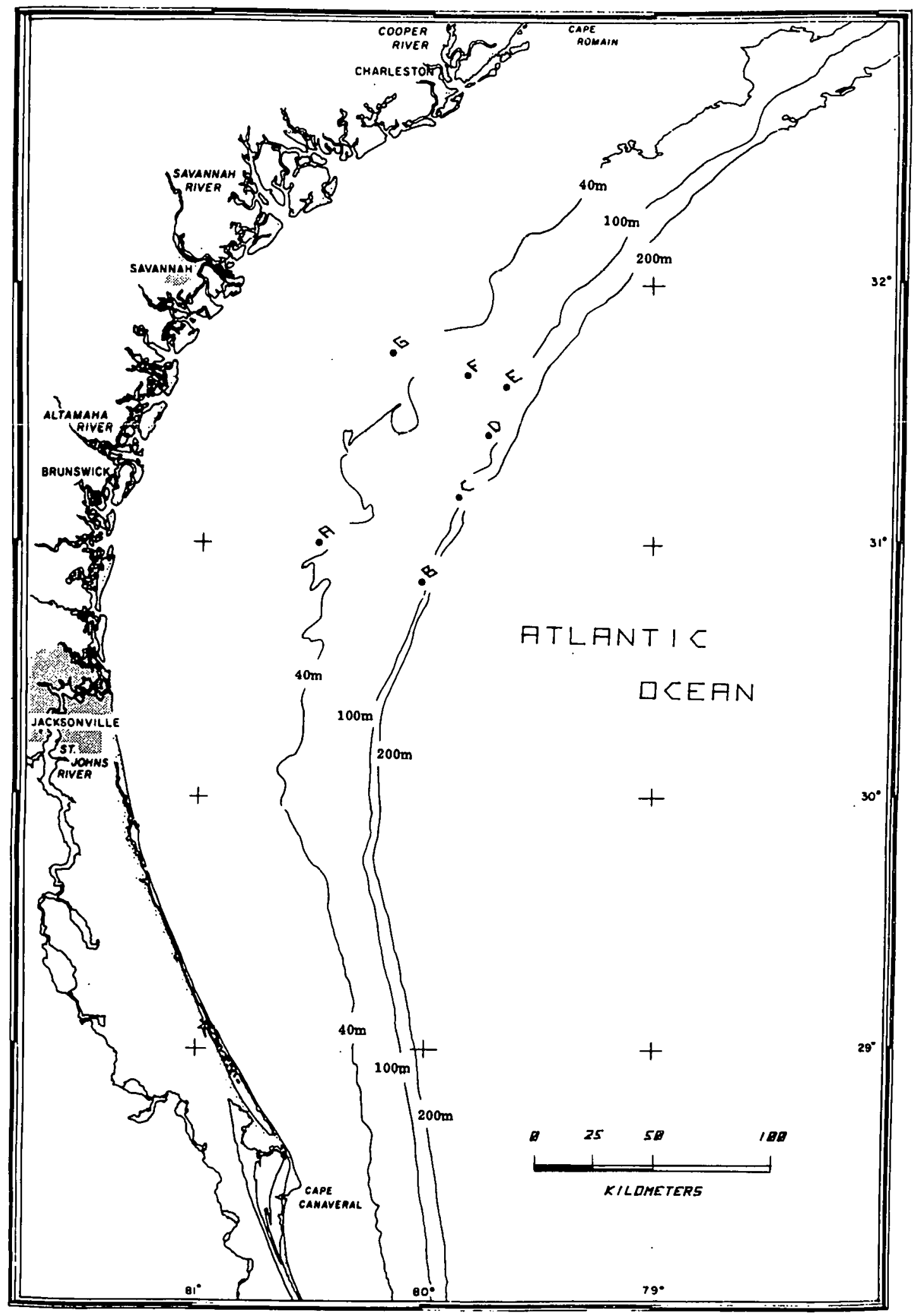

Figure 1. The Georgia Bight. Current/Temperature/Pressure moorings are designated A through $G$. 


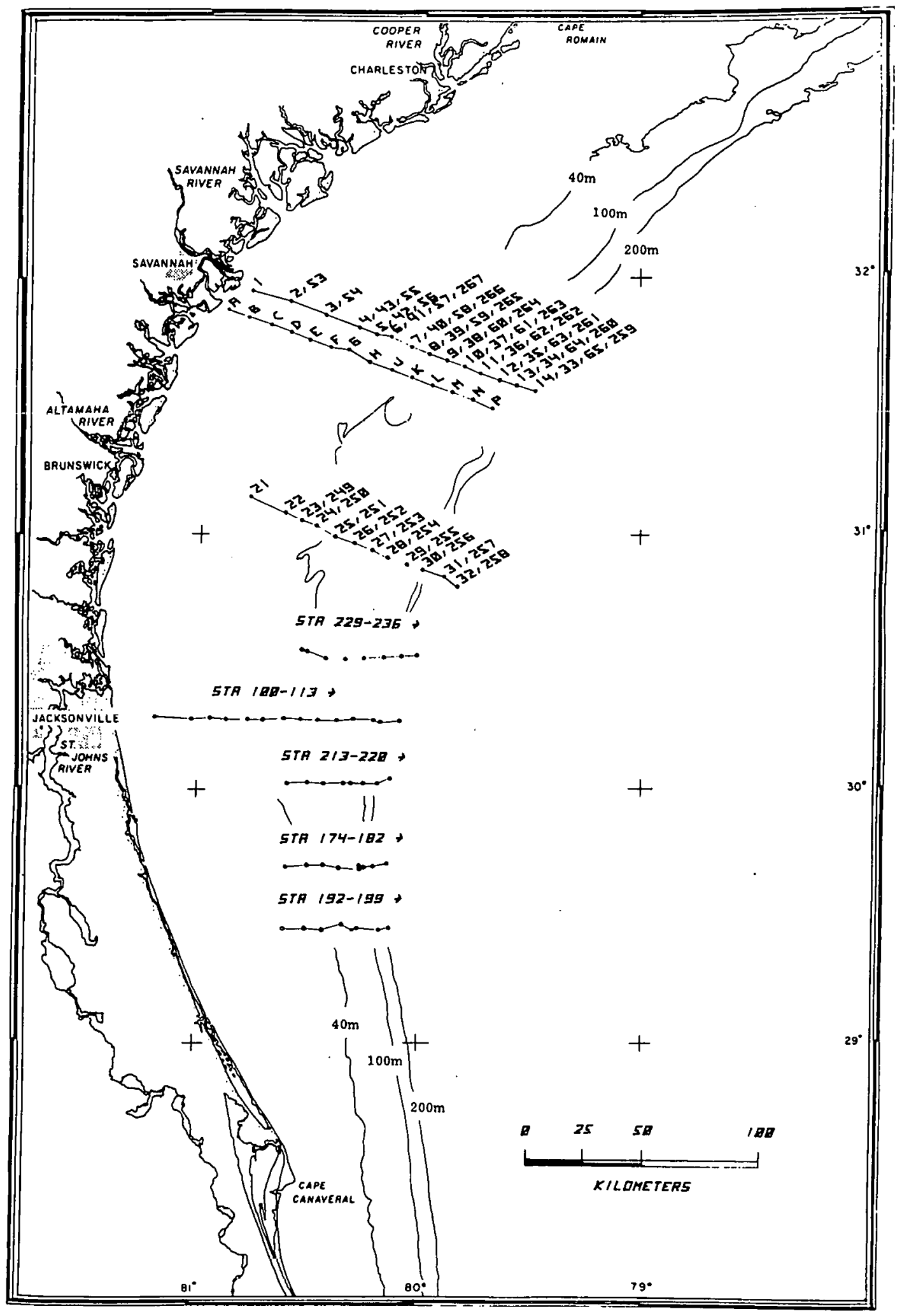

Figure 2. The study area showing station locations for cruises AD-4-77 (numbered stations) and BF-29-77 (lettered stations). 
Four hydrographic sections and one XBT transect were made adjacent to and through this event. The final two sections were made off St. Simons and Savannah to provide additional data in the area of the array. Throughout the ADVANCE II cruise, surface temperature/salinity distribution was mapped by means of a thermosalinograph. The BLUE FIN cruise on 19-20 April consisted of one onshore/offshore XBT section off Savannah (Fig. 2).

A typical hydrographic section consisted of alternate CTD (conductivity/temperature/depth) Rosette casts and XBT (expendable bathythermograph) firings at approximately 10 kilometer intervals. On occasion, specifically during investigation of the eddy event, sampling intensity was increased. Two sections, Jacksonville (North), 15 April 1977, and St. Simons, 16 April 1977, consisted exclusively of XBT stations at approximately 10. kilometer intervals. The average time required to complete a hydrographic section, excluding the first Savannah section which took 15 hours, was approximately 6 hours. The average time of an XBT section was 2 hours.

At CTD stations, a General Oceanics Model 1015 Mark 5 Rosette multi-bottle array was mated to the Plessey 9400 CTD sensor unit and equipped with 1.7 liter Niskin bottles for water sampling. Niskin sampling depths were determined from the temperature structure obtained from the CTD. Samples were taken near the surface, just above or below the thermocline, at the bottom, and occasionally at other depths. Samples were analyzed for salinity, nitrate, phosphate, silicate, and dissolved oxygen contents.

Chemical and Physical Procedures

Salinity samples were analyzed conductometrically using a Plessey Model $6230 \mathrm{~N}$ portable laboratory salinometer. Values obtained were used 
to calibrate the Plessey Model 9400 CTD system. A separate section of this report details the CTD calibration procedure. Temperature was determined with deep sea reversing thermometers, XBT's, and the CTD system.

Dissolved oxygen analyses were performed onboard the research vessel within 24 hours of collection using a modified Winkler procedure (Strickland and Parsons, 1965).

Nutrient samples were immediately frozen in polyethylene bottles and stored in the dark until thawed and analyzed ashore. Colorimetric determinations of nutrient concentrations were made utilizing a Bausch and Lomb Spectronic 88 spectrophotometer with a sample sipper. Silicate was determined by the method of Mullin and Riley (1955) as modified by Strickland and Parsons (1965), phosphate by the method of Murphy and Riley (1962), and nitrate by the cadmium column reduction technique as modified by Gardner et al. (1976) XBT Data Acquisition and Processing

A Sippican Model LM3A handheld launcher equipped with type T10 probes $(200 \mathrm{~m})$, coupled to a Sippican Model MK2A-1 recorder, was used for XBT casts. The temperature/depth plots were digitized on a Hewlett-Packard Model 9864A digitizer interfaced to a Hewlett-Packard Model $9825 \mathrm{~A}$ calculator. The digitized data was placed in NODC format and merged on magnetic tape with processed CTD data. Depths at which temperature was a whole or half degree are reported as are depths at which a significant mixed layer began or ended.

\section{CTD Data Aequisition}

The CTD unit consisted of a Plessey Model 9400 CTD sensor system with a Model 8400 digital data logger and Kennedy Model 1600 incremental 
magnetic tape recorder for data acquisition and storage. A redundant XYY' plot was made of all casts using a Hewlett-Packard Model $7046 \mathrm{X}-\mathrm{Y}$ recorder which was calibrated with a precision 10VDC source.

With the exception of two stations (53S and 54S), digitized data was collected as the CTD sensor unit was lowered at $15 \mathrm{~m} / \mathrm{min}$ on single conductor cable. All three parameters (C, T, and $D)$ were sampled once each $229 \mathrm{milliseconds}$ or every $6 \mathrm{~cm}$ at the $15 \mathrm{~m} / \mathrm{min}$ lowering rate. For primary calibration of temperature and salinity, a Niskin bottle equipped with paired protected deep sea reversing thermometers was tripped after a four minute equilibration period at the maximum sample depth. Other water samples were collected during ascent at depths selected after examination of the downcast temperature structure. The average time for stations less than 100 meters in depth was 16 minutes; for those greater than 100 meters, average time was 44 minutes, with a maximum of 60 minutes at station 65 .

The acquisition of CTD data during the downcast and water samples during the upcast creates some problems:

1) CTD data is of higher quality during the down than up cast since the sensors are located at the bottom of the sub-surface unit to maximize response during the downward motion. During upward motion, the CTD sensors lie in the wake of the Rosette.

2) Water samples are taken during the upcast since surface water samples taken during the downcast may be diluted by deeper waters.

3) Although horizontal advection may alter the coherence of downcast CTD data versus upcast water sample data, the minor advective motions during the time of a station cause negligible mismatch of nutrient data 
since horizontal gradients in nutrients are typically quite low.

Upcast CTD data is reported for stations $53 \mathrm{~S}$ and $54 \mathrm{~S}$ since those collected on the downcast were not recorded on magnetic tape. CTD Data Processing

CTD plots were logged and stored with their respective station sheets. All data recorded on magnetic tape were extracted and processed according to the flow scheme (Scarlet, 1975) shown in Table 1. Computation and data manipulation were performed on a CDC Cyber 70 computer. MAGREAD converts binary coded data to frequencies and CTDUNIT converts frequencies to engineering units. LAGFILT treats the data for the temperature lag of the temperature sensor and coarse filters the data for noise. Next, SIGSALP calculates uncorrected sigma-t and salinity values. At this stage, salinity and temperature offset corrections are made from the primary calibration data. Flow is then resumed by repeating SIGSALP with the added correction factors. DLATCH deletes lines with decreasing or repeated depths caused by ship roll and CTDAVE presents the data in average one meter increments. NODCFO converts the data to NODC format and NODMER merges additional data (i.e., nutrients, weather, latitude, longitude, etc.) for submission to NODC. CEMLIST calculates specific volume anomalies, oxygen saturation and apparent oxygen utilization (from the International Oceanographic Tables, 1973), the distance between successive stations, reads all other data and formats the data for presentation in a technical report. The final product is stored on magnetic tape in our computer system and all data (i.e., CTD, XBT, chemical, etc.) are available through NODC. At the stations and to the depths listed in Table 2, a Hewlett-Packard Model $9825 \mathrm{~A}$ calculator was used to record data on cassette tape because of a 
Table 1. CTD/Data Flow. Shipboard acquisition to NODC submission.

\begin{tabular}{|c|c|c|}
\hline Data Source/Disposition & Program & Data File \\
\hline \multirow[t]{6}{*}{ Tape from Data Logger } & MAGREAD & $\begin{array}{l}\text { (Converts binary coded data to } \\
\text { decimal) }\end{array}$ \\
\hline & & BIRANG \\
\hline & CTDUNIT & $\begin{array}{l}\text { (Converts decimal units to engi- } \\
\text { neering units) }\end{array}$ \\
\hline & & LAG \\
\hline & LAGFILT & (Course filter and temperature lag) \\
\hline & & CAL \\
\hline \multirow{9}{*}{$\begin{array}{l}\text { Primary calibration } \\
\text { from bottle casts }\end{array}$} & SIGSALP & (Calculates sigma-t and salinity) \\
\hline & & LATCH \\
\hline & DLATCH & $\begin{array}{l}\text { (Removes decreasing and repeated } \\
\text { depths) }\end{array}$ \\
\hline & & CTDATA \\
\hline & CTDAVE & (One meter average data) \\
\hline & & AVE \\
\hline & NODCFO & (Converts to NODC format) \\
\hline & & $N O D C+H E A D$ \\
\hline & NODMER & $\begin{array}{l}\text { (Merges NODC data with Headers and } \\
\text { chemical data) }\end{array}$ \\
\hline \multirow[t]{3}{*}{ Submission to NODC } & & NODCFNL \\
\hline & CEMLIST & $\begin{array}{l}\text { (Calculates specific volume } \\
\text { anomally, oxygen utilization, etc.) }\end{array}$ \\
\hline & & TECHNICAL REPORT \\
\hline
\end{tabular}


Table 2. Stations at which Hewlett-Packard 9825A was used as the primary data acquisition system.

\begin{tabular}{cc}
\hline Stations Number & Depth Range (m) \\
\hline $65 S$ & $3-21$ \\
$113 S$ & $4-29$ \\
$182 S$ & $3-18$ \\
1995 & $3-36$ \\
$220 S$ & $4-16$ \\
$259 S$ & $3-84$ \\
$261 S$ & $3-37$ \\
\hline
\end{tabular}


malfunction in the primary collection system. At the time, software for the HP system was being developed. These data were treated essentially in the same manner as described above. The correction for temperature sensor lag is not applied, however, since most of the data are from mixed layers where the lag effect is considered minimal.

The Hewlett-Packard system yielded a discrete data point at approximately 0.5 meter depth increments. This relatively infrequent sampling, compared to the primary acquisition system, resulted in considerable scatter $( \pm 0.09 \%)$ in the salinity generated from the three parameters collected. Therefore, binomial smoothing was performed on salinity data after interpolation for values at whole meter increments.1 CTD Calibration

The data derived from the CTD sensor system are critical to the correct interpretation of the oceanographic processes. To insure data of the highest possible quality, an extensive calibration was performed.

The CTD system was calibrated only against bottle casts in mixed layers to insure that the sensors and the bottles were sampling the same water. However, since a mixed layer was not always observed, comparisons could not be made at every station. Consequently, the resulting mean offset, $-0.010 \%$ (Figure 3 ), for the mixed layer salinity data was originally used for the entire data set. On later cruises, it became apparent that the head of the conductivity sensor was effected by increased pressure at depth. To further refine the data,

${ }^{1}$ The expression used, as adapted from Broenkow et al. (1977), is:

$S_{F}=\left(S_{D-2 m}+4 S_{D-1 m}+6 S_{D}+4 S_{D+1 m}+S_{D+2 m}\right) / 16$

where $S_{F}$ is the salinity reported at depth $D$ and $S_{D}$ is the unsmoothed salinity at depth $D$. 


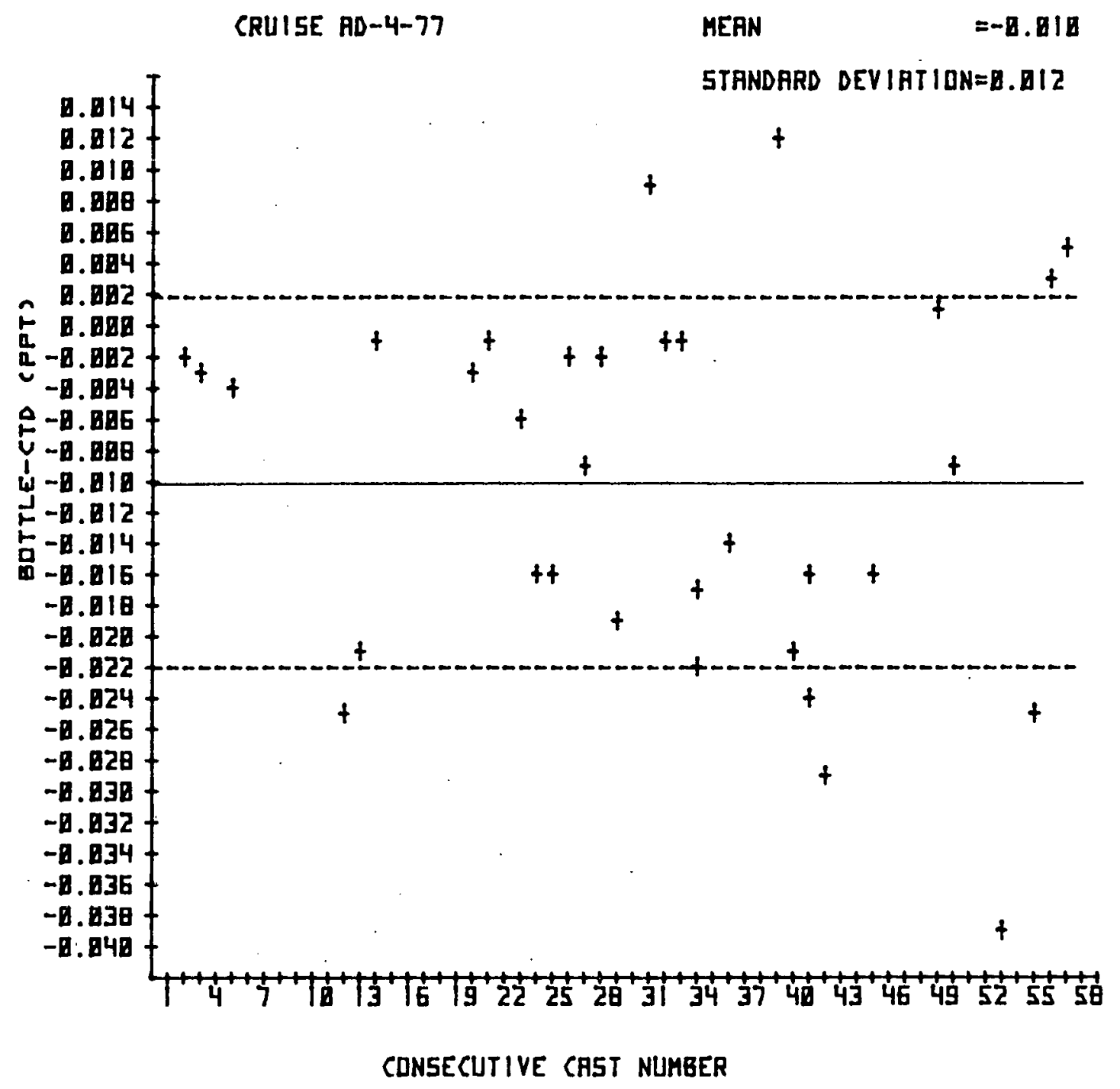

Figure 3. Salinity offset for cruise $A D-4-7.7$ (— mean offset; .... standard deviation). 
a regression analysis was performed (Figure 4) and an expression $\left(S+S_{0}+0.007-4.97 \times 10^{-4} D\right.$, where $S$ is corrected salinity, $S_{0}$ is calculated salinity without calibration offset, and $D$ is depth of sample) was obtained. This expression was applied to generate corrected salinities at all CTD stations at which the maximum sampling depth was greater than 50 meters. At other CTD stations, the original offset was preserved. The calibration data used to generate both the original offset and the subsequent expression for the depth effect are listed in Table 3. Station numbers are discontinuous since thermosalinograph stations were established at intervals between hydrographic sections.

A depth offset of -1.714 meters was applied to the entire data set as the depth sensor consistently recorded a depth of 1.714 meters at the surface. No temperature offset was necessary since the CTD temperature sensor agreed with the protected reversing thermometers within the range of accuracy $\left( \pm 0.02^{\circ} \mathrm{C}\right)$. CTD Error Analysis

The Plessey Model 9400 CTD system has the following rated accuracy, resolution, and time constants (Table 4 ).

Table 4. Specifications for Plessey Model 9400 CTD system.

\begin{tabular}{lccc}
\hline & Conductivity & Temperature & Depth \\
\hline Accuracy & $\pm 0.03 \mathrm{mmho} / \mathrm{cm}$ & $\pm 0.02^{\circ} \mathrm{C}$ & $\pm 1.5 \mathrm{~m}$ \\
Resolution & $0.0001 \mathrm{mmho} / \mathrm{cm}$ & $0.0001^{\circ} \mathrm{C}$ & $0.0012 \mathrm{~m}$ \\
Time Constant & $0.1 \mathrm{sec}$ & $0.35 \mathrm{sec}$ & $0.1 \mathrm{sec}$ \\
\hline
\end{tabular}




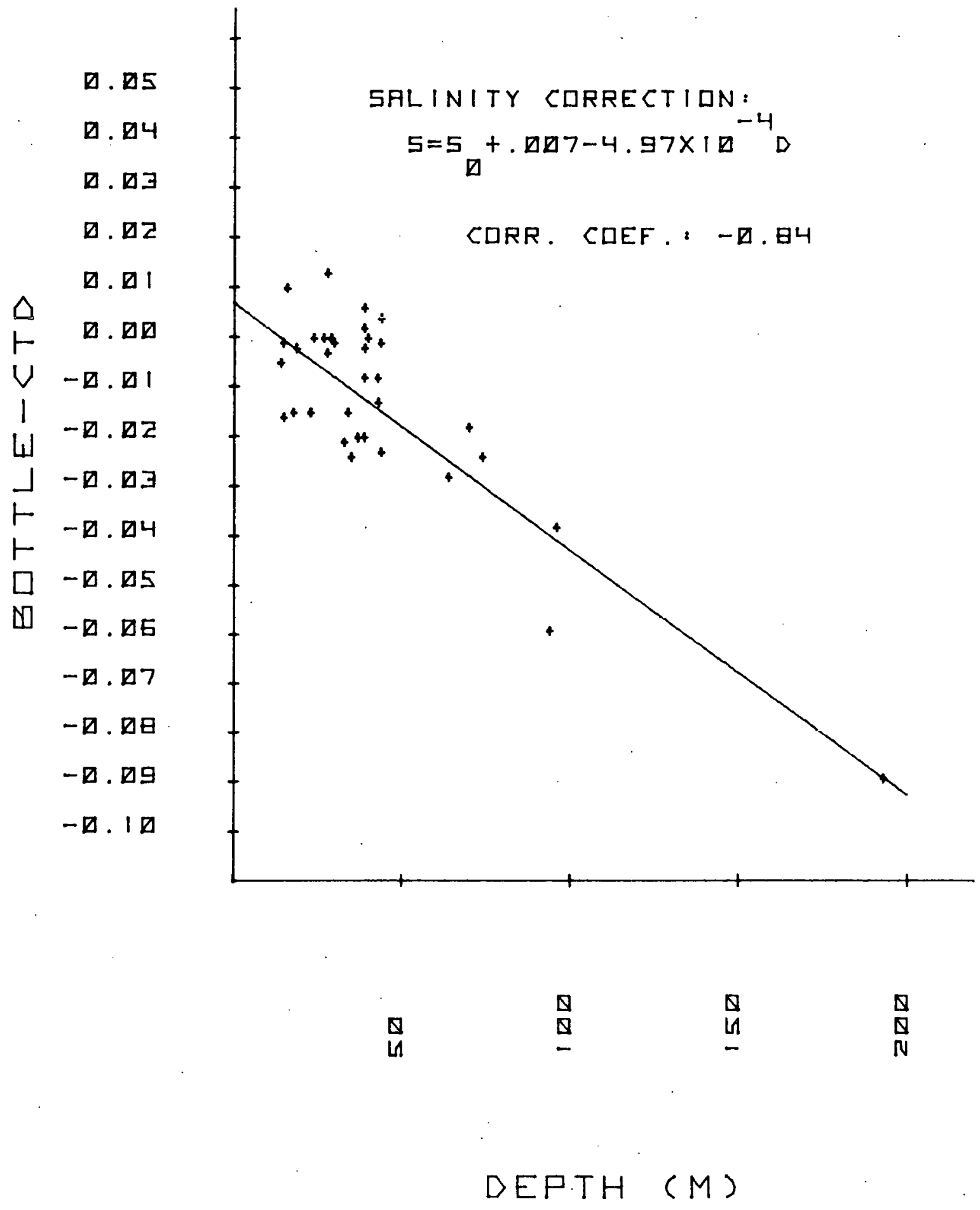

Figure 4. Regression analysis of salinity offset versus depth of sensor, cruise AD-4-77. 
Table 3. Cruise AD-4-77 Salinity Calibration Data.

\begin{tabular}{|c|c|c|c|c|c|}
\hline $\begin{array}{c}\text { Consecutive } \\
\text { Cast No. }\end{array}$ & $\begin{array}{l}\text { Station } \\
\text { No. }\end{array}$ & $\begin{array}{l}\text { Depth } \\
(m)\end{array}$ & $\begin{array}{l}\text { Bottle } \\
0 / 00\end{array}$ & CTD $\%$ & $\begin{array}{c}\text { Difference } \\
\text { Bottle-CTD }(0 / 00)\end{array}$ \\
\hline $\begin{array}{r}2 \\
3 \\
5 \\
9 \\
12\end{array}$ & $\begin{array}{r}2 S \\
3 S \\
6 S \\
14 S \\
24 S\end{array}$ & $\begin{array}{r}14 \\
18 \\
27 \\
192 \\
34\end{array}$ & $\begin{array}{l}32.897 \\
34.005 \\
35.154 \\
35.930 \\
35.297\end{array}$ & $\begin{array}{l}32.899 \\
34.008 \\
35.158 \\
36.020 \\
35.322\end{array}$ & $\begin{array}{l}-0.002 \\
-0.003 \\
-0.004 \\
-0.090 \\
-0.025\end{array}$ \\
\hline $\begin{array}{l}13 \\
14 \\
20 \\
21\end{array}$ & $\begin{array}{l}26 S \\
28 S \\
39 S \\
41 S\end{array}$ & $\begin{array}{l}38 \\
39 \\
38 \\
28\end{array}$ & $\begin{array}{l}36.006 \\
36.251 \\
35.549 \\
34.973\end{array}$ & $\begin{array}{l}36.027 \\
36.252 \\
35.552 \\
34.974\end{array}$ & $\begin{array}{l}-0.021 \\
-0.001 \\
-0.003 \\
-0.001\end{array}$ \\
\hline $\begin{array}{l}23 \\
24 \\
25 \\
26\end{array}$ & $\begin{array}{l}53 S \\
54 S \\
55 S \\
57 S\end{array}$ & $\begin{array}{l}13 \\
17 \\
22 \\
29\end{array}$ & $\begin{array}{l}32.902 \\
33.955 \\
34.679 \\
35.042\end{array}$ & $\begin{array}{l}32.908 \\
33.971 \\
34.695 \\
35.044\end{array}$ & $\begin{array}{l}-0.006 \\
-0.016 \\
-0.016 \\
-0.002\end{array}$ \\
\hline $\begin{array}{l}27 \\
28 \\
29 \\
31\end{array}$ & $\begin{array}{r}59 S \\
61 S \\
63 S \\
100 S\end{array}$ & $\begin{array}{l}38 \\
43 \\
69 \\
15\end{array}$ & $\begin{array}{l}35.509 \\
35.528 \\
35.807 \\
35.263\end{array}$ & $\begin{array}{l}35.518 \\
35.530 \\
35.826 \\
35.254\end{array}$ & $\begin{array}{l}-0.009 \\
-0.002 \\
-0.019 \\
+0.009\end{array}$ \\
\hline $\begin{array}{l}32 \\
33 \\
34\end{array}$ & $\begin{array}{l}101 S \\
103 S \\
105 S \\
105 S\end{array}$ & $\begin{array}{l}23 \\
26 \\
32 \\
14\end{array}$ & $\begin{array}{l}35.623 \\
35.724 \\
35.927 \\
35.934\end{array}$ & $\begin{array}{l}35.624 \\
35.725 \\
35.949 \\
35.951\end{array}$ & $\begin{array}{l}-0.001 \\
-0.001 \\
-0.022 \\
-0.017\end{array}$ \\
\hline $\begin{array}{l}36 \\
37 \\
39 \\
40 \\
41\end{array}$ & $\begin{array}{l}109 \mathrm{~S} \\
111 \mathrm{~S} \\
174 \mathrm{~S} \\
176 \mathrm{~S} \\
177 \mathrm{~S}\end{array}$ & $\begin{array}{l}42 \\
93 \\
27 \\
36 \\
43\end{array}$ & $\begin{array}{l}36.196 \\
35.937 \\
35.784 \\
36.081 \\
36.019\end{array}$ & $\begin{array}{l}36.210 \\
36.000 \\
35.772 \\
36.102 \\
36.043\end{array}$ & $\begin{array}{l}-0.014 \\
-0.063 \\
+0.012 \\
-0.021 \\
-0.024\end{array}$ \\
\hline $\begin{array}{l}42 \\
45 \\
48\end{array}$ & $\begin{array}{l}177 \mathrm{~S} \\
178 \mathrm{~S} \\
192 \mathrm{~S} \\
213 \mathrm{~S}\end{array}$ & $\begin{array}{l}33 \\
63 \\
22 \\
38\end{array}$ & $\begin{array}{l}36.022 \\
35.587 \\
35.958 \\
36.151\end{array}$ & $\begin{array}{l}36.038 \\
35.616 \\
35.974 \\
36.150\end{array}$ & $\begin{array}{l}-0.016 \\
-0.029 \\
-0.016 \\
+0.001\end{array}$ \\
\hline $\begin{array}{l}50 \\
53 \\
55 \\
56 \\
57\end{array}$ & $\begin{array}{l}215 S \\
220 S \\
261 S \\
263 S \\
265 S\end{array}$ & $\begin{array}{l}42 \\
95 \\
73 \\
43 \\
38\end{array}$ & $\begin{array}{l}36.140 \\
35.439 \\
35.980 \\
36.100 \\
35.736\end{array}$ & $\begin{array}{l}36.149 \\
35.478 \\
36.005 \\
36.097 \\
35.731\end{array}$ & $\begin{array}{l}-0.009 \\
-0.039 \\
-0.025 \\
+0.003 \\
+0.005\end{array}$ \\
\hline
\end{tabular}


From the above parameters, and using the equation of Bennett (1976), the in situ conductivity, $c(s, t, p)$, was reduced to salinity.

1) The conductivity ratio is expressed as:

$R(S, t, p)=C(S, t, p) / C\left(35 \%, 00,15^{\circ} C, 0\right)$

where $C(S, t, p)$ is the in situ conductivity

and $C\left(35^{\circ} / 00,15^{\circ} \mathrm{C}, 0\right)=42.906 \mathrm{mmho} / \mathrm{cm}$.

2) A correction is made for the effect of pressure

$R(S, t)=R(S, t, p) /(1+F)$

where $F=\frac{1.60836 \times 10^{-5} p-5.4845 \times 10^{-10} p^{2}+6.166 \times 10^{-15} p^{3}}{1+3.0786 \times 10^{-2} t+3.169 \times 10^{-4} t^{2}}$

$F$ is the fractional increase in conductivity at pressure $p$ dbar and temperature $t^{\circ} \mathrm{C}$.

3) A correction is made for the effect of temperature

$R(S)=R(S, t) / r_{t}$

where $r_{t}=0.676518+0.200402 \times 10^{-1} t$

$+0.122700 \times 10^{-3} t^{2}-0.218091 \times 10^{-5} t^{3}$

$+0.663405 \times 10^{-7} t^{4}-0.95646 \times 10^{-9} t^{5}$

4) The corrected conductivity ratio is converted to salinity $S=-0.08996+28.8567 R+12.18882 R^{2}$

$-10.61869 R^{3}+5.98624 R^{4}-1.32311 R^{5}$

$+R(R-1)\left\{0.442 \times 10^{-1} t-0.46 \times 10^{-3} t^{2}\right.$

$\left.-4 \times 10^{-3} R t+\left(1.25 \times 10^{-4}-2.9 \times 10^{-6} t\right) p\right\}$

Bennett estimates the overall accuracy of this equation as $0.0042 \%$

r.m.s. Additional sources of error(summarized in Table 5) are attributed to the reported accuracy of the conductivity, temperature, and depth sensors. These values were obtained by varying observed extremes in $C, T$, and $D$ data by the rated sensor accuracies. 
Table 5: Sources of salinity error due to the reported accuracy of the sensors and the salinity equation.

\begin{tabular}{lc} 
Parameter & Maximum Error \\
\hline Conductivity & \pm 0.032 \\
Temperature & \pm 0.020 \\
Depth & \pm 0.001 \\
Equation & \pm 0.004 \\
Total & \pm 0.057 \\
\hline
\end{tabular}

The standard deviation of all mixed layer sampies taken for salinity calibration purposes implies an accuracy, after offset, of $\pm 0.012 \%$. We believe this value is, except in strong thermoclines $\left(\Delta T>1^{\circ} \mathrm{C} / \mathrm{m}\right)$, a more realistic measure of the quality of the data set, particularly in mixed layers, than the composite maximum error of the sensor package reported above.

\section{METEOROLOGICAL CONDITIONS}

Wind data from Jacksonville, Florida, are presented in Figure 5. These data are derived from the monthly summary for April 1977 (U.S. Department of Commerce, April 1977) and are plotted in GMT at three hour intervals.

Winds in the first part of the month were generally southwesterly. April 6-9 was characterized by winds gradually changing from southwesterly to easterly. The easterly wind continued from April 10-18 when it changed to southeasterly and remained as such until April 21. Winds were strongest on April 4-5, averaging $6.2 \mathrm{~m} / \mathrm{sec}$.

The average daily air temperature of the study period ranged from $14.4^{\circ} \mathrm{C}$ to $21.1^{\circ} \mathrm{C}$. There was no precipitation during the study. 


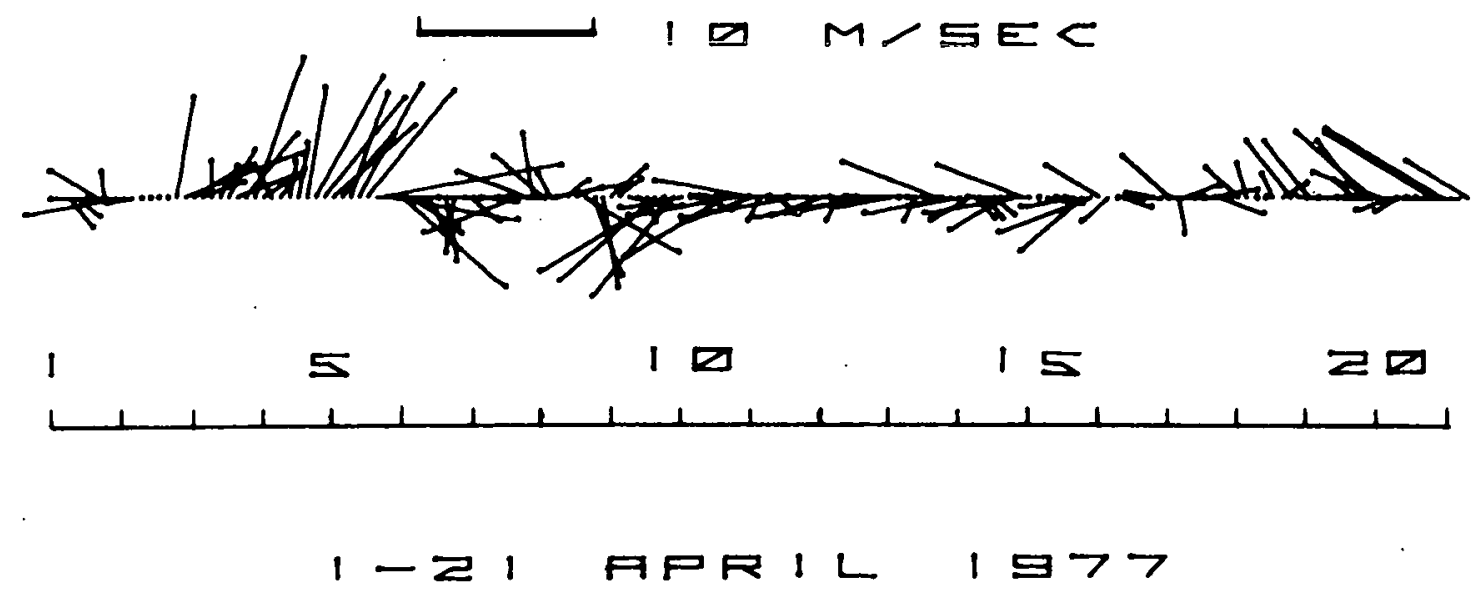

Figure 5. Wind data, Jacksonville, Florida, 1-20 April, 1977 at three hour intervals (U.S. Dept. of Comm. Apri1, 1977). 
Meteorological data were also collected by the ship's personnel at each station. These additional data are presented with the data sheets.

The Jacksonville, Florida, weather station is located at International Airport, which is approximately 27 kilometers inshore. Consequently, the meteorological data presented in Figure 5 may not be indicative of the actual conditions at a particular hydrographic station.

\section{RESULTS AND DISCUSSION}

In the following figures, vertical temperature plots are derived from CTD and XBT data, salinity plots from CTD data, sigma-t from temperature and salinity and nutrients $\left(\mathrm{NO}_{3}, \mathrm{PO}_{4}\right.$, and $\left.\mathrm{SiO}_{2}\right)$, and dissolved oxygen from water samples collected at selected depths indicated by dots on the respective plots. Horizontal surface temperature plots are derived from continuous thermosalinograph mapping conducted during the ADVANCE II cruise.

On all vertical plots, except those for cruise BF-29-77, the "S" or "X" following the station number indicates a CTD or XBT station, respectively. The plots are arranged chronologically by section. The Vertical Distribution of Physical and Chemical Properties

Savannah Section, 8-9 April 1977. (Figures 6-7) The temperature, salinity, and density structures seen in Figure 6 are indicative of typical continental shelf conditions expected in the Georgia Bight in April. Nearshore is cold, low salinity, low density water resulting from high spring runoff. Further offshore is warmer; more saline and denser continental shelf water. At the shelf break, the sharp horizontal thermal gradient indicates the thermal wall of the Gulf Stream with its characteristically higher salinity surface water $(z 35.00 \%)$. The $20.0^{\circ} \mathrm{C}$ isotherm and $36.00 \%$ isohaline at 35 meters showed an interlayering intrusion of the Gulf Stream onto the continental shelf as described by 
Atkinson (1977), i.e., the shelf water was stratified with low salinity water lying on top of more saline, denser water, and intermediate density Gulf Stream water intruded between the two.

Phosphate and silicate plots of the same section (Figure 7) show elevated concentrations in both the nearshore runoff water and the deep, cold Gulf Stream water. These nutrients were fairly depleted in the shelf water. Nitrate was essentially depleted from shore out to the shelf break. As with the other nutrients, the Gulf Stream water below the euphotic zone had higher concentrations of nitrate.

St. Simons Section, 10 April 1977. (Figures 8-9) The St. Simons transect, 10 April 1977, (Figures 8-9) revealed well mixed water from nearshore almost to the shelf break. The temperature and density plots showed a possible Gulf Stream perturbation around station 28S, as temperature increased and then decreased and density correspondingly decreased and then increased from onshore to offshore. Additionally, isotherms which sloped down to the west (see $10.0^{\circ}-21.0^{\circ} \mathrm{C}$ isotherms, Figure 8 ) indicate an eddy event (Lee, 1975). Current meter data, now being processed at the University of Miami, should elucidate the nature of the event.

Savannah Sections, 11 and 12 April 1977. (Figures 10-13) A bottom intrusion of dense Gulf Stream water onto the shelf was observed during the Savannah sections of 11 and 12 April, 1977 (Figures 10-13). Note particularly the relatively high nutrient concentrations at depth at station 39S (Figure 11) and station 59S (Figure 12). Also, the presence of cool, nitrate-rich water at the shelf break (Figure 11) demonstrated the availability of this water as a potential source of nutrients to the continental shelf. 
Jacksonville Section, 13-14 April 1977. (Figures 14-15) A bottom intrusion was observed during the Jacksonville section, 13-14 April 1977. Figure 14 shows that the $19.0^{\circ} \mathrm{C}$ isotherm was on the continental shelf. Associated with this cool water were high nutrient concentrations (Figure 15).

St. Augustine (South) Section, 14 April 1977. (Figures 16-17) The vertical plots (Figures 16-17) of the St. Augustine (South) section, 14 April 1977, reveal the presence of a Gulf Stream spin-off eddy. Taking temperature as an example, proceeding from onshore to offshore, an increase, then decrease, and finally an increase occurred. The first significant increasing horizontal temperature gradient resulted from the water being of Gulf Stream origin. This water spun off from the main body of the Stream and was transported as a cyclonic countercurrent. Lee (1975) described a similar process in the Florida Current.

Strong upwelling was observed at stations $177 \mathrm{~S}$ through $180 \mathrm{~S}$ and, as can be seen in Figure 17, nutrients are advected upwards with the deep Gulf Stream water. The ratio between nitrate and phosphate at station $178 \mathrm{~S}$ at a sample depth of 39 meters is $15.7: 1$, which suggests that the water is of deep origin. The low oxygen concentrations observed support this contention.

Ormond Beach Section, 15 Apri1 1977. (Figures 18-19) During the Ormond Beach section, 15 April 1977, some upwelling was observed. The $17.0^{\circ} \mathrm{C}$ to $22.0^{\circ} \mathrm{C}$ isotherms (Figure 18 ) best demonstrated this feature as they curved downwards to the west. Comparison of the nutrient and oxygen plots (Figure 19) with those of the St. Augustine (South) section (Figure 17), however, confirms that the observed upwelling was not as strong as during the eddy event since nutrient concentrations were 
significantly lower and dissolved oxygen concentrations higher at the shelf break.

St. Augustine (North) Section, 15 April 1977. (Figures 20-21) Another hydrographic section, St. Augustine (North), 15 April 1977, was run through the eddy event. The results are presented graphically in Figures 20 and 21. Again, a strong upwelling of cold, nutrient-rich, low oxygen water was apparent. Note that this water extended well onto the shelf: the $1.0 \mu$ mole/l nitrate isopleth extended almost to station 213S (Figure 21). Thus, assuming that the fate of a spin-off eddy is eventual dissipation in the shelf water, an eddy event can increase the supply of available nutrients on the shelf.

Jacksonville (North) Section, 15 April 1977. (Figure 24a) An XBT transect was conducted to the north of the eddy center (Jacksonville (North) 15 April 1977). Figure 24a shows the characteristic increase, decrease and increase in surface water temperature found during an eddy event. Upwelling of cold water at stations $233 \mathrm{X}$ and $234 \mathrm{X}$ was observed. No nutrient or oxygen data was collected.

St. Simons Section, 16 April 1977. (Figure 24b) The St. Simons XBT section, 16 April 1977, (Figure 24b) through the northern portion of the eddy also showed upwelling at the shelf break but this upwelling was not as strong as during the preceding section since the corresponding isotherms were not as shallow.

Savannah Section, 16 April 1977. (Figures 22-23) The results of the last hydrographic section occupied (Savannah, 16 April 1977) are shown graphically in Figures 22 and 23 . The plots do not indicate an eddy; however, there was a bottom intrusion since high salinity water $(>36.10 \%$ ) was observed on the continental shelf at station 2635 (Figure 22). Associated with this water was high nutrient and low oxygen concentrations (Figure 23). 
Savannah Section, 19 April 1977. (Figure 24c) Changes which can occur over a short period of time are demonstrated by comparing Figure 24C, which presents the results of XBT Cruise BF-29, 19 Apri1 1977, with Figure 22 (Savannah section, 16 April 1977). In three days, the upper 10 meters stratified, possibly as a result of surface heating in response to insolation, and a cold water core $\left(<17.0^{\circ} \mathrm{C}\right.$ at the center) moved into the mid-shelf region. Since Gulf Stream spin-off eddies are advected northward (Lee, 1975), it is likeiy that this is the same water mass observed upwelling in response to the eddy mechanism but which later completely separated from the parent Gulf Stream. This is again evidence that spin-off eddies are a significant source of nutrients to the continental shelf. The Horizontal Distribution of Temperature

The results of continuous mapping of surface temperature during the ADVANCE II cruise are presented graphically in Figures 25 (12-14 April 1977) and 26 (14-16 Apri7 1977). Note in Figure 25 the cold water surface core $\left(<21^{\circ} \mathrm{C}\right)$ of the eddy at a latitude of $29^{\circ} 40^{\prime} \mathrm{N}$. To the west was a warmer tongue $\left(>22^{\circ} \mathrm{C}\right)$ spun off from the Gulf Stream. Figure 26 reveals that the cold water core and the entire eddy increased in size. Also, the core center advected northward while water warmer than $23^{\circ} \mathrm{C}$ in the tongue extended more to the south. Additionally, water warmer than $24^{\circ} \mathrm{C}$ was evident in portions of the tongue. Clearly, these two figures, in combination with Figures 16 and 20 (St. Augustine (South) and (North)), provide a unique documentation of an eddy event. 


\section{T-S Relationship}

The relation of temperature to salinity observed during cruise AD-4-77 is presented graphically in Figure 27. The nearshore and shelf waters are at the left and center of the plot, respectively. The generally vertical band at the right hand side of the plot is characteristic of the Gulf Stream T-S relationship. Within this band are found the T-S relationships of the waters at the shelf break during the eddy event, identifying their origin.

\section{SUMMARY}

During cruises AD-4-77 and BF-29-77 in April 1977, the following observations were made:

1. Water on the continental shelf was generally well mixed vertically. On the outer shelf, exceptions occurred when Gulf Stream water was deposited on the shelf in the form of an intrusion or as a spin-off eddy.

2. An interlayering intrusion of Gulf Stream water into the continental shelf water was seen at the shelf break off Savannah on Apri1 8-9, 1977.

3. Bottom intrusions of cool, nutrient-rich water onto the shelf occurred during the Savannah transects of 11 and 12 Apri1, the Jacksonville transect of 13-14 April, and the Savannah transect of 16 Apri], 1977.

4. A Gulf Stream spin-off eddy centered off St. Augustine and at the shelf break had associated with it cool, nutrient-rich, low oxygen water which was advected upward from its origin off the continental shelf. Within a week, this water was on the mid-shelf, isolated from the parent Gulf Stream. Therefore, a spin-off eddy can be identified as a mechanism for nutrient enrichment of the continental shelf waters. 
FIGURES: $\quad 6-27$ 

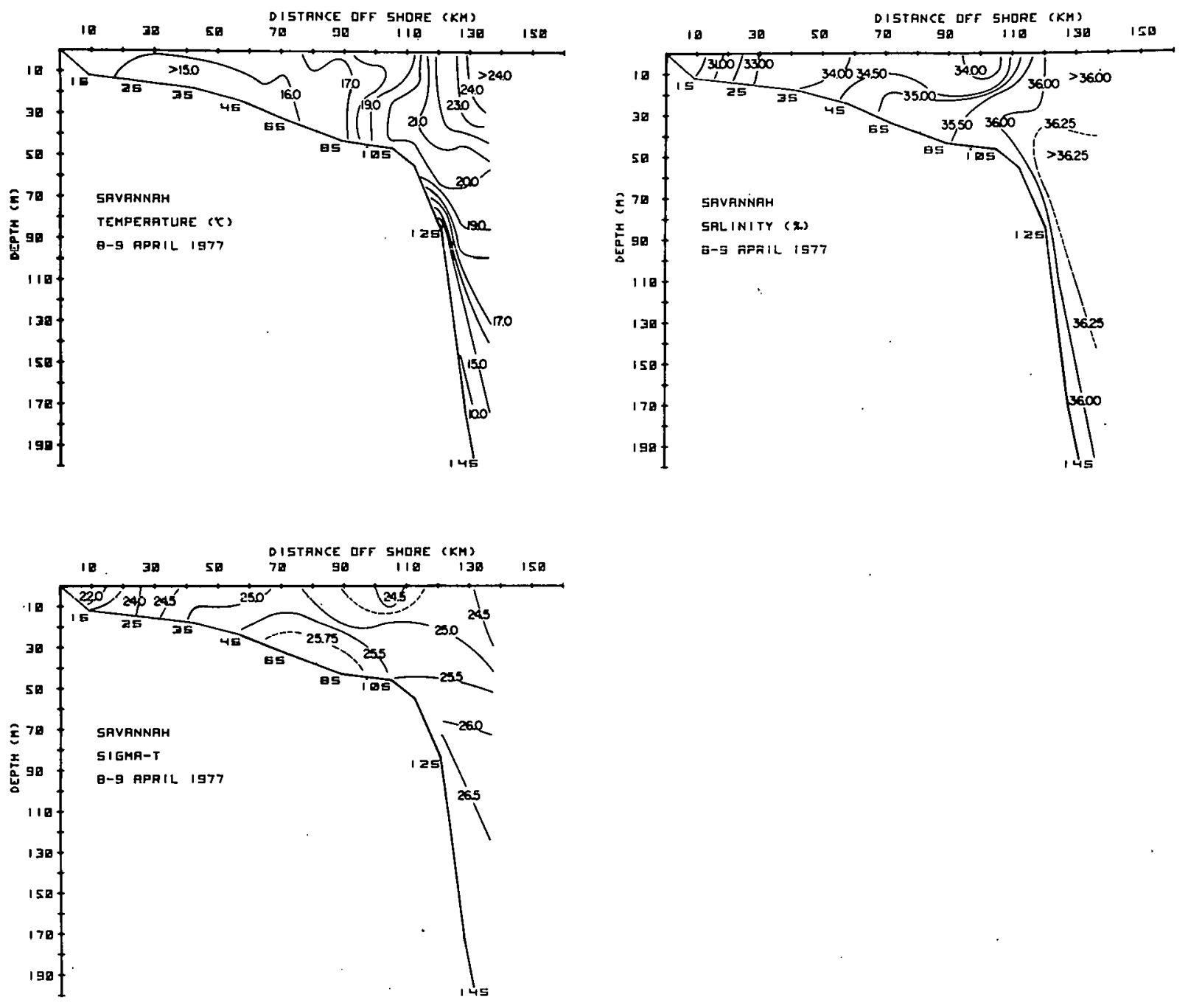

Figure 6. Vertical distribution of temperature, salinity, and sigma-t, Savannah section, 8-9 April 1977. 

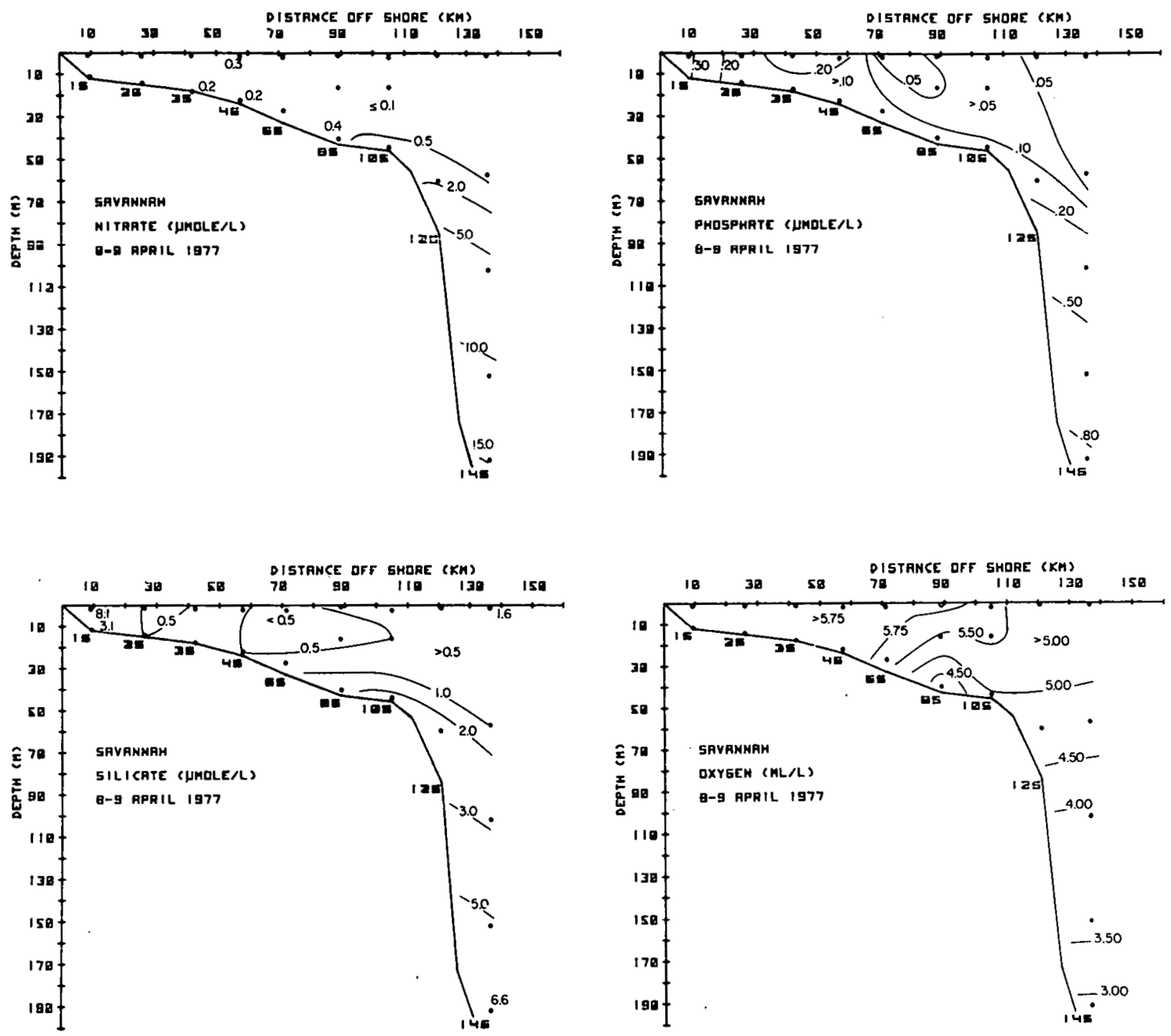

Figure 7. Vertical distribution of nutrients and oxygen, Savannah section, 8-9 April 1977. 

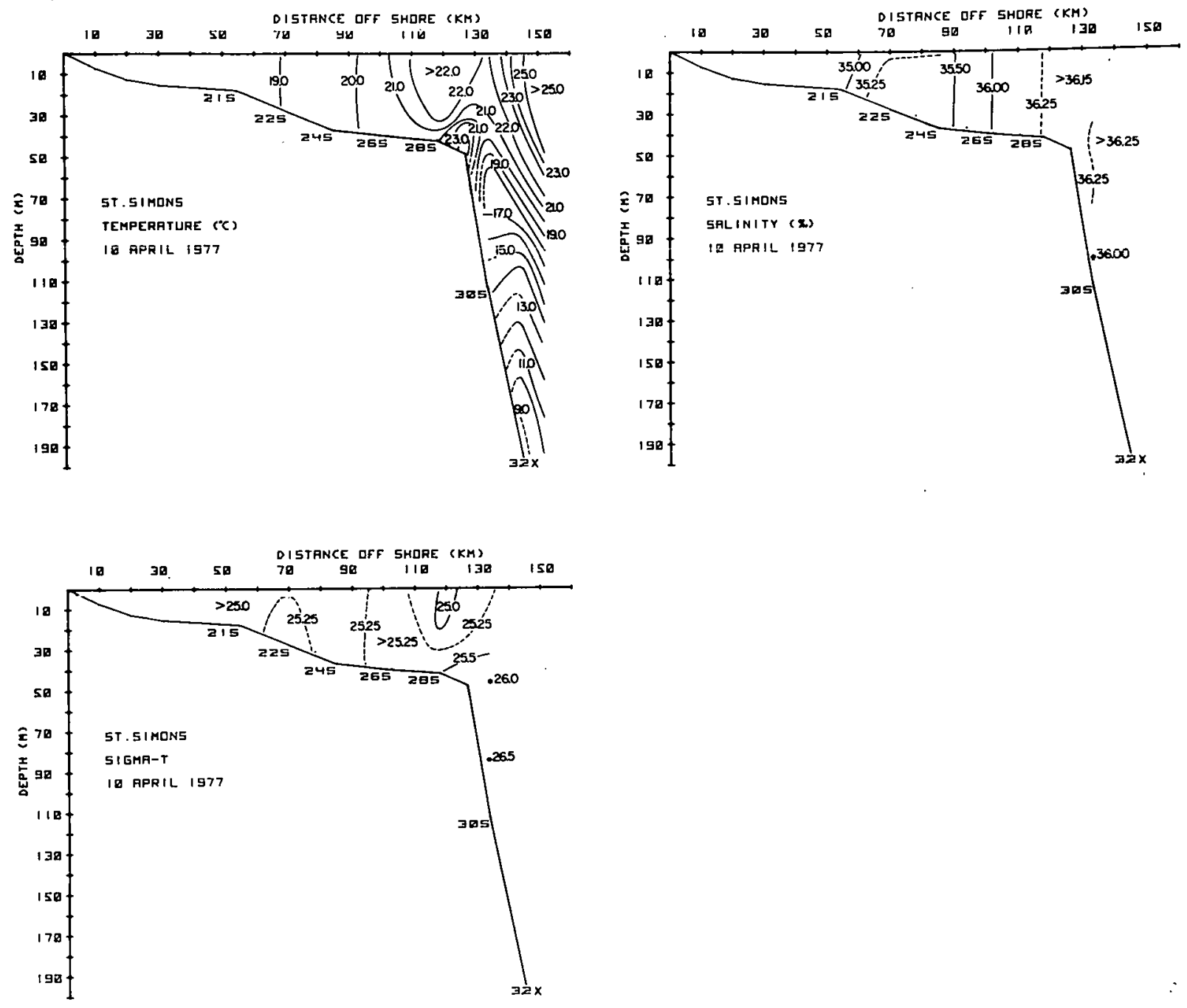

Figure 8. Vertical distribution of temperature, salinity, and sigma-t, St.Simons section, 10 April 1977. 

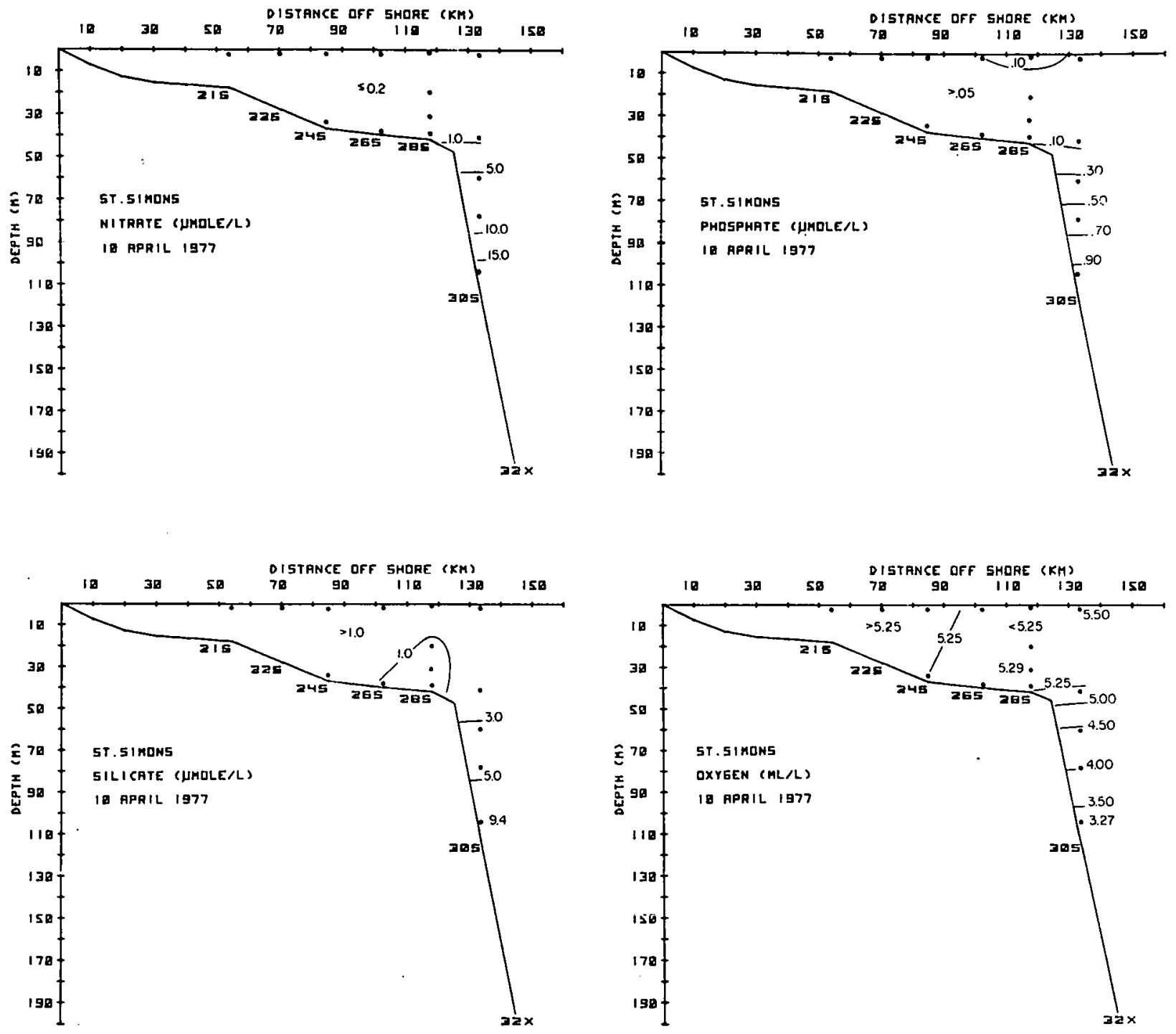

Figure 9. Vertical distribution of nutrients and oxygen, St. Simons section, 10 Apri1 1977. 

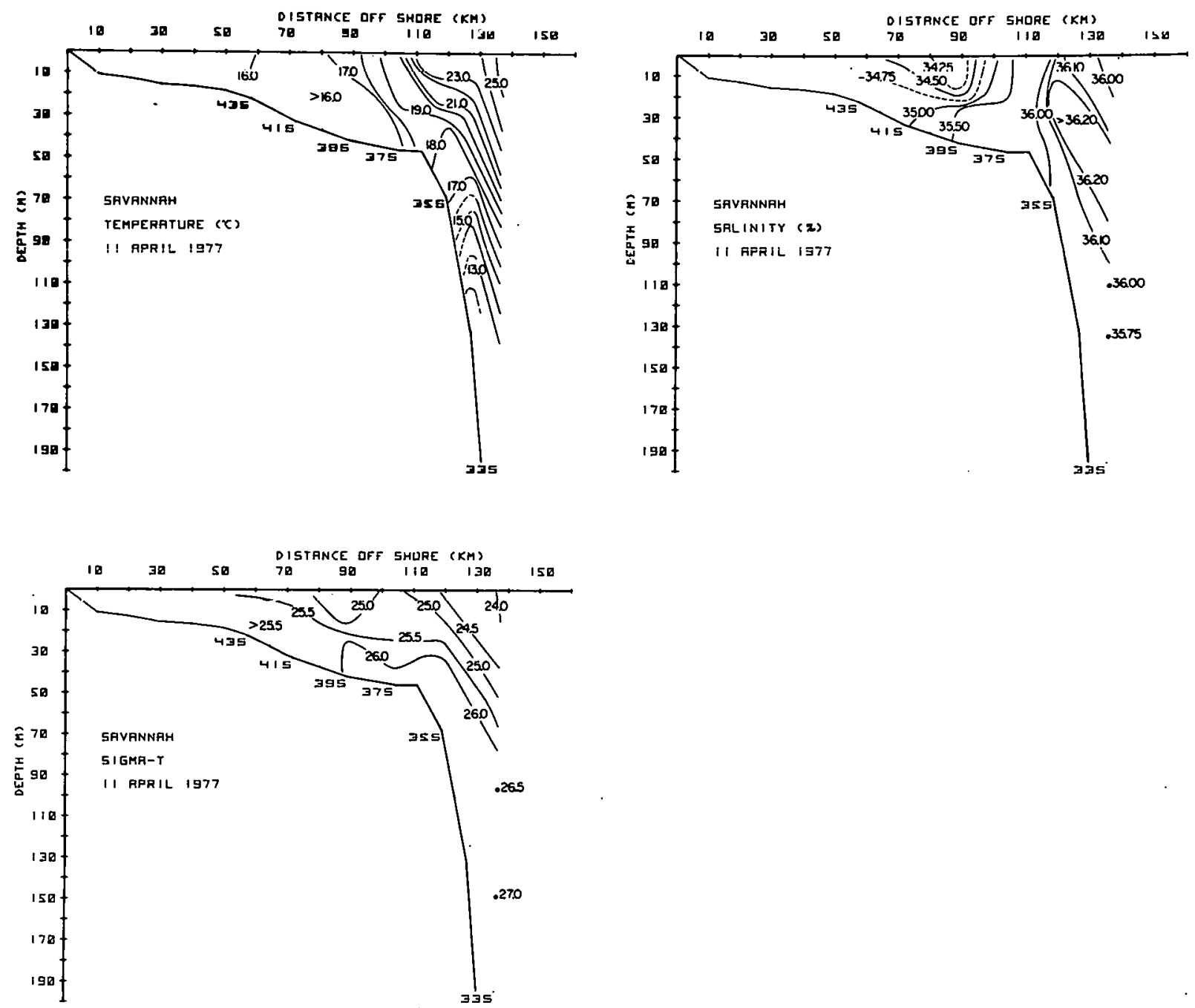

Figure 10. Vertical distribution of temperature, salinity, and sigma-t, Savannah section, 11 Apri1 1977. 

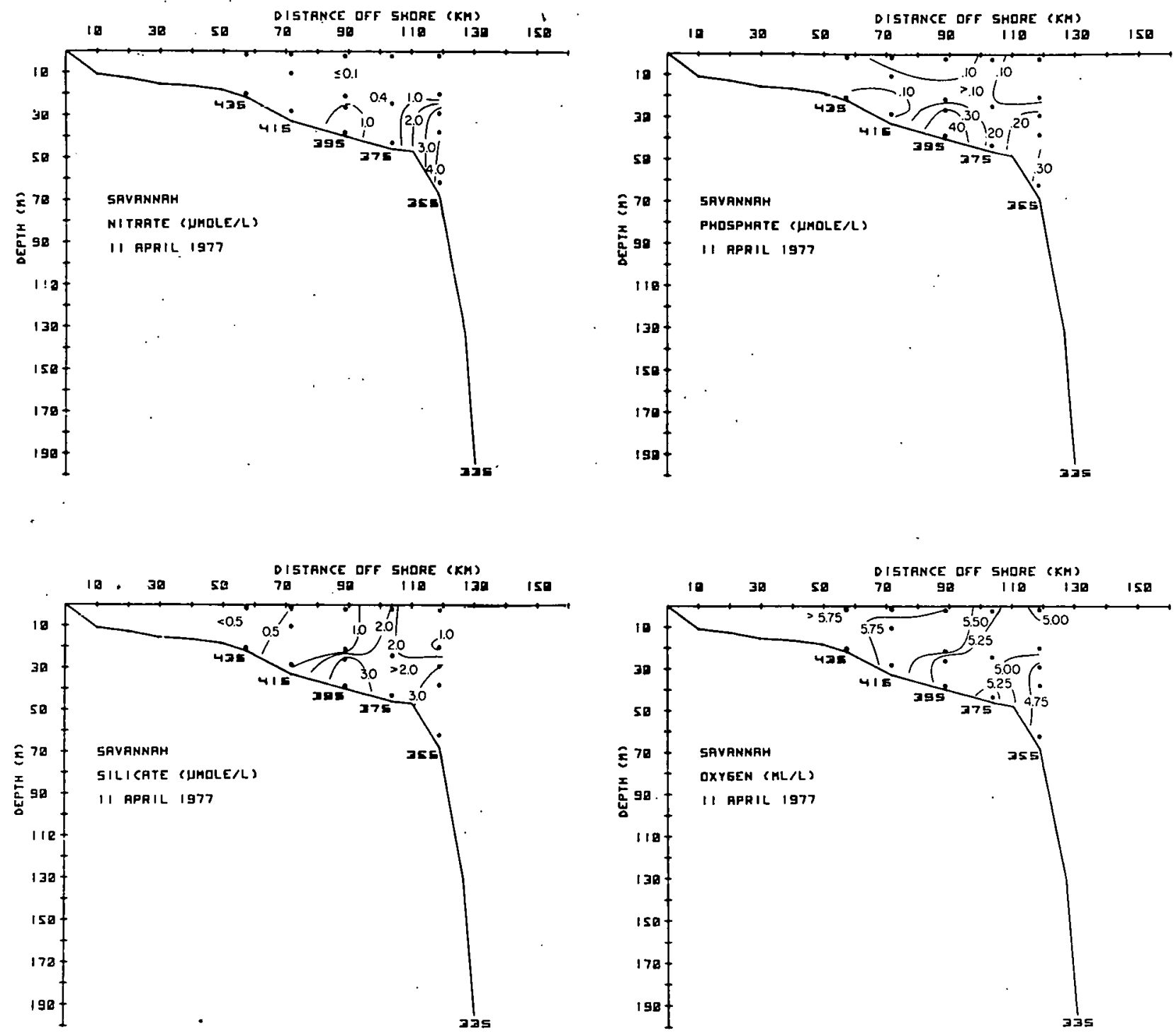

Figure 11. Vertical distribution of nutrients and oxygen, Savannah section, 11 April 1977. 

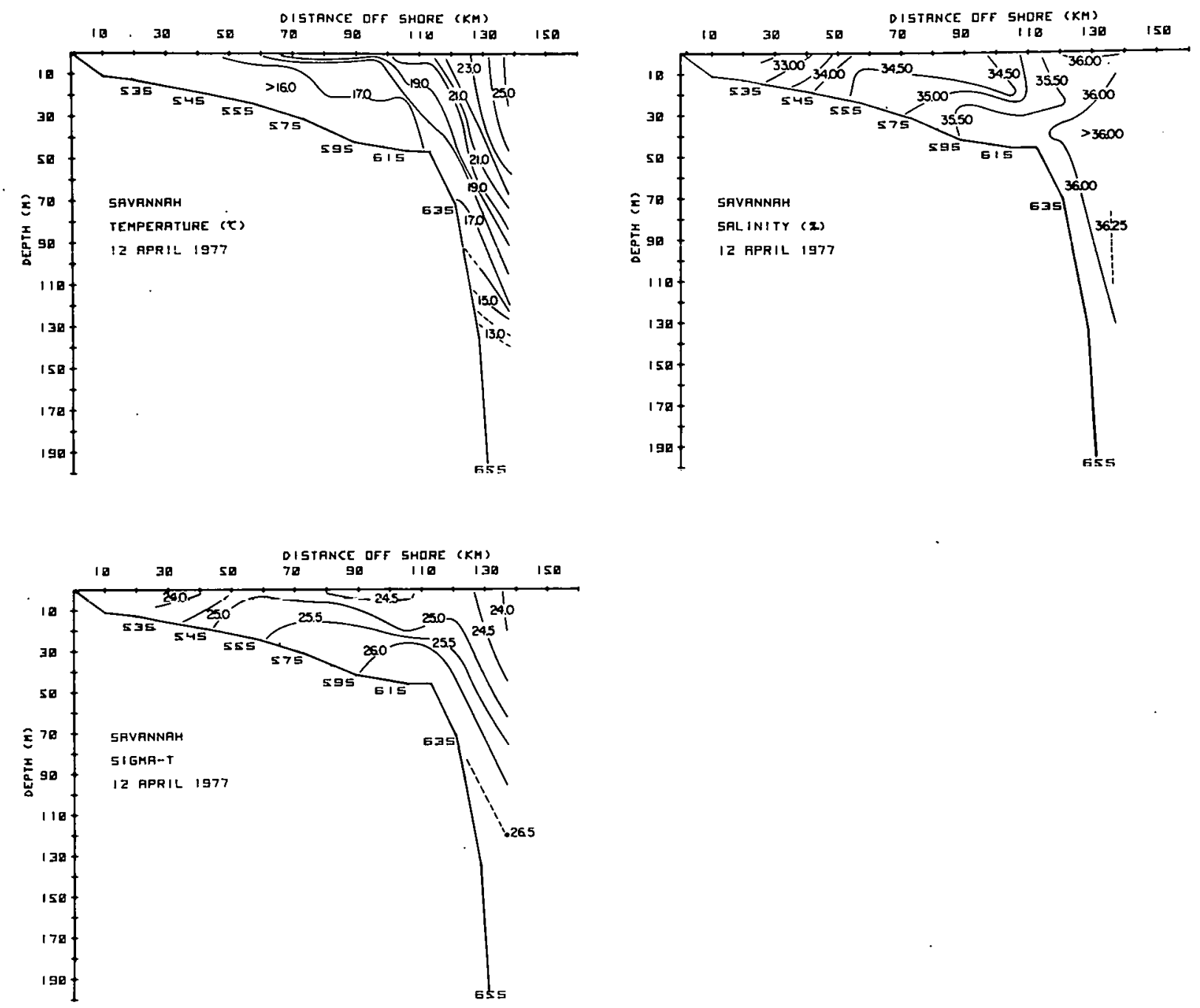

Figure 12. Vertical distribution of temperature, salinity, and stgma-t, Savannah section, 12 Apri1 1977. 

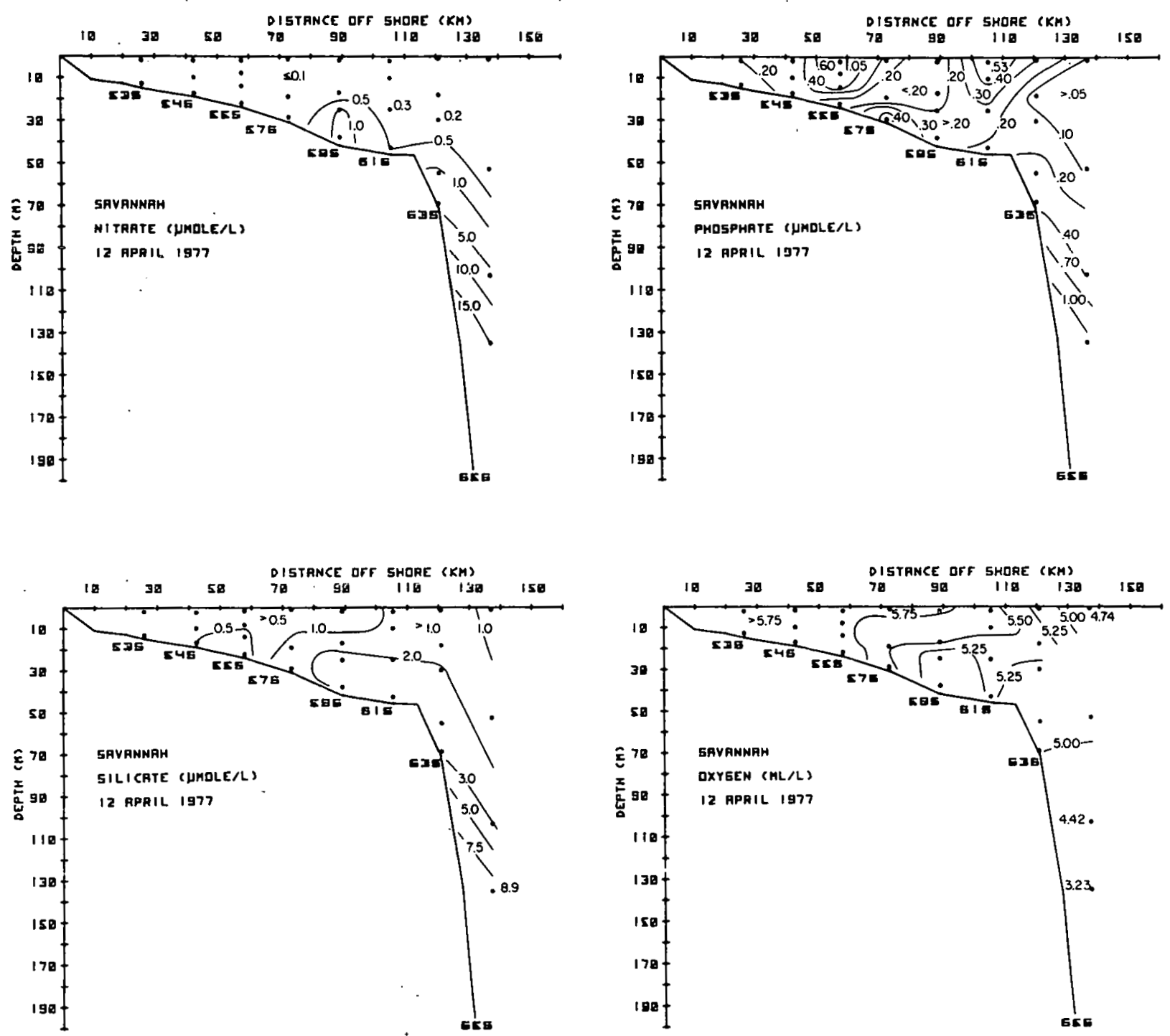

Figure 13. Vertical distribution of nutrients and oxygen, Savannah section, 12 April 1977. 

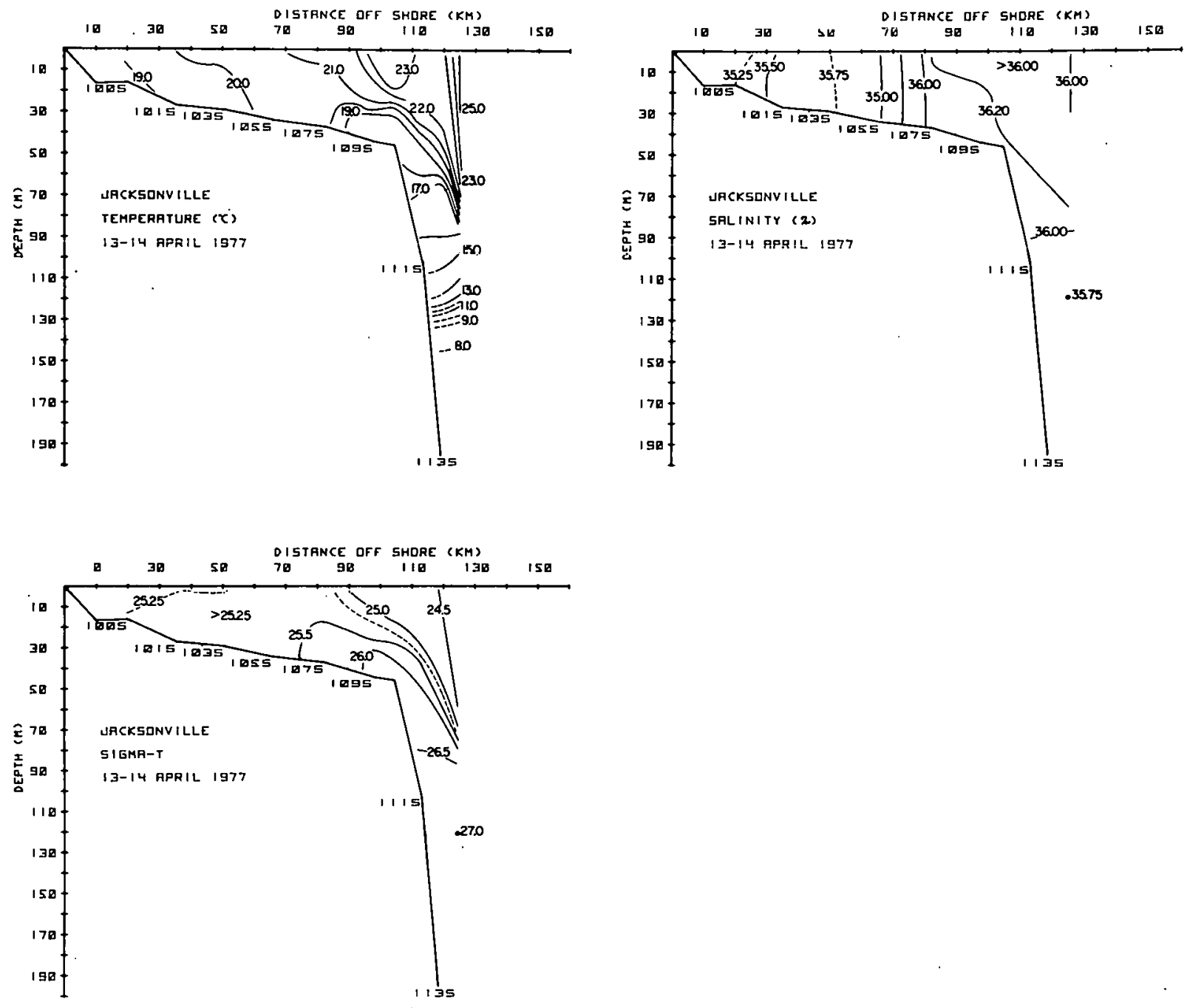

Figure 14. Vertical distribution of temperature, salinity, and sigma-t, Jacksonville section, 13-14 Apri1 1977. 

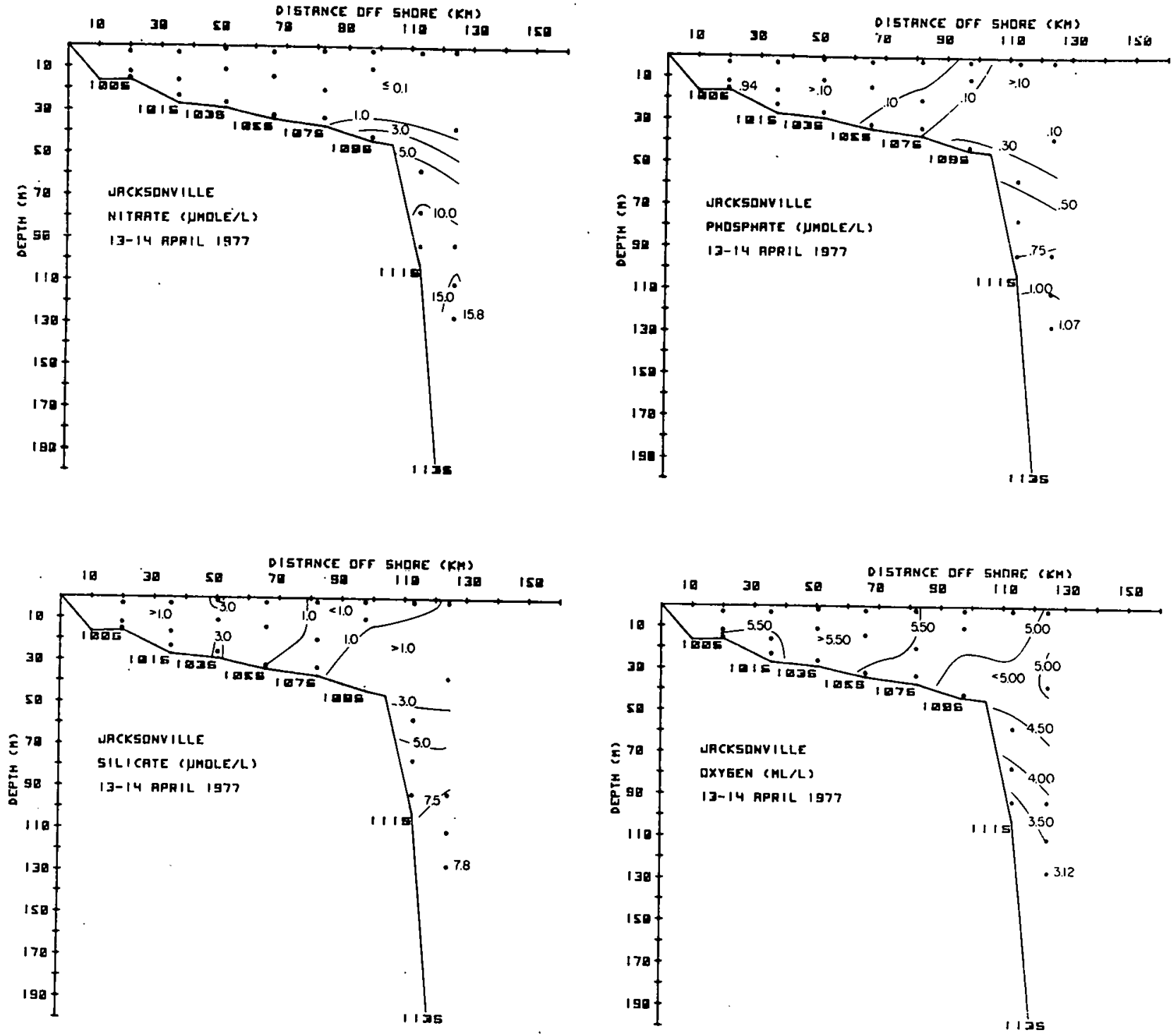

Figure 15. Vertical distribution of nutrients and oxygen, Jacksonville section, 13-14 April 1977. 

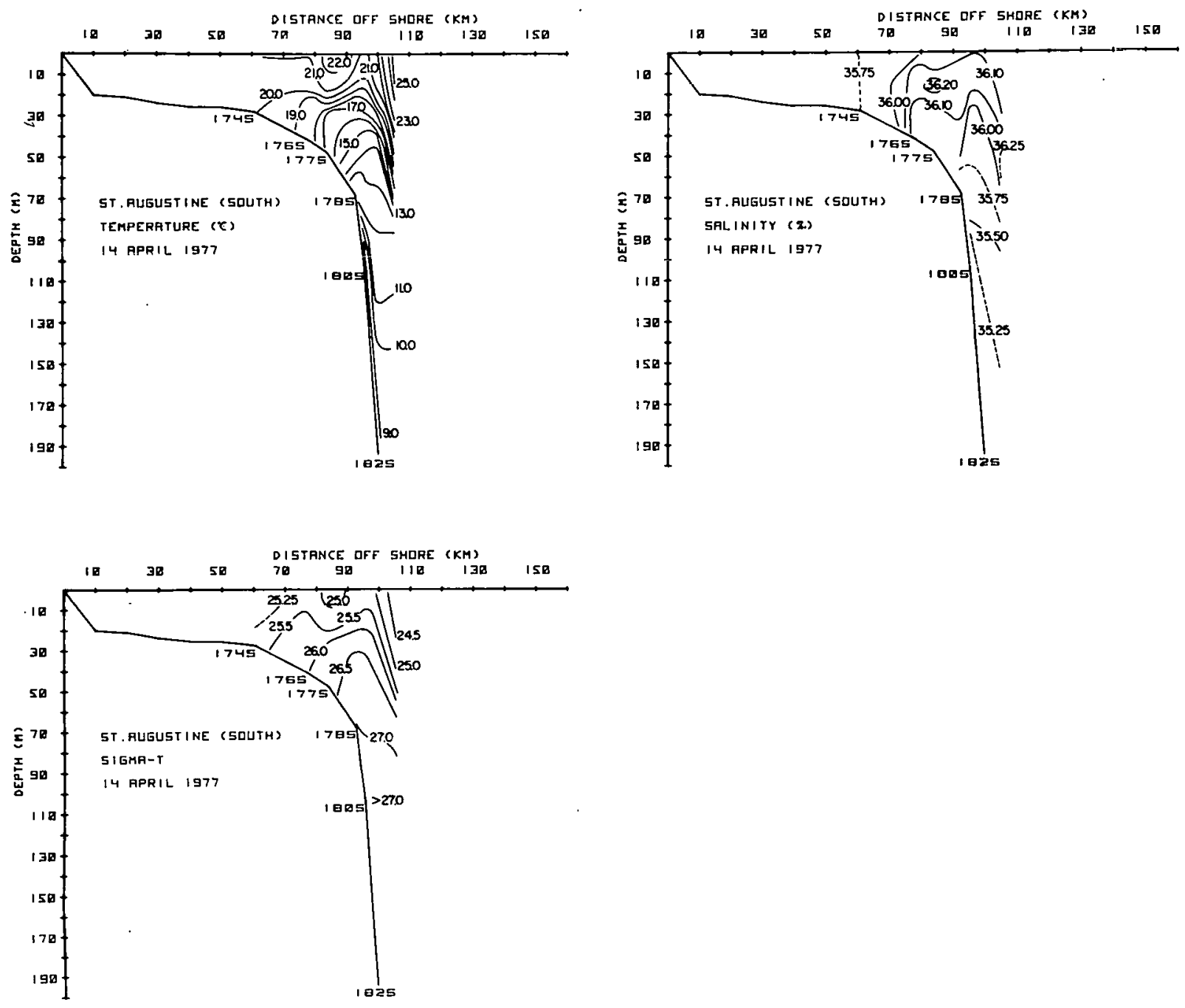

F1gure 16. Vertical distribution of temperature, salinity, and sigma-t, St.Augustine (South) section, 14 Apr11 1977. 

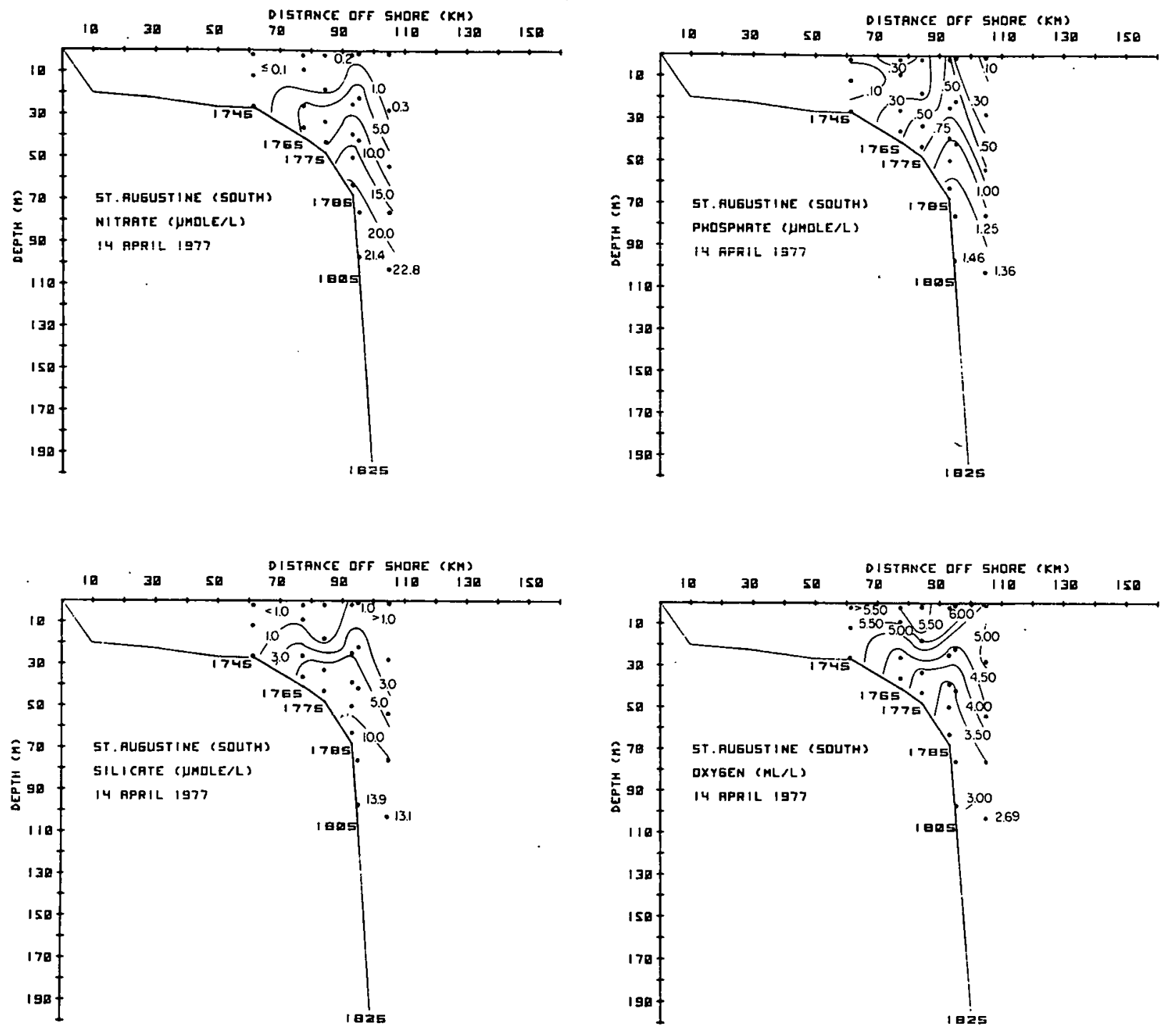

Figure 17. Vertical distribution of nutrients and oxygen, St. Augustine (South) section, 14 April 1977. 

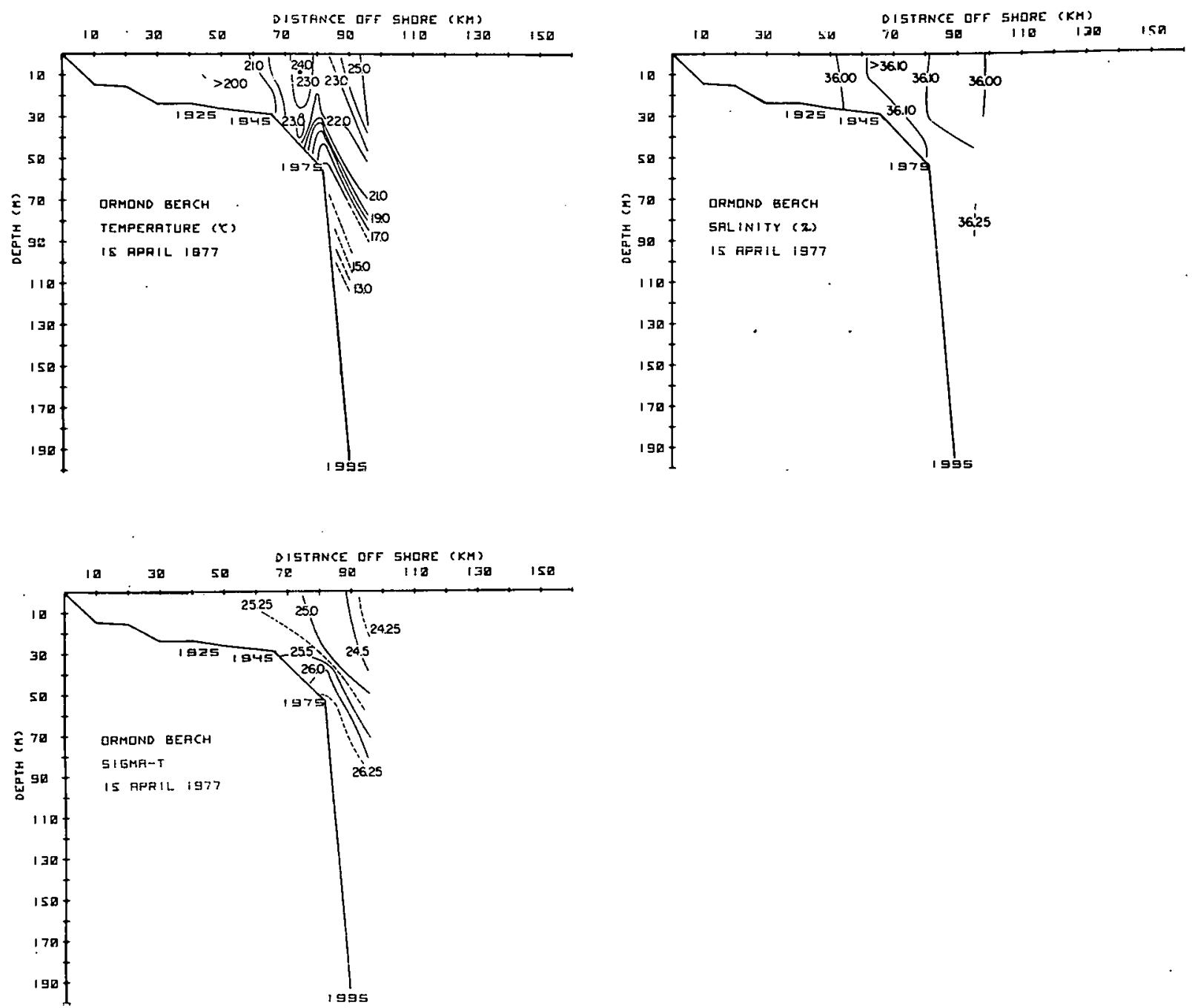

Figure 18. Vertical distribution of temperature, salinity, and sigma-t, Ormond Beach section, 15 April 1977. 

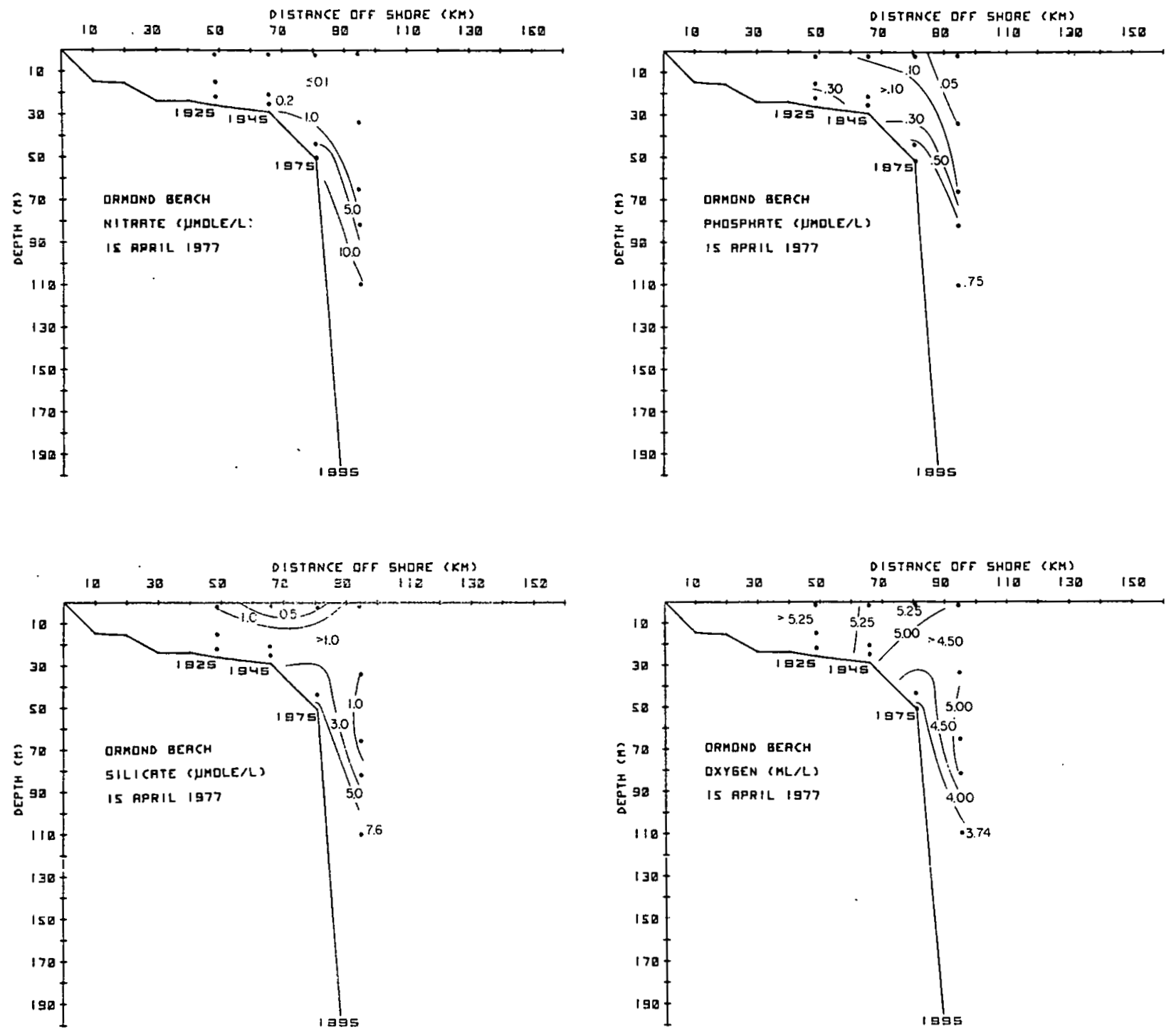

Figure 19. Vertical distribution of nutrients and oxygen, ormond Beach section, 15 April 1977. 

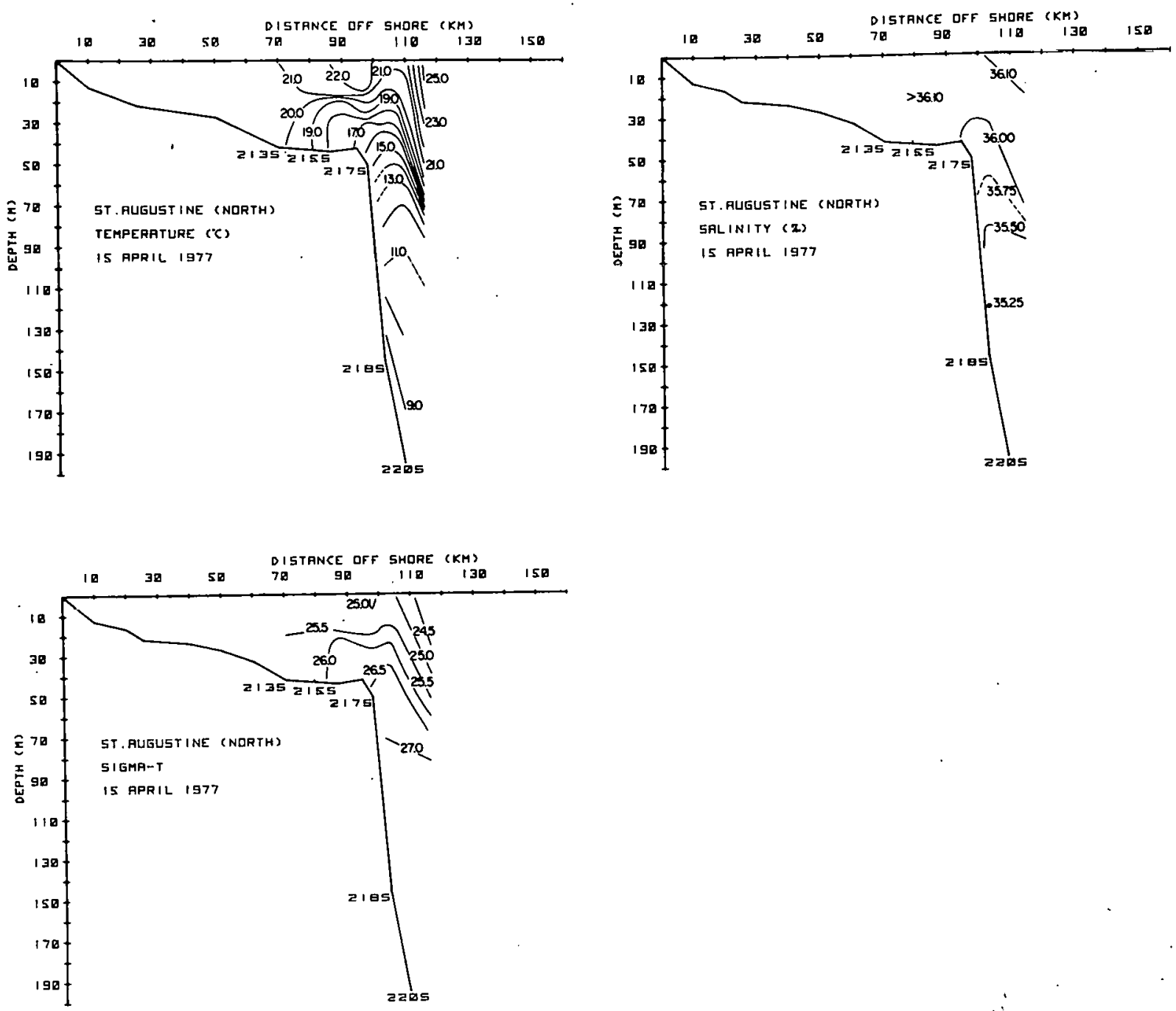

Figure 20. Vertical distribution of temperature, salinity, and
sigma-t, St.Augustine (North) section, 15 Apri1 1977. 

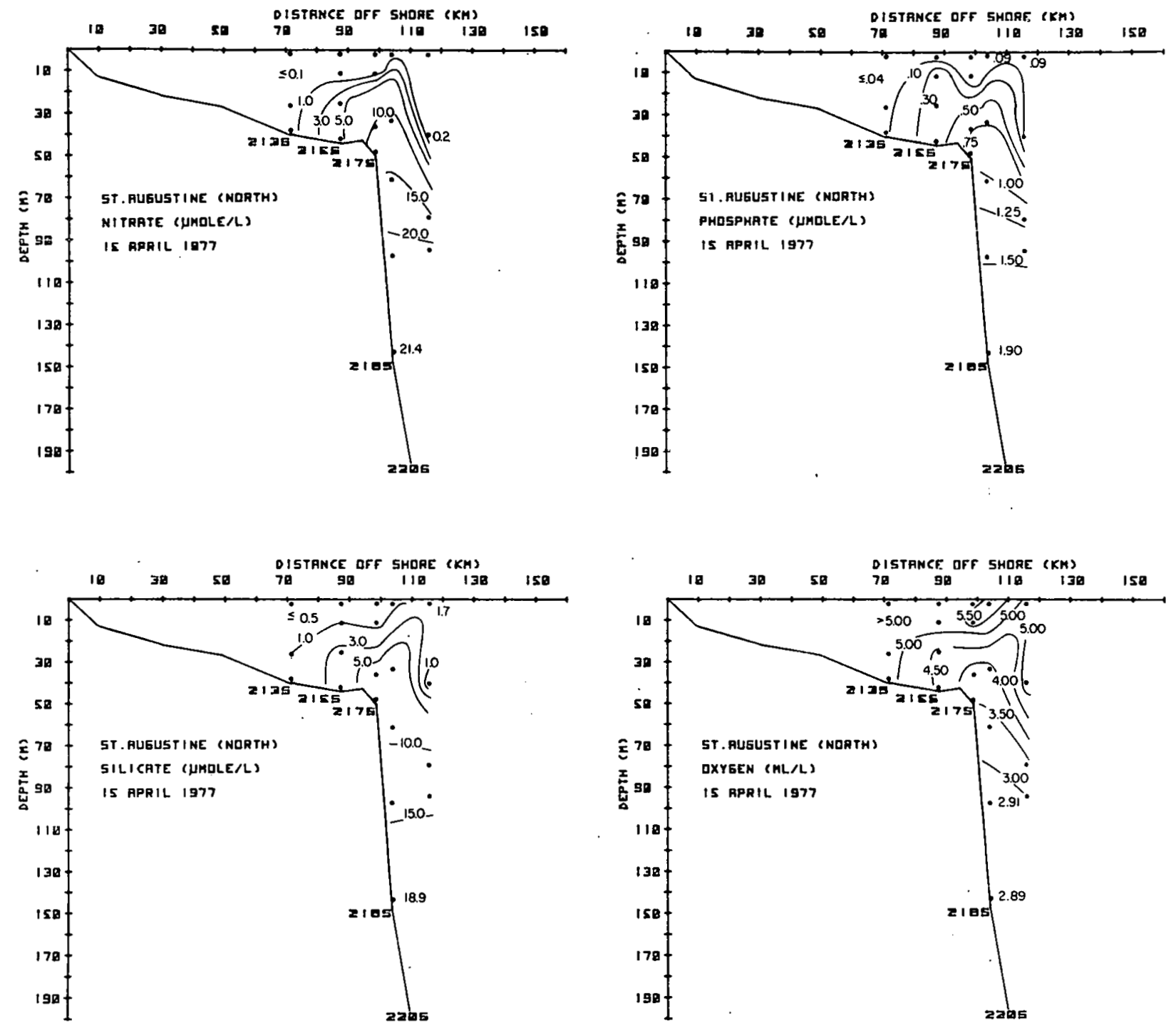

Figure 21. Vertical distribution of nutrients and oxygen, St. Augustine (North) section, 15 Apri1 1977. 

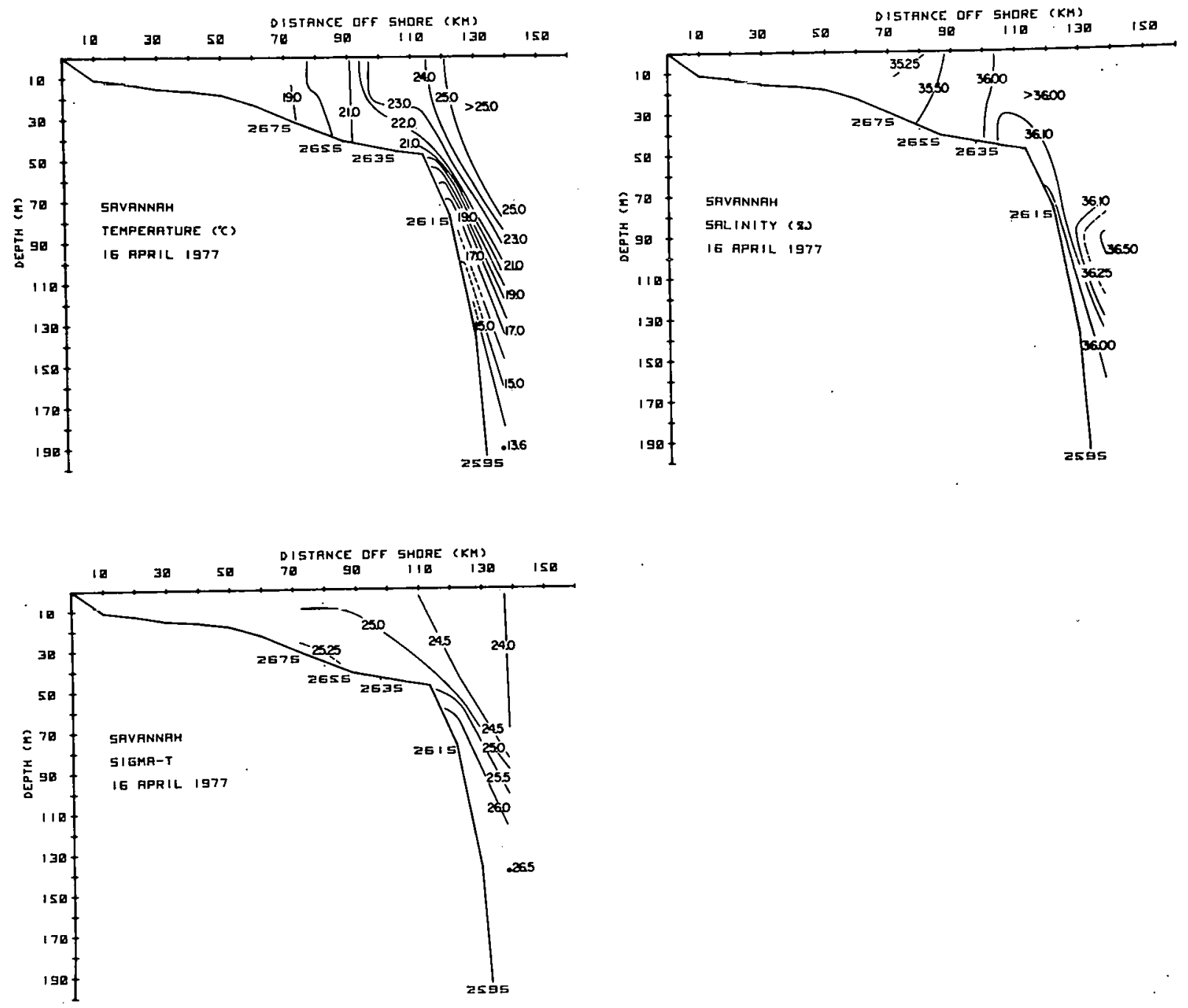

Figure 22. Vertical distribution of temperature, salinity, and sigma-t, Savannah section, 16 April 1977. 

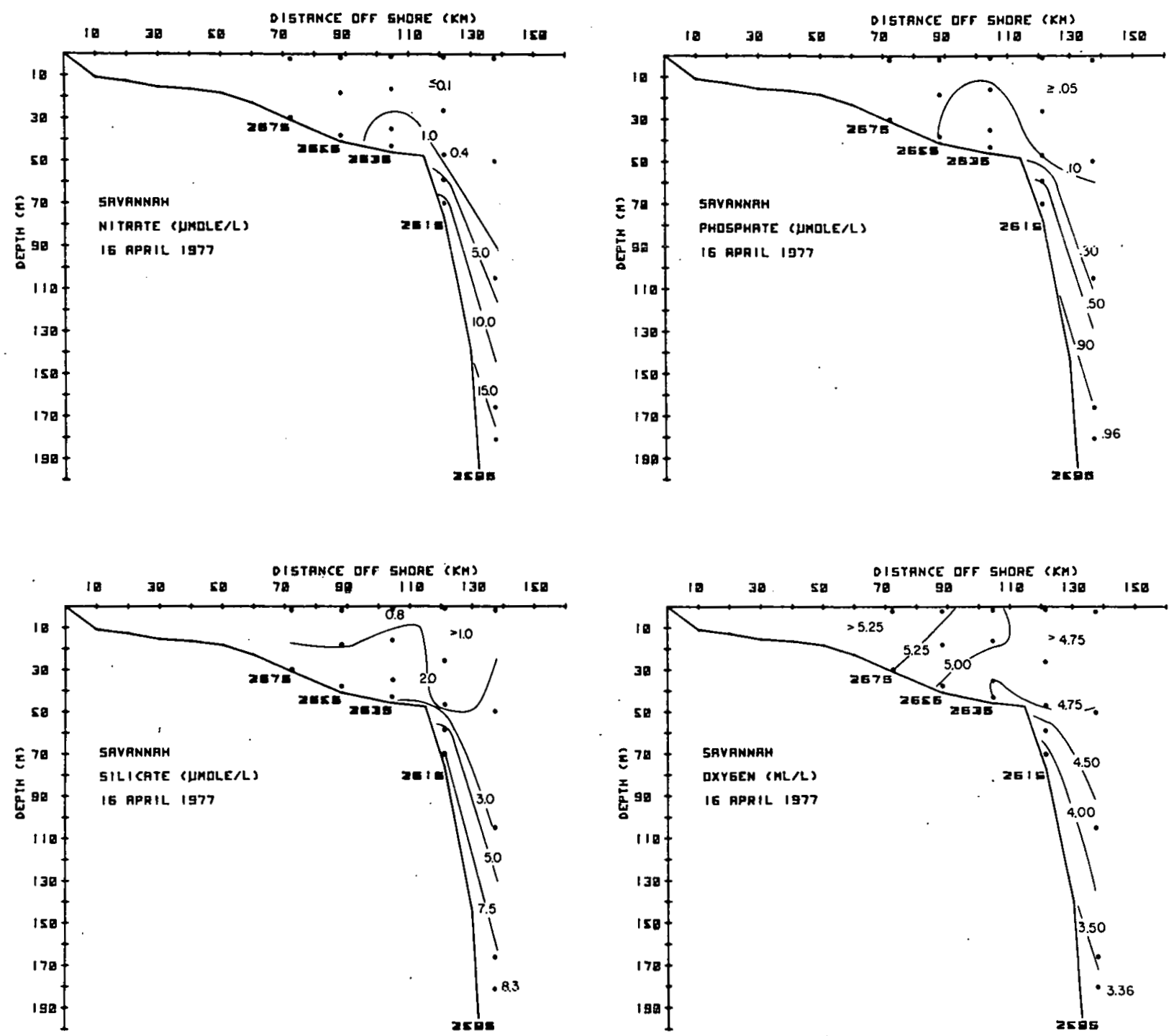

Figure 23. Vertical distribution of nutrients and oxygen, Savannah section, 16 April 1977. 

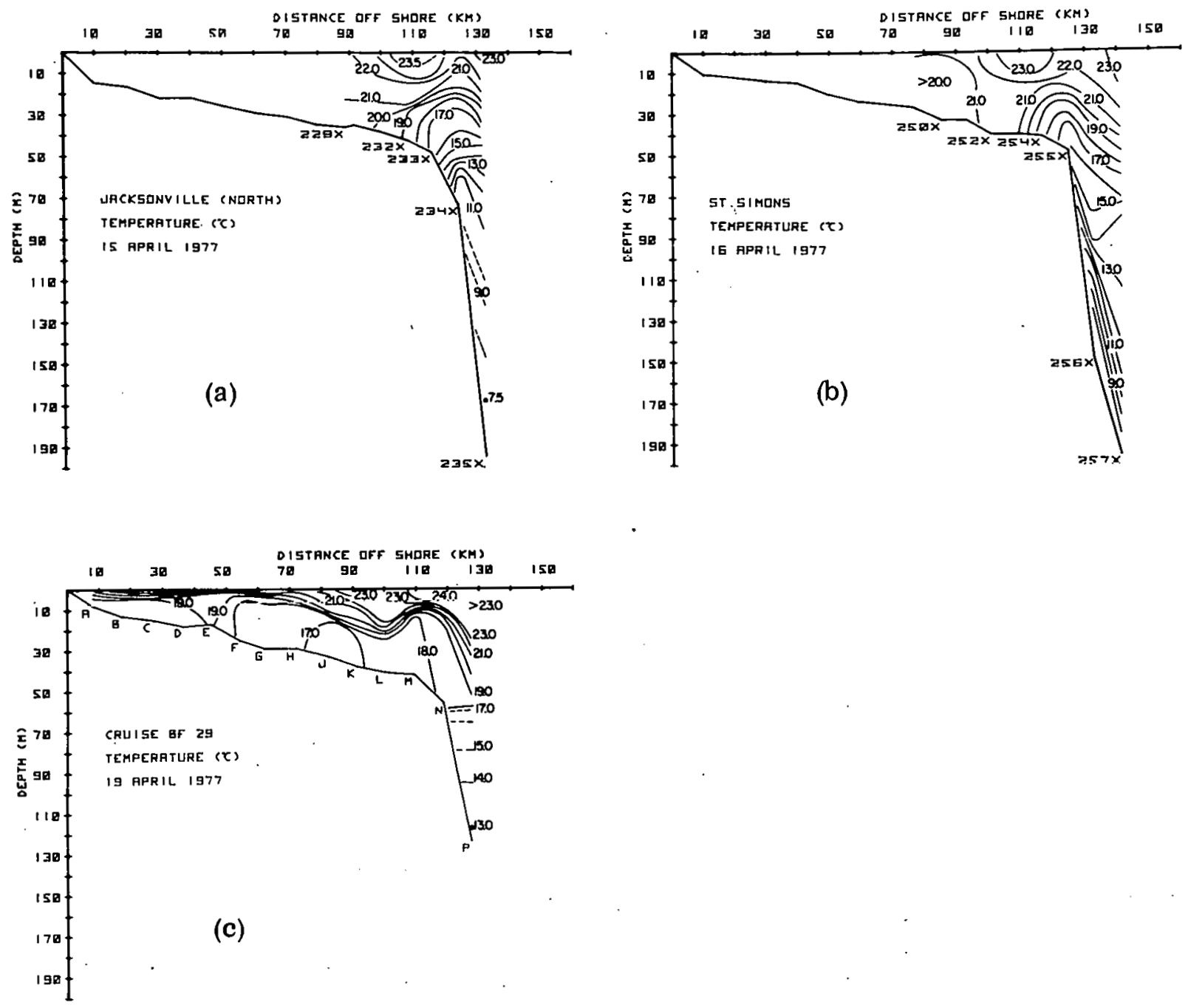

Figure 24. Vertical distribution of temperature, (a) Jacksonville (North) section, 15 April 1977, (b) St.Simons section, 16 April 1977, and (c) cruise BF-29-77 (Savannah), 19 Apri1 1977. 


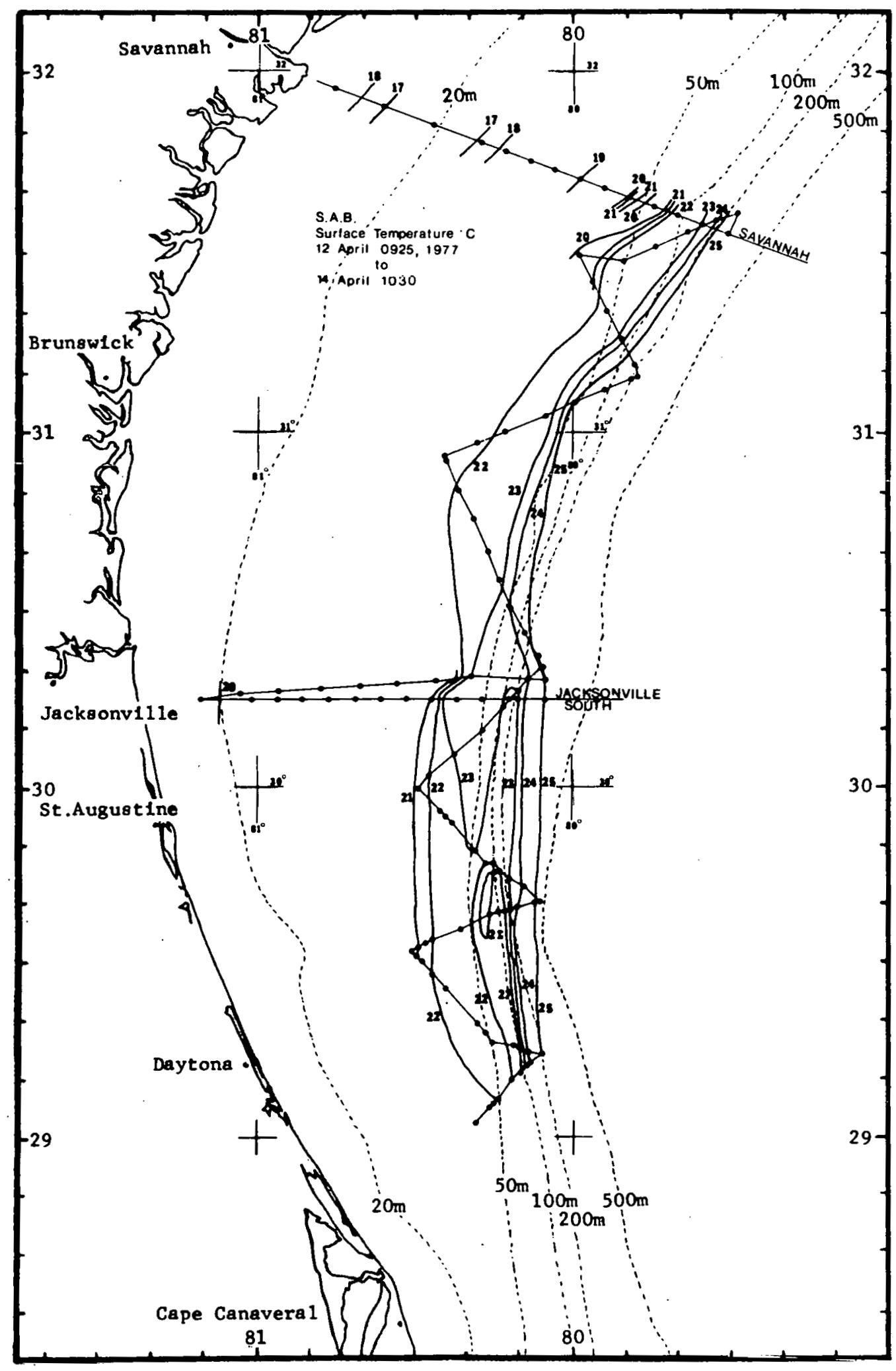

Figure 25. Horizontal surface temperature distribution, 12-14 Apri1 1977. 


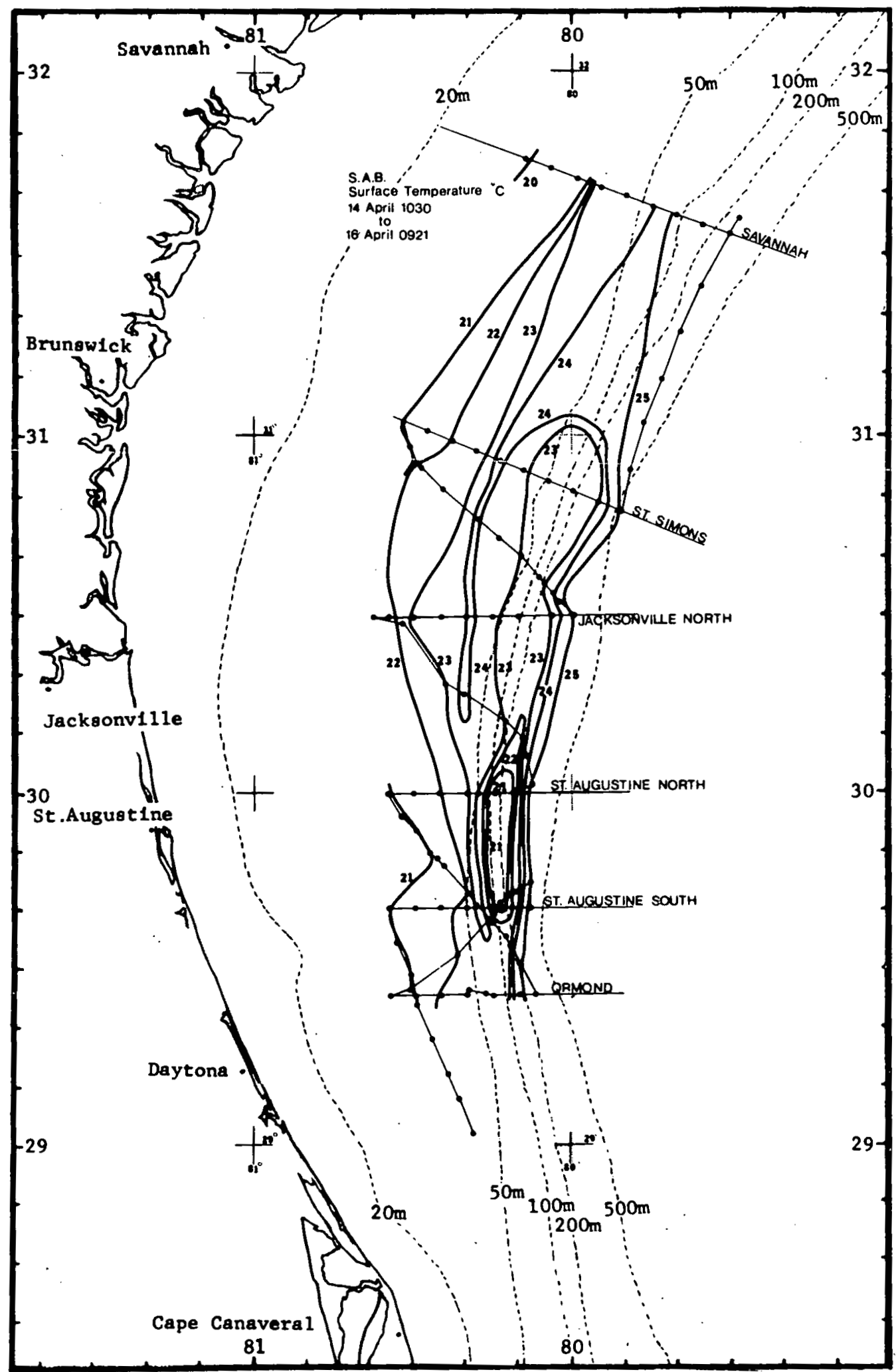

Figure 26. Horizontal surface temperature distribution, 14-16 Apr11 1977. 


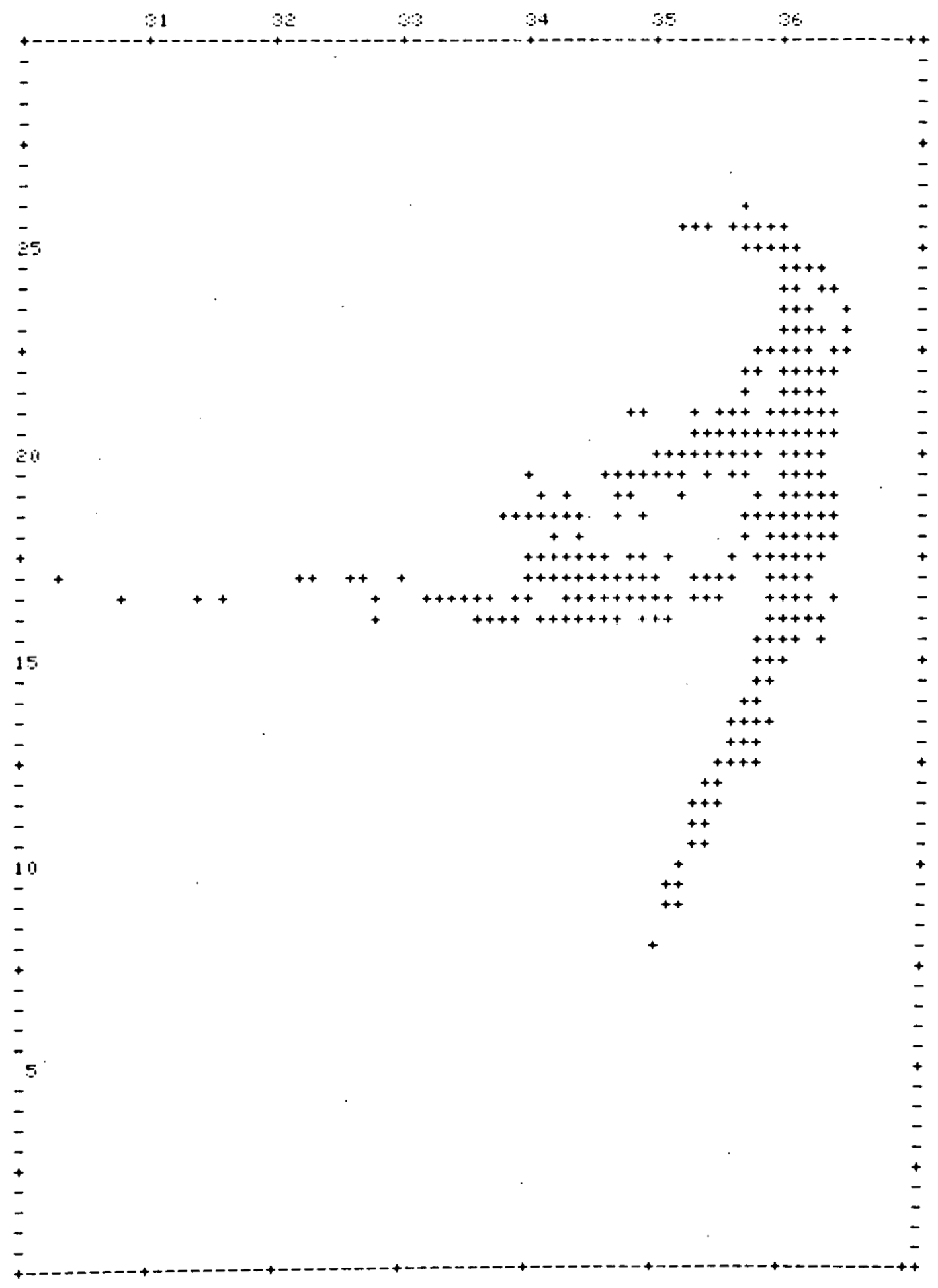

Figure 27. Temperature-Salinity plot, cruise AD-4-77, Apri1 1977. 


\section{REFERENCES}

Atkinson, L. P. 1977. Modes of Gulf Stream intrusion into the South Atlantic Bight shelf waters. Geophys. Res. Let., 4: 583-586.

Bennett, A. S. 1976. Conversion of in situ measurements of conductivity to salinity. Deep-Sea Res., 23: 157-165.

Broenkow, W. W., W. B. Abrahams and R. R. McInnis. 1977. A CTD data acquisition system for coastal applications: Proceedings, Fourth STD/Ocean Systems Conference, San Diego, California.

Gardner, W. S., D. S. Wynne and W. M. Dunstan. 1976. Simplified procedure for the manual analysis of nitrate in sea water. Mar. Chem., 4: 393-396.

Lee, T. 1975. Florida Current spin-off eddies. Deep-Sea Res., 22: 753-765. Mullin, J. B. and J. P. Riley. 1955. The colorimetric determination of silicate with special reference to sea and natural waters. Ana1. Chim. Acta, 12: 162-176.

Murphy, J. and J. P. Riley. 1962. Modified single solution method for the determination of phosphate in natural waters. Anal. Chim. Acta, $27: 31-36$.

National Institute of Oceanography of Great Britain and UNESCO. 1973. International Oceanographic Tables, Vol. 2, Wormley, Godalming, Surrey, England.

Scarlet, R. I. 1975. A data processing method for salinity, temperature, depth profiles. Deep-Sea Res., 22: 590-515.

Strickland, J. D. M. and T. R. Parsons. 1965. A manual of sea water analysis. Fish Res. Bd. Canada, Bu11. No. 125 (2nd ed.), Ottawa. 
Appendix I .

Hydrographic Data 


\section{HYDROGRAPHIC DATA}

The following printouts are from our CEMLIST programming of the data set. An explanation of the listing follows.

Header Data: $\quad$ Times are GMT (EST +5 hours)

Latitude and Longitude are from Loran A or Loran C

Weather Data: These data are from the ship's log.

Wind speed (knots)

Wind direction (degrees)

Air temperature (degrees C)

Weather code (WMO code 4501)

Barometric pressure (millibars)

Sea state (WMO code 3700 )

Wave direction (not given)

Cloud type (not given)

Cloud amount (not given)

Visibility code (not given)

Observations: $\quad Z=$ Depth in meters

$\mathrm{T}=$ Temperature in ${ }^{\circ} \mathrm{C}$

$S=$ Salinity in $\%$

D. $=$ Sigma $-t$

SVA $=$ Specific volume anomaly $\times 10^{5}$

$0_{2}=$ Dissolved oxygen in milliliters/liter

$0_{2}{ }_{2}=$ Oxygen saturation value (from International

Oceanographic Tables, Vol. ? (1973)

$\mathrm{AOU}=$ Apparent oxygen utilization $\left(\mathrm{O}_{2}-\mathrm{O}_{2}\right)$

$\mathrm{PO}_{4}=$ Phosphate concentration in $\mu$ mole/liter

$\mathrm{NO}_{3}^{4}=$ Nitrate concentration in $\mu \mathrm{mole} / \mathrm{liter}$

$\mathrm{Si}^{\mathrm{S}}=$ Silicate concentration in umole/liter 


\begin{tabular}{|c|c|c|c|c|c|c|c|c|c|c|c|}
\hline CRUISE & STATIDN & LAT & I TUDE & Lary & FI TUNE & YR & $M N$ & DY & $\begin{array}{l}\text { HQUR } \\
\text { GMT }\end{array}$ & $\underset{M}{\text { IJEPTH }}$ & $\begin{array}{l}\text { C.DN_SEC } \\
\text { NIIMBER }\end{array}$ \\
\hline 4 & 1 & 31 & $56.7 N$ & 80 & اليا3. . & 77 & 4 & 8 & 14.8 & 12 & 1 \\
\hline 4 & 2 & 31 & $54 . \mathrm{EN}$ & 80 & 36.014 & 77 & 4 & 8 & 15.8 & 15 & $\Xi$ \\
\hline 4 & 3 & 31 & 51 . Oly & 80 & $26.5 w$ & 77 & 4 & 8 & 17.0 & 19 & 3 \\
\hline 4 & 4 & 31 & 4:3. ON & 80 & 17.5 & 77 & 4 & 8 & 21.4 & 24 & 4 \\
\hline 4 & 5 & 31 & $46.5 \mathrm{~N}$ & 80 & 1.3. 1. & 77 & 4 & 8 & 22.1 & 29 & 5 \\
\hline 4 & $E$ & 31 & $45.0 N$ & 80 & 9.019 & 77 & 4 & 8 & 22.4 & 33 & $E$ \\
\hline 4 & 7 & 31. & $43.6 \mathrm{H}$ & 80 & 3.64 & 77 & 4 & 8 & 23.6 & 35 & 7 \\
\hline 4 & 8 & 31 & 42 . ONy & 79 & 58.91, & $7 \overrightarrow{7}$ & 4 & 9 & .1 & 43 & $\Xi$ \\
\hline 4 & 9 & 31 & 40.514 & 79 & 54. (1) & 77 & 4 & 9 & .9 & 45 & 9 \\
\hline 4 & 10 & 31 & $39.0 \mathrm{~N}$ & 79 & 49.36 & 77 & .4 & 9 & 1.4 & 45 & 10 \\
\hline 4 & 11 & 31 & 37.54 & 79 & 45. Old & 77 & 4 & 9 & E. 3 & 5.5 & 11 \\
\hline 4 & $1 \mathrm{E}$ & 31 & 3E. ON & 79 & 40. & 77 & 4 & 9 & 2.9 & 34 & 12 \\
\hline 4 & 13 & 31 & $34.7 H$ & 79 & إراي5. ـ & 77 & 4 & 9 & 4.0 & 172 & 15 \\
\hline 4 & 14 & 31 & 33.414 & 79 & 30.510 & 77 & 4 & 9 & 4.4 & 30 & 14 \\
\hline 4 & 21 & 31 & P.PHA & 30 & $45.51,1$ & $P P$ & 4 & 10 & 1.4 & 19 & 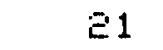 \\
\hline 4 & シこ & $\$ 1$ & 4. DH & 80 & إ. & $7 P$ & 4 & 10 & E. & 23 & $\Xi \Xi$ \\
\hline 4 & 23 & 31 & ت. 314 & 90 & 3E. 01,1 & 77 & 4 & 10 & 3.4 & $\$ 1$ & 23 \\
\hline 4 & 34 & $\because 1$ & 1. ont & 50 & 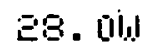 & 77 & 4 & 10 & 3.9 & 37 & 54 \\
\hline 4 & 25 & 30 & 58.54 & 80 & 23.04 & 77 & 4 & 10 & 4.8 & 37 & 25 \\
\hline 4 & $\Xi E$ & 30 & $57.0 N$ & 80 & 18. & 77 & 4 & 10 & 5.3 & 40 & EE \\
\hline 4 & 27 & 30 & $5=4 \mathrm{M}$ & 80 & 13. . & $P P$ & 4 & 10 & 6.0 & 41 & $\vec{i}$ \\
\hline 4 & $2:$ & 30 & $53.7 \mathrm{PH}$ & 80 & $9.1 \mathrm{w}$ & 77 & 4 & 10 & 6.5 & $4 \Xi$ & 80 \\
\hline 4 & 29 & 30 & БE. EH & 80 & $3.91,1$ & 77 & 4 & 10 & 7.3 & $4 \vdots$ & 29 \\
\hline 4 & 31 & 30 & 50.914 & 79 & 59.81, & 77 & 4 & 10 & 7.8 & 113 & 30 \\
\hline 4 & 31 & 30 & 49.34 & 79 & $5: 84$ & 77 & 4 & 10 & 8.9 & $\Xi E 1$ & $\because 1$ \\
\hline 4 & 30 & 30 & 47 . Dint & 79 & 50.51 .51 .5 & 77 & 4 & 10 & 9.4 & 351 & 30 \\
\hline 4 & 3 & $\because 1$ & $3.41 t$ & 79 & 30.010 & 77 & 4 & 11 & $\Xi .1$ & 30 & 3 \\
\hline 4 & 34 & $\because 1$ & 35.014 & 79 & : & 77 & 4 & 11 & 5.0 & 124 & 34 \\
\hline 4 & 35 & 31 & ZE. EH & 99 & 40.810 & 77 & 4 & 11 & 5.7 & $B:$ & 35 \\
\hline 4 & 36 & 31 & 3E. Et & 79 & $45.41,1$ & 77 & 4 & 11 & 5.5 & $4 E$ & $B$ \\
\hline 4 & 37 & 31 & $39.0 \mathrm{y}$ & 79 & 49.910 & 77 & 4 & 11 & 7.0 & $4 E$ & 37 \\
\hline 4 & 38 & 31 & 40.314 & 79 & 54.411 & 78 & 4 & 11 & $7 . E$ & 44 & 30 \\
\hline 4 & 39 & 31 & 4 U. ON & 79 & $58.7 \mathrm{r}$ & 77 & 4 & 11 & $\Xi . \Xi$ & $4 \pi$ & 39 \\
\hline 4 & 40 & 31 & 43.414 & 80 & $4.1 \mathrm{ll}$ & 77. & 4 & 11 & 9.1 & 37 & 40 \\
\hline 4 & 41 & 31 & $45.01+4$ & $\$ 0$ & $9 .[11$, & $7 P$ & 4 & 11 & 9.6 & $3: 3$ & 41 \\
\hline 4 & $4 \Xi$ & 31 & 45.11 & 80 & 13.56 & $p 7$ & 4 & 11 & 10.2 & $\Xi 7$ & $4 \Xi$ \\
\hline 4 & 43 & 31 & 4P.PH & 80 & 17.50 & 77 & 4 & 11 & $10 . E$ & $\Xi \Xi$ & 43 \\
\hline 4 & 53 & 31 & 54 . art & $E 0$ & $\exists B .20$ & $\vec{i}$ & 4 & $1 i$ & 15.4 & 1.5 & $5: 3$ \\
\hline 4 & 54 & $\because 1$ & 51 . Dort & $\$ 0$ & Ë. & 77 & 4 & $1 \Xi$ & 16.5 & 19 & 54 \\
\hline 4 & 5.5 & 31 & 47.41 .4 & 30 & إ!اוي. . & 77 & 4 & $1 \geq$ & $17 . E$ & $\Xi 4$ & 5.5 \\
\hline 4 & שפ & $\vdots 1$ & 45. ort & 10 & 13.011 & $7 P$ & 4 & $1 z$ & 18.3 & $\Xi E$ & E \\
\hline 4 i! & 57 & 31 & 45. alt & $B 0$ & $8.41,1$ & 77 & 4 & $1 e$ & 18.8 & 31 & 57 \\
\hline 4 & 58 & 31 & $4: 5.54$ & $B 0$ & 3 . El & 77 & 4 & $1 \geq$ & 19.0 & 37 & 50 \\
\hline 4 & 59 & 31 & 41 . Br. & 79 & 58.8 & 77 & 4 & $1 \Xi$ & $=0$ & $4 \Xi$ & 5 \\
\hline 4 & $E 0$ & 31 & 40.41. & 79 & 53.21 & 77 & 4 & 12 & 20.8 & 44 & - \\
\hline
\end{tabular}




\begin{tabular}{|c|c|c|c|c|c|c|c|c|c|c|c|}
\hline CRUISE & STATIDN & LAT & I I TUNE & LDME & ITUIIE & 'YR. & MN & DY & $\begin{array}{l}\text { HOUR } \\
\text { GMT }\end{array}$ & $\underset{M}{\text { DEPTH }}$ & $\begin{array}{l}\text { CDNSEC: } \\
\text { HUMBER }\end{array}$ \\
\hline 4 & 61 & 31 & $39.2 N$ & 79 & $48.9(1)$ & $\vec{P}$ & 4 & 12 & 21.2 & 46 & 61 \\
\hline 4 & 62 & 31 & $37.5 \mathrm{~N}$ & 79 & $44.6 \mathrm{l}$ & 37 & 4 & 12 & 22.0 & 47 & 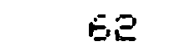 \\
\hline 4 & 63 & 31 & $36.1 \mathrm{~N}$ & 79 & $39.8 w$ & 77 & 4 & 12 & 22.4 & 71 & 63 \\
\hline 4 & 64 & 31 & $34.9 N$ & 79 & $35.1 \mathrm{w}$ & 77 & 4 & 12 & 23.4 & 132 & 64 \\
\hline 4 & 65 & 31 & $33.4 M$ & 79 & $30: 04$ & $P 7$ & 4 & 12 & 23.8 & 235 & 8.5 \\
\hline 4 & 100 & 30 & $15.3 \mathrm{H}$ & 81 & $10.4 W$ & 77 & 4 & 13 & 17.8 & 16 & 100 \\
\hline 4 & 101 & 30 & 14.91 & 81 & إرا8 & 77 & 4 & 13 & 18.9 & 27 & 101 \\
\hline 4 & $10 \Xi$ & 30 & 1.5. 2H & 80 & $55.8 w$ & $P 7$ & 4 & 13 & 19.5 & 29 & $10 \Xi$ \\
\hline 4 & 103 & 30 & 14. 91 & 80 & 51.46 & 37 & 4 & 13 & 19.9 & 29 & 103 \\
\hline 4 & 104 & 30 & 15. ort & 80 & 45.86 & 77 & 4 & 13 & 20.7 & 29 & 104 \\
\hline 4 & 10.5 & 30 & 15. ON & 80 & 41. Eil & 77 & 4 & 13 & $=1.1$ & 34 & 10.5 \\
\hline 4 & 106 & 30 & $15.3 \mathrm{M}$ & 80 & 36.24 & 77 & 4 & $1: 3$ & EE. 0 & 35 & 105 \\
\hline 4 & 107 & 30 & 15. Dit & 80 & 31.5b & 77 & 4 & 13 & E. 4 & 37 & 107 \\
\hline 4 & 108 & 30 & 15. Uit & 80 & 27.011 & 78 & 4 & 13 & 23.1 & 40 & 100 \\
\hline 4 & 109 & 30 & 15. ort & 80 & ㄹ. 0 , & 77 & 4 & 13 & 23.5 & 44 & 109 \\
\hline 4 & 110 & 30 & 15.414 & 80 & $17.6 \mathrm{w}$ & 77 & 4 & 14 & .1 & $4 E$ & 110 \\
\hline 4 & 111 & 30 & $15.1 \mathrm{H}$ & 80 & 12. & 77 & 4 & 14 & .5 & 102 & 111 \\
\hline 4 & 112 & 30 & 14. PN & 80 & 10.310 & $P P$ & 4 & 14 & 1.7 & 185 & $11 \Xi$ \\
\hline 4 & 113 & 30 & 15.14 & 80 & 5. & 77 & 4 & 14 & $\Xi .1$ & 30 & 113 \\
\hline 4 & 174 & 29 & 4 II. Int & 80 & 35.014, & 77 & 4 & 14 & 19.1 & 20 & 174 \\
\hline 4 & 175 & 29 & 40.514 & 90 & $29.31,1$ & $P P$ & 4 & 14 & 19.9 & 33 & 175 \\
\hline 4 & $17 E$ & 29 & 40.54 & 80 & 25.011, & $P 7$ & 4 & 14 & 20.4 & 41 & $17 \mathrm{E}$ \\
\hline 4 & 177 & 29 & 39.314 & 80 & 20.80 & 7 & 4 & 14 & $\Xi 1 . \Xi$ & $4:$ & 177 \\
\hline 4 & 178 & 29 & 39. Btt & 80 & 15.34 & $7 \overline{7}$ & 4 & 14 & $\Xi \because .0$ & 83 & 178 \\
\hline 4 & 179 & 29 & 40. EH & 30 & $15.41,1$ & 77 & 4 & 14 & 20.6 & 68 & 179 \\
\hline 4 & 190 & 29 & 40.114 & 80 & 14.11. & 77 & 4 & 14 & 3.0 & 104 & 180 \\
\hline 4 & $1: 1$ & 29 & 4 II. Elt & 1 & 11. Ellol & 77 & 4 & 14 & 2.7 & $=00$ & $1: 1$ \\
\hline 4 & $18 E$ & 29 & 41. Ort & $\theta 0$ & s. $E$ & $7 r$ & 4 & 15 & .1 & 385 & $1 \Xi \Xi$ \\
\hline 4 & 193 & 29 & 25. EN & 80 & 35.510 & 77 & 4 & 1.5 & 4.1 & ジ & 193 \\
\hline 4 & 193 & 29 & 25. 3Ny & 80 & $29.7 \mathrm{l}$ & 77 & 4 & 15 & 5.0 & 3 & 193 \\
\hline 4 & 194 & 29 & 25. 014t & 90 & 25.01, & 77 & 4 & 15 & 5.4 & 29 & 194 \\
\hline 4 & 195 & 29 & EE. 4 tt & 80 & $19.91,1$ & 77 & 4 & 1.5 & 6.3 & 43 & 195 \\
\hline 4 & 196 & 29 & 25. 2N & 80 & 16.9 & $P 7$ & 4 & 15 & $E .6$ & 48 & 190 \\
\hline 4 & 197 & 29 & 25.5. & 80 & 15. & 77 & 4 & 15 & 6.9 & 5.5 & 197 \\
\hline 4 & 195 & 29 & ES. EN & 80 & 9.91, & 77 & 4 & 15 & 7.5 & 125 & $19:$ \\
\hline 4 & 199 & 29 & E5. BH & 80 & 7.314 & $7 P$ & 4 & 15 & 8.1 & 370 & 199 \\
\hline 4 & こ1: & 30 & 0. 014 & 80 & $3.5 .011,0$ & $P 7$ & 4 & 15 & $1 \geq .1$ & 41 & $E 13$ \\
\hline 4 & 214 & 30 & $.11 \mathrm{t}$ & 80 & تو & $P 7$ & 4 & 15 & $1 己 .9$ & $4 E$ & E14 \\
\hline 4 & 215 & 30 & a. ant & 80 & 25.11 & 77 & 4 & 1.5 & 13.3 & 44 & $=15$ \\
\hline 4 & 215 & 30 & 0. ont & E0 & 20.010 & $P 7$ & 4 & 1.5 & 14.0 & $4 \Xi$ & E1E \\
\hline 4 & 217 & 30 & 0. Doft & 30 & 19. 014 & $P 7$ & 4 & 1.5 & $14 . \Xi$ & 50 & $\Xi 17$ \\
\hline 4 & 213 & 30 & D. Dint & 30 & $14.31,1$ & $P i$ & 4 & 15 & 14.9 & 146 & $\Xi 15$ \\
\hline 4 & シ19 & 30 & a. out & 80 & 11. & 77 & 4 & 15 & $1 E .2$ & 270 & $\Xi 19$ \\
\hline 4 & 200 & 30 & 1. EH & 80 & 7.5101 & 77 & 4 & 15 & 16.6 & 370 & $\Xi E 0$ \\
\hline 4 & EQ & 50 & 31 . Elt & 80 & $31 \cdot 7 w$ & 77 & 4 & 15 & $\Xi 0.8$ & 30 & อᄅ9 \\
\hline 4 & 230 & 30 & 31. EN & 80 & $30 . \quad[1,1$ & 77 & 4 & 1.5 & $=1.0$ & 35 & 200 \\
\hline
\end{tabular}


ADWANCE II CRUISE

\begin{tabular}{|c|c|c|c|}
\hline CRIUISE & STRTIUA & \multicolumn{2}{|c|}{ LAT I TUDE } \\
\hline 4 & 231 & 30 & $29.5 \mathrm{~N}$ \\
\hline 4 & 232 & 30 & $29.4 \mathrm{~N}$ \\
\hline 4 & 233 & 30 & $29.7 \mathrm{H}$ \\
\hline 4 & 234 & 30 & 30.014 \\
\hline 4 & 235 & 30 & 30. EN \\
\hline 4 & 235 & 30 & $30.5 \mathrm{H}$ \\
\hline 4 & 249 & 31 & $\Xi .5 N$ \\
\hline 4 & 250 & 31 & .814 \\
\hline 4 & 251 & 30 & 59.04 \\
\hline 4 & 25こ & 30 & $57.2 M$ \\
\hline 4 & $25 \%$ & 30 & 5.5 .54 \\
\hline 4 & 254 & 30 & 53.84 \\
\hline 4 & 255 & 30 & SE. . \\
\hline 4 & 256 & 30 & 50.514 \\
\hline 4 & 257 & 30 & 43.514 \\
\hline 4 & 258 & 30 & 49.14 \\
\hline 4 & 259 & 31 & 33.014 \\
\hline 4 & シேす & 31 & 34.6 .14 \\
\hline 4 & EE 1 & 31 & 35.914 \\
\hline 4 & EE & 31 & BE. EN \\
\hline 4 & $=0$ & 31 & 3.11 \\
\hline 4 & 264 & 31 & 41.41. \\
\hline 4 & E5.5 & 31 & $4 E$ EN \\
\hline 4 & EEE & 31 & 43.514 \\
\hline $4 !$ & $E E$ & 81 & 45.514 \\
\hline
\end{tabular}

\section{[COHT INUED]}

LDHII I TUIIE

$8025.2 W$ 50 20. 014

80 15. 01!

809.71

50 5. 010

301.16

80 3e. $01 \mathrm{w}$

80 27. on!

80 22. 54

8018.04

8013.314

$30 \quad 8.94$

$80 \quad 4.011$

7959.46

7954.74

7950.010

7929.64

79 34. E.

$79 \quad 39.54$

7944 . Dllal

7949.01

795.5 .014

7958.81

Bu 3.86

Bu 8.81,
'YP MN D'r' HUIN EMT

7741521.3

$77 \quad 4 \quad 15$ 21.7

77415 ㄹ. 1

$77 \quad 4.15$ อ2. 4

$774152 E .8$

P7 415 23.0

$7 P 4$ 16 2.7

77 4 $15 \quad 3.1$

$77416 \quad 3.4$

$77416 \quad 3.7$

77416

77416

77416

77416

77418

$P \vec{P}$

77

77

77

77

77

7

77

$7 ?$
415

415

ㅂ. 7

41611.3

41610.8

41611.7

$41 E 1 \mathrm{E} .1$

41810.8

41613.3

4 1E 14.0

41614.4
IIEPTH C.DHSEE:

$M$ NIMMEER

$38 \quad 231$

42 ट3E

$49 \quad 233$

$73 \quad 234$

240 235

E83 236

$26 \quad 249$

39

30

40

40

41

48

149

236

30

Eno

132

77

48

45

43

41

39

31
250

251

252

253

254

25.5

25

257

250

259

EE

ED 1

EE

ES:

204

ES.5

एE 


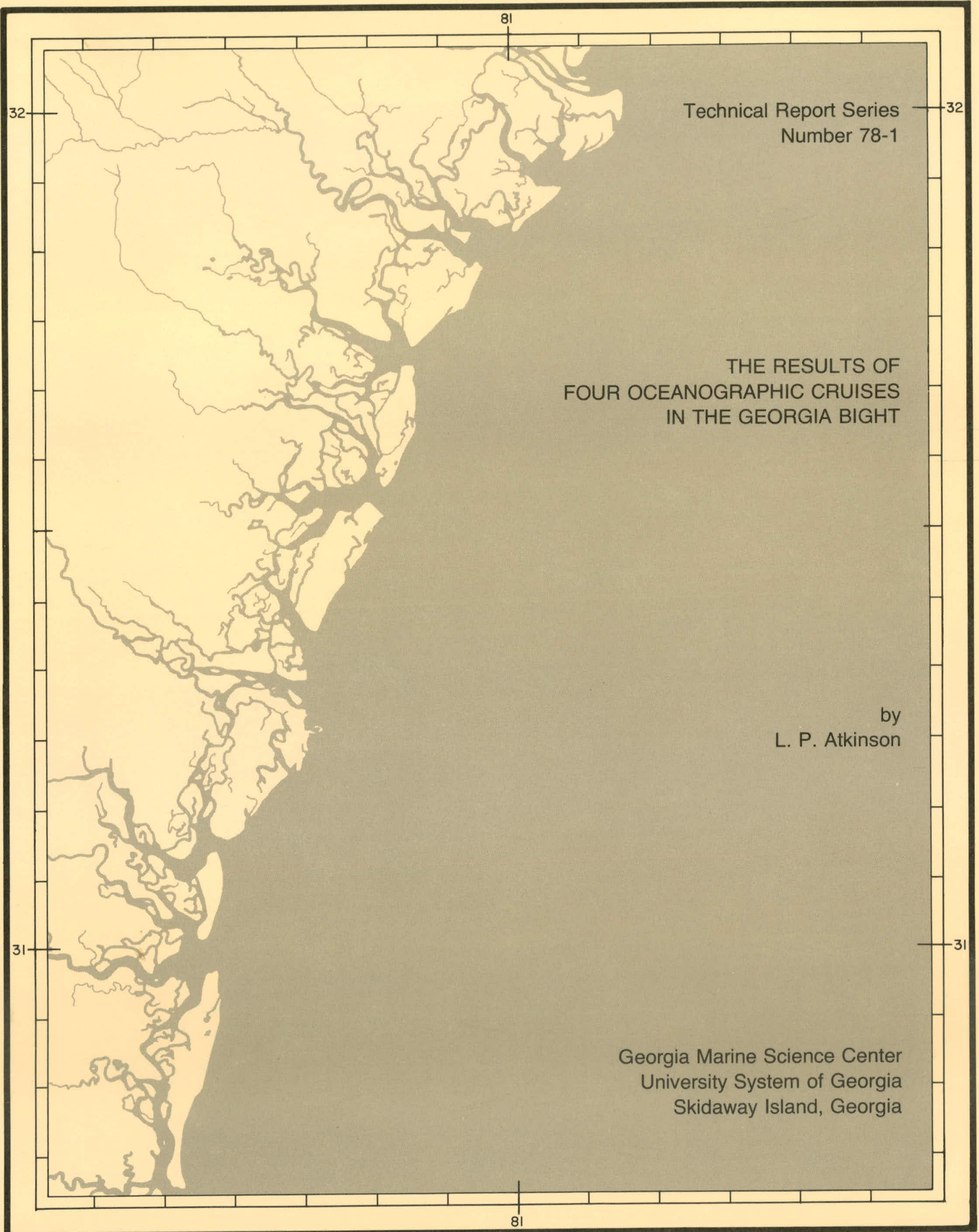




\title{
THE RESULTS OF FOUR OCEANOGRAPHIC CRUISES
}

IN THE GEORGIA BIGHT

L. P. Atkinson

\author{
Skidaway Insti.tute of Oceanography \\ P. 0. Box 13687 \\ Savannah, Georgia 31406
}

The Technical Report Series of the Georgia Marine Science Center is issued by the Georgia Sea Grant Program and the Marine Extension Service of the University of Georgia on Skidaway Island (P. 0. Box 13687, Savannah, Georgia 31406). It was established to provide dissemination of technical information and progress reports resulting from marine studies and investigations mainly by staff and faculty of the University System of Georgia. In addition, it is intended.for the presentation of techniques and methods, reduced data and general information of interest to industry, local, regional, and state governments and the public. Information contained in these reports is in the public domain. If this prepublication copy is cited, it should be cited as an unpublished manuscript. 
List of Tables...................... . . . . iii

List of Figures ..................... . . . . . iv

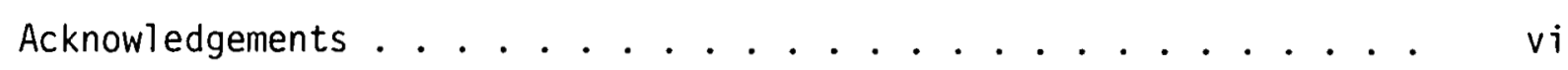

Introduction . . . . . . . . . . . . . . . . . . . . . 1

Results of Four Seasonal Cruises . . . . . . . . . . . . . 2

Data ......................... . . . . . 2

Horizontal Distributions . . . . . . . . . . . . . . 3

Surface Temperature ................. 3

Bottom Temperature ................. . 3

Surface Salinity.................. 3

Surface Density . . . . . . . . . . . . . . . 4

Bottom Nutrients.................. 4

Vertical Sections.................... . . . . 5

Cruise E-13-73, 5-10 September 1973 ......... 5

Cruise E-19-73, 10-15 December 1973 ......... 6

Cruise E-3-74, 24-29 April 1974 . . . . . . . . . 7

Cruise E-12-74, 23-30 July 1974 ........... . 7



Freshwater Volume . . . . . . . . . . . . . . . . . . 9

Drift Bottle Returns .................. 10

Apparent Oxygen Utilization . . . . . . . . . . . . . 11

0xygen Anomaly ........................... 12

Summarized Horizontal Effect of Runoff and Intrusions . . . . 13

The Ranges of Temperature . . . . . . . . . . . . . . . . 13

T-S Relationship . . . . . . . . . . . . . . . . 15

Nitrate-Phosphate-Silicate-Temperature Relationships . . . . 16

Conclusions ......................... . . . 18

References......................... . . . 19

Figures .......................... . . . 20 


\section{LIST OF TABLES}

Page

1. Sample Inventory . . . . . . . . . . . . . . . 2

2. Average Onshore Extent of Intrusions and Offshore Extent of Runoff........................ 14 
1. Station Locations, Cruise E-13-73 .......... 21

2. Station Locations, Cruise E-19-73 . . . . . . . 22

3. Station Locations, Cruise E-3-74 ......... . 23

4. Station Locations, Cruise E-12-74 .......... 24

5. Surface Temperature .............. 25

6. Bottom Temperature . . . . . . . . . . . 26

7. Surface Salinity ................. 27

8. Surface Density. . . . . . . . . . . . 28

9. Bottom Nitrate ............... . . 29

10. Vertical Section, Cruise E-13-73, Section I ...... 30

11. Vertical Section, Cruise E-13-73, Section II ...... 31

12. Vertical Section, Cruise E-13-73, Section III...... 32

13. Vertical Section, Cruise E-13-73, Section IV ...... 33

14. Vertical Section, Cruise E-13-73, Section V....... 34

15. Vertical Section, Cruise E-19-73, Section I....... 35

16. Vertical Section, Cruise E-19-73, Section II ...... 36

17. Vertical Section, Cruise E-19-73, Section III...... 37

18. Vertical Section, Cruise E-19-73, Section IV ...... 38

19. Vertical Section, Cruise E-19-73, Section V....... 39

20. Vertical Section, Cruise E-19-73, Section VI ...... 40

21. Vertical Section, Cruise E-3-74, Section I ....... 41

22. Vertical Section, Cruise E-3-74, Section II ....... 42

23. Vertical Section, Cruise E-3-74, Section III ....... 43

24. Vertical Section, Cruise E-3-74, Section IV ....... 44

25. Vertical Section, Cruise E-3-74, Section V....... 45

26. Vertical Section, Cruise E-3-74, Section VI ...... 46 
27. Vertical Section, Cruise E-12-74, Section I....... 47

28. Vertical Section, Cruise E-12-74, Section II ...... 48

29. Vertical Section, Cruise E-12-74, Section III....... 49

30. Vertical Section, Cruise E-12-74, Section IV ...... 50

31. Vertical Section, Cruise E-12-74, Section V....... 51

32. Vertical Section, Cruise E-12-74, Section VI ...... 52

33. Distribution of Freshwater ........... 53

34. Drift Bottle Trajectories . . . . . . . . . 54

35. Apparent 0xygen Utilization, Cruise E-13-73...... 55

36. Apparent Oxygen Utilization, Cruise E-19-73 ...... 56

37. Apparent 0xygen Utilization, Cruise E-3-74 . . . . . 57

38. Apparent 0xygen Utilization, Cruise E-12-74 ....... 58

39. Oxygen Anomaly, Cruise E-13-73 . . . . . . . 59

40. Oxygen Anomaly, Cruise E-19-73 .......... 60

41. Oxygen Anomaly, Cruise E-3-74 ........... 61

42. Oxygen Anomaly, Cruise E-12-74 ........... 62

43. Summarized Horizontal Extent of Runoff and Intrusions

44. Summarized Horizontal Extent of Runoff and Intrusions E-19-73....................... 64

45. Summarized Horizontal Extent of Runoff and Intrusions E-3-74 ....................... 65

46. Summarized Horizontal Extent of Runoff and Intrusions E-12-74..................... 66

47. Temperature-Salinity Plot . . . . . . . . 67

48. Schematic Seasonat T-S Plot . . . . . . . . . 68

49. Phosphate-Nitrate Plot ............. 69

50. Nitrate-Apparent 0xygen Utilization Plot ....... 70

51. Nitrate-Temperature Plot ............. 71 
INTRODUCTION

During 1973 and 1974 we conducted four oceanographic cruises in the Georgia Bight with the purpose of gaining background seasonal data with which to plan more specific experiments. In this technical report the data are presented in graphical form with interpretation. The data itself was published in two technical reports (Atkinson, 1975 and 1976). Some of the interpretations in this report will be given in more detail in published journal articles. 


\section{RESULTS OF FOUR SEASONAL CRUISES}

Data

The basic station grid was sampled four times as shown in Figures 1-4. In addition to the onshore/offshore line of stations samples were occasionally taken between sections.

The dates and sampling activities for the four Georgia Bight cruises are summarized in the following table:

Table 1. Sample Inventory

\begin{tabular}{lcccc}
\hline & & & & \\
Cruise Name & E-13-73 & E-19-73 & & \\
Date (Inclusive) & $4-11 / I X / 73$ & $8-15 / X I I / 73$ & $23-30 / I V / 74$ & E-12-74 \\
\hline \# Stations & 55 & 62 & 63 & 68 \\
\# Sample Depths & 278 & 239 & 215 & 296 \\
\# Salinity Samples & 274 & 233 & 213 & 288 \\
\# Oxygen Samples & 256 & 135 & 207 & 291 \\
\# Temperature & & & 295 \\
Observations & 278 & 238 & 212 & 244 \\
\# Nitrate Samples & 276 & 199 & 180 & 291 \\
\# Phosphate Samples & 276 & 198 & 204 & 293 \\
\# Silicate Samples & 260 & 200 & 208 & $36 / 18$ \\
$\begin{array}{l}\text { Drift Bottles Released } \\
\text { (\#/Stations) }\end{array}$ & $60 / 15$ & $60 / 15$ & $36 / 18$ & \\
\hline
\end{tabular}

All of the hydrographic data and bathythermograph profiles are stored with the National Oceanographic Data Center and are available under the appropriate cruise name.

The horizontal plots are presented first, followed by the vertical plots. Cruises are referred to by the name (e.g., E-19-73) or the month during which the cruise took place. 
Horizontal Distributions

Surface Temperature. Surface temperatures (Figure 5) were observed to range from less than $14^{\circ} \mathrm{C}$ to greater than $29^{\circ} \mathrm{C}$. The higher temperature are always found in the vicinity of the Gulf Stream. During the summer (E-13-73 and E-12-74) solar heating is effective in raising the surface temperature of the Bight uniformly. Thus the horizontal temperature gradients are minimal during the summer. During the winter and spring (E-19-73 and E-3-74) a definite offshore gradient in temperature occurs. On E-19-73 the waters are cooling in response to lower air temperatures. During E-3-74 the shelf waters are generally warmer in response to warmer air temperatures and solar insolation. In the spring (E-3-74) horizontal gradients are minimal except in the vicinity of the Gulf Stream.

Bottom Temperature. The bottom temperature distributions (Figure 6) must be compared to the surface temperature distributions. In three cases (upper and lower left, and lower right) bottom temperatures decrease towards the offshore. This is in contrast to the surface water temperatures that increase in the offshore direction. This occurs because relatively cold, deep, Gulf Stream water is moving onshore along the bottom. This is normally referred to as the intrusion process. This process is very important because it brings new water onto the shelf, replacing what was there. The intrusion process is also evident in the December cruise (upper right) but because the shelf waters are relatively cold $(15-20 \mathrm{C})$ the intruding Gulf Stream water appears warm.

Surface Salinity. Surface salinities (Figure 7) range from 31 to greater than $36^{\circ} \% 0$. The lower salinities are found near the shore as 
expected. In general the $35^{\circ} / 00$ isohaline follows the $18 \mathrm{~m}$ (10 fathom) isobath. However south of the Altamaha River the isohalines begin to intersect the coast. The surface shelf water salinities generally are greater than $36^{\circ} / 00$ with a tendency for higher salinities to the south and lower salinities to the north at the same isobath.

During cruise E-13-73 a special situation existed. The low surface salinities on the outer shelf were hypothesized to originate from the Mississippi River during periods of high runoff. See Atkinson and Wallace (1975) for additional discussion.

Surface Density. The surface density plots (Figure 8) show the effect of low salinity water lying along the coast. The central shelf waters are quite often of higher density than inner or outer shelf waters because of the combination of relative high salinities and low temperatures in contrast to higher offshore salinities (and temperatures).

Nearshore geostrophic currents to the south are indicated in all cruises except E-19-73.

Bottom Nutrients. The intrusion of deeper-nutrient rich water onto the shelf is one of the principal sources of phytoplankton nutrients. One way of identifying intruding waters is by looking at the near bottom concentrations of the phytoplankton nutrients and especially nitrate (Figure 9).

As Figure 9 demonstrates nitrate is usualiy at very low concentrations in the shelf waters, typically being less than 1 um. However, in the vicinity of an intrusion it is higher, often reaching $10 \mu \mathrm{m}$. The figures show a steady increase in the nitrate concentration in the near bottom waters towards the offshore with the only variant being where the increase starts in the cross-shelf direction. 
The wave-like structures in these plots are not significant since they could reflect the bias in the time required for sampling. It is significant however that there always appeared to be an intrusion of nitrate-rich water off the St. Johns River.

\section{Vertical Sections}

The vertical sections indicate, when combined with the horizontal data, a three dimensional view of the shelf. The data presented are sample location and depth, temperature, salinity, sigma-t (density), oxygen, phosphate, nitrate and silicate.

The legend above the section refer to station numbers. The Roman numerals inset in the section refer to the onshore/offshore sections, I being the most northerly and VI the most southerly. Since station numbers, locations and sections were nearly invariant during the cruises the reader may easily compare various stations and sections. For each cruise the sections proceed from north to south. The stations in a section were either 5,10 , or 15 nautical miles $(9.3,18.5$ or $27.8 \mathrm{~km})$ apart.

\section{Cruise E-13-73, 5-10 September 1973. (Figures 10-14) On al1} sections a strong thermocline extended to varying distances across the shelf. If one compares the vertical temperature profiles with the horizontal distribution of bottom temperatures the cause of the cold bottom waters becomes evident. The steeply sloping isotherms can expose cold water to very shallow depths. For example on Section $V$ (Figure 14) at station $5418{ }^{\circ} \mathrm{C}$ water is found at about $220 \mathrm{~m}$, whereas at station 51 , which is 25 nautical miles $\left(46 \mathrm{~km}\right.$ ) to the west, $18^{\circ} \mathrm{C}$ water is found at $50 \mathrm{~m}$ : a rise of $3.7 \mathrm{~m} \mathrm{per} \mathrm{km}$.

The intense thermocline in the outer shelf waters caused by the invasion of deeper, cold Gulf Stream waters has many important consequences. 
The outer shelf is extremely stable because of the extreme vertical density gradients. The cold water contains many dissolved constituents that are lacking in shelf water and thus becomes an important source of these constituents.

Nitrate, phosphate and silicate are quite high on the outer shelf in relation to the lower temperatures because their source is cold, deep water. The onshore movement of nutrient-rich water is especially noticeable in Section $V$ (Figure 14).

An area of maximum salinity is always found at depths of 100-300 meters. In this area salinities often reach $36.5^{\circ} / 00$ and occasionally $36.7^{\circ} / 00$. Nearshore salinities progressively decrease. As the nearshore is approached the surface salinity is nearly always less than the bottom salinity. This is expected since fresher water flows out at the surface and salt water flows shoreward to replace that entrained in the surface flow. Silica and phosphate also increase towards the coast with higher concentrations usually found at the surface. This is because the river water carries high concentrations of these nutrients.

The lens of low salinity water that appears in the surface waters near the shelf break, which is especially noticable in sections III, IV, and $V$ (Figures 12-14), represents water that we hypothesized is of Mississippi River origin.

An oxygen minimum is associated with the zone of high salinity. Concentrations often are less than $3.5 \mathrm{ml} \mathrm{O}_{2} / 1$.

Cruise E-19-73, 10-15 December 1973. (Figures 15-20) This cruise was during a period of strong winds and cooling and the data reflect that. Nearly all isolines are vertical which indicate the complete absence of vertical gradients in the shelf waters. 
Temperature and salinity progressively decrease towards the coast indicative of atmospheric cooling and the influence of river runoff, respectively. In all sections the colder deep water is poised at the shelf edge and nutrient concentrations are higher in that area. In fact in spite of the intense wind mixing the temperature and nutrient profiles at the shelf break look much like Cruise E-13-73.

Temperature data indicates the Gulf Stream lies nearer to the shelf break in the southern part of the study area relative to the northern sections.

Cruise E-3-74, 24-29 April 1974 (Figures 21-26). This cruise was during a time of moderation of the stronger winter winds and seasonal heating. Shelf water temperatures are $18-21^{\circ} \mathrm{C}$ with little horizontal or vertical structure. The outer shelf waters on section VI (Figure 26) are significantly affected by an intrusion of colder Gulf Stream water. This results in the coldest shelf waters being in the most southerly section.

Salinities in the shelf waters decrease towards the coast and exhibit estuarine type structure with higher salinities near bottom. A salinity maximum usually occurs well east of the shelf break at depths of $100-200 \mathrm{~m}$.

The isotherms in deeper water slope up to the east in section I and II then down (Figures 21-22). At other more southerly sections, they slope down to the east. This implies a counter-current near the shelf break in the northern part of the area: isotherms sloping down to the west indicate the possible presence of a southerly flowing current (flowing counter to the Gulf Stream). 
The nutrient concentrations reflect the presence of colder water at the shelf break and are relatively high. Sections I and VI (Figures $21,26)$ show an especially active intrusion of deeper Gulf Stream water into the outer shelf waters.

0xygen concentrations show a consistent minimum at 100-200 m. Cruise E-12-74, 23-30 July 1974 (Figures 27-32). This cruise was in July during the typical summer season. The area is dominated by southerly winds. In all sections there was a significant intrusion of colder water onto the shelf.

On section I (Figure 27) water of $20^{\circ} \mathrm{C}$ is present at the sheif break. This cold water was accompanied by nutrient concentrations of .3, 2 and 2 um for phosphate, nitrate and silicate, respectively. There is an indication of a counter-current at $200-$ to $300 \mathrm{~m}$ in the slope of the isotherms and isopycnals. Low salinity water is present in the nearshore surface waters implying an offshore movement of surface waters. No salinity maxima is observed which implies that the Gulf Stream lies farther to the east as is also implied by the isotherm slopes.

Section II is similar to section I with $20^{\circ} \mathrm{C}$ water at the shelf break. And again this water is accompanied by high nutrient concentrations. The lack of a well-developed salinity maximum and the isotherm position indicates that the Gulf Stream is well to the east of our stations. Salinities decrease near the coast. There is also an indication of offshore flow of low salinity water at mid-depth in the middle shelf. There are no we11-developed oxygen minima.

In Section III (Figure 29) there are indications that the Gulf Stream is near the shelf break. None of the isopycnals or isotherms 
slope down to the west and the presence of a salinity maximum indicate that the Gulf Stream is closer to the shelf. $20^{\circ} \mathrm{C}$ water is still at the shelf break and accompanied by high nutrient concentrations.

In Section IV (Figure 30) the position of the isohalines indicates that the Stream is still near the shelf break. Nutrient concentrations are low because of the Gulf Stream position.

In Section $V$ (Figure 31) a current reversal is indicated near the shelf break. The isotherms and isopycnals dip at about $100 \mathrm{~m}$ near the shelf break. Nutrient concentrations are higher.

Section VI (Figure 32) represents an eastern movement of the Stream with a current reversal indicated. This could be caused by an eddy like feature. The presence of high salinity water $\left(36.5^{\circ} / 00\right)$ at shallow depths (Stations 58 and 59) confirms this conclusion. High nutrient concentrations also accompany the high salinity water and nutrient concentrations in the shelf waters have been raised. It is concluded that water had intruded into these shelf waters and then was cut off, which is typical for the intrusion process.

\section{DISCUSSION}

In the previous sections the data were examined by plotting in horizontal and vertical planes. In this section, we will look at the relationship between the parameters, such as the temperature-salinity relationship. In addition we will calculate new parameters based on the original observations.

Freshwater Volume

The offshore distribution of river runoff (freshwater) is a useful indicator of the potential distribution of a river borne pollutant and of the gross circulation and diffusive characteristics of shelf waters. 
Freshwater volume is the amount of freshwater $\left(S^{0} / 00=0\right)$ in $\mathrm{m}^{3}$ required to reduce the salinity of a water column $\left(1 \mathrm{~m}^{2}\right)$ at $36 \%$ to the observed salinity. The key assumption is that Georgia Bight waters would have a salinity of $36.0 \%$ if no runoff waters were present. At any geographic location the amount of required freshwater to affect the observed salinity reduction is:

$$
\text { freshwater volume }=\sum_{i=1}^{n-1}\left[\frac{72-\left(s_{i}+s_{i+1}\right)}{72}\right] \cdot\left(z_{i}-z_{i+1}\right)
$$

where $n=$ number of depths sampled

72 = twice the base salinity

$S_{j}=$ observed salinity at depth $Z_{i}$

$z_{i}=$ depth of sample $i$

This calculation is made for each oceanographic station yielding a set of values for freshwater volume in $\mathrm{m}^{3} / \mathrm{m}^{2}$ that can be plotted and contoured as shown in Figure 33.

\section{Drift Bottle Returns}

The drift bottle returns (Figure 34 ) essentially confirm the results of Bumpus (1973). The offshore releases were within $45 \mathrm{~km}$ of the coast and not subject to the direct influence of the Gulf Stream which dominates flow at the shelf break. Thus these returns indicate the general direction of circulation of the shelf waters.

The September returns $(E-13-73)$ all indicate a southerly flow with velocities greater than $20 \mathrm{~km} /$ day. The very high return rate and consistent southern direction implies a strong coherent flow during this time.

The December 1973 release had no returns al though the release pattern was similar to the September release. 
The April 1974 returns were also sparse with only two bottles returned. They indicated a weak northerly flow.

The July 1974 returns were high with a strong northerly flow in the northern part of the Georgia Bight and a southerly flow indicated in the inshore part of the southern part of the Bight. The July data may indicate the transition from a predominant northward flow in the winter, spring and early summer to a southerly flow in later summer and fall. Apparent Oxygen Utilization

In deeper ocean waters the decomposition of plant and animal tissue produces higher concentrations of phosphate, nitrate, and silicate and reduces the amounts of oxygen present: the oxidation process consumes oxygen. The loss of oxygen is measured by subtracting the measured amount $\left(\mathrm{O}_{2}\right)$ from that which should be there if no oxidation had occurred. The amount of $\mathrm{O}_{2}$ that should be in solution is the saturation value $\left(\mathrm{O}_{2}^{\prime}\right)$ which is the amount of $\mathrm{O}_{2}$ that dissolved in seawater if that water is equilibrated with air at the observed temperature and salinity. The apparent oxygen utilization (AOU) is $0_{2}^{\prime}-O_{2}$. Since the oxygen loss (AOU) is dependent on biological oxidative processes it is proportional to the nitrate, phosphate, and silicate produced. The high AOU (low oxygen) water (Figures 35-38) usually inclined with depth as did the isotherms. These values, although low, are not in any way restrictive to biological activity. The initial oxygen concentrations are 5-6 ml $\mathrm{O}_{2} / 1$ so even an AOU of $3 \mathrm{ml} \mathrm{O}_{2} / 1$ leaves $2-3 \mathrm{ml} \mathrm{O}_{2} / 1$ in the water. While the $\mathrm{AOU}$ is an interesting parameter the oxygen anomaly is in many ways more useful. 


\section{Oxygen Anomaly}

The water flowing north in the Gulf Stream has at least two origins. One is the Florida Strait between Florida and Cuba. The second is the Antilles current which flows northward in the area east of the Bahamas. These waters have a common origin in the central north Atlantic Ocean, however, the path for some water is more circuitious than others. The waters that emerge from the Straits of Florida have spent much time in the Caribbean Sea and the Gulf of Mexico and their chemical characteristics have changed. The Gulf Stream water that traveled through the Caribbean and Gulf of Mexico has lower oxygen content than water of an identical temperature that moved in the Antilles current. The amount of this difference is the oxygen anomaly. Thus this tracer is useful to define the two water masses and was originally discussed by Rossby (1936). Since the tracer indicates water of tropical origin it is useful in the interpretation of the shelf flora and fauna which often has tropical components.

During the September cruise (E-13-73) (Figure 39) the zones of high oxygen anomaly coincided with temperatures of ca. $22^{\circ} \mathrm{C}$. In Sections I through IV the oxygen anomaly water is not abundant; however, Section $V$ shows large amounts and what appears to be two masses. This correlates with the temperature and density structure which indicates an eddy feature.

During the December cruise (E-19-73) (Figure 40) the oxygen anomaly occurs in large quantities in Section VI which coincides with high nutrient concentrations. Contrasting Section II and VI temperatures and oxygen anomaly the oxygen anomaly occurs when the isotherms tilt up steeply to the continental slope. This condition corresponds to an east position of the Gulf Stream with no eddy structures present. 
The E-3-74 data (April) (Figure 41) shows the pattern displayed previously. Where the isotherms indicate an eddy structure we find oxygen anomaly water at the shelf break.

Data from Cruise E-12-74 (July) (Figure 42) shows the most amounts of oxygen anomaly. This correlates with the eddy structure present in many of the sections (I, III, V, and VI).

The distribution of the anomaly is difficult to predict although it does correlate with the presence of eddies (isotherms tilting down to the west) and possibly with Gulf Stream positions. The important observation is the extreme variability of the position and amount of anomalous water. This could be partly due to bias induced by our discrete sampling, however we feel more is indicated. It is indicated that the amounts of various water masses vary with time in the Gulf Stream.

Summarized Horizontal Effect of Runoff and Intrusions.

The offshore extent of runoff and the onshore extent of intrusions were determined from all the data to see if a pattern exists. The composite data (Figures 43-46) for the four cruises are summarized in Table 2. Runoff averages $56 \mathrm{~km}$ offshore in the north but less than $3 \mathrm{~km}$ in the south. Conversely intrusions extend onshore an average of $20 \mathrm{~km}$ but extend much further onshore in the south than the northern part of the area.

The Ranges of Temperature

The annual range in water temperature is important since it will effect animal growth rates or, in extreme cases, the survival rate. While the nearshore waters have an annual range of $12.3^{\circ} \mathrm{C}$ the offshore surface waters have an average range of $6.4^{\circ} \mathrm{C}$ and the shelf break bottom waters an annual range of $4.2^{\circ} \mathrm{C}$. This results from the influence 
TABLE 2

Average offshore extent of runoff

\begin{tabular}{|c|c|c|c|}
\hline Section & I & $56.5 \pm 33.3$ & $n=4$ \\
\hline & II & $42.3 \pm 23.6$ & $n=4$ \\
\hline & III & $33.8 \pm 15.0$ & $n=4$ \\
\hline & IV & $37.8 \pm 23.0$ & $n=4$ \\
\hline & v & $19.5 \pm 1.3$ & $n=4$ \\
\hline & VI & $2.7 \pm 4.6$ & $n=3$ \\
\hline Average for all sections & & $33.4 \pm 24.7 \mathrm{~km}$ & $n=23$ \\
\hline $\begin{array}{c}\text { Average inshore extent of } \\
\text { intrusions }\end{array}$ & & & \\
\hline Section & I & $15.5 \pm 17.2$ & $n=4$ \\
\hline & I I & $12.8 \pm 10.5$ & $n=4$ \\
\hline & II I & $27.3 \pm 9.5$ & $n=4$ \\
\hline & IV & $11.5 \pm 1.3$ & $n=4$ \\
\hline & v & $13.5 \pm 13.4$ & $n=4$ \\
\hline & VI & $40.0 \pm 30.8$ & $n=3$ \\
\hline Average for all sections & & $19.2 \pm 16.6 \mathrm{~km}$ & $n=23$ \\
\hline
\end{tabular}


of the Gulf Stream. The nearshore waters are subject to extreme cooling and heating causing the large annual range. The offshore surface waters, while also subject to seasonal heating and cooling are moderated by the consistently warm Gulf Stream waters. The deep waters offshore are not subject to atmospheric cooling or heating; but only minor variations caused by Gulf Stream meandering.

These results are important to fisheries since many tropical species cannot tolerate the large temperature ranges observed in the nearshore waters. However they can tolerate the minor temperature ranges in the deeper waters at the shelf break.

\section{T-S Relationship}

The relationship of temperature to salinity, a T-S plot, is a standard oceanographic procedure used to analyze data. In the central oceans the TS plot is very characteristic for each ocean and each depth in that ocean (i.e., water of $10^{\circ} \mathrm{C}$ always has a salinity of about $\left.35.0^{\circ} / 00\right)$. The relationship is very predictable for subsurface waters. However, surface waters can easily change temperature because of atmospheric conditions, and the salinity may change as a result of runoff, rain, or evaporation. Therefore, while the T-S relationship of deeper waters such as the deeper Gulf Stream waters is constant, the T-S relationship of Georgia shelf waters is quite variable depending on the season. Figure 47 shows the T-S plots for the four cruises.

The early winter cruise is a time of minimum temperatures and low runoff, consequently observed temperatures were at a minimum and salinities were relatively high.

During April 1974, which is during the high runoff and warming season, higher temperatures were observed and the lowest salinities of any cruise. 
In July 1974, during a period of highest temperatures and decreasing runoff, higher temperatures were observed and lower salinities than in September 1973 when runoff is lower.

The T-S relationship of shelf water closely reflects the runoff and air temperature. That relationship is shown in the following schematic (Figure 48). This diagram was made by taking the minimum observed salinities and temperature for the four cruises, plotting them (heavy dots) and then connecting the dots. This represents the seasonal cycle of salinity and temperature in the nearshore zone for the whole coast. The pattern reflects the combined effect of seasonally varying temperatures and runoff that peaks in the late winter and again in the late summer. Thus from January to April the water continues to warm, but the runoff decreases causing salinity to increase. From July to September the temperatures stabilize while runoff increases, decreasing the salinity. Finally, from 0ctober to December the temperature decreases, because of lowering air temperature, while salinity increases because of decreased runoff. This is caused by the subtropical runoff pattern: the runoff pattern in most temperate areas is unimodal. Nitrate-Phosphate-Silicate-Temperature Relationships

The various relationships between nitrate, phosphate, silicate and temperature are useful to confirm the quality of the data and to elucidate some of the chemical, biological, and physical processes at work.

The ratio between nitrate and phosphate concentrations in deeper water is usually $16: 1$. This results from the $16: 1$ ratio of $N$ to $P$ in phytoplankton tissue. The subsequent bacterial mineralization of this tissue in deep water produces the observed 16:1 ratio. All of our 
nitrate-phosphate data is plotted in Figure 49. The theoretical 16 to 1 line is also shown. Note that at low concentrations there is usually excess phosphate with respect to nitrate. These samples are from shallow areas where nitrate is consumed and not quickly released while phosphate is quickly released.

The plot of nitrate vs AOU (apparent oxygen utilization; Figure 50) demonstrates that nitrate is produced at the expense of oxygen: an oxidation/reduction reaction.

Since all nutrient concentrations generally increase with depth and temperature decreases one may expect a relationship between these parameters. Figure 51 shows a nitrate-temperature plot of all of our data. At lower temperatures the relationship is very consistent and essentially allows one to predict nitrate given the water temperature. 


\section{CONCLUSIONS}

The preceding data presentation and discussions make many points. It should be apparent that many things about the Georgia Bight are predictable. Temperature-salinity relationships and patterns are consistent and reasonably predictable as are the nutrient relationships. Knowledge of the processes that control these is where we fall short. Intrusions, although easily recognized, are not understood. We do not know to what extent they occur or how often. The distribution of freshwater in the offshore waters is also easily detected but we do not understand the forces that disperse the waters and produce the distribution we observe.

The understanding of these processes is more important in many cases than knowing the distribution of some compound resulting from the process. We must know the process if we are to make reasonable judgments concerning the effects of man's activities on the ocean system. 


\section{REFERENCES}

Atkinson, L. P., Oceanographic observations in the Georgia Bight, R/V EASTWARD cruises E-13-73 and E-19-73. Georgia Marine Science Center Technical Report 75-6, 1975.

Atkinson, L. P., Oceanographic observations in the Georgia Bight, R/V EASTWARD cruises E-3-74 and E-12-74. Georgia Marine Science Center Technical Report 76-1, 1976.

Atkinson, L. P. and D. Wallace, The source of unusually low surface salinities in the Gulf Stream off Georgia. Deep-Sea Res., 29:913$916,1975$.

Bumpus, D. F., A description of the circulation on the continental shelf of the east coast of the United States, in Progress in Oceanography, Vol. 6., 1973.

Rossby, C.-G., Dynamics of steady ocean currents in the light of experimental fluid dynamics. Papers in Physical Oceanog. and Meterol., 5(1), 1936. 
FIGURES 


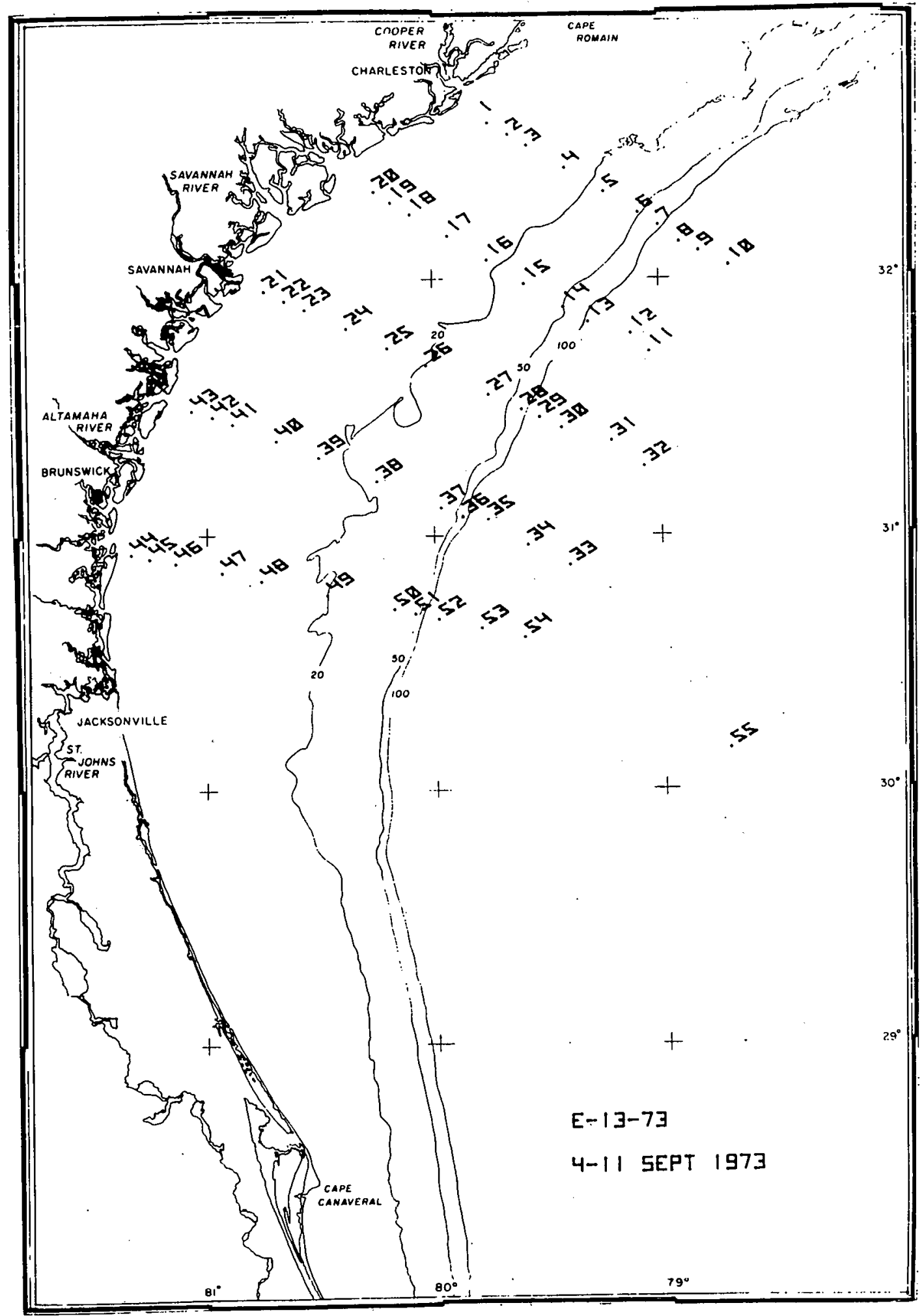

Figure 1. Station locations, Cruise E-13-73 


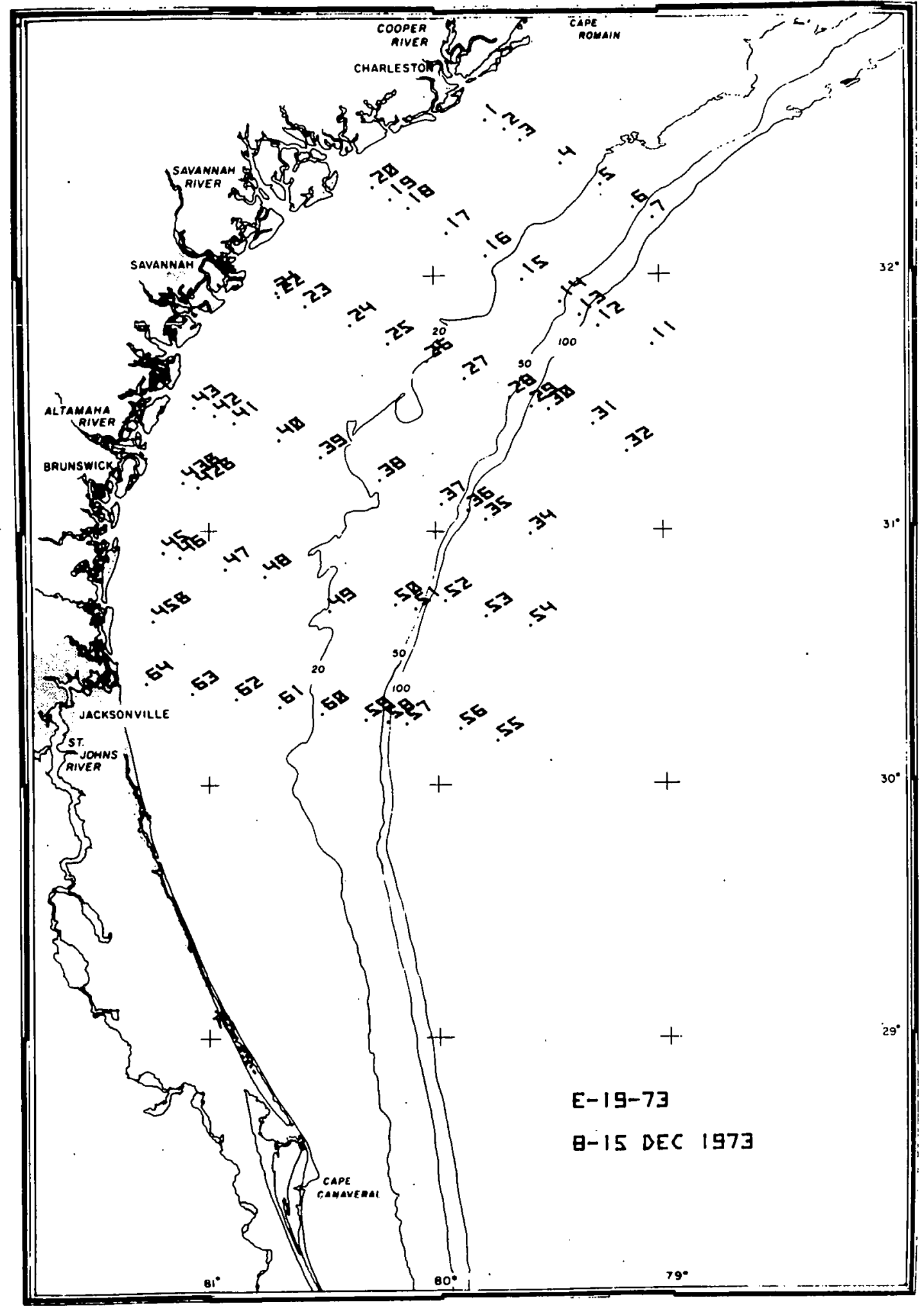

Figure 2. Station Locations, Cruise E-19-73 


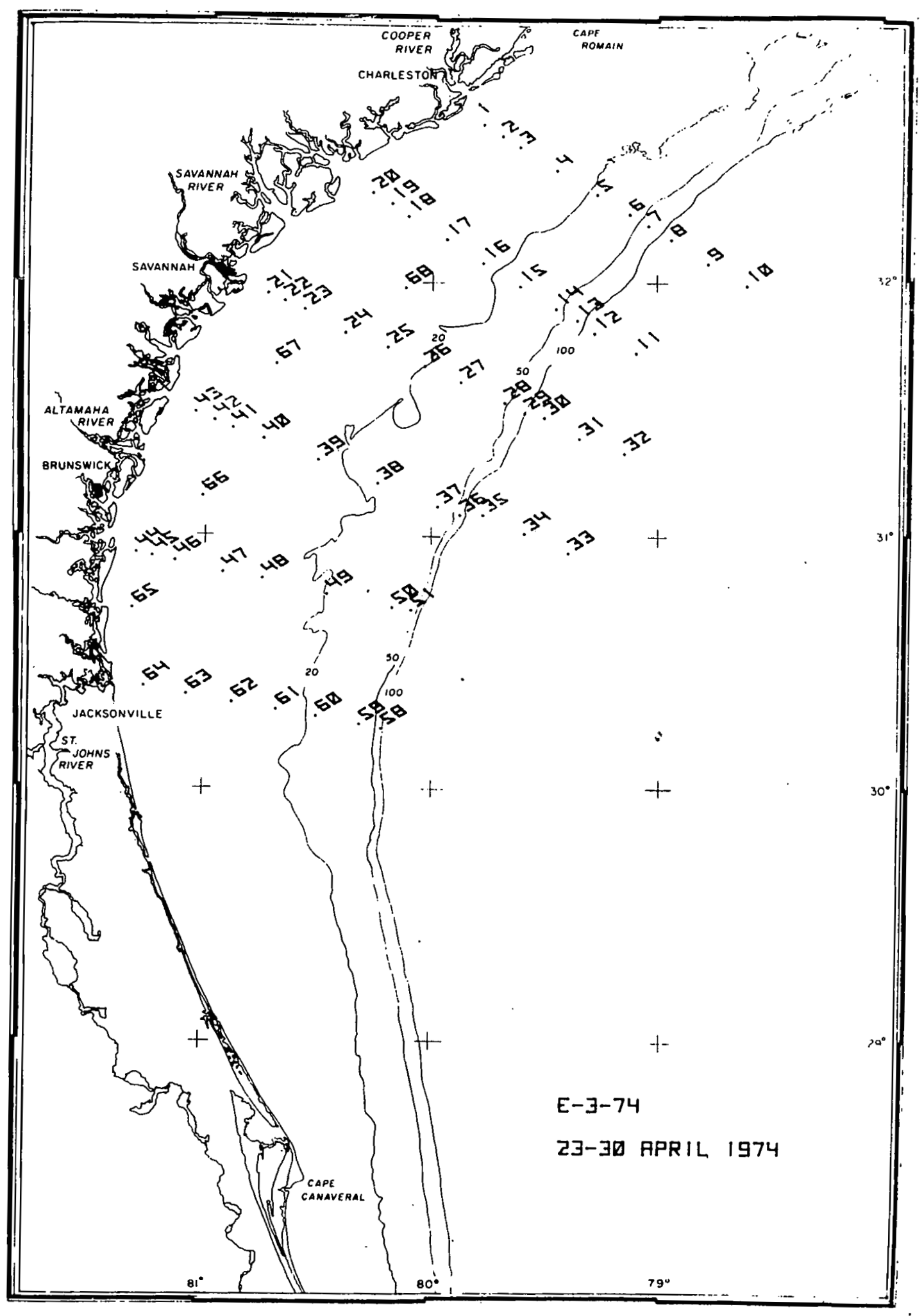

Figure 3. Station Locations, Cruise E-3-74 


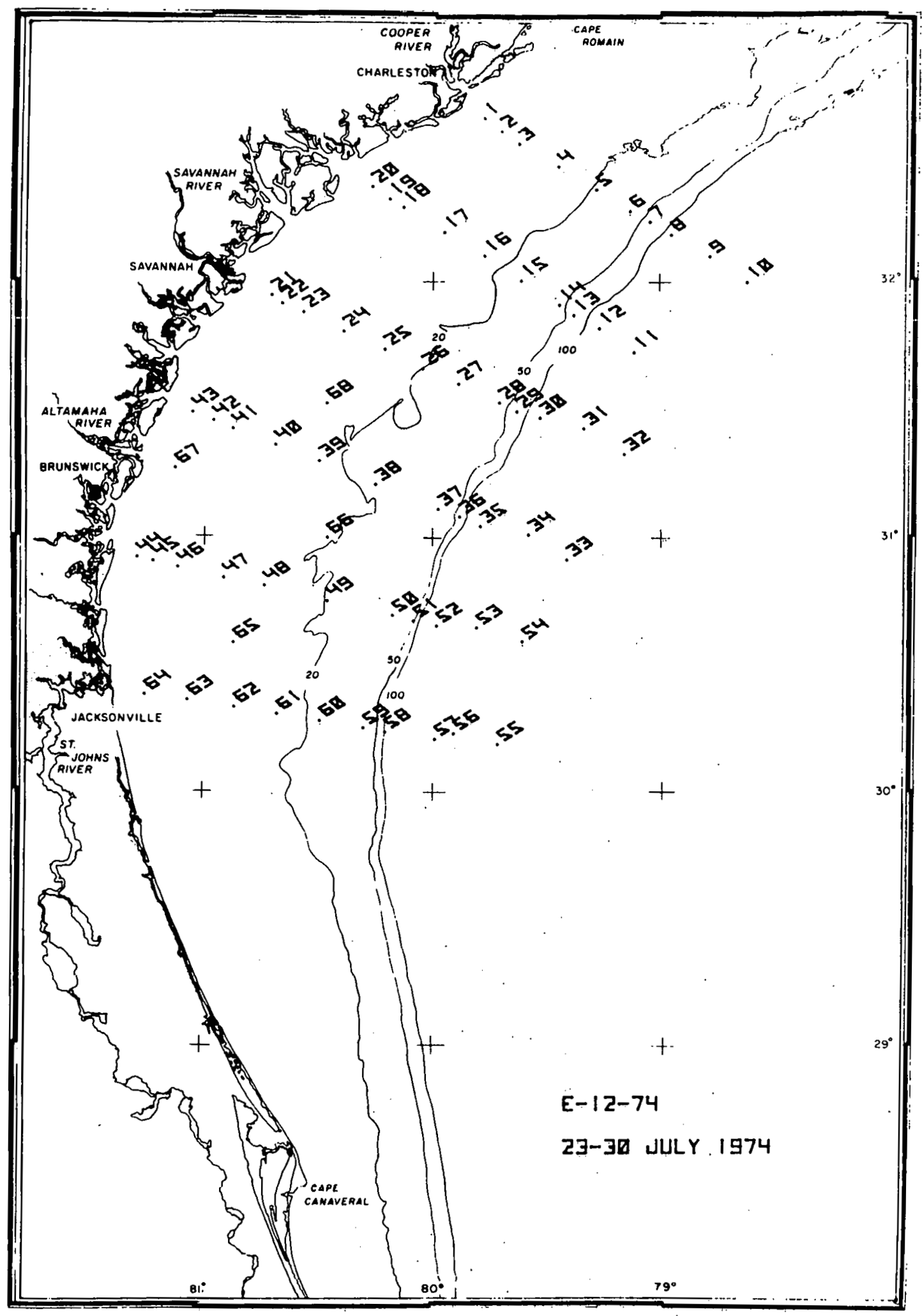

Figure 4. Station Locations, Cruise E-12-74 

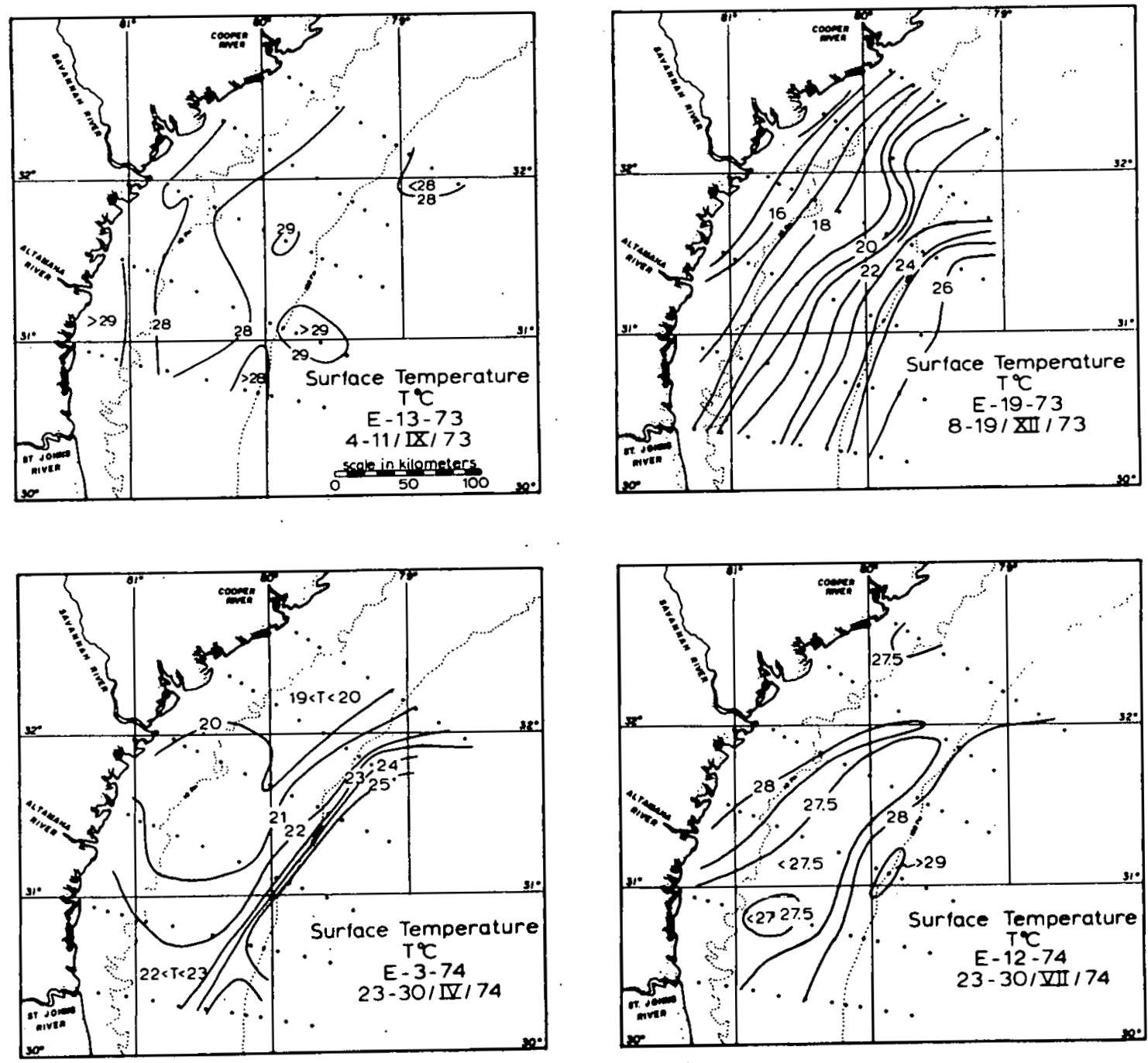

Figure 5. Surface Temperature 

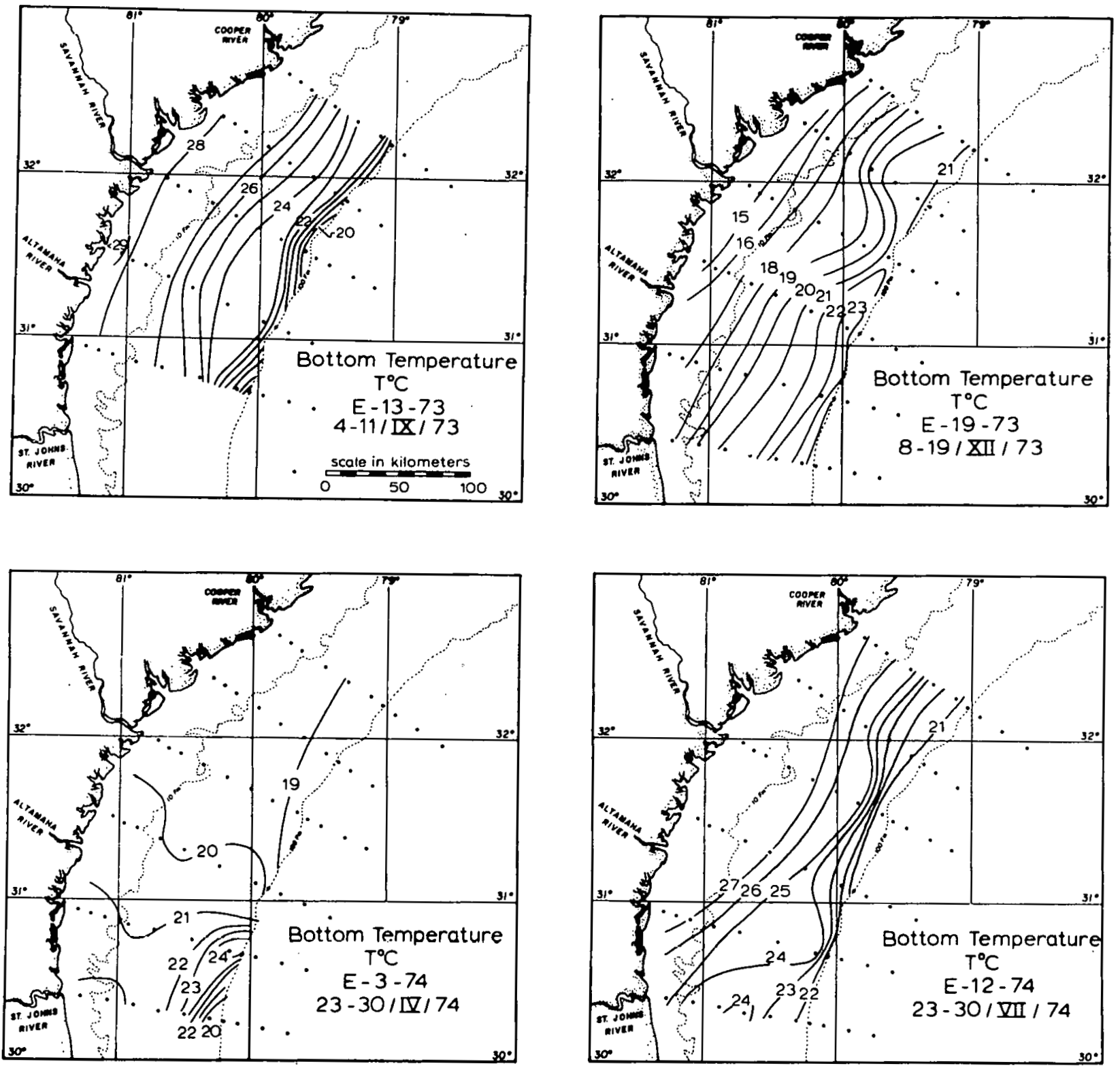

Figure 6. Bottom Temperature 

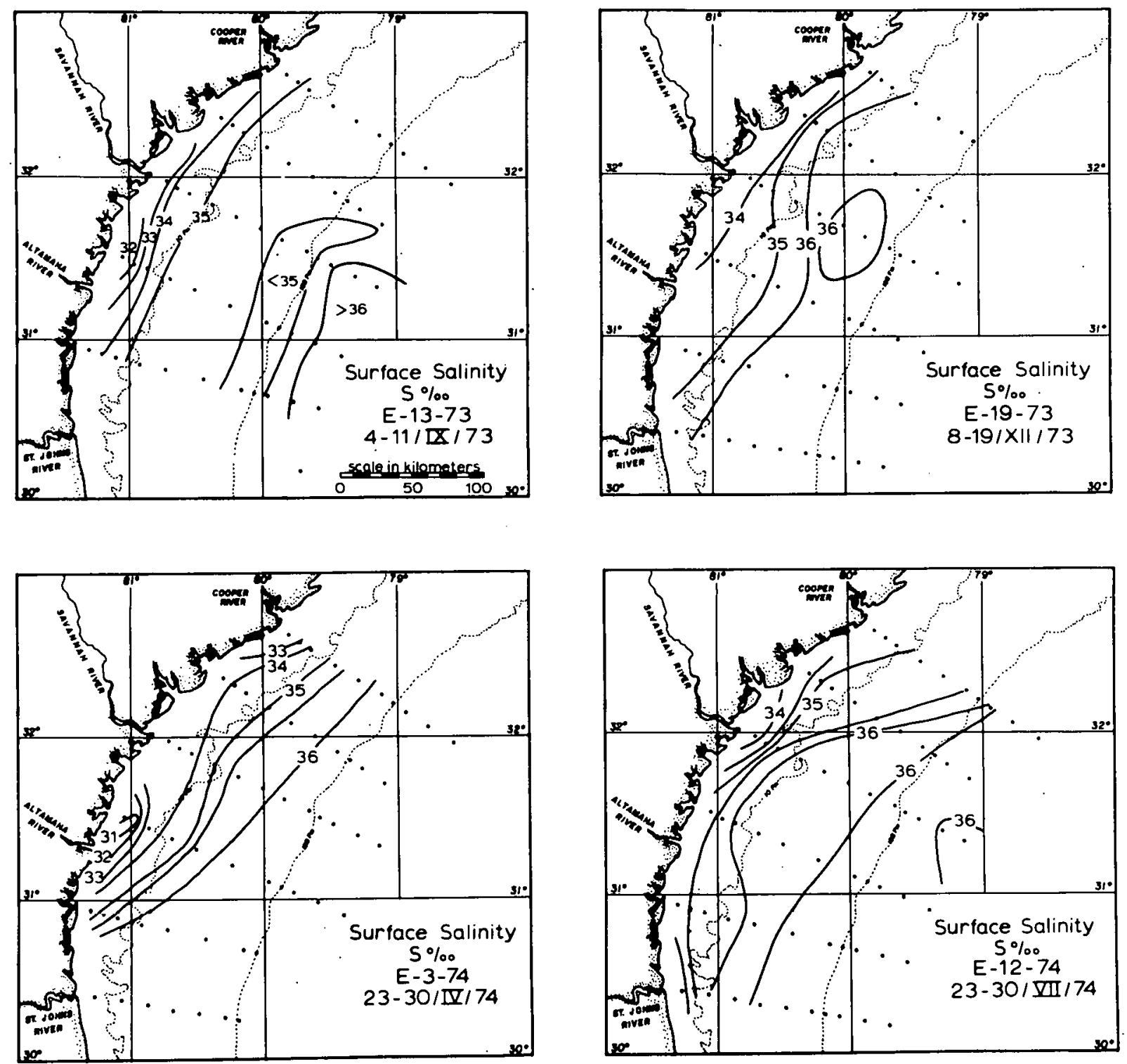

Figure 7. Surface Salinity 

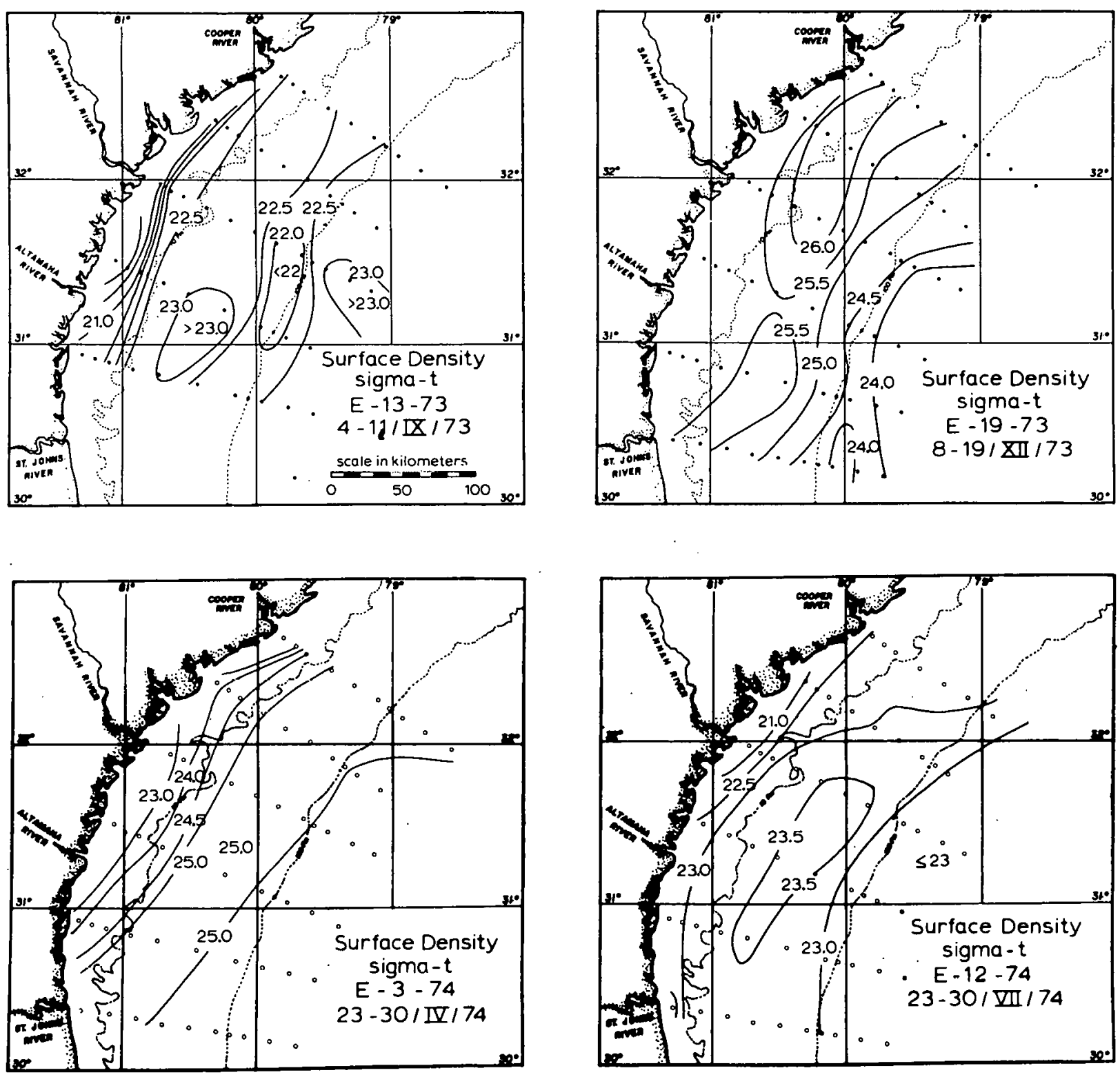

Figure 8. Surface Density 

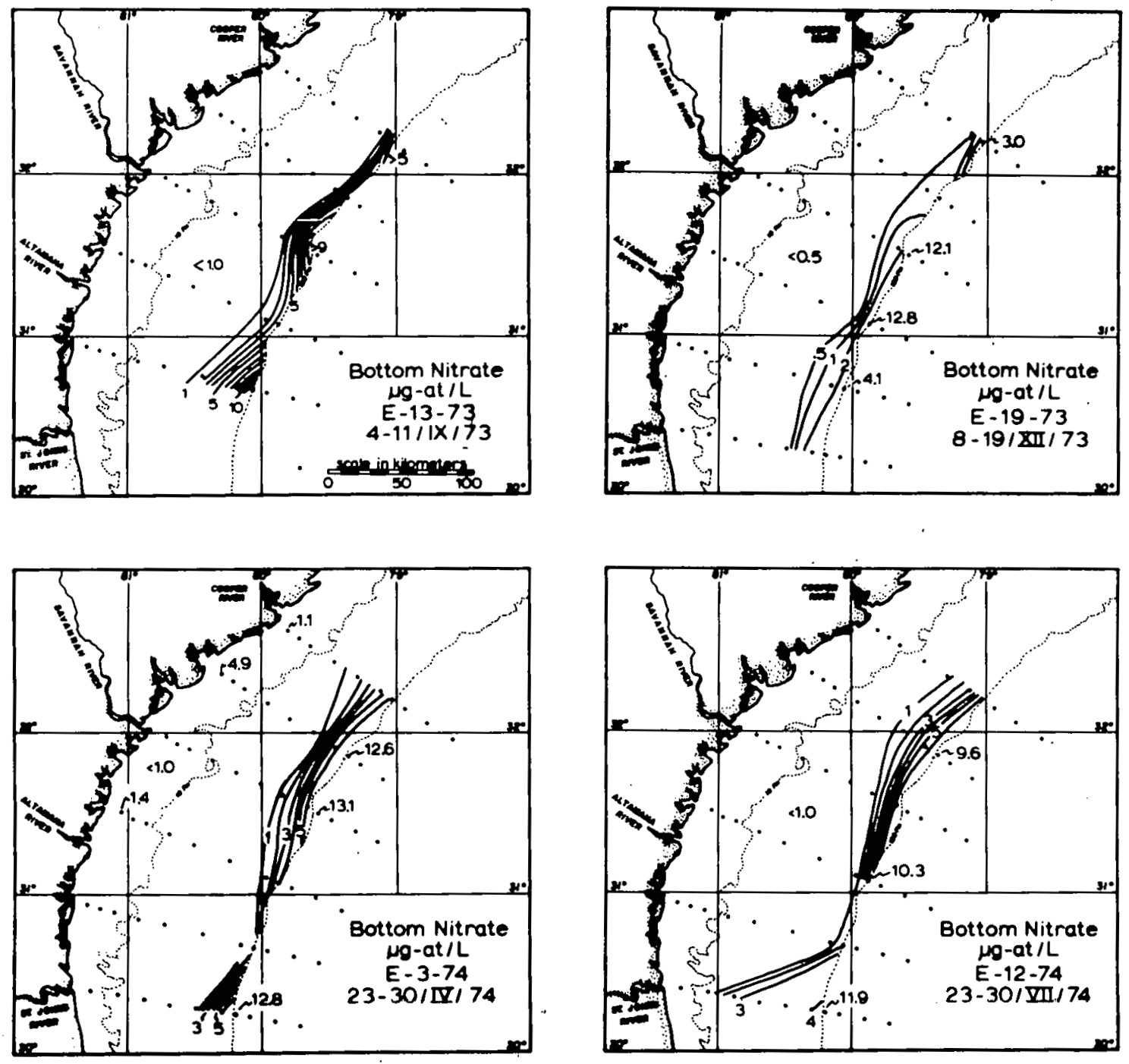

Figure 9. Bottom Nitrate 

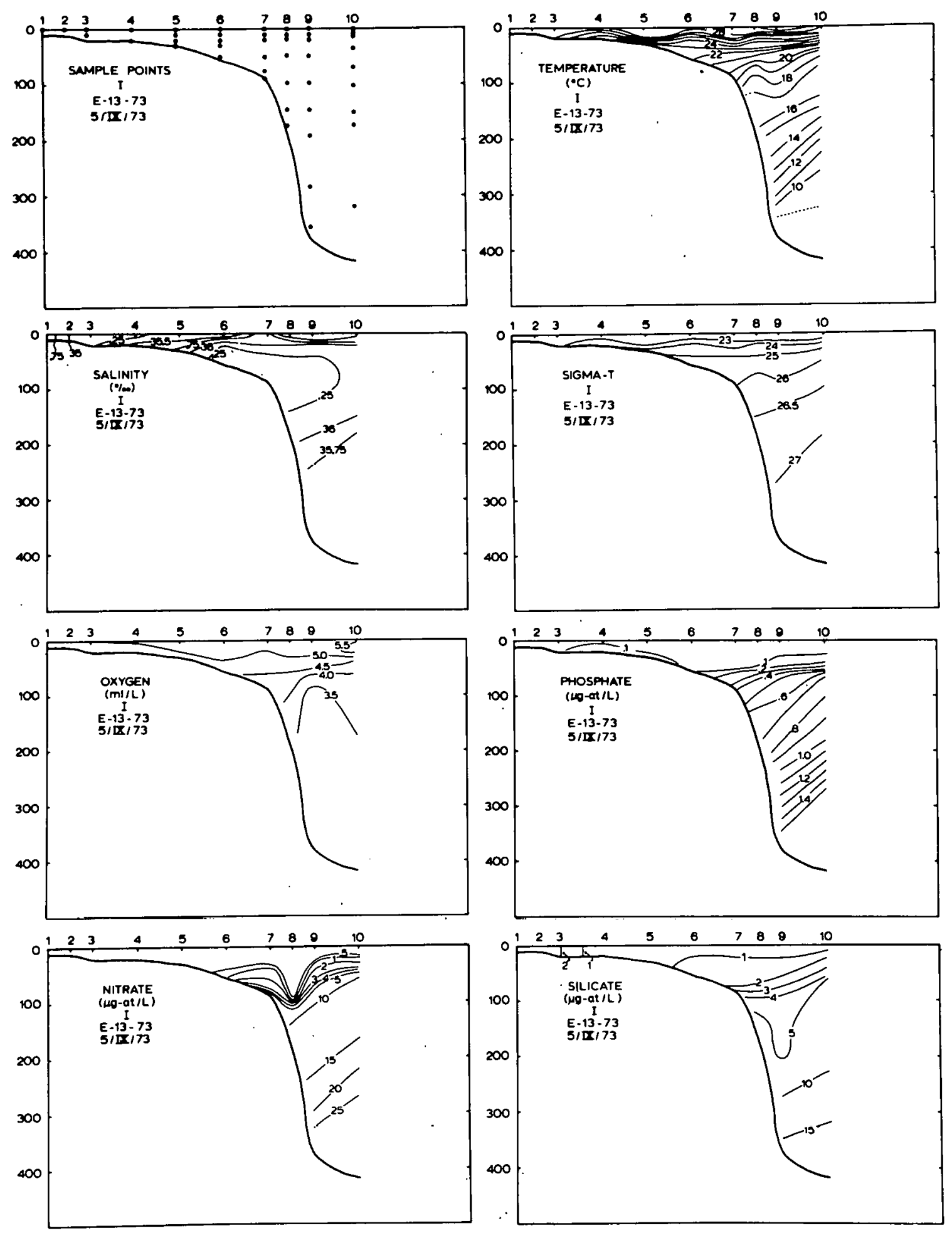

Figure 10. Vertical Section, Cruise E-13-73, Section I 

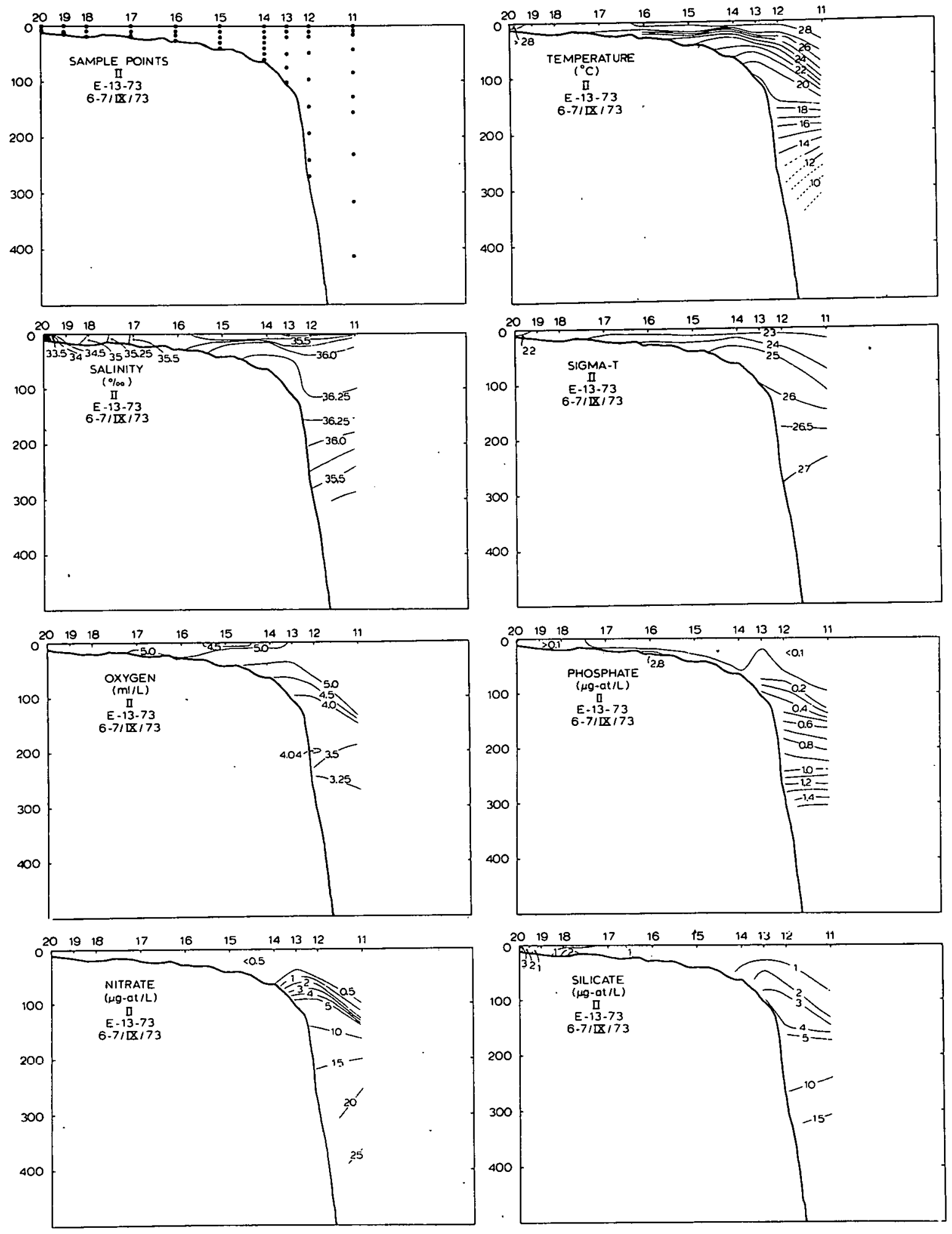

Figure 11. Vertical Section, Cruise E-13-73, Section II 

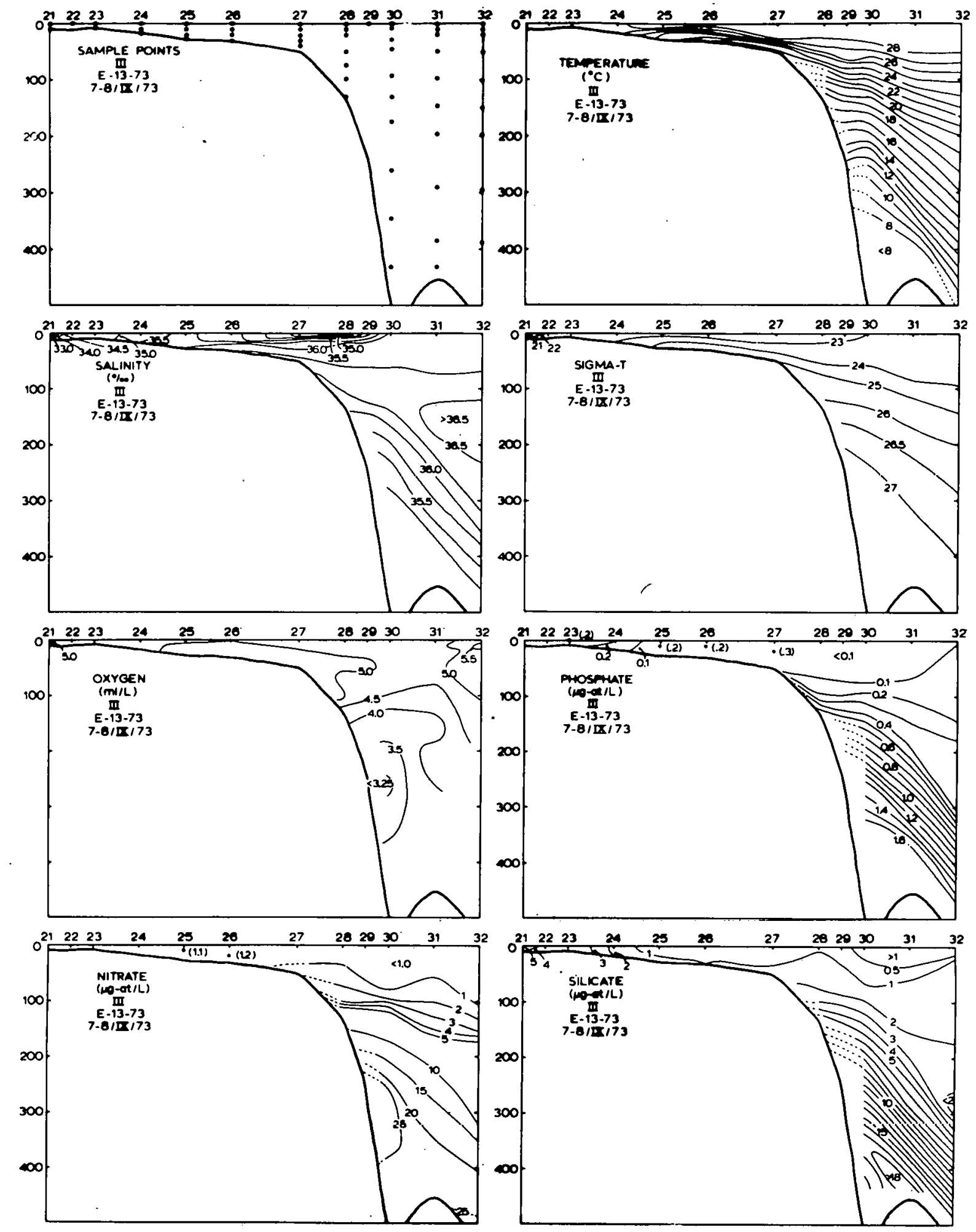

Figure 12. Vertical Section, Cruise E-13-73, Section III 


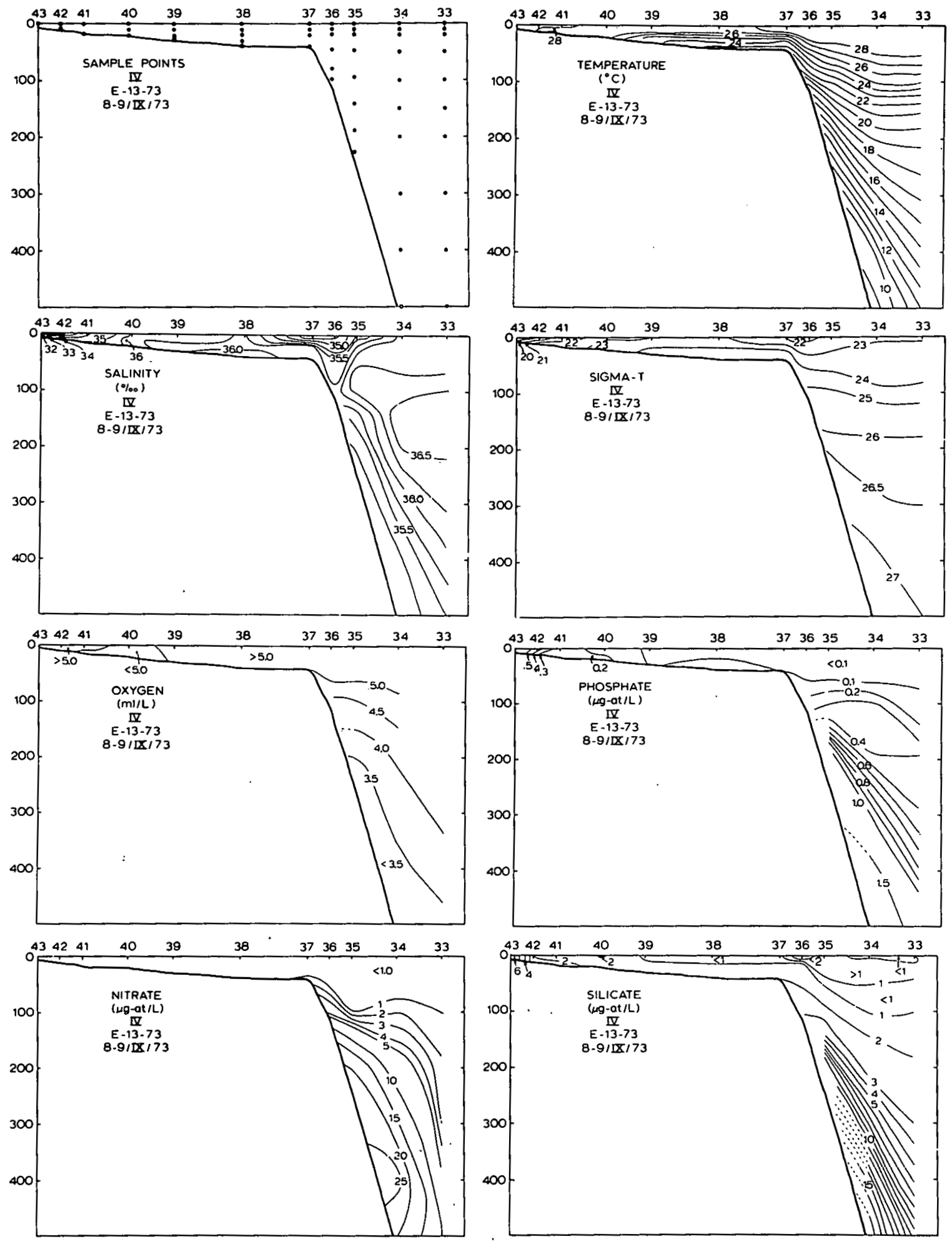

Figure 13. Vertical Section, Cruise E-13-73, Section IV 


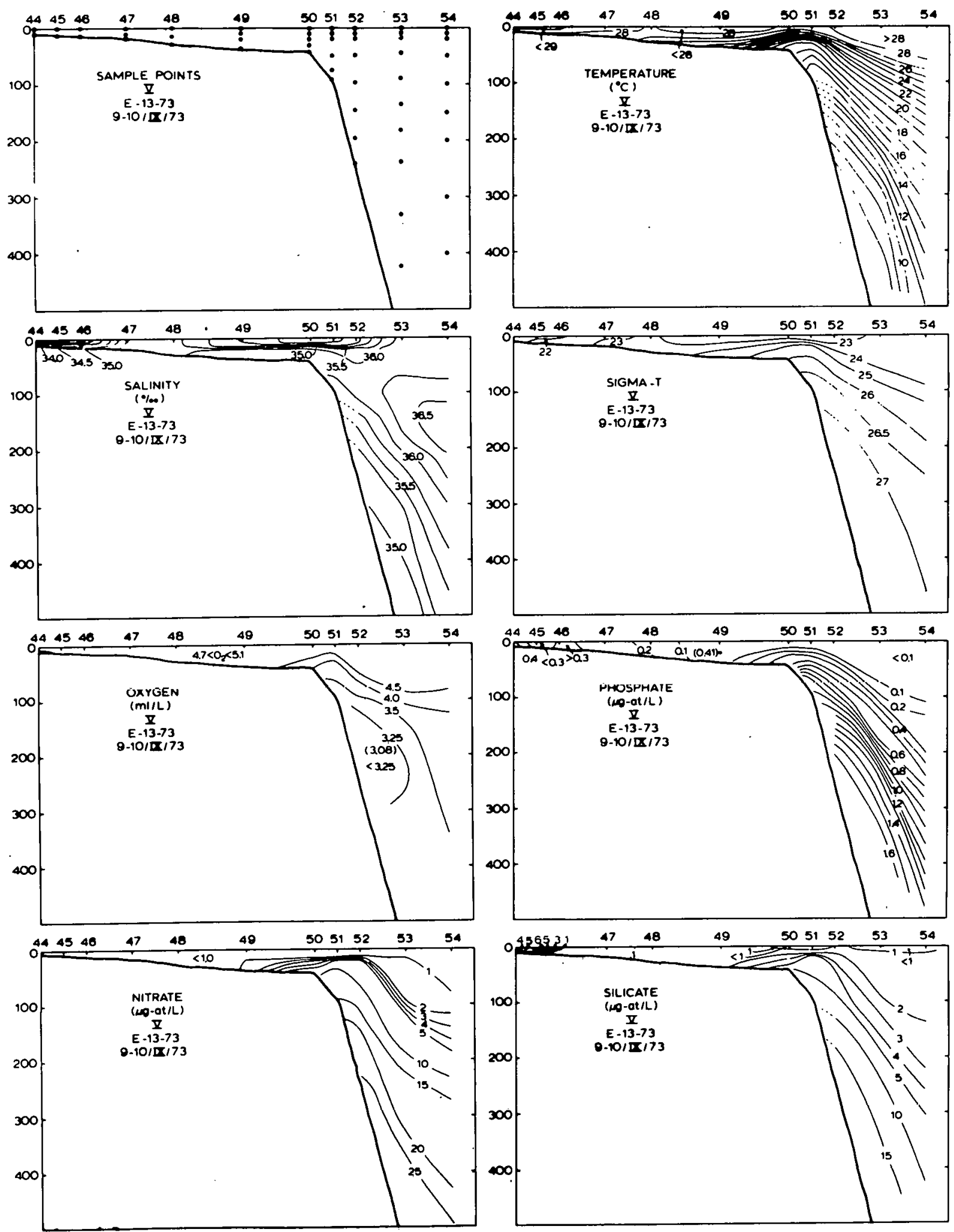

Figure 14. Vertical Section, Cruise E-13-73, Section V 

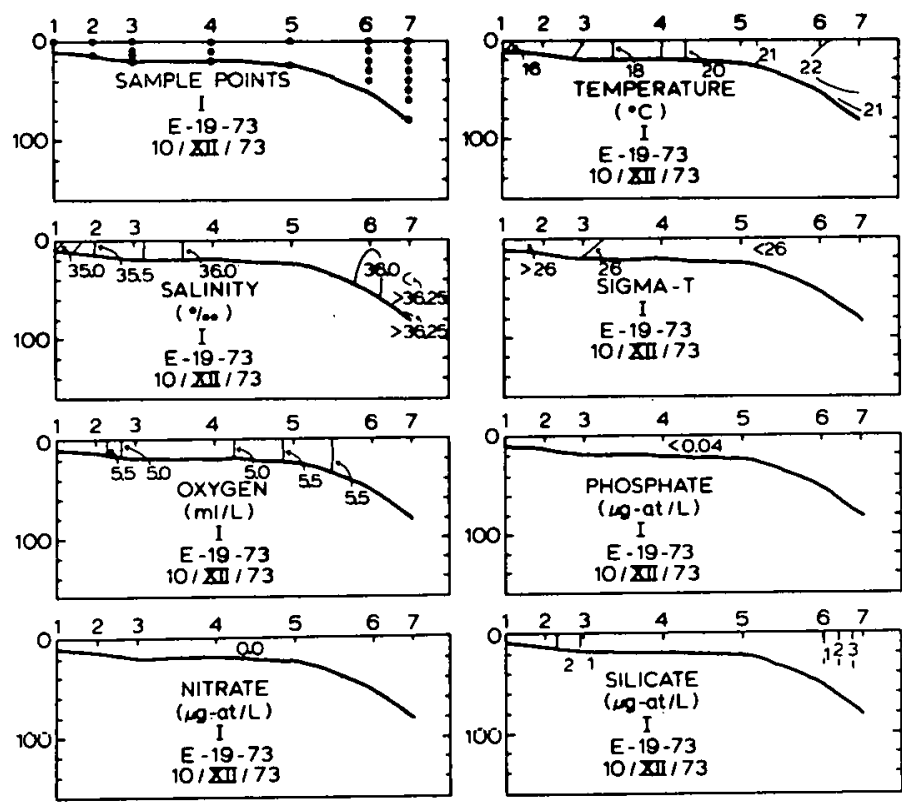

Figure 15. Vertical Section, Cruise E-19-73, Section I 

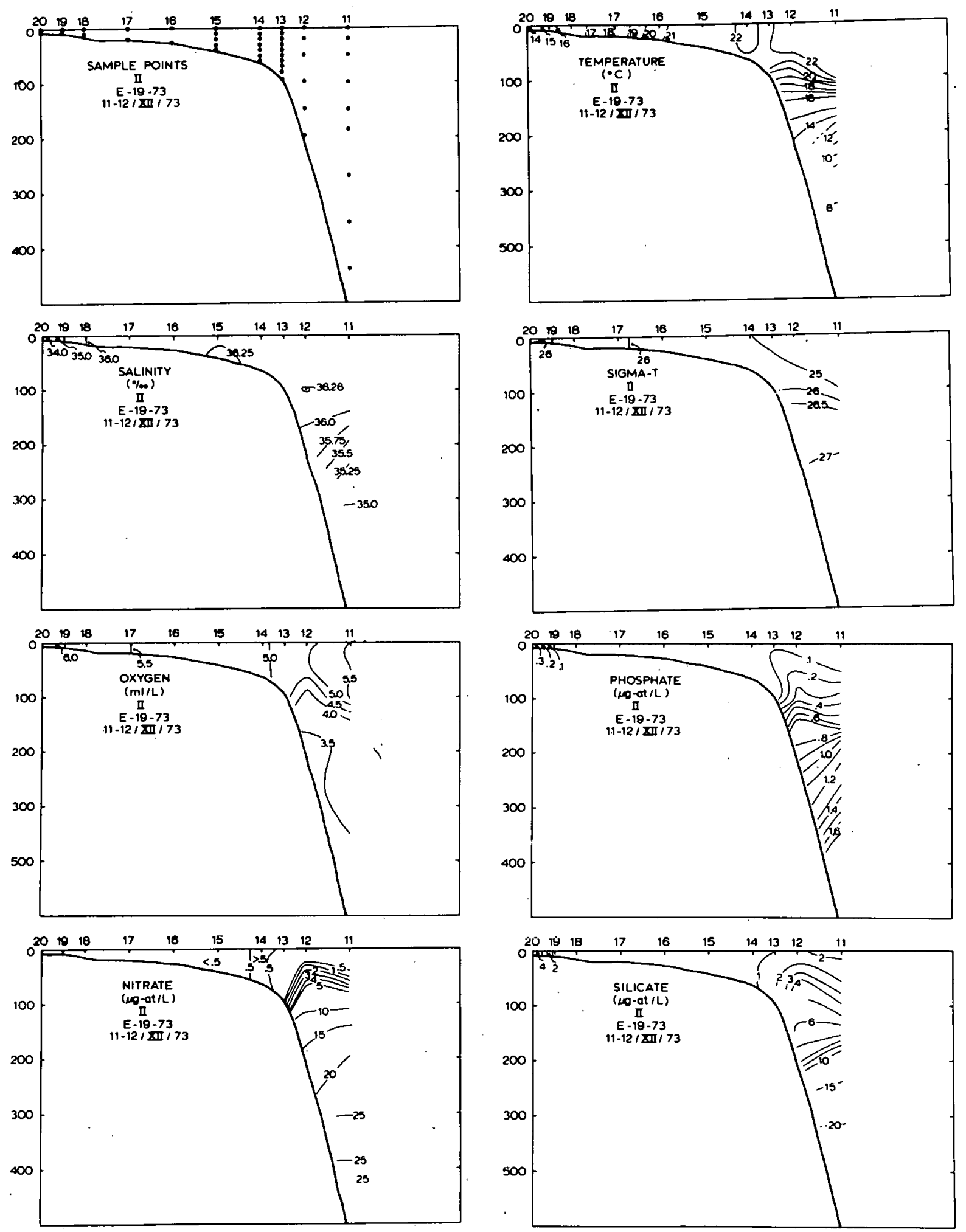

Figure 16. Vertical Section, Cruise E-19-73, Section II 

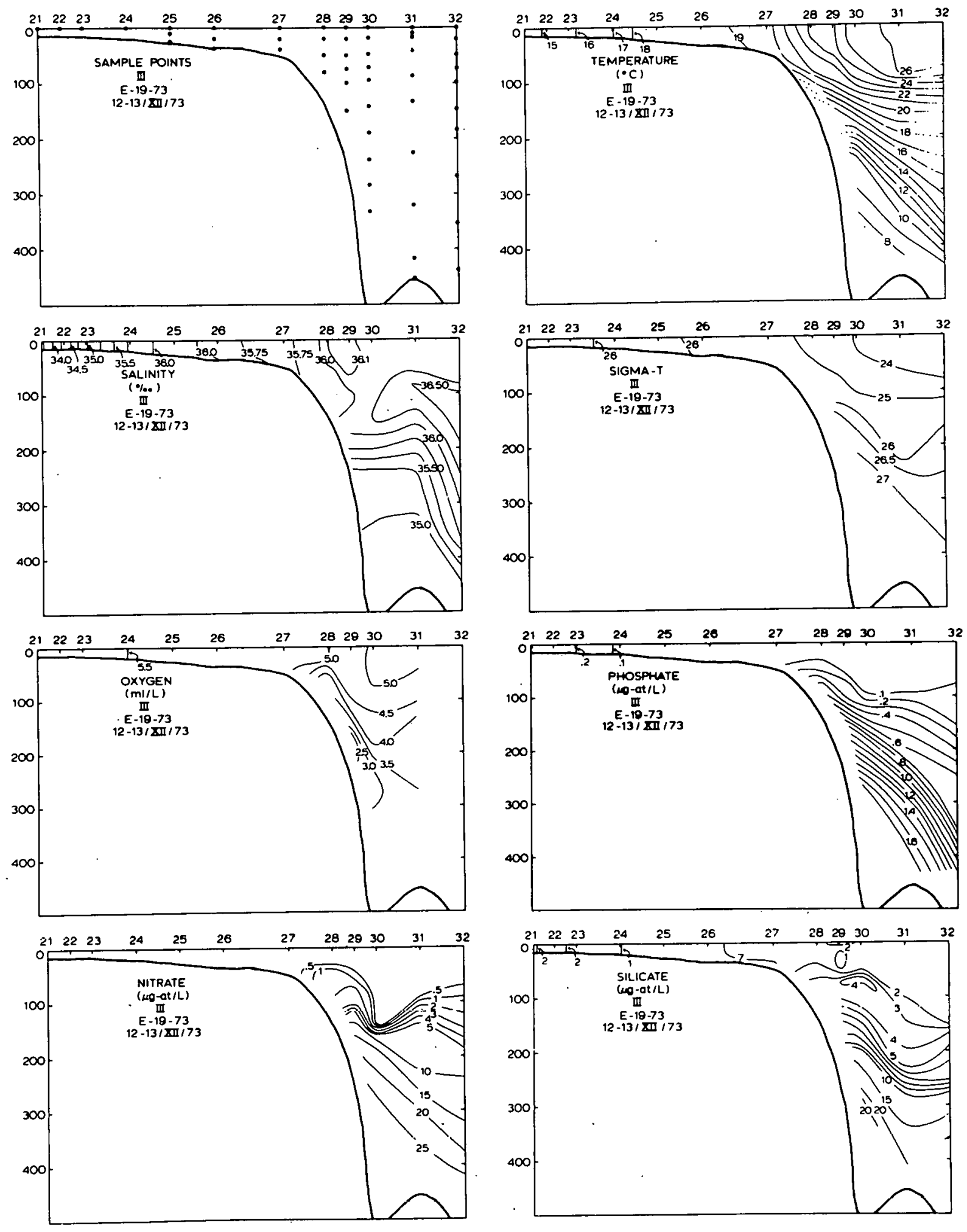

Figure 17. Vertical Section, Cruise E-19-73, Section III 

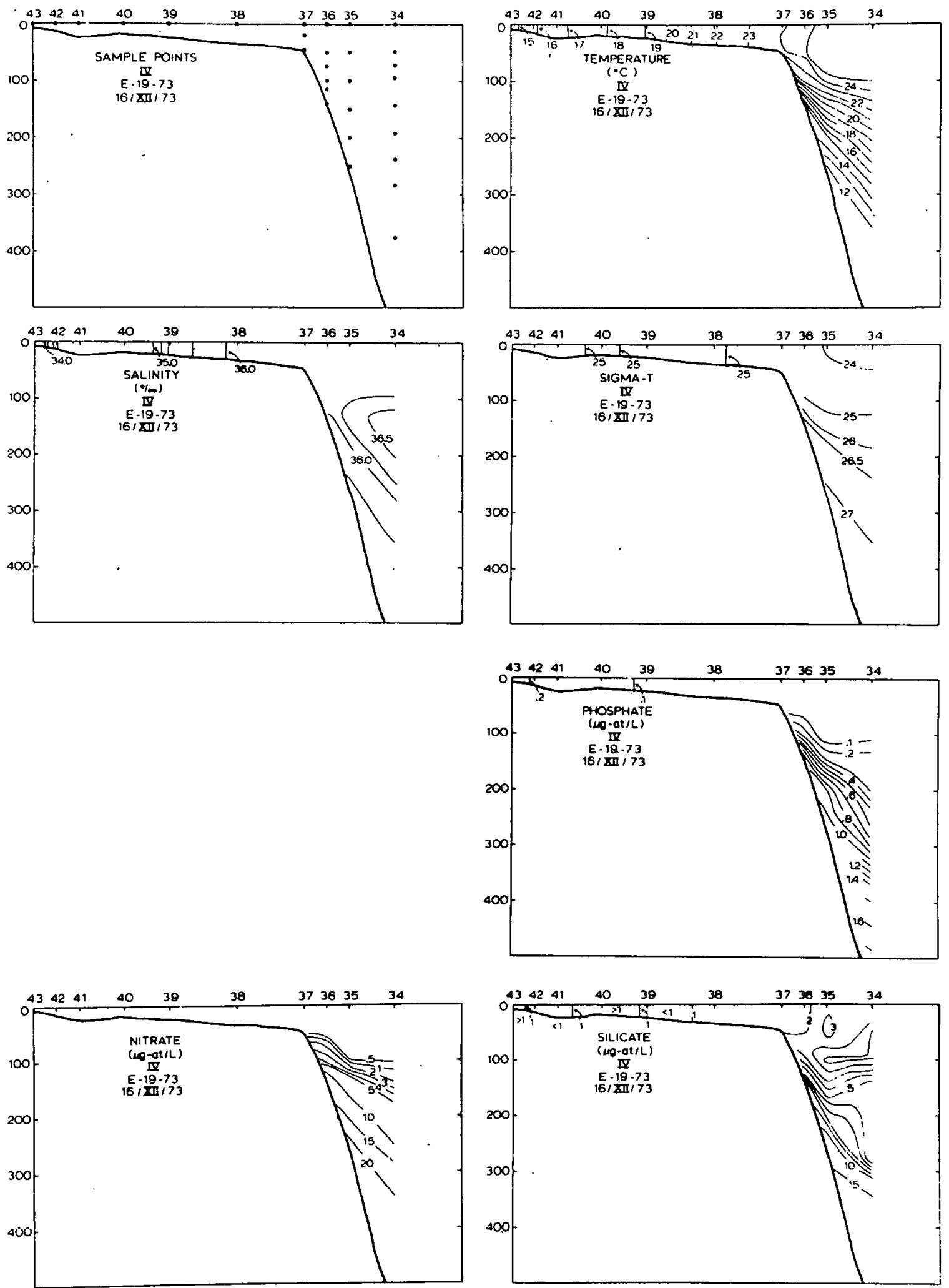

Figure 18. Vertical Section, Cruise E-19-73, Section IV 

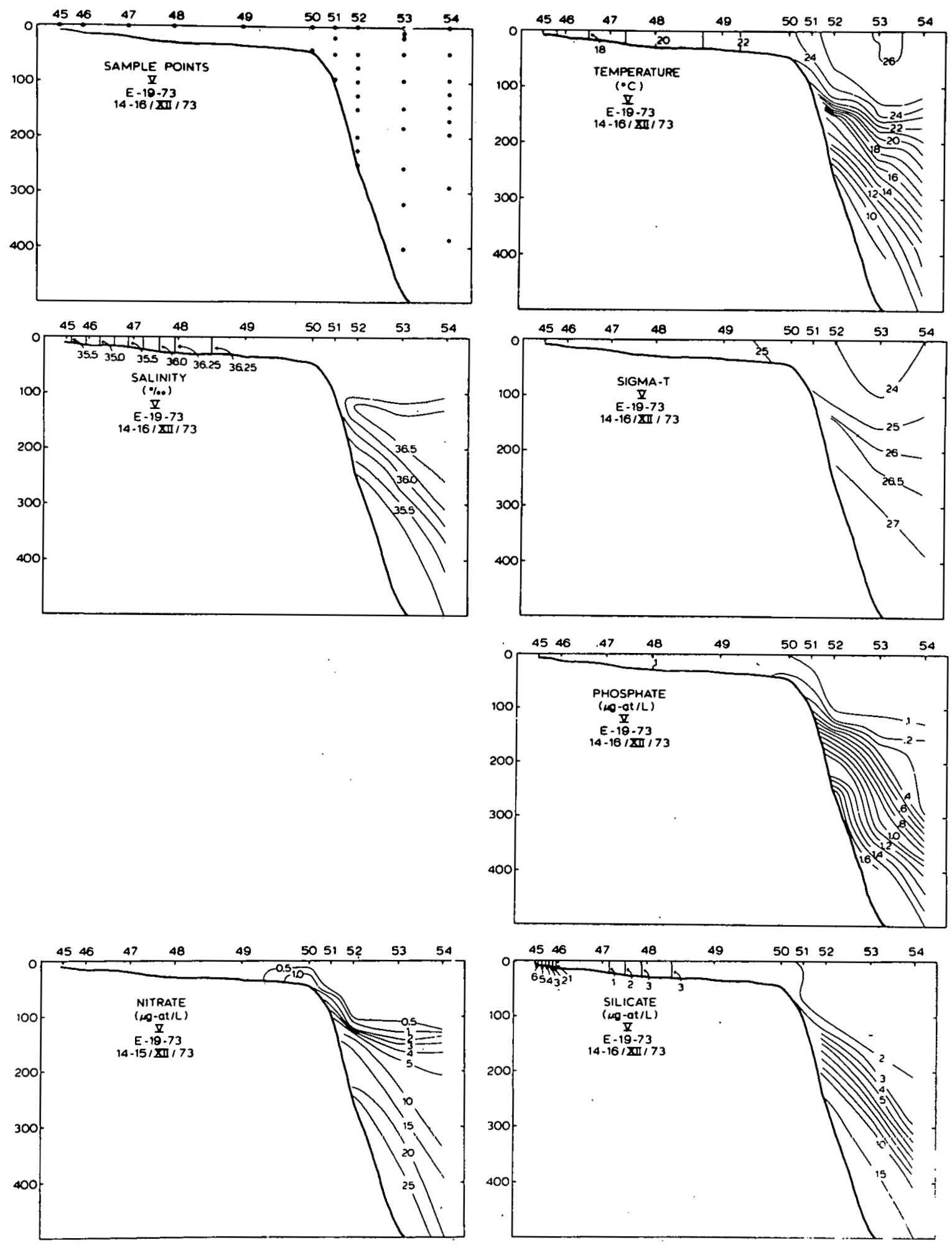

Figure 19. Vertical Section, Cruise E-19-73, Section V 

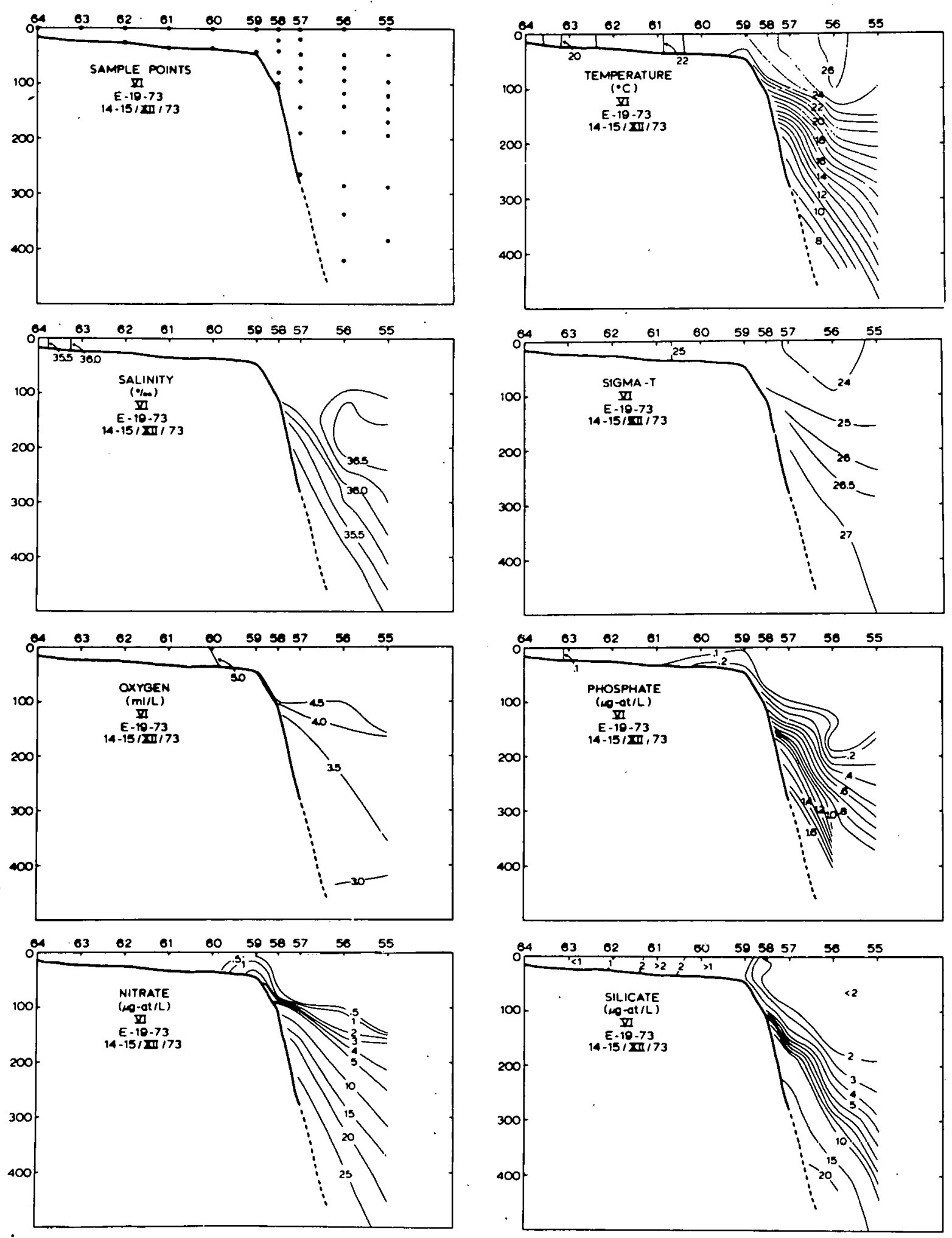

Figure 20. Vertical Section, Cruise E-19-73, Section VI 

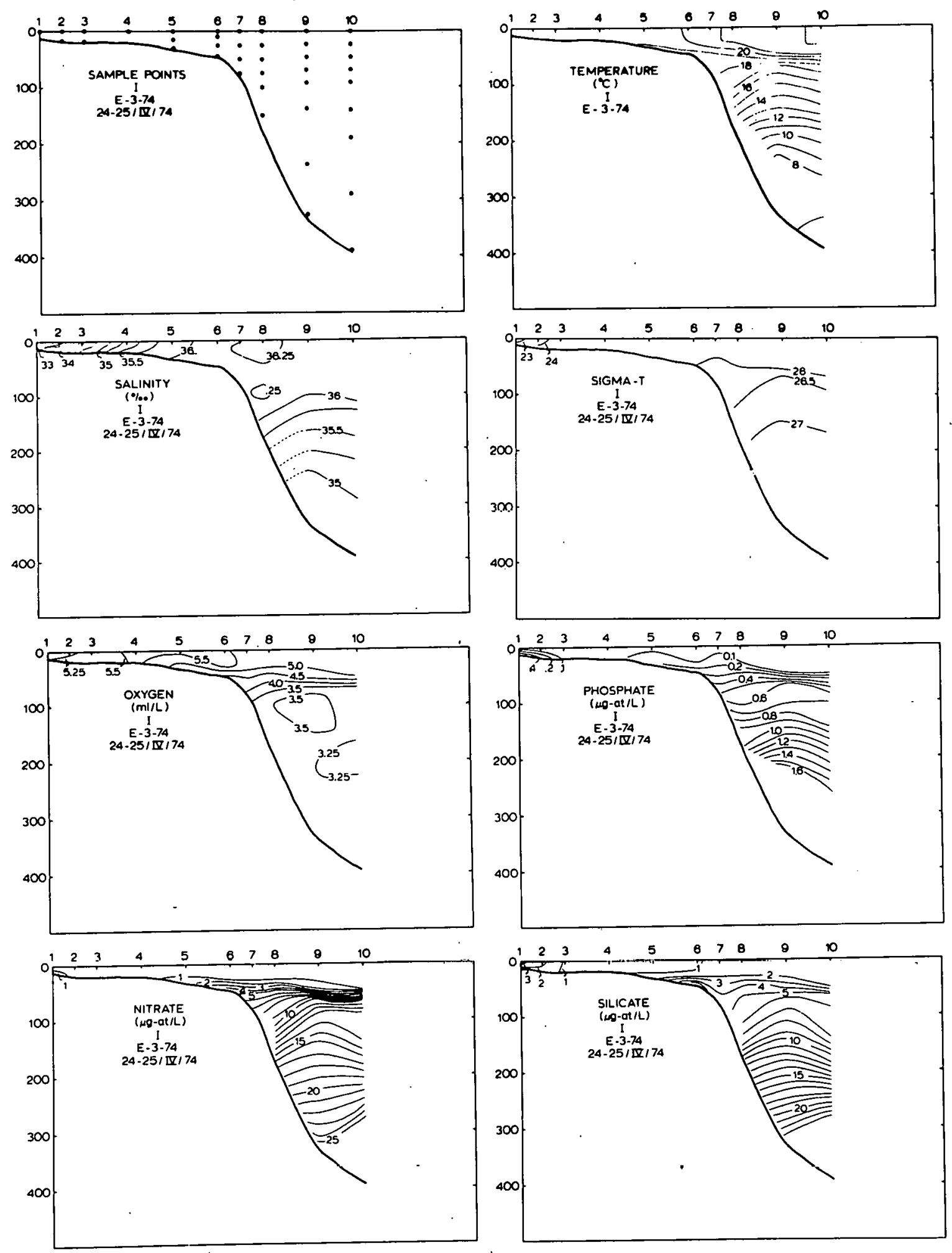

Figure 21. Vertical Section, Cruise E-3-74, Section I 

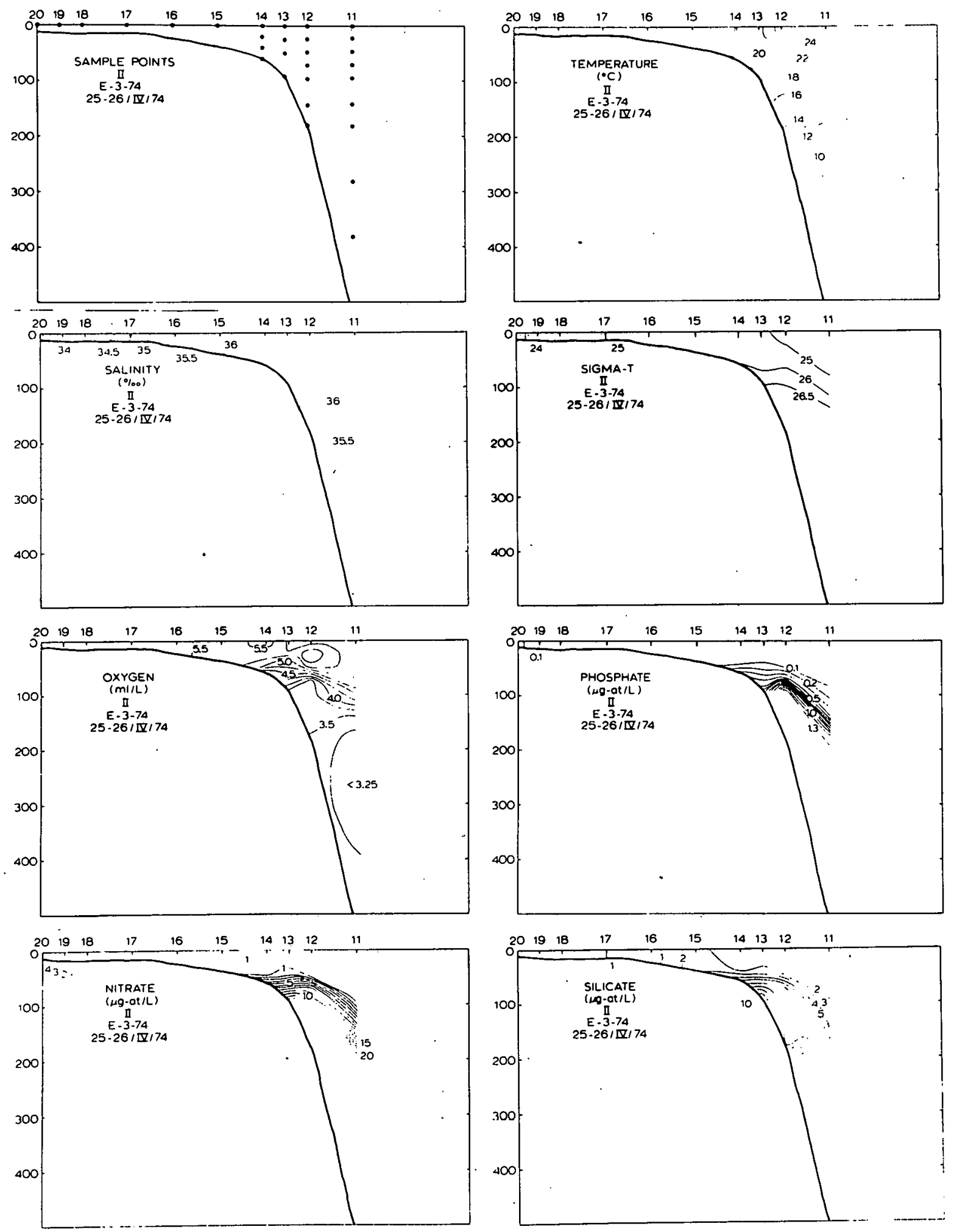

Figure 22. Vertical Section, Cruise E-3-74, Section II 

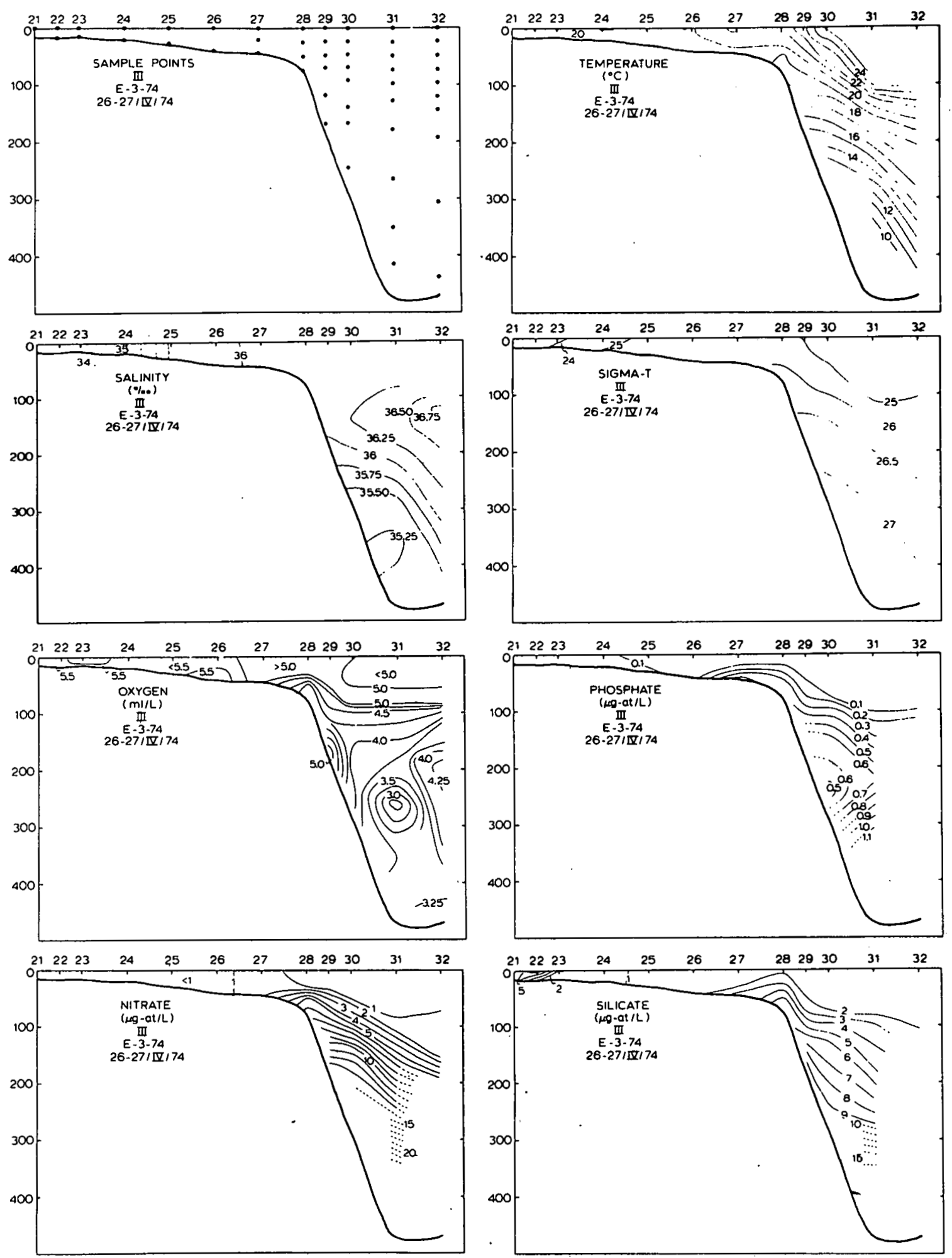

Figure 23. Vertical Section, Cruise E-3-74, Section III 

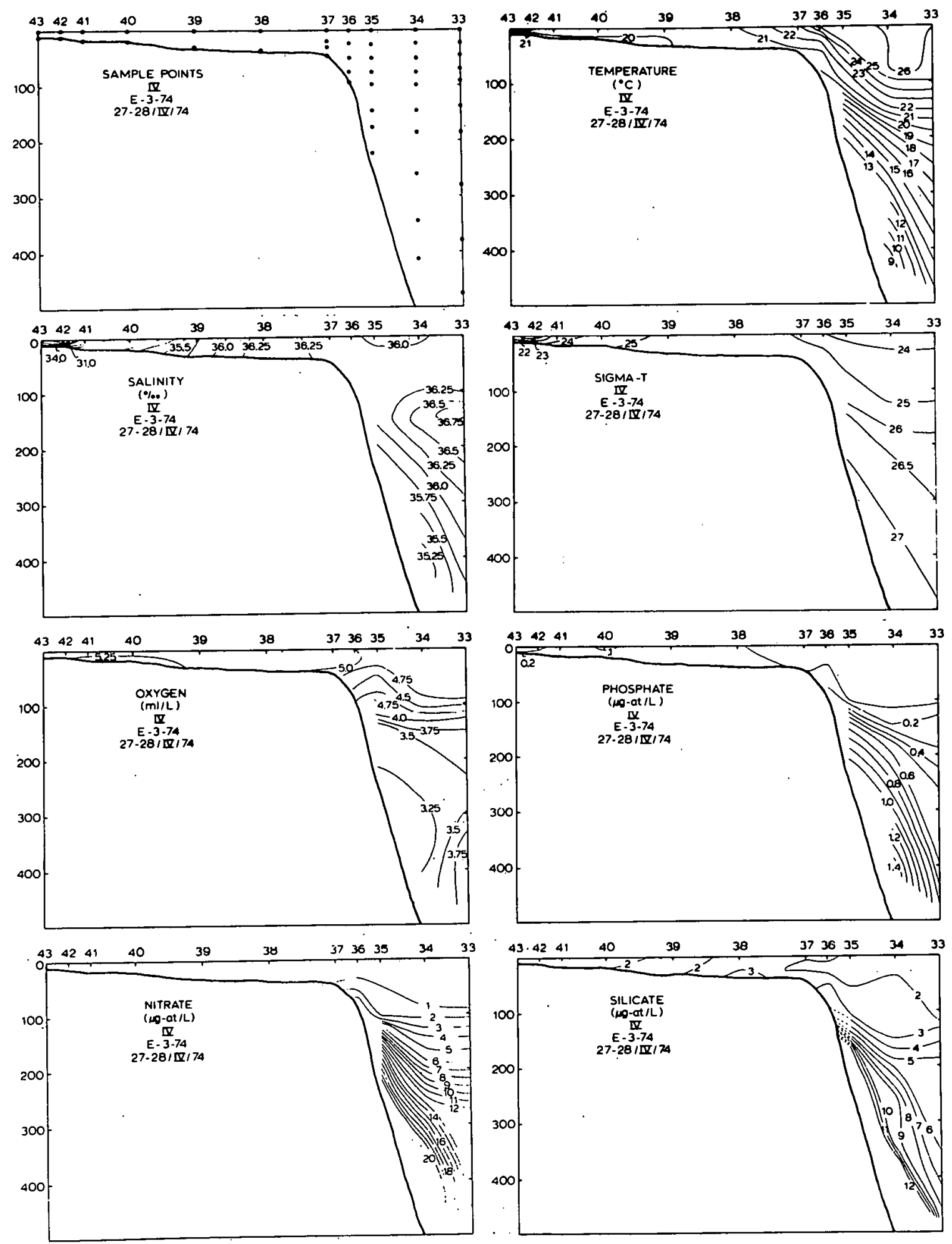

Figure 24. Vertical Section, Cruise E-3-74, Section IV 

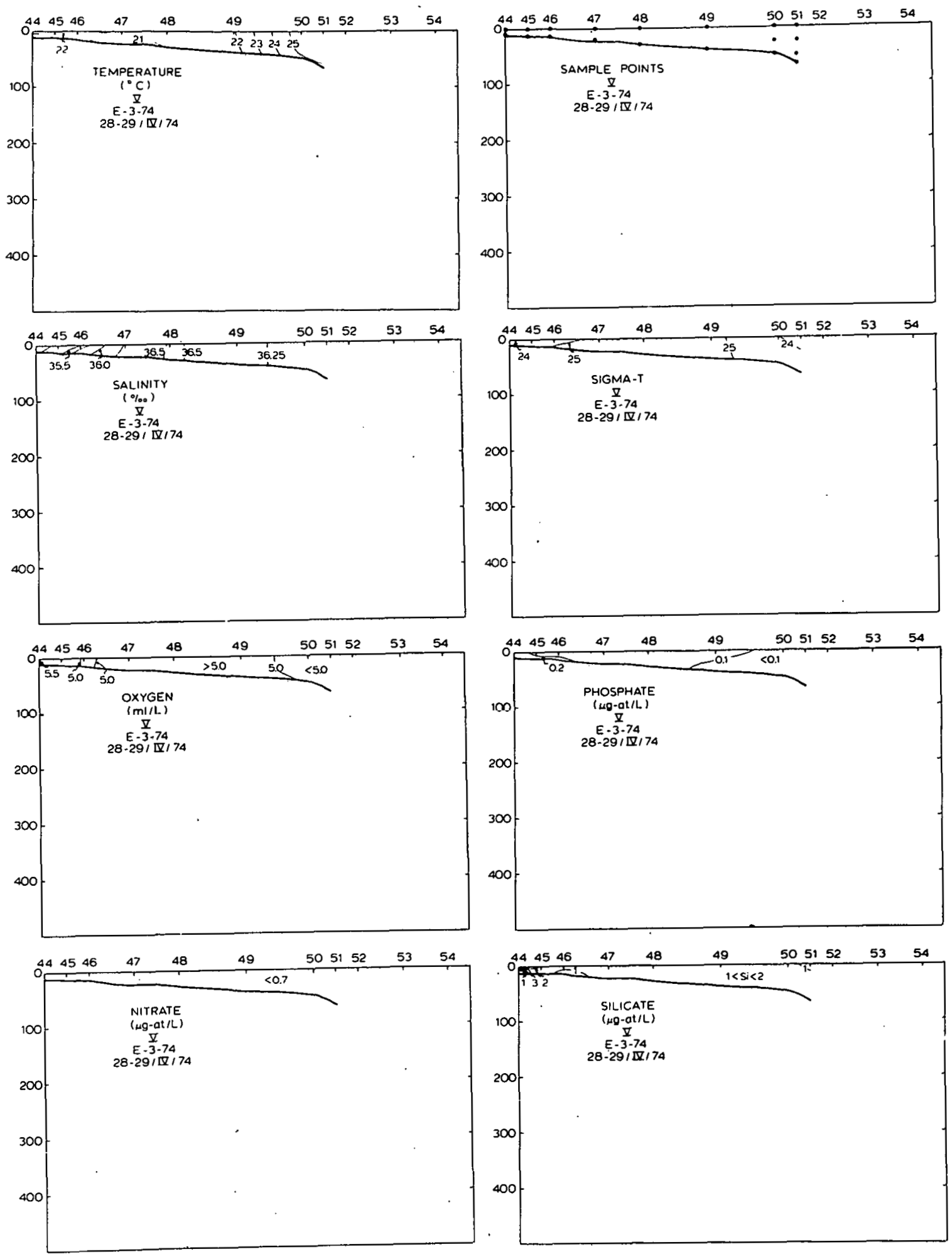

Figure 25. Vertical Section, Cruise E-3-74, Section V 

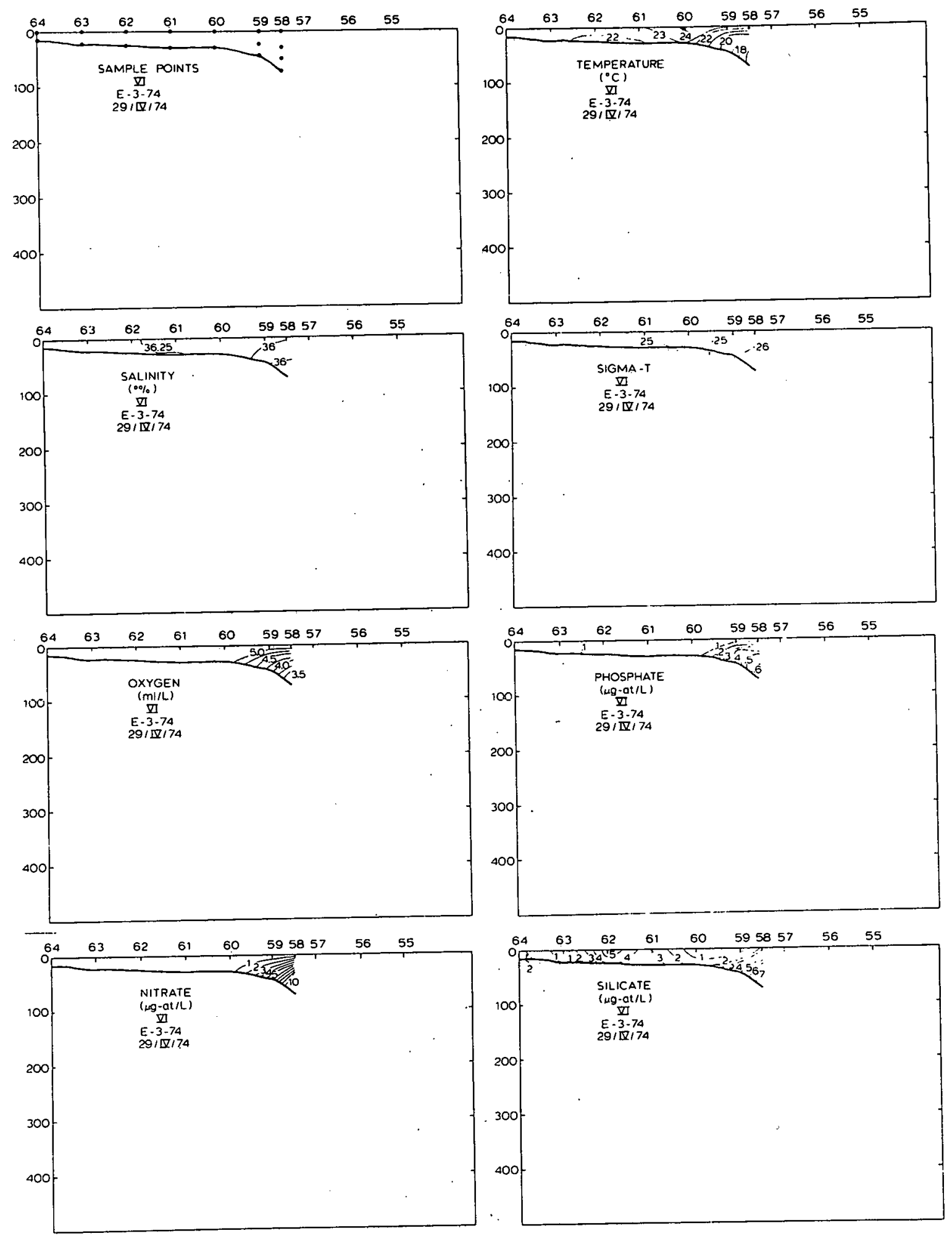

Figure 26. Vertical Section, Cruise E-3-74, Section VI 

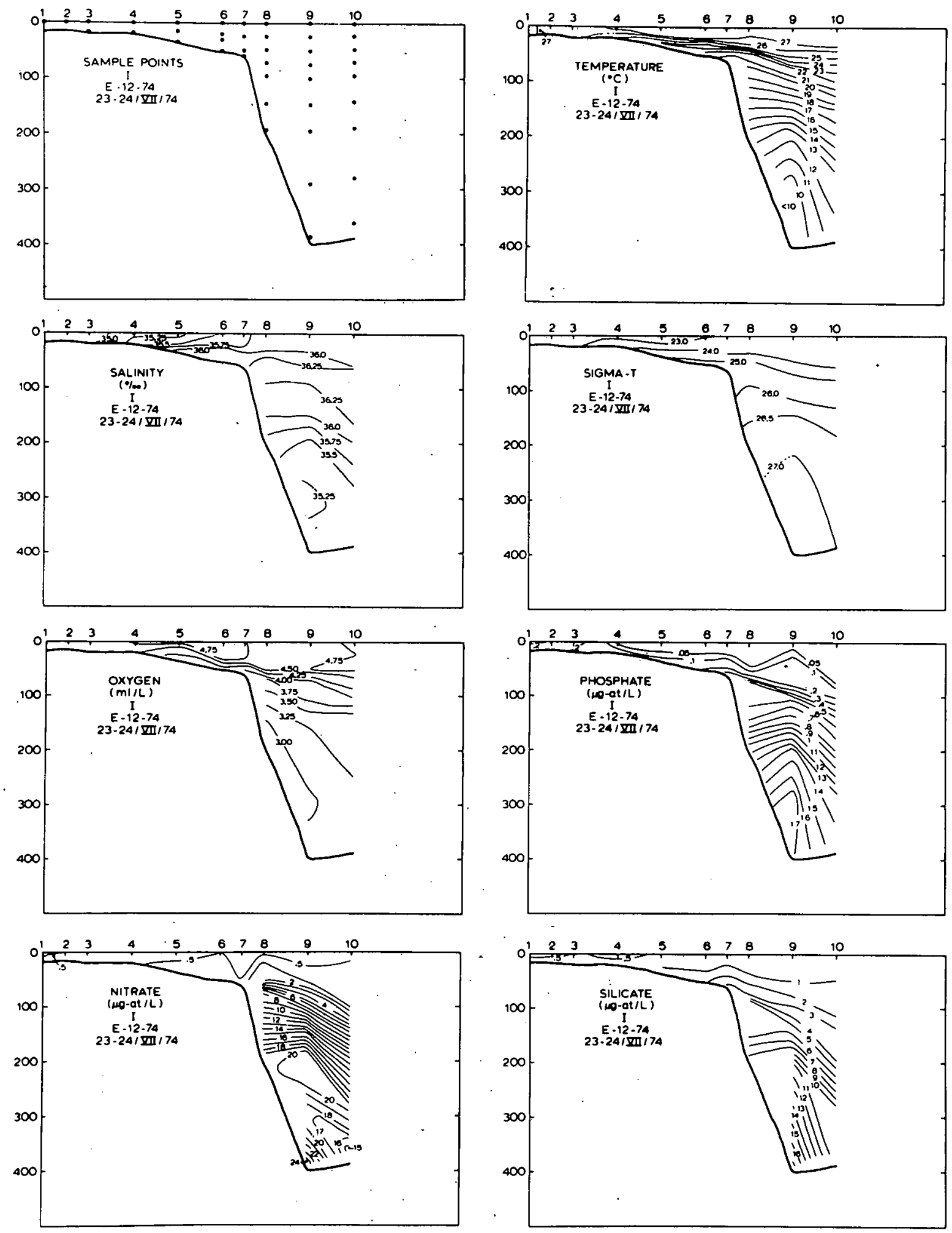

Figure 27. Vertical Section, Cruise E-12-74, Section I 

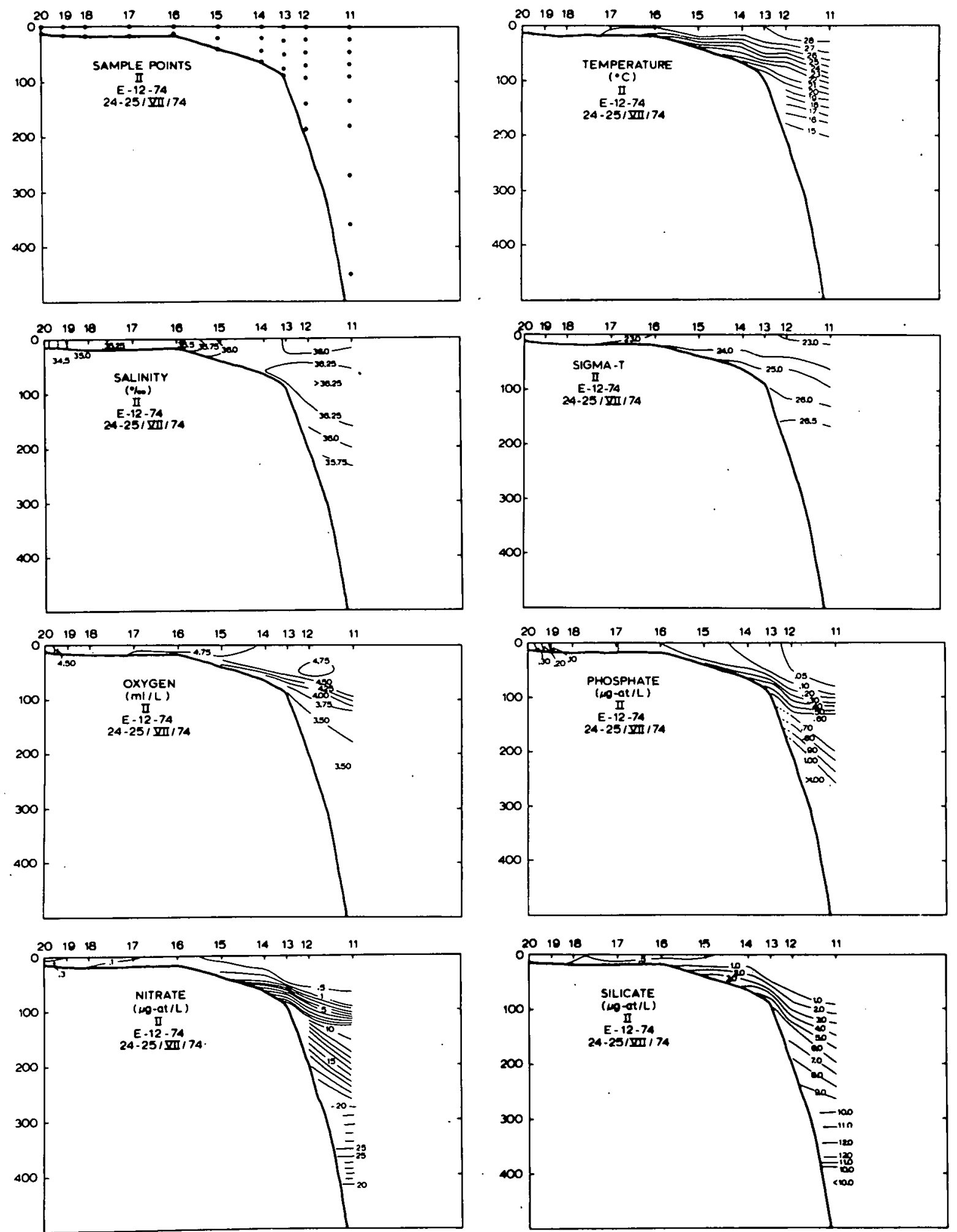

Figure 28. Vertical Section, Cruise E-12-74, Section II 

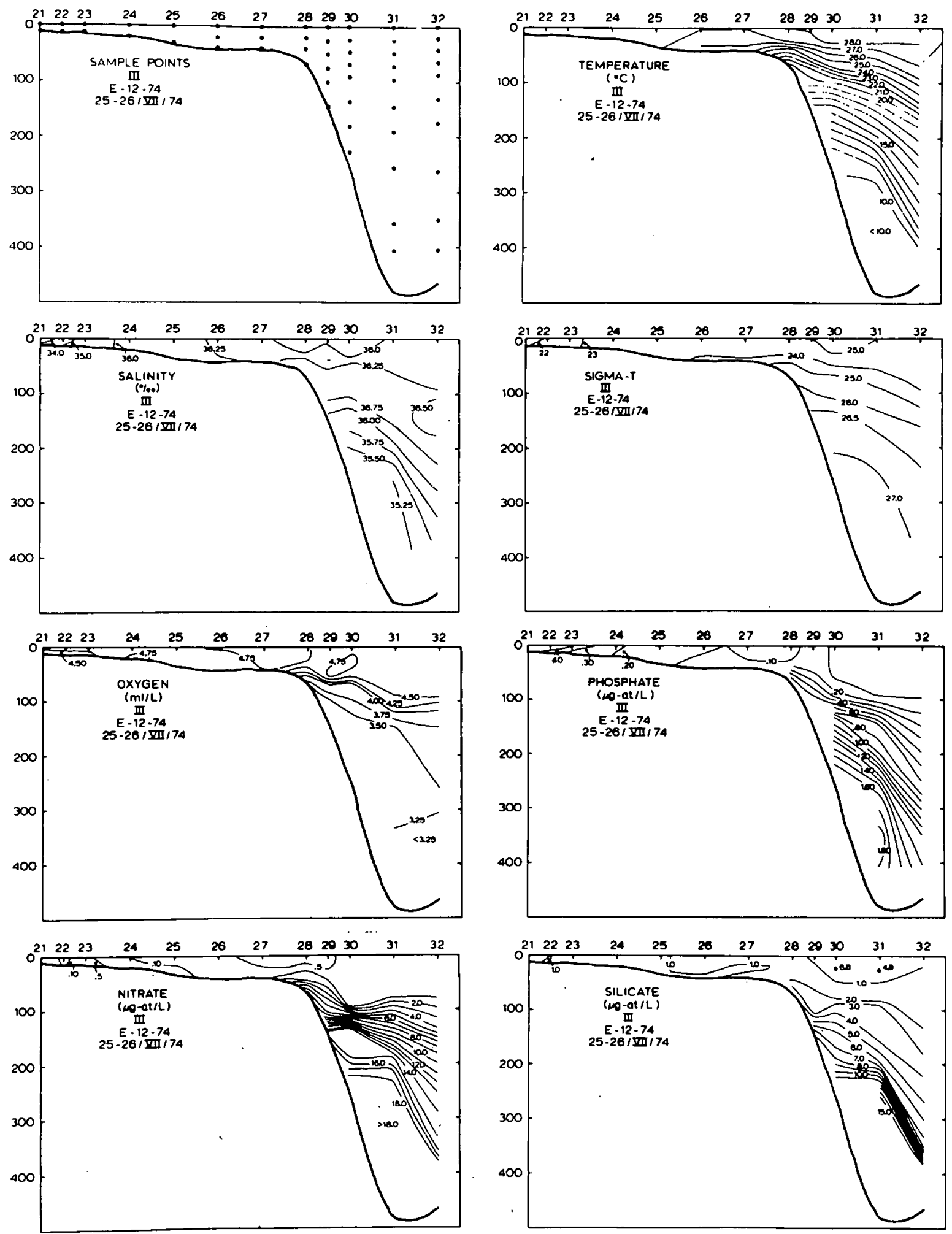

Figure 29. Vertical Section, Cruise E-12-74, Section III 

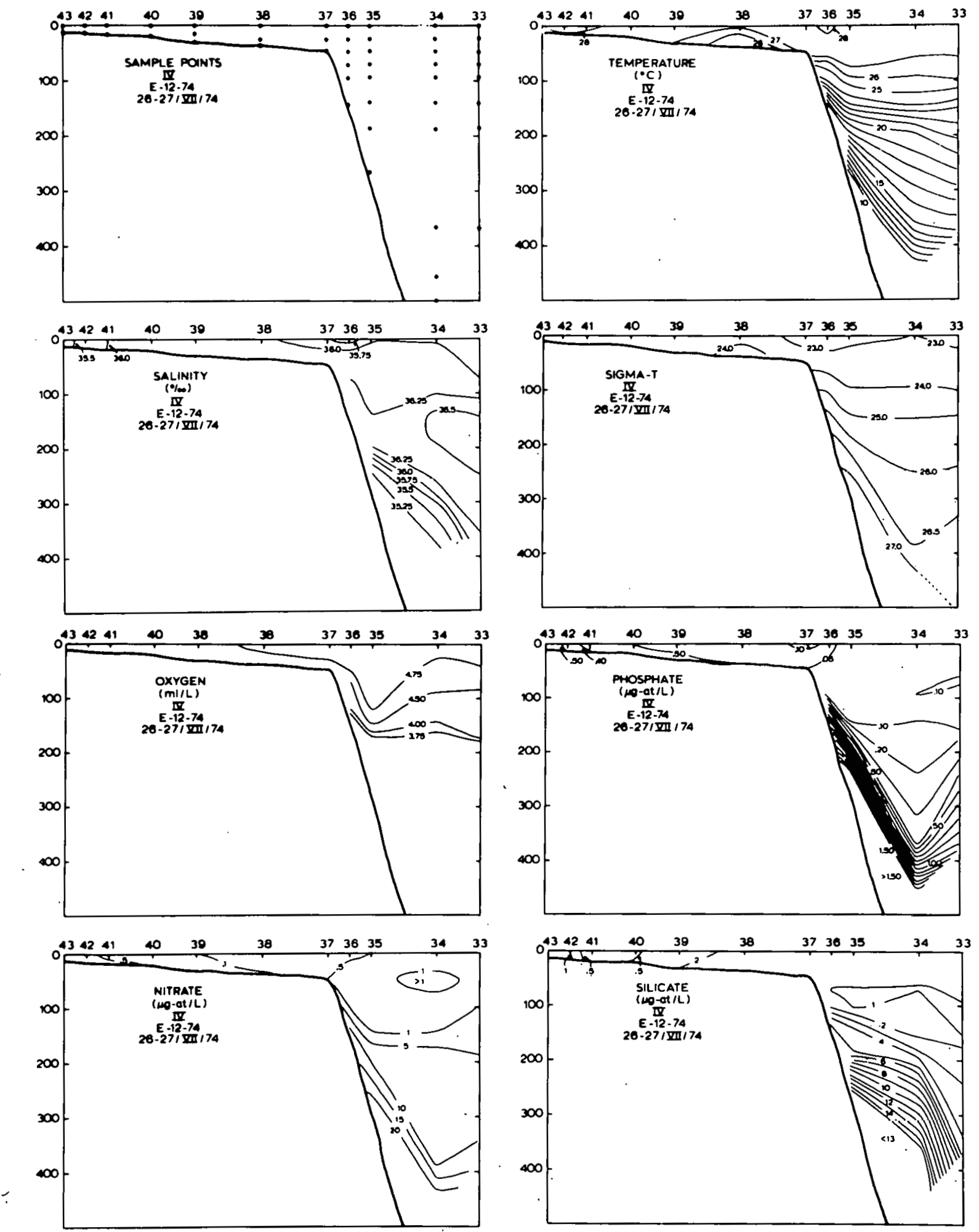

Figure 30. Vertical Section, Cruise E-12-74, Section IV 

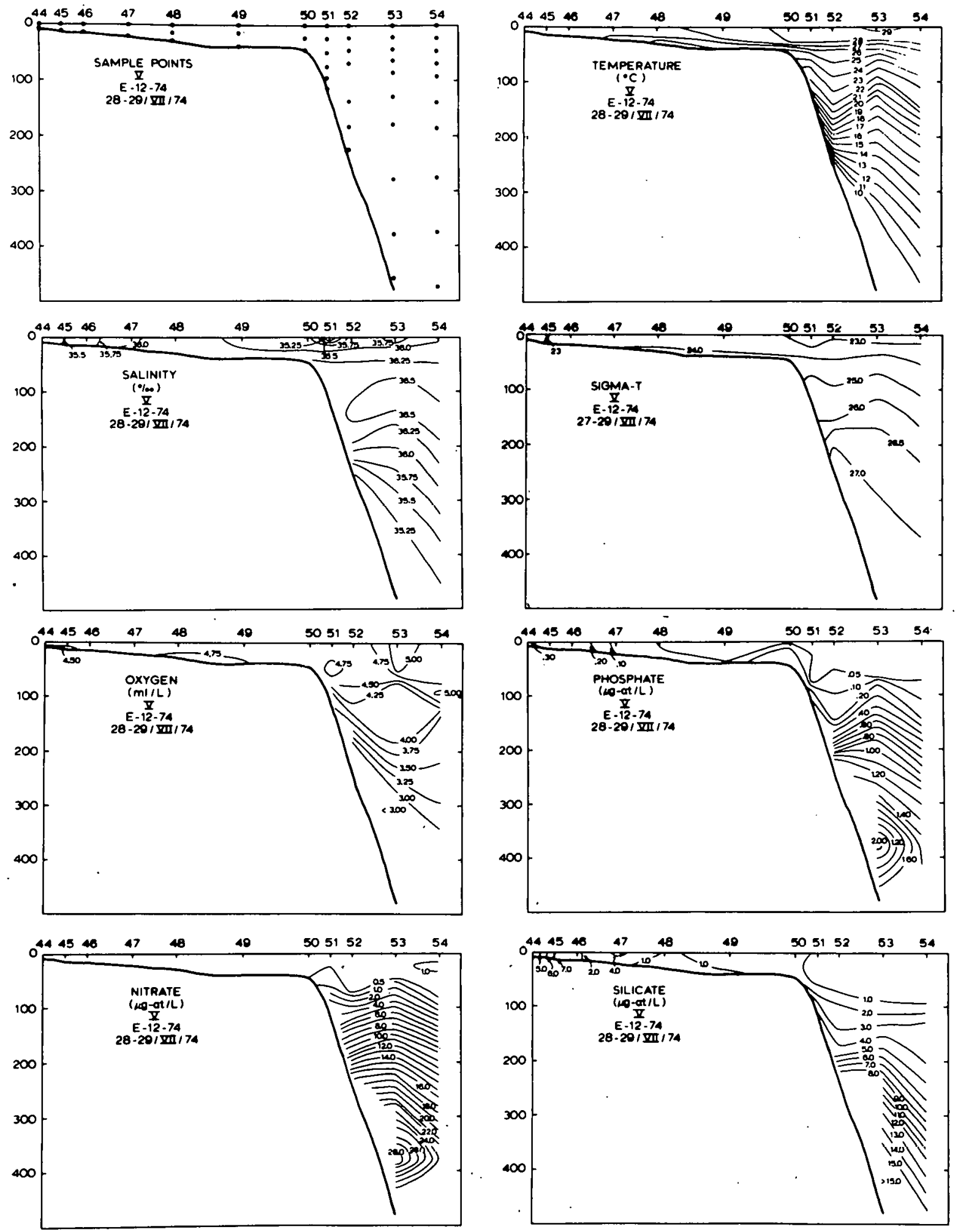

Figure 31. Vertical Section, Cruise E-12-74, Section V 

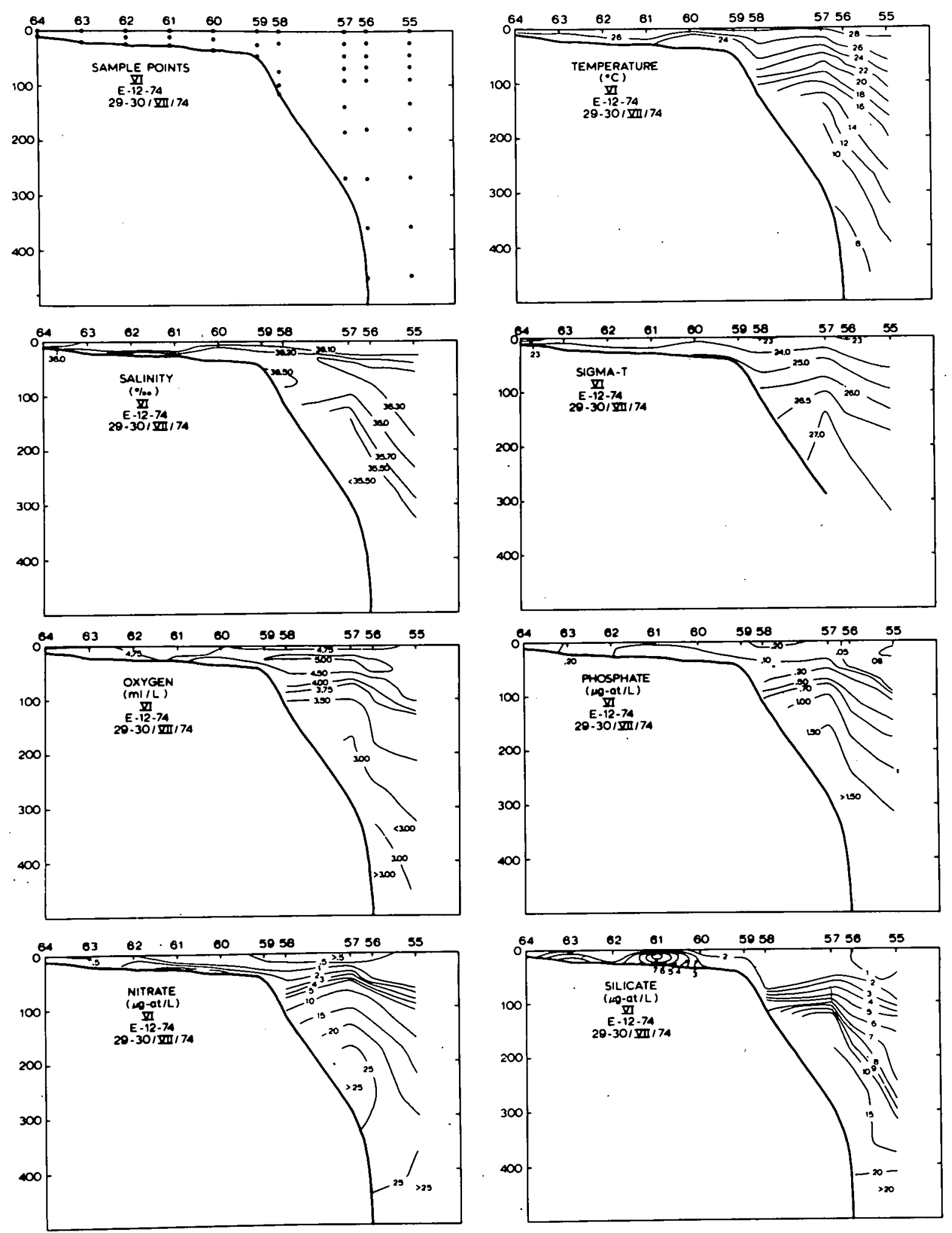

Figure 32. Vertical Section, Cruise E-12-74, Section VI 

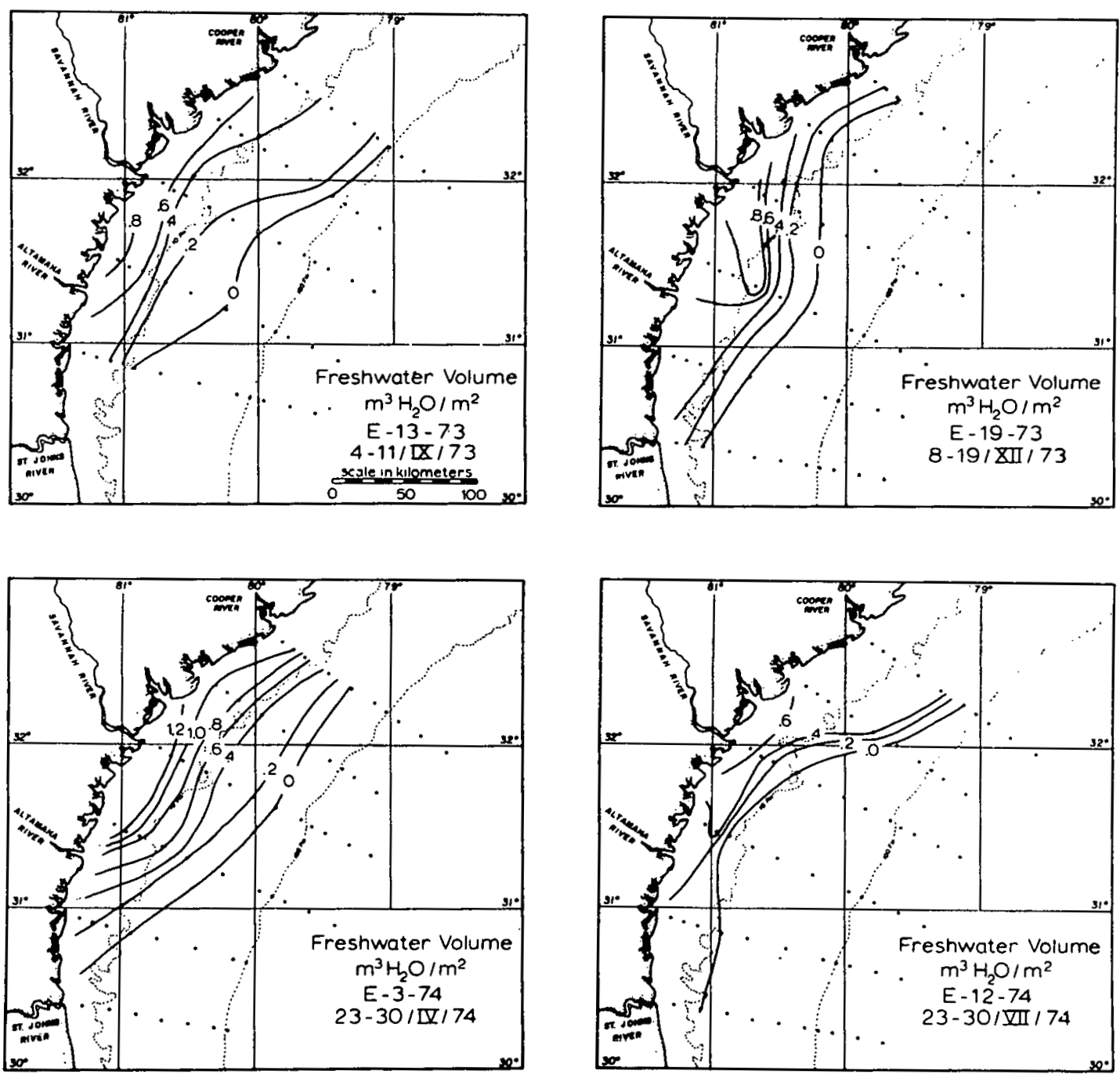

Figure 33. Distribution of Freshwater 

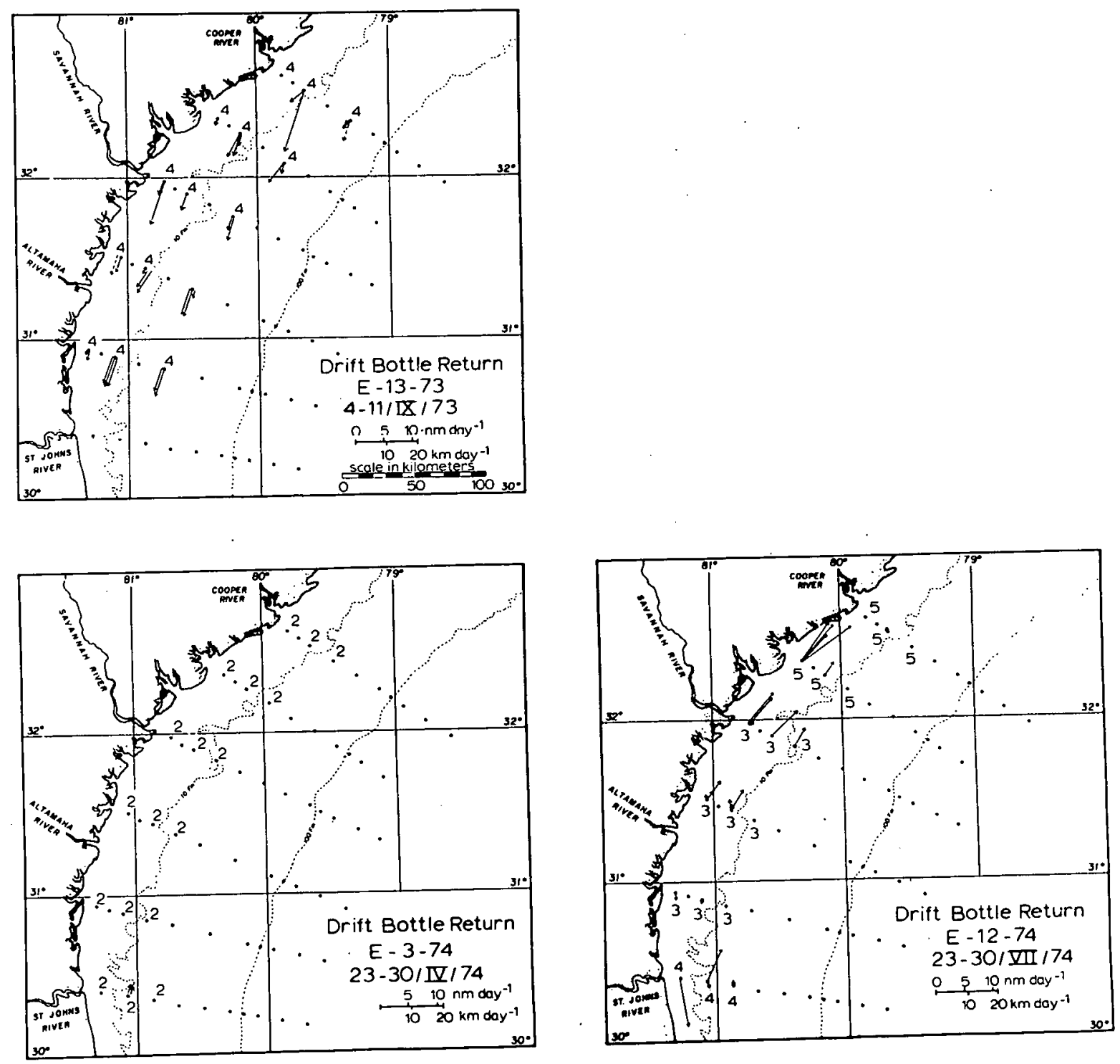

Figure 34. Drift Bottle Trajectories 

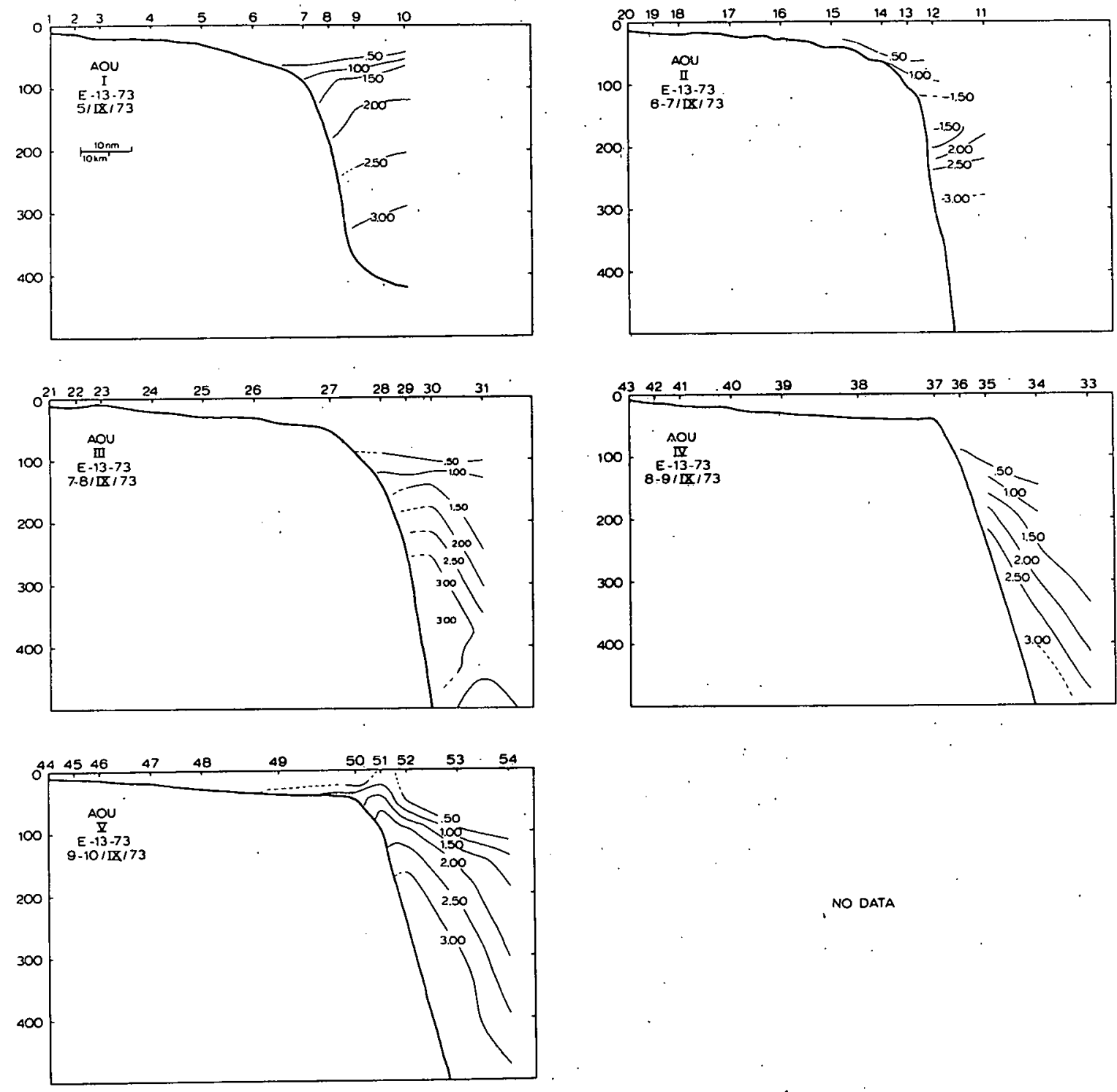

Figure 35. Apparent Oxygen Utilization, Cruise E-13-73 
NO DATA
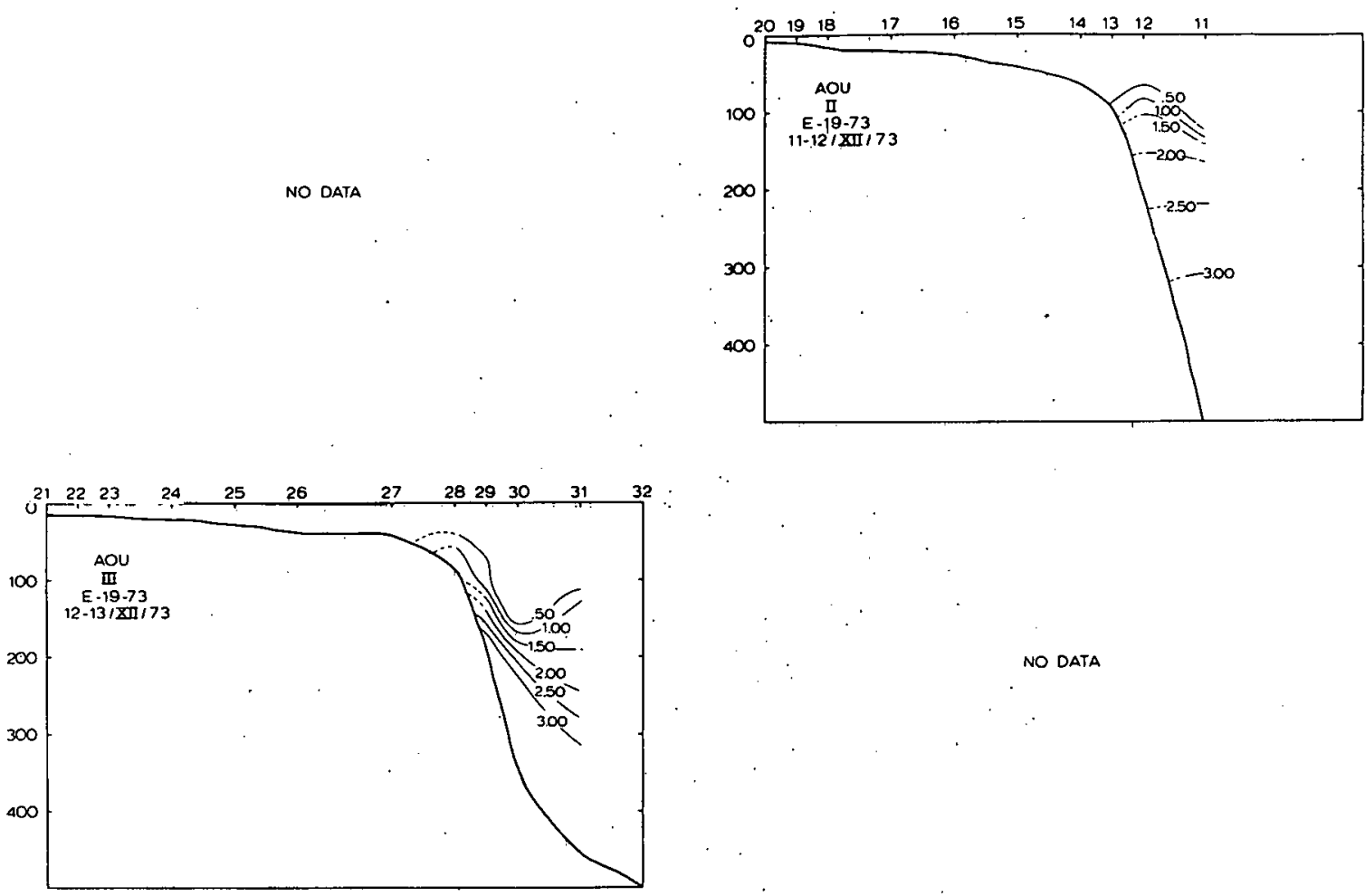

NO DATA

NO DATA

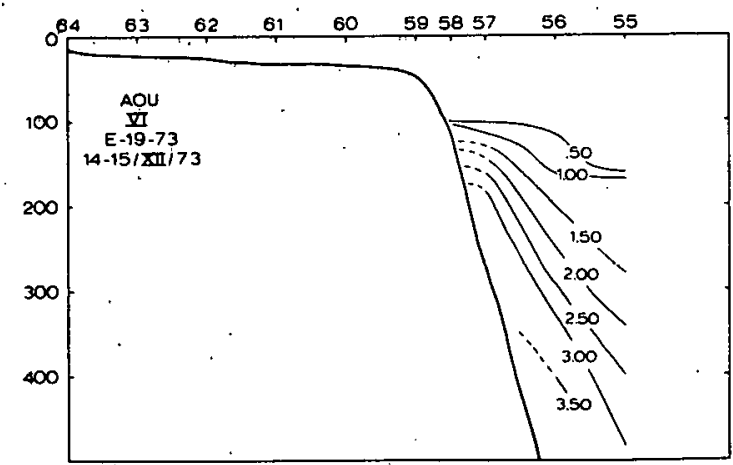

Figure 36. Apparent 0xygen Ut17ization, Cruise E-19-73 

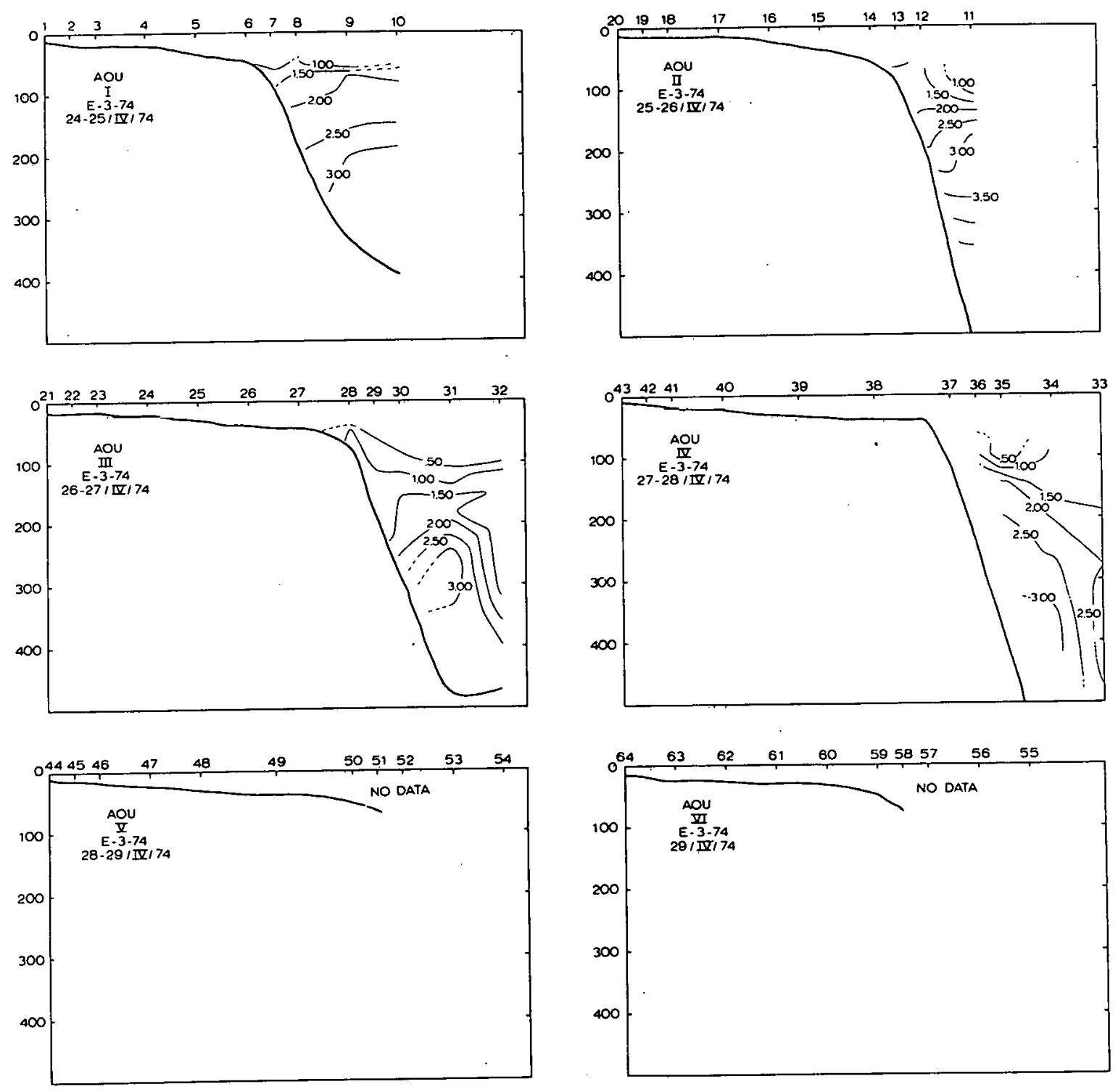

Figure 37. Apparent Oxygen Utilization, Cruise E-3-74 

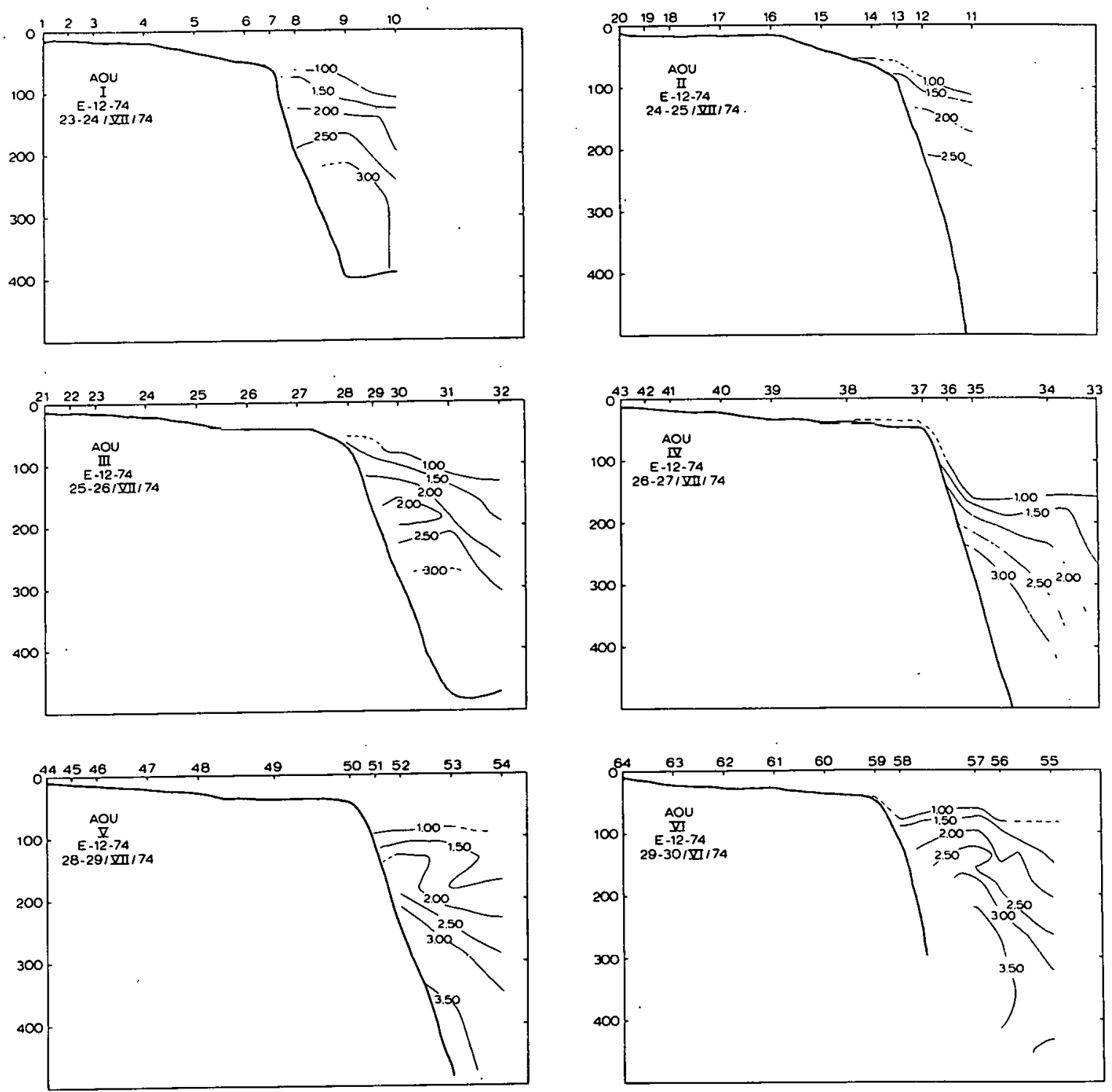

Figure 38. Apparent Oxygen Utilization, Cruise E-12-74 

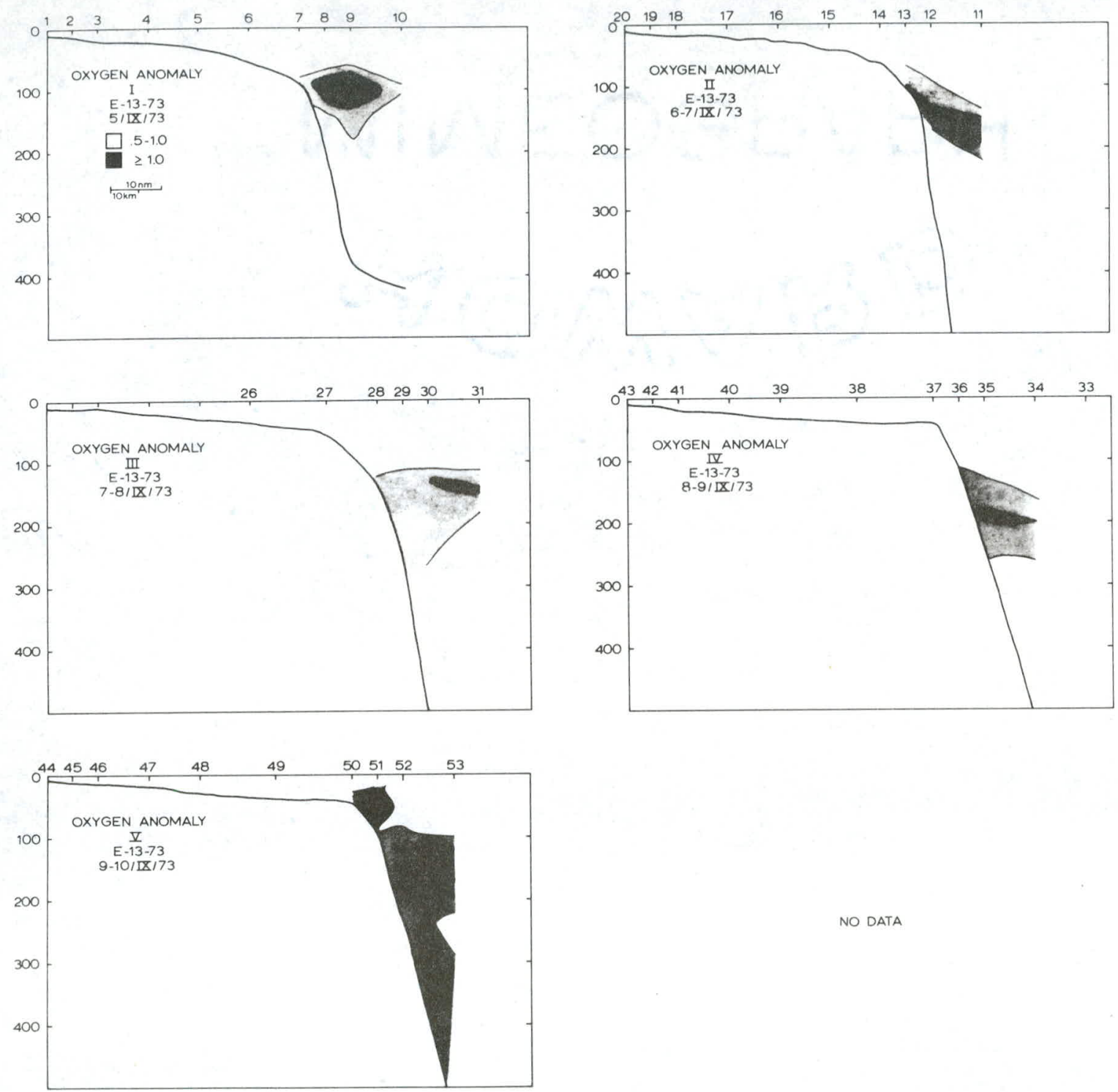

NO DATA

Figure 39. Oxygen Anomaly ( $\mathrm{ml} \mathrm{O}_{2} / \mathrm{L}$ ), Cruise E-13-73. 

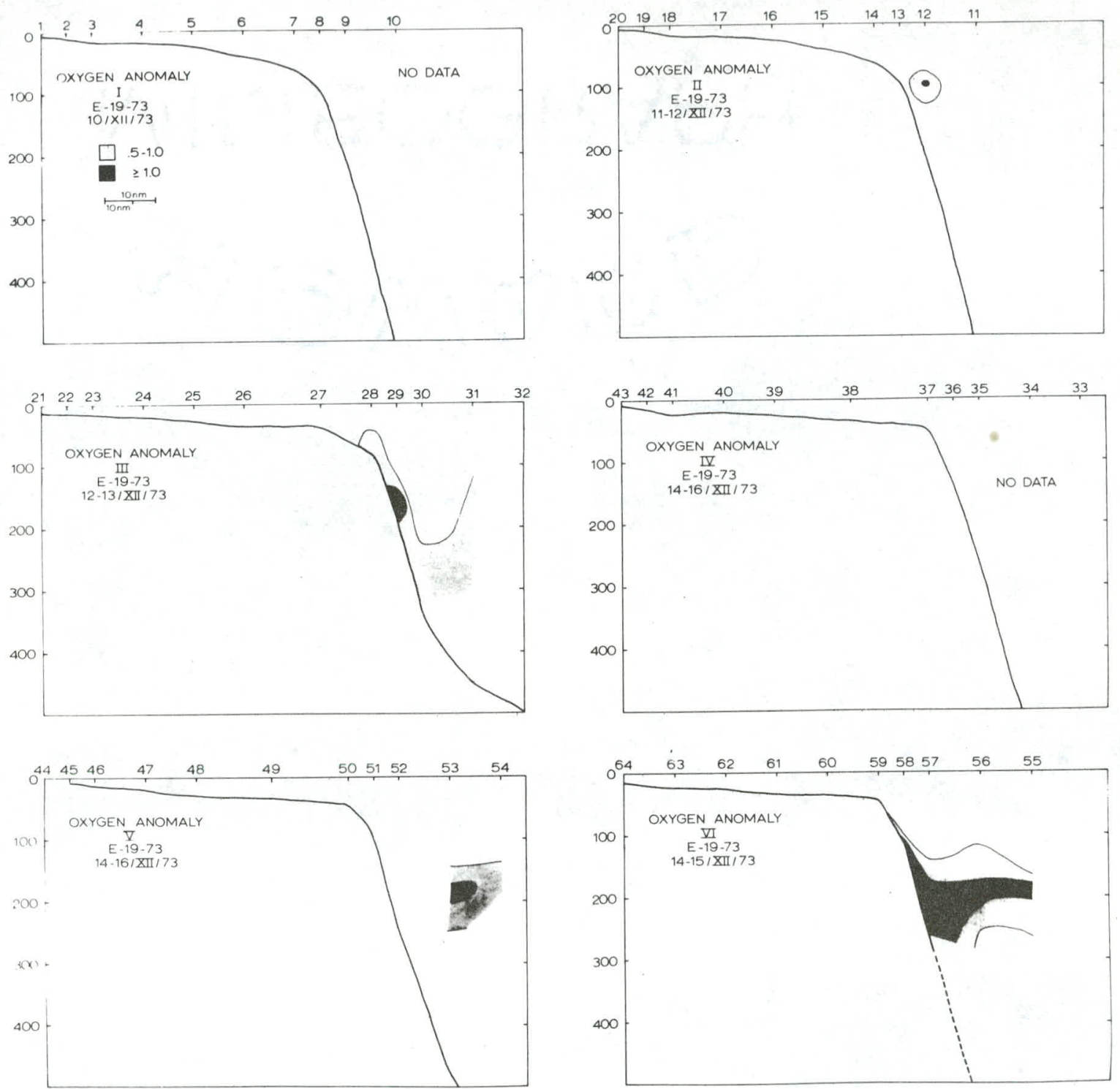

Figure 40. Oxygen Anomaly ( $\mathrm{ml} \mathrm{O}_{2} / \mathrm{L}$ ), Cruise E-19-73. 

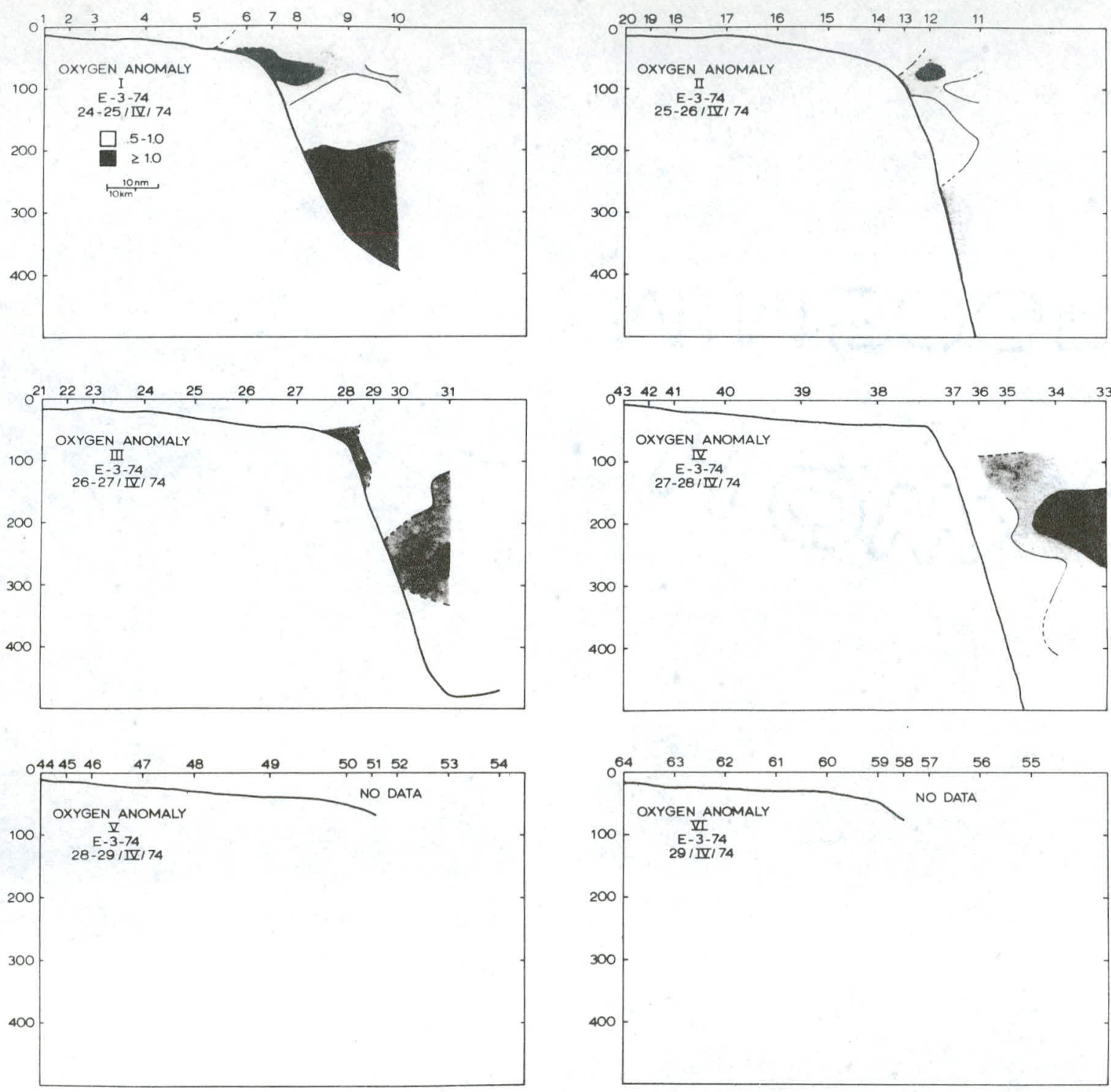

Figure 41. Oxygen Anomaly ( $\left.\mathrm{ml} \mathrm{O}_{2} / \mathrm{L}\right)$, Cruise E- 3-74. 

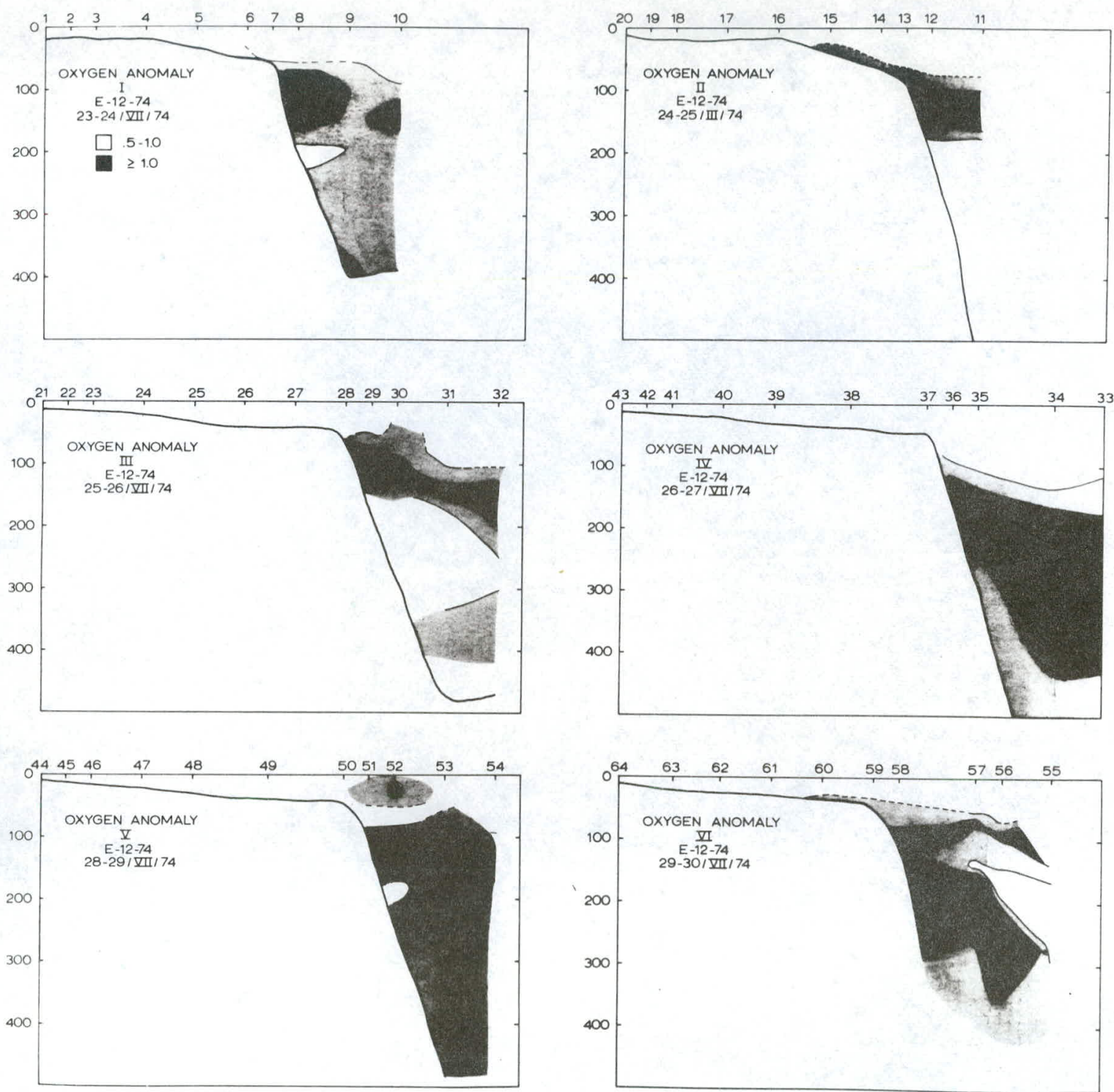

Figure 42. Oxygen Anomaly $\left(\mathrm{ml} \mathrm{O}_{2} / \mathrm{L}\right)$, Cruise E-12-74. 


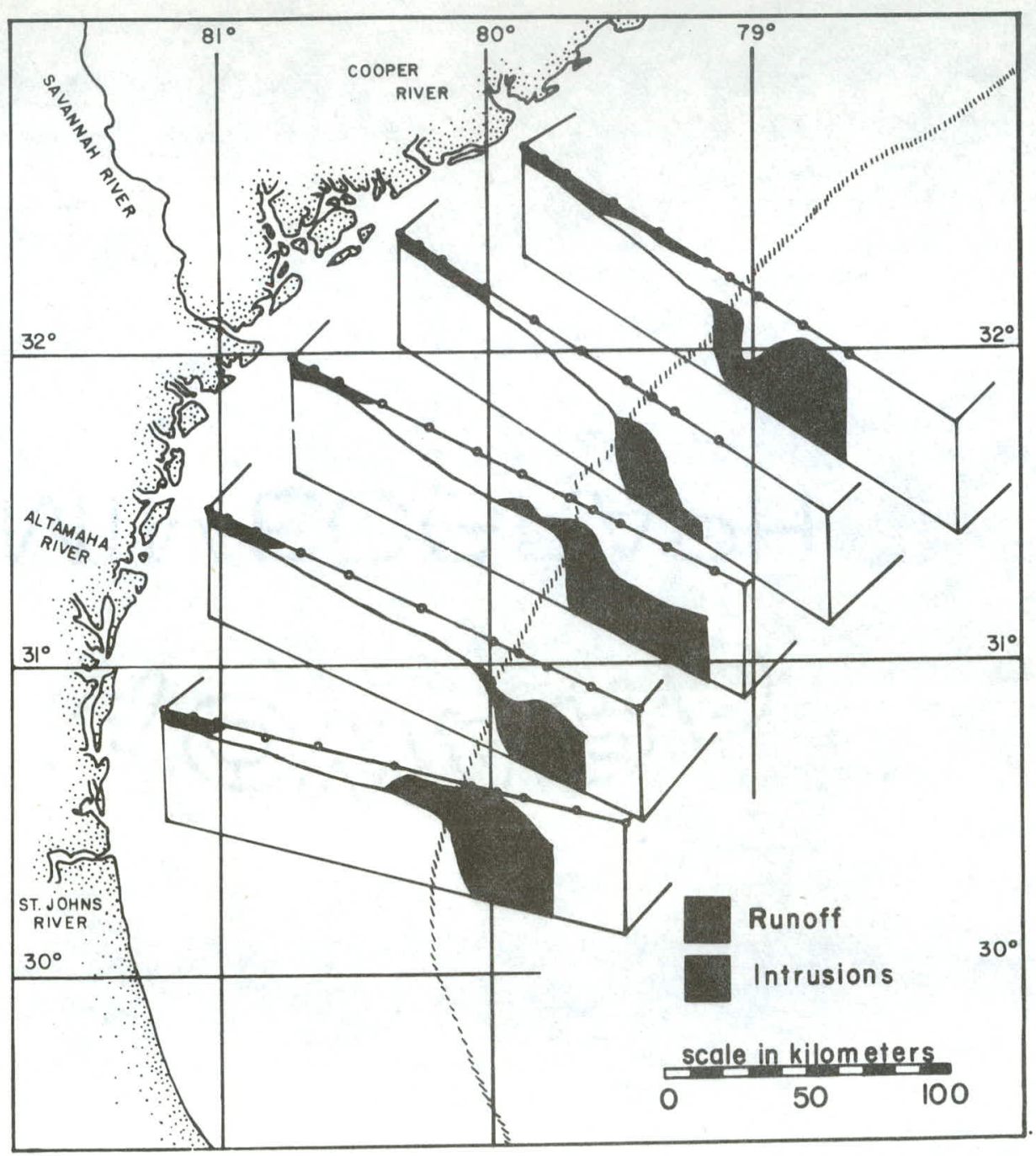

Figure 43. Summarized Horizontal Extent of Runoff and Intrusions E-13-73 


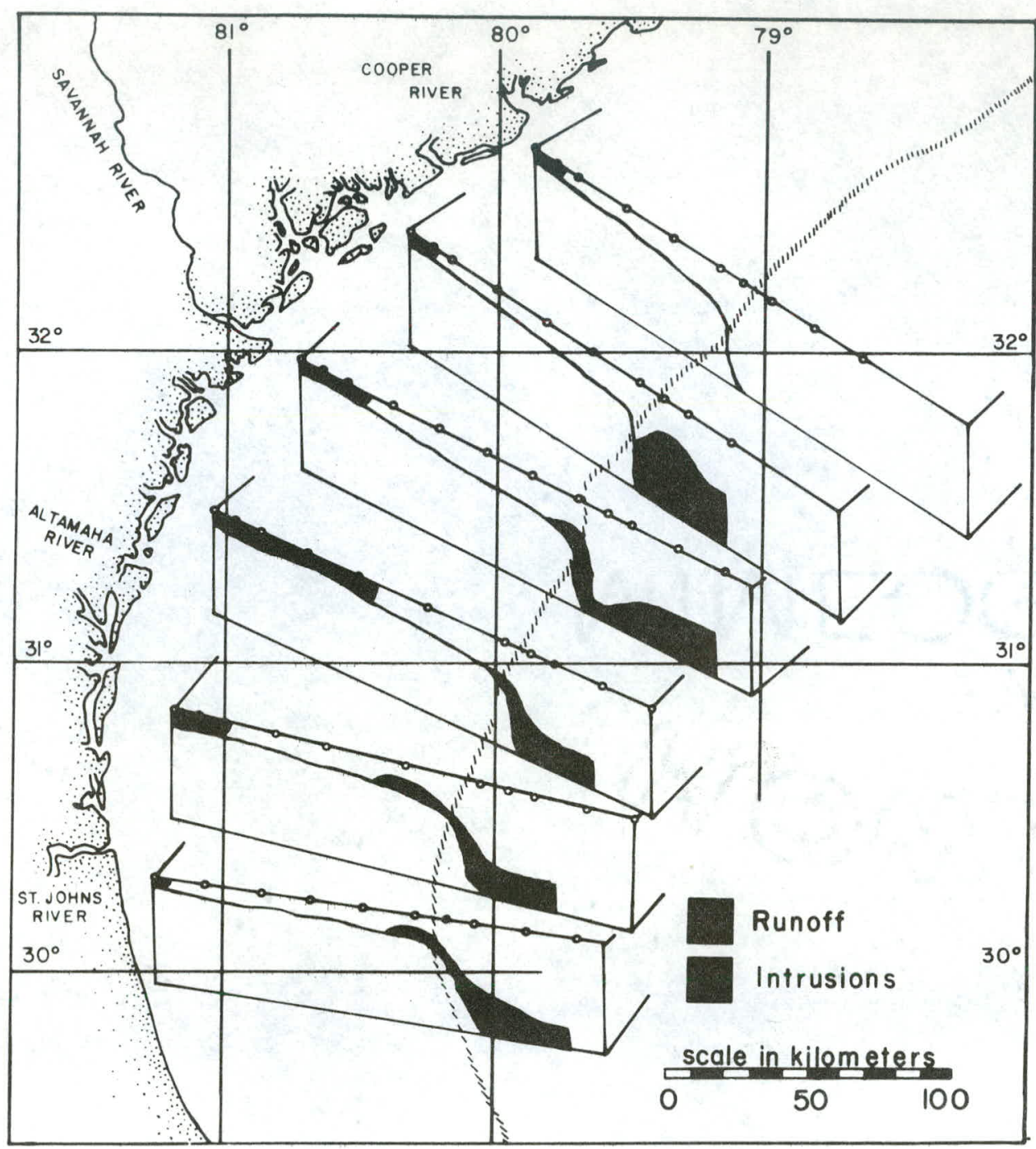

Figure 44. Summarized Horizontal Extent of Runoff and Intrusions E-19-73 


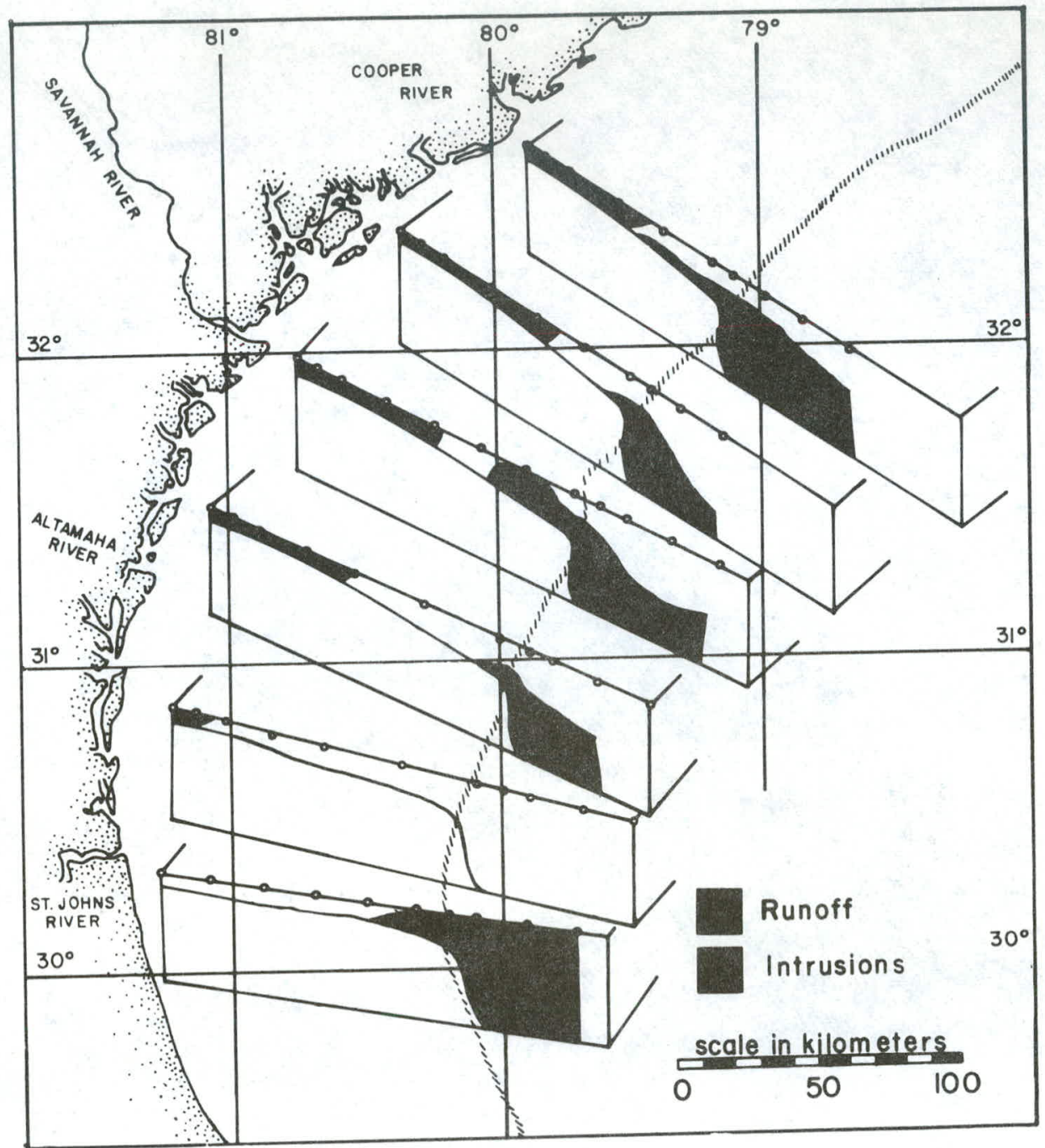

Figure 45. Summarized Horizontal Extent of Runoff and Intrusions E-3-74 


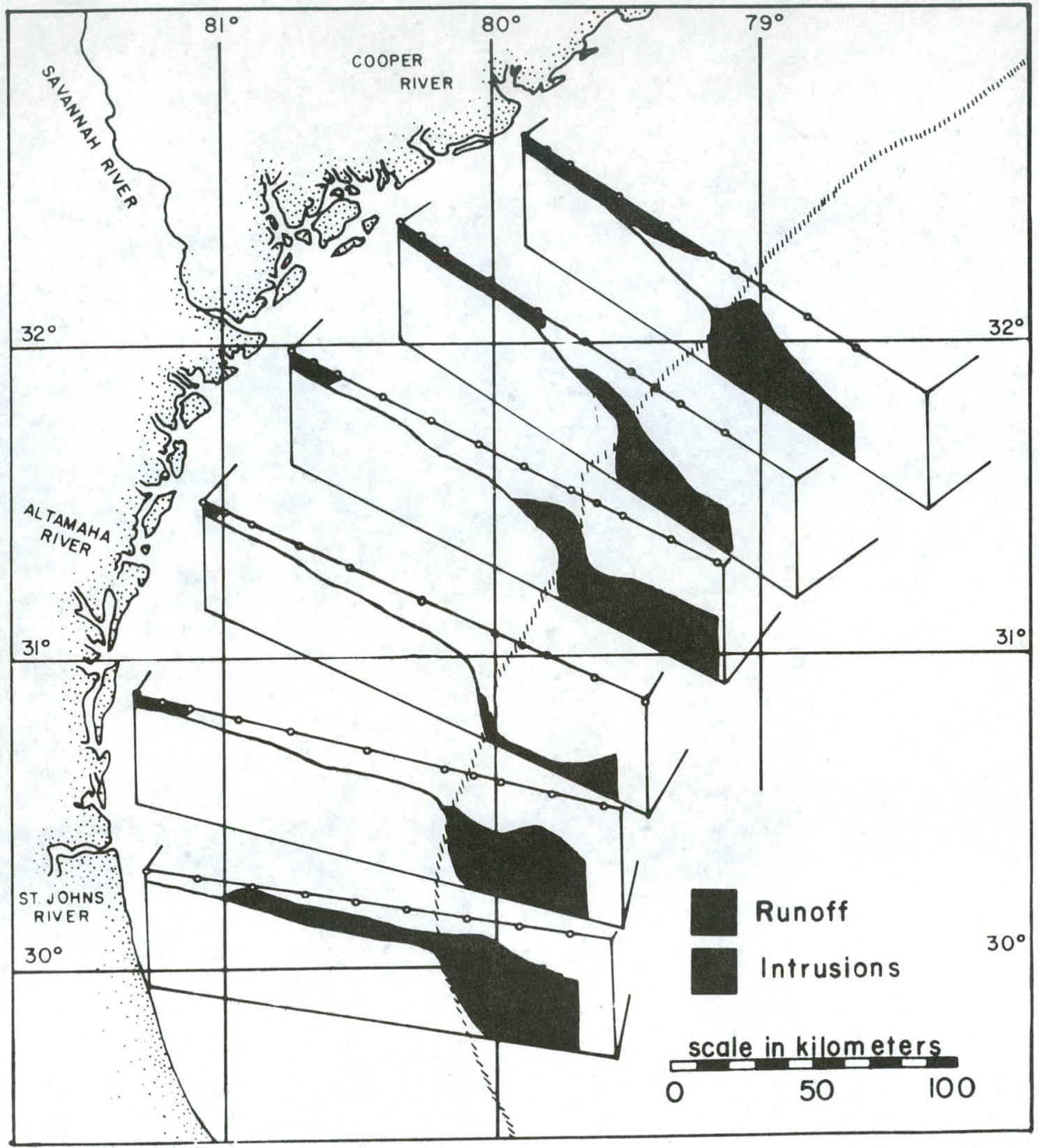

Figure 46. Summarized Horizontal Extent of Runoff and Intrusions E-12-74 

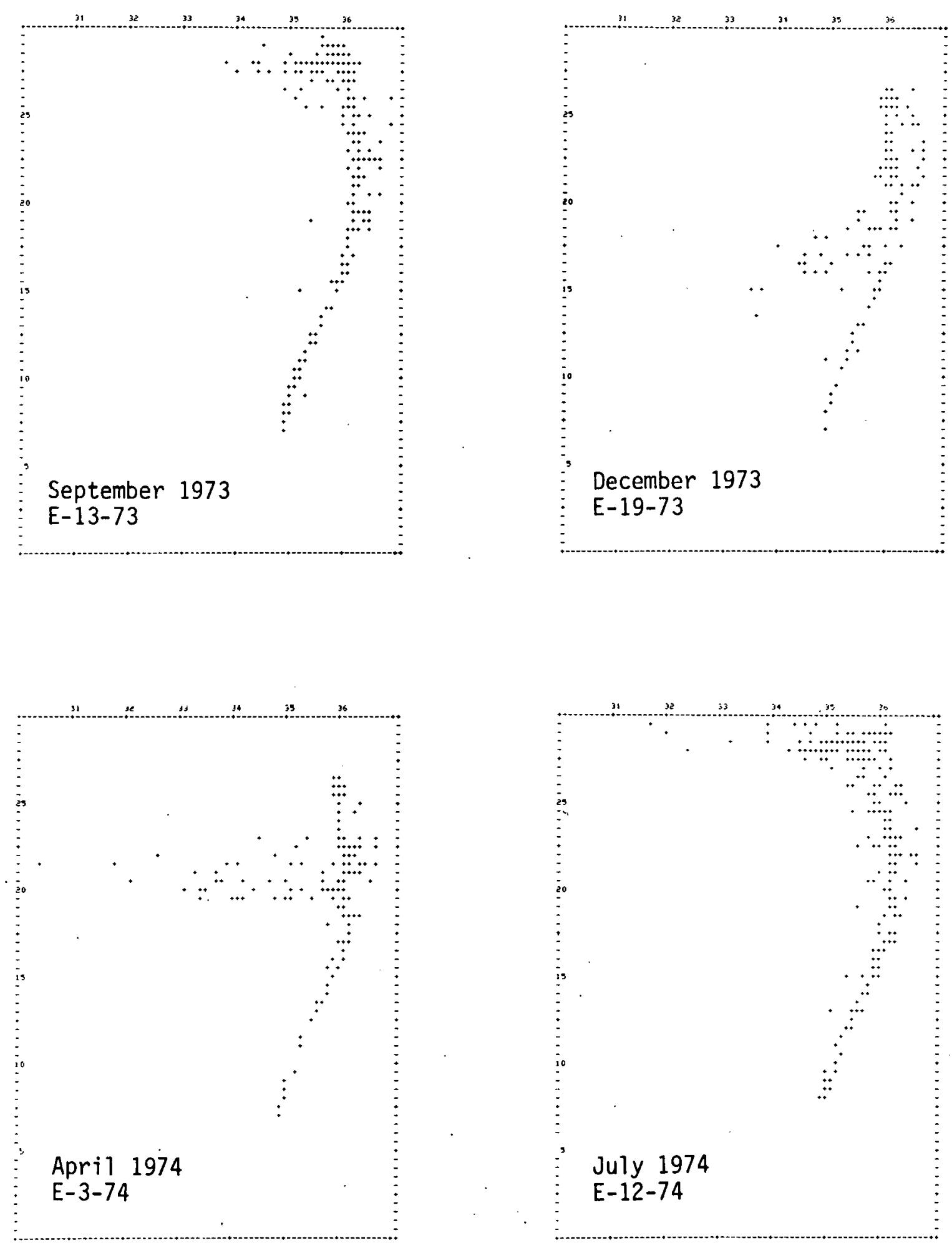

Figure 47. Temperature-Salinity Plot 


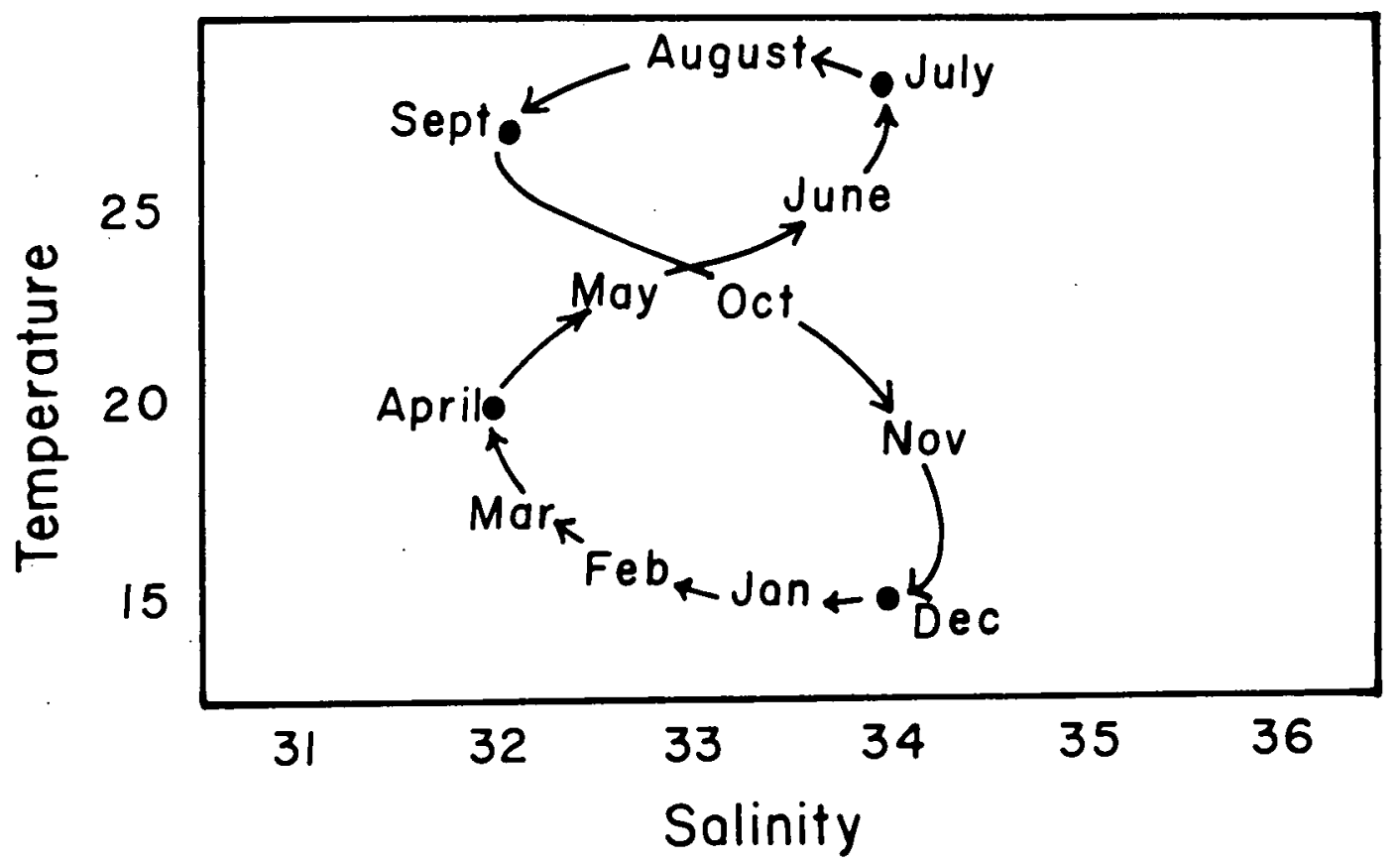

Figure 48. Schematic Seasonal T-S Plot 


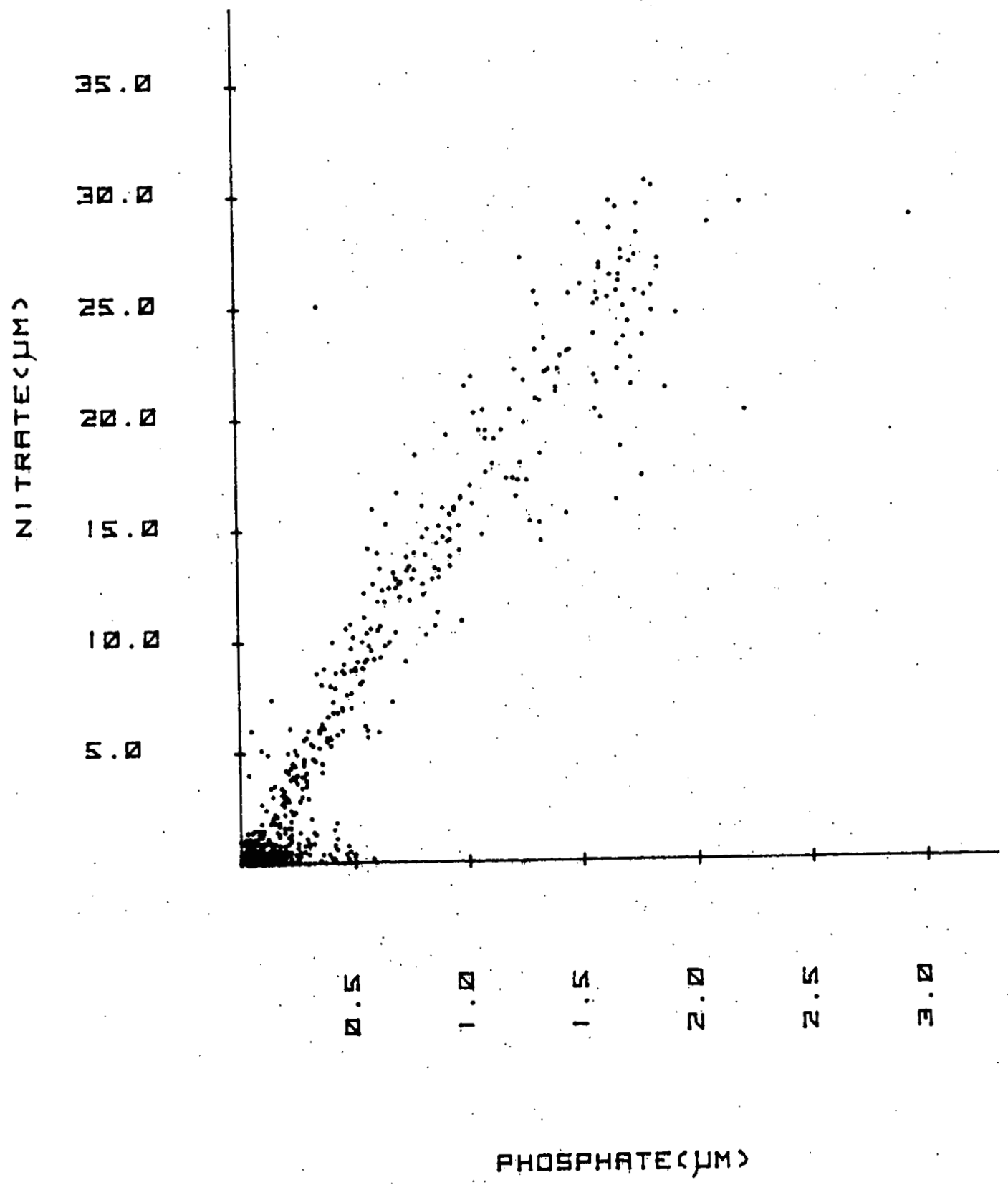

Figure 49. Phosphate-Nitrate Plot 


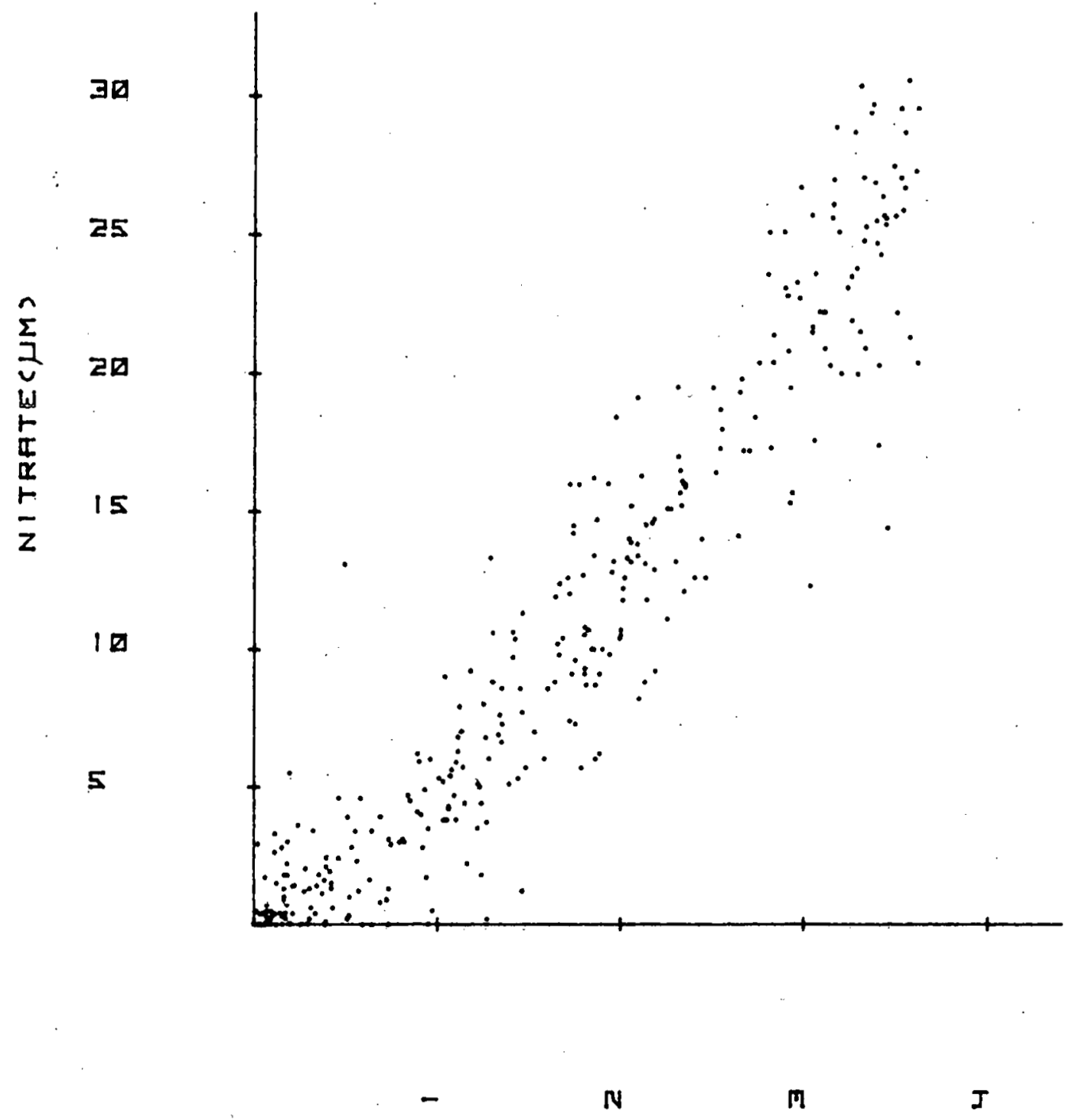

ROU (ML/L)

Figure 50. Nitrate-Apparent 0xygen Utilization Plot 


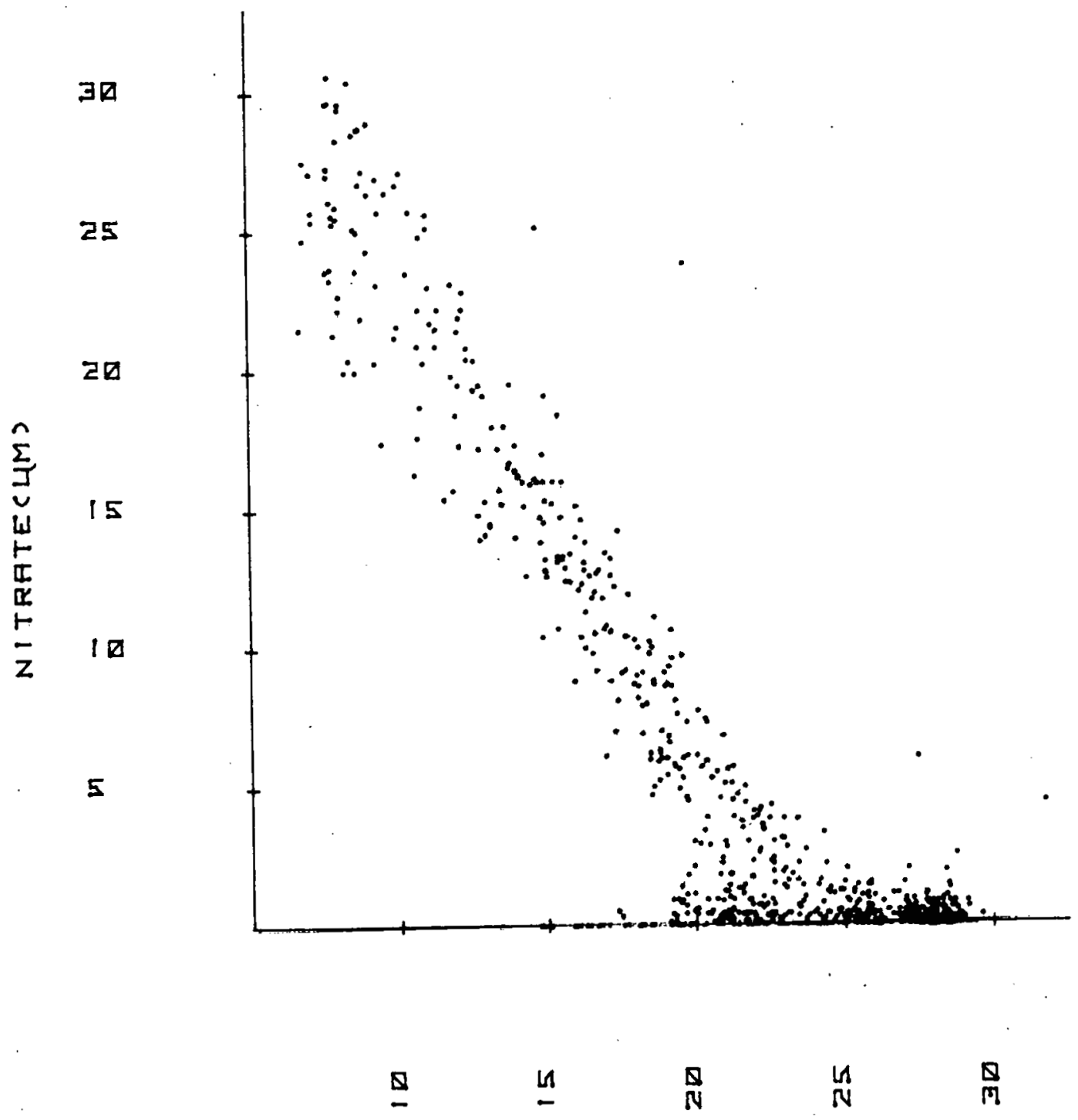

TEMPCCS

Figure 51. Nitrate-Temperature Plot 